biological : inventories

Ecuador:

Serranías CofánBermejo, Sinangoe 


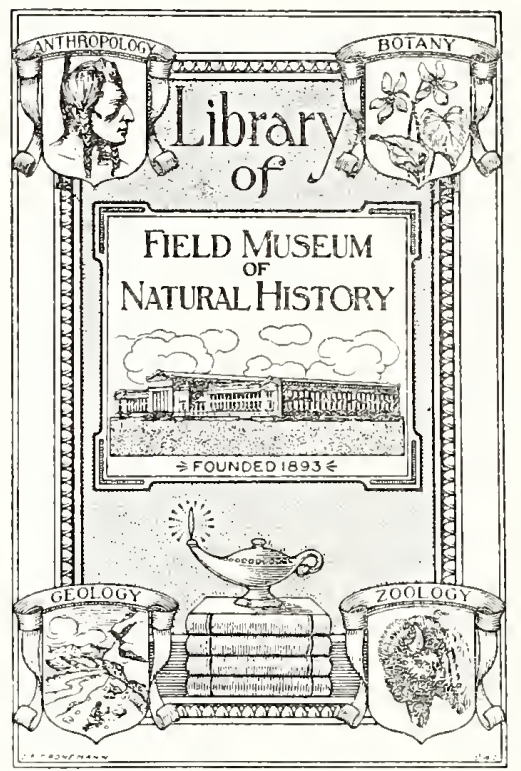




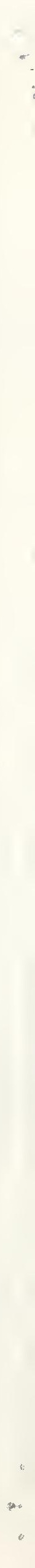



inventories

Ecuador:

Serranías Cofán-

Bermejo, Sinangoe 
Ecuador:

Serranías CofánBermejo, Sinangoe

Nigel Pitman,

Debra K. Moskovits,

William S. Alverson, y/and

Randall Borman A.,

editores/editors

ENERO / JANUARY 2002

Instituciones Participantes /

Participating Institutions:

The Field Museum

Fundación para la Sobrevivencia del Pueblo Cofán/Cofán Survival Fund

Federación Indígena de la

Nacionalidad Cofán del Ecuador (FEINCE)

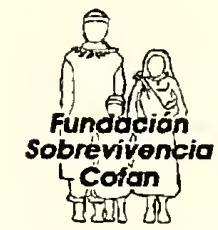


Los Inventarios Biológicos Rápidos son publicados por/ Rapid Biological Inventories Reports are published by:

\section{THE FIELD MUSEUM}

Environmental and Conservation Programs

1400 South Lake Shore Drive

Chicago, Illinois 60605-2496 USA

312.665.7430 tel, 312.665.7433 fax

www.fieldmuseum.org

Editores/Editors: Nigel Pitman, Debra K. Moskovits,

William S. Alverson, y/and Randal Borman A.

Diseño/Design: Costello Communications, Chicago

Traducciones/Translations: Angela Padilla, y/and Tyana Wachter (español/Spanish); Randal Borman A., Roberto Aguinda, Michacl L. Cepck, Fclipc Borman, Hugo Lucitantc, y/and Toribio Aguinda (Cofán)

El Field Museum es una institución sin fines de lucro exenta de impuestos federales bajo la sección 501 (c) (3) del Código Fiscal Interno./

The Field Museum is a non-profit organization exempt from federal income tax under section 501 (c) (3) of the Internal Revenuc Code.

ISBN $0-914868-52-7$

(- 2002 por el Field Museum. Todos los derechos reservados./

- 2002 by The Field Museum. All rights reserved.

Cualquiera de las opiniones en los Informes de los Inventarios Biológıcos Rápidos son expresamente las de los autores y no reflejan necesariamente las del Field Museum./Any opinions expressed in the Rapid Biological Inventories Reports are those of the writers and do not necessarily reflect those of The Field Museum.
Esta publicación ha sido financiada en parte por la John D. and Catherine T. MacArthur Foundation./ This publication has been funded in part by the John D. and Catherine T. MacArthur Foundation.

Cita Sugerida/Suggested Citation: Pitman, N., D. K. Moskovits, W. S. Alverson, y/and R. Borman A. (eds.). 2002. Ecuador : Serranías Cofán-Bermejo, Sinangoe. Rapid Biological Inventories Report 3. Chicago, Illinois: The Field Museum.

Fotografía de la carátula / Cover photograph: Oso de anteojos / Spectacled bear (Tremarctos ornatas), por/by Roy Toft, ○ Roy Toft Photography. Diseño/Design effects: James Costello. Fotografía de la carátula interior/Inner-cover photograph: Sucumbíos, Ecuador, por/by Thomas S. Schulenberg

Impreso en papel reciclado./Printed on recycled paper. 
ESPAÑOL

4 Integrantes del Equipo

6 Perfiles Institucionales

8 Agradecimientos

9 Resumen Ejecutivo

12 ¿Por qué las Serranías Cofán?

13 Láminas a Color

21 Panorama General de los Resultados

21

22

23

25

26

26

27

30

31

33

39

39

45

47

62

65

68

76

83

$$
\text { Perfil Ecológico }
$$

Comunidades Cofanes Locales

Vegetación y Flora

Anfibios y Reptiles

Aves

Mamíferos Grandes

Amenazas

Objetos de Conservación

Oportunidades para la Conservación

Recomendaciones

Descripción de los Sitios Muestreados

Geología, Fisiografía, y Clima

Flora y Vegetación

Plantas Endémicas

Anfibios y Reptiles

Aves

Mamíferos Grandes

Jonguesune Condase'cho

(Resumen Ejecutivo en Cofán/

Cofán Report at a Glance)

\section{Informe Técnico}

ENGLISH

87 Table of Contents for English Text

88 Participants

90 Institutional Profiles

92 Acknowledgements

93 Report at a Glance

96 Why the Serranías Cofán?

97 Overview of Results

114 Technical Report

BILINGÜE/BILINGUAL

153 Apéndices/Appendices

154 1) Plantas Vasculares/Vascular Plants

180 2) Anfibios y Reptiles/ Amphibians and Reptiles

182 3) Aves/Birds

210 4) Mamíferos Grandes/Large Mammals

214 5) Iniciativas Cofán para la Conservación/ Cofán Conservation Initiatives

218 6) Oportunidades para la Conservación alrededor de La Bonita/Conservation Opportunities in Adjacent Areas (La Bonita)

\section{Literatura Citada/Literature Cited}




\section{EQUIPO DE CAMPO}

\section{Roberto Aguinda (plantas)}

Fundación para la Sobrevivencia del Pueblo Cofán Federación Indígena de la

Nacionalidad Cofán del Ecuador

Quito y Zábalo, Ecuador

\section{Randall Borman A. (mamiferos grandes)}

Fundación para la Sobrevivencia del Pueblo Cofán Federación Indígena de la

Nacionalidad Cofán del Ecuador

Quito y Zábalo, Ecuador

cofan@attglobal.net

\section{Daniel Brinkmeier (comunicación)}

Environmental and Conservation Programs

The Field Museum, Chicago, IL, U.S.A.

dbrinkmeier@fieldmuseum.org

Felipe Campos Y. (anfibios y reptiles)

The Nature Conservancy

Quito, Ecuador

fcampos@ecnet.ec

Freddy Espinosa (logística de campo)

Fundación para la Sobrevivencia del Pueblo Cofán Quito, Ecuador

cofan@attglobal.net
Robin B. Foster (plantas)

Environmental and Conservation Programs The Field Museum, Chicago, IL, U.S.A. rfoster@fieldmuseum.org

\section{Debra K. Moskovits (coordinadora)}

Environmental and Conservation Programs The Field Museum, Chicago, IL, U.S.A. dmoskovits@fieldmuseum.org

Nigel Pitman (plantas)

Center for Tropical Conservation

Duke University, Durham, NC, U.S.A.

ncp@duke.edu

Lily O. Rodríguez (anfibios y reptiles)

Asociación Peruana para la Conservación de la Naturaleza (APECO), Lima, Perú

lilyrodriguez@pop.terra.com.pe

Thomas S. Schulenberg (aves)

Environmental and Conservation Programs The Field Museum, Chicago, IL, U.S.A. tschulenberg@fieldmuseum.org 


\section{COLABORADORES}

Tatzyana Wachter (logística de campo)

Environmental and Conservation Programs

The Field Museum, Chicago, IL, U.S.A.

twachter@fieldmuseum.org

Amelia Yiyoguaje (naturalista, logística de campo)

Fundación para la Sobrevivencia del Pueblo Cofán

Quito, Ecuador

cofan@attglobal.net

\section{Comunidad Cofán Alto Bermejo}

Ecuador

\section{Comunidad Cofán Chandia Na'e}

Ecuador

\section{Comunidad Cofán Doreno}

Ecuador

\section{Comunidad Cofán Sinangoe}

Ecuador

\section{Comunidad Cofán Zábalo}

Ecuador

Patricio Fuentes y Ximena Aguirre

Fundación La Bonita-Sucumbíos

La Bonita, Ecuador

Ministerio del Ambiente

Quito, Ecuador

Herbario Nacional del Ecuador (QCNE)

Quito, Ecuador 
The Field Museum

El Field Museum es una institución de educación y de investigación, basada en colecciones de historia natural, que se dedica a la diversidad natural y cultural. Combinando las diferentes especialidades de Antropología, Botánica, Geología, Zoología y Biología de Conservación, los científicos del museo investigan asuntos relacionados a la evolución, biología del medio ambiente y antropología cultural. El Programa de Conservación y Medio Ambiente (ECP) es la rama del museo dedicada a convertir la ciencia en acción que crea y apoya una conservación duradera. Con la acelerada pérdida de la diversidad biológica en todo el mundo, la misión de ECP es de dirigir los recursos del museo-conocimientos científicos, colecciones mundiales, programas educativos innovativos - a las necesidades inmediatas de conservación a un nivel local, regional, e internacional.

The Field Museum 1400 S. Lake Shore Drive Chicago, IL 60605-2496 U.S.A.

312.922.9410 tel

www.fieldmuseum.org
Fundación para la Sobrevivencia del Pueblo Cofán

La Fundación para la Sobrevivencia del Pueblo Cofán es una organización sin fines de lucro dedicada a la conservación de la cultura indígena Cofán y de los bosques amazónicos que la sustentan. Junto con su brazo internacional, la Cofán Survival Fund, la Fundación apoya programas de conservación y desarrollo en siete comunidades Cofán del Oriente ecuatoriano. Los proyectos actuales apuntan a la conservación e investigación de la biodiversidad, la legalización y protección del territorio tradicional Cofán, el desarrollo de alternativas económicas y ecológicas, y oportunidades para la educación de los jóvenes Cofán.

Fundación para la Sobrevivencia del Pueblo Cofán Casilla 17-11-6089

Quito, Ecuador

593.22.470.946 tel/fax

www.cofan.org 


\section{Federación Indígena de la Nacionalidad Cofán del Ecuador (FEINCE)}

La Federación Indígena de la Nacionalidad Cofán del Ecuador (FEINCE) es la principal organización política de los Cófan del Ecuador, representando sus cinco comunidades legalizadas - Chandia Na'e, Doreno, Dovuno, Sinangoe y Zábalo-a nivel nacional. La FEINCE forma parte de dos organismos nacionales dedicados a defender los derechos de las comunidades indígenas ecuatorianas: la Confederación de Nacionalidades Indígenas del Ecuador (CONAIE) y la Confederación de Nacionalidades Indígenas de la Amazonía Ecuatoriana (CONFENIAE). La FEINCE es dirigida por una mesa directiva elegida por la comunidad Cofán cada tres años.

Lago Agrio, Ecuador

\section{Herbario Nacional del Ecuador}

El Herbario Nacional del Ecuador (QCNE) es una sección del Museo Ecuatoriano de Ciencias Naturales (MECN), una institución del gobierno ecuatoriano fundada en 1978. El Herbario Nacional dirige programas de inventario, investigación y conservación de la flora y vegetación ecuatoriana, y almacena una colección de 160,000 especímenes de plantas y una biblioteca botánica de 2,000 volúmenes. La institución sirve como el centro de información nacional sobre la flora del Ecuador, situándose entre las principales instituciones científicas y culturales del país. Debido a su acceso público, el Herbario representa un recurso fundamental para los científicos, conservacionistas y estudiantes del Ecuador, y es una voz activa en el foro nacional sobre la biodiversidad y el medio ambiente. Durante las últimas dos décadas el Herbario ha formado cientos de botánicos jóvenes ecuatorianos mediante sus cursos de taxonomía y ecología, y llevado al cabo decenas de inventarios botánicos intensivos alrededor del país.

Herbario Nacional del Ecuador Casilla Postal 17-21-1787

Avenida Río Coca E6-115 e Isla Fernandina

Quito, Ecuador

593.22.441.592 tel/fax

qcne@q.ecua.net.ec 
Nuestra exploración de las escarpadas Serranías Cofán no hubiera sido posible sin la enorme ayuda de nuestros contrapartes y guías Cofán. Los Cofán se encargaron de toda la logística de campo, cortando senderos, cargando el material, montando los campamentos, cocinando, y manteniendo la expedición dentro del programa planeado. Por su incansable - y casi sobrehumana - ayuda les damos las gracias a Alfonso Yiyoguaje, Lauriano Quenama, Nivaldo Yiyoguaje, Eliberto Alvarado, Ciro Alvarado, Sebastián Descanse, Jorge Criollo, José Omenda, Angel Omenda, Abrám Omenda, Aurelio Omenda, Fabian Omenda, Daniel Omenda, Eliseo Alvarado, José Descanse, Marceliana Alvarado, Marisol Alvarado, Beatriz Descanse, Alicia Descanse, Bacilio Descanse, Jesus Queta, Pablo Queta, y Tiberio Queta, al igual que a los demás residentes de las comunidades del Alto Bermejo, Sinangoe y Chandia Na'e, que nos recibieron calurosamente a sus bosques.

Roberto Aguinda trabajó con las comunidades de Bermejo por varios meses antes de nuestra llegada, para asegurar que todas las operaciones salieran bien. Durante el inventario, su dominio de Cofán y su entrenamiento en botánica resultó en una colaboración etnobotánica muy valiosa con Bacilio Descanse, José Omenda, y otros. La dedicación de Roberto, su paciencia, y su buen humor continuarán siendo fundamentales para el éxito de la conservación de las Serranías Cofán.

Mientras que Roberto se encargaba de los preparativos en el campo, Freddy Espinosa se aseguraba de conseguir los permisos en Quito, de comprar el equipo, y de mantener abiertas las líneas de comunicación entre las Serranías Cofán, Lago Agrio, Quito, y Chicago. Su entusiasmo y perseverancia fueron clave en lograr la compleja coordinación antes, durante y después del viaje. Su incansable energía y las miles de millas que recorrió entre Lago Agrio y Quito fueron indispensables para el éxito de la expedición y para las reuniones posteriores. La esposa de Freddy - Maria Luisa Lopez-se encargó de la contabilidad y de las actividades, y facilitó las reuniones antes y después de la expedición en Quito y Lago Agrio. La energía de Maria Luisa y de Freddy, y su tremendo interés en el proyecto, continúan siendo esenciales para resolver los obstáculos grandes y pequeños a lo largo del camino.

Durante la expedición, fue Amelia Yiyoguaje con su tremenda eficiencia, quien coordinó serenamente nuestra complicada logística. Ella se encargó de que todos los campamentos estuvieran en orden, con suficientes provisiones y con la mejor comida.

Y Amelia por arte de magia consiguió incluir las cosas especiales que uno siempre aprecia en el campo. La habilidad de Amelia como naturalista nos llevó a varias observaciones muy importantes para reptiles, mamíferos y aves.

A pesar de ser muy jóvenes Federico y Joshua Borman escalaron todos los senderos en las Serranías Cofán, ayudando a montar los campamentos y hasta colectaron una especie de lagartija nueva para la ciencia. Felipe Borman ayudó mucho con la logística, traducciones, observaciones, y cocinando en los campamentos en Bermejo.

En el Ministerio del Ambiente en Quito, agradecemos sinceramente a Laura Altamirano, por la ayuda con las recomendaciones para el seguimiento; Pati Galeano, por los permisos de colecta; Danilo Silva, por alentarnos en los esfuerzos de las Serranías Cofán desde el principio, y Hans Thiel, Roberto Ulloa, y Domingo Paredes, por las discusiones para poder implementar los siguientes pasos para la conservación.

Por su ayuda en identificar las muestras de plantas, les damos las gracias a José Manuel Manzanares (bromelias), Lorena Endara y Calaway Dodson (orquídeas), Jon Shaw (Sphagnum), Peter Jørgensen (Passifloraceae), Alejandra Jaramillo (Piper), Charlotte Taylor (Rubiaceae), Larry Skog (Gesneriaceae), Grady Webster (Euphorbiaceae), Lucia Lohmann (Bignoniaceae), y M. Lucia Kawasaki (Myrtaceae). David Neill y Rogelio Rojas nos ayudaran mucho en el Herbario Nacional del Ecuador. Lou Jost revisó secciones del manuscrito, y Carlos Cerón generosamente compartió con nosotros sus conocimientos sobre las plantas de las regiones de Sinangoe y Bermejo.

Por su ayuda con los registros de aves, agradecemos a Douglas Stotz, quien compartió con nosotros sus notas de Bermejo (1998) y revisó la lista en el informe, y Mark B. Robbins, quien compartió sus observaciones de Bermejo (1993).

Patricio Fuentes y Ximena Aguirre de la Fundación La Bonita-Sucumbios nos brindaron generoso acceso a la información sobre el área que rodea La Bonita y La Sofia (Apéndice 6). Les agradecemos las horas de discusiones que nos llevaron a las recomendaciones finales.

Helga Karsten y Jennifer Eagleton ayudaron a organizar y escanear las diapositivas. Helga también trabajó con Jessica Smith de Futurity, Inc. para preparar los mapas de los datos de imágenes de satélite digitales. Mary Giblin y Heike Betz ayudaron a escanear las imágenes de plantas. Rodrigo Sierra nos ayudó a conseguir las imágenes en la Figura 7 y Elsevier Science nos dió permiso de publicar sus imágenes. Heinz Plenge generosamente nos concedió el derecho de usar su fotografía del Oso de Anteojos (Figura 1). Roy y Robin Toft nos ayudaron con el uso de sus fotos del oso (portada). Jerry Coe acompañó al equipo a Ccuccono y contribuyó con excelentes fotos. John Terborgh y el Centro para la Conservación Tropical en la Universidad de Duke nos proporcionó espacio para escribir este informe.

Tyana Wachter, como siempre, contribuyó con la coordinación en el Ecuador y en Chicago. Su capacidad de facilitar operaciones complicadas nunca deja de sorprendernos. Daniel Brinkmeier nos prestó su magia produciendo materiales visuales instantáneos para las presentaciones y desarrollando materiales educativos a partir de nuestros resultados. Les agradecemos profundamente a Jennifer Shopland su valiosa aportación editando una parte del informe, Angela Padilla por sus traducciones rápidas al español, y Roberto Aguinda, Mike Cepek, Felipe Borman, Hugo Lucitante y Toribio Aguinda por las traducciones relámpago al Cofán (de las cuales se encargó Mike). Les agradecemos a Nora Oleas, Douglas Stotz y Susan Donoghue por sus correcciones y comentarios de todo el manuscrito. Jim Costello otra vez hizo milagros con nuestros requisitos de diseño adicional. Y Sophie Twichell, aún estando ausente durante la expedición, logró ser de una gran ayuda.

Agradecemos profundamente a John W. McCarter Jr., y Avecita Chichón por su interés y apoyo. Los fondos para este inventario fueron proporcionados por John D. and Catherine T. MacArthur Foundation y The Field Museum. 
RESUMEN EJECUTIVO

Fechas del trabajo de campo: 24 de julio-16 de agosto 2001

Sitios muestreados:

Tres áreas en la vertiente oriental de los Andes ecuatorianos, entre los $450 \mathrm{y}$

$2.341 \mathrm{~m}$ : las cabeceras de los ríos Bermejo y Chandia Na'e, incluyendo el cerro

Sur Pax; el cerro Shishicho, cerca a la comunidad Cofán de Sinangoe, y los bosques a sus alrededores; $y$ la cuenca del río Ccuccono, al oeste de Sinangoe (vea Figura 2).

Organismos estudiados:

Plantas vasculares, anfibios y reptiles, aves y mamíferos grandes

Resultados principales:

El equipo del inventario biológico rápido identificó oportunidades importantes para la conservación en la región de Bermejo y Sinangoe: áreas extensas de bosque del piedemonte andino, aún en excelente estado, a lo largo de toda una gradiente altitudinal, desde las tierras bajas de la Amazonía hasta los bosques andinos por encima de los $2.200 \mathrm{~m}$. Los bosques que visitamos resguardan una mezcla muy diversa de la biota de la selva baja y de los bosques montanos, la cual incluye un gran número de especies endémicas o nuevas para la ciencia que no están protegidas en ninguna otra parte del mundo. Estos bosques, históricamente bajo el manejo y protección de facto de las pequeñas comunidades Cofán que han vivido en la región por siglos, ahora se ven amenazados por la fragmentación y colonización a lo largo de la nueva Vía Interoceánica.

Durante tres semanas en el campo, nuestro equipo registró una gran cantidad de especies raras y geográficamente restringidas en los cuatro grupos de organismos muestreados. Varias de las especies son nuevas para la ciencia, otras son nuevas para el Ecuador, y un gran número aparentemente son restringidas (endémicas) al área. Aquí se presenta un breve resumen de los resultados:

Vegetación: Bosques húmedos y extremadamente diversos, sobre suelos arcillosos, ascienden desde los 400 a más de $2.000 \mathrm{~m}$. Esta es una zona de transición entre la flora de la selva baja amazónica y la de los bosques andinos, con una marcada transición entre las dos a los $1.500 \mathrm{~m}$. Otra comunidad de plantas distinta parece crecer a través de la región en los afloramientos de roca ácida. Áreas extensas están sujetas a deslizamientos frecuentes y están cubiertas con bosques de regeneración de diferentes edades, especialmente a lo largo del río Bermejo y en la zona entre Ccuccono y Sinangoe.

Plantas: El equipo identificó 800 especies de plantas, recolectó 1.000 especimenes botánicos, fotografió 600 especies y muestreó casi 1.000 árboles y arbustos en transectos. Estimamos una flora regional de 2.000 a 3.000 especies. Ya se confirmaron diez especies nuevas; se anticipan por lo menos otras diez. Una especie nueva de la familia Bromeliaceae (Figura 4B), aparentemente 
preferida del oso de anteojos, cubrió tramos enteros de los senderos en el cerro Sur Pax. La región bien podría ser el centro mundial de diversidad para la familia Rubiaceae, con por lo menos 35 géneros y más de 100 especies presentes. El área es también extremadamente rica en Orchidaceae, Gesneriaceae, Sapotaceae, Bromeliaceae y pteridofitas. Los botánicos registraron la mitad de las palmas conocidas en el Ecuador oriental.

Mamíferos Grandes: El equipo confirmó 42 especies de mamíferos grandes en el área, de las cuales ocho están citadas en el CITES Apéndice I (especies globalmente amenazadas de extinción), y 17 en el Apéndice II (posiblemente amenazadas de extinción). Registros notables incluyen 12 especies de primates y altas concentraciones de oso de anteojos y de tapir amazónico. Observamos lo que podría ser una nueva especie de ardilla, e informes locales sugieren la presencia en esta área de otras especies de mamíferos nuevos para la ciencia, incluyendo una raposa y un mono chorongo pequeño.

Aves: Encontramos una sorprendente riqueza en la comunidad de aves del bosque de laderas altas y poblaciones grandes de especies usualmente raras en otras partes de los Andes. El equipo registró 399 especies de aves en la región, de un estimado total de 700, y muchas de estas observaciones amplían el rango de distribución conocido para estas especies. Una especie es nueva para el Ecuador (Tinamus osgoodi) y otra sólo era conocida anteriormente en dos localidades (Myiopagis olallai).

Anfibios y Reptiles: Nuestro muestreo herpetológico se realizó solamente en el área de Sinangoe, aunque registramos un cecílido en Bermejo. Documentamos un total de 31 especies, con 17 sapos, seis serpientes, cinco lagartijas (incluyendo una especie aparentemente no descrita del género Dactyloa, Figura 5E), un cecílido y una salamandra. Anticipamos que adicionales especies nuevas serán descubiertas en los bosques de elevaciones altas.

Principales amenazas:

Los bosques de esta zona han sido divididos a la mitad por la nueva Vía Interoceánica (Figura 2A) que va de Lago Agrio a Tulcán. Estos bosques ahora están siendo deforestados y fragmentados por las olas de colonos que siguen la carretera. Compañías madereras han comenzado a talar árboles de valor a lo largo de los caminos, mientras que las incursiones dentro de la Reserva Ecológica Cayambe-Coca, para la caza y pesca ilegal, se intensifican. La meta urgente para la conservación es prevenir que este desarrollo desorganizado llegue a los bosques intactos al este y sur de la carretera.

Estado actual: Una parte del área de Bermejo tiene protección legal como Patrimonio Forestal, pero esa designación es demasiado débil como para defender la región del avance de la colonización. Mientras se escribía este informe, el Ministerio del Ambiente 


\section{RESUMEN EJECUTIVO}

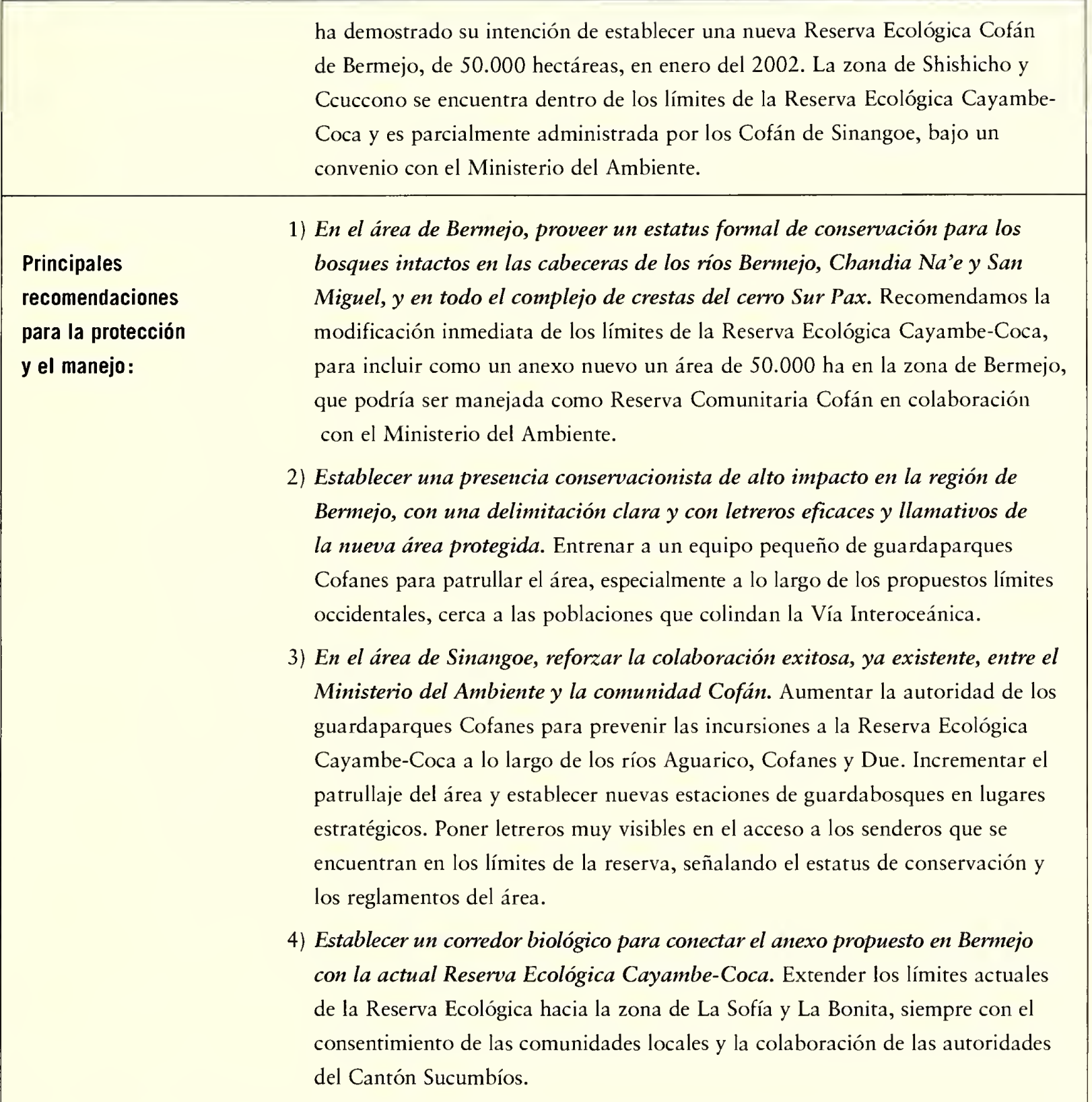

\section{Beneficios para}

la conservación

a largo plazo:
1) Un área nueva de conservación, globalmente importante, uniendo bosques montanos protegidos desde Colombia hasta la parte central del Perú.

2) Protección eficiente de un sector nuevamente vulnerable de la Reserva Ecológica Cayambe-Coca-una de las áreas protegidas más grandes e importantes en el Ecuador.

3) Conservación de las cuencas de los ríos Aguarico, San Miguel, Due y Bermejo.

4) Un modelo exitoso de conservación basada en la ciencia, resaltando la custodia por parte de una comunidad indígena de sus tierras ancestrales. 


\section{¿Por qué las Serranías Cofán?}

Sigamos la línea ecuatorial hacia el occidente, cruzando la cuenca amazónica hasta las estribaciones de los Andes, donde la cordillera más diversa del mundo se levanta de entre el bosque más rico de la tierra. Aquí, las tormentas originadas en la selva baja chocan directamente con el macizo andino, tallando profundos desfiladeros donde comienzan su vida los ríos amazónicos, como torrentes de agua blanca. Retorcidas cimas y picos aislados se levantan sobre el paisaje como un choque de tren geológico, rodeadas por los signos del levantamiento progresivo de las montañas: humeantes volcanes sobre el horizonte, laderas arrasadas por avalanchas y fallas activas que corren por debajo.

Estas son las Serranías Cofán, que se levantan de la planicie amazónica en una compleja enredadera de topografía y biodiversidad. Nos sentimos atraídos a ellas debido a que el clima y la geología particulares de sus bosques de transición-intermedios entre los nevados hacia el occidente y las cálidas selvas amazónicas hacia el oriente-han fomentado comunidades biológicas únicas, donde las comunidades vegetales y animales de las selvas bajas conviven junto a la flora y fauna andina, acompañadas de cientos de especies endémicas de la zona. A un día de escalada desde aquí, un biólogo puede desayunar en una selva amazónica y cenar en un bosque andino, deteniéndose para almorzar en la angosta franja a mediana elevación donde se sobreponen brevemente dos de las biotas más diversas del mundo, con una mezcla de especies no encontradas en ningún otro lugar del mundo.

Pero la situación de las Serranías se vuelve más y más crítica. Una nueva carretera, abierta en agosto del 2000, ha dividido en dos los bosques de Bermejo y Sinangoe, que antes eran contiguos. La colonización, la tala del bosque a pequeña escala y las actividades madereras están aumentando en los bosques adyacentes, y este frente ha llegado ya hasta el valle de Bermejo. Incluso en el punto más elevado que estudiamos, la cima de $2.275 \mathrm{~m}$ justo al sur del cerro Sur Pax, pudimos escuchar las motosierras en los claros colonizados a lo largo del río Chingual. Nuestras exploraciones, colecciones y recomendaciones para la acción se ven impulsadas por la certeza de que algunos de estos bosques están apenas a meses de su destrucción. 


\section{r}

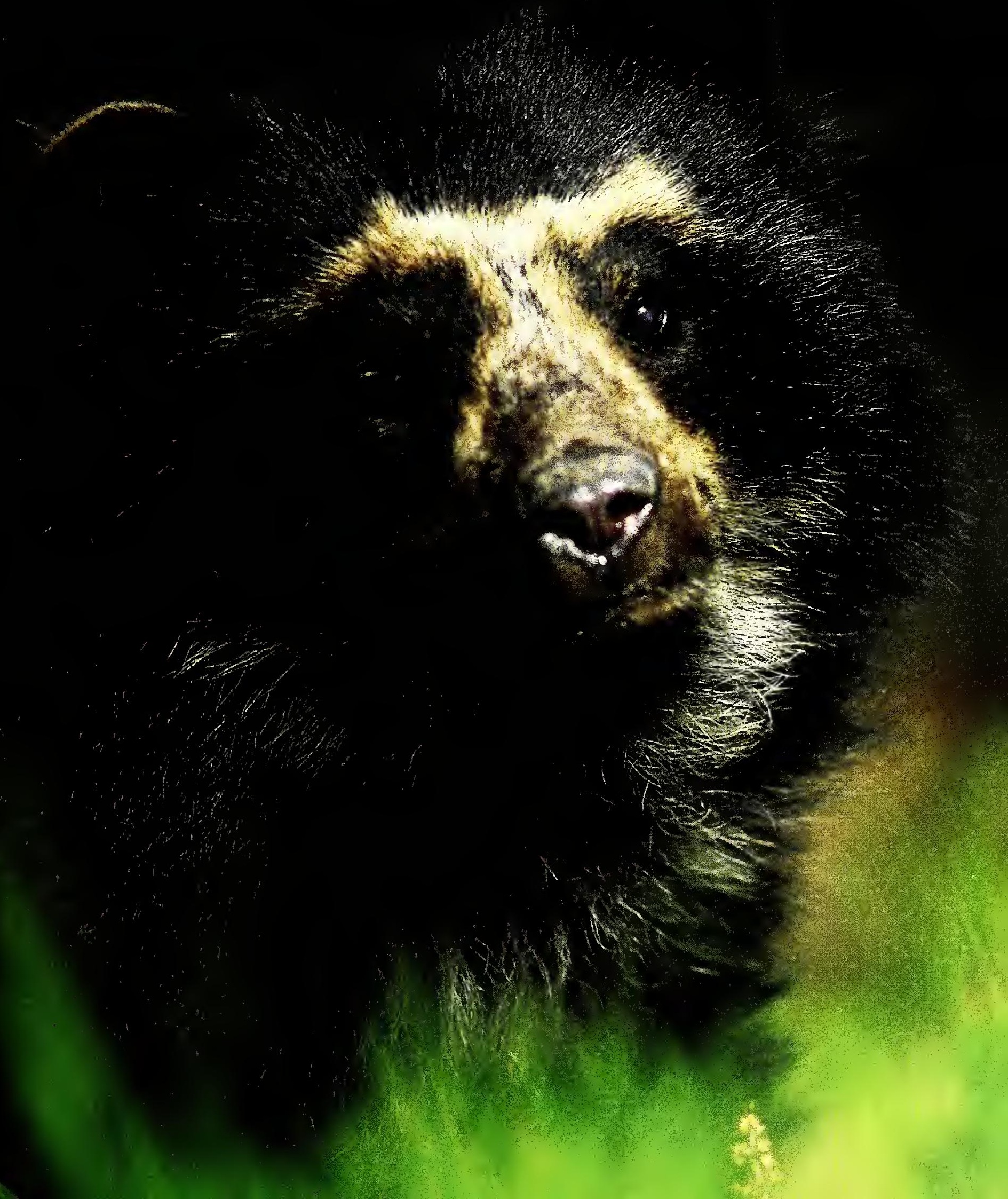




\section{ECUADOR}

FIG.2 Linderos, ríos, colonizaciones, y sitios de estudio del inventario biológico rápido en una imagen satélite de las regiones de Bermejo y Sinangoe (septiembre del 2001). Los cuadros claros corresponden a las fotografías en la página abajo.

Marrón indica bosques. Verde claro representa deforestación (vea las plantaciones de coca al norte de la frontera). El color rojizo en las cimas de las montañas indica vegetación enana. Las manchas blancas son nubes. Recuadro: ubicación de la imagen satélite en América del Sur. Boundaries, rivers, setzlements, and rapid biological inventory study sițes on a satellite image of the Bermejo and Sinangoe region in September 2001. Pale squares correspond to photographs below. Brown indicates forest. Light green represents deforestation (note coca plantations north of the border). Pale reddish on top of mountains is stunted vegetation. White puffs are clouds. Inset: location of satellite image in South America.
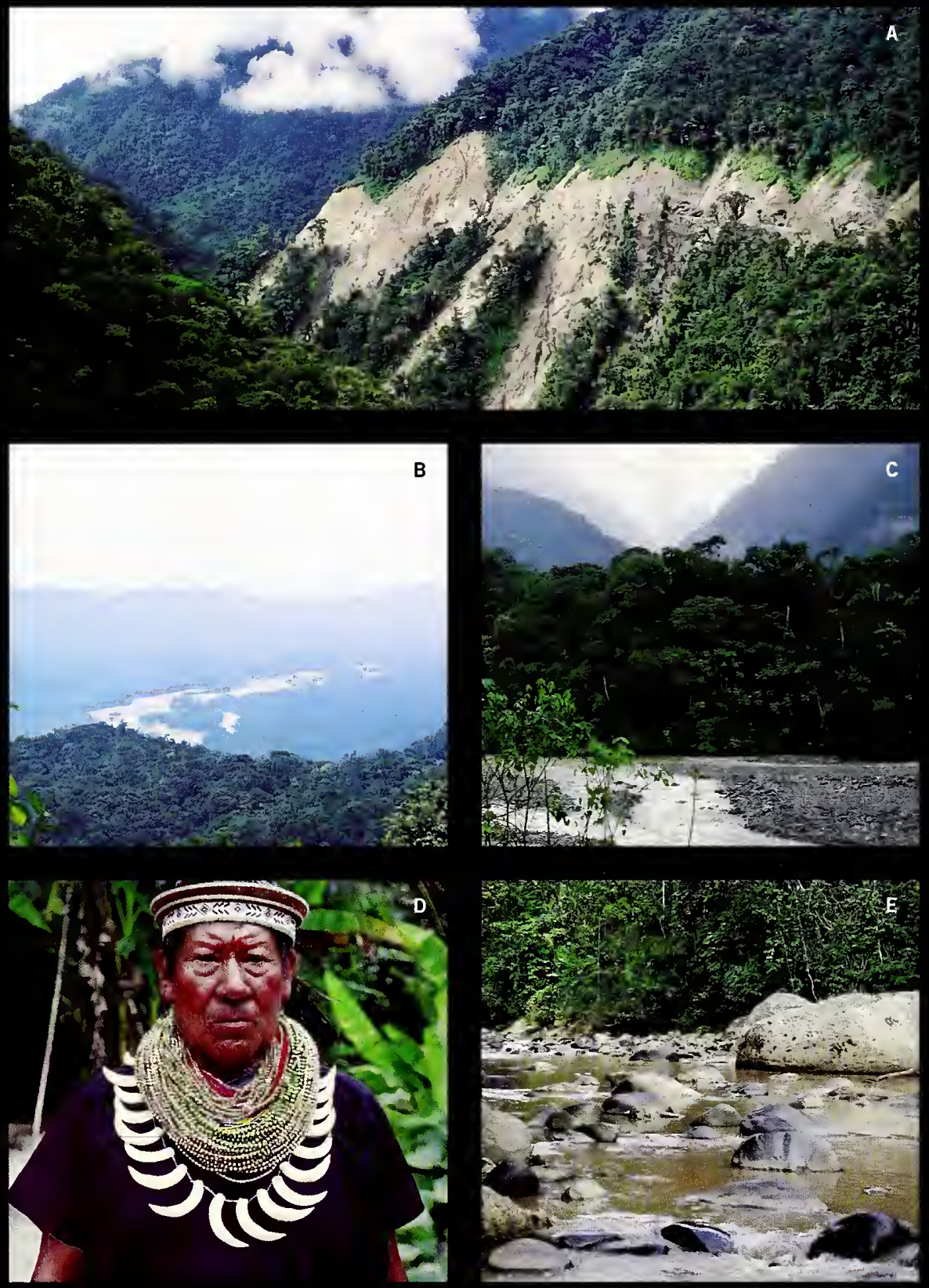

FIG.2A La Via Interoceánica-

una línea angosta azul claro visible en la imagen satèlite - corta a través de bosques intactos más al norte de Puerto Libre. The new Interoctanic Highway, visible on the sateliste image as a thin, light blue line, cuts through intact forest above Puerto Libre.

FIG.2B Mirando hacia el: sudeste desde el cerro Shishicho hasta el valle del rio Aguarico, mas allá de Puerto Libre. Looking southeast from the Sin tich ridge into the Aguarico River valley, past Puerto Libre

FiG. 2C Bosques intactos cubren las tierras bajas del río Aguarico hasta los $3.000 \mathrm{~m}$ de elevación. Intacl forest's ascend from the lowland Aguarico River to above $3,000 \mathrm{~m}$ in elevation.

FIG.2D Los Cofán han habitado estos bosques por siglos. The Cofán people have inhabited these forests for centuries.

FIG.2E. Erosión natural a lo largo del río Bermejo le da su color rojizo. Natural erosion along the Bermelo River gives it a reddish tint. 


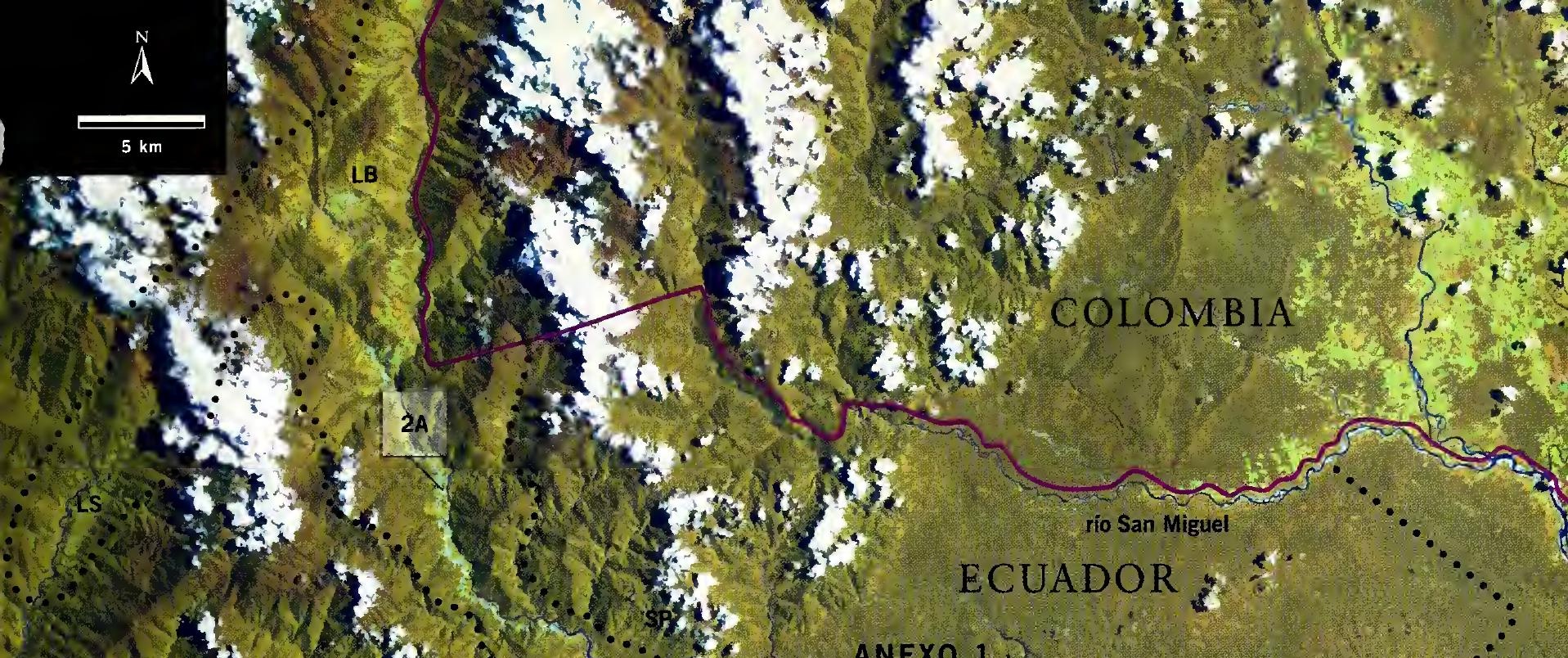

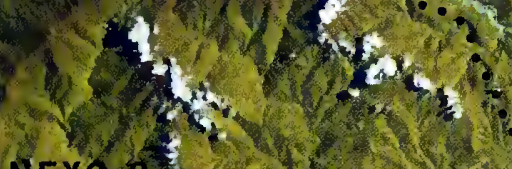

ANEXO 2 the
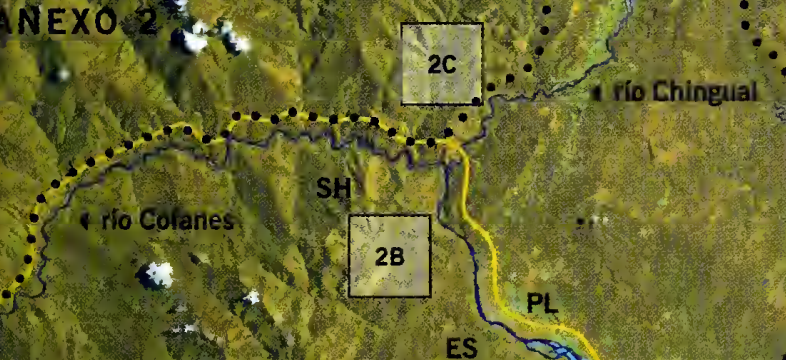

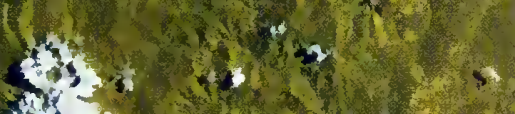
$x+2$

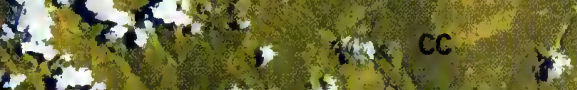

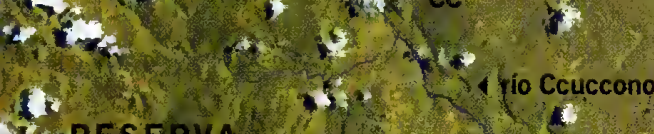

MRESERVA KCAM KB EOCA

tor
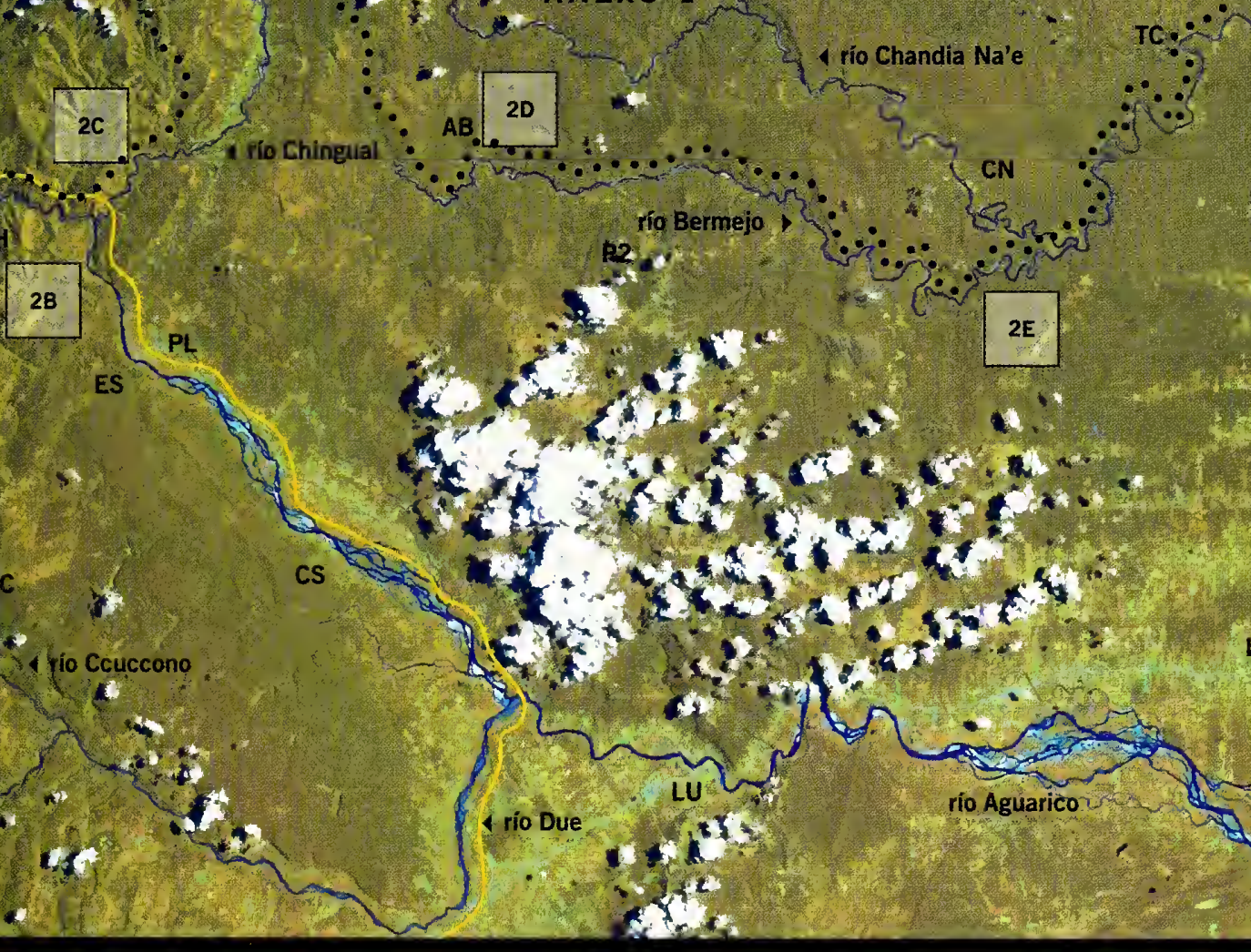


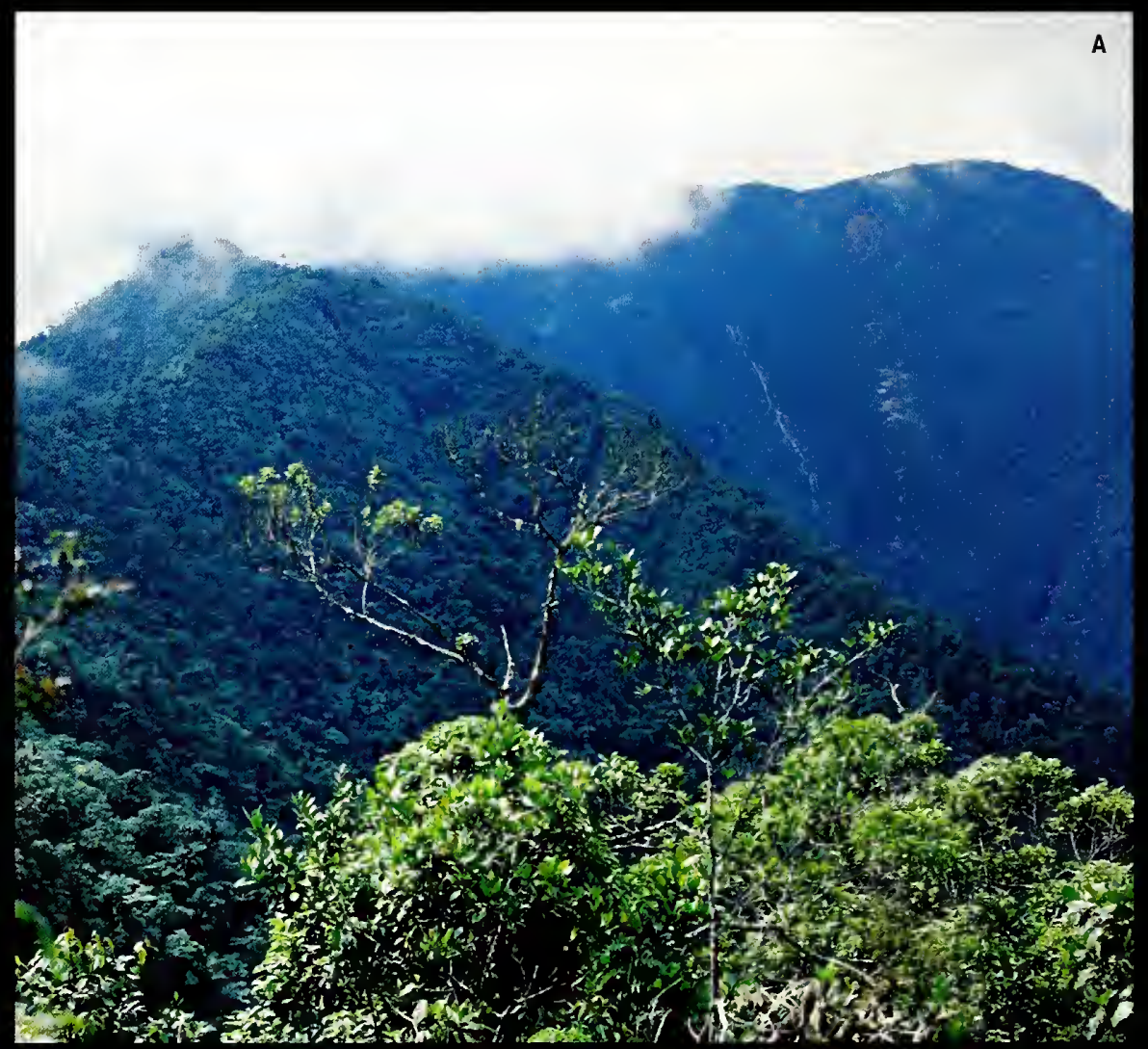

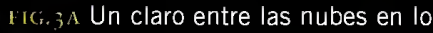
alto de Sur Pax demuestra las crestas inexploradas hacia el norte. A break

in the clouds high on Sur Pax shows the unexplored, high-elevation ridge to the north.

I IG. $3 \mathrm{~B}$ Flores silvestres alfombran la pared sur de la cascada de Sur Pax. Witdflowers carpet a waterfall on the southern face of Sur Pax

IIG.3C Ricos en epífitas, los bosques en la cima de Sur Pax se quedan permanentemente cubiertos de neblina. The epiphyte-rich forests on the summit of Sur Pax are permanently enveloped in fog

I IG. 31 El riachuelo cristalino Ccangopacho fluye hacia el río Ccuccono Pequeño. The crystal-clear Ccangopacho Stream flows into the Smaller Ccuccono River

IIG. $3 \mathrm{E}$ Las áreas dominadas por la palmera Iriartea deltoidea son frecuentes hasta los $1.000 \mathrm{~m}$. Gloves of the common patm Iriartea deltordea are frequent up to $1.000 \mathrm{~m}$
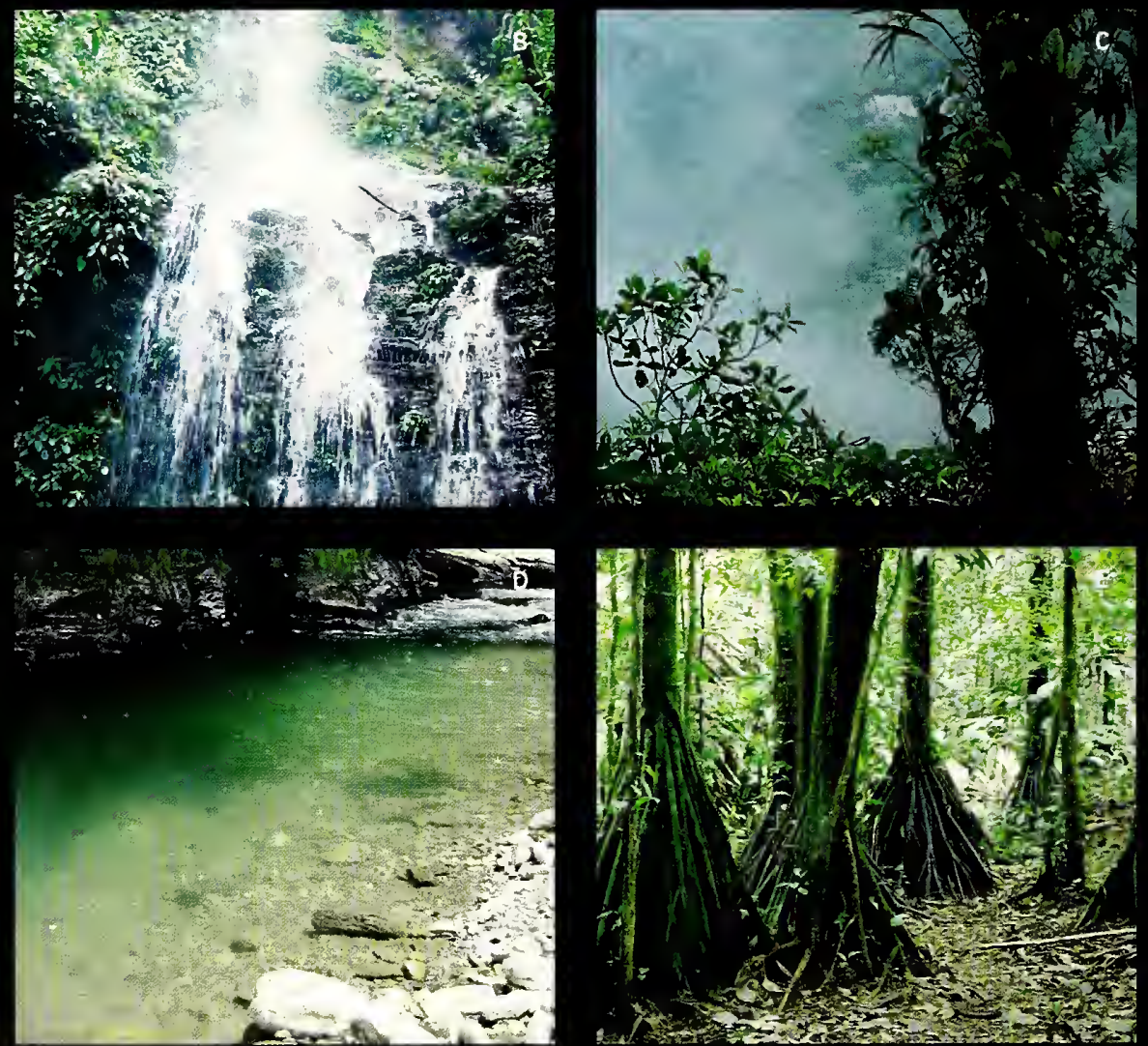
$\| c_{i}+1$ Este arbusto nuevo para la ciencia, un Calyptranthes (Myrtaceae) usado en ceremonias Cofán para marcar la transición a la pubertad, parece ser endémico a sólo una ladera cerca de la Estación Sinangoe.

This undescribed shrub, a

Calyptranthes (Myrtaceae) used in

Cofan comng-of-age ceremonies,

appears to be endemic to a hiliside

near the Sinangoe field station.

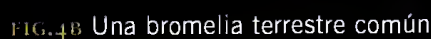
en Sur Pax, previamente desconocida por la ciencia, es una de las plantas favoritas de la que se alimentan los osos de anteojos (Figura 1).

A common terrestrial bromeliad on Sur Pax, previously unknown to science, Is one of the favorite food plants of spectacled bears (Figure 1)

Iri.tc. Especies de helechos Danaea son comunes en todo el sotobosque. Dandea fern species are common throughout the forest understory.

IIGi.tD Los frutos grandes de Billia rosea, uno de los árboles más comunes en los bosques de selva alta de la región, son un recurso valioso para los animales. The large fruits of Billia

rosea, one of the most common trees in the upland forests of the region, are a valuable resource for animals.

I'IG. Esta Calathea comùn es una de las diez especies de plantas nuevas para la ciencia. This common Calathea is one of ten plant species new to science.
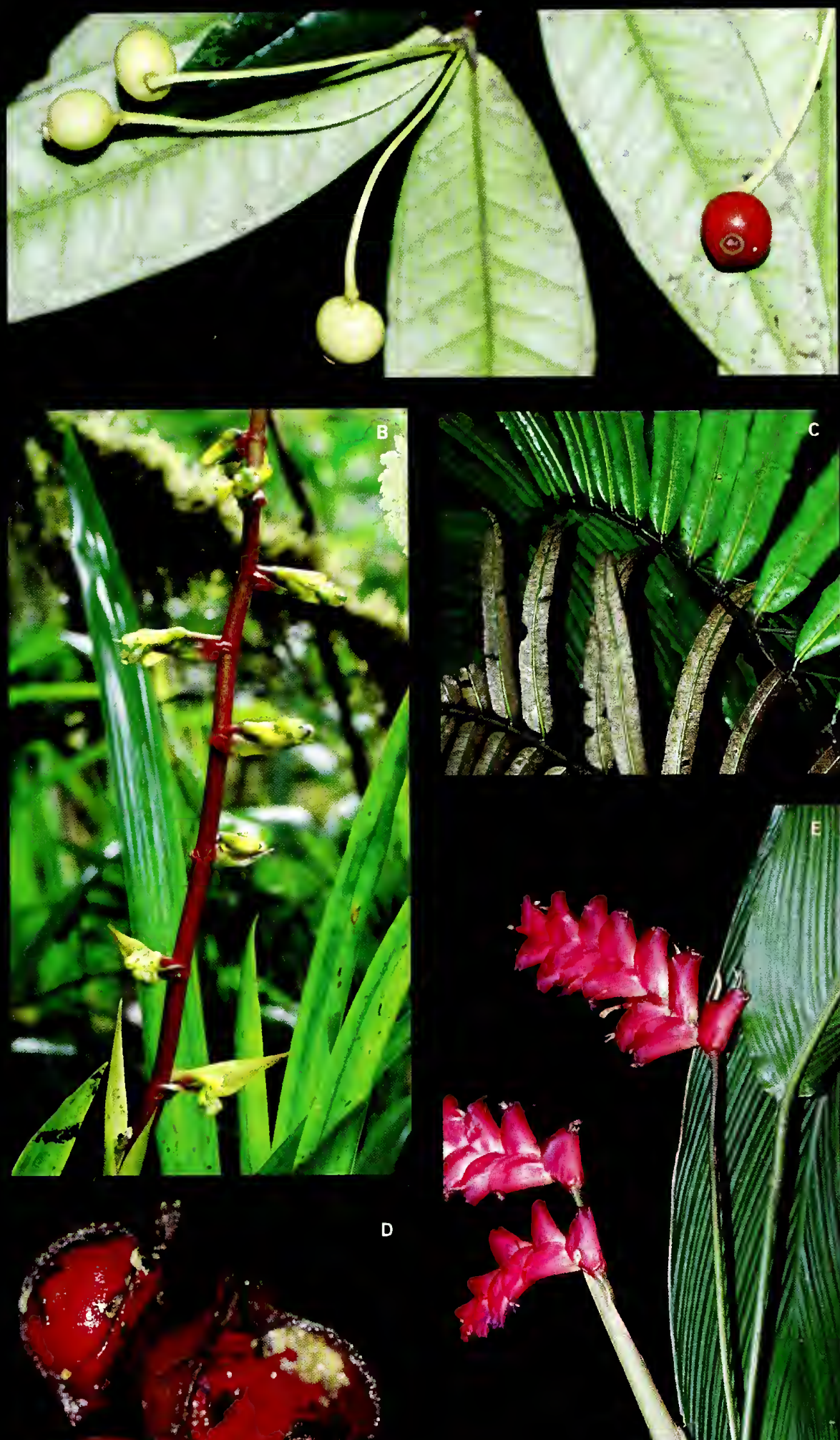

D
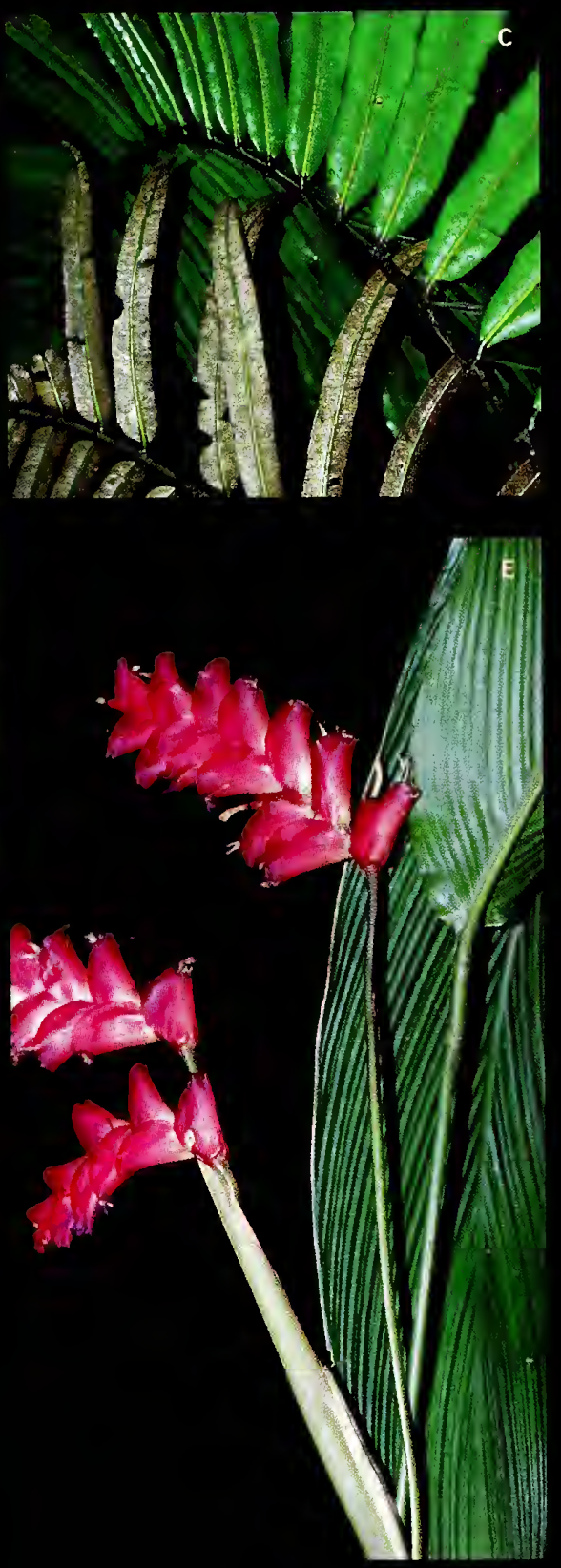

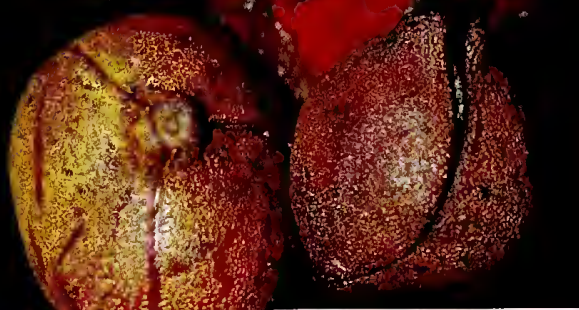


Fig.6A-B José Omenda, botánico Cofán, teje una canasta de las raíces aéreas de un Philodendron

The Cofan botanist José Omenda weaves a backpack from the aerial roots of a Philodendron.

11G.6C La Estación Sinangoe alberga a los guardaparques e investigadores The Simangoe field station houses Cofán park guards and visiting researchers

FiG.6D Un sendero botánico en Sinangoe tiene los nombres científicos y Cofanes. A marked botanical

trail In Sinangoe has both Cofán and scientific plant names

IIG.61: Uno de los botánicos colecta una muestra a lo largo de un tributario del río Ccuccono. One of the botanists coliects a specimen along a tributary of the Ccuccono River

IG. Go Naturalistas Cofán empiezan a explorar el bosque desde pequeños. Cofan naturalists start exploring the forest at an early age.

ITG GG: Randy Borman y Amelia Yiyoguaje salen para su censo de mamiferos. Randy Borman and Amelia Yiyoguaje set off on a mammał survey
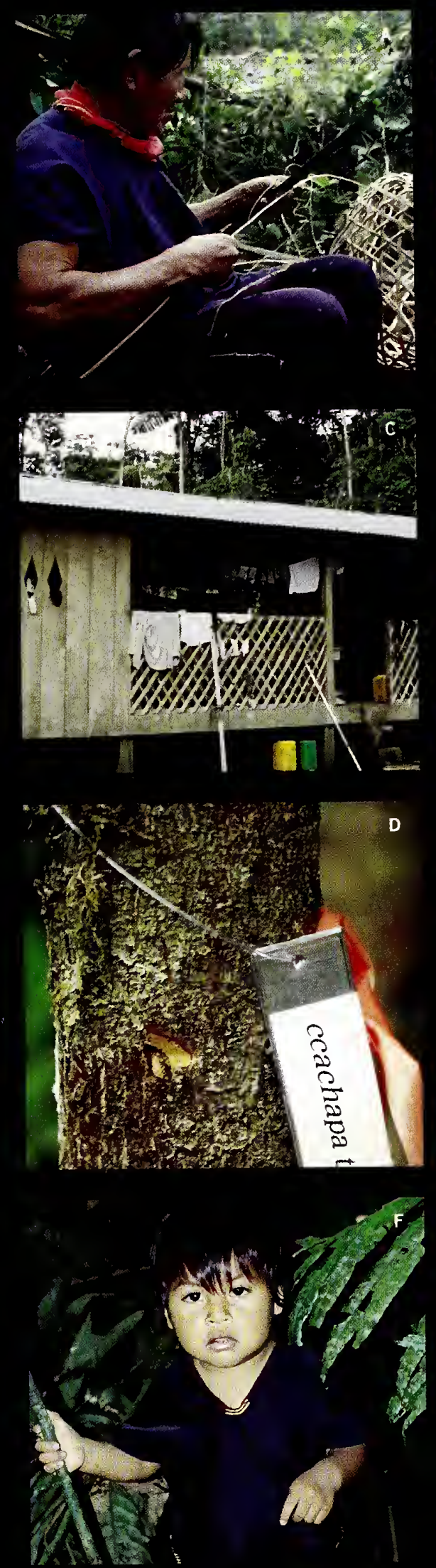
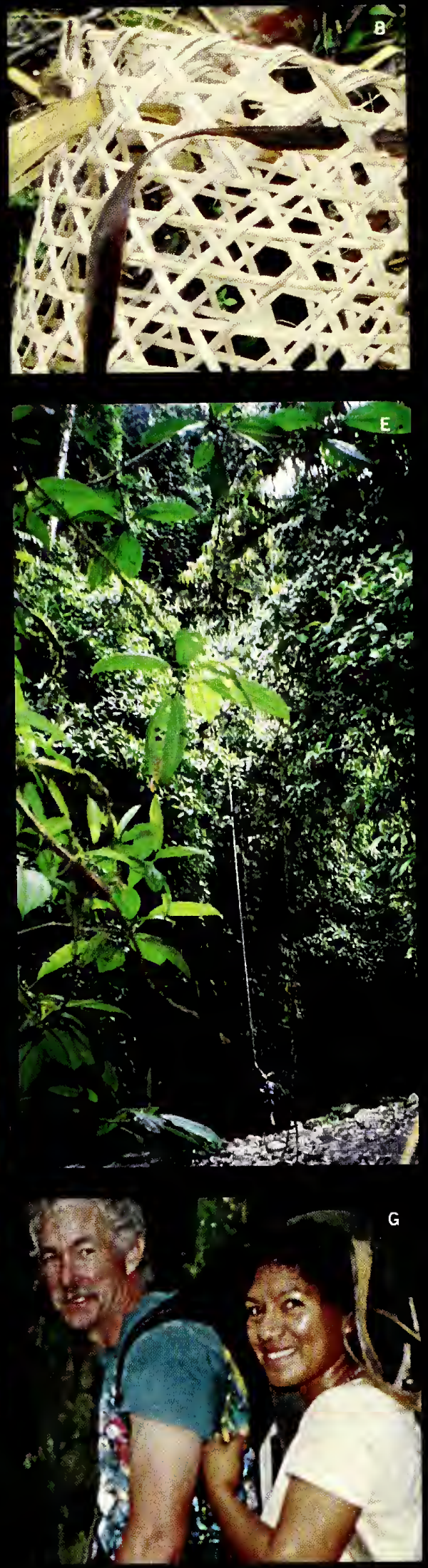


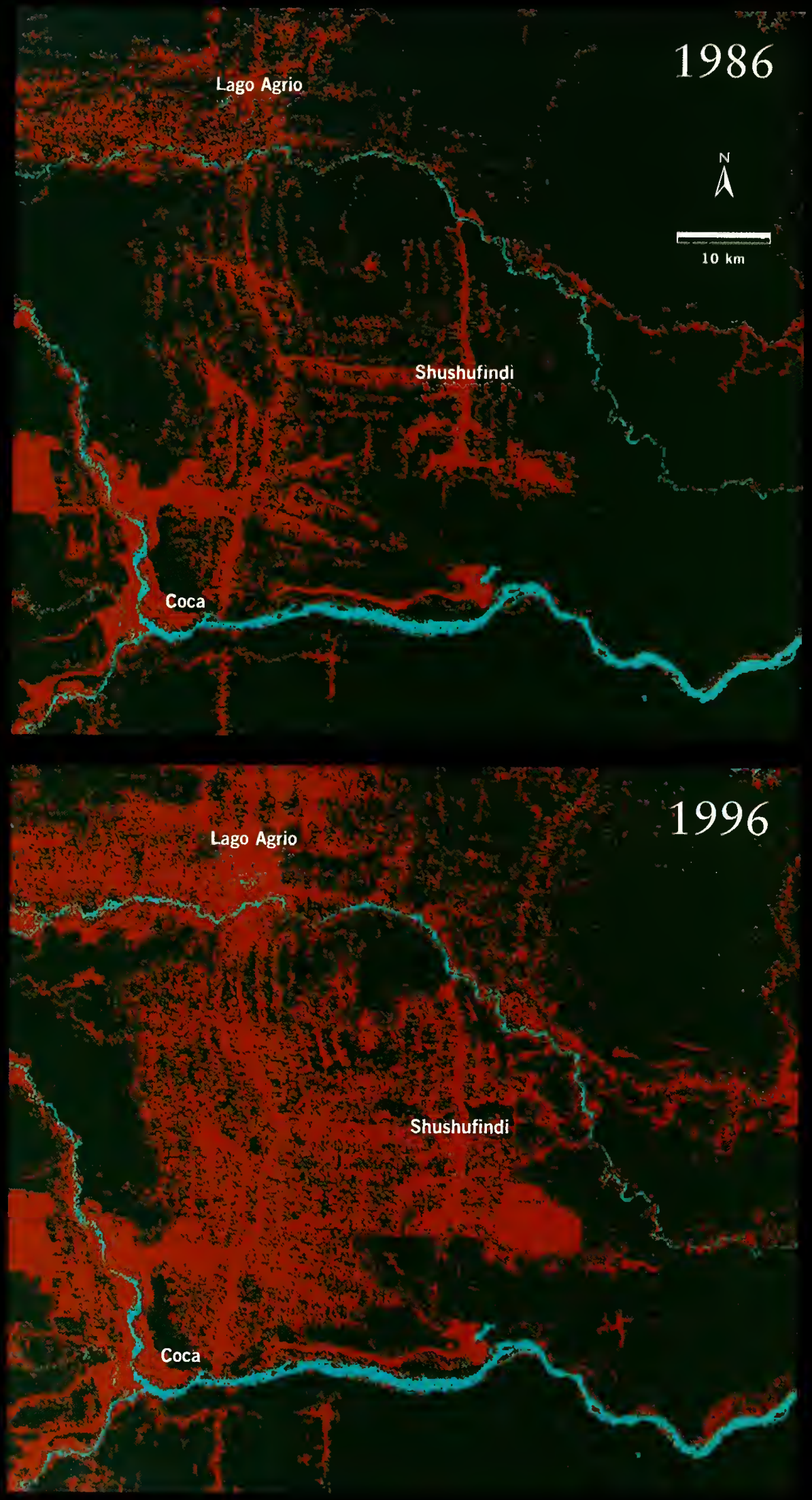

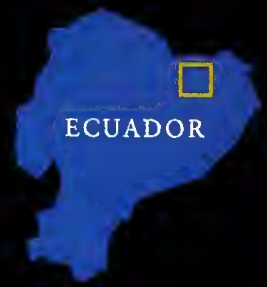

FIG.7 Una comparación de las imágenes de satélite de 1986 y 1996, de las selvas bajas, al este de las Serranias Cofán, demuestra la desenfrenada deforestación a lo largo de los caminos. Observa la destrucción de Santa Cecilia - el lugar con más alta diversidad de herpetofauna documentada en todo el mundo $-20 \mathrm{~km}$ al oeste de Lago Agrio, y la supervivencia de una extensión de bosque alrededor de la comunidad Cofán de Doreno, $20 \mathrm{~km}$ al sudeste de la ciudad. El análisis y figura han sido reimpreso de Sierra (2000), con permiso de Elsevier Science. A comparison of 1986 and 1996 satellite images of the lowlands just east of the Serranias Cofán shows the rampant deforestation along roads. Note the destruction of the worid's most diverse documented herpetofauna at Santa Cecilia, $20 \mathrm{~km}$ to the west of Lago Agrio, and the survival of a large patch of forest around the Cofán community of Doréno, $20 \mathrm{~km}$ to the southeast of the city. Analysis and figure reprınted from Sierra (2000), with permission from Elsevier Science.

\section{LEYENDA/LEGEND}

$$
\begin{aligned}
= & \text { Rios y lagos } / \\
& \text { Rivers and Lakes } \\
= & \text { Bosque/Forest } \\
= & \text { Deforestado/Deforested }
\end{aligned}
$$

Créditos fotográficos/Photo credits :

Fig. 1 Oso de anteojos/Spectacled bear (Tremarctos ornatus) fotografia cortesia de/ photograph courtesy of Heinz Plenge.

Figs. 2A, 2B, 2C, 3A, 3C, 3E, 4A, 4B, 4C,

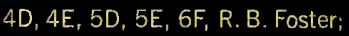
Figs. 2E, 5B, 6C, T. S. Schulenberg; Fig. 2D, S.B. Twichell; Figs. 3B, 3D, 5A, 5C, D. K. Moskovits; Figs. 6A, 6B, 6D, 6E, 6G, J. Coe 


\section{Panorama General de los Resultados}

Contribuyentes/Autores: Nigel Pitman, Randall Borman A., Debra K. Moskovits, Robin B. Foster, Thomas S. Schulenberg, Lily O. Rodríguez, Jennifer M. Shopland, Felipe Campos

\section{PERFIL ECOLÓGICO}

Vistos desde el espacio en imágenes de satélite, los bosques de Bermejo y Sinangoeen las estribaciones nororientales del Ecuador-parecieran ser selvas no habitadas. Pero al contrario, estos bosques han sido habitados durante siglos por el pueblo indígena Cofán, que vive ahora en cuatro pequeñas comunidades a lo largo de los ríos Aguarico, Bermejo y Chandia Na'e. Durante tres semanas en julio y agosto del 2001, nuestro equipo de inventario - que contó con varios naturalistas Cofanesenfocó su atención en las plantas y animales de tres sitios en estas Serranías: (1) el valle del río Bermejo, que se eleva desde su piso a $450 \mathrm{~m}$ hasta la cima del cerro Sur Pax de $2.341 \mathrm{~m}$, cerca de la frontera con Colombia; (2) el cerro Shishicho y los bosques a su base, cerca de la confluencia de los ríos Cofanes y Aguarico; y (3) la cuenca del río Ccuccono (Figura 2). Nuestra meta no era un inventario completo del área-algo imposible de realizar en tan corto tiempo-sino un retrato lo suficientemente detallado de sus comunidades biológicas que nos permitiera evaluar la importancia de su conservación para el Ecuador y para el mundo.

Gran parte de lo que vimos constituía territorio desconocido para los científicos, quienes nunca habían visitado el cerro Sur Pax, el cerro Shishicho, o el drenaje del río Ccuccono, pero que durante años han sido sitios muy familiares para los habitantes Cofán. El equipo documentó por lo menos 1.000 especies de plantas, de una flora regional estimada en 2.000 a 3.000. Registramos 399 especies de aves de una avifauna regional estimada en 700, y 42 de las 46 especies de mamíferos grandes esperados en esa región. Dentro de un paisaje tan poco estudiado, no nos sorprendió descubrir que una gran cantidad de las especies encontradas eran nuevas para el Ecuador o completamente desconocidas por la ciencia. Incluso en esta primera etapa, antes de identificar la mayor parte de nuestras muestras de plantas, los especialistas taxonómicos han confirmado que por lo menos diez de las mismas son nuevas para la ciencia, y por lo menos una representa un género nunca antes recolectado en el Ecuador. Registramos una nueva especie de ave para el Ecuador, una especie no descrita de lagartija y grandes poblaciones de especies de mamíferos que han sido cazados prácticamente hasta su extinción en otras áreas del Oriente ecuatoriano. Una gran 
cantidad de las especies de aves y mamíferos que documentamos son raras o están bajo amenaza en otros lugares dentro de su hábitat y existen en mayor abundancia en las Serranías Cofán de lo que hemos visto en cualquier otro lugar.

En las siguientes secciones proveemos un resumen de los principales resultados de nuestro estudio, junto con recomendaciones para acciones de conservación. Esta es básicamente una versión breve del informe técnico, que comienza en la página 39. Empezamos esta visión general advirtiendo que el paisaje descrito aquí está bajo un constante estado de renovación, sujeto a cambios de un momento a otro. Ubicados en una zona de sismos, junto a uno de los volcanes más activos de los Andes orientales y arrasados periódicamente por enormes deslizamientos e inundaciones, los bosques de este lugar probablemente se encuentran entre los más dinámicos a gran escala de la zona neotropical. Hace muy poco, en 1987, un gran sismo arrancó todo el bosque de un territorio de varios miles de kilómetros cuadrados, justo al sur de la región de las Serranías. Las imágenes de satélite actuales del área están salpicadas con las cicatrices de los recientes deslizamientos y de peñascos que han colapsado (Figura 2), y en muchas áreas la enmarañada selva joven que se va recuperando de recientes derrumbes cubre una porción significativa del paisaje.

\section{COMUNIDADES COFÁN LOCALES}

Estos bosques han sido habitados por el pueblo Cofán desde que se comenzaron a llevar registros, y probablemente varios siglos antes de la llegada de los europeos. Los conquistadores españoles que exploraron el área en el siglo XVI entraron en contacto con los Cofán en 1536, como lo describió Juan de Velasco en su clásico Historia del Reino de Quito. Casi 400 años después, al iniciar las compañías petroleras la perforación a gran escala en el nororiente ecuatoriano, los Cofán continuaban siendo el grupo indígena predominante en el área.
Conocido también como los A'i, el pueblo Cofán es autóctono de las cuencas de los ríos Aguarico y San Miguel en el noreste ecuatoriano y el sur de Colombia. El idioma Cofán es lingüísticamente único, sin un pariente cercano, aunque comparte algunas características de los idiomas Chibchas del centro de Colombia y del occidente del Ecuador. Formando ahora uno de los ocho grupos indígenas que habitan la Amazonía ecuatoriana, los Cofán ecuatorianos ascienden a 1.000 hablantes nativos en siete comunidades aisladas de las Serranías Cofán y las selvas amazónicas aledañas. Casi un tercio de ellos-320 personas-viven en cuatro communidades en el área visitado por el equipo de inventario rápido en 2001. En vista del leve "rastro" de estas cuatro comunidades y la magnitud de los bosques que los rodean, la mayor parte de las Serranías continua siendo una selva intacta, con una densidad poblacional regional de menos de media persona por kilómetro cuadrado. Sin embargo, los conocimientos, el uso y la presencia histórica de los Cofán en el área, al igual que su creciente participación en las iniciativas de conservación (vea Apéndice 5), los convierten en actores claves de la conservación de la región a largo plazo.

La comunidad Cofán más grande y accesible en la región es Sinangoe, donde aproximadamente 150 personas viven en la ribera sur del Aguarico, entre las desembocaduras de los ríos Candue y Sieguyo, justo al otro lado del río de la nueva Vía Interoceánica (Figura 2A). Ya que la comunidad queda dentro de la Reserva Ecológica Cayambe-Coca, ha sido durante mucho tiempo objeto de interés para biólogos y conservacionistas (Cerón et al. 1994, Altamirano y Quiguango 1997, Mena 1997). Guardabosques Cofán patrullan un segmento grande de la reserva, bajo un acuerdo con el Ministerio del Ambiente del Ecuador. La comunidad de Sinangoe viene trabajando en un plan de manejo que equilibra sus aspiraciones con la meta común y a largo plazo de proteger la reserva. Utilizamos como base para parte de nuestro inventario en esta región a la estación de campo-para investigación y vigilancia-que los Cofán construyeron hace poco en la desembocadura del río Sieguyo (Figura 6C). 
La mayor parte de las actividades cotidianas en Sinangoe están dedicadas todavía a la agricultura a pequeña escala, caza, pesca y artesanías para el turismo. Otras tres comunidades Cofán más pequeñas se ocupan en actividades similares en el valle del río Bermejo, las que complementan con la recolección de productos forestales medicinales como la "uña de gato" (la liana Uncaria tomentosa, Rubiaceae) y la "sangre de drago" (el árbol Croton lechleri, Euphorbiaceae). No visitamos las dos comunidades en la parte inferior de la cuenca (Chandia Na'e y Tayosu Canqque, visibles en las imágenes satelitales como pequeños claros rodeados de bosque, cada una con unos 80 habitantes; Figura 2). En cambio, visitamos el Alto Bermejo, una aldea de apenas 12 personas cerca de la cuenca del río Bermejo, empezando la primera etapa de nuestro inventario en la nueva estación de campo que se construyó hace poco en ese lugar.

\section{VEGETACIÓN Y FLORA}

La mayor sorpresa botánica al llegar a las Serranías Cofán-tan cerca de ciudades como Lago Agrio y Tulcán y bordeadas por dos carreteras principales-fue encontrar un paisaje natural prácticamente intacto. Estos bosques han permanecido excepcionalmente bien conservados a pesar de la larga historia de ocupación Cofán y no se han visto aislados todavía de grandes áreas silvestres adyacentes en los Andes y en la Amazonía. Desde nuestra posición de ventaja en un campamento a $1.200 \mathrm{~m}$, mirando desde lo alto al valle de Bermejo, podíamos disfrutar de una vista espectacular de selva que se extiende ininterrumpida hasta el horizonte. Es sólo a lo largo de la Vía Interoceánica que se puede ver la degradación y fragmentación del bosque, tan característica de otros lugares de los trópicos (Figura 2A).

Dos de las floras más grandes del mundo-la amazónica y la andina-se juntan aquí para producir una comunidad de plantas sumamente variada y compleja. Registramos más de 1.500 especies en la flora regional y calculamos la existencia de entre 2.000 a 3.000 (Apéndice 1). Para los propósitos de este informe, dividimos el paisaje en tres principales tipos de bosque: uno a elevaciones menores (grupos taxonómicos principalmente amazónicos), otro a las elevaciones más altas (grupos taxonómicos principalmente andinos) y otro a elevaciones intermedias (una mezcla compleja de ambos). Esta zonificación altitudinal parece estar impulsada más por el clima que por otros factores. Las transiciones más conspicuas entre las floras de tierras bajas y las de tierras altas ocurren en elevaciones donde persisten las nubes casi todo el año, la lluvia llega a su mayor nivel (OAS 1987) y los rayos solares son un raro lujo. Sí observamos una heterogeneidad significativa de la composición y estructura forestal en cada una de estas divisiones principales (es decir, de sitio en sitio dentro de la misma franja de elevación), pero estas diferencias por lo general no eran pronunciadas. Esto se debe probablemente a que hay pocas áreas de condiciones geológicas o de suelo "extremas" en la región, en comparación con las que se observan, por ejemplo, en la Cordillera del Cóndor (Schulenberg y Awbrey 1997).

\section{BOSQUE DE LADERAS BAJAS (400-950 m)}

Los bosques de elevación más baja en estas Serranias son una extensión de los famosos bosques diversos de la selva oriental ecuatoriana. Casi todas las familias y géneros de plantas encontrados aquí se encuentran también en las selvas amazónicas a pocos kilómetros al este, como en el Parque Nacional Yasuní y en la Reserva de Producción Faunística Cuyabeno. La mayoría de las especies individuales también son compartidas, aunque varios grupos taxonómicos demuestran una clara preferencia por el clima más húmedo en la base de los Andes. Al igual que en el resto del Oriente ecuatoriano, la diversidad local de árboles y lianas está entre las más altas del mundo. En uno de nuestros transectos de árboles de dosel en el bosque de laderas bajas registramos cerca de 60 diferentes especies en una muestra de 100 árboles. Como resultado de esta diversidad, la mayoría de 
las especies de árboles y lianas crecen en densidades infinitesimales. Las palmas son una familia dominante, junto con Fabaceae s.l., Myristicaceae, Vochysiaceae, Meliaceae y otras. El árbol más común aquí, al igual que en la mayor parte del Oriente ecuatoriano, es la palma Iriartea deltoidea (Figura 3E).

Ya evidente a esta altura hay una característica que distingue a las Serranías Cofán de cualquier otro bosque que conocemos: una sorprendente diversidad de especies de la familia del café, Rubiaceae. Es difícil encontrar un lugar en este bosque-sin importar la elevación-donde no se pueda apreciar una docena de diferentes especies de arbustos y árboles jóvenes y adultos rubiáceos. En total, registramos por lo menos 129 especies de esta familia, en 39 géneros diferentes. Muchas de éstas son desconocidas por la ciencia. Por ejemplo, $17 \%$ de las especies de Psychotria que recolectamos durante una visita a esta región en el 2000 han sido confirmadas como nuevas especies.

Las altas murallas de arcilla roja que constituyen una característica dramática del valle del río Bermejo parecen también albergar una comunidad de plantas únicas en sus cimas. Las condiciones climáticas y del suelo en estas cimas son diferentes a las encontradas en otros lugares del bosque bajo de las Serranías: los árboles en la parte superior de la muralla interceptan gran parte del aire húmedo que sopla desde el valle, y la constante erosión podría hacer que los estratos ácidos se encuentren particularmente cerca de la superficie. Encontramos varias especies interesantes en este lugar, no encontradas en ningún otro lugar, incluyendo el árbol Humiriastrum diguense (Humiriaceae), característico de suelos ácidos, al igual que una hermosa flor silvestre gencianácea aún no identificada.

\section{BOSQUE DE LADERAS ALTAS (950-1.500 m)}

En elevaciones mayores, la composición de las comunidades muestra una transición gradual. La riqueza de árboles comienza a disminuir, mientras que hay una explosión en la diversidad de hierbas terrestres y epífitas. Es aquí también donde se empieza a registrar el cambio de especies a lo largo de la gradiente de elevación. Cada paso a lo largo de un sendero ascendente en estas elevaciones parece cruzar la frontera del rango geográfico de alguna especie. Desaparecen unas especies de la selva baja, mientras comienzan a aparecer grupos taxonómicos exclusivos de las tierras altas. En Bermejo, hasta un $20 \%$ del dosel en estas elevaciones mayores consistía de Billia rosea (Hippocastanaceae), un árbol de semilla grande, principalmente montano, que se encuentra con frecuencia en la región (Figura 4D). En contraste, el árbol predominante en Ccuccono, constituyendo por lo menos el $26 \%$ de nuestro transecto y visible a kilómetros de distancia debido a sus hojas distintivas color naranja viva, fue Dacryodes olivifera (Burseraceae).

Varias de las crestas visitadas a mayor altitud en el bosque de laderas altas-particularmente en el área de Sinangoe-estaban cubiertas de una vegetación parcialmente enana. La flora en estas crestas es característica de suelos ácidos, probablemente porque los estratos rocosos están expuestos. En uno de estos sitios en Bermejo, recolectamos Purdiaea nutans (Cyrillaceae), un árbol cuya distribución en el Ecuador se consideraba restringida a las montañas ácidas de las provincias del sur. A lo largo de la cresta del cerro Shishicho, recolectamos la hierba gigante Symbolanthus calygonus (Gentianaceae)-también conocida en el Ecuador únicamente en las provincias del sur-y el arbusto Basistemon (Scrophulariaceae), siendo éste el primer registro de este género en el Ecuador (Jørgensen y León-Yánez 1999). También en Shishicho, justo bajo la cima más alta, encontramos una nueva especie de bromelia terrestre del género Pitcairnia (J. M. Manzanares, com. pers.). Al continuar identificando otras colecciones de estas crestas, creemos que continuarán apareciendo otras extensiones y especies nuevas.

\section{BOSQUES MONTANOS (POR ENCIMA DE LOS $1.500 \mathrm{~m}$ )}

En el tipo de bosque más alto que visitamos, la flora cambia definitivamente de géneros principalmente de 
selva baja a géneros primordialmente montanos. Familias de altas elevaciones, como Podocarpaceae, Brunelliaceae, Cunoniaceae y Clethraceae, aparecen en el dosel, aunque Billia rosea continuó dominando en un transecto en la cresta de $1.900 \mathrm{~m}$ debajo del cerro Sur Pax. El dosel del bosque es notablemente más bajo y húmedo que en elevaciones más bajas; las epífitas pesan sobre las ramas y helechos y musgos cubren el suelo como una alfombra. En este mismo transecto registramos apenas 24 especies en una muestra de 100 árboles.

Esta decreciente diversidad en el dosel es compensada por una explosión de diversidad de hierbas terrestres y epífitas. En la angosta cima justo debajo de Sur Pax recolectamos por lo menos una docena de especies de bromelias, siendo la más común de éstas una especie nueva de Guzmania terrestre (J. M. Manzanares, com. pers.; Figura 4B) que prácticamente cubre algunas secciones del sendero. Las orquídeas, los helechos y las aráceas abundan también y son muy variados en estas elevaciones. La rica comunidad herbácea es particularmente aparente en la cima de $2.275 \mathrm{~m}$ justo al sur de Sur Pax, donde el bosque bajo, abierto e intacto-castigado repetidamente por relámpagos - se encuentra prácticamente sepultado bajo una extravagancia de musgos, epífitas y flores silvestres.

\section{PLANTAS ENDÉMICAS}

Las observaciones en el campo y la experiencia de otras regiones adyacentes indican que un gran número de estas especies herbáceas, particularmente de las familias Orchidaceae, Bromeliaceae, Araceae y Gesneriaceae, son endémicas (restringidas geográficamente) de esta sección de los Andes. Más de 100 especies de plantas en la Reserva Ecológica CayambeCoca, por ejemplo, nunca han sido recolectadas fuera del Ecuador. Por lo menos 15 de las especies de plantas que registramos durante este inventario son también endémicas del país, y esta cifra probablemente se elevará más allá de 100 al realizar identificaciones adicionales. Quizá el mejor ejemplo de una especie con un rango muy restringido a las Serranías Cofán es un arbusto que recolectamos de la familia de la guayaba (Myrtaceae). Esta especie, la cual se encuentra ahora en el proceso de describirse como Calyptranthes ishoaquinico sp. nov. ined., era utilizada antiguamente por las comunidades Cofán para ceremonias al llegar a la mayoría de edad, y los Cofán nos confirmaron que la planta no se había encontrado en ningún otro lado fuera de una pequeña área cerca de la estación de campo de Sinangoe (Figura 4A).

\section{ANFIBIOS Y REPTILES}

Los bosques que estudiamos están a $20 \mathrm{~km}$ al oeste de la localidad más rica en herpetofauna jamás documentada-Santa Cecilia, Ecuador (Duellman 1978, 1988). La comunidad de anfibios y reptiles de Bermejo y Sinangoe puede ser comparativamente diversa, si no más diversa, al combinar la mayoría de los elementos de la fauna de selva baja en Santa Cecilia con un grupo diferente de especies de mayores elevaciones restringidas a las estribaciones de los Andes. Además, las Serranías Cofán protegen muchas de las especies que se han extinguido localmente en Santa Cecilia, cuyos bosques fueron destruidos en la década de los noventa. (Su desaparición queda documentada de forma estremecedora en el par de imágenes satélite de la Fig. 7.)

Aunque el equipo herpetológico trabajó únicamente en el área de Sinangoe y no visitó la zona de Bermejo, registramos 31 especies durante el viaje (Apéndice 2). La lista incluye 17 ranas y sapos, seis especies de culebras, un cecílido (fotografiado por el equipo en Bermejo), una salamandra y seis lagartijas, incluyendo una aparentemente no descrita del género Dactyloa (Figura 5E). De éstas, la lagartija Cercosaura ocellata es una especie nunca antes registrada en el Ecuador. Las elevaciones sobre $1.500 \mathrm{~m}$ probablemente albergan comunidades herpetológicas distintas de las que pudimos muestrear y anticipamos que varias especies desconocidas más serán descubiertas ahí. 
$\mathrm{Al}$ igual que en otras comunidades anfibias alrededor del mundo, se han registrado desapariciones y fluctuaciones de población justo al sur de las Serranías Cofán, pudiéndose extender esto a las áreas aparentemente prístinas que visitamos. La situación parece ser particularmente crítica para varias especies de ranas de vidrio (Centrolenidae) y ranas veneno flecha del género Colostethus, las que han desaparecido de algunos arroyos y cascadas de la Reserva Ecológica Cayambe-Coca durante la última década (F. Campos, obs. pers). Sólo encontramos una especie de este grupo.

\section{AVES}

Nuestro breve estudio ornitológico de los bosques circundantes a Bermejo y Sinangoe indican que deben ser considerados como una de las más importantes áreas de conservación de aves en el Oriente ecuatoriano. Las elevaciones altas en particular, parecen servir de refugio para muchas aves consideradas en peligro o amenazadas en otros lugares de los Andes. Registramos extensiones de hábitat significativas para muchas especies, tanto en elevación como geografía, y fue gratificante encontrar con frecuencia en el área algunas aves notóriamente raras. Por ejemplo, nunca antes habíamos visto poblaciones tan grandes de Campylopterus villaviscensio (Ala-deSable del Napo), Phylloscartes gualaquizae (Moscareta Ecuatoriana) y Snowornis subalaris (Piha de Cola Gris).

Registramos 399 especies de aves y estimamos un total regional de 700 (Apéndice 3). La avifauna del bosque de laderas altas es particularmente notable por su integridad; en apenas pocos días encontramos casi todas las especies esperadas para esta latitud y para estas elevaciones. En otras palabras, un ornitólogo que suba desde el valle de Bermejo puede observar una comunidad intacta de aves amazónicas hasta una avifauna intacta de bosque de ladera en cuestión de horas-una experiencia cada vez más rara en otros lugares de los Andes.
Quizá la observación más notable fue Myiopagis olallai, un ave descrita tan recientemente (Coopmans y Krabbe 2000) que ni siquiera aparece en el nuevo volumen de The Birds of Ecuador (Ridgely y Greenfield 2001). Aunque se conoce $M$. olallai en apenas tres otras localidades del Ecuador y Perú, este nuevo registro a menos de $10 \mathrm{~km}$ de la frontera colombiana prácticamente garantiza que la especie eventualmente sea registrada también en ese país. Igual de significativa fue la observación del tinamú negro, Tinamus osgoodi, conocido previamente por un solo sitio de Colombia, y en otro al sur de Perú. Aunque los ornitólogos nunca antes habían registrado esta especie en el Ecuador antes de verlo y escucharlo nosotros en la cima del Shishicho, los Cofanes que nos acompañaban nos indicaron haber visto la misma especie hasta muy al sur, en las cascadas de San Rafael.

En toda el área, y particularmente en las elevaciones mayores, encontramos poblaciones relativamente grandes de especies vistosas y típicamente vulnerables a la caza, incluyendo al Guacamayo Militar (Ara militaris), el Paujil de Salvin (Crax salvini) y la Pava Carunculada (Aburria aburri). La implicación es que las Serranías Cofán podrían constituir un importante santuario para especies cuyas poblaciones están disminuyendo en grandes áreas en otras partes del Oriente ecuatoriano.

\section{MAMÍFEROS GRANDES}

Pudimos realizar un inventario intensivo de mamíferos grandes durante el viaje, particularmente porque varios Cofanes con décadas de experiencia en el rastreo de animales en estos bosques acompañaron al equipo en el campo. Encontramos una fauna muy variada e intacta, incluyendo 12 especies de monos y grandes poblaciones de varias especies amenazadas a nivel mundial. Quizá la observación más significativa fue del perro de orejas cortas, Atelocynus microtis, visto aquí en la elevación más alta $(1.200 \mathrm{~m})$ registrada para esta especie. 
Confirmamos la presencia de 42 especies de mamíferos grandes en el área, siendo más de la mitad de estas especies raras o bajo amenaza mundialmente (ver Apéndice 4). Veinticinco especies de la lista están incluidas en los Apéndices I (amenazadas mundialmente) o II (potencialmente amenazadas) de CITES, incluyendo las 12 especies de monos. Al igual que con la comunidad de aves (ver arriba), muchas de estas especies vulnerables existen en abundancia en la zona. Particularmente comunes fueron los osos de anteojos (Tremarctos ornatus, Figura 1), dantas (Tapirus terrestris), monos chorongo (Lagothrix lagothricha) y sahínos (Tayassu tajacu). En la cresta del cerro Shishicho, justo al otro lado del río de la nueva Vía Interoceánica y a pocos kilómetros de la ciudad de Puerto Libre, encontramos grupos de monos a diario.

No pudimos confirmar los informes repetidos sobre una nueva especie de mono chorongo miniatura en los bosques de elevación alta alrededor del cerro Sur Pax. Sí encontramos evidencia, sin embargo, de otras especies de mamíferos en la región que posiblemente no han sido descritos, particularmente de una ardilla gris grande. Vale la pena mencionar, como ejemplo de cuan poco se conoce todavía la región, que una de las plantas favoritas como alimento del oso de anteojos en cerro Sur Pax, una bromelia terrestre (Figura 4B), es una especie nueva para la ciencia.

\section{AMENAZAS}

Al igual que en la mayoría de las selvas tropicales del mundo, las comunidades biológicas de las Serranías Cofán enfrentan una desconcertante gama de amenazas. La situación de estos bosques se ha vuelto progresivamente nefasta desde que fueron divididos en dos por la Vía Interoceánica, concluida en agosto del 2000 (Figura 2A). Esta carretera principal-la primera vía pavimentada entre la sierra ecuatoriana y la selva amazónica-probablemente se convertirá en una ruta muy transitada en las siguientes décadas. Para los conservacionistas de la región, el desafío inmediato está en restringir la futura inundación de actividades humanas a una pequeña franja de tierra lindando con la carretera, donde no ponga en peligro a las comunidades biológicas de las tierras Cofán adyacentes y de la Reserva Ecológica Cayambe-Coca.

Históricamente, la mayor destrucción de los bosques a lo largo de las nuevas carreteras en el Ecuador ha sido el resultado de la desorganizada colonización y tala del bosque a pequeña escala por parte de campesinos y cooperativas. La Figura 7, adaptada de un estudio realizado por Sierra (2000) demuestra con cuánta rapidez se ha avanzado este tipo de devastación a pocos kilómetros al este de Bermejo, en la zona de Lago Agrio-Coca-Shushufindi. Junto a la nueva Vía Interoceánica, los colonos ya han comenzado a despejar el bosque para usar la tierra en ganadería, cultivos agrícolas y explotación maderera a pequeña escala. Se podía escuchar el chillido de las motosierras incluso en nuestro campamento más alto, desde donde se podía mirar abajo a las parcelas recientemente taladas a lo largo del río Chingual. Entre Puerto Libre y La Bonita, se han deforestado grandes áreas para el cultivo de la naranjilla (Solanum quitoense, Solanaceae). Este cultivo es notoriamente susceptible a ataques de nematodos; en la mayoría de los casos, los campesinos tienen que optar entre aplicar grandes cantidades de pesticidas o abandonar los cultivos después de unas pocas cosechas (NRC 1989). Una vez agotada la capacidad agrícola marginal de estas zonas, las tierras deforestadas-muchas de ellas en laderas sumamente empinadas-representarán un peligro aun mayor para toda la cuenca del Aguarico (y para la nueva carretera) durante muchos años hacia el futuro. Las laderas descubiertas de arcilla, en rápida erosión, exacerbarán la tendencia natural de la región a los masivos deslizamientos de tierra e inundaciones.

A la proliferación de colonización a pequeña escala le acompañan amenazas asociadas con intereses comerciales más grandes. Por ejemplo, ya que la nueva carretera ofrece una ruta más rápida a los aserraderos de la sierra, las compañías madereras han comenzado a explotar maderas duras de alto valor de los bosques 
adyacentes. Los vagones teleféricos (tarabitas) con cargas de madera aserrada desde los bosques de colina hasta la carretera son ya un acontecimiento común en la región. Predecimos que la mayoría de los árboles de madera valiosa a un kilómetro de la carretera habrán sido talados hasta fines del 2002. Una vez que esto suceda, las operaciones madereras tanto a pequeña como gran escala se adentrarán en el bosque, a través de una creciente red de pequeños caminos madereros en toda la zona.

Incluso en lugares muy alejados de la nueva carretera, donde los bosques permanecen en pie, la afluencia de cazadores y pescadores puede comprometer seriamente la integridad de las comunidades biológicas. La caza comercial de venado, paca y danta parece estar incrementándose. Incluso la caza a pequeña escala-ya sea para alimentación (sahínos, grandes monos, dantas, venados, paujiles y otras aves grandes), para proteger al ganado y a los animales domésticos (jaguares, pumas y aves de rapiña), o para la venta (pieles de jaguar, plumas de loros)-puede causar serios desequilibrios en las poblaciones animales del área, conduciendo a perturbaciones a largo plazo del ecosistema regional. Por ejemplo, la eliminación de las aves grandes y monos que se alimentan de frutas de un bosque que con excepción de eso permanece intacto, podría llevar a un serio colapso de la diversidad arbórea de la región. La descomposición resultante del mecanismo de dispersión por semilla en el bosque dificulta mucho más el que las semillas y plántulas puedan escapar de los herbívoros y las enfermedades (efectos JanzenConnell) que se concentran en torno a sus progenitores (Janzen 1970, Connell 1971, Terborgh et al. en prensa).

Las comunidades indígenas también son capaces de cazar en exceso, al igual que los colonos más recientes, lo que constituye una seria amenaza en otras selvas amazónicas (Peres and Zimmerman 2001). Un ejemplo bien documentado del Oriente ecuatoriano es la descripción de Mena et al. (1997) de la caza altamente insostenible de monos chorongo en los bosques que rodean las comunidades Huaorani. Igualmente, una disminución de las poblaciones de pava de monte en torno a la comunidad Cofán de Zábalo llevó hace poco a los cazadores locales a aplicar un estricto programa de veda y linderos ( $R$. Borman, obs. pers.). En vista de la baja densidad poblacional de la comunidad Cofán en Bermejo y el leve rastro de la comunidad de Sinangoe, la excesiva caza por parte de los habitantes indígenas no parece constituir una amenaza severa en este momento, pero podría llegar a serlo mientras que las comunidades continúan creciendo y cambiando.

En Bermejo, las perspectivas de conservación a largo plazo dependen en gran parte de los planes de desarrollo de la compañía petrolera que opera los yacimientos a pocos kilómetros al sur oriente de la comunidad de Alto Bermejo. Tecpecuador, una subsidiaria de la compañía argentina Tecpetrol, produce 7.700 barriles de petróleo por día en el campo de Bermejo y tiene una concesión (esto es, permiso para explorar y desarrollar recursos petroleros) que se extiende a todo el valle inferior del río Bermejo, hasta la comunidad Cofán de Chandia Na'e. La futura expansión de las operaciones petroleras a gran escala traería muchos de los mismos problemas asociados con la nueva Vía Interoceánica, además de la posibilidad de derrames de petróleo y fugas de químicos como los que han envenenado áreas enormes de los bosques ancestrales Cofán alrededor de Lago Agrio y Cuyabeno durante los últimos 40 años. Desde la terminación de la nueva Vía Interoceánica, la colonización y el despeje de la selva se han intensificado a lo largo de los caminos al yacimiento de Bermejo. Grandes áreas de bosque fueron deforestadas en los seis meses antes de nuestro inventario (febrero-agosto 2001); se pueden encontrar pilas de madera recientemente talada a lo largo del camino. No está claro en este momento si las operaciones de la compañía petrolera se incrementarán en la región, ni la forma que pudiera tener esa expansión, o las áreas que se verían más afectadas, pero está claro que ésta es una importante amenaza a monitorear.

En la región de Sinangoe, la mayor amenaza es la intensificación de las presiones existentes sobre el 
lindero oriental de la Reserva Ecológica CayambeCoca. Las expediciones no autorizadas de caza y pesca en la Reserva por parte de los colonos son comunes en este momento, aunque probablemente son todavía demasiado pequeñas y no lo suficientemente frecuentes como para constituir un mayor peligro para las comunidades de animales que la habitan. Una excepción es el uso ocasional de dinamita y veneno para capturar peces en los ríos Ccuccono y Cofanes, lo que puede ser devastador incluso a pequeña escala.

Estas incursiones amenazan con llegar a ser más serias en el futuro cercano, particularmente al empezar a escasear los animales de caza a lo largo de la nueva carretera. Si-como lo recomendamos más abajo—se establece una nueva área protegida en la zona de Bermejo, otras incursiones similares serán una gran amenaza ahí: gran parte de la tierra reclamada recientemente a lo largo de la carretera queda a poca distancia del lindero occidental propuesto.

La minería a pequeña escala es otra actividad ocasional en la Reserva Ecológica Cayambe-Coca, principalmente a lo largo de los bancos de arena del río Cofanes. Durante nuestro inventario nos encontramos con una familia de colonos que cruzaba el cerro Shishicho en una expedición minera de una semana. Esta actividad probablemente es demasiado irregular y poco frecuente como para constituir una real amenaza, pero algún hallazgo grande podría desatar una gran actividad o incluso atraer el interés de las compañías mineras comerciales, con consecuencias muy peligrosas para los bosques en, y alrededor de, la Cayambe-Coca. Durante varios años, las compañías mineras comerciales han demostrado un interés recurrente en los recursos mineros tanto de la región de Bermejo como de Sinangoe, particularmente cuando sube el valor de los metales preciosos (R. Borman, obs. pers.).

Otro peligro para los bosques de la región constituye la guerra civil en Colombia, con el potencial de trastornar los planes a largo plazo de las comunidades fronterizas ecuatorianas. Las imágenes satelitales de la zona fronteriza demuestran con desgarrante claridad lo serio que es este conflicto para las comunidades biológicas de Colombia (Figura 2). Aproximadamente el $80 \%$ de los bosques al norte de la frontera han desaparecido bajo un mar de plantaciones de coca, muchas de las cuales han sido deshojadas recientemente por la iniciativa del Plan Colombia. Si la historia hubiese ubicado la frontera colombiana unos $25 \mathrm{~km}$ al sur de su posición actual, gran parte de los bosques que describimos en este informe ya habrían sido destruidos. 


\section{OBJETOS DE CONSERVACIÓN}

Las siguientes especies y comunidades son el enfoque primario de conservación dentro de la región de las

Serranías Cofán debido a su: 1) rareza global o regional, 2) influencia sobre la dinámica de la comunidad, y/o

3 importancia en los procesos del ecosistema, como la protección de las cuencas.

\section{Grupo de Organismos}

Comunidades biológicas

\section{Objetos de Conservación}

Bosques de estatura baja en las crestas y comunidades de plantas únicas que crecen en la roca ácida expuesta

Bosques de laderas altas y bosques montanos con altas concentraciones de especies restringidas en su extensión

Arroyos y riachuelos (hábitat importante para peces, anfibios y reptiles)

Comunidades diversas de árboles de selva baja, con poblaciones de Cedrelinga (tornillo, chuncho), Cedrela (cedro) y otras especies de madera valiosa y frecuentemente explotada en exceso

Páramo aislado de la cordillera Murallas, al oeste de Bermejo (Figura 2)

Muestras funcionales, representativas de todos los tipos de hábitat; expansiones de tipos de bosque contiguos que se extienden en toda la gradiente de elevaciones

Plantas Cedrela odorata y C. fissilis (cedro, Meliaceae)

Cedrelinga cateniformis (tornillo, chuncho, Mimosaceae)

Dacryodes olivifera (copal, Burseraceae)

Billia rosea (Hippocastanaceae)

Grupos taxonómicos endémicos (especies de plantas únicas del Ecuador o con rangos geográficos restringidos), particularmente de las familias Orchidaceae, Bromeliaceae, Gesneriaceae y Araceae

Reptiles y anfibios

Enyalioides cofanorum y otras especies de selva baja compartidas anteriormente con Santa Cecilia pero que se han extinguido en esa zona

Especies de Centrolenidae (ranas de vidrio) y Colostethus (ranas veneno flecha) que potencialmente están sufriendo reducciones de sus poblaciones

Comunidades herpetológicas a mayores elevaciones

Aves Comunidades de aves de bosques de laderas altas

Aves endémicas y restringidas en altitud

Aves grandes de caza (p.ej., Crax, Aburria)

Loros grandes, especialmente Ara militaris

Mamíferos
Primates (particularmente Lagothrix lagothricha y Ateles belzebuth)

Dispersadores y depredadores de semillas

Atelocynus microtis (perro de orejas cortas; raro)

Otras especies de CITES I y CITES II:

Lontra longicaudis (nutria neotropical), Panthera onca (jaguar),

Priodontes maximus (armadillo gigante), Speothos venaticus (perro de monte),

Tapirus terrestris (danta), Tayassu pecari (huangana),

Tremarctos ornatus (oso de anteojos, oso andino) 
El corto tiempo que estuvimos en el campo fue suficiente para demostrar que los bosques alrededor de Bermejo y Sinangoe tienen un valor biológico destacable y ameritan protección a largo plazo. Más allá de proteger los importantes objetos de conservación (ver arriba), las Serranías Cofán ofrecen la rara oportunidad para proteger comunidades biológicas intactas a lo largo de una gradiente altitudinal de 400 a $2.000 \mathrm{~m}$.

Una nueva y eficiente reserva en las Serranías protegerá también la biota única centrada en Colombia - que no se encuentra en ningún otro lugar del Ecuadorque ha sido eliminada por la deforestación y por las plantaciones de coca al norte de la frontera internacional. A continuación, resaltamos algunos de los beneficios a largo plazo de la conservación de esta región para el Ecuador y el mundo.

1) Una nueva área de conservación en el Ecuador con importancia mundial, vinculando bosques andinos protegidos desde Colombia hasta el centro del

Perú. Las laderas húmedas de los Andes orientales - desde Venezuela hasta Bolivia-contienen especies y asociaciones de plantas y animales únicas a lo largo de su extensión. Muchas de las especies andinas se limitan a un segmento único de la cordillera: si se elimina ese bloque o franja de elevación, también se eliminan comunidades biológicas que no existen en ningún otro lugar. La conservación de las Serranías Cofán agregará un vínculo vital a la cadena de áreas protegidas, conectando estas diferentes comunidades a lo largo de los Andes.

\section{2) Protección efectiva de un sector vulnerable de la Reserva Ecológica} Cayambe-Coca, una de las áreas protegidas más grandes del Ecuador. La Reserva Ecológica, que ya enfrenta una serie de desafíos, está afrontando una nueva presión intensa a lo largo de la nueva Vía Interoceánica (Figura 2A) que se acaba de construir. El profundo interés de la comunidad Cofán local en participar en las actividades de conservación y custodia-y la posibilidad de extender la Reserva hacia el norte y occidente (Anexo 2 en Figura 2; Apéndice 6)-resguardaría efectivamente una de las principales áreas de conservación del Ecuador. 
3) Protección de las principales cuencas en la provincia de Sucumbios.

Sucumbíos ya está experimentando grandes inundaciones debido a la deforestación a lo largo de las márgenes de los ríos. La conservación de las cuencas evitará enormes fluctuaciones, al igual que las devastadoras consecuencias de las mismas para toda la provincia.

4) Preservación de importantes reservorios de bosque Amazónico muy húmedo. Al acelerarse el calentamiento global durante el próximo siglo, la cuenca Amazónica se irá secando. Las zonas cercanas a la base de los Andes, particularmente las que quedan cerca de la línea ecuatorial, donde los cambios de temporada son menos severos, se convertirán en reservorios de creciente importancia del hábitat húmedo. Estas áreas se convertirán en refugios seguros para poblaciones de especies que de otra forma podrían desaparecer durante sequías extremas.

5) Un modelo científico y exitoso de conservación de tierras ancestrales por parte de una comunidad indígena. Un centro de conservación operado por los Cofán ofrecerá una protección por parte de los habitantes locales para esta región altamente vulnerable, formando un núcleo para el manejo a largo plazo centrado en la ciencia rigurosa y en la tradición cultural. 


\section{RECOMENDACIONES}

El futuro de conservación que imaginamos para la región-donde las pequeñas comunidades Cofán al mismo tiempo que protegerían se beneficiarían de la selva que les rodea-no es dramáticamente diferente del estado actual del paisaje. El lograr esta visión, sin embargo, exigirá acción inmediata, debido a las amenazas inminentes y a largo plazo. A continuación delineamos algunas recomendaciones preliminares para (1) la protección y el manejo para enfrentar los peligros inmediatos, (2) la planificación de la conservación a mediano plazo y hacia el futuro, y (3) información para afinar las metas y estrategias de conservación. Para tener éxito, estas acciones requerirán una planificación financiera coordinada y financiamiento continuo.

\section{Protección y manejo:} Bermejo
1) Establecer un área protegida en los bosques de las cuencas de los ríos Bermejo, Chandia Na'e y San Miguel, y a lo largo de todo el complejo de cimas del cerro Sur Pax. La protección inmediata es crítica; de otro modo, el activo frente de colonización a lo largo de la nueva Vía Interoceánica alcanzará estos bosques intactos. Recomendamos la inmediata modificación de los linderos de la Reserva Ecológica Cayambe-Coca para incluir gran parte de la zona de Bermejo como nuevo anexo, a ser administrado conjuntamente con los Cofán (Anexo 1 en Figura 2). El anexo propuesto, con un tamaño de aproximadamente 50.000 ha, protegerá a los bosques desde la frontera con Colombia en el norte hasta el valle del río Bermejo en el sur, y desde la cuenca del río Chingual en el occidente hasta la selva amazónica en el oriente. Una vez constituido el anexo, recomendamos la reclasificación del Bosque Protector Bermejo existente al sur del río Bermejo (degradado actualmente por la colonización y por las operaciones petroleras) como zona de amortiguamiento.

2) Negociar un convenio legal entre la Federación Indígena de la Nacionalidad Cofán del Ecuador (FEINCE) y el Ministerio del Ambiente del Ecuador para asegurar la conservación a largo plazo de las comunidades biológicas de la zona. El Ministerio promovería el interés en la conservación de la reserva a nivel nacional e internacional y proveería el apoyo legal e institucional para prevenir daños a estas comunidades, ya sea por el mal uso dentro de sus linderos 0 por las incursiones de colonos o de los intereses comerciales. Por su parte, la Federación Cofán y las comunidades Cofanes locales se comprometerían a un plan de manejo científico para que el $85-90 \%$ de la nueva reserva se mantenga en perpetuidad como tierra de conservación, con un uso humano ecológicamente compatible en los 10-15\% alrededor de los asentamientos. La cooperación entre la comunidad Cofán de Zábalo y la Reserva de Producción Faunística Cuyabeno podría ser un modelo para un manejo similar de la zona de Bermejo. 
3) Establecer un corredor biológico entre el nuevo anexo de Bermejo y la Reserva Ecológica Cayambe-Coca. Ya que las tierras que dividen a ambas tienen un alto valor biológico (particularmente el aislado páramo de la cordillera Murallas; ver Apéndice 6), una solución lógica sería extender los linderos de la Reserva hacia el norte, para incluir las áreas naturales circundantes a las poblaciones de La Sofía y La Bonita (Anexo 2 en Figura 2). Para tener éxito, esta modificación tendría que contar con el apoyo de las comunidades locales y autoridades regionales. Recomendamos que la planificación de conservación en la región aproveche el excelente trabajo de la Fundación La Bonita-Sucumbíos. Este grupo local no gubernamental, asentado en La Bonita, ha realizado inventarios biológicos, levantando un mapa detallado del área, y ha comenzado la planificación de conservación con las comunidades locales de la zona (Apéndice 6). Podría ser una coordinadora excelente de los esfuerzos de conservación en esta región.

4) Proteger los bosques de La Ranchería, cruzando la frontera con Colombia desde el anexo propuesto y contiguo al mismo. Con excepción de La Corota (una reserva de $8 \mathrm{ha}$, a $80 \mathrm{~km}$ de la frontera internacional), este tramo de 25.000 ha de bosque administrado por los Cofán representa la única área protegida en esta región de Colombia. Ni bien sea posible, recomendamos que el Ministerio del Ambiente de Colombia emprenda acciones de conservación para la preservación a largo plazo de los bosques de La Ranchería. Una meta a largo plazo sería la designación de las reservas conjuntas de Bermejo y La Ranchería como parque multinacional, administrado por Ecuador, Colombia y los Cofán.

5) Trazar el mapa, demarcar y anunciar los linderos de la nueva reserva de Bermejo. De particular importancia serán los linderos bien demarcados, al igual que la señalización en los senderos de acceso a lo largo del lindero occidental de la nueva reserva, este es el más cercano a la nueva Vía Interoceánica. La señalización dará un claro recordatorio del estado de conservación de la zona y de las regulaciones a ser observadas dentro de sus límites.

6) Establecer una programa de vigilancia permanente y a largo plazo en las áreas más vulnerables a las incursiones, particularmente a lo largo del lindero occidental de la reserva propuesta. Un pequeño equipo de guardabosques Cofán debería patrullar el lindero y los senderos cercanos desde una estación de vigilancia bien ubicada. Nos imaginamos un arreglo similar al que tiene la comunidad Cofán de Zábalo con la Reserva de Producción Faunística Cuyabeno. Para ser protectores efectivos de la biodiversidad, estos guardabosques deben tener autoridad para hacer cumplir los reglamentos. 


\section{RECOMENDACIONES}

7) Desarrollar programas de conservación con las comunidades Cofán de Alto Bermejo, Chandia Na'e y Tayuso Canqque, en base a los valores biológicos, las amenazas regionales y las necesidades locales. Para ser exitosos, estos programas deben equilibrar las nuevas responsabilidades (esto es, la vigilancia de la nueva reserva, haciendo respetar los linderos y las temporadas para la caza de animales) con alternativas económicas sensibles al medio ambiente, para responder a las necesidades de las comunidades. Las actividades a ser dirigidas por las comunidades Cofán locales deben involucrar a los colonos vecinos en un trabajo de conservación a lo largo de los linderos.

8) Administrar el aprovechamiento de las poblaciones de aves de caza, mamíferos grandes y peces alrededor de las comunidades Cofán, dentro del área protegida propuesta. Hasta poder desarrollar un sistema más detallado de temporadas, linderos y zonificación, nuestra recomendación es continuar manteniendo la presión de la caza y pesca en los niveles actuales (esto es, únicamente para la subsistencia de los moradores locales).

Protección y manejo: Sinangoe
1) Establecer un convenio entre el Ministerio del Ambiente del Ecuador y la Federación Cofán que delinee una clara estrategia de conservación para los territorios Cofán dentro de la Reserva Ecológica Cayambe-Coca (Figura 2). Esto debe ampliar el convenio existente entre la comunidad Cofán de Sinangoe y el Ministerio del Ambiente, respondiendo a las crecientes amenazas a la región y utilizándose como modelo el convenio entre la comunidad Cofán de Zábalo y el Ministerio del Ambiente. Un aspecto clave de la relación debería ser la realización de reuniones periódicas para revisar las amenazas y oportunidades actuales de conservación y para coordinar acciones.

2) Establecer un programa de vigilancia permanente y a largo plazo a lo largo de los linderos de las áreas protegidas norte y este de la Reserva Ecológica. Las patrullas regulares y frecuentes por parte de los guardabosques Cofán deben concentrarse en áreas donde es más seria la presión de la caza o colonización. Estas patrullas exigirán cierta infraestructura, en la forma de tres o cuatro estaciones de guardabosques adicionales, ubicadas en lugares estratégicos entre los ríos Aguarico y Due, junto con un sistema de senderos que las conecten.

3) Colocar señalización informativa en los senderos de acceso a lo largo del lindero oriental de la Reserva Ecológica Cayambe-Coca. Estas señales deben constituir claros recordatorios del estado de conservación del área y de las regulaciones a ser observadas dentro de sus linderos. 


\section{RECOMENDACIONES}

4) Eliminar el puente teleférico (tarabita) que facilita el acceso cruzando el río Aguarico desde Puerto Libre hasta los bosques de Cayambe-Coca.

Su eliminación reducirá de inmediato las incursiones por parte de cazadores y pescadores no autorizados.

5) Impedir la construcción de caminos o infraestructura maderera dentro de la Reserva Ecológica. El monitoreo de actividades similares a lo largo de los costados de la nueva Vía Interoceánica (ver Monitoreo, más abajo) complementará esta meta.

Manejo de información:

Bermejo y Sinangoe

1) Iniciar y mantener una base de datos con referencias de mapas de las características físicas, biológicas y políticas de la región. Este sistema de información geográfica (SIG) debe incorporar características geográficas y políticas básicas, al igual que información derivada de los programas de monitoreo. Al renovar y analizar los diferentes niveles de información de esta base de datos, los administradores de la reserva podrán desarrollar y revisar las estrategias de manejo, identificar y actualizar las amenazas a la reserva, y comprender mejor sus comunidades tanto humanas como no humanas.

2) Establecer una red para compartir datos entre las partes interesadas.

Inventario adicional: Bermejo y Sinangoe
1) Llevar a cabo un inventario de las características físicas no incluidas en el inventario biológico rápido. Entre las necesidades identificadas durante nuestro trabajo de campo están :

a. Un estudio del agua y suelo en las cuencas hidrográficas en riesgo debido a las actividades petroleras, mineras o madereras. Sobresalen entre éstas el valle inferior del río Bermejo y el río Cofanes y sus tributarios. Este inventario proveerá datos de línea base para medir los efectos de un incremento en la construcción de caminos o de una expansión de las actividades petroleras, mineras o madereras a gran escala en la región.

b. Un inventario de la geología de la superficie de la zona. Esta información, a ser incorporada en el SIG, es vital para poder identificar comunidades vulnerables de plantas o animales y para proteger a la zona contra incursiones mineras. 
2) Llenar los vacios en la cobertura geográfica y taxonómica de los inventarios hasta la fecha. Entre los vacios más sobresalientes están:

a. Los inventarios de ecosistemas que continúan poco explorados, particularmente en elevaciones más altas. En la región de Bermejo, estas áreas incluyen las crestas altas y los valles entre los cerros Pax y Sur Pax (Figura $3 A$ ); el valle aislado que forma la cuenca hidrográfica del río Chandia Na'e; y las crestas expuestas en la ribera norte del río Bermejo. En Sinangoe, las áreas de interés inmediato son las crestas altas de la sección occidental del drenaje del río Ccuccono (especialmente el punto alto de $2.686 \mathrm{~m}$ de esa cresta y un pico sobre los $3.100 \mathrm{~m}$ en otro sistema de crestas al sur); y los picos al occidente del cerro Shishicho, especialmente una montaña señalada en el mapa topográfico del IGM como el cerro de Cal. Estos sitios se describen en mayor detalle en la sección Descripción de los Sitios Muestreados, del Informe Técnico, más abajo.

b. Un programa ampliado de exploración y recolección botánica, enfocado en tiempos, sitios y grupos taxonómicos no bien cubiertos hasta la fecha. Las necesidades incluyen colecciones botánicas a lo largo del año (especialmente en enero y febrero), enfocándose en las elevaciones mayores y en las pequeñas plantas herbáceas epifitas.

c. Inventarios de la herpetofauna de Bermejo, tanto para elevaciones altas como bajas. Los estudios completos de los grupos taxonómicos de ranas que posiblemente están experimentando una disminución de su población (Centrolenidae y Colostethus) son también de alta prioridad.

d. Una expedición corta al cerro Sur Pax específicamente para evaluar los informes de una nueva especie de primate. Deben investigarse también otros informes de especies de mamíferos inusuales en la región de Bermejo.

Investigación:

Bermejo y Sinangoe
1) Determinar los efectos de las amenazas a gran escala sobre la dinámica del bosque y sus habitantes. La colonización y las incursiones ilegales, la construcción de caminos y la deforestación a gran escala están entre las amenazas más obvias a este nivel. La información proveniente de las frecuentes patrullas por parte de guardabosques Cofanes contribuirá en mucho a esta investigación. EI análisis del SIG identificaría áreas problemáticas y amenazas emergentes.

2) Evaluar la capacidad de carga de la región en cuanto a caza y pesca. Los sahínos, dantas, monos y crácidos parecen ser los animales más presionados por la caza actual. 


\section{RECOMENDACIONES}

3) Investigar las causas de la aparente disminución y fluctuaciones poblacionales entre los anfibios de la región. De particular preocupación son las ranas de vidrio (Centrolenidae) y las ranas veneno flecha del género Colostethus (Dendrobatidae). Esta investigación a largo plazo requerirá de estudios relacionados con la biogeografía, preferencias en cuanto a hábitat, y el calendario reproductivo.

4) Promover el uso de las estaciones de campo existentes como sitios para realizar estudios a largo plazo de biología de conservación. Al contrario de muchos otros sitios remotos y ricos en biodiversidad en las estribaciones de los Andes, se puede acceder a estos bosques fácilmente y hay una comunidad de moradores listos y dispuestos a participar en la recolección de información. Recomendamos particularmente explorar:

a. La composición, estructura y función de las comunidades (plantas, aves y anfibios) en los sistemas de crestas múltiples, a lo largo de todo el rango de elevación. Estos estudios proveerán con información sobre la distribución, tamaño de la población y estado de conservación de las especies raras o geográficamente restringidas.

b. La interacción entre las especies de plantas y los dispersores de sus semillas. Las investigaciones en otras partes de los trópicos han revelado que las alteraciones en la comunidad de animales dispersores de semillas pueden llevar a la alteración masiva de comunidades de plantas que de otra forma permanecen intactas. El poder contar con detalles sobre esta relación resulta de importancia crítica para el manejo efectivo y la conservación de los bosques habitados.

Monitoreo:

Bermejo y Sinangoe
1) Medir la efectividad de las estrategias de conservación para alcanzar las metas. Entre muchas otras, las variables a medirse podrían incluir (1) el efecto de la demarcación de los linderos y las patrullas para impedir incursiones y el mal uso de los recursos, (2) las actividades de las comunidades locales (resultados de los programas de educación), y (3) la popularidad, porcentaje de implementación y efectividad de las autoregulaciones sobre la caza y pesca. La participación de los moradores de las comunidades en la planificación e implementación de estos proyectos de monitoreo será crítica para el éxito del monitoreo y de los programas de conservación.

2) Monitorear las poblaciones de anfibios a través de censos frecuentes.

Debe prestarse especial atención a los grupos taxonómicos que aparentemente han disminuido en áreas cercanas; como son, las ranas de vidrio (Centrolenidae), las ranitas venenosas del género Colostethus (Dendrobatidae), y otros anfibios que viven alrededor de los arroyos y cascadas. 


\section{Informe Técnico}

\section{DESCRIPCIÓN DE LOS SITIOS MUESTREADOS}

El equipo del inventario biológico rápido basó su exploración de las regiones de Bermejo y Sinangoe en seis campamentos principales. Dos de éstos eran casas construidas durante el último año por las comunidades Cofán con la intención de que sirvan como bases permanentes para los investigadores científicos y guardabosques; los otros cuatro eran campamentos temporales. En esta sección resumimos las características principales de cada uno de estos sitios y de los senderos que exploramos en sus inmediaciones. Incluimos también una breve descripción de las áreas exploradas en una visita preliminar para recolectar plantas, en julio del 2000.

Muchos de los senderos, campamentos, crestas y arroyos descritos aquí han sido nombrados durante nuestra visita para facilitar la exploración futura del área. La ortografía de los nombres tradicionales Cofán podría diferir en algunos casos de la encontrada en los mapas de la zona. Para información adicional sobre la realización de visitas o investigaciones en las estaciones de Bermejo o Sinangoe, favor contactar al Cofán Survival Fund (www.cofan.org).

\section{BERMEJO}

\section{Estación Bermejo}

$\left(00^{\circ} 14^{\prime} 44.7^{\prime \prime} \mathrm{N}, 77^{\circ} 23^{\prime} 04.9^{\prime \prime} \mathrm{O}\right.$, ca. $\left.450 \mathrm{~m}\right)$

Esta vivienda en la comunidad Cofán de Alto Bermejo fue el punto de partida y campamento base de nuestra exploración del valle del río Bermejo. Llegamos a este lugar luego de una caminata de cuatro horas desde el camino más cercano, en un sendero desde el Pozo Dos (Figura 2), una instalación petrolera del campo Bermejo. El sendero desciende larga y gradualmente unos $200 \mathrm{~m}$ hasta el valle, cruzando un bosque mayormente maduro de selva baja y atravesando dos crestas y arroyos principales.

La comunidad de Alto Bermejo consiste de una media docena de casas dispersas y claros de cultivos en una terraza baja a lo largo de la ribera sur del río Bermejo. En las imágenes de satélite apenas aparece como un pequeño punto en un mar de selva (Figura 2). La casa de la estación se ubica en un pequeño claro rodeado de bosque primario y secundario y de huertas vecinas. Docenas de senderos cruzan el bosque alrededor de la comunidad, de los cuales exploramos tres: 
Sendero Pozo Seco - Este sendero se aleja del río, subiendo por el lado sur del valle hacia un pozo abandonado, Pozo Seco. El primer kilómetro del sendero atraviesa por una densa población de la palma de sotobosque Chelyocarpus ulei; en las partes más altas son comunes árboles enormes y antiguos de Cedrelinga y Parkia. El sendero atraviesa bosques de laderas altas y bajas, cruzando por profundas quebradas antes de subir por una larga cresta empinada (de casi $1.100 \mathrm{~m}$ ), para luego descender nuevamente al Pozo Seco, cerca de los $600 \mathrm{~m}$. El difícil ascenso se ve ampliamente compensado por las hermosas vistas desde diferentes miradores.

\section{Sendero Precipicio - Comenzando por el} lado norte del río Bermejo, este sendero conduce por un pendiente empinado, cubierto de bosque, antes de seguir el borde de las altas escarpas de arcilla roja que constituyen una característica notoria de la ribera norte del Bermejo. La mayor parte del bosque a lo largo del sendero es estructural y florísticamente similar al encontrado en los alrededores de la Estación Bermejo, aunque este sendero también atraviesa grandes áreas de bosque de transición que crecen sobre los antiguos derrumbes.

Senderos del río - Exploramos varios senderos semi-permanentes a lo largo del río Bermejo. El río estaba suficientemente bajo y sus orillas lo suficientemente anchas para poder caminar sobre su lecho, resguardado por árboles de Inga ruiziana (Mimosaceae). Había otros senderos en las franjas ocasionales de bosque aluvial y en los pendientes empinados que bordean el río. La mayoría de estos senderos parecen ser muy antiguos y han sido utilizados por los Cofán durante generaciones. Las poblaciones de la mayoría de los animales de caza estaban presentes, pero cautelosos en el bosque cercano a la comunidad. Sólo el mono chorongo y algunas especies de pavas parecen haber sido cazados hasta desaparecer del área inmediata.

\section{Campamento Mirador Bermejo}

$\left(00^{\circ} 18^{\prime} 13.8^{\prime \prime} \mathrm{N}, 7^{\circ} 24^{\prime} 32.0^{\prime \prime} \mathrm{O}\right.$, ca. $\left.1.200 \mathrm{~m}\right)$

Este fue nuestro campamento a mediana elevación en

Bermejo, al que llegamos luego de un ascenso de cinco horas desde la comunidad más abajo. El sendero desde la Estación Bermejo, en el piso del valle, sigue a lo largo de un tributario del Bermejo (el Sisipa) durante la primera hora y luego asciende bruscamente hasta la meseta que se forma en la parte superior de los acantilados sobre la ribera norte del río Bermejo. La vegetación en la parte superior de esta meseta es muy similar a la del bosque alrededor de la estación, con apenas unas pocas especies de árboles montanos. Es sólo después de la larga travesía de la meseta, interrumpida por una que otra quebrada, que el sendero asciende hasta una plataforma húmeda debajo del cerro Sur Pax donde son más frecuentes las especies de árboles montanos.

Acampamos sobre esta plataforma, donde un claro a unos $800 \mathrm{~m}$ sobre el piso del valle ofrece una vista impresionante del paisaje. Hacia el este, la selva amazónica se extiende hasta el horizonte; al sur, más allá del valle de Bermejo, se pueden ver los campos petroleros en la cordillera opuesta, al igual que los volcanes Reventador y Sumaco sobre el horizonte; y hacia el norte se levanta el flanco sur casi vertical de la cordillera Sur Pax, marcado por las largas cascadas del descendiente río Ttonoe. Desde este mirador, los bosques de la región parecen estar esencialmente intactos en todas las direcciones. Los únicos indicios obvios de la presencia humana son las oscilantes luces nocturnas de las llamaradas de gas en el yacimiento petrolero de Bermejo, un deslumbrante faro en la frontera colombiana y las luces de las pequeñas poblaciones amazónicas en el horizonte.

Sendero Chandia $\mathrm{Na}$ 'e - Este sendero se dirige desde el campamento hacia el este, bajando hasta el río Chandia Na'e. El descenso de una a dos horas hasta el río, bajando unos 200-300 m de elevación, conduce por una angosta cresta cubierta de bosque, con manchas de bosque de transición, cubriendo recientes deslizamientos, dispersas a ambos costados. El sendero termina en la confluencia del río Chandia Na'e con el más pequeño Ttonoe. El angosto Chandia $\mathrm{Na}$ 'e baja tumultuosamente por una gradiente inclinada de rocas de cuarcita blanca, dándole una apariencia notable- 
mente distinta a la de la mayoría de los ríos que vimos en el área de Bermejo. Hay que notar que este río está trazado en los mapas del área con el nombre de Zarayacu ó Sarayacu. Ya que este nombre Quichua relativamente reciente no es familiar a los habitantes del área, para los propósitos de este informe utilizaremos el nombre Cofán tradicional.

Sendero Chingual - En el lado oeste del campamento Mirador, un sendero desciende abruptamente hacia el occidente, atravesando los altos del río Bermejo y saliendo hasta las fincas de los colonos a lo largo del río Chingual. No exploramos este sendero, pero podrá ser una ruta clave para la vigilancia de los guardabosques una vez que se establezca una reserva en la zona. En buenas condiciones, la caminata hasta la carretera tarda aproximadamente ocho horas.

\section{Campamento Cordillera de los Osos}

$\left(00^{\circ} 19^{\prime} 17.7 ” \mathrm{~N}, 77^{\circ} 25^{\prime} 10.0^{\prime} \mathrm{O}\right.$, ca. $\left.1.920 \mathrm{~m}\right)$

Este fue el campamento más alto de la expedición, al que se llegaba luego de un ascenso empinado desde el campamento Mirador Bermejo y una caminata a lo largo de la cresta ascendente, a través de un bosque bajo muy húmedo y enmarañado. Establecimos el campamento sobre una angosta cresta a una hora de caminata más abajo del Sur Pax. El bosque de estatura baja alrededor del campamento parece haber crecido sobre una maraña de raíces cubiertas de musgo, sin rocas o suelo mineral visible sobre la superficie y con un goteo casi permanente de agua, debido a que está constantemente cubierto por nubes y niebla (Figura 3C). Otra característica del lugar es la persistente brisa fresca que cruza la cresta y que cambia periódicamente desde el este al oeste. Un pequeño mirador panorámico en el claro del campamento ofrece una vista de la cresta del Shishicho y la Estación Sinangoe hacia el sur (ver descripción más abajo), y del río Chingual ỳ la nueva Vía Interoceánica hacia el oeste.

\section{Sendero Cordillera de los Osos - El principal}

sendero desde este campamento continúa hacia el norte sobre una cresta ascendente, cruzando el mismo tipo de bosque muy húmedo y enmarañado que rodea al campamento. $\mathrm{Al}$ aumentar la elevación se reduce la estatura del bosque, con una vegetación cerca de la cima que alcanza apenas 10-20 m. Luego de un ascenso de una hora, el sendero termina en una cima de $2.275 \mathrm{~m}$ justo al sureste del cerro Sur Pax (coordenadas de la cima: $00^{\circ} 19^{\prime} 54.5^{\prime \prime} \mathrm{N}, 77^{\circ} 25{ }^{\prime} 25.4$ ”). Un barranco infranqueable no nos permitió llegar al Sur Pax desde esta dirección, aunque se lo veía perfectamente y se habría necesitado apenas una media hora de camino de existir un sendero. Un claro grande orientado hacia el este en la cima de $2.275 \mathrm{~m}$ permite una vista de la cordillera en forma de herradura que rodea la parte alta del río Chandia Na'e. Los puntos más altos de esta cresta parecen contener un tipo de bosque que no vimos en ningún otro lugar, con vegetación enana mucho más baja de lo encontrado en Sur Pax. La extensión del sendero hacia el norte (o el abrir uno nuevo desde el río Chingual), para poder llegar hasta las crestas más altas al norte de Sur Pax, sin duda les permitirá a los biólogos acceder a comunidades biológicas enteras que no pudimos explorar en este estudio (Figura 3A).

Sendero Ttonoe - Este sendero representó nuestro intento por llegar hasta una característica interesante de los mapas topográficos de la zona de Sur Pax-un valle de hondonada ancha-a $3 \mathrm{~km}$ al este del pico. Este valle es particularmente interesante porque es muy profundo (más de un kilómetro vertical debajo de la cima del Sur Pax); está aislado efectivamente de otros bosques de elevación similar por pendientes empinados en sus cuatro costados y tiene una llanura aluvial curiosamente ancha y plana, muy diferente de los barrancos en forma de "V" que caracterizan los otros valles de la zona. El sendero, que termina justo antes de llegar a este valle, se abre de forma muy empinada hacia abajo, al este del sendero principal entre el campamento y Sur Pax. Eventualmente cruza los peñascos del torrentoso río Ttonoe que forma las cascadas que se pueden observar desde el campamento Mirador Bermejo (ver arriba), para terminar luego de cruzar una cresta más. El bosque a lo largo del Ttonoe, en comparación con el de la cresta, se caracteriza por los altos árboles maduros 
que crecen en pendientes relativamente suaves. Fue aquí donde uno de los miembros del equipo avistó un oso de anteojos.

\section{SINANGOE}

\section{Estación Sinangoe}

$\left(00^{\circ} 10^{\prime} 49.4 " \mathrm{~N}, 7^{\circ} 29^{\prime} 50.0 " \mathrm{O}\right.$, ca. $\left.600 \mathrm{~m}\right)$

En julio del 2000, la comunidad de Sinangoe construyó una pequeña casa cerca de la confluencia de los ríos Sieguyo y Aguarico, enfrente de la población de Puerto Libre. (Figuras 2, 6C). La cercanía de esta estación a Puerto Libre y a la nueva Vía Interoceánica-apenas a dos minutos cruzando el Aguarico en canoa-la convirtió en un campamento base ideal para nuestros inventarios en la región. La Estación Sinangoe está cerca al comienzo de dos de los principales senderos del área: uno que accede al sistema tributario del río Ccuccono hacia el occidente y el otro que se dirige hacia el norte, subiendo y pasando por encima de la cordillera del Shishicho y de ahí hasta el río Cofanes (ver descripciones de estas zonas más abajo). Debido a su ubicación estratégica sobre los linderos de la Reserva Ecológica Cayambe-Coca (el Aguarico constituye el lindero del parque en esta zona), los guardabosques que operan desde la estación de campo pueden cumplir un gran papel en impedir que la colonización a lo largo de la nueva carretera incursione en la reserva.

Sendero Lazo - El bosque en las proximidades de la Estación Sinangoe tiene una composición similar al bosque de laderas bajas del valle del río Bermejo, aunque es más seco y con un elemento secundario mucho más fuerte. Unas áreas significativas aquí tienen un predominio de árboles maduros de la familia pionera Cecropiaceae. A diferencia de Bermejo, donde la mayor parte del bosque de transición está claramente relacionado con deslizamientos de tierra, la abundancia de especies pioneras alrededor de Sinangoe resulta un tanto misteriosa. Una pequeña fracción de la transición está teniendo lugar en claros y asentamientos abandonados (el claro en el que está la estación fue alguna vez un arrozal) y algunos de los demás pedazos podrían corresponder a asentamientos mucho más antiguos. El resto parece ser la consecuencia de una gran perturbación natural, posiblemente de algún episodio de un gran vendaval o inundación durante el último siglo.

Senderos Botánicos - Durante las visitas del 2000 y 2001, Robin Foster, Roberto Aguinda y José Omenda identificaron más de 300 especies de plantas a lo largo de los senderos cercanos a la Estación Sinangoe. Estas plantas han sido marcadas con etiquetas laminadas con el nombre científico y el nombre Cofán, tanto para que los botánicos visitantes puedan aprender los nombres de las plantas en Cofán como para que los botánicos Cofán puedan aprender los nombres científicos y para que otros investigadores puedan aprender cómo identificar algunas de las especies de plantas más comunes de la zona (Figura 6D).

Sendero Candoe - Este sendero corre en sentido oeste-suroeste desde la Estación Sinangoe, atravesando el río Fetsavoe antes de subir por una amplia cresta levemente inclinada, hasta aproximadamente los $1.000 \mathrm{~m}$. De ahí da la vuelta por la cabecera del Fetsavoe, estrechándose hasta una afilada cresta que separa al Fetsavoe del Candoe. Los recientes derrumbes, enmarañados con nuevo crecimiento, se alternan con antiguos bosques de Dacryodes. Nos interesaba visitar este lugar en particular porque aquí se les permite a los Cofán cazar bajo el plan de manejo de la comunidad de Sinangoe. Encontramos pocas diferencias en la vida silvestre o cautela por parte de los animales individuales que encontramos, lo que indica un bajo uso de esta región. Más arriba de la cabecera del Candoe, el sendero eventualmente se conecta con otro que se vincula a la Estación Sinangoe con el Ccuccono (ver más abajo).

\section{Campamentos Playa y Cresta Ccuccono} $\left(00^{\circ} 07^{\prime} 48.5^{\prime \prime} \mathrm{N}, 77^{\circ} 33^{\prime} 19.9^{\prime \prime} \mathrm{O}\right.$, ca. $940 \mathrm{~m}$ y $00^{\circ} 08^{\prime} 09.0$ "N, $77^{\circ} 32^{\prime} 48.1^{\prime \prime O}$, ca. $980 \mathrm{~m}$ ) Caminamos cinco horas hacia el oeste de la Estación Sinangoe para llegar hasta el drenaje del río Ccuccono, subiendo una cresta que asciende gradualmente hasta nivelarse cerca de los $1.100 \mathrm{~m}$, para luego descender rápidamente hacia la cabecera. El sendero pasa junto a 
un antiguo bosque de transición durante los primeros kilómetros, luego por un alto dosel de árboles pioneros de la familia Cecropiaceae, para eventualmente llegar a un bosque mucho más maduro. Notamos también una aparente gradiente de humedad a lo largo de esta cordillera, ya que el bosque cerca de la estación, más seco y carente en epífitas, cede ante un bosque de mayor elevación cerca al Ccuccono, mucho más húmedo y cargado de epífitas, donde predominan enormes y antiguos árboles de madera dura.

Una vez en la cuenca del Ccuccono, el equipo de aves y herpetofauna estableció su base sobre una cresta baja justo encima del arroyo de Ccangopacho (Figura 3D), un tributario del río Ccuccono Chico. El grupo de plantas y mamíferos siguió por el Ccangopacho hasta su confluencia con el Ccuccono Chico, acampando sobre la playa abierta del mismo río.

Para comprender el paisaje actual del drenaje del Ccuccono, uno tiene que referirse al masivo sismo que azotó la región en marzo del 1987, el que desencadenó al mismo tiempo enormes derrumbes a lo largo de varios miles de kilómetros cuadrados de bosque. $\mathrm{Al}$ romperse las represas temporales formadas por estos derrumbes, una serie de inundaciones repentinas-lo suficientemente altas como para destruir el puente de Lumbaqui a más de $15 \mathrm{~km}$ río abajoarrasaron la vegetación del valle a por lo menos $20 \mathrm{~m}$ sobre el nivel actual del río, dejando bosque maduro únicamente en las crestas altas. Las imágenes de satélite actuales del área demuestran cómo hasta la mitad de ciertas partes de la cuenca se encuentran en etapa de regeneración (Figura 2). Dada la inestable geología de la región, la frecuencia de los sismos y la proximidad a volcanes activos, las catástrofes de este tipo sin duda constituyen una característica relativamente frecuente en el paisaje del Ccuccono.

El río cerca de nuestro campamento sobre la playa todavía tenía indicios claros de los cambios del 1987. Los miembros del equipo Cofán que habían acampado en el mismo sitio antes del sismo se sorprendieron de encontrar que el hermoso y estrecho río que recordaban estaba ahora a cielo descubierto con un ancho de al menos $50 \mathrm{~m}, \mathrm{y}$ con enormes campos de piedras desordenadas, franjas de arena e islotes de maleza a ambos costados de la modesta corriente (ca. 5 $\mathrm{m}$ de ancho). Incluso a lo largo de los tributarios más pequeños del Cuccono Chico como el arroyo de Ccangopacho, grandes franjas de la ribera que tradicionalmente hubieran estado cubiertas de un bosque alto se encontraban sepultados bajo una maraña de lianas y árboles bajos. Esto era particularmente notorio en las curvaturas internas de los ríos, donde el roce de las inundaciones repentinas debe haber dejado la mayor destrucción a su paso.

Investigamos una variedad de pequeños tributarios y sistemas de crestas alrededor de nuestros dos campamentos. A continuación describimos los más interesantes de éstos:

Sendero Arroyo Ccopaye Fensi (Guácharo) Este es un tributario pequeño que desemboca en el Ccuccono Pequeño, justo al lado opuesto de nuestro campamento en la playa y que corre unos $200 \mathrm{~m}$ a través de un bosque plano, principalmente de transición, hasta una cascada. Una de las características más interesantes de este arroyo es un pequeño precipicio, donde tres o cuatro pájaros-probablemente gallitos de la peña, o quizás guácharoshan anidado en la pared de piedra, a plena vista. Sendero Cresta Ccuccono - Este sendero, que comienza sobre la ribera opuesta a nuestro campamento en la playa, asciende por la cresta que divide las dos principales ramas del río Ccuccono. Al contrario de la mayoría de las crestas en las cercanías a nuestros campamentos en Ccuccono, que raramente sobrepasan los $1.500 \mathrm{~m}$, ésta asciende a $1.800 \mathrm{~m}$ en unos pocos kilómetros. Sólo pudimos explorar parte de este sendero, siguiendo huellas de danta y oso hasta los $1.500 \mathrm{~m}$, pero la cresta continúa hacia el oeste hasta un pico aislado (sin nombre) de casi $2.700 \mathrm{~m}$, a $12 \mathrm{~km}$ al oeste de nuestro campamento en la playa. Esta cordillera-casi a la misma altura que la ciudad de Quito-debe contener un gran número de especies de plantas endémicas y se queda como una alta prioridad para futuras expediciones a la región. 


\section{Campamento Shishicho}

$\left(00^{\circ} 12^{\prime} 01.3 " \mathrm{~N}, 77^{\circ} 31^{\prime} 54.3\right.$ "O, ca. $\left.1.020 \mathrm{~m}\right)$

Este campamento queda a dos horas de caminata colina arriba de la Estación Sinangoe, subiendo unos $400 \mathrm{~m}$ hasta la base de la empinada pared oriental del cerro Shishicho. Alrededor del campamento y a lo largo del sendero desde la estación, el bosque es maduro, con predominio de especies arbóreas características de la selva baja (particularmente Myristicaceae), intercalado con pequeños parches de bambú o de bosque de transición. Unos pocos senderos temporales se dirigen hacia abajo en diferentes direcciones desde el campamento, a través de un bosque muy similar al del sendero principal. Justo encima del campamento hay una mancha de varias hectáreas de bosque secundario cubriendo un antiguo derrumbe. Sendero Cordillera Shishicho - El sendero sube desde el campamento por la ladera casi vertical del Shishicho, subiendo casi $400 \mathrm{~m}$ antes de llegar a la cumbre, debajo del pico principal. Esta sección del sendero tiene parches de esquisto desmenuzado y afloramientos del mismo material, dispersado a lo largo de la ruta. La característica redimible de este difícil ascenso es la cantidad de espectaculares miradores a lo largo de la ruta que ofrecen una vista panorámica del valle del río Aguarico (Figura 2B).

Una vez que se llega al pico del Shishicho, el sendero se nivela y comienza a seguir la cordillera principal, que curva hacia el norte al continuar a umentando gradualmente en elevación. La vegetación aquí consiste de una mezcla de árboles antiguos, sorpresivamente altos en las partes bajas de la cordillera y de árboles más bajos y muy cargados de epífitas en las secciones más altas, junto con algunos bosques de transición en áreas de perturbación. A una hora de ascenso desde la primera cumbre se llega al punto más alto de la cordillera, a los $1.570 \mathrm{~m}$. Al igual que en el bosque de la cima de Sur Pax, los árboles en esta cima son relativamente bajos (hasta $10 \mathrm{~m}$ de altura) y el suelo desaparece bajo una maraña de raíces cubiertas de musgo. La flora arbórea pierde aquí la mayor parte de los elementos de selva baja que aparecen con frecuencia en las partes bajas de la cordillera y adopta una naturaleza más montana, con géneros dominantes como Viburnum, Brunellia, Tibouchina y Clusia y tapetes de Sphagnum y otros musgos sobre el suelo. El bosque de la cima parece también estar en una etapa de transición bastante temprana, aunque no está claro si esto se debe principalmente a daños por vientos, tormentas y relámpagos, o por la costumbre Cofán de talar unos pocos árboles en puntos altos para tener miradores.

El sendero se divide en esta cima. Ambos ramales continúan hacia abajo hasta el río Cofanes; uno sigue por la cordillera principal hacia el norte y el otro por una cordillera diferente hacia el noroeste. $\mathrm{Al}$ igual que en la mayor parte de la cordillera del Shishicho, el sendero norte pasa por un bosque un tanto seco, expuesto a vientos secos que soplan desde el valle del Aguarico. El sendero noroeste, que aparentemente está más bajo y por eso más protegido de los vientos, se abre a través de una vegetación mucho más densa y húmeda.

\section{VÍA INTEROCEÁNICA}

(Entre Lumbaqui y La Bonita, ca. 500-1.000 m)

En julio del 2000, Robin Foster, Roberto Aguinda, Margaret Metz, Terra Theim y varios miembros de la comunidad de Sinangoe realizaron un estudio florístico preliminar de las comunidades de plantas a lo largo de la nueva carretera que divide los bosques anteriormente contiguos de Bermejo y Sinangoe (Figura 2A). Ya que en el momento de esa visita la vía se encontraba todavía bajo construcción y no había empezado la colonización a gran escala de las tierras en sus costados, el viaje nos ofreció un fácil acceso a un bosque intacto y botánicamente no explorado. Ahora que se ha abierto la carretera, la colonización en los bosques adyacentes avanza muy rápidamente. Para cuando se haya publicado este informe, la mayor parte del bosque que exploramos durante el año 2000 probablemente habrá desaparecido. 


\section{GEOLOGÍA, FISIOGRAFÍA Y CLIMA}

Autores: Nigel Pitman y Robin Foster

\section{GEOLOGÍA Y FISIOGRAFÍA}

El paisaje alrededor de Bermejo y Sinangoe representa una mezcla de diferentes tipos de rocas y formaciones geológicas. Durante los últimos diez millones de años, a lo largo de la elevación de las cordillera andina, enormes láminas de roca de diferentes edades y materiales han sido partidas en dos y torcidas hacia arriba, dobladas una alrededor de otra y luego sometidas a climas extremos. Gran parte de la roca levantada es de la era cretácea (con 65-146 millones de años de edad), pero hay formaciones jurásicas e incluso precámbricas más antiguas que salpican el paisaje (Baldock 1982, Nieto 1991). Para complicar aun más este cuadro, los diferentes grupos de rocas incluyen estratos individuales que varían desde esquistos hasta conglomerados, calizas y gres. Cada uno de éstos es diferente en términos del efecto que tienen sobre los suelos que se derivan de los mismos, dejando a la adivinanza los caracteres edáficos de cualquier sitio en particular.

A mayor escala, el panorama geológico es más similar a las provincias ecuatorianas no volcánicas de Morona-Santiago, Zamora-Chinchipe y Loja, al sur, en comparación con las zonas adyacentes de la parte central del Ecuador. La razón de esto es que las Serranías Cofán quedan justo al norte de la zona de volcanes jóvenes y activos que van desde el Sangay hasta el Reventador. Aunque su parte sur está afectada por la actividad del Reventador (ver abajo), la parte norte podría estar más estrechamente asociada con la cordillera oriental no volcánica de Colombia y con las provincias no volcánicas del sur del Ecuador.

La topografía del área es tan variada como la geología, determinada por lo general por la inclinación y composición de las formaciones levantadas. En las tierras bajas, la mayoría de los bloques geológicos se han levantado sin mayor inclinación, resultando en terrazas de superficie rasa justo al norte de los ríos
Bermejo y Aguarico. Más cerca al cuerpo principal de los Andes, donde la historia geológica es mucho más compleja, las muy retorcidas e inclinadas formaciones, con los embates del clima durante millones de años, han dado lugar a los escarpados barrancos alrededor del cerro Sur Pax y del río Cofanes.

\section{PERTURBACIÓN CATASTRÓFICA}

De igual importancia que el panorama edáfico de la región es el reconocimiento de que todo esto está sujeto a cambios en cualquier momento. Inmensos desastres naturales han cambiado el paisaje en los alrededores de Bermejo y Sinangoe con gran frecuencia, desnudando las capas sucesivas de materia en la superficie durante terremotos, erupciones volcánicas, inundaciones y deslizamientos de tierra. Ya que la zona consiste de una mezcla de diferentes estratos de roca, el resultado de esta constante formación y alteración del paisaje es que el grupo de rocas y la química de los suelos de un sector en particular del bosque puede variar de año en año, al revelarse las sucesivas capas de roca.

Apenas a diez kilómetros al sur de nuestros campamentos en Ccuccono se levanta uno de los volcanes más activos de los Andes orientales: el Reventador, de $3.562 \mathrm{~m}$. Este volcán ha erupcionado 24 veces desde 1541, salpicando el paisaje circundante con toneladas de ceniza y lava, acumulando fuerza progresivamente y luego erupcionando otra vez. Durante el siglo XX, el volcán erupcionó de forma continua desde 1900 a 1906 y luego nuevamente en 1912, 1926, 1929, 1936, 1944, 1955, 1958, 1960, 1972, 1973-1974 y 1976. La implicación de toda esta actividad, que data por lo menos a la era pliocena, es que la parte sur de las Serranías Cofán ha sido cubierta de ceniza y salpicadas de bombas piroclásticas del Reventador de forma continua durante por lo menos los últimos dos millones de años (Nieto 1991).

La zona está cruzada también por una maraña de fallas a lo largo de las cuales el paisaje cambia ocasionalmente y con gran violencia, como parte de la continua orogenia andina. La noche del 5 de marzo del 
1987, dos sismos, midiendo 6.1 y 6.9 en la escala de Richter, azotaron la región. Se calcula que los sismos, precedidos por fuertes lluvias, causaron el deslave de 100 millones de metros cúbicos de suelo desde los empinados pendientes, en avalanchas de lodo y bosque, desnudando miles de kilómetros cuadrados. Las fotos aéreas tomadas luego del desastre indican que un área de por lo menos $2.500 \mathrm{~km}^{2}$ perdió entre 75 a $100 \%$ de sus bosques con los deslaves. Un área de un tamaño por lo menos tres veces mayor perdió entre 25 a $75 \%$ de su cobertura forestal (Nieto et al. 1991).

Estos masivos derrumbes represaron temporalmente un gran número de ríos en la zona; a pocos kilómetros río abajo del epicentro, el río Coca se secó completamente durante varias horas después de los sismos (Nieto et al. 1991). La ruptura de estas represas provocó inundaciones repentinas que arrasaron (o sepultaron debajo de los escombros) los bosques de la llanura aluvial a lo largo de la mayoría de los ríos de la zona, incluyendo los que visitamos a lo largo del río Ccuccono. De hecho, los epicentros de estos sismos han sido rastreados justamente hasta debajo de la cuenca hidrográfica del Ccuccono, casi exactamente debajo de los campamentos utilizados durante el inventario biológico rápido (Espinosa et al. 1991).

Aún cuando el paisaje no está siendo completamente alterado por procesos físicos catastróficos, gran parte del mismo está colapsando de manera menos dramática. La cuenca del valle de Bermejo está rodeada de un anillo de precipicios en erosión que se deslizan hacia el río con tanta frecuencia que las aguas del Bermejo tienen un color rojizo permanente. Las imágenes de satélite del área muestran las cicatrices de derrumbes grandes y pequeños, nuevos y antiguos (Figura 2). Estos derrumbes son tan frecuentes en la base misma de los Andes que forman una línea casi continua a lo largo de la primera línea de estribaciones (aproximadamente a los $1.000 \mathrm{~m}$ ). No es coincidencia que en estas elevaciones cae la mayor precipitación de esta parte de los Andes (OAS 1987).

Las inundaciones a gran escala son también un fenómeno frecuente en las estribaciones andinas; éste probablemente ha sido el caso desde que los Andes comenzaron a desarrollarse hace unos diez millones de años. La comunidad de Alto Bermejo fue destruida por una inundación durante la última década. Las historias sobre otras inundaciones catastróficas son un soporte principal de las leyendas Cofán. El polen cuaternario recolectado a pocos kilómetros al este ha llevado a los paleoecólogos a sugerir que un episodio masivo y prolongado de inundación cambió el paisaje del Oriente ecuatoriano hace apenas 800-1.300 años (Colinvaux et al. 1988). Enormes piedras de cuarcita, como las que cubren actualmente las riberas del río Aguarico, salpican también las terrazas aledañas, como un recordatorio de inundaciones pasadas.

\section{CLIMA Y FENOLOGÍA}

El clima en las Serranías Cofán es persistentemente húmedo debido a que los vientos que predominan en la línea ecuatorial-soplando de este a oeste-recogen evaporación sobre las tierras bajas amazónicas y la dejan caer en forma de lluvia al llegar a los Andes. La precipitación anual en las tres estaciones climáticas más cercanas (Reventador, El Chaco y Santa Cecilia) fluctúa entre dos metros y medio hasta más de seis metros; la gran carga de epífitas y musgos en Bermejo y Sinangoe sugieren que los sitios visitados se encuentran en el extremo alto de este rango (OAS 1987). Incluso en esta zona relativamente pequeña, sin embargo, la cantidad de precipitación que recibe cualquier sitio puede variar dramáticamente a lo largo del paisaje. Las elevaciones intermedias reciben más lluvia que las más altas o más bajas (con el máximo a $1.000 \mathrm{~m}$; OAS 1987) y los sitios en la misma elevación, pero con drenajes diferentes, pueden recibir cantidades dramáticamente distintas de lluvia, ya que la complicada topografía genera un complejo patrón de precipitación (sombras de lluvia).

La lluvia cae aquí todo el año, marcada por débiles temporadas secas de corta duración. La época más seca parece darse en enero-febrero, lo que corresponde a la temporada seca del hemisferio norte (como es esperado justo al norte del ecuador; 
OAS 1987). Puede haber períodos secos, cortos e impredecibles, en cualquier momento del año, pero con mayor probabilidad en agosto, lo que corresponde a la época seca del hemisferio sur. Estas sequías probablemente son más severas en las cordilleras lo suficientemente bajas para quedar bajo la línea de nubes, pero lo bastantemente expuestas para ser barridas por los vientos secos. A elevaciones sobre los $950 \mathrm{~m}$, donde la vegetación con frecuencia está envuelta en nubes, la condensación se suma de forma significativa a la cantidad total de precipitación que cae al suelo.

Las temperaturas en las Serranías Cofán varían linealmente con la elevación, debido al enfriamiento adiabático. En el bosque de laderas bajas, las temperaturas alcanzan un promedio de $25^{\circ} \mathrm{C}$ todo el año; a los $1.000 \mathrm{~m}$, este promedio desciende a ca. $20^{\circ} \mathrm{C}$; y a los $2.000 \mathrm{~m}$, a ca. $15^{\circ} \mathrm{C}$ (OAS 1987).

A pesar de la ausencia en general de estaciones y de cambios mínimos en la duración del día, muchas especies de plantas parecen estar básicamente sincronizadas en cuanto a su comportamiento reproductivo y de floración. Esta sincronía probablemente tiene lugar para la mayoría de las especies debido al usual-aunque no confiable-corto período seco en enero y febrero. Para algunas puede deberse a la repentina caída de temperatura, acompañada de alguna tormenta específica, o a unos pocos días de sequía en cualquier momento del año. Un ejemplo es una de las especies de Faramea (Rubiaceae), un arbusto en el cual todos los individuos florecieron y se marchitaron en una semana durante nuestra visita. Otro ejemplo es el árbol común Dacryodes olivifera (Burseraceae), del cual todos los árboles adultos parecían estar brotando nuevas hojas durante el tiempo de nuestra estadía.

Menos especies tenían individuos que estaban floreciendo, dando fruto o brotando hojas, mezclados en la misma población o incluso en el mismo árbol individual. Estas especies asincrónicas pueden estar respondiendo ya sea a señales repetidas a lo largo del año, o simplemente a señales internas sobre el estado de los nutrientes del árbol o rama. Un ejemplo es el árbol común Billia rosea (Hippocastanaceae), al que en ocasiones encontramos con flores, otras veces con fruto maduro (Figura 4D) y en otros casos $\sin$ ninguno de los dos pero con brotes de hojas nuevas. El cerezo silvestre de elevaciones altas, Prunus herthae (Rosaceae), fue inusual: todos los individuos observados en las partes altas de Bermejo estaban dando fruto, mientras que en las crestas altas de Sinangoe todos estaban floreciendo. La explicación más probable de esto es algún evento climático local que afectó a uno de los lados de los valles del Aguarico y Chingual pero no al otro.

\section{FLORA Y VEGETACIÓN}

Participantes/Autores: Robin Foster, Nigel Pitman y

Roberto Aguinda

Objetos de conservación: Bosques de laderas altas y bajas; bosques montanos; bosques de cimas y de cordilleras bajas; comunidades de plantas en afloramientos ácidos; bosques de selva baja con árboles comúnmente sobre-explotados

\section{MÉTODOS}

Éste fue un estudio corto, avanzando rápidamente por una gran región, con la meta de esbozar los patrones de vegetación en el área. Durante nuestras tres semanas en el campo nos movimos constantemente, en un intento por cubrir cuanto terreno fuera posible y visitar el mayor número de hábitats posibles. Utilizamos una variedad de técnicas de muestreo formales e informales y aprovechamos en la medida posible la experiencia de toda una vida de los naturalistas Cofán que habitan en la zona.

Las bases para nuestra exploración de la zona de Bermejo y Sinangoe fueron sentadas por el excelente trabajo previo realizado por Carlos Cerón y sus colegas (1994), de la Universidad Central del Ecuador. Algunas de las observaciones incorporadas aquí han sido tomadas de visitas anteriores realizadas por RF, RA, M. Metz, T. Theim y G. Baker a Sinangoe y a la nueva Vía Interoceánica en junio del 1999 y julio del 
2000. No se realizó ningún muestreo cuantitativo durante esas visitas, pero sí se recolectaron o fotografiaron varios centenares de plantas.

Durante el inventario del 2001 continuamos recolectando y fotografiando cuantas especies no reconocidas nos fuera posible, llevando a la misma vez una lista constante de las especies identificadas en el campo pero que no fueron recolectadas. La base de datos incluye ahora más de 1.000 especímenes de herbario, representando por lo menos 800 especies, y 1.400 fotografías de por al menos 700 especies. La lista preliminar, presentada en el Apéndice 1, incorpora y actualiza el inventario de Cerón et al. (1994) en las inmediaciones de la comunidad de Sinangoe. Obviamente, no constituye un catálogo completo de la flora, al igual que nuestro trabajo ecológico apenas provee un panorama inicial para estimular la investigación adicional de las comunidades de plantas de la zona.

Recolectamos también datos cuantitativos a lo largo de transectos en varios de los principales tipos de hábitat, tomando muestras de 969 árboles y arbustos en total. Los transectos se establecieron según las oportunidades permitidas (esto es, tiempo adecuado sin lluvia), dando prioridad a los árboles de dosel y del sotobosque. Para varios transectos continuos, a lo largo de los senderos existentes, usamos el método de Foster et al. (manuscrito no publicado). Muestreamos los árboles de dosel en transectos individuales y continuos de 100 individuos, o de menos cuando se agotaba el tiempo. Los transectos tenían $20 \mathrm{~m}$ de ancho ( $10 \mathrm{~m}$ a cada lado del observador) y el muestreo incluyó a todos los árboles con un diámetro de tronco mayor a $30 \mathrm{~cm}$ a la altura del pecho (DAP; ca. 1,3 m del suelo). Las identificaciones de especies, con frecuencia a "morfoespecies" temporales, se realizaron utilizando observaciones del dosel con binoculares, de las hojas caídas y de cortes en la corteza. No incluimos los árboles sin suficiente follaje visible. Muestreamos el sotobosque por separado, en transectos "interrumpidos" que incorporaban 100 a 200 tallos midiendo 1-10 $\mathrm{cm}$ DAP. Estos transectos tenían $1 \mathrm{~m}$ de ancho a cada lado del sendero, con sub-muestras de 20 individuos, cada uno separado por intervalos de $100 \mathrm{~m}$. Se recolectaron "vouchers" de las morfoespecies fértiles y también de las más abundantes. Recolectamos e hicimos observaciones de plantas en todos los hábitats, pero concentramos nuestro esfuerzo cuantitativo en el bosque de laderas altas, con transectos adicionales en el bosque de cresta y en el bosque de laderas bajas. No establecimos transectos en la cumbre de montaña, ni tampoco en las comunidades ribereñas.

Estos datos fueron complementados con observaciones cualitativas de la dinámica de la vegetación, composición del hábitat y otros aspectos de la ecología de las plantas. Además, ya que uno de nosotros (RA) habla el idioma Cofán, pudimos registrar los nombres indígenas y los usos de varias plantas, a través de entrevistas con personas mayores de las comunidades de Alto Bermejo y Sinangoe.

Las colecciones fueron preservadas en alcohol en el campo y secadas posteriormente en Quito. Los especimenes fértiles fueron depositados en el Herbario Nacional del Ecuador (QCNE), enviándose duplicados adicionales al Field Museum (F), a especialistas y a la Pontificia Universidad Católica del Ecuador (QCA) cuando posible.

\section{RIQUEZA FLORÍSTICA, COMPOSICIÓN Y ESPECIES DOMINANTES}

Nuestra lista preliminar de plantas vasculares (ver Apéndice 1) contiene 1.596 especies. Sobre la base de las observaciones de campo y de nuestra experiencia en áreas mejor conocidas de los Neotrópicos, calculamos una flora vascular de entre 2.000 a 3.000 especies en la zona de Bermejo y Sinangoe. Ésta es obviamente una aproximación; la cifra real dependerá de cómo se tracen los linderos de la zona (esto es, cuánto de las selvas bajas y de los bosques andinos adyacentes se incluyan). Al igual que en otros bosques andinos, una estimación aproximada de la diversidad florística del área dependerá de una buena estimación de su diversidad de orquídeas, ya que esta familia forma gran parte de la flora de bosques muy húmedos. 
La diversidad a escala tanto regional como local de las Serranías Cofán parece ser típica de los bosques andinos orientales-sumamente alta, particularmente en las familias Orchidaceae, Melastomataceae, Rubiaceae, Piperaceae y Bromeliaceae. La diversidad a escalas intermedias (esto es, de uno a varios cientos de kilómetros cuadrados) podría ser ligeramente más baja que en otras partes de las estribaciones andinas ecuatorianas, que experimentan mayores extremos geológicos o microclimáticos.

La excepción obvia en las Serranías Cofán es la sorprendente concentración de especies de la familia del café, Rubiaceae. Encontramos al menos 39 géneros y más de 129 especies de la familia durante nuestro corto tiempo de observación y recolección. Esta familia cuenta con el mayor número de especies de plantas leñosas en las selvas bajas del Neotrópico y se encuentra por lo general en abundancia en el sotobosque de las selvas del Neotrópico. En nuestra experiencia, sin embargo, ninguna otra área del Ecuador, Sudamérica o del mundo tiene una concentración tan alta de Rubiaceae como la encontrada en la zona que visitamos.

Las vertientes del Pacífico en Ecuador y Colombia han sido reconocidas durante mucho tiempo por los botánicos como un centro de diversidad de las familias Gesneriaceae, Araceae y Ericaceae. Con relación a las Gesneriaceae (41 especies encontradas) y Anthurium (el género más grande de aráceas; 38 especies encontradas), la riqueza de especies en los alrededores de Bermejo y Sinangoe probablemente compite con la de un área de tamaño similar en la vertiente del Pacífico y ciertamente es más alta que cualquier otro bosque que hemos estudiado en la base oriental de los Andes. En cuanto a las ericáceas y el resto de las aráceas, por otra parte, el área no parece ser muy diversa. La presencia de al menos una docena de especies de helechos arbóreos (mayormente Cyathea) en el área nos parece alto en comparación con cualquier otra área al sur del río Marañón, pero podría ser comparable a la cordillera del Cóndor y a la zona norte del drenaje del Putumayo.

\section{TIPOS DE BOSQUE Y VEGETACIÓN}

La diversidad de hábitats y de comunidades de plantas en la región de Bermejo-Sinangoe es típica de la base de los Andes. Aunque la región contiene una mezcla de diferentes formaciones geológicas, no se observan los extremos en la química de la roca subyacente como en otras áreas, por ejemplo en la cordillera del Cóndor (Schulenberg y Awbrey 1997). En ese sentido, las Serranías Cofán no son tan ricas en hábitats y tampoco existen en las Serranías diferencias extremas en cuanto a la disponibilidad de humedad a cualquier elevación dada. Pero sí hay una magnífica transición intacta en las laderas sur del cerro Sur Pax-que va desde las selvas bajas hasta los bosques nublados, incluyendo todos los hábitats a menor escala de crestas, pendientes, quebradas y derrumbes. Estos tipos de transectos de elevación intactos se están volviendo más y más raros en las vertientes de los Andes, por lo cual las Serranías Cofán constituyen un excelente laboratorio al aire libre para estudiar los cambios en las poblaciones y comunidades de plantas a lo largo de una gradiente altitudinal.

Utilizamos aquí el término general de "bosque de laderas" para la mayor parte del bosque en las Serranías Cofán, distinguiendo para los propósitos de este informe tres tipos amplios de hábitat: bosque de laderas bajas (400-950 m), bosque de laderas altas (950-1.500 m), y bosque de crestas y cimas de montaña (encima de los $1.500 \mathrm{~m}$ ). Dentro de éstos hemos identificado unos pocos hábitats obvios a menor escala, como orillas de las quebradas, bosque de transición sobre derrumbes y vegetación sobre afloramientos ácidos. Todas estas clasificaciones son subjetivas, especialmente en un área como ésta donde la distribución de las especies es muy irregular y donde la mayoría de los cambios en la vegetación son graduales. Nuestras principales categorías reflejan diferencias altudinales en la presencia de las especies, en la relativa abundancia de las mismas y en la estructura de la vegetación. 
BOSQUe de Laderas Bajas (400-950 m)

Este tipo de bosque cubre gran parte del valle del río Bermejo, las crestas bajas y las terrazas elevadas e inclinadas entre el río Ccuccono y la comunidad de Sinangoe. Nuestras mejores oportunidades para estudiar los bosques de laderas bajas fueron en las inmediaciones de las estaciones de campo de Bermejo y Sinangoe y en las excursiones hacia y desde los campamentos Mirador Bermejo y Shishicho. El bosque en estas elevaciones es esencialmente una extensión un tanto menos variada que la selva baja amazónica unos pocos kilómetros al este. Al igual que en las comunidades de plantas alrededor del Parque Nacional Yasuní y de la Reserva de Producción Faunística Cuyabeno, éste es un bosque de estatura alta y de dosel cerrado, donde la diversidad local de árboles se ubica entre las más altas del mundo y donde la mayoría de las especies son sumamente raras. La composición de especies en estos bosques varía en forma dramática de una pequeña área a la otra-en una forma que continúa siendo poco entendida por los ecólogosmientras que al mismo tiempo un pequeño grupo de especies está presente de manera consistente en todo el paisaje, aunque a densidades bajas.

$\mathrm{Al}$ igual que en los bosques de selva baja más al este, el árbol de dosel más común en el bosque de laderas bajas es la palma Iriartea deltoidea (Figura 3E). En general, las palmas son frecuentes en el paisaje, compartiendo su predominio con las familias de Myristicaceae, Fabaceae s.l., Meliaceae, Euphorbiaceae, Melastomataceae, Rubiaceae, Vochysiaceae y Moraceae. En un transecto de 100 árboles de dosel en crestas moderadamente empinadas al sur de Bermejo, a los 500-600 m, las especies más comunes fueron Minquartia guianensis (Olacaceae) y Vochysia braceliniae (Vochysiaceae), aunque ninguna de las dos contó con más del $10 \%$ de los árboles. Una consecuencia de la ausencia de dominantes de dosel-algo muy característico de las selvas amazónicas del Ecuador-es que éstas son comunidades sumamente diversas. De los 100 árboles de dosel muestreados en nuestro transecto, registramos 59 especies diferentes. Cerón et al. (1994) reporta una diversidad similarmente alta de árboles y arbustos en cuatro parcelas establecidas en el bosque de laderas bajas en las inmediaciones de Sinangoe.

La gran densidad de árboles de estatura muy alta $(40-45 \mathrm{~m})$ fue otra característica notoria del bosque de laderas bajas sobre la cresta que estudiamos. Entre éstos sobresalían varios Fabaceae s.l. gigantes, incluyendo Cedrelinga cateniformis, varias especies del género Parkia y lo que posiblemente podría ser el Melastomataceae más grande del mundo: un Tessmannianthus heterostemon de $50 \mathrm{~m}$ de altura, con un diámetro del tronco de $1 \mathrm{~m}$. Nos sorprendió encontrar un árbol "bala de cañón," Couroupita guianensis (Lecythidaceae), sobre la cresta, ya que por lo general se encuentra en la llanura aluvial. Otros árboles notorios del dosel del bosque de laderas bajas son las diferentes especies de Sterculia (Sterculiaceae), con sus grandes hojas redondeadas y, en el caso de S. apeibophylla, con grandes frutos redondos que caen al suelo del bosque. Tanto Otoba parvifolia como O. glycycarpa (Myristicaceae) son comunes en el dosel, junto con varias especies de Virola. Los bosques de laderas bajas sobre las pequeñas crestas en las inmediaciones de Sinangoe parecen tener una composición similar (Cerón et al. 1994).

En elevaciones mayores en el bosque de laderas bajas, sobre la terraza plana al norte de Bermejo, a los 800-900 m, el bosque parecía considerablemente más húmedo. El dosel aquí tenía una altura de $30-35 \mathrm{~m}$, con pocos árboles de gran diámetro, pero la diversidad era igual de impresionante, registrándose 41 especies en un transecto de 70 árboles de dosel. Una vez más, las Fabaceae s.l. y Myristicaceae eran las familias dominantes. La especie pequeña más abundante era Matisia bracteolosa s.l. (Bombacaceae), dando cuenta del 13\% de los árboles. El árbol de subdosel Tovomita weddelliana (Clusiaceae)—quizá el árbol pequeño más común en la región y que aparece en abundancia en una amplia zona altitudinal-era más notorio y abundante en este sotobosque que en otros bosques de laderas bajas. La comunidad de arbustos (plantas de hasta $5 \mathrm{~m}$ de altura) tenía una densa presencia de Rubiaceae y 
Melastomataceae, junto con una abundancia relativamente alta de helechos arbóreos-todas estas especies características también de elevaciones más altas en las Serranías. Los helechos terrestres, especialmente del género Danaea, probablemente dan cuenta de la mitad de la cobertura herbácea terrestre (Figura 4C), mientras que densos rodales en torno a la arácea Dieffenbachia harlingii se encontraban casi inevitablemente presentes en las hondonadas más húmedas. La Marantaceae Ctenanthe ericae es la hierba más dominante, cubriendo gran parte de los pendientes del bosque de laderas bajas de Sinangoe, hasta aproximadamente los $900 \mathrm{~m}$. Sin embargo, Ctenanthe está completamente ausente en la zona de Bermejo.

Una palma del sotobosque, Chelyocarpus ulei, es el árbol pequeño más abundante y notorio en varios kilómetros cuadrados en las inmediaciones de la comunidad de Alto Bermejo, pero no fue visto en ningún otro lugar de la región. Aparece abruptamente en el sendero desde Pozo Dos a Bermejo, volviéndose casi inmediatamente común en unos pocos arroyos pequeños al oeste del río Rayo, al lado sur del río Bermejo. La población de esta palma se extiende hacia el sur por un kilómetro, sobre el sendero a Pozo Seco, pero no parece cruzar al lado norte del río Bermejoalgo extraño en una especie con un fruto pequeño dispersado por las aves. Observamos otro gran sector similar de C. ulei en la selva baja del Parque Nacional Yasuní, tampoco relacionado con alguna característica edáfica o topográfica obvia. La población encontrada en Bermejo es la más norteña que se conoce en Sudamérica.

Aunque estos bosques de laderas bajas comparten la mayoría de los elementos con los bosques amazónicos al este, nos sorprendió notar destacadas ausencias: varias especies comunes en las selvas bajas no se registraron aquí, incluyendo Spondias mombin y Astronium graveolens (Anacardiaceae); Astrocaryum chambira y Geonoma deversa (Arecaceae); Hevea guianensis, Omphalea diandra y Pausandra trianae (Euphorbiaceae); Casearia aculeata y C. sylvestris (Flacourtiaceae); y Swartzia arborescens (Fabaceae), Ficus paraensis (Moraceae), Palicourea guianensis
(Rubiaceae), y Rinorea lindeniana (Violaceae). Los jardines de hormigas—esto es, los nidos de hormigas con especies de plantas características cultivadas y protegidas por las hormigas-se ven rara vez aquí $y$ consisten de poco más que la bromelia Aechmea longifolia y la hierba Codonanthe (Gesneriaceae), en vez de la gama más variada de especies encontradas en lugares más alejados de los Andes.

Otros grupos taxonómicos, aunque presentes, escaseaban notablemente aquí, incluyendo Attalea y Bactris (Arecaceae); Brownea y Hymenaea (Caesalpiniaceae); Brosimum y Naucleopsis (Moraceae); Hamelia patens y Geophila (Rubiaceae); y Anaxagorea (Annonaceae), Cordia nodosa (Boraginaceae), Hirtella (Chrysobalanaceae), Heliconia velutina (Heliconiaceae), Gustavia (Lecythidaceae), Mouriri (Melastomataceae), Zygia (Mimosaceae), Ouratea (Ochnaceae), Chrysophyllum (Sapotaceae), y Petrea (Verbenaceae). Es posible que todos estos grupos taxonómicos prefieren suelos un tanto más secos de lo que se puede encontrar en esta zona.

\section{Ríos y Orillas de Quebradas}

Son muy escasos los bosques de llanura aluvial en las Serranías Cofán. En algunos casos, esto se debe a que los valles son demasiado jóvenes y empinados como para haber desarrollado una planicie aluvial, con pendientes que bajan hasta los rocosos lechos de los ríos (como sucede a lo largo de los ríos Bermejo y Sieguyo). En otros casos-particularmente en el valle más plano de Ccuccono-se debe a que grandes áreas del bosque de llanura aluvial han sido destruidas por un deslave reciente (vea Descripción de los Sitios Muestreados).

$$
\text { La vegetación asociada con los ríos y }
$$
quebradas, aunque demuestra cierta variación con respecto al tamaño y substrato de la corriente de agua, era bastante regular en su composición a lo largo de la región, aunque los arroyos individuales casi siempre tuvieron poblaciones grandes de unas especies presentes pero no comunes en otros lugares. A lo largo de los 
ríos, grandes y pequeños, se encuentra Blakea repens (Melastomataceae), que ocurre ya sea como una hemiepífita sobre el tronco inferior de un árbol ribereño, estrechándose hacia el río en busca del sol, o crece sobre rocas o troncos caídos. Esta misma especie con frecuencia crece en el bosque alejado del río como una hemiepífita, pero es notoriamente dominante sólo a lo largo de los ríos lindados de árboles. Otras especies características de las riberas son Trophis caucana (Moraceae), Myriocarpa stipitata (Urticaceae), Bauhinia tarapotensis (Caesalpiniaceae) y Calliandra trinervia (Mimosaceae).

Los ríos grandes y ocasionalmente los más pequeños tienen algunas pequeñas áreas de meandros, con playas de arena o grava relativamente estables. El árbol más común en las partes más antiguas de estas zonas es Inga ruiziana (Mimosaceae), una especie propia de la llanura aluvial del alto Amazonas. En las riberas estables de grava crecen densos rodales de una especie de caña probablemente no descrita del género Gynerium (Poaceae). Esta especie es similar apero claramente distinta de - la robusta y cosmopolita 'caña brava,' Gynerium sagittatum. Observamos ambos creciendo juntos sin evidencia alguna de formas intermedias. Aunque la caña más pequeña es considerada por los taxónomos botánicos como una forma de G. sagittatum, este taxón merece ser reconocido como una especie distinta.

Otras especies de la playa ribereña, menos predecibles en cuanto a su presencia, incluyen Brugmansia candida y Solanum spp. (ambas Solanaceae), Cleome sp. (Capparidaceae), Tovaria pendula (Tovariaceae), Tessaria integrifolia y Mikania micrantha (ambas Asteraceae), Commelina erecta (Commelinaceae) e incluso una ocasional Bocconia integrifolia (Papaveraceae). En un arroyo tributario del Ccuccono, la abundancia de Canna jaegeri (Cannaceae)-una especie extensamente cultivada por los Cofán y otras comunidades amazónicas por sus semillas, que son utilizadas como las principales pepas pequeñas de sus collares-señala la anterior ocupación humana del área.
En las rocas que revisten la mayoría de estos ríos crece una serie de arbustos pequeños y hierbas perennes capaces de sobrevivir las frecuentes inundaciones. La más cosmopolita es una Cuphea (Lythraceae), de tamaño mediano, encontrada a lo largo de todos los ríos y arroyos donde hay suficiente exposición a los rayos solares. Otros miembros comunes de esta comunidad de rocas incluyen especies más pequeñas de Cuphea, dos especies de Justicia (Acanthaceae), Liabum amplexicaule (Asteraceae), Thelypteris angustifolia (Pteridophyta) y, a los lados de grandes rocas estables, la elegante orquídea Phragmipedium pearcei. Otra importante comunidad herbácea crece en las ramas de los árboles de la ribera y muchas de estas especies parecen ser también propias de los hábitats de corriente. Incluyen particularmente helechos, pero también orquídeas, Peperomia (Piperaceae) y bromelias.

La mayoría de las especies de plantas a lo largo de las riberas son especies propias de regeneración, encontradas típicamente sobre los pendientes del bosque de laderas después de derrumbes o algún vendaval grande. Es sólo a lo largo de los ríos y arroyos que su "parche" es largo y lineal. Estas especies incluyen dos especies de Sanchezia (Acanthaceae); Acalypha sp., Croton lechleri, y Mabea sp. (Euphorbiaceae); Guettarda crispiflora y Isertia laevis (Rubiaceae); y Saurauia cf. herthae (Actinidiaceae), Eirmocephala megaphylla (Asteraceae), Ochroma pyramidale (Bombacaceae), Senna ruiziana (Caesalpiniaceae), Podandrogyne brachycarpa (Capparidaceae), Cecropia putumayonis (Cecropiaceae), Banara guianensis (Flacourtiaceae), Piper umbellatum (Piperaceae), Triplaris americana (Polygonaceae) y Trema micrantha (Ulmaceae).

Ausentes o raros de encontrar en estas riberas son el árbol Zygia longifolia (Mimosaceae) y los arbustos Calliandra angustifolia (Mimosaceae) y Adenaria floribunda (Lythraceae), tan propias de la vegetación aluvial a lo largo de otros ríos pequeños del alto Amazonas. Podría ser que las playas de arcilla y orillas rocosas de estos ríos son demasiado inestables 
como para soportarlos, pero resulta difícil explicar cómo son lo suficientemente estables para soportar a Inga ruiziana.

Los arroyos más pequeños pero permanentes, sombreados en parte y rocosos, están asociados con frecuencia a una serie de especies distintivas. Éstas incluyen por lo general a la hierba Dicranopygium (Cyclanthaceae), varias especies de Pilea (Urticaceae) y los arbustos Urera baccifera (Urticaceae) y Hoffmannia (Rubiaceae). En algunos de los pequeños tributarios del Bermejo encontramos un par de especies inusuales asociadas estrictamente con las orillas de los arroyos: Calathea gandersii (Marantaceae), que hasta hace poco era conocida únicamente de la colección tipo cerca al Tena, y una nueva variedad de una de las especies herbáceas más conocidas y extendidas en los Neotrópicos, Cyclanthus bipartitus (Cyclanthaceae; ver abajo en notas sobre las especies).

\section{Bosque de Laderas Altas (950-1.500 m)}

Pudimos estudiar esta franja altitudinal más a fondo que ninguna otra, al haber establecido tres de nuestros campamentos entre los 950 y 1.200 m. Las características físicas de los bosques en esta elevación no son muy diferentes a los del bosque de laderas bajas. Los árboles en promedio no son tan grandes en altura o circunferencia y los troncos contienen mayores densidades de epífitas, si bien la corteza en su mayor parte continúa descubierta.

A pesar de la considerable superposición en la composición de especies de elevaciones menores, es dentro de este rango de elevación que se comienza a ver límites abruptos en las distribuciones de especies. Parece que muchas especies de plantas sólo comienzan a aparecer sobre aproximadamente los ca. $950 \mathrm{~m}$, mientras que otras especies desaparecen repentinamente en esta elevación. Por ejemplo, una Aphelandra (Acanthaceae) de flor color rojo encendido apareció más o menos a esta elevación en los tres sitios, mientras que la común hierba Ctenanthe ericae (Marantaceae) desapareció de dos de los sitios en
Sinangoe (la especie no aparecía en la zona de Bermejo). No notamos ninguna transición de este tipo en elevaciones más bajas, pero se necesitaría una investigación completa para establecer este hecho. Hay también una transición en la flora dentro de esta faja de bosque de laderas altas, esto es, especies que sólo crecen por encima de los $1.300 \mathrm{~m}$ o especies que no crecen a alturas mayores de $1.200 \mathrm{~m}$, pero las variaciones en el paisaje en relación con clima y geología hacen poco probable el que estos límites se puedan considerar como constantes en toda la región.

Como se esperaba, en nuestro muestreo de árboles de dosel en el bosque de laderas altas encontramos una diversidad de especies un tanto menor, y mayor predominio de unas pocas especies en comparación con el bosque de laderas bajas. Notamos también una considerable variación en los árboles predominantes de un sitio a otro. En la empinada cresta debajo del campamento Mirador Bermejo, un transecto de 100 árboles de dosel contenía 47 especies (en comparación con 59 del transecto comparable de selva baja; ver arriba). Casi un tercio de los árboles pertenecían a sólo dos especies: Billia rosea (Hippocastanaceae; $18 \%$ de la muestra) y Otoba glycycarpa (Myristicaceae; 12\%). En la cresta inclinada debajo del campamento Shishicho, nuestro transecto de 100 árboles contenía 50 especies. Minquartia guianensis (Olacaceae) daba cuenta del $12 \%$ de los árboles, mientras que tres especies de Myristicaceae (Compsoneura ulei, Otoba glycycarpa y Virola sp.) conformaban el $20 \%$ (7\%, $7 \%$ y $6 \%$, respectivamente.) Y sobre la cresta empinada sobre el campamento de cresta de Ccuccono, un transecto de 80 árboles contenía 37 especies. Los predominantes en este lugar eran Dacryodes olivifera (Burseraceae; $26 \%$ del total), Billia rosea $(9 \%$ ) y dos Euphorbiaceae (Conceveiba sp. y Hyeronima macrocarpa; $8 \%$ y $6 \%$ respectivamente). Otras especies de árboles notoriamente abundantes en estas elevaciones, aunque no en los transectos, son el gran Ficus coerulescens (Moraceae) emergente y los Grias neuberthii (Lecythidaceae) y Wettinia anomala (Arecaceae) del subdosel. 
El predomino de especies individuales es bastante irregular y esta irregularidad es aparente desde la escala espacial más pequeña hasta la más grande. En un tramo largo del sendero de la cresta Ccuccono, por ejemplo, casi la mitad de los arbustos parece ser Psychotria deflexa (Rubiaceae), mientras que en otros dos tramos en la misma cresta los predominantes son una Alibertia sp. (Rubiaceae) y una Miconia sp. (Melastomataceae), respectivamente. A mayor escala, la especie más común del sotobosque en nuestro transecto del campamento Shishicho, la palma Hyospathe elegans, está ausente u ocurre raramente a sólo unos pocos kilómetros de distancia, sobre la cresta de la Estación Sinangoe en dirección al Ccuccono. Pero esta especie se vuelve nuevamente común en la cresta del campamento Mirador Bermejo, a muchos kilómetros de distancia. Parte de esta variación en las especies predominantes refleja la heterogeneidad a pequeña escala o la limitación de dispersión dentro de un sitio, mientras que otra parte de la variación representa diferencias ambientales a gran escala a lo largo del paisaje. Por ejemplo, aunque Dacryodes olivifera y Compsoneura ulei no aparecían en nuestro transecto del campamento Mirador Bermejo, ambos aparecían en bastante abundancia justo encima del campamento, entre los 1.200 y $1.300 \mathrm{~m}$. En contraste, no hay duda de la excepcional abundancia de Dacryodes a lo largo del área del Ccuccono, ya que se podían ver grandes franjas de sus nuevas hojas anaranjadas en las crestas circundantes.

Nuestro único transecto de arbustos en el bosque de laderas altas fue del campamento Shishicho, de los 950 a los $1.000 \mathrm{~m}$. Los 200 tallos muestreados contenían 90 especies, siendo los grupos taxonómicos más comunes la pequeña palma Hyospathe elegans (11\% de los tallos) y el arbusto Psychotria bertieroides (Rubiaceae; 7\%). En el ámbito de familias, Rubiaceae (18 especies) y Melastomataceae (14 especies) eran las dominantes. Estas dos familias representan más de la tercera parte de las especies del transecto, lo que apoya nuestras observaciones casuales de que estas familias predominan en el sotobosque a lo largo de esta región.
Además de las muchas Psychotria, las Rubiaceae comunes incluyen varias especies de Faramea, Coussarea, Rudgea y un pequeño árbol de Chomelia encontrado ampliamente. Las Melastomataceae comunes incluyen muchas Miconia, al igual que varias especies de Ossaea y Clidemia.

\section{Crestas ácidas del bosque de laderas altas}

Todas las cimas angostas en la zona de Sinangoe sobre los $1.350 \mathrm{~m}$, incluyendo el cerro Shishicho, parecen caracterizarse por una vegetación enana y una flora que apunta a suelos altamente ácidos. En los lugares descubiertos por deslaves, la materia progenitora en este lugar es una roca muy dura, probablemente cuarcita. Las zonas visitadas tenían como característica un bosque enano (ca. 10-15 m de altura) y árboles con coronas pequeñas, una alfombra sólida de raíces que cubría el suelo, agrupaciones o alfombras frecuentes de Sphagnum y otros musgos en el suelo, pero poca cubierta de musgos o epífitas en las cortezas de los árboles. A pesar de su estatura similar, esta vegetación es muy diferente a la de las cimas de las montañas más elevadas del cerro Sur Pax (descrito abajo).

Esta vegetación distintiva crece muy

estrechamente a lo largo de las puntas de las crestas en este terreno tipo "montaña rusa". Esto se debe probablemente a que tanto los suelos ácidos como las condiciones secas causadas por la exposición al viento se restringen a una franja muy angosta en los puntos más altos de las crestas. En los puntos bajos de la cordillera y en sus laderas, el suelo se vuelve nuevamente de arcilla oscura, la carga de epífitas en los troncos y la cubierta de musgo es casi tan densa como en cualquiera de las crestas más húmedas y la vegetación es mucho más similar a la del típico bosque de laderas altas, con especies como Tovomita weddelliana predominantes nuevamente en el sotobosque. Al transitar por los puntos más altos de la cordillera se entra y sale de la vegetación de cresta ácida.

Uno de los componentes más notorios de esta vegetación de cresta ácida, además de Sphagnum, es Trichomanes cristatum, un helecho terrestre erecto, con un indumento anaranjado. Otras taxa notorias y 
características son Graffenrieda y Tibouchina (Melastomataceae), Guzmania squarrosa y Racinaea undulifolia (Bromeliaceae) y Sphaeradenia

(Cyclanthaceae). También se encuentran los grupos montanos que se pueden llegar a elevaciones más bajas sobre suelos ácidos. Éstos incluyen géneros como Brunellia (Brunelliaceae), Symbolanthus (Gentianaceae), Weinmannia (Cunoniaceae), Prunus (Rosaceae), Centronia (Melastomataceae) y Myrsine (Myrsinaceae). También comunes aquí hay Miconia (Melastomataceae), Cybianthus (Myrsinaceae), Palicourea (pero no Psychotria; Rubiaceae), Vochysia (Vochysiaceae), Ericaceae, Myrtaceae, Sapotaceae y Chrysobalanaceae. Las Fabaceae s.l. son raras, con excepción de una Inga que no pudimos identificar en la guía de campo publicada recientemente sobre las Inga ecuatorianas (Pennington y Revelo 1997). La palma más común a lo largo de la cordillera de Shishicho era una pequeña Geonoma encontrada únicamente en Bermejo por encima de los $1.700 \mathrm{~m}$, en la cordillera al sur del cerro Sur Pax.

En un transecto de sotobosque de las crestas ácidas, una Myrsine (Myrsinaceae) de hojas pequeñas daba cuenta del $11 \%$ de los individuos, una Miconia (Melastomataceae) del 9\% y la Geonoma sp. del $8 \%$. De los 120 tallos había 49 especies. En un transecto de hábitat mixto de árboles de dosel que incluía parte de la cresta ácida al igual que de las laderas y depresiones adyacentes de suelo arcilloso, una Pouteria (Sapotaceae) representaba de $14 \%$ de los individuos, Macrolobium sp. nov. (Caesalpiniaceae) 10\%, Vochysia sp. (Vochysiaceae) $8 \%$, una Licania (Chrysobalanaceae) $6 \%$, otra Pouteria 5\% y una nueva Conceveiba (Euphorbiaceae) para el Ecuador 5\%. De los 99 árboles en el lugar, había 39 especies. Se encontró el mismo Macrolobium sp. nov. también en abundancia a los $1.300 \mathrm{~m}$ en las laderas sur de la cordillera del cerro Sur Pax. La Vochysia, aunque similar en apariencia a la $V$. braceliniae de las selvas bajas, probablemente se trata de una especie distinta.

En el área de Bermejo parece haber poca exposición de rocas ácidas, con excepción quizás de las cimas más altas. En elevaciones menores, se aprecia la presencia de cuarcita en forma de escarpados precipicios. Encontramos especies acidófilas únicamente en los bordes o frentes de esos precipicios. El filo de las murallas de arcilla directamente al norte del río Bermejo fue el único lugar en el que encontramos el árbol Humiriastrum diguense (Humiriaceae), una taxa propia de suelos ácidos, al igual que una hierba gentianácea no identificada. En el borde de un precipicio más alto de ca. $1.700 \mathrm{~m}$ en la cordillera del Sur Pax, encontramos varios individuos de Purdiaea nutans (Cyrillaceae), una especie conocida en las montañas de roca ácida de las provincias sureñas de Zamora-Chinchipe y Morona-Santiago, pero que nunca antes había sido recolectada al norte de las mismas en el Ecuador.

Crestas y Cimas de Montañas (I.500-2.300 m) Crestas La principal ruptura que ocurre en la composición florística con la elevación tiene lugar aproximadamente a los $1.500 \mathrm{~m}$. A esta altura, la flora cambia a géneros principalmente montanos. En nuestra ruta ascendente hacia las laderas sur del cerro Sur Pax, la transición coincidió con la presencia de un empinado precipicio a los $1.500 \mathrm{~m}$. El abrupto cambio en flora puede haberse debido en parte a un cambio en la composición química de la roca y suelo sobre y debajo del precipicio, aunque es más probable que sea el resultado de una transición en el régimen de las nubes. La marca de los $1.500 \mathrm{~m}$ parece ser el límite inferior de la línea de nubes aquí-la elevación inferior en la cual las nubes golpean contra estas montañas con mayor frecuencia, particularmente durante la temporada seca. Por encima de los $1.500 \mathrm{~m}$, el dosel en su mayor parte tiene una altura de $20-30 \mathrm{~m}$ y las hojas son notablemente más gruesas que en elevaciones menores. Los troncos de los árboles están densamente cubiertos de helechos y otras epífitas vasculares, al igual que de una capa relativamente delgada e irregular de diferentes musgos. También característica del área es la mayor frecuencia de grandes hemiepífitas como 
Clusia (Clusiaceae), Schefflera (Araliaceae) y Blakea o Topobea (Melastomataceae), que crecen en las ramificaciones de los árboles; muchos árboles grandes con raíces zancos y una alta frecuencia de nuevos brotes; una alta densidad de hierbas suculentas como Gesneriaceae y bromelias terrestres (principalmente Guzmania y Pitcairnia); relativamente más cepas que sirven como 'troncos almácigos' (plataformas para la germinación y el establecimiento de los arbolitos), en comparación con los bosques de menor elevación; y más materia orgánica y musgo (rara vez Sphagnum) en el suelo.

Hay menos especies de árboles en las crestas de las montañas que en el bosque de laderas, pero la flora de ninguna forma está empobrecida. En nuestro transecto de árboles de dosel en la cresta que asciende al cerro Sur Pax desde el sur (a los 1.900-2.100 m), los 100 árboles muestreados representaban 24 especies. Billia rosea (Hippocastanaceae) constituían el 17\% de los árboles, Calatola sp. 15\% (Icacinaceae; identificación en duda, pero frutos de Calatola fueron encontradas bajo uno de los árboles), una especie arbórea de Clusia (Clusiaceae) 10\%, Tovomita weddelliana (Clusiaceae) 9\%, Myrsine sp. (Myrsinaceae) $8 \%$, Weinmannia cf. pinnata (Cunoniaceae) 7\% y Clethra revoluta (Clethraceae) $5 \%$. El transecto incluía principalmente géneros montanos como Podocarpus (Podocarpaceae), Ilex (Aquifoliaceae), Prumus (Rosaceae) y Cinchona (Rubiaceae). Otros géneros pequeños, principalmente montanos, de la muestra incluían Meriania (Melastomataceae), Hedyosmum (Chloranthaceae), Ruagea (Meliaceae) y Monnina (Polygalaceae). La arácea Stenospermation, por lo general una epífita de tronco en elevaciones menores, aparecía aquí como una planta terrestre arbustiva.

\section{Con excepción de Disterigma y}

Sphaerospermum, las Ericaceae no son particularmente abundantes en estas cordilleras altas, especialmente en comparación con una de las crestas ácidas visitadas en Sinangoe. Encontramos Rubiaceae con frecuencia en forma de árboles antes que como arbustos, aunque la especie más común es una pequeña Palicourea de hojas pequeñas y flores anaranjadas. También son comunes un arbolito de Eschweilera (Lecythidaceae) de hojas recurvadas, tres especies de Guatteria (Annonaceae) y varios helechos arbóreos cortos y palmas de Geonoma. Las bromelias son también notorias aquí en forma de epífitas del sotobosque, además de la usual alta variedad de Araceae y Pteridophyta. Una especie trepadora excepcionalmente común en los troncos de los árboles es una Burmeistera (Campanulaceae). El único bambú que encontramos en estas elevaciones era una Chusquea (Poaceae) poco frecuente, delgada y trepadora. La única Fabaceae s.l. era un árbol grande, Abarema killipii.

A lo largo de gran parte de las estribaciones andinas, como en el drenaje del río Salado al sur de la zona de Sinangoe, la palma Dictyocaryum lamarckianum reemplaza Iriartea deltoidea sobre los $1.500 \mathrm{~m}$, pero no aquí. Mientras que Iriartea desaparece en estas elevaciones, vimos apenas unos pocos Dictyocaryum jóvenes en el sotobosque, y se detectaron un par de individuos emergentes en las crestas al norte y sur de Sur Pax. Podría ser que Dictyocaryum se ha adaptado mejor a los suelos ácidos que se encuentran raramente en la zona de Bermejo. Esta especie probablemente aparecerá en mayor abundancia en la parte sur de la zona de Sinangoe, no muy lejos del drenaje del río Salado. Dos palmas del género Wettinia, relacionado con Iriartea, son también abundantes en las Serranías Cofán. Wettinia maynensis es común en el bosque de laderas bajas y Wettinia anomala es común en el bosque de laderas altas, extendiéndose hasta el bosque de la cresta. La transición entre las dos especies no está bien marcada, pero podría ocurrir aproximadamente a $\operatorname{los} 1.000 \mathrm{~m}$.

Los colonos más frecuentes de los derrumbes y brechas por la caída de árboles en estas elevaciones son especies con hojas lobadas de Croton (Euphorbiaceae), similar en sus hábitos a Croton lechleri pero sustituyéndolo en estas elevaciones, una Vismia (Clusiaceae) de hoja anaranjada, y varias especies de Miconia (Melastomataceae). Rara vez encontramos una especie grande de Cecropia (Cecropiaceae) de hojas blancas, del tipo que es fácil de ver desde lejos, pero éstas no 
son un elemento tan notorio aquí como en las estribaciones occidentales de los Andes en esta misma latitud.

Cimas El pico sur del cerro Sur Pax (2.275 m) -el punto más alto al que llegamos en este estudiotiene un dosel mucho más bajo y más abierto que en las crestas más abajo. La mayoría de las especies aquí crecen también a lo largo de las crestas a menor elevación, pero la estatura de los árboles del dosel se reduce a 10-20 m, la corteza de los árboles está más cubierta de musgo y otras epífitas arbóreas, las especies asociadas con perturbaciones son más abundantes y las epífitas del dosel son más visibles y accesibles.

La explicación de la baja estatura y aparente régimen de perturbación activa parece revelarse en las agrupaciones de árboles muertos esparcidos en la cima. Éstos son síntomas de frecuentes golpes de relámpagos que por lo general pegan en los árboles más altos, particularmente en aquellos con crecimiento monopodial (tipo árbol de Navidad), pero que también matan muchos de los tallos adyacentes más pequeños, al calentar el relámpago su savia hasta el punto de ebullición. Las temperaturas frescas y la cubierta nubosa casi permanente podría también reducir el ritmo de crecimiento de los árboles. Ambos factores probablemente explican la gran acumulación de troncos muertos, ramas, musgo y otro material orgánico en la superficie, los cuales hacen precario el caminar en estos bosques.

El pico norte de Sur Pax, apenas un poco más alto $(2.341 \mathrm{~m})$ que el pico sur que visitamos, parece tener una vegetación muy similar. Pero a lo largo de la cresta al este de Sur Pax, en una serie de altas cimas que forman la muralla norte de la cabecera del río Chandia Na'e, la comunidad de plantas es un tanto diferente. Estas cimas, las mismas que no pudimos visitar, en su mayor parte tienen una vegetación más corta y arbustiva. Están bordeadas también de escarpados derrumbes recientes que han expuesto grandes áreas de roca plana cerca de la cumbre. Esto contrasta fuertemente con el bosque abierto y enmarañado de las laderas de Sur Pax, el que-a pesar de estar sujeto a derrumbes-tiene poca roca expuesta. No está claro si hay un diferente tipo de roca debajo de estas cimas de arbustos, si el estrato de roca que existe está inclinado de forma tan empinada que el bosque nunca se desarrolla, o si simplemente hay una mayor frecuencia de relámpagos en la cara norte del valle. La presencia en esa zona de unos pocos individuos emergentes aislados de la palma Dictyocaryum lamarckianum (ver sección anterior), sugiere que la baja vegetación de estas crestas orientales podría resultar en gran parte de una química distintiva del suelo relacionada con la roca subyacente.

\section{Perturbaciones naturales en PENDIENTES Y CRESTAS}

Las imágenes de satélite indican que hasta una cuarta parte de las Serranías Cofán está cubierta de bosques jóvenes de transición que están creciendo sobre derrumbes recientes. Algunos de éstos son apenas diminutas franjas de menos de una hectárea; otros cubren varios kilómetros cuadrados. Un derrumbe en forma de herradura al occidente de Sinangoe es tan grande como la cordillera entera del Shishicho (Figura 2). El patrón de perturbación en las crestas en toda la zona-ya sea a gran o pequeña escala—es básicamente la misma. Al erosionar y mermar los arroyos a los pendientes, los derrumbes arrasan secciones enteras de vegetación, dejando grandes espacios de suelo mineral expuestos a los rayos solares. Estas áreas abiertas eventualmente se llenan de una sucesión de especies pioneras. En las partes superiores del derrumbe, donde la roca está expuesta o el suelo es poco profundo, el proceso es lento. Hacia la parte inferior del derrumbe, donde se depositan grandes pilas de escombros mezclados, la renovación es rápida, con hierbas grandes y árboles de crecimiento rápido desarrollándose hasta formar un bosque de dosel cerrado. El gran bambú Guadua angustifolia se encuentra con frecuencia en densas franjas asociadas con antiguas perturbaciones, pero no es un miembro consistente de la comunidad de regeneración. 
En contraste con las crestas, algunas de las pendientes graduales tienen un régimen de perturbación muy distinto. Están sujetas a un deslizamiento lateral continuo del suelo y de la suave roca subyacente. La consecuencia es que muchas de estas terrazas inclinadas inestables (a veces cientos de kilómetros cuadrados de bosque) existen en un estado de constante perturbación al hundirse y deslizarse el suelo colina abajo. Gran parte de la vegetación sobrevive este desprendimiento-un poco más abajo de donde había ocurrido y con frecuencia con considerables daños a las raíces-intercalada ahora con un mosaico de grietas en el suelo y dosel, donde las especies pioneras pueden colonizar entre las especies del bosque maduro. Las lianas y enredaderas se benefician también de estos deslizamientos, en virtud de un sistema altamente flexible para el establecimiento de nuevos puntos donde pueden echar raíces (al igual que aprovechando los antiguos), expandiéndose rápidamente por las grietas y subiendo y pasando por encima de árboles dañados. Así, una gran parte de estos derrumbes inestables están cubiertos de una maraña desorganizada de plantas muy difícil de penetrar. Los moradores Cofán en ambas áreas indican que estos pendientes siempre han sufrido de un deslizamiento lento y continuo, y que la regeneración ahí no es el resultado de un sismo.

\section{NUEVAS ESPECIES Y OTROS REGISTROS SIGNIFICATIVOS}

Aunque la mayoría de las plantas colectadas durante el inventario no han sido identificadas todavía, muchas de las colecciones han sido confirmadas ya como nuevas especies. De las 23 especies de Psychotria (Rubiaceae) colectadas en la zona de Sinangoe en nuestra visita preliminar del 2000 , cuatro (17\%) han sido confirmadas como nuevas para la ciencia (C. Taylor, com. pers.). Al menos dos bromelias terrestres - una de ellas colectada en la ladera sur del Sur Pax (Figura 4B) y la otra en la cordillera del Shishicho-no han sido descritas (J. M. Manzanares, com. pers.). Una de las pocas Myrtaceae recolectadas en condición reproductiva está siendo descrita actualmente como una nueva especie de Calyptranthes (M.L. Kawasaki, com. pers.; ver Figura 4A y una descripción más completa de la planta abajo). Una especie de Calathea (Marantaceae) ha sido confirmada como nueva y otras dos probablemente lo son, también (Figura 4E y H. Kennedy, com. pers.).

Varios otros grupos taxonómicos que sospechamos son nuevos aguardan su confirmación. La Inga más común sobre las crestas ácidas del Shishicho es diferente a las descritas e ilustradas en una reciente monografía sobre las Inga en el Ecuador (Pennington y Revelo 1997). Otros grupos taxonómicos que parecen ser especies nuevas incluyen una Heistera (Olacaceae) con hojas notoriamente diminutas, una Gynerium (Poaceae) y una Cyclanthus (Cyclanthaceae).

Muchas de las especies en nuestra lista no están incluidas en el nuevo Catálogo de las Plantas Vasculares del Ecuador (Jørgensen y León-Yánez 1999) y por lo menos un arbusto de flores amarillas, de Basistemon (Scrophulariaceae), representa un género nuevo para Ecuador. En algunos casos, estas especies podrían haber sido recolectadas ya en Ecuador, pero los especimenes o no eran fértiles o no habían sido analizados por algún especialista involucrado en la preparación del catálogo. Pero otras especies claramente son los primeros especimenes conocidos en el país. Un ejemplo es Conceveiba sp. (Euphorbiaceae), que es uno de los árboles más comunes tanto en el bosque de laderas altas como en el bosque de cresta, aunque muy diferente a las dos especies de Conceveiba listadas para el Ecuador. Otras colecciones representan extensiones amplias de rango. Por ejemplo, Cassia grandis (Caesalpiniaceae), aunque conocida en la costa del Pacífico del Ecuador, no había sido encontrada antes en la Amazonía ecuatoriana.

Calculamos que al menos el $75 \%$ de las especies recolectadas en Sur Pax y Shishicho nunca han sido reportadas para la provincia de Sucumbíos. Esto se debe a que la parte occidental montañosa de Sucumbíos ha recibido pocas visitas de botánicos. Un mapa reciente de las localidades de colección de 
plantas en el Ecuador indica una gran brecha en torno a la zona de Bermejo (Jørgensen y León-Yánez 1999).

\section{PLANTAS IMPORTANTES PARA LA VIDA SILVESTRE}

Prácticamente todos los árboles dominantes en la zona de Bermejo-Sinangoe tienen frutos dispersados por los animales, al igual que la mayoría de las demás especies de dosel. Muchos de éstos, como las dominantes Billia y Dacryodes y la Grias de subdosel, producen grandes nueces, que son un gran recurso para muchos mamíferos terrestres como venados y sahínos, aunque probablemente son dispersados únicamente por roedores como agutíes, pacas y ardillas. Otros árboles dominantes como Minquartia, Tapirira, Otoba, Virola, Pouteria, las muchas Inga y Lauraceae y los gigantes y dispersos Ficus, tienen frutos que atraen a grandes aves, monos y mamíferos terrestres. Las observaciones de las dantas en el valle del Ccuccono sugieren que el fruto dulce del árbol Bellucia pentamera (Melastomataceae) es un alimento favorito (R. Borman, com. pers.). En el sotobosque, la preponderancia de arbustos y arbolitos dispersados por aves en las familias Rubiaceae, Melastomataceae, Myrtaceae y otras, es responsable en parte por la rica avifauna de la región.

Las observaciones del equipo de mamíferos sobre la cordillera del cerro Sur Pax indican que los osos de anteojos comen las tiernas bases de las hojas de los densos rodales de bromelias terrestres (Guzmania y Pitcairnia), al igual que los cogollos de las pequeñas palmas Geonoma. No está claro si éstos son realmente los alimentos preferidos o si simplemente son recursos comestibles que abundan donde escasean las especies de bambú montano. Es interesante notar que de las dos bromelias más consumidas una es una especie no descrita y la otra podría ser nueva para el Ecuador.

\section{PLANTAS USADAS COMÚNMENTE POR LAS COMUNIDADES COFÁN LOCALES}

(Roberto Aguinda y Robin Foster)

$\mathrm{Al}$ igual que con la mayoría de las comunidades autóctonas un tanto aisladas de la cultura occidental, hay un conocimiento y uso considerable de las plantas nativas en la vida cotidiana de los moradores Cofán. Particularmente en la comunidad de Alto Bermejo, donde hay un contacto muy limitado con el exterior, los conocimientos botánicos parecen sobrepasar lo encontrado entre la gente mayor de las demás comunidades Cofán. Incluso especies de pequeñas plantas inconspicuas que en su mayor parte son ignoradas u olvidadas en los bosques alrededor de otras aldeas Cofán, son fácilmente reconocidas por los habitantes de Bermejo y tienen nombres de uso común.

Un proyecto continuo entre los Cofán es catalogar los nombres y usos tradicionales de estas plantas antes de que se pierda la información, y vincular la taxonomía Cofán a los especimenes de herbario y nombres científicos. Este esfuerzo aprovecha la obra ya publicada de Cerón y sus colegas (1994) en cuanto a la zona circundante a la comunidad de Sinangoe; Cerón (1986, 1988, 1995), para el área en torno a la comunidad Cofán de Doreno y a bases de datos de colecciones e imágenes de plantas (Aguinda y Foster, no publicado) para el área en torno a la comunidad Cofán de Zábalo. A continuación se provee un breve resumen de las plantas que utilizan con mayor frecuencia las comunidades de las Serranías Cofán, de acuerdo con las entrevistas y observaciones realizadas.

Para la construcción de viviendas, los postes enterrados son por lo general de la muy duradera seña'mba quinicco (Minquartia guianensis, Olacaceae); los pisos son confeccionados de troncos partidos de la común palma bom'bo (Iriartea deltoidea, Arecaceae) y los travesaños son de pequeños árboles muy flexibles, con frecuencia de la familia Annonaceae, particularmente la tsao quini'cco (Cremastosperma gracilipes). En Bermejo, con sus densos rodales de la pequeña palma de abanico tananácco (Chelyocarpus ulei), éste 
es el material preferido para los techos, con una larga duración. En otras áreas, la uttuvo (Carludovica palmata, Cyclanthaceae), encontrado a lo largo de los arroyos de selva baja, es el material preferido para los techos. Estas plantas no son fácilmente disponibles para los Cofán río abajo, quienes por lo general utilizan palmas de Geonoma y Attalea (o láminas de zinc) para sus techos.

Las canoas más grandes son fabricadas por lo general de cuticho (Cedrelinga cateniformis, Mimosaceae; "chuncho" en castellano). Cuando las canoas más viejas ya no son utilizables, son recicladas como asientos y bancas y se convierten en la principal fuente de muebles. Los largos tallos de la hierba ribereña upe caufa (Gynerium sagittatum, Poaceae) son utilizados como varas o palancas para las canoas. Los arpones para la pesca son fabricados por lo general de troncos partidos de ccu'ye (palmas del género Wettinia, Arecaceae) o en su momento por una pequeña especie no descrita de Gynerium que es común a lo largo de las orillas del río (ver la sección arriba sobre ríos y orillas). La soga proviene principalmente de las raíces colgantes de un gran Philodendron (Araceae), en vez de la Heteropsis utilizado comúnmente en otros lugares, y los cinchos provienen en su mayor parte de la corteza de árboles de Sterculia (Sterculiaceae). Las hojas de la nijon'cho (Oenocarpus batana) son una fuente de las elegantes mochilas que son tejidas rápidamente para llevar cargas pesadas; también se usan raíces aéreas de Philodendron (Figuras 6A-B).

Aunque la ropa que usan los Cofán es importada ahora, los collares decorativos de semillas son fabricados de raquis flexibles de hojas de las pequeñas palmas espinosas Aiphanes. La palma tuinfa (Astrocaryum chambira), utilizada como fibra por las comunidades Cofán río abajo, está ausente aquí. Como perfume y desodorante, se utiliza la fragante patisa'cco (Ammandra dasyneura, Arecaceae) y una Hedyosmum (Chloranthaceae) de las crestas de los montes. La goma resinosa de los árboles de Burseraceae (en su mayoría de los géneros Protium, Dacryodes y Trattinnickia) es utilizada comúnmente para encender fogatas y como velas.

Al igual que en la mayor parte de la Amazonía, las espinosas raíces con zancos de la palma Socratea exorrhiza son utilizadas para rallar plátano verde o camote (Ipomoea, Convolvulaceae). Las hojas de Cecropia (Cecropiaceae) son usadas en el proceso de fermentación para producir las importantes bebidas de chicha derivadas de plátano verde machucado (principalmente) y yuca. Hay una variedad de frutos silvestres comestibles, pero las principales utilizadas incluyen bocha tsa'ja (Pourouma spp., Cecropiaceae), que es un tipo de uva silvestre, fiño (Inga spp., Mimosaceae), ttetteccu'cho (Grias neuberthii, Lecythidaceae), tssinimbo suvu (Brosimum spp., Moraceae), Ammandra dasyneura (Arecaceae) y Oenocarpus bataua (Arecaceae), con los cuales se produce una bebida dulce.

Las plantas medicinales más importantes incluyen los famosos estimulantes yaje (Banisteriopsis caapi, Malpighiaceae) y yoco (Paullinia yoco, Sapindaceae). La conguju (Senna ruiziana, Caesalpiniaceae) es utilizada comúnmente para el dolor de cabeza, avune'cho (Begonia rossmanniae, Begoniaceae) para reducir la inflamación y el dolor, shendu (Tournefortia, Boraginaceae) para el dolor y las infecciones, Croton lechleri (Euphorbiaceae) para cicatrizar heridas, y tanto Triolena pileoides (Melastomataceae) y ya'picho (Antrophium cajenense, Pteridophyta) para infecciones de la garganta. Por supuesto, los chamanes incluyen muchas otras plantas en su repertorio.

\section{NOTAS SOBRE ESPECIES ADICIONALES}

- Miconia calvescens (Melastomataceae), con sus grandes hojas rojizas, por lo general con un color rojo en la parte inferior cuando nacen, fue encontrada ocasionalmente a lo largo de las orillas y otros lugares intactos, principalmente en elevaciones medianas sobre $\operatorname{los} 800 \mathrm{~m}$. Lo que hace que esta especie sea importante es que de alguna forma llegó a Hawai, Samoa y muchas otras islas del Océano Pacífico, donde se ha convertido en una de las principales yerbas invasoras que está amenazando la flora autóctona. En esta región del Ecuador, parece sufrir frecuentes daños por los 
insectos herbivoros que comen las hojas, algo no visto en las islas del Pacífico. La clave para controlar esta especie en otros lugares podría encontrarse entre sus pestes naturales en el Ecuador.

- Piper (Piperaceae) es un género grande de arbustos caracterizados por largas espigas angostas de diminutas flores y frutos, que se conoce son dispersados mayormente por murciélagos (principalmente el género Carollia). Los murciélagos remueven toda la espiga madura durante el vuelo y lo consumen más tarde, mientras están posados. En elevaciones más altas encontramos en el sotobosque una alta frecuencia de varias especies de Piper con inflorescencias muy cortas, al igual que Piper piluliferum, una especie con una inflorescencia orbicular. Aunque al menos una de estas especies aparecía en las tierras bajas y unas cuantas más de las especies de espiga larga fueron encontradas en la cordillera, la abundancia de estas especies de Piper en las montañas sugiere que ahí hay todo un espectro diferente de dispersores o polinizadores.

- En la zona de Bermejo colectamos una pequeña variedad de Cyclanthus bipartitus (Cyclanthaceae) asociada con las riberas de varios de los pequeños arroyos en sombra, pero también en la orilla norte del río Bermejo. En vista de R. Foster, probablemente se comprobará que se trata de una nueva especie oculta de Cyclanthus, que se considera ahora como un género monotípico. La nueva 'variedad' se encuentra en densos rodales a lo largo de las corrientes de agua, ya sea sobre las rocas o en playas sólidas, y es más pequeña $(<1 \mathrm{~m})$, angosta, oscura, brillante y con una menor inflorescencia que la variedad común. Aunque es difícil de distinguir entre los jóvenes de la variedad típica, no se encuentra a lo largo de muchos de los arroyos, aún cuando está presente la variedad típica más grande.

- La palma del sotobosque, Hyospathe elegans, forma con frecuencia densas franjas en el bosque de laderas altas, de los 950 a los $1.300 \mathrm{~m}$, aunque está dispersa en el bosque de laderas bajas. Si bien se considera que H. elegans es una especie altamente variable de morfología, la variedad de hojas púrpuras, con hojas consistentemente angostas y espatas más persistentes, encontrada únicamente en el bosque de la cordillera, parece ser lo suficientemente diferente para ameritar su reconocimiento como una especie distinta.

- Los arbustos bajos de ciertas especies de Melastomataceae, como Clidemia heterophylla y Tococa guianensis, se encuentran con frecuencia en densos parches asociadas con nidos abandonados y colonias de hormigas cortadoras de hojas Atta. Al crear sus colonias subterráneas, las Atta colocan subsuelo de sus excavaciones en la superficie, creando un techo prácticamente impermeable sobre el nido. Una vez abandonadas las colonias, pocas plantas parecen colonizar estas áreas y hay muy poca competencia para las que lo hacen. Las asociaciones de hormigas con estas dos especies, con grandes myrmecodomatia en la base de las láminas de las hojas, podrian cumplir también un papel en permitir que las plantas se establezcan mientras continúa todavía activa la colonia de Atta.

- Otra planta hormiguera, el pequeño árbol Duroia hirsuta (Rubiaceae), tiene otras especies asociadas con los claros creados por las hormigas alrededor de sus tallos. Dos de los asociados más frecuentes son el pequeño arbusto Psychotria polyphlebia (Rubiaceae) y el arbusto Ossaea boliviensis (Melastomataceae). El último es también ocasional en los nidos abandonados de Atta, aunque en sí no alberga a las hormigas.

\section{HISTORIA INFERIDA DEL IMPACTO HUMANO}

\section{Alto Bermejo}

La comunidad de Alto Bermejo demuestra el usual mosaico de parcelas cultivadas actualmente y de otras anteriores en regeneración. El impacto humano más allá de este aspecto apenas se percibe. Incluso a poca distancia de los senderos, hay una abundancia de especies de madera valiosa, como Cedrelinga cateniformis (Mimosaceae). Las palmas y otras especies importantes para la construcción de viviendas son taladas ahí cerca, pero a pequeña escala. 
Dado el pequeño rastro de la comunidad de Alto Bermejo, no es de sorprender que en los varios kilómetros de sendero que caminamos para ascender de $\operatorname{los} 450$ a los $2.300 \mathrm{~m}$ vimos pocos indicios del impacto humano. Las excepciones son los pocos campamentos cerca de los arroyos o en promontorios como nuestro campamento Mirador Bermejo y un pequeño claro a los 1.600-1.700 m en la ladera sur del Sur Pax, abierto hace diez años en un intento por cultivar papa. Este claro se ha regenerado ahora en un bosque de $10 \mathrm{~m}$ de altura, dominado por Croton y Vismia. Es interesante también notar que la palma pejibaye o pijuayo (Bactris gasipaes) crece con frecuencia a lo largo de los senderos ribereños cercanos a la comunidad de Alto Bermejo. Los moradores locales también describen haber encontrado caimito (Pouteria, Sapotaceae), achiote (Bixa orellana, Bixaceae), tabaco y otras plantas cultivadas que crecen de forma silvestre en estos lugares. Todos los indicios señalan una presencia humana larga en la zona, quizá incluso con una densidad de población más alta que en el momento.

\section{SINANGOE}

La Estación Sinangoe, que nos sirvió de base de operaciones en esta región, está construida sobre una pequeña terraza plana que fue despejada para cultivar arroz hace aproximadamente 30 años. Otras áreas cercanas hacia el este parecen haber sido despejadas al mismo tiempo. Antes de ser abierta nuevamente para construir esta estación en el 2000, el nuevo crecimiento de esta terraza consistía principalmente de árboles de Jacaranda copaia (Bignoniaceae) y Cecropia sciadophylla (Cecropiaceae) de tamaño mediano. Más cerca de la confluencia de los ríos Sieguyo y Aguarico hay muchos claros pequeños abandonados por los intentos de colonización durante la última década. Toda esta colonización fracasada apoya adicionalmente la impresión de que la zona no es adecuada para la agricultura (OAS 1987).

Justo al norte de la Estación Sinangoe, el sendero a Shishicho pasa junto a una gran cepa de lo que parece ser un cedro (Cedrela fissilis, Meliaceae), cortado en tablas con una motosierra. Es probable que la mayoría de los cedros adultos a esta distancia tan cercana de Puerto Libre ya han sido talados. Sin embargo, incluso en lugares alejados de los asentamientos humanos, sólo se encuentra el cedro esporádicamente, llevándonos a la conclusión de que probablemente nunca fue un importante recurso maderero en la zona. Es aparentemente más común en las cercanías de La Sofía (L. Narvaez, com. pers.). Este sendero a Shishicho sigue en parte a un sendero antiguo tan usado en el pasado que ahora está marcado de hondonadas profundamente erosionadas. Dispersos a lo largo del sendero al río Ccuccono hay unos pocos campamentos pequeños, pero el impacto humano parece ser mínimo. Cualquier impacto humano al fondo del valle del Ccuccono sin duda fue borrado con los deslaves masivos que siguieron al sismo del 1987.

\section{PLANTAS ENDÉMICAS}

Participantes/Autores: Nigel Pitman, Robin Foster y Roberto Aguinda

Objetos de Conservación : especies con rangos geográficos restringidos, particularmente orquídeas de la subtribu Pleurothallidinae, bromelias terrestres, aráceas y otras hierbas epífitas

\section{INTRODUCCIÓN}

Las cordilleras tropicales en todo el mundo son famosas por sus extravagantes niveles de endemismo de plantas, lo cual significa que sus bosques contienen grandes cantidades de especies no conocidas en ningún otro lugar (Gentry 1992). En las Serranías Cofán, localizadas en la encrucijada de dos de las bioregiones más diversas del mundo y divididas por la línea ecuatorial, la expectativa es de una enorme cantidad de plantas endémicas.

Esta hipótesis se ve apoyada por las

comunidades de plantas apenas a unos pocos kilómetros al sur. Casi $20 \%$ de las 4.011 especies de plantas consideradas como endémicas al momento del Ecuador 
han sido recolectadas dentro de la delgada franja de bosque andino que va desde la ciudad de Tena en el sur hasta la frontera con Colombia en el norte-un área que constituye apenas el 3-4\% del territorio del país (Valencia et al. 2000). A menor escala, el angosto triángulo de bosque entre los volcanes del Sumaco y Reventador y la cordillera de los Guacamayos está atestado de plantas endémicas. Más de 100 especies de plantas endémicas del Ecuador han sido colectadas hasta la fecha en la Reserva Ecológica Cayambe-Coca y más de 90 en el Parque Nacional Sumaco-NapoGaleras, y estas cifras por lo menos se duplicarán al explorarse más la zona.

La lista de endémicas para estas áreas protegidas es dominada por pequeñas plantas herbáceas, especialmente epífitas de las familias Orchidaceae, Gesneriaceae, Araceae y Bromeliaceae. Por lo menos 21 especies de orquídeas y ocho especies de bromelias endémicas del Ecuador han sido registradas en el Sumaco-Napo-Galeras y los inventarios de otras áreas de los Andes ecuatorianos sugieren que docenas más están a la espera de ser descubiertas. La nueva reserva que proponemos para la región de Bermejo protegería a un gran número de estas especies.

Esto tiene una importancia crítica, porque las plantas con rangos geográficos restringidos enfrentan un alto riesgo de extinción. El Libro Rojo de las

Plantas Endémicas del Ecuador, publicado recientemente, delinea el precario estado de conservación de la flora endémica del país (Valencia et al. 2000). El 36\% de todas las endémicas ecuatorianas se encuentran en una sola población, el $75 \%$ nunca ha sido registrada dentro de un área protegida, y el $83 \%$ califica como amenazadas por la extinción bajo los lineamientos de la Unión Mundial para la Conservación (UICN).

A continuación presentamos algunas observaciones iniciales sobre el endemismo de las plantas en las Serranías Cofán. Es todavía muy temprano para llegar a conclusiones precisas sobre el endemismo en esta región poco explorada y hemos intentado evitar caer en la trampa de pensar que todas las plantas no familiares que observamos en el campo se tratan de especies endémicas. Más bien, nuestro propósito es iniciar la discusión con algunas observaciones preliminares desde el campo y herbario, y sugerir algunas líneas para estudios futuros. En vista de la abundancia de especies endémicas en áreas adyacentes de los Andes orientales, nuestra precaución probablemente es infundada. Es muy probable que una gran proporción de las plantas que registramos son únicas a la zona.

\section{ENDEMISMO A ESCALA REGIONAL}

La lista preliminar de plantas preparada para la región de Bermejo y Sinangoe (ver Apéndice 1 y el capítulo anterior) contiene al menos 15 especies consideradas endémicas del Ecuador. Ya que la mayoría de las plantas en nuestra lista para la región no han sido identificadas hasta nivel de especie (y ya que primero se identifican las especies con rangos geográficos extensos), predecimos que el actual número de endémicas es quizá diez veces mayor. Irónicamente, el descubrimiento de estas especies en las Serranías Cofán prácticamente garantiza que la mayoría de las mismas eventualmente perderán su condición de endémicas nacionales, porque nuestros sitios de recolección quedan a apenas unos pocos kilómetros de la frontera con Colombia. Al continuar los programas de recolección de plantas en los Andes orientales de Colombia (particularmente a lo largo de la carretera de Pasto a Mocoa), un gran número de especies consideradas actualmente como endémicas del Ecuador y muchas de las encontradas en nuestra zona probablemente serán eliminadas de la lista.

Sin embargo, las evidencias sugieren que muchas de las mismas resultarán ser endémicas de un pequeño sector de las estribaciones andinas orientales (esto es, con rangos geográficos que no pasan de unos pocos grados de latitud). Los botánicos que vienen trabajando a lo largo de los Andes han documentado miles de especies de plantas que parecen estar muy restringidas a secciones muy angostas de la cordillera (p.ej., Henshold 1999, Valencia et al. 2000) y es poco probable que todas sean el resultado de un bajo nivel de muestreo. 
Destacándose entre las endémicas ecuatorianas confirmadas en la lista de las Serranías Cofán-y en la lista de endémicas que se espera encontrar ahí-están las orquídeas y bromelias epífitas. Las dos especies no descritas de bromelias colectadas alrededor del cerro Sur Pax y en las crestas del Shishicho probablemente tienen también rangos geográficos muy restringidos (J. M. Manzanares, com. pers.). En contraste, encontramos una diversidad y abundancia relativamente escasa de micro-orquídeas de la subtribu Pleurothallidinae y especialmente del género Lepanthes que contiene cientos de especies endémicas de los Andes ecuatorianos. Tan sólo en el valle del río Pastaza, L. Jost documentó hace poco 90 especies de Lepanthes; 25-30 de las cuales pueden encontrarse en una sola montaña que cubra el mismo rango de elevaciones que el cerro Sur Pax (L. Jost, com. pers.). Pero el único sitio en el que encontramos Lepanthes durante nuestro estudio fue en las laderas más elevadas del Sur Pax, entre los 1.900 y los $2.275 \mathrm{~m}$. Incluso ahí, en nuestras búsquedas metódicas del sotobosque y dosel durante tres días, apenas encontramos siete $u$ ocho plantas individuales, casi todas de la misma especie. Es posible que hayamos dedicado muy poco tiempo o cubierto poco terreno en los bosques de elevaciones altas que estas taxas parecen preferir. O simplemente pudimos haber pasado por alto estas plantas notoriamente inconspicuas (Endara y Jost 2000).

\section{ENDEMISMO A PEQUEÑA ESCALA}

Los botánicos que han trabajado en el lado opuesto de los Andes ecuatorianos han sugerido que los niveles de "micro-endemismo" entre las plantas de las estribaciones occidentales podrían ser astronómicamente elevados. La idea es que un gran número de especies endémicas de los bosques del occidente ecuatoriano podría, además, estar restringido a una sola cresta, valle o cumbre. En la famosa descripción de Gentry (1986) del cerro Centinela, justo al sur de Santo Domingo, planteó la hipótesis de que varias docenas de especies de plantas podrían no ocurrir en ningún otro lugar del mundo fuera de esa colina de $5-10 \mathrm{~km}^{2}$ al pie de los Andes. Aunque el informe de Gentry resultó ser un poco prematuro-ya que la mayoría de las especies citadas como endémicas del Cerro Centinela han sido recolectadas desde entonces en otras partes de la costa ecuatoriana y sólo se conocen cinco especies exclusivas de esa montaña (Valencia et al. 2000)_la idea de que esta única cresta nada extraordinaria pudiera albergar cinco especies únicas de plantas es en sí sorprendente (Dodson y Gentry 1991). De confirmarse la hipótesis del cerro Centinela, esto implicaría la existencia de cientos de micro-endémicas en las Serranías Cofán.

El ejemplo más intrigante de este tipo de endemismo que pudimos encontrar durante el inventario rápido fue un arbusto no descrito del género Calyptranthes (Myrtaceae, familia de la guayaba; Figura 4A). Este arbusto era muy conocido por los miembros Cofán del equipo como ishoaquinico, una planta que las comunidades Cofán utilizaban hasta hace poco para las ceremonias de entrada a la edad adulta de los jóvenes. La especie era particularmente abundante en los senderos alrededor de la Estación Sinangoe y en la parte inferior del sendero al campamento Shishicho, pero no pudimos encontrarla en ningún otro lugar de la región. De hecho, aparentemente los Cofán solían hacer largas expediciones a esta parte de Sinangoe para recolectar la planta, ya que nunca la habían podido encontrar en otro lugar. La especie está siendo descrita al momento como Calyptranthes ishoaquinico sp. nov. por M. L. Kawasaki, especialista en la taxonomía de Myrtaceae. Colectamos también un par de especies de Calathea (Marantaceae) muy similares que podrían ilustrar este patrón. Una de ellas, una hermosa hierba con flores púrpuras y brácteas rosadas (Figura 4E), podía ser apreciada en todo lado en el sendero del campamento Mirador Bermejo hasta las laderas sur del cerro Sur Pax. En la misma elevación en la cresta del Shishicho, a $10 \mathrm{~km}$ al sur, encontramos una planta superficialmente similar que, al estudiarla más de cerca, resultó ser diferente en varios sentidos. Si estos taxa están todavía en proceso de evolución o simplemente remplazándose una a otra en drenajes 
alternos es algo que queda por determinarse. Entre tanto, es interesante notar que el taxón más cercano a éstas en la Flora del Ecuador es una especie recolectada por primera vez en el cerro Centinela por Al Gentry (Kennedy et al. 1988).

\section{OTRAS ENDÉMICAS DE INTERÉS}

- Passiflora popenovii (Passifloraceae), una trepadora endémica del Ecuador pero aparentemente extinta en estado natural (Jorgensen 2000), se encuentra cultivada a lo largo del nuevo camino de La Bonita a Puerto Libre (P. Fuentes y X. Aguirre, com. pers.). La Fundación La Bonita-Sucumbíos, en La Bonita, está desarrollando actualmente un programa para preparar mermelada de esta fruta.

- La bromelia Werauhia haltonii era conocida sólo por una población en la cordillera de los Guacamayos (a más de $100 \mathrm{~km}$ al sur) antes de que la encontráramos creciendo en la cumbre de $2.275 \mathrm{~m}$ al sur del cerro Sur Pax.

\section{AMENAZAS Y RECOMENDACIONES}

Estos patrones de endemismo son importantes para los conservacionistas porque las especies con pequeños rangos geográficos serán las primeras en extinguirse al intensificarse la pérdida de hábitats y los cambios climáticos. En el caso de las micro-endémicas, incluso la tala de áreas pequeñas de bosques en cumbres y crestas aisladas, donde las endémicas podrían persistir en diminutas poblaciones remanentes, podría conducir a las extinciones globales (Dodson y Gentry 1991). A mayor escala, las especies con rangos geográficos limitados se encuentran protegidas en menos parques y reservas que las especies más comunes. Las especies de plantas endémicas de las cuencas del San Miguel o Bermejo-como, aparentemente, la nueva especie de Guzmania que descubrimos en el cerro Sur Pax-no están protegidas en ninguna área protegida ecuatoriana o colombiana, ni se encuentran dentro de los linderos actuales de la Reserva Ecológica Cayambe-Coca.

La medición del número exacto de especies endémicas de esta zona-y de cualquier sector en particular de la región andina-todavía no está al alcance de los científicos. Dada la importáncia de este tema para la conservación efectiva de la flora andina, nos sorprende la poca atención de su investigación hasta la fecha. Dentro de las Serranías Cofán, el primer paso a darse sería muestrear sistemáticamente las crestas a lo largo de la región, enfocando la atención en los grupos taxonómicos con propensión al endemismo (esto es, las orquídeas, bromelias, Gesneriaceae, etc.). Diseñado y llevado a cabo cuidadosamente, un esfuerzo de este tipo resultaría en datos invaluables tanto para los conservacionistas como para los biólogos.

\section{ANFIBIOS Y REPTILES}

Participantes/Autores: Lily O. Rodriguez (campo) y Felipe Campos (museo)

Objetos de conservación: especies con rangos geográficos restringidos; especies de elevaciones altas (Hyla phyllognatha, Liophis epinephelus, Neusticurus cochranae, Chironius monticola); taxa con poblaciones en disminución, por ejemplo, ranitas de vidrio (Centrolenidae) y ranas del género Colostethus (Dendrobatidae); Enyalioides cofanorum y otras especies de selva baja ahora extintas en Santa Cecilia (Figura 5A).

\section{MÉTODOS}

Este informe combina el trabajo de campo durante el inventario de L. Rodríguez, con las observaciones previas de las comunidades herpetológicas de la región por parte de F. Campos (quien no pudo acompañarnos en el campo). Otros miembros del equipo de inventario rápido tomaron datos complementarios, en forma de fotografías tomadas en Bermejo. El trabajo de campo se limitó a los bosques de laderas bajas y altas en los alrededores de Sinangoe, en elevaciones entre los 800 y $1.450 \mathrm{~m}$.

Durante mi (LR) estadía de 11 días en el campo, dediqué 78 horas a buscar activamente anfibios y reptiles, principalmente alrededor del campamento de la cresta del Ccuccono y del campamento Shishicho. El muestreo consistió de observaciones visuales y 
auditivas en excursiones a lo largo de los senderos existentes, tanto de día como de noche. Enfoqué mis búsquedas en los grupos taxonómicos menos comunes y que podrían mostrar mejor las diferencias singulares de varios hábitats (p. ej., Anuros, particularmente Eleutherodactylus y dendrobátidos). También presté atención a los hábitats de riachuelos y corrientes preferidos por muchas especies. Registré algunos cantos en el campo, a ser comparados más tarde con los registros publicados. Recolecté diez especies que no pude identificar en el campo (un espécimen de cada una), los cuales deposité en las colecciones del museo zoológico de la Pontificia Universidad Católica del Ecuador (QCAZ). Dos especies de la lista corresponden a fotografías tomadas por otros miembros del equipo en la región de Bermejo.

Se ha hecho poco trabajo de campo en esta zona montañosa de Sucumbíos. El estudio realizado por Altamirano y Quiguango (1997) en Sinangoe se enfocó en reptiles y anfibios entre los 565 y $670 \mathrm{~m}$. No es de sorprender que las especies registradas en su inventario de 34 días (utilizando transectos y parcelas) fueron todas taxa de selva baja compartidas con las listas anteriores de Santa Cecilia, con la excepción de Eleutherodactylus cf. incomptus. Campos et al. (2001) muestrearon la herpetofauna en los alredores de La Bonita (entre 1.700 y $2.000 \mathrm{~m}$ ) y de Rosa Florida $(1.400 \mathrm{~m})$. Presentamos un resumen de sus resultados en el Apéndice 6.

\section{RESULTADOS DEL INVENTARIO HERPETOLÓGICO}

Observamos 85 anfibios y reptiles (exceptuando de renacuajos) durante el inventario biológico rápido, correspondientes a 31 especies diferentes. La lista incluye seis especies de culebras, seis lagartijas, 17 ranas y sapos, una salamandra y un cecílido (Apéndice 2). Entre los registros más notables está una nueva especie de lagartija del género Dactyloa (Figura 5E) y el primer registro ecuatoriano de la lagartija Cercosaura ocellata. Creemos que un estudio más completo, particularmente a elevaciones más altas, revelará especies adicionales no descritas y extenderá los rangos altitudinales de varias especies conocidas.

Las Serranías Cofán quedan justo $20 \mathrm{~km}$ al oeste de Santa Cecilia, cuyos bosques mantenían el récord mundial en diversidad de anfibios hasta que fueron destruidos en la década de los noventa (Duellman 1988; ver también la Figura 7). La implicación es que las elevaciones más bajas de nuestro sitio de estudioparticularmente el fondo del valle del río Bermejo, a los $450 \mathrm{~m}$-albergan también comunidades muy diversas, incluyendo la mayoría de las especies exterminadas durante las últimas décadas en Santa Cecilia (vea la Figura 5A).

La riqueza de las especies disminuye significativamente al aumentar la elevación, aunque nuestros datos no fueron los suficientes como para proveer un cuadro claro de la diversidad de esta región en comparación con áreas de tamaño similar en otros localidades de los Andes. Entre los 900 a $1.200 \mathrm{~m}$ en los Andes, se espera encontrar típicamente 30 o menos especies de anfibios (Duellman 1988; registros de especies de las cordilleras del Cóndor y Cutucú en el Ecuador y en las estribaciones de Manu en Perú). En apenas 11 días en el campo, registré la mitad de esta cifra, lo que probablemente indica que la riqueza de especies en la región es alta. En contraste, el endemismo es bajo. La mayoría de las especies en esta región se encuentran también en los bosques de Colombia, o en la selva baja de la Amazonía occidental (Lynch et al. 1997).

No es de sorprender que la comunidad herpetológica de las Serranías Cofán consiste de una superposición compleja de fauna amazónica y andina. La mayoría de las especies observadas en el campo tienen rangos altitudinales que van desde la base de los Andes hasta una elevación de aproximadamente $2.000 \mathrm{~m}$ y muchas de ellas son más conocidas en las selvas bajas amazónicas adyacentes. Por ejemplo, Eleutherodactylus nigrovittatus y al menos otras siete especies de anfibios en nuestra lista han sido recolectadas en Santa Cecilia (Duellman 1978), en el Parque Nacional Yasuní (Ron 2000) y en la selva baja más al 
este (Lynch et al. 1997). Como de costumbre en estos bosques, las pequeñas ranas de difícil identificación del género Eleutherodactylus conformaban un número desproporcionado de las especies que pude registrar en el campo. Incluimos nueve en la lista, aunque observamos cuatro más que no fueron identificadas.

Otros grupos son más característicos del bosque montano. Entre los anfibios, por ejemplo, la especie montana Hyla phyllognatha (Figura 5C) se extiende ampliamente en los Andes desde Colombia hasta Bolivia, siempre entre los 600 y $1.700 \mathrm{~m}$. Vale la pena notar, sin embargo, que las diferentes poblaciones de $H$. phyllognatha podrían eventualmente ser especies distintas; los cantos que escuchamos en este estudio eran diferentes de los típicos cantos de esta especie en el sureste del Perú (LR, obs. pers.) y de los registros de Ecuador publicados en Duellman (1972). Parecería que las comunidades herpetológicas en las estribaciones andinas cerca de la línea ecuatorial tienen rangos de elevación más amplios (aunque una diversidad similar), en comparación con las comunidades de las estribaciones en latitudes mayores, como las del Parque Nacional Manu en el Perú. Se necesitarán estudios más detallados para confirmar esto. Por otra parte, ninguna de las especies en nuestra lista que yo consideraría como taxa de los bosques montanos (Hyla pbyllognatha, Liophis epinephelus, Neusticurus cochranae, Chironius monticola) fueron reportados por Altamirano y Quiguango (1997) en su sitio de estudio a menor elevación alrededor de Sinangoe.

Aunque gran parte de la herpetofauna que registramos en las Serranías Cofán es compartida con sitios de selva baja como Santa Cecilia, la mayoría de las especies poseen adaptaciones particulares al paisaje accidentado de las estribaciones andinas, donde son raras las áreas pantanosas y la mayor parte del agua tiene forma de rápidas corrientes. Así, los ejemplares jóvenes de Eleutherodactylus nacen directamente de huevos, mientras que los H. phyllognatha y Cochranella midas se reproducen en riachuelos torrentosos.

Los reptiles rara vez proveen información en los inventarios biológicos rápidos porque sus densidades de población son tan bajas que las observaciones resultan apenas esporádicas. Me sorprendió, por lo tanto, encontrar un número considerable de reptiles durante el estudio, registrando seis especies de culebras sin ningún esfuerzo especial. Una de estas era una verrugosa (Lachesis muta; Figura 5B) enrollada junto a una de nuestras carpas en el campamento Shishicho. Al menos dos culebras más-Liophis epinephelus en Shishicho y Chironius cf. monticola en Ccucconoparecen estar restringidas al bosque de mayor elevación. Identificamos también seis especies de lagartijas. Neusticurus cochranae-una lagartija conocida únicamente en las laderas orientales de los Andes ecuatorianos, donde puede llegar hasta los $1.300 \mathrm{~m}$ - parece ser común en la región. La encontramos tanto en el campamento de Ccuccono como de Shishicho, cerca de los arroyos, aproximadamente a los $1.000 \mathrm{~m}$. De todas las Neusticurus, esta especie parece ser la menos acuática (Uzzell 1966).

Aunque la densidad de los anfibios se encontraba dentro del rango típico para bosques de este tipo, los animales no parecían estar en una temporada activa. Las grandes cantidades de animales jóvenes que pudimos observar y la escasez de machos cantores sugieren que nuestro estudio puede haber coincidido con el fin de la temporada de apareamiento. Aunque Crump (1974) y Duellman (1978) han fijado el comienzo de la temporada de apareamiento en Santa Cecilia (a los $350 \mathrm{~m}$ ) entre agosto y septiembre, podría ser que la época de apareamiento y la actividad de las especies compartidas con ese sitio son diferentes aquí debido a la mayor elevación. Este tipo de variación altitudinal en la época de apareamiento de una sola especie ha sido documentado para anfibios y pájaros en el sur oriente peruano.

Notorias por su ausencia en el estudio fueron las especies de los géneros Colostethus (Dendrobatidae), Bufo y Rhamphophryne (Bufonidae) y Hemiphractus (Hylidae), al igual que las ranitas de vidrio (Centrolenidae), todas las cuales normalmente se encuentran presentes en los bosques de esta elevación. Estas ausencias podrían relacionarse con las alarmantes 
disminuciones observadas en otros lugares de la Reserva Ecológica Cayambe-Coca (ver abajo y Apendice 6). Sin embargo, la presencia de Hyla phyllognatha, Cochranella midas y otras especies en los arroyos alrededor de nuestros campamentos sugiere que su ausencia no está relacionada con la calidad ambiental. Los estudios más profundos podrían eventualmente registrar las especies faltantes, en densidades de población más bajas. Es también posible que las ranas Microhylidae como Syncope antenori se encuentren en las crestas cubiertas de musgo en la cordillera del Shishicho, o en las bromelias epífitas comunes de la cuenca del río Ccuccono. Encontramos un hábitat perfecto para Colostethus cf. marchesianus en el bosque más abajo de nuestro campamento de Shishicho y en las inmediaciones de nuestro Campamento Cresta Ccuccono, pero no a la rana misma. Escuché (pero no logré registrar) cantos que podrían haber sido de esta especie; la especie podría simplemente haber no sido detectada.

Incluso después de un período tan corto en el campo (cuatro días en cada sitio), los patrones de abundancia en cada sitio y las diferencias entre los sitios eran bastante claras. Eleutherodactylus nigrovittatus era la especie de rana más común en Shishicho, mientras que Bolitoglossa peruviana domina en Ccuccono y Epipedobates femoralis en Sinangoe.

De las tres, E. nigrovittatus parece tener la distribución local más amplia, como se pudo registrar en los tres sitios. La especie dominante de un estudio anterior en Sinangoe (Eleutherodactylus lanthanites; Altamirano y Quiguango 1997) se encontró de forma apenas moderadamente abundante en nuestro estudio y ni siquiera pudimos registrar al anfibio más común encontrado en Santa Cecilia (Eleutherodactylus variabilis; Duellman 1978). Las causas de este tipo de variabilidad temporal y espacial son poco entendidas por los biólogos, pero las diferencias de hábitat entre los sitios muestreados sin duda juegan un papel importante.

\section{AMENAZAS Y RECOMENDACIONES}

Se han observado algunas disminuciones alarmantes pero poco comprendidas entre las poblaciones de anfibios de esta zona del Ecuador, particularmente en las elevaciones más altas de la Reserva Ecológica Cayambe-Coca. Aun más notoriamente, algunas especies de las familias Centrolenidae (ranitas de vidrio) y Dendrobatidae (ranitas venenosas; especialmente el género Colostethus) que anteriormente eran comunes en elevaciones entre los 1.000 y $2.000 \mathrm{~m}$ han experimentado fluctuaciones dramáticas en los últimos 10-15 años. La mayoría de las especies en estos grupos se encontraban antes con frecuencia a lo largo de arroyos y cascadas, pero ahora han desaparecido en su mayor parte, con la única (y misteriosa) excepción de Colostethus bocagei.

El descubrir los factores responsables de estas disminuciones (o fluctuaciones) en la población es una prioridad inmediata para la conservación de la zona. $\mathrm{Si}$, como ha ocurrido en comunidades de anfibios alrededor del mundo, estas disminuciones se extienden eventualmente a otros anfibios en la región, una acción efectiva de conservación exigirá información básica en cuanto a (1) la distribución y abundancia de cada especie en diferentes elevaciones y en diferentes hábitats a lo largo de los bosques de Bermejo y Cayambe-Coca, y (2) la temporada de reproducción de cada especie. $\mathrm{Al}$ momento no existe ninguna información de este tipo.

\section{AVES}

Participante/Autor: Thomas S. Schulenberg

Objetos de conservación: Comunidades de aves de los bosques de laderas; aves con rangos geográficos y altitudinales restringidos; aves grandes de caza; Ara militaris.

\section{MÉTODOS}

Thomas S. Schulenberg fue el principal ornitólogo del equipo. Otros miembros realizaron observaciones suplementarias, principalmente Debra K. Moskovits y Randy Borman. Además, nuestros registros fueron complementados con las listas de especies registradas en Bermejo por Douglas F. Stotz, Moskovits y 
Jennifer M. Shopland durante una corta visita del 7 al 9 de noviembre del 1998.

El protocolo básico para el inventario rápido fue caminar por los senderos del bosque para ubicar e identificar a las aves. Intenté estar en el campo a primera luz del día (o poco después), aunque las lluvias temprano en la mañana, en ocasiones, obligaron a retardar la salida. Por lo general permanecía en el campo hasta entrada la tarde o hasta el anochecer. Hice un esfuerzo por estudiar todos los hábitats del área, pero enfoqué la mayor parte de mi tiempo en el bosque de dosel cerrado. Llevé una radiograbadora portátil, con un micrófono direccional, para grabar los sonidos de las aves. Estas grabaciones serán depositadas en la Biblioteca de Sonidos Naturales del Laboratorio de Ornitología de la Universidad de Cornell. No establecí transectos o conteo por puntos, pero sumé el número de individuos observados de cada especie de ave a diario, como ayuda para evaluar las abundancias relativas.

\section{RESULTADOS DEL INVENTARIO DE AVES}

El equipo registró un total de 350 especies durante las tres semanas en el campo en las Serranías Cofán. Stotz y otros registraron unas 49 especies adicionales en la zona de Bermejo en noviembre del 1998. La avifauna que pudimos documentar suma 399 especies hasta la fecha (ver Apéndice 3).

Ha habido muy poco trabajo de campo en esta región de Sucumbíos. La Academia de Ciencias Naturales de Philadelphia (ANSP) realizó un corto estudio ornitológico del 11 al 17 de marzo del 1993 entre los 850 y $1000 \mathrm{~m}$ en los yacimientos petroleros de Bermejo, en un sitio a unos $12-13 \mathrm{~km}$ al sur-sureste de la comunidad Cofán de Alto Bermejo (M. Robbins, com. pers.; el equipo de campo estuvo conformado por Mark B. Robbins, Francisco Sornoza M. y Marco Jácome). Por separado, Mena (1997) realizó observaciones de aves en la comunidad Cofán de Sinangoe y en dos sitios a unos $8 \mathrm{~km}$ al suroeste de Sinangoe. Su lista incluye alrededor de 70 especies no registradas por nuestros inventarios rápidos. Tomando como base a la lista de especies de Mena (con la excepción de unas cuantas aparentemente mal identificadas, p. ej. Heliodoxa jacula, una especie de la cordillera occidental) y considerando las distribuciones publicadas de las aves ecuatorianas (Ridgely y Greenfield 2001), calculo que el número total de especies encontradas en las Serranías Cofán podría exceder las 700 especies. Esta estimación representa una avifauna esencialmente "completa" para el rango altitudinal de esta área.

De las 399 especies de aves registradas durante el inventario y la visita anterior de Stotz, el $85 \%$ (339 especies) fueron observadas en la región de Bermejo. En contraste, nuestros totales para Shishicho (135 especies; $34 \%$ del total) y para Ccuccono/ Sinangoe (209 especies; $52 \%$ del total) son notablemente más bajos. La lista de Bermejo refleja en parte una mayor intensidad de muestreo en este sitio. (Estuve allí 13 días durante el inventario biológico rápido y Stotz estuvo allí dos días adicionales, mientras que sólo estuve cinco días en Shishicho y diez días en Ccuccono y Sinangoe). Además, Bermejo ha sido visitado también durante diferentes temporadas (durante julio y agosto para el inventario biológico rápido y en noviembre por Stotz), de modo que la lista de esa región refleja un poco de las variaciones estacionales en la comunidad de aves, que no pudimos documentar en los otros sitios. Finalmente, el valle de Bermejo abarca el mayor rango de elevaciones de los sitios de estudio (440$2.250 \mathrm{~m}$ ), lo que nos lleva a esperar encontrar ahí la mayor diversidad de aves. De hecho, sin duda hubiéramos podido registrar muchas más especies alrededor de Bermejo de no haber sido por los períodos de lluvia el 3 y 4 de agosto.

En las Serranías Cofán, la avifauna de las selvas bajas amazónicas se superpone con, y a mayores elevaciones es remplazada por, una avifauna andina. En los bosques entre los 400 y $900-1.000 \mathrm{~m}$ (a los que se hace referencia a lo largo de este informe como el bosque de laderas bajas), la avifauna es principalmente de selva baja en su composición, con apenas unas pocas especies andinas presentes al pie de los Andes, alrededor de los $400 \mathrm{~m}$. A elevaciones mayores, en el bosque de laderas altas (típicamente por encima de los 
$1.000-1.100 \mathrm{~m}$ ), virtualmente no se ve ya ninguna especie amazónica y la comunidad de aves es principalmente andina en su composición. Esta comunidad de aves, a su vez, es remplazada a elevaciones mayores por una serie diferente de especies de aves andinas, representativas de lo que se podría denominar un bosque montano o bosque nublado. Algunos elementos de esta comunidad del bosque nublado ocurren en los picos más altos que visitamos en las Serranías Cofán, incluyendo algunas especies con una distribución muy limitada dentro del Ecuador, o con poblaciones globalmente pequeñas y amenazadas. En las siguientes secciones presento un resumen de las comunidades de aves encontradas en estos tipos de bosque.

\section{Aves del Bosque de Laderas Bajas}

(400 A 900-I.000 m)

Es en los extensos bosques de laderas bajas de las Serranías Cofán donde se espera encontrar la mayor riqueza de especies, debido a la similitud de este tipo de bosque con las selvas bajas adyacentes sumamente diversas. El endemismo, por otra parte, es bajo: la mayoría de las especies tienen una amplia distribución. Aunque las mejores oportunidades para estudiar esta avifauna se vieron limitadas por la lluvia (especialmente en Bermejo), sí pudimos registrar algunas especies de interés.

Un de los descubrimientos interesantes fue Hemitriccus zosterops (Tirano-Todi de Ojos Blancos), una especie amazónica de aparición regular en el bosque de laderas bajas a lo largo de las Serranías Cofán. Esta especie era conocida anteriormente en el Ecuador sólo en áreas al sur del río Napo (Ridgely y Greenfield 2001), aunque Mena (1997) también registró $H$. zosterops en todos sus sitios de estudio cerca de Sinangoe y hay unos pocos registros en la adyacente región amazónica de Colombia (Hilty y Brown 1986). Nuestros registros extienden la distribución de la especie en Ecuador y ayudan a "llenar" lo que había sido un vacío anómalo en su distribución.

Se han encontrado relativamente pocas especies de aves realmente andinas en los bosques de laderas bajas de las Serranías Cofán, pero entre estas hay varias de particular interés. Chlorothraupis carmioli (Frutero Aceitunado) es conocido en el Ecuador principalmente en Sucumbíos. La angosta distribución de esta especie en el Ecuador es un tanto sorprendente, ya que más al sur (en el sur de Perú y en Bolivia) C. carmioli tiene amplia distribución y es común en el bosque de laderas bajas. En contraste, Snowornis subalaris (Piha de Cola Gris), un ave de los bosques de laderas conocida en unas pocas localidades dentro de su distribución geográfica, fue encontrada frecuentemente hasta alrededor de los $450 \mathrm{~m}$, cerca de Bermejo, que quizá es la elevación más baja en la que se ha encontrado a esta especie.

Fue en el bosque de laderas bajas, en la Estación Sinangoe, que pude ver bien al raro y poco conocido vencejo, Cypseloides lemosi (Vencejo Pechiblanco). Sospeché la presencia de esta especie también en la Estación Bermejo, pero no logré confirmarlo. Hasta hace poco, se había registrado la presencia de Cypseloides lemosi únicamente en el suroeste de Colombia, pero en los últimos años se han reportado registros en varios sitios en el Oriente ecuatoriano y en una localidad del Perú (Schulenberg et al. 1997). Esta ave no utiliza el bosque de laderas bajas en sí, pero presuntamente percha y quizá incluso se reproduce en los barrancos y cascadas en elevaciones más altas de las Serranías. Otros vencejos menos conocidos, como C. cryptus (Vencejo Barbiblanco) y C. cherriei (Vencejo Cuatro Ojos), podrían estar también presentes en las Serranías Cofán. Debido a las muchas similitudes entre todos los Cypseloides y especialmente entre C. cryptus y $C$. cherriei, su presencia en la región sería muy difícil de confirmar. Debe prestarse atención, sin embargo, a la posible presencia de estas especies cerca de cascadas y otros probables sitios de anidamiento.

Registramos Crax salvini (Paujil de Salvin) en las elevaciones más altas del bosque de laderas altas (de los 900 a 1.000 o $1.100 \mathrm{~m}$ ) en nuestros tres sitios de estudio. Esta gran ave de caza es principalmente una 
especie de selva baja, conocida únicamente en lugares de la cuenca nororiental amazónica, desde el sur de Colombia y cruzando el Oriente ecuatoriano y al sur hasta el noroccidente peruano. Crax salvini ha sido intensamente cazado y exterminado en muchas áreas dentro de su distribución geográfica (especialmente en el Ecuador). Aunque fue alentador descubrir que esta especie continúa distribuida extensamente dentro de las Serranías Cofán, el hecho de que el paujil parece ser mucho más común en-o incluso restringido a-las elevaciones superiores del bosque de laderas altas en la región, podría ser una señal de la presión de la caza que enfrenta, incluso en una zona con una población humana relativamente baja.

No tuvimos registros durante nuestro breve inventario de Heliodoxa gularis (Brillante de Garganta Rosada), un colibrí considerado globalmente como casi amenazado (BirdLife International 2000) o amenazado (vulnerable; Ridgely y Greenfield 2001). Sin embargo, el grupo del ANSP encontró esta rara especie al sureste de Bermejo, y también a lo largo del río Due (Ridgely y Greenfield 2001). El estudio ANSP registró también otra especie casi amenazada, Pipreola chlorolepidota (Frutero de Garganta Fuego). Ambas especies probablemente están presentes en o cerca de nuestros sitios de estudio.

Aunque no lo registramos en nuestro inventario del 2001, Stotz observó Falco deiroleucus (Halcón Pechinaranja) en su visita anterior a Bermejo. Este halcón es una especie muy extendida que, sin embargo, escasea dentro de su distribución geográfica. Otras especies interesantes registradas por Stotz incluyen Tinamus tao (Perdiz Azulada) y Touit purpurata (Lorito de Rabadilla Purpúrea), dos especies con una amplia distribución geográfica, a pesar de lo cual, sólo se conocen unos pocos registros de cada una en Ecuador (Ridgely y Greenfield 2001).

\section{Aves del Bosque de laderas Altas}

(I.000-I.I OO A I.500 m)

El bosque de laderas altas, una angosta y frágil franja de hábitat que recorre a lo largo de los Andes, tiene una de las avifaunas menos estudiadas de Sudamérica. Aunque algunos elementos de las comunidades de aves de esta región son ampliamente distribuidos, la gran parte de las especies se caracterizan por sus distribuciones muy restringidas, tanto en geografía como en elevación. Históricamente, las comunidades de aves del bosque de laderas altas mejor conocidas en el Ecuador se encuentran en la región de Sumaco, una región que ha sido visitada en repetidas ocasiones a lo largo de los años por ornitólogos y por observadores aficionados de pájaros. Algunas de las especies de aves más raras de la región de Sumaco han sido descubiertas en otras localidades del Oriente ecuatoriano, pero incluso éstas se conocen, en la mayoría de los casos, en sólo unas pocas localidades cada una. La avifauna del bosque de laderas altas en la provincia de Sucumbíos, en particular, parece haber sido mayormente desconocida antes de nuestra visita.

Durante el corto período de nuestro inventario biológico rápido, y a pesar de haber visitado sólo unos pocos sitios, encontramos algunas de las especies de aves menos conocidas y más restringidas geográficamente en el bosque de laderas altas. La más importante de éstas podría ser Myiopagis olallai (Elainia Bajo Andino), una especie descubierta muy recientemente (Coopmans y Krabbe 2000). Este pequeño atrapamoscas era conocido anteriormente sólo en otras tres localidades: Sumaco y el valle del río Bombuscaro, en el Oriente ecuatoriano, y en un sitio en la zona surcentral del Perú. Siempre creíamos que esta ave poco conocida sería descubierta también en otros lugares; nuestro registro de las Serranías Cofán, sin embargo, constituye una extensión de rango significativa.

Otro gran descubrimiento fue el primer registro para Ecuador de Tinamus osgoodi (Perdiz Negra). Esta rara ave había sido conocida previamente sólo en dos regiones pequeñas: en la cabecera del valle Magdalena, en el sur de Colombia, y en los Andes al este de Cusco, en el sur de Perú. Sin embargo, podría estar más extendida en el Ecuador; se ha visto aves que se cree pertenecen a esta especie incluso muy al sur, como en las cascadas de San Rafael (R. Borman, com. pers.). 
Tinamus osgoodi está considerado como globalmente amenazado (vulnerable; BirdLife International 2000).

Otros hallazgos sobresalientes entre las especies del bosque de laderas altas incluyen Hylophilus semibrunneus (Verdillo de Nuca Rufa), el que previo a nuestro inventario era conocido en Ecuador sólo en Sumaco y en la carretera adyacente a Archidona; Hemitriccus rufigularis (Tirano-Todi de Garganta Anteada), registrado anteriormente en sólo tres sitios en el Ecuador (y no conocido en Colombia); y Phlogophilus hemileucurus (Cola-pintado Ecuatoriano), un pequeño colibrí conocido anteriormente en Ecuador únicamente en cinco sitios (y en otros países apenas por un solo sitio en Colombia y en dos sitios en el norte de Perú).

Dos aspectos importantes de la comunidad de aves de los bosques de laderas altas en las Serranías Cofán son que muchas de estas especies-incluso las que se consideran más raras y distribuidas más localmente-se encontraron (1) en todos nuestros sitios de estudio y (2) de forma regular. Por ejemplo, Campylopterus villaviscensio (Ala de Sable de Napo), Phylloscartes gualaquizae (Moscareta Ecuatoriana) y Snowornis subalaris parecían ser más comúnes en las Serranías Cofán que en cualquier otro lugar en los que se los he encontrado. La alta abundancia relativa de estas especies es particularmente importante porque dos de ellas (Campylopterus villaviscensio y Phylloscartes gualaquizae), al igual que el colibrí Phlogophilus, son completamente restringidas a la pequeña zona de los Andes entre Colombia y el Oriente ecuatoriano en el norte, y la parte más norte de Perú en el sur, ocupando estas especies apenas una angosta faja de elevación dentro de esta región.

También presente en las Serranías Cofán se encuentra una población de Ara militaris (Guacamayo Militar). Aunque esta especie tiene una amplia distribución geográfica, su abundancia a lo largo de su extensión está disminuyendo, sus poblaciones se están volviendo más fragmentadas y la especie se considera amenazada globalmente (vulnerable; BirdLife International 2000). En el Ecuador, se tenían registros de A. militaris únicamente en seis sitios (ninguno de ellos en la provincia de Sucumbíos). Ya que encontramos la especie en todos nuestros sitios de estudio (aunque siempre en densidades bajas), las Serranías Cofán podrían constituir un refugio importante en el Ecuador para este loro espectacular.

\section{Registramos Aburria aburri (Pava}

Carunculada) en varios de nuestros sitios de muestreo. Esta Aburria tiene una distribución geográfica relativamente grande, pero sus poblaciones están disminuyendo y la especie se considera mundialmente casi amenazada (BirdLife International 2000). No encontramos Chamaepetes goudotii (Pava de Ala de Hoz) durante nuestra corta visita, aunque se ha reportado su presencia en el área (R. Borman, com. pers.) Chamaepetes continua siendo relativamente común en Ecuador, pero Aburria es por lo general poco común en esta parte de su rango y podría ser vulnerable a la presión de la caza.

Contamos con algunos datos sobre la presencia en las Serranías Cofán de migrantes neárticos (especies de aves que se crían en el hemisferio norte y luego pasan el invierno del norte en latitudes tropicales), gracias a la visita de Stotz a Bermejo en noviembre del 1998. Durante los dos días que estuvo en la región, Stotz registró ocho especies de migrantes neárticos, que constituyen casi la mitad de paserinos migrantes que se esperaría encontrar en las Serranías. Stotz no registró Dendroica cerulea (Reinita Cerúlea), pero el equipo de estudio ANSP lo encontró en marzo al sur oriente de Bermejo (M. Robbins, com. pers.). Las poblaciones de D. cerulea están experimentando disminuciones drásticas en sus hábitats de nidificación en Norteamérica y esta especie constituye una preocupación para la conservación (Robbins et al. 1992).

\section{Aves de los Bosques Montanos}

( $1.500 \mathrm{~A} 2.300 \mathrm{~m}$ )

En vista del área relativamente pequeña de hábitat de bosque montano en la cresta de las cimas del cerro Sur Pax, fue sorprendente encontrar allí tantas especies de aves montanas. Entre las aves propias de elevaciones 
mayores, pero que encontramos en Sur Pax, habian varias especies con distribuciones sumamente limitadas dentro del Ecuador. Quizá la más significativa de ellas es Grallaria alleni (Tororoi Bigotudo). Esta especie se considera actualmente amenazada globalmente (en peligro; BirdLife International 2000). Hasta hace poco se conocían únicamente dos especimenes en Colombia, pero ahora ha sido encontrada en otros sitios de Ecuador (Krabbe y Coopmans 2000). Aunque G. alleni continúa siendo un ave poco conocida, registrada a unos pocos lugares dentro de un área geográfica limitada, la clasificación de "en peligro" podría exagerar el nivel de amenaza. También de interés fueron Eriocnemis alinae (Calzadito de Vientre Esmeralda), un pequeño colibrí conocido anteriormente en otros tres sitios del Ecuador y Campylorhamphus pucherani (Pico-Guadaña Grande), una especie rara registrada anteriormente en sólo seis localidades del Ecuador.

Otras especies claramente montanas observadas en el cerro Sur Pax incluyen Adelomyia melanogenys (Colibrí Moteado), Coeligena torquata (Inca de Collar), Haplophaedia aureliae (Calzadito Verdoso), Aglaiocercus kingi (Sílfo de Cola Larga), Trogon personatus (Trogón Enmascarado), Andigena nigrirostris (Tucán Andino de Pico Negro), Dendrocincla tyrannina (Trepador Tiranino), Xiphorhynchus triangularis (Trepador de Dorso Olivo), Pseudocolaptes boissonneautii (Barba-Blanca Rayado), Thamnophilus unicolor (Batará Unicolor), Scytalopus spillmanni (Tapaculo de Spillman), Mecocerculus minor (Tiranillo de Pecho Amarillo), Leptopogon rufipectus (Mosquerito de Pecho Rufa), Pseudotriccus ruficeps (Tirano-Pigmeo de Cabeza Rufa), Hemitriccus granadensis (Tirano-Todi de Garganta Negra), Myiophobus pulcher (Mosquerito Hermoso), Ochthoeca diadema (Pitajo de Vientre Amarillo), Pipreola riefferii (Frutero Verde y Negro), Snowornis cryptolophus (Piha Olivácea), Cinnycerthia olivascens (Cucarachero de Sharpe), Cyphorinus thoracicus (Cucarachero de Pecho Castaño), Basileuterus luteoviridis (Reinita Citrina), Chlorornis riefferii (Tangara Verde Esmeralda) y Chlorospingus ophthalmicus (Tangara de Monte Común).
Nos sorprendió también encontrar evidencia de una transición de especies a elevaciones más altas, con algunas sustituciones congenéricas incluso entre el campamento Cordillera de los Osos y la línea de cimas justo debajo de la cresta del cerro Sur Pax. Coeligena coeligena (Inca Bronceado), por ejemplo, alcanzó una elevación de $1.900 \mathrm{~m}$, pero fue remplazado a los $2.100 \mathrm{~m}$ por Coeligena torquata.

\section{BERMEJO}

Muestreamos tres sitios en la zona de Bermejo entre el 24 de julio y el 5 de agosto del 2001. Nuestra base fue la Estación Bermejo (440 m), donde pasé las noches del 24 de julio y del 2 al 4 de agosto. Realicé observaciones casuales a lo largo del sendero al Pozo Dos, al entrar (24 julio) y salir ( 5 agosto) de la zona de Bermejo, ambos días con un cielo extraordinariamente claro. Además, dediqué parte de los días 3 y 4 de agosto a investigar el sendero a Pozo Seco, pero las frecuentes lluvias en ambos días obstaculizaron el trabajo de campo. Las noches del 25-26 julio y del 30 julio-1 agosto permanecí en el campamento Mirador Bermejo $(1.200 \mathrm{~m})$. En este sitio estudié la parte inferior del sendero desde el campamento Mirador Bermejo hacia el campamento Cordillera de los Osos, regresando por el sendero principal a la Estación Bermejo (hasta aproximadamente $850 \mathrm{~m}$ ) y luego bajando el sendero al río Chandia $\mathrm{Na}$ 'e, hasta aproximadamente $900 \mathrm{~m}$. Desde el campamento Cordillera de los Osos estudié el sendero hasta la cima de 2.275 $\mathrm{m}$ y, en una ocasión, volví por el sendero hacia el campamento Mirador Bermejo, hasta unos $1.700 \mathrm{~m}$.

En la Estación Bermejo era notoria la presencia, a una elevación tan baja, de Snowornis subalaris, una especie del bosque de ladera conocida únicamente en un reducido número de sitios dentro de su rango geográfico. Me impresionó también en Bermejo la relativa abundancia de Frederickena unduligera (Batará Undulado), una especie amazónica con una amplia distribución pero que por lo general es escasa. 
Fue en el área alrededor del campamento

Mirador Bermejo que tuve los primeros indicios de que las Serranías Cofán contienen un número significativo de especies de aves de bosque de laderas con rangos geográficos o altitudinales restringidos. Entre éstas habían unas pocas especies que habíamos notado solamente en Bermejo durante nuestro estudio, como Myiopagis olallai y Ampelioides tschudii (Frutero Escamado). Muchas de las especies encontradas en Bermejo, sin embargo, fueron registradas también más tarde en otros sitios, como Campylopterus villaviscensio, Heliodoxa schreibersii (Brillante de Garganta Negra), Phylloscartes gualaquizae, Hemitriccus rufigularis y Snowornis subalaris. Phlogophilus hemileucurus, que no observamos en la región de Bermejo, fue encontrada por Stotz alrededor de los 900 m en una cresta entre Pozo Seco y la comunidad de Alto Bermejo.

Había mucha actividad de hormigas guerreras alrededor de Bermejo, hasta una elevación sorprendente de $1.400 \mathrm{~m}$ y observamos un gran número de aves que siguen de forma regular y obligadamente a las hormigas, que se consideran por lo general como aves de la selva baja, en elevaciones de hasta los $1.200 \mathrm{~m}$ : Neomorphus geoffroyi (Cuco-Terrestre de Vientre Rufo), Myrmeciza fortis (Hormiguero Tiznado), Pithys albifrons (Hormiguero de Plumón Blanco) y Gymnopithys leucaspis (Hormiguero Bicolor). Tambiên fue notorio en este sitio un grupo familiar (dos adultos y dos ejemplares jóvenes) de Aramides calopterus (Rascón de Monte de Alas Rojas), una especie ampliamente distribuida pero rara, que ha sido reportada apenas unas cuantas veces en el Ecuador.

La breve visita a la cresta del Sur Pax constituyó nuestra única investigación de las áreas más altas de las Serranías Cofán (sobre los $1.500 \mathrm{~m}$ ). Las crestas muestreadas en las Serranías Cofán apenas alcanzan la elevación en la que es remplazada en parte la avifauna del bosque de laderas altas por una comunidad de aves montanas. Con frecuencia en estas situaciones, la mayoría o todas las especies de aves de mayor elevación están ausentes (presumiblemente debido a que el área de hábitat adecuado en la cima de la cresta es demasiado reducida) y las especies de aves de elevaciones más bajas pueden llegar a extender sus distribuciones a elevaciones más altas. En las Serranías Cofán, sin embargo, encontramos un cambio significativo en la composición de la comunidad de aves en las crestas de las cimas más altas.

En vista de la poca extensión de estos bosques montanos en las crestas muestreadas, me sorprendió encontrar algunas especies con distribuciones sumamente limitadas dentro del Ecuador. Las más significativas fueron la rara Grallaria alleni, la casi amenazada Campyloramphus pucherani y la escasa y local Eriocnemis alinae.

\section{SHISHICHO}

Permanecí en el campamento Shishicho (1.000 m) las noches del 6 al 9 de agosto. Realicé observaciones casuales a lo largo del sendero entre la Estación Sinangoe y el campamento Shishicho, tanto en la ascensión (6 agosto) como en el descenso (10 agosto). Desde el campamento Shishicho exploré principalmente las elevaciones más altas de la cordillera Shishicho (7, 9 agosto), hasta aproximadamente los $1.500 \mathrm{~m}$. El día 8 de agosto, sin embargo, exploré a lo largo del sendero entre el campamento Shishicho y la Estación Sinangoe, a elevaciones de 900-1.000 m.

El descubrimiento más importante en Shishicho fue el poco conocido tinamú Tinamus osgoodi, registrado previamente sólo en dos poblaciones aisladas, una al sur de Colombia y otra al sur de Perú. Pude ver bien un solo pájaro a los $1.400 \mathrm{~m}$ el 7 de agosto y escuché el canto de un tinamú que imagino pertenece a esta especie, en pocos intervalos a elevaciones comparables, tanto el 7 como el 9 de agosto.

Entre otras especies observadas únicamente en Shishicho están el escaso colibrí Colibri delphinae (Colibrí Oreja-Violacea Marrón), alimentándose en un árbol de Palicourea (Rubiaceae) de flores azules; Pipreola frontalis (Frutero de Pecho Escarlata), una cotinga que no ha sido registrada en Colombia 
(conocida previamente sólo al norte de la región de Sumaco); y Piranga flava (Tangara Bermeja), una especie muy extendida a lo largo de los Andes pero no conocida en los Andes orientales de Colombia (los pocos registros anteriores para el Oriente ecuatoriano son todos al sur, en las provincias de Morona-Santiago y Zamora-Chinchipe). Fue interesante también encontrar un atrapamoscas Knipolegus no identificado, visto una sola vez a los $1.450 \mathrm{~m}$. Este individuo se diferenciaba de la especie esperada, K. poecilurus (Viudita de las Estribaciones), por tener un iris marrón (no rojizo) y apariencia marrón medio claro (no gris claro o marrón-gris) en su parte superior, con leves listones en su pantalón anteado marrón.

\section{Ccuccono y Sinangoe}

Permanecí las noches de 11-14 agosto en Ccuccono, en una cresta sobre el río, a los $1.000 \mathrm{~m}$. Los días $12 \mathrm{y}$ 14 de agosto trabajé hacia el noreste, a lo largo del sendero desde el campamento de Ccuccono de regreso a la Estación Sinangoe, bajando hasta aproximadamente los $900 \mathrm{~m}$. El 14 de agosto descendí desde el campamento hasta el río Ccuccono y trabajé también en las zonas a lo largo de los arroyos de Ccangopacho y Ccopaye Fensi. Permanecí en la Estación Sinangoe las noches del 5, 10 y 15-16 de agosto. Durante la mayor parte de estas visitas nos encontrábamos en ruta a algún otro sitio, como Shishicho o Ccuccono, por lo que sólo realicé observaciones casuales alrededor de la estación. Sin embargo, gran parte del día 16 de agosto la dediqué a investigar los senderos cercanos a la estación, y principalmente la parte inferior del sendero hacia el Ccuccono, al igual que de la estación descendiendo por el río Sieguyo hacia el río Aguarico.

El Ccuccono fue el único sitio donde vi Phlogophilus hemileucurus durante el inventario rápido. Sin embargo, tanto Stotz como el equipo ANSP lo habían registrado en el área de Bermejo y parece tener una distribución amplia en la región. Este pequeño colibrí podría ser común localmente, como lo era en el Ccuccono, pero tiene una limitada distribu- ción geográfica, abarcando unas pocas localidades que van desde el extremo sur de Colombia al extremo norte del Perú. Otra observación interesante en el Ccuccono fue la presencia de un enjambre de hormigas guerreras, observado a los $1.000 \mathrm{~m}$. No había presencia de las obligadas aves hormigueras, pero en dos días consecutivos observé un Neomorphus geoffryoi en este enjambre.

Notamos varios nidos grandes, vacíos, en forma de tazón, en la pared de un pequeño precipicio cerca de un arroyo que desembocaba en el río Ccuccono. Había pilas de semilla de palma y plántulas de palma en germinación debajo de ambos nidos, al pie del precipicio. La identificación inicial de los mismos como nidos de guácharo (Steatornis caripensis) llevaron al equipo a nombrar al río adyacente ("Arroyo Guácharo" en Cofán), pero el gran tamaño de los nidos de tazón sugiere que podrían haber sido más bien los nidos de otra especie (Rupicola peruviana, Gallito de las Rocas Andino).

\section{IMPORTANCIA PARA LA CONSERVACIÓN}

Nuestro breve estudio de las Serranías Cofán fue suficiente para establecer la presencia de una rica comunidad de aves de bosque de laderas, especialmente en las elevaciones altas. Dos características de esta comunidad de aves la hacen de particular importancia para la conservación: la presencia de un número significativo de especies endémicas de un área geográficamente limitada de los Andes, o que han sido registrados en apenas unas pocas localidades; y el hecho que la mayoría de estas especies fueron encontradas en casi todos o en todos nuestros sitios de estudio, lo que indica que las Serranías constituyen un importante centro de población para estas especies. Algunas de estas aves son consideradas globalmente amenazadas, como Tinamus osgoodi, Touit stictoptera (Lorito de Alas Moteadas, considerado vulnerable; BirdLife International 2000) y Grallaria alleni (sin embargo, ver mi nota sobre esta especie más arriba), al igual que varias especies consideradas casi amenazadas, como Aburria aburri, Campylopterus villaviscensio, 
Phlogophilus hemileucurus, Campylorhamphus pucherani y Hemitriccus rufigularis. De hecho, el número de especies de aves amenazadas y casi amenazadas registrado en este breve estudio de las Serranías Cofán es suficiente para considerar a la región como uno de los sitios más importantes para la conservación de aves en el Oriente ecuatoriano (Wege y Long 1995).

Otras especies de interés para la conservación incluyen aves conocidas en relativamente pocos sitios, como Myiopagis olallai, Phylloscartes gualaquizae y Hemitriccus rufigularis. Los estudios más profundos probablemente revelarán la presencia de otras especies de rangos geográficos restringidos dentro de las Serranías.

\section{AMENAZAS Y RECOMENDACIONES}

Las Serranías Cofán son un importante refugio para las poblaciones de aves grandes vulnerables, como el loro Ara militaris y los grandes crácidos Crax salvini y Aburria aburri. Ara militaris es considerado mundialmente amenazado (BirdLife International 2000). Tanto Crax salvini como Aburria aburri están disminuyendo en Ecuador y Aburria se considera casi amenazado mundialmente. Estos crácidos están amenazados no sólo por la pérdida de su hábitat (deforestación), sino también por la caza, ya que son aprovechados comúnmente como alimento. No se conoce el nivel de presión actual que ejerce la caza en estas aves, ni tampoco la cantidad de caza que pueden soportar, pero la caza dentro de las Serranías deberá ser regulada para mantener poblaciones estables a largo plazo. $\mathrm{La}$ comunidad Cofán de Zábalo ha aplicado una regulación comunitaria en cuanto a la carga de la caza, iniciando un programa de censo de la vida silvestre, lo cual constituye un buen modelo para los moradores Cofán de esta zona.

La mayoría-si no todas-las especies de aves de la región que son de importancia para la conservación están restringidas a hábitats relativamente intactos. Por consiguiente, esta avifauna está amenazada debido a la colonización que está teniendo lugar a lo largo de la nueva Vía Interoceánica desde Tulcán hasta
Lago Agrio (Figuras 2, 2A). Las especies que son cazadas para alimento (como pavas y paujiles) serán particularmente vulnerables a la creciente presencia humana e incluso a los impactos relativamente transitorios (p. ej., mineros que ingresan a la región durante períodos cortos).

Los estudios a futuro de la avifauna de las Serranías Cofán indudablemente incrementarán el número total de especies conocidas en la región. Las especies que se podrían esperar encontrar en estas estribaciones y que deben ser el objeto de futuras investigaciones incluyen dos especies amenazadas consideradas como vulnerables (BirdLife International 2000), Galbula pastazae (Jacamar de Pecho Cobrizo) y Dysithamnus occidentalis (Batarito Bicolor), al igual que varias especies de aves casi amenazadas: Heliodoxa gularis, Xenerpestes singularis (Cola-Gris Ecuatorial), Pipreola chlorolepidota y Chloropipo flavicapilla (Saltarín Cabeciamarilla).

\section{MAMÍFEROS GRANDES}

Participante/Autor: Randall Borman A.

Objetos de conservación: Mamíferos clasificados como CITES Apėndice I (amenazados con extinción) y CITES Apéndice II (potencialmente amenazados si no se emprende alguna acción), incluyendo Alouatta seniculus, Aotus vociferans, Ateles belzebuth, Callicebus moloch cupreus, Callicebus torquatus, Cebuella pygmaea, Cebus albifrons, Cebus apella, Herpailurus yaguarondi, Lagothrix lagothricha humboldtii, Leopardus pardalis, Leopardus wiedii, Lontra longicaudis, Myrmecophaga tridactyla, Panthera onca, Pithecia monachus, Priodontes maximus, Puma concolor, Saimiri sciureus, Sanguinus nigricollis, Speothos venaticus, Tapirus terrestris, Tayassu pecari, Tayassu tajacu y Tremarctos ornatus; además, mamiferos raros (Atelocynus microtis) y dispersores y depredadores de semillas. Los nombres se ciñen a Emmons y Feer (1997).

\section{MÉTODOS}

La fauna de los mamíferos grandes de las Serranías Cofán constituía una mancha en blanco sobre el mapa para los biólogos al momento de este inventario, aunque ha sido bien conocida durante siglos por los 
cazadores y naturalistas Cofán que habitan en el área. Ya que crecí dentro de la cultura Cofán, hablo el idioma y he cazado y pescado con los Cofán la mayor parte de mi vida, me resultó relativamente fácil bosquejar una lista de las especies esperadas para la zona. El mayor desafío en el campo fue confirmar la presencia de las especies ya conocidas por los habitantes Cofán y estimar sus abundancias locales durante el transcurso de nuestros 24 días en el campo.

Para empezar, recopilamos una lista de 46 especies esperadas de mamíferos, abarcando seis órdenes y 14 familias, sobre la base de la literatura taxonómica, la experiencia personal y las entrevistas con Cofán que viven en la zona de Bermejo y

Sinangoe. Excluimos de nuestra lista a los murciélagos, marsupiales y la mayoría de los pequeños roedores, porque el inventariar estos grupos de forma efectiva en un estudio tan rápido resulta prácticamente imposible. Más bien, nos concentramos en especies que o son importantes para los habitantes Cofán como animales de caza o que ofrecen buenos indicios sobre el estado de conservación de la región.

En el campo intenté cubrir cuanto terreno y cuántos hábitats me era posible en cada una de las zonas visitadas, siguiendo con frecuencia senderos no marcados o rastros de animales lejos de los senderos principales. Me mantuve alerta por cualquier observación visual, y también registré huellas identificables, deyecciones, olores y comederos. Llevé también un registro de todos los mamíferos vistos por otros durante el inventario rápido-tanto por parte de los miembros del equipo científico como por los más de 30 Cofán que nos asistieron en el campo. De estos datos, complementados con conversaciones con los Cofán de la localidad y mi propia experiencia previa de la zona, derivé estimaciones sobre el tamaño de la población de cada una de las especies.

\section{RESULTADOS DEL INVENTARIO DE MAMÍFEROS GRANDES}

De las 46 especies de mamíferos grandes esperadas en la zona, 42 fueron confirmadas y 32 detectadas directamente durante el inventario (ver Apéndice 4 para la lista de especies y cálculos de abundancia). El total incluye 12 especies de primates, nueve de las cuales fueron detectados durante los 24 días que permanecimos en el campo. También encontramos decenas de registros de dantas y pecarís en toda la zona, lo que indica la existencia de una abundante comunidad de mamíferos en su mayor parte intacta, a pesar de la caza a pequeña escala por parte de los moradores locales. Diez especies más han sido confirmadas por los moradores Cofán de la localidad, dejando cuatro especies sin verificar (Mazama rufina, Nasuella olivacea, Tapirus pinchaque y Aotus lemurinus). Éstas son todas especies montanas similares a las especies de selva baja, con las que los moradores locales fácilmente podrían confundirse.

Varias de las especies de mamíferos confirmadas para las Serranías Cofán son sumamente raras o consideradas mundialmente amenazadas por la Unión Mundial para la Conservación (UICN). Ocho especies constan en la lista de CITES, Apéndice I, 17 en el Apéndice II, y seis en el Apéndice III. El Libro Rojo de Mamíferos del Ecuador (Tirira 2001), confirma a seis de nuestras 42 especies como amenazadas, con una de éstas clasificada como En Peligro (Priodontes maximus) y cinco como Vulnerables. Dos de las cuatro especies no confirmadas constan en Apéndices I o II de CITES; la primera de éstas califica como En Peligro (Tapirus pinchaque), mientras que la segunda es considerada Vulnerable (Aotus lemurinus). Varias de las demás especies que registramos, como el perro de orejas cortas, Atelocynus microtis, son tan raras que su estado de conservación es desconocido, pero potencialmente crítico.

Durante el trabajo de campo no pudimos validar las versiones de cazadores locales Cofán sobre un mono chorongo miniatura que se dice habita los bosques de elevaciones altas en Bermejo. Según los informes, este animal ha sido detectado varias veces $y$ cazado en dos ocasiones por los Cofán, quienes insisten que difiere no sólo en tamaño sino también en comportamiento, sonidos y patrones de coloración en 
comparación con el más común Lagothrix lagothricha. Cabe notar que los cazadores Cofán a los que acompañé en una expedición anterior al cerro Sur Pax nunca antes habían visto al mono machin negro, Cebus apella, que recolectamos ahí, y podría ser que los individuos inusualmente oscuros y de pelo grueso de la región de Bermejo son la base de las versiones sobre el pequeño mono chorongo. Por otro lado, frente a un espécimen del poco conocido C. apella, los cazadores Cofán indicaron de inmediato que no se trataba del pequeño mono chorongo que habían capturado. Hay todavía una posibilidad de que una nueva especie o sub-especie de Lagothrix habite en estos bosques, y el resolver esta duda constituye una alta prioridad para los estudios de mamíferos en la zona.

Tampoco pudimos verificar los informes de otros mamíferos inusuales en la región. Los cazadores de Bermejo, por ejemplo, sostienen haber visto un pequeño oso rubio en los bosques de elevaciones altas que investigamos alrededor del cerro Sur Pax. En anteriores visitas a Bermejo, he observado dos raposos diferentes - una se trataba de un ejemplar joven en cautiverio y la otra de un adulto en estado naturalque no he podido identificar. Una de las ardillas más comunes en Bermejo y Sinangoe, un animal grande de vientre blanco, parece ser una especie no descrita. Por el momento, todas estos aparentes descubrimientos esperan ser confirmados.

Las comunidades de mamíferos grandes de Bermejo y Sinangoe son muy similares en su composición, pero la densidad de los animales parece ser sustancialmente mayor en Sinangoe. Sospecho que estas diferencias se deben a la mayor productividad de los bosques de Sinangoe. Una hipótesis alternativa, ya que las comunidades Cofán cazan en ambos bosques, es que la comunidad de Bermejo está capturando animales con mayor intensidad que la comunidad de Sinangoe. Sin embargo, esta hipótesis probablemente puede ser descartada. La población de Sinangoe es diez veces más grande que la de Bermejo y en el bosque de Sinangoe hay también ocasionales cazadores externos, lo que sugiere que los animales son capturados ahí con mayor frecuencia que en Bermejo. Es cierto que los cazadores en Bermejo se extienden más y cazan más agresivamente que los de Sinangoe, pero sospecho que ésta es consecuencia de las bajas densidades de animales y no su causa. La causa real de la discrepancia probablemente se encuentra en los suelos más ricos, con la consiguiente producción más alta de frutos, junto con una distribución más amplia de los tipos de hábitat adecuados en la región de Sinangoe.

\section{BERMEjo}

Mi evaluación inicial de la comunidad de mamíferos grandes en Bermejo divide la región en tres subregiones importantes, distinguiéndose una de otra por las diferencias en elevación y productividad: (1) tierras bajas poco productivas; (2) bosque productivo de mediana elevación; y (3) laderas empinadas y crestas del bosque de elevaciones altas.

Gran parte del bosque de laderas bajas en el valle del río Bermejo- a elevaciones de entre $400 \mathrm{y}$ $1.000 \mathrm{~m}$-crece sobre colinas de una suave arcilla rojiza muy inestable y en constante estado de erosión. Parece haber derrumbes de buen tamaño con cada precipitación, lo que le da al río Bermejo su distintivo color rojizo, y los suelos anegados y carentes de nutrientes, probablemente son poco productivos tanto para cultivos de frutos silvestres como para la agricultura. Como resultado, los bosques naturales de la sub-región están salpicados de franjas de bosque en transición ahogado en enredaderas y matorral. Venados, armadillos y los roedores más grandes prosperan en este paisaje, pero los sahínos (Tayassu tajacu), que habitualmente se adaptan bien a los bosques secundarios y fácilmente resisten la presión de la caza, escaseaban de manera sorprendente.

Los sahínos eran mucho más abundantes en los bosques más maduros de la segunda sub-región, entre los $1.000 \mathrm{~m}$ y $1.200 \mathrm{~m}$. Esta región se caracteriza por suelos orgánicos oscuros que parecen rendir cantidades de frutos más grandes que los suelos rojizos inestables alrededor de Bermejo. Los derrumbes son 
también comunes aquí, pero las áreas de bosques maduros, antiguos bosques de transición y reciente matorral en transición están distribuidos más igualmente, ofreciéndoles a los mamíferos varios hábitats grandes. Los sahínos, dantas (Tapirus terrestris), monos chorongo (Lagothrix lagothricha), monos aulladores (Alouatta seniculus) y otros mamíferos más pequeños se encontraban todos en abundancia en esta rica región. Los osos de anteojos (Tremarctos ornatus) también estaban presentes, aunque no con la misma frecuencia que en elevaciones mayores. Tuvimos varios registros aquí de monos cariblancos (Cebus albifrons) y monos ardilla (Saimiri sciureus), pero ninguno de los dos parecía estar presentes más allá de los $1.200 \mathrm{~m}$. De igual manera, los rastros de felinos terminan aquí. Los venados de selva baja (Mazama americana y M. gouazoubira) son comunes en toda esta región.

La tercera sub-región corresponde a las laderas relativamente empinadas y crestas de la cordillera del cerro Sur Pax, sobre los $1.200 \mathrm{~m}$. Grandes piedras de cuarcita y un profundo fango orgánico son característicos de la superficie, con árboles altos cada vez más cargados de musgo y epífitas, conforme aumenta la altitud. Monos chorongo, monos aulladores, venados y dantas cohabitan todos a lo largo de las laderas más bajas, pero desaparecen a elevaciones mayores, comenzando con los venados y dantas $(1.200 \mathrm{~m})$, seguidos por los monos aulladores $(1.350 \mathrm{~m})$ y monos chorongo $(1.500 \mathrm{~m})$. El mono machín negro (Cebus apella) y el mono araña de vientre blanco (Ateles belzebuth) aparecen cerca de la cresta, desde los $1.600 \mathrm{~m}$ hacia arriba. En estas laderas también comenzamos a registrar una especie no identificada de coatí, con pelaje rojizo claro y una cola sin anillos (posiblemente no Nasuella olivacea), aparentemente autóctono de los bosques de laderas altas. Los osos de anteojos son comunes en toda esta región y nos encontramos con frecuencia con trochas bastante utilizadas por ellos y con áreas grandes de comedero. Las pequeñas huellas de venado en el límite de los $1.800 \mathrm{~m}$ son probablemente indicios de la pequeña corzuela roja, Mazama rufina.
Los bosques enanos, cargados de musgo, que crecen a lo largo de las crestas entre los 1.600 y 2.200 in son tan angostos que dan la impresión de no ser un hábitat importante para los mamíferos. Sin embargo, aquí habitan tanto osos como monos machín negros, probablemente atraídos por las bromelias que crecen en abundancia a lo largo de las crestas. El coatí no identificado también utiliza este hábitat. Ésta fue también la zona en la que vimos con mayor frecuencia a una gran ardilla gris no identificada. Notoria fue la ausencia de Tapirus pinchaque, un animal muy común sobre los $2.000 \mathrm{~m}$ en otros lugares del Oriente ecuatoriano. Debería estar presente en las zonas de elevación más alta al norte del cerro Sur Pax.

\section{SiNANGOE}

El paisaje de Sinangoe parece ser mucho más sencillo que lo de Bermejo, en parte porque carece de los suelos rojizos pobres que dominan gran parte del bosque de laderas bajas en Bermejo. La distribución de hábitats para mamíferos es mucho más equilibrada y la distribución de las especies es más regular. Por ejemplo, en las dos principales sub-regiones del área de Sinangoela enorme y casi plana llanura aluvial entre los ríos Ccuccono y Aguarico y el paisaje más accidentado hacia el norte y oeste-se ven pocas diferencias en la composición de mamíferos, aparte de algunos cambios predecibles relacionados con la elevación.

Una de las pocas diferencias que notamos entre los mamíferos de las dos sub-regiones en Sinangoe fue la sorprendente ausencia de la mayoría de especies de primates en la llanura aluvial. Muestreamos esta región en tres ocasiones diferentes y discutimos su fauna largamente con la comunidad de Sinangoe.

Notablemente, y a pesar de la gran cantidad de hábitat disponible, el único primate grande común aquí es el mono aullador. Las entrevistas con habitantes Cofán mayores confirmaron que aunque se han visto ocasionalmente monos araña en la región, nunca se han detectado monos chorongo. Esto resulta misterioso, particularmente en vista de que la presión de la caza 
ha sido bastante baja por lo menos durante el último siglo y dado que avistamos varios grupos de monos chorongo en el adyacente cerro Shishicho. Podría ser que alguno de los eventos geológicos catastróficos que parecen ser fenómenos comunes en el drenaje del río Ccuccono (esto es, sismos, inundaciones, erupciones volcánicas) eliminó las poblaciones de mono chorongo en el pasado reciente y que la subsiguiente recolonización está ocurriendo a ritmo lento.

\section{Notas adicionales:}

\section{Cebus apella (Mono Machin Negro)}

Encontramos esta especie sólo una vez durante el inventario, a los $2.100 \mathrm{~m}$ sobre las laderas sur del cerro Sur Pax. Lo he visto en ese lugar en por lo menos tres ocasiones distintas, entre los 1.800 y $2.000 \mathrm{~m}$, durante los últimos dos años. La abundancia de frutos parcialmente consumidos y de hojas de bromelias chupadas y con marcas de dientes que corresponden a la dentición de C. apella sugieren que la especie es común en estas elevaciones-hasta $600 \mathrm{~m}$ más alto que el límite de elevación de los $1.500 \mathrm{~m}$ sugerido por Emmons y Feer (1997).

Creo que los dos especimenes que capturé ahí en el 1999 constituyen los únicos registros confirmados para Ecuador de C. apella al norte de la cuenca del Pastaza. Mi propia experiencia de campo de décadas en la Amazonía ecuatoriana y las numerosas conversaciones con cazadores Cofán, Secoya, Siona, Quechua y Huaorani no han podido redundar en algún indicio de la presencia de esta especie en las cuencas del Napo y Aguarico. Los informes de C. apella en Cuyabeno y Yasuní por lo general han sido de científicos no familiarizados con las poblaciones de C. apella en otras regiones, y en la mayoría de los casos creo que se pueden atribuir a una confusión con los grandes machos C. albifrons de grueso pelaje. A esto se suma el hecho de que los cazadores indígenas de la selva amazónica con frecuencia utilizan un nombre distinto para estos machos.

\section{Ateles belzebuth (Mono Araña de Vientre Blanco)}

Esta especie parece no ser común en la región de Bermejo. Los cazadores Cofán informaron de un solo encuentro, hace casi una década, cerca del cerro Sur Pax. Localizamos sólo un grupo en Bermejo, de más de diez individuos, también cerca al Sur Pax. Los monos eran muy mansos y curiosos, inclusive se acercaron a investigarnos. Dos días después, encontramos un solo individuo a una elevación mucho más baja, a los 1.600 $\mathrm{m}$. La baja densidad de monos araña en el área-y su aparente restricción a los bosques de elevaciones altas, junto con C. apella-podrían ser el resultado de la poca disponibilidad de alimentos a elevaciones bajas. La caza humana no parece ser responsable por estos patrones, ya que sólo se conoce de un caso en el que fue cazado un mono araña en el área durante la última generación.

En claro contraste con la situación en Bermejo, A. belzebuth era común en la región de Sinangoe. Una vez más, parece estar limitado a elevaciones bastante altas, sobreponiéndose con Lagothrix lagothricha (ver abajo). Se detectaron grupos en cinco diferentes ocasiones en el cerro Shishicho, siempre por encima de los $1.300 \mathrm{~m}$. Los monos eran mansos y curiosos, a pesar de que el sendero a Shishicho ha sido muy utilizado por los colonos e indígenas durante al menos el último siglo. Esto se debe en parte a que la entrada a Shishicho está ahora prohibida para los cazadores Cofán (ver abajo).

\section{Lagothrix lagothricha humboldtii (Mono Chorongo)}

Aunque el equipo no vio monos chorongo durante nuestro inventario en Bermejo, sus moradores encontraron por lo menos cuatro grupos en expediciones de caza durante el mismo período. Estos cuatro encuentros se dieron todos en el área relativamente productiva de la meseta debajo del campamento de Mirador Bermejo, entre los 600 y 900 m. A los Cofán que están familiarizados con los monos chorongo en el Oriente ecuatoriano les sorprendió la robustez de los individuos encontrados en Bermejo. 
En la región de Sinangoe, la distribución de

L. lagothricha indica algunos patrones interesantes. Aguas abajo, el río Aguarico forma el lindero entre las sub-especies humboldtii (hacia el norte) y papaegi (hacia el sur). En la cabecera del Aguarico, este lindero sigue por el río Due, uno de los principales y anchos tributarios del Aguarico. Parece que humboldtii ha logrado cruzar los tributarios del alto Aguarico (Chingual y Cofanes), pero no el Due. Igual de interesante es la distribución irregular de monos chorongo entre el Due y el Aguarico (ver esta discusión en la sección sobre Sinangoe, más arriba).

El hecho de que existen poblaciones saludables de Ateles y Lagothrix en las inmediaciones del cerro Shishicho, una región donde está vedada la caza por parte de la comunidad de Sinangoe, sugiere que estas poblaciones serán más viables y estables a largo plazo, si se pudiera minimizar las incursiones de los colonos. Podrían servir como poblaciones "semilla" para recolonizar las zonas adyacentes.

\section{Tremarctos ornatus (Oso de Anteojos, Oso Andino)}

Basándonos de evidencias indirectas, los osos de anteojos son comunes tanto en la región de Bermejo como en Sinangoe; uno de los miembros del equipo del inventario del 2001 avistó uno brevemente cerca del cerro Sur Pax. Las huellas de oso, las bromelias y palmas destruidas y otras señales son obvias y generalizadas en elevaciones más altas a lo largo de la región, y en Bermejo pude registrar indicios de un oso de anteojos a una elevación incluso tan baja como $450 \mathrm{~m}$.

\section{Atelocynus microtis (Perro de Orejas Cortas)}

Este animal, quizá el más escurridizo y menos estudiado carnívoro de la cuenca Amazónica, fue visto en Bermejo por D. Moskovits. A las 4:30 de una tarde de lluvia, observó a un perro solitario que venía hacia ella a lo largo de un sendero muy utilizado en el bosque maduro cerca del campamento Mirador Bermejo, justo encima de los $1.200 \mathrm{~m}$. Aparentemente sin darse cuenta de su presencia, el animal pasó a ca. $30 \mathrm{~cm}$ de donde se encontraba ella, antes de desaparecer en el sotobosque.
Ésta es la mayor elevación en la que se ha registrado la presencia de Atelocynus (Leite y Williams, en prensa).

\section{AMENAZAS Y RECOMENDACIONES PRELIMINARES}

El desarrollo de planes de manejo apropiados para estos bosques exigirá estudios sobre las actuales prácticas de caza y sus efectos. La comunidad de Sinangoe ya ha aplicado algunas reglas sencillas para los cazadores, estableciendo principalmente algunas áreas de caza vedadas y otras no vedadas. Nuestras observaciones de las densas comunidades de animales tanto en Shishicho (área vedada) como en Candue (caza no vedada) sugieren que el manejo de estas áreas es acertado, al menos por el momento. En Bermejo, por otra parte, no se ha hecho ningún intento por manejar las poblaciones de animales de caza y la aparente abundancia de monos en ese lugar es apenas la consecuencia de una pequeña población de cazadores. El establecimiento de reglas sencillas de caza para los cazadores Cofán de Bermejo y el fortalecimiento de las reglas establecidas en Sinangoe debe ser una de las más altas prioridades de conservación y manejo de la vida silvestre de la región. Inicialmente, un sistema de zonificación probablemente rendiría los mejores resultados, desarrollando otras herramientas de manejo acorde con la ética y las necesidades de la comunidad. La participación de los moradores Cofán locales en programas de censo de la vida silvestre proveería datos importantes sobre las dinámicas y niveles de caza de las poblaciones, lo mismo que ayudaría a establecer un plan de manejo sensato. 

Jonguesune Condase'cho 


\section{JONGUESUNE CONDASE'CHO}

Tsampini jacan'cho:

Mani Ta'tacho:
24 de julio-16 de agosto, 2001

Coanifoe ande, Andes ccottacco andepa'ttisuma, 450 metros asta 2.341 metros; tsa coanifuoe andeta tsu; Bermejo tsutoni, toya'caen Chandia Nae tsutoni, asta Ocomari Ccottaccopie; toya'caen Sieguyo estacion'tti asta Shishicho Ccottaccopie; toya'caen Ccuccono'qqui'su sinju, toya'caen tsenisu ccottacco. (Canja Figura 2, toya'caen y.)

Jongoesuma atesuye jacan'cho: Quinicco'su, toya'caen sapo, iyo, shishittoshe'su, toya'caen ca'tse'su, toya'caen osha'cho aña'cho'su.

Jonguesuma gi attefa :
Jacasundenccu tsu atte, ñoa'me tsu injenge pacco va andema coiraye. Injantsse ccottacco'su tsampi tsu toya doengatsse jin'cho, sinjuccune asta se'fatsia ccottacconga. Oshacho echoccopa tsu tseni jin'cho, sinju'su cansia, toyacaen ccottacco'su cansia, pa'cco fue'ttini. Tsaimbittse tsenisu cansia tsu ccani cansefambi, tsambita tsu tayo sefaji. Vani tsu doengattse sheque. Toya'caen injanttse vanisu añacho, toyacaen quini'si, tsu tansi tse'tti jincho. Va tsampi tsu tayopi Cofandeccumbe andesi tsu tseni a'ija tsave canse. Tsa'ma ja'ño cocama bo'asi tsu pa'cco tsampija sefaye ashen.

Coanifue avuja'qquinga gi injan'ttse cuna o zie atesuyembichoa quini'si, toya'caen añachoma atte'fa. Enttinge ta tsu cuna Ecuadorne, enttingeta tsu cientificondeccu toya atesumbichoa. Enttingeta tsu fuesu andeni me'io. Va'ttinga gi aqque re'ricco ingi attechone condase'faye.

Tsampine condasecho: Tsampi tsu oshacho ccaninga'pa, 400 metros asta $2.000 \mathrm{~m}$. Andeta tsu bove ñottsimbi, jombachone. Bermejoni tsu pasha injantsse tsaccupa. Sinangoeni tsu tittse santsi. Vanisu tsampi tsu cambian'jecho tsampi, tsa sinjuccu'su tsampi tsu vani tsangaeyi tsutonga, toyacaen tsa ccottaccosu tsampi tsu vani tsangaeyi sefangi. Tsacamba tsu echoccopa jincho. 1.500 metronga tsu ñoa'me ccottaccosu tsampija ashaen. Tansicho'fanga tsu fuesu tsampija jincho, tse'ttisu patu sombocho pasha quini'sine inzatssia andesi. Pa'cco a'ta tsa ccottacconi tsu in'jattse ccappoppoenje, tsacansi tsu injanttse coentti tsampive me'io.

Quinisine condasecho: Atefa gi 800 quini'si. 1.000 caccyema gi samboemba anga'fa, toya'caen 600 caccyejema gi isian'fa. Toya'caen 1.000 quini'jima gi agatto'fa, tsaiquiquiamba. Asittaenfa gi, osha'ta tsu 2.000 , tsambita $3.000 \mathrm{ma}$ pan'shaen tsu quini'sija jincho. Tayo tsu cientificondeccuja tansian'fa, diez quinisisi tise attembichoama atte'fa. Osha'ta tsu fuesu diez tsu toya cca'i attembichoa. Foe shincapa ocomari an'jencho tsu injanttse sheque Occomari Ccottaconi, tsa tsu cientifico toya attembichoa. Rubiaceae qquen su'cho tsu vani ñoa'me injan'ttse sheque. 35 genero, toya'caen 100 especie tsu va'su'suja jin. Orchidaceae, Gesneriaceae, Sapotaceae, Bromeliaceae, y Pteridofitas qque tsu sheqque. Osha'cho palma'suqque tsu sheque. Enttinge va oriente'su palmama tsu vani attefa. 
Rande Añachone condasecho: Ingija attefa 42 rande añacho'su especie. Ocho tsu pa'cco ande'su listanga tevoen'cho ñoa'me catsa sefajichove, toya'caen 17 tsu tsa listanga tevoen'cho, junde coirambini nepiye tson'jechove. 12 tive'pasu especiema cachi'fa, toyacaen inja'ttse ocomari, toya'caen ccovi cansechoma gi attefa. Cientificondeccu toya atesumbichoa tutuyema gi atte'fa, toya'caen gi asittaen'fa, osha'ta tsu tsenisu coshombi, toya'caen cca'i su'cho chipiri con'siqque tsu cientifico toya attembichoa.

Ca'tsene (sanccopapa) condase'cho: Tsaimbitssia chhiririama gi cachipa asittaen'fa. 399 especiema gi agatto'fa, tsa'ma osha'ta tsu 700 ma panshaeña, vasi'ttse can'jemba tta'ttani. Fue'cco tsu Ecuadorni toya cientifico attembichoa, tsa si'an fongo.

Sapo'sune condase'cho: Tansi Sinangoefama gi can'fa, oshacho sapo, toyacaen iyove. Tseni gi atte'fa 31 especie, tsa tsu 17 sapo, 6 iyo, 5 saramaquesa'can, toya'caen 1 salamandre, 1 ttanjesi. Fuesuma ja'i ja'canda gi attefaye.

Jongoesu tsu va ñottsia tsampima in'jambiye dañoye:
Va tsampita tsu vana'jen ccoangi naccuve attufapa. Lago Agrione caretera ji'cho interosianica tsu tsa tsampi enttingeye jacho Tulcani. Tsa tsampita tsu daño'masia. Tsa'ma tsu jañojan tsangae caretera jinchosi cocamanjan tsangae canimba tsa tsampisu quini'jima daño'jen'fa. Toya'caen tsu tsampisu aña'cho na'eni canseqque'suma tsu cocamajan daño'jenfa'fa.

Tsa Bermejo ande'ttita tsu coira'je'cho ande tsa'ma tsu oshayembi'qquia'caon ñame ñotsse ambiañe'da tse'tti tsu jin ppurotsse Shishicho Ccuccono jinchoma tsu linderoiccu tsa Reserva Ecologica Cayambe Coca ma puiyi'cco pañaccopa semajen'fa a'i Sinaguesu deccuiccu. Toya'caen tsu fae tevoen'jema conveniome tson'fa Ministerio del Ambientesuiccu. 
Injenge'cho conda'cho ma'caen coiraya'chove:

1) Tsa Bermejo andene tsu injenge ñoñañe ande tsampi caentsu coiraje'chove daye nijogaesu maqque fi'ttimasia o dañomasiave. Bermejo tsutoni toya'caen chandia na'en tsutoni, san miguel na'en tsutonima'qque toya'caen ccotta'cco sur pax tti'su ccotta'ccondeccumaqque. Condaye gi injanfa cuentsu junde chattu'faye reserva jiñe 50.000 etaria tsa Bermejo ni cuintsu a'i deccu reserva comunitario cofan me daye vamatsu faite'fa Ministerio del Ambientesu nasundeccu.

2) Notsse tisumbe qquen injamba coiraye Bermejonimanda toya'caentsu semaña'cho lindero tsaiquimanda tsu ñame randepa a'tatssia've. Caentsu jinchoye letreroiccu a'tatsse puiyi'cco camba injanje'faye cuna coiraje'cho andeqquen. A'indeccuma condase injaemba o atisiamba mandaya'cho cuentsu coirasunde ccuve dapa cañajeñe pa'cco a'i andema tsama jacamba tsu semaña'cho. Toya'caen tsu injenge cocama ndeccucanjecho pporotsse jacañe.

3) Sinague andettima tsu ñotsse injamba fuiteccopa semaña'cho a'i

Ministeriodeccuiccu. Tsomba tsu somboeña'cho nasundeccuve caentsu pa'cco ccane jipa canisudeccuma cañajeñe mingae dañofasane Reserva ecologica Cayambe Coca toya'caen cañajeña'cho Due battipa'tte asuccoe Avarico ye ne'pi'tsse rio cofonesni. Somboeñe tsu injenge cuna cañasundeccuve cuentsu ñame injenge'ttima o pa'cco comunama cañajeñe. Toya'caen letrero ma ccutsiaña'cho a'tatssiave ma'tti lindero jinquingata. Letrero tsu jiña conda'choiccu a'i andaqquen.

4) Andema isuye cuintsu Cayambe Coca toya'caen Bermejo fue reservave daye. Randiañe lindero tsai'quima asta La Sofia toya'caen asta La Bonita'ttinga. Sucumbios'su na'sundeccu fuite'cho toya'caen comuna'su a'indeccu'qque ju suninda gi tsa andema isuye osha'faya.

Tsampima coiraya'choma fuite'cho tsangae jiñe:
1) Cuna ande'ttima coiraya'cho pa'cco andene injienge'chosi. Colombia'tte asta Peru enttinge'ttinga ccotta'cco tsampi jin'choma coira'chove daye.

2) Cayambe Cocani tsu vueyi carro tsai'quive tsai'quian va tsai'quinda tsu tsa coiraje'choma da'ñoña tsa'ma va cuna coiraya'choda tsu fuiteya.

3) Aguarico San Miguel Due tsomba Bermejo andema coira'faya.

4) Notssi tson'cho'caen coiraye tsa ciencia'caen tsa ñotssi tson'cho daye. A'indeccu yayandeccu coiraye in'jan'choma. 
(for Color Plates, see pages 13-20)

$\begin{aligned} 88 & \text { Participants } \\ 90 & \text { Institutional Profiles } \\ 92 & \text { Acknowledgements } \\ 93 & \text { Report at a Glance } \\ 96 & \text { Why the Serranías Cofán? } \\ 97 & \text { Overview of Results } \\ 97 & \text { Ecological Profile } \\ 98 & \text { Local Cofán Communities } \\ 99 & \text { Vegetation and Flora } \\ 101 & \text { Amphibians and Reptiles } \\ 101 & \text { Birds } \\ 102 & \text { Large Mammals } \\ 102 & \text { Threats } \\ 105 & \text { Conservation Targets } \\ 106 & \text { Conservation Opportunities } \\ 108 & \text { Recommendations }\end{aligned}$

$\begin{array}{ll}114 & \text { Technical Report } \\ 114 & \text { Overview of Inventory Sites } \\ 119 & \text { Geology, Physiography, and Climate } \\ 122 & \text { Flora and Vegetation } \\ 135 & \text { Endemic Plants } \\ 138 & \text { Amphibians and Reptiles } \\ 141 & \text { Birds } \\ 148 & \text { Large Mammals } \\ 153 & \text { Appendices } \\ 154 & \text { 1) Vascular Plants } \\ 180 & \text { 2) Amphibians and Reptiles } \\ 182 & \text { 3) Birds } \\ 210 & \text { 4) Large Mammals } \\ 215 & \text { 5) Cofán Conservation Initiatives } \\ 220 & \text { 6) Conservation Opportunities in } \\ & \text { Adjacent Areas (La Bonita) } \\ 223 & \text { Literature Cited }\end{array}$


Roberto Aguinda (plants)

Cofán Survival Fund

Federación Indígena de la

Nacionalidad Cofán del Ecuador

Quito and Zábalo, Ecuador

Randall Borman A. (large mammals)

Cofán Survival Fund

Federación Indígena de la

Nacionalidad Cofán del Ecuador

Quito and Zábalo, Ecuador

cofan@attglobal.net

Daniel Brinkmeier (communications)

Environmental and Conservation Programs

The Field Museum, Chicago, IL, U.S.A.

dbrinkmeier@fieldmuseum.org

Felipe Campos Y. (amphibians and reptiles)

The Nature Conservancy

Quito, Ecuador

fcampos@ecnet.ec

Freddy Espinosa (field logistics)

Cofán Survival Fund

Quito, Ecuador

cofan@attglobal.net
Robin B. Foster (plants)

Environmental and Conservation Programs

The Field Museum, Chicago, IL, U.S.A.

rfoster@fieldmuseum.org

Debra K. Moskovits (coordinator)

Environmental and Conservation Programs

The Field Museum, Chicago, IL, U.S.A.

dmoskovits@fieldmuseum.org

Nigel Pitman (plants)

Center for Tropical Conservation

Duke University, Durham, NC, U.S.A.

ncp@duke.edu

Lily O. Rodríguez (amphibians and reptiles) Asociación Peruana para la Conservación de la Naturaleza (APECO), Lima, Peru

lilyrodriguez@pop.terra.com.pe

\section{Thomas S. Schulenberg (birds)}

Environmental and Conservation Programs

The Field Museum, Chicago, IL, U.S.A.

tschulenberg@fieldmuseum.org 


\section{COLLABORATORS}

Tatzyana Wachter (field logistics)

Environmental and Conservation Programs

The Field Museum, Chicago, IL, U.S.A.

twachter@fieldmuseum.org

Amelia Yiyoguaje (naturalist, field logistics)

Fundación para la Sobrevivencia del Pueblo Cofán

Quito, Ecuador

cofan@attglobal.net

\section{Cofán Community of Alto Bermejo}

Ecuador

Cofán Community of Chandia Na'e

Ecuador

Cofán Community of Doreno

Ecuador

Cofán Community of Sinangoe

Ecuador

Cofán Community of Zábalo

Ecuador

Patricio Fuentes and Ximena Aguirre

Fundación La Bonita-Sucumbíos

La Bonita, Ecuador

Ministry of the Environment

Quito, Ecuador

National Herbarium of Ecuador (QCNE)

Quito, Ecuador 
The Field Museum

The Field Muse um is a collections-based research and educational institution devoted to natural and cultural diversity. Combining the fields of Anthropology, Botany, Geology, Zoology, and Conservation Biology, museum scientists research issues in evolution, environmental biology, and cultural anthropology. Environmental and Conservation Programs (ECP) is the branch of the museum dedicated to translating science into action that creates and supports lasting conservation. With losses of natural diversity accelerating worldwide, ECP's mission is to direct the museum's resources—scientific expertise, worldwide collections, innovative education programs-to the immediate needs of conservation at local, national, and international levels.

The Field Museum

1400 S. Lake Shore Drive

Chicago, IL 60605-2496

U.S.A.

312.922.9410 tel www.fieldmuseum.org

\section{Cofán Survival Fund}

The Cofán Survival Fund (CSF) is a non-profit organization dedicated to the survival of the Cofán indigenous culture and its rainforest environment. Together with its Ecuadorian counterpart, the Fundación para la Sobrevivencia del Pueblo Cofán, the CSF supports an array of conservation and ecologically compatible development work in all seven Cofán communities in the Ecuadorian Amazon. The Fund's current projects are focused on biodiversity conservation and research, procuring legal rights and protection for traditional Cofán territory, the development of environmentally sound economic alternatives, and educational opportunities for young Cofán students.

Cofán Survival Fund

21118 Celtic Street.

Chatsworth, CA 91311

U.S.A.

818.468.6355 tel

www.cofan.org 


\section{Federación Indígena de la Nacionalidad Cofán del Ecuador (FEINCE)}

The Indigenous Federation of the Cofán Nation in Ecuador is the political arm of the Ecuadorian Cofán, representing the five legalized communities in the country-Chandia Na'e, Doreno, Dovuno, Sinangoe, and Zábalo-at the national level. FEINCE works to defend the human rights of the Ecuadorian Cofán, is a member of the larger umbrella groups supporting indigenous groups in Ecuador, the Confederation of the Indigenous Nationalities of Ecuador (CONAIE), and the Confederation of the Indigenous Nationalities of the Ecuadorian Amazon (CONFENIAE). The Federation is directed by a board of officers elected by the Cofán community every three years.

Lago Agrio, Ecuador

\section{National Herbarium of Ecuador}

The National Herbarium of Ecuador is a section of the Ecuadorian Museum of Natural Sciences, a government institution founded in 1978. The National Herbarium carries out programs of inventory, research and conservation of the Ecuadorian flora and vegetation, and houses a collection of 160,000 plant specimens and a botanical library of 2,000 volumes. The Herbarium serves as the national center for information on the flora and vegetation of Ecuador, with broad public access, and is among the principal scientific and cultural institutions of the country. It provides a public service to scientists, natural resource managers and students, and makes its voice heard in nationwide forums dealing with environmental and biodiversity issues. In the past two decades the Herbarium has provided training for hundreds of young Ecuadorian botanists, and carried out dozens of intensive botanical inventories throughout Ecuador.

Herbario Nacional del Ecuador

Casilla Postal 17-21-1787

Avenida Río Coca E6-115 e Isla Fernandina

Quito, Ecuador

593.22.441.592 tel/fax

qcne@q.ecua.net.ec 
Our rapid exploration of the rugged, wet slopes of the Serranias Cofán would not have been possible without the invaluable help of our Cofán guides and counterparts. The Cofán took charge of field logistics throughout the inventory, cutting trails to give the team access a wide range of habitat types, carrying loads, setting up camp, cooking, and keeping the expedition on schedule under difficult field conditions. For their tireless - often super-humanassistance we sincerely thank Alfonso Yiyoguaje, Lauriano Quenama, Nivaldo Yiyoguaje, Eliberto Alvarado, Ciro Alvarado, Sebastián Descanse, Jorge Criollo, José Omenda, Angel Omenda, Abrám Omenda, Aurelio Omenda, Fabian Omenda, Daniel Omenda, Eliseo Alvarado, José Descanse, Marceliana Alvarado, Marisol Alvarado, Beatriz Descanse, Alicia Descanse, Bacilio Descanse, Jesus Queta, Pablo Queta, and Tiberio Queta, along with the other residents of the communities of Alto Bermejo, Sinangoe, and Chandia Na'e, who warmly welcomed us to their forests.

Roberto Aguinda worked with the Bermejo and Sinangoc communitics for months bcforc our arrival, to sccurc smooth operations and set up the field stations (Estación Bermejo and Estación Sinangoe). During the inventory, Roberto's fluency in Cofán and botanical training resulted in an invaluable ethnobotanical collaboration with Bacilio Descanse, José Omenda, and others. Roberto's dedication, patience, and good humor will continue to be central to the success of the Cofán conservation efforts in the Andean foothills.

While Roberto was laying the groundwork in the field, Freddy Espinosa was securing permits in Quito, purchasing equipment, and keeping the lines of communication open between the Serranías Cofán and Lago Agrio, Quito, and Chicago. Freddy's enthusiasm and perseverance were key during the complex coordination before, during, and after the trip. His unflagging energy and the multiple miles he logged in drives between Quito and Lago Agrio were instrumental to the success of the expedition and of follow-up meetings in Lago Agrio and Quito. Freddy's wife, Maria Luisa Lopez, kept track of all accountings and activities, and facilitated the pre- and post-expedition meetings in Quito and Lago Agrio. Maria Luisa and Freddy's energy and deep interest in the project continue to be key in resolving big and small roadblocks along the way.

During the expedition, it was Amelia Yiyoguaje, with her tremendous efficiency and poise, who quietly coordinated our complicated logistics. Amelia made sure that all the campsites ran smoothly, were stocked with adequate supplies, and had the best in food. And Amelia managed to include the extra treats that are so appreciated under rough conditions in the field. Amelia's remarkable skills as a naturalist led to several important sightings for the herpetological, mammal, and bird inventories.

Despite their young age, Federico and Joshua Borman hiked all trails in the Bermejo region, helping to set up camp and even collecting an undescribed species of lizard. Felipe Borman helped with logistics, translations, observations, and cooking in the Bermejo camps.

In the Ministerio del Ambiente in Quito, we sincerely thank Laura Altamirano, for helping with follow-up to the recommcndations; Pati Galeano, for arranging the collecting pcrmits;
Danilo Silva, for encouraging the Serranías Cofan effort in the first place; and Hans Thiel, Roberto Ulloa, and Domingo Paredes, for continued discussions to implement the next steps for conservation. For their help in identifying plant specimens, we thank José Manuel Manzanares (bromeliads), Lorena Endara and Calaway Dodson (orchids), Jon Shaw (Sphagnum), Peter Jørgensen (Passifloraceae), Alejandra Jaramillo (Piper), Charlotte Taylor (Rubiaceae), Larry Skog (Gesneriaceae), Grady Webster (Euphorbiaceae), Lucia Lohmann (Bignoniaceae), and M. Lucia Kawasaki (Myrtaceae). David Neill and Rogelio Rojas were extremely helpful in the National Herbarium of Ecuador. Lou Jost reviewed sections of the manuscript, and Carlos Cerón was exceptionally generous in sharing all he knows about plants of the Sinangoe and Bermejo regions.

For help with bird records, we thank Douglas Stotz, who shared his notes from 1998 (Bermejo) and reviewed the entire list, and Mark B. Robbins, who shared his observations from 1993 (Bermejo oil fields).

Patricio Fuentes and Ximena Aguirre of the Fundación La Bonita-Sucumbíos gave us generous access to all of their information about the area surrounding La Bonita and La Sofia (see Appendix 6). We thank them for hours of invaluable discussions that led to some of our final recommendations.

Helga Karsten and Jennifer Eagleton helped organize and scan all slides. Helga, and Jessica Smith of Futurity, Inc., prepared maps from the digital satellite image data. Mary Giblin and Heike Betz helped scan all plant images. Rodrigo Sierra made available the satellite images in Figure 7 and Elsevier Science gave us permission to republish these images. Heinz Plenge gave us access to his spectacled bear slides, along with permission to use the photograph in Figure 1. Roy and Robin Toft were helpful with access to their bear photos (see cover credits). Jerry Coe accompanied the team to Ccuccono and contributed many excellent photographs. John Terborgh and the Center for Tropical Conservation at Duke University provided office space during the writing of the report.

Tyana Wachter, as always, was instrumental in overseas and in-country coordination. Tyana's capacity to facilitate complicated operations with charm and good humor never ceases to amaze us. Daniel Brinkmeier lent his magic in producing quick visuals for the presentations and developing community outreach materials from our results. We sincerely thank Jennifer $M$. Shopland for her invaluable input in editing part of the report, Angela Padilla for quick translations into Spanish, and Roberto Aguinda, Mike Cepek, Felipe Borman, Hugo Lucitante, and Toribio Aguinda for lightningfast work with the Cofán translations, which Mike spearheaded. We thank Nora Oleas, Douglas F. Stotz, and Susan Donoghue for their thorough reading of and comments on the entire manuscript. Jim Costello again performed miracles with our additional design requests. And Sophie Twichell, despite being on official leave during the expedition, managed to lend tremendous help.

We are deeply grateful to John W. McCarter, Jr., and Avecita Chicchón for their strong interest and support. Funding for this rapid inventory came from The John D. and Catherine T. MacArthur Foundation and from The Field Museum. 


\section{REPORT AT A GLANCE}

Dates of field work:

Region surveyed:
24 July-16 August 2001

Three areas in the eastern foothills of the Ecuadorian Andes, between 450 and 2,341 m elevation: the headwaters of the Bermejo and Chandia Na'e Rivers, including the Sur Pax ridge complex; Cerro Shishicho and the forests at its base, near the Cofán community of Sinangoe; and the Ccuccono River basin (Figure 2).

Organisms surveyed: Vascular plants, reptiles and amphibians, birds, and large mammals

Highlight of results:

The rapid biological inventory team identified significant opportunities for conservation in the Bermejo and Sinangoe region: large expanses of endangered foothill forests that stretch unbroken from the Amazonian lowlands to above $2,300 \mathrm{~m}$ in the Andes. The forests we inventoried contained a spectacularly diverse mix of lowland and montane biota, including a large number of undescribed and endemic species protected nowhere else. Historically under the de facto management and protection of small Cofán communities who have inhabited the region for centuries, these forests now face fragmentation and clearing as streams of colonists spread out from the new Interoceanic Highway.

During our three weeks in the field, the inventory team registered many rare or geographically restricted species in the four groups of organisms sampled. Several of the species are new to science, others are new for Ecuador, and many are apparently endemic to the area. A brief summary of results follows.

Vegetation and flora: Extremely wet, diverse forests on clay soils ascend from 400 to more than $2,300 \mathrm{~m}$ in elevation. The region is a crossroads for the lowland Amazonian and montane Andean floras, with a conspicuous shift between the two at $1,500 \mathrm{~m}$. A distinct, slightly stunted vegetation grows on scattered outcrops of acidic rock throughout the region. Regenerating forest of varying ages covers large areas subject to repeated landslides, especially along the Bermejo River and in the eastern half of the Sinangoe area.

The team identified 800 species of plants, collected 1,000 herbarium specimens, photographed 600 species, and sampled nearly 1,000 trees and shrubs in transects. We estimate the region's flora to contain 2,000 to 3,000 species. Ten new plant species already have been confirmed; we expect at least ten others. One new bromeliad species, apparently a favorite food plant of spectacled bears, carpeted whole sections of the higher ridges of Cerro Sur Pax (Figure 4B). The region appears to be the world center of diversity for the coffee family, Rubiaceae, with more than 39 genera and 129 species present. It is also exceptionally rich in Orchidaceae, Gesneriaceae, Sapotaceae, and pteridophytes (ferns and their relatives). Many of these species are narrowly endemic to this section of the Andes. Half of all the palm species known from eastern Ecuador were recorded in the area. 


\section{REPORT AT A GLANCE}

Large mammals: The team registered 42 species of large mammals during the inventory, eight of which are listed in CITES Appendix I (globally threatened species); 17 others are listed in Appendix II (potentially threatened). At least 12 primate species inhabit these forests, as do large populations of spectacled bear and lowland tapir. We observed what may be a new species of squirrel, and local reports suggest that other undescribed mammal species-including an opossum and a miniature woolly monkey-might occur in the area.

Birds: We found a surprisingly rich bird community in the upper hill forests of the region, including large populations of many species that are rare or threatened elsewhere in the Andes. The team recorded 399 bird species out of an estimated regional total of 700 and registered several significant range extensions. One species on the list is new for Ecuador (Tinamus osgoodi, the Black Tinamou), and another was known previously from only three sites (Myiopagis olallai, the Foothill Elaenia).

Amphibians and reptiles: Our herpetological survey was confined to the Sinangoe area, where we documented 31 species. The list includes 17 frogs and toads, six snakes, five lizards (including what is likely a new species in the genus Dactyloa, Figure $5 \mathrm{E}$ ), a caecilian, and a salamander. We expect that several additional new species await discovery in the higher-elevation forests of the region.

Main threats:

The new Interoceanic Highway, connecting Tulcán with Lago Agrio (Figure 2A), has bisected this once continuous stretch of foothill forests, and waves of invading colonists are rapidly clearing and fragmenting the area. Commercial logging interests have begun to cut hardwoods along the road, and incursions into the Cayambe-Coca Ecological Reserve for illegal hunting and fishing are intensifying. The most immediate threat is that spreading, disorganized development will reach the intact forests to the east and south of the road.

Current status:

The Bermejo area has minimal legal protection, mostly under Patrimonio Forestal status, but that designation is too weak to provide an effective defense against the spreading colonization. As this report was being written, Ecuador's Ministry of the Environment expressed their intent to establish a new, 50,000 ha ecological reserve in the Bermejo area (Reserva Ecológica Cofán de Bermejo) to be declared officially in January 2002. Cerro Shishicho and the Ccuccono River are currently within the boundaries of the Cayambe-Coca Ecological Reserve (Figure 2), and are managed in part by the Sinangoe Cofán community under a convenio with the Ministry of the Environment. 


\section{REPORT AT A GLANCE}

Principal

recommendations

for protection and

management:

1) In the Bermejo area, designate formal conservation status for the intact forests in the headwaters of the Bermejo, Chandia Na'e, and San Miguel Rivers and throughout the Sur Pax ridge complex. Modify the current borders of the Cayambe-Coca Ecological Reserve to include a new 50,000-ha annex in the Bermejo area as a Cofán-administered "community reserve" (Reserva Comunitaria Cofán), managed in collaboration with the Ministry of the Environment (Figure 2; see also Current Status).

2) Establish a high-profile, effective conservation presence in the Bermejo region, with clear delimitation and posting of the new reserve. Train a small team of Cofán guards to patrol the area, especially along the proposed western border, closest to new settlements along the Interoceanic Highway.

3) In the Sinangoe region, strengthen the existing collaboration between the Ministry of the Environment and the Cofán community. Expand the management authority of Cofán park guards to prevent incursions into the Cayambe-Coca Ecological Reserve along the Aguarico, Cofanes, and Due Rivers. Increase patrolling of the area and construct new, strategically placed trails and guard stations. Post prominent signs at access trails along the borders of the reserve, with clear reminders of the area's conservation status and regulations.

4) Establish a biological corridor to connect the proposed Bermejo annex with the rest of the Cayambe-Coca Ecological Reserve. Extend the current northern border of the park to the vicinity of La Sofía and La Bonita, in cooperation with the local communities and the authorities of Sucumbíos Canton (Figure 2).

\section{Long-term conservation} benefits:
1) A globally important new conservation area linking protected montane forests from Colombia to central Peru

2) A model of successful, science-based conservation stewardship of ancestral lands by an indigenous community

3) Effective protection of a newly vulnerable sector of the Cayambe-Coca Ecological Reserve, one of the largest conservation areas in Ecuador

4) Preservation of the major watersheds in the Sucumbios region 


\section{Why the Serranías Cofán?}

Follow the equator westwards across the Amazon basin to the foothills of the Andes, where the most diverse mountain range in the world rises out of the richest lowland forest on Earth. Here, thunderstorms coming off the wet lowlands run head-on into the Andean massif, carving deep mountain gorges where Amazonian rivers begin their lives as white-water torrents. Twisted ridges and isolated peaks steam on the landscape like a geological train-wreck, and everywhere are reminders of the mountain-building in progress: smoldering volcanoes on the horizon, mountainsides swept clean by avalanches, and active faultlines beneath your feet.

These are the Serranías Cofán, rising up from the Amazonian lowlands in a complex tangle of topography and biodiversity. We were drawn to them because the distinctive climate and geology of their transitional forestsintermediate between the snowcapped peaks to the west and the hot Amazonian plains to the east-have fostered unique biological communities, where plant and animal communities from the lowland forests rub shoulders with the Andean flora and fauna, in the company of hundreds of endemic and undescribed taxa. In a day's climb here, a biologist can eat breakfast in an Amazonian forest and dinner in an Andean one, stopping for lunch in the narrow, mid-elevation ribbon where two of the world's most diverse biotas overlap briefly in a mix of species found nowhere else on Earth.

But the situation in these foothills is increasingly critical. A new highway, opened in August 2000, has split the formerly contiguous forests of Bermejo and Sinangoe in two. Colonization, small-scale clearing, and logging are gaining momentum in the adjacent forests, and the front has already reached the Bermejo Valley. Even at the highest point we surveyed, the 2,275-m summit just south of Cerro Sur Pax, we could hear chainsaws working in the colonist clearings below. Our explorations, collections, and recommendations for action were all spurred on by the recognition that some of these forests are months away from destruction. 


\section{Overview of Results}

Contributors/Authors: Nigel Pitman, Randall Borman A., Debra K. Moskovits, Robin S. Foster, Thomas S. Schulenberg, Lily O. Rodríguez, Jennifer M. Shopland, Felipe Campos

\section{ECOLOGICAL PROFILE}

Seen from space on satellite images, the forests around Bermejo and Sinangoein the Andean foothills of northeastern Ecuador-look like uninhabited wilderness. But the picture is misleading. These forests have been inhabited for centuries by the indigenous Cofán people, who now live in four small communities along the Aguarico, Bermejo, and Chandia Na'e Rivers. For three weeks in July and August 2001, our inventory team, which included several Cofán naturalists, focused on the plants and animals at three sites in these foothills: (1) the headwaters of the Bermejo River, rising from the 450-m valley floor to the summit of 2,341-m Cerro Sur Pax, near the Colombian border; (2) the Shishicho ridgeline, near the confluence of the Cofanes and Aguarico Rivers, and the forests at its base; and (3) the watershed of the Ccuccono River (Figure 2). Our goal was not a comprehensive inventory of the area-impossible in such a short time-but instead a portrait of its biological communities detailed enough to allow us to assess their conservation value for Ecuador and the world.

Much of what we saw was unmapped terrain for scientists-who never before had visited Cerro Sur Pax, Cerro Shishicho, or the Ccuccono River drainage-but it has been familiar to local Cofán inhabitants for years. The team documented at least 1,000 species of plants out of an estimated regional flora of 2,000 to 3,000, sighted 399 species of birds out of an estimated regional avifauna of 700, and registered 42 of the 46 species of large mammals expected for the region. In such a poorly studied landscape, we were not surprised to find that a large proportion of the species we encountered were new to Ecuador or totally unknown to science. Even at this early stage, before the bulk of our plant specimens have been identified, at least ten of them have been confirmed by taxonomic specialists as new to science; at least one represents a genus never before collected in Ecuador. We registered a new species of bird for Ecuador, an undescribed species of lizard, and large populations of mammal species that have been hunted nearly to extinction in large areas of eastern Ecuador. A large number of the bird and mammal species we documented are rare or threatened elsewhere in their ranges, and many were more 
abundant in the Serranias Cofán than we had seen anywhere else.

In the following sections we summarize the principal results of our survey and outline our recommendations for conservation action. In most respects this is an abridged version of the technical report, which begins on page 114 . We begin this overview with the caveat that the landscape described here is in a constant state of renewal, and is subject to change at any moment. Located in an active earthquake zone, adjacent to one of the eastern Andes' liveliest volcanoes, swept periodically by massive landslides and flooding events, the forests here are probably more dynamic at a large scale than most other sites in the Neotropics. As recently as 1987, a massive earthquake stripped all of the forest from several thousand square kilometers of terrain just south of the foothills region. Satellite images of the area are dotted with the scars of recent landslides and collapsing cliffs (Figure 2), and in some areas tangled young forest recovering from recent washouts covers a significant portion of the landscape.

\section{LOCAL COFÁN COMMUNITIES}

These foothill forests have been inhabited by the Cofán people for as long as records have existed, and probably for several centuries prior to the arrival of Europeans. Spanish conquistadors scouting the area in the 16th century came into contact with the Cofán as early as 1536 , as described in Juan de Velasco's Historia del Reino de Quito. Almost exactly 400 years later, when oil companies initiated large-scale drilling in northeastern Ecuador, the Cofán were still the predominant indigenous group in the area.

Also known as the $\mathrm{A}^{\prime} \mathrm{i}$, the Cofán people are indigenous to the Aguarico and San Miguel watersheds of northeastern Ecuador and southern Colombia. The Cofán language is linguistically unique, with no close living relative, though it shares some features with the Chibchan languages of central Colombia and western Ecuador. Now one of eight indigenous groups living in Amazonian Ecuador, the Ecuadorian Cofán number about 1,000 native speakers in seven isolated communities in the Andean foothills and Amazonian lowlands. Nearly a third of these-about 320 peoplelive in four communities in the area visited by the rapid inventory team in 2001. Given the tiny "footprint" of these four communities and the immensity of the forests surrounding them, most of the foothills remains wilderness, with a regional population density of less than half a person per square kilometer. The Cofán's knowledge, use, and historical residence of the area, and their growing involvement in conservation initiatives (see Appendix 5), however, make them critical players in the long-term conservation of the region.

The largest and most accessible Cofán community in the region is Sinangoe, where approximately 150 people live on the south bank of the Aguarico, between the mouths of the Candue and the Sieguyo Rivers, and just across the river from the new Interoceanic Highway (Figure 2A). Because the community lies inside the Cayambe-Coca Ecological Reserve, it has long attracted the interest of biologists and conservationists (Cerón et al. 1994, Altamirano and Quiguango 1997, Mena 1997). Cofán park guards patrol a large segment of the reserve, under an agreement with the Ecuadorian Ministry of the Environment. The Sinangoe community is working on a management plan that balances its aspirations with the common, longterm goal of protecting the reserve. We based part of our inventory of this region at a field station that the Cofán built recently - for research and surveillance- at the mouth of the Sieguyo River (Figure 6C).

Most of the day-to-day activity in Sinangoe is still devoted to small-scale agriculture, hunting, fishing, and craft-making for tourism. Similar activities occupy the three smaller Cofán communities in the Bermejo River valley, where they are complemented by the harvest of medicinal forest products like uña de gato (the liana Uncaria tomentosa, Rubiaceae) and sangre de drago (the tree Croton lechleri, Euphorbiaceae). We did not visit the two communities in the lower half of the basin (Chandia Na'e and Tayosu Canqque, each with about 80 people and visible on satellite images as 
tiny clearings surrounded by forest; Figure 2). We did visit Alto Bermejo, a village of just 12 people near the headwaters of the Bermejo River, basing the first stage of our inventory at the new field station recently constructed there.

\section{VEGETATION AND FLORA}

The greatest botanical surprise upon arriving in the Cofán foothills-so close to major cities like Lago Agrio and Tulcán, and bordered by two major highways - was to find it an essentially untouched wilderness. These forests have remained exceptionally well-preserved despite a long history of Cofán occupation, and they have not yet been cut off from large adjacent wilderness areas in the Andes and Amazonia. From the vantage point of our 1,200m campsite, overlooking the Bermejo valley, we had a spectacular view of forest stretching unbroken to the horizon. It is only along the new Interoceanic Highway that one sees the forest degradation and fragmentation that are so common elsewhere in the tropics (Figure 2A).

Two of the largest floras on Earth-the Amazonian and the Andean-come together here to produce an extremely diverse and complex plant community. We registered at least 1,000 species out of a regional flora we estimate at between 2,000 and 3,000 (Appendix 1). For the purpose of this report, we divide the landscape into three major forest types: one at lower elevations (mostly Amazonian taxa), one at the highest elevations (mostly Andean taxa), and one at intermediate elevations (a complicated mixture of the two). This altitudinal zonation appears to be driven more by climate than other factors. The most conspicuous transitions between lowland and upland floras occur between 950 and $1,500 \mathrm{~m}$ at the elevations where cloud cover persists almost yearround, rainfall is highest (OAS 1987), and sunlight becomes a scarce commodity. We did observe some significant heterogeneity in forest composition and structure within each of these major divisions (i.e., from site to site in the same elevational band), but those differences were usually not pronounced. This is probably because there are few instances of "extreme" geological or soil conditions in the region, like those seen, for example, in the Cordillera del Cóndor (Schulenberg and Awbrey 1997).

\section{LOWER HILL FOREST (400-950 m)}

The lowest-elevation forests in these foothills are an extension of the famously diverse lowland forests of eastern Ecuador. Nearly all of the plant families and genera found here are shared with Amazonian forests a few kilometers to the east, like Yasuní National Park and the Cuyabeno Wildlife Reserve. Most individual species also are shared, though several taxa do show a strong preference for the wetter climate at the base of the Andes. As in the rest of eastern Ecuador, local diversity of trees and lianas here is among the highest on Earth. In one of our canopy tree transects in the lower hill forest, we recorded nearly 60 different species in a sample of 100 trees. As a result of this diversity, most individual tree and liana species grow at infinitesimal densities. Palms are a dominant family, along with legumes, Myristicaceae, Vochysiaceae, Meliaceae, and several others. The most common tree here, as in most of eastern Ecuador, is the palm Iriartea deltoidea (Figure 3E).

Already evident at this elevation is a feature that sets apart the Cofán foothills flora from any other forests we have seen: an astonishing diversity of species in the coffee family, Rubiaceae. It is hard to find a place in this forest-whatever the elevationwhere one is not in sight of a dozen different species of rubiaceous shrubs, treelets, and trees. Overall we recorded more than 129 species of this family, in at least 39 different genera. Many of these are unknown to science. Seventeen percent of the Psychotria species we collected during a trip to this region in 2000 , for example, have since been confirmed as new species.

The high, red clay escarpments that are such a dramatic feature of the Bermejo River valley also appear to support a distinctive plant community along their clifftops. Soil and climate conditions on these 
ridgelines are quite different from those elsewhere in the lower foothills forest: trees at the top of the escarpment intercept much of the moist air blowing up the valley, and the constant erosion may mean that acidic outcrops are especially close to the surface. We found several intriguing species here and nowhere else, including the tree Humiriastrum diguense (Humiriaceae), characteristic of acidic soils, and a beautiful, unidentified wildflower in the Gentianaceae.

\section{UPPER HILL FOREST (950-1,500 m)}

At higher elevations, community composition begins a gradual, though dramatic, shift. Tree richness progressively declines, while the diversity of terrestrial herbs and epiphytes explodes. It is here, too, that one starts to record species turnover along the elevational gradient. Every step on an ascending trail at these elevations appears to cross the boundary of some species' range-lowland species vanish one by one, while exclusively highland taxa begin to appear. In Bermejo, as much as $20 \%$ of the canopy at these higher elevations was taken up by Billia rosea (Hippocastanaceae), a large-seeded, mostly montane tree that is frequent in the region at least southwards to Sumaco (Figure 4D). In contrast, the dominant tree in Ccuccono, accounting for $26 \%$ of our transect and visible for kilometers around because of its distinctive orange flushing leaves, was Dacryodes olivifera (Burseraceae).

Several of the ridges we visited in the higher portions of the upper hill forest-especially in the Sinangoe area-were topped with slightly stunted vegetation. The flora on these ridgetops is characteristic of acidic soils, probably because rocky outcrops are exposed here. On one such site in Bermejo, we collected Purdiaea nutans (Cyrillaceae), a treelet whose distribution in Ecuador was previously restricted to the acidic mountains in the southern provinces. On the Shishicho ridgeline, we collected the giant herb Symbolanthus calygonus (Gentianaceae), similarly known in Ecuador only from the southern provinces, and the shrub Basistemon (Scrophulariaceae), the first record of this genus in Ecuador (Jørgensen and LeónYánez 1999). Also on Shishicho, just under the highest summit, we found a new species of terrestrial bromeliad in the genus Pitcairnia (J. M. Manzanares, pers. comm.). As additional collections from these ridges are identified, we anticipate several other such range extensions and new species to emerge.

\section{MONTANE FORESTS (ABOVE 1,500 m)}

In the highest forest type, the flora shifts definitively from mainly lowland genera to mainly montane genera. High-elevation families like Podocarpaceae, Brunelliaceae, Cunoniaceae, and Clethraceae make their appearance in the canopy, though Billia rosea remained dominant in a transect on the 1,900 -m ridge below Cerro Sur Pax. The forest canopy is noticeably lower and wetter than at lesser elevations; epiphytes weigh down the branches and filmy ferns and mosses carpet the forest floor. This same transect registered only 24 species in a sample of 100 trees.

This declining diversity in the tree canopy is richly compensated by an explosion of diversity in terrestrial and epiphytic herbs. On the narrow ridge just below Sur Pax we collected at least a dozen species of bromeliads; the most common of these, a terrestrial Guzmania that practically carpeted some sections of the trail, is new to science (J. M. Manzanares, pers. comm.; Figure 4B). Orchids, ferns, and aroids are also very abundant and very diverse at these elevations. The rich herbaceous community is especially apparent on the 2,275-m summit just south of Sur Pax, where the low, open, and disturbed forest-punished repeatedly by lightning strikes-is practically buried under an extravagance of epiphytic mosses and wildflowers.

\section{ENDEMIC PLANTS}

Observations in the field and experience from adjacent regions indicate that a large proportion of these herbaceous species, particularly in the families Orchidaceae, Bromeliaceae, Araceae, and Gesneraceae, are endemic (geographically restricted) to this section 
of the Andes. More than 100 plant species in the Cayambe-Coca Ecological Reserve, for example, have never been collected outside of Ecuador. At least 15 of the plant species we registered during this inventory are also endemic to the country, and this number will probably soar past 100 as additional identifications are made. Perhaps the best example of a species with a very restricted range in the Cofán foothills is a shrub we collected in the guava family (Myrtaceae). This species, currently being described as Calyptranthes ishoaquinico, was previously used by Cofán communities for comingof-age ceremonies, and the Cofán confirmed that the plant had never been found anywhere but a small area in the vicinity of the new Sinangoe field station (Figure 4A).

\section{AMPHIBIANS AND REPTILES}

The forests we studied are $20 \mathrm{~km}$ to the west of the richest herpetofauna locality ever documented-Santa Cecilia, Ecuador (Duellman 1978, 1988). The reptile and amphibian community at Bermejo and Sinangoe may be comparably diverse, if not more diverse, as it combines most elements of the lowland fauna at Santa Cecilia with a different suite of higher-elevation species restricted to the Andean foothills. In addition, the Serranías Cofán protect many of the species that became locally extinct at Santa Cecilia when the last of its forests were destroyed in the 1990s. (Their disappearance is documented chillingly in the paired satellite images in Figure 7.)

Although the herpetological team worked only in the Sinangoe area and did not survey the Bermejo foothills, we registered 31 species during the trip (Appendix 2). The list includes 17 frogs and toads, six species of snakes, a caecilian (photographed by the team in Bermejo), a salamander, and six lizards, including an apparently undescribed species in the genus Dactyloa (Figure 5E). Of these, three snakes, two lizards, a frog, and the salamander are apparently restricted to the upper hill forests. One of these, the lizard Cercosaura ocellata, is a species never before recorded in Ecuador. Elevations above 1,500 $\mathrm{m}$ are almost certain to harbor herpetological communities different from those we were able to sample, and we expect that several additional new species await discovery there.

As in other amphibian communities around the world, population declines and disappearances have been recorded just south of the Serranías Cofán and may be spreading through the apparently pristine areas we visited. The situation appears particularly critical for several species of glass frogs (Centrolenidae) and poison-arrow frogs in the genus Colostethus, which have disappeared from some streams and waterfalls in the Cayambe-Coca Ecological Reserve over the last decade (F. Campos, pers. obs.). We encountered only one species in this group.

\section{BIRDS}

Our brief ornithological survey of the forests around Bermejo and Sinangoe indicates that they should be considered one of the most important bird conservation areas in eastern Ecuador. The upper elevations in particular appear to be a refuge for many birds considered rare or threatened elsewhere in the Andes. We registered significant range extensions, both elevational and geographic, for many species, and many rare birds were gratifyingly frequent and abundant in the area. For example, never before had we seen such large populations of Campylopterus villaviscensio (Napo Sabrewing), Phylloscartes gualaquizae (Ecuadorian Tyrannulet), and Snowornis subalaris (Gray-tailed Piha).

We recorded 399 bird species and estimate a regional total of 700 (Appendix 3). The avifauna of the upper hill forest was especially remarkable for its completeness; in just a few days there we encountered nearly all of the species expected at this latitude and these elevations. In other words, an ornithologist hiking up from the valley floor in Bermejo can pass from a complete lowland Amazonian bird community into a complete hill forest avifauna in a matter of 
hours-an increasingly rare experience elsewhere in the Andes.

Perhaps our most notable sighting was of the Foothill Elaenia, Myiopagis olallai, a bird described so recently by scientists (Coopmans and Krabbe 2000) that it does not even appear in the new volume The Birds of Ecuador (Ridgely and Greenfield 2001). Although $M$. olallai had been known from just three localities in Ecuador and Peru, this new register, less than $10 \mathrm{~km}$ from the Colombian border, almost guarantees that the species eventually will be recorded in that country as well. Just as significant was our sighting of the Black Tinamou, Tinamus osgoodi, previously known only from one site in Colombia and another in southern Peru. Although ornithologists never had recorded this species in Ecuador before we saw and heard it on the Shishicho ridge, the Cofán accompanying us reported having seen the same species as far south as the San Rafael falls.

Throughout the area, and particularly at higher elevations, we encountered relatively large populations of showy bird species that are typically vulnerable to hunting, including the Military Macaw (Ara militaris), Salvin's Curassow (Crax salvini), and the Wattled Guan (Aburria aburri). The implication is that the Cofán foothills may be an important sanctuary for species whose populations are declining over large areas elsewhere in eastern Ecuador.

\section{LARGE MAMMALS}

We were able to carry out an intensive inventory of large mammals during the trip, partly because several Cofán with decades of experience tracking animals in these forests accompanied the team in the field. We found a very diverse, intact mammalian fauna, including 12 species of monkeys and large populations of several globally threatened species. Perhaps the most significant individual sighting was of the rare Shorteared Dog, Atelocynus microtis, seen here at the highest elevation $(1,200 \mathrm{~m})$ recorded for the species.
We confirmed the presence of 42 species of large mammals in the area, more than half of these globally threatened or rare (see Appendix 4). Twentyfive species on the list are included in CITES Appendices I (globally threatened) or II (potentially threatened), including the 12 species of monkeys. As with the bird community (see above), many of these vulnerable species are abundant in the area. Especially common were spectacled bears (Tremarctos ornatus, Figure 1), tapirs (Tapirus terrestris), woolly monkeys (Lagothrix lagothricha), and collared peccaries (Tayassu tajacu). On the Shishicho ridge, just across the river from the new Interoceanic Highway and a few kilometers from the town of Puerto Libre, we encountered groups of monkeys daily.

We were unable to confirm persistent reports of a new species of miniature woolly monkey from the high-elevation forests around Cerro Sur Pax. We did find evidence, however, of other potentially undescribed mammal species in the region, especially a large, gray squirrel. It is worth noting, as an example of how poorly known the area remains, that one of the favorite food plants of the spectacled bear on Cerro Sur Pax, a terrestrial bromeliad it strips for the tender leaf bases, is itself an undescribed species (Figure 4B).

\section{THREATS}

As in most tropical forests around the world, the biological communities of the Cofán foothills face a bewildering array of threats. The situation in these forests has grown increasingly ominous since they were bisected by the Interoceanic Highway, completed in August 2000 (Figure 2A). This major road, the first paved connection between Andean Ecuador and lowland Amazonia, is likely to be a heavily traveled route for decades to come. For conservationists in the region, the immediate challenge is to confine the coming flood of human activity to a narrow corridor of land bordering the highway, where it will not endanger biological communities in adjacent Cofán lands and the 
nearby Cayambe-Coca Ecological Reserve.

Historically, most forest destruction along new roads in Ecuador has resulted from rapid, disorganized colonization and small-scale forest clearing by farmers and cooperatives. Figure 7, adapted from a study by Sierra (2000), demonstrates just how quickly this sort of devastation has taken place just a few kilometers to the east of Bermejo, in the Lago Agrio-CocaShushufindi area. Along the new Interoceanic Highway, colonists have already begun to clear forest for cattle ranching, crop land, and small-scale timber harvesting. The whine of chainsaws was audible even at our highest-elevation campsite, which looked down on newly felled plots along the Chingual River. Between Puerto Libre and La Bonita, large areas have been cleared for the cultivation of naranjilla fruit (Solanum quitoense, Solanaceae). This crop is notoriously susceptible to attack by root-knot nematodes; in most cases farmers must choose between applying large amounts of pesticides and abandoning the crop after a few harvests (National Research Council 1989). Once the marginal agricultural capacity of these areas has been exhausted, the deforested lands-many of them on remarkably steep slopes-will pose a great danger to the entire Aguarico watershed (and to the new highway) for many years to come. The bare, quickly eroding clay slopes will only exacerbate the region's natural tendency for massive landslides and flooding. Mixed in with the flood of small-scale colonization come threats associated with larger commercial interests. For example, since the new road provides a quick route to timber mills in the Andes, logging companies already have begun to harvest high-value hardwoods in the adjacent forests. Cable-cars ferrying loads of lumber from forested hills down to the road are now a common sight in the region. We predict that most of the valuable hardwoods within a kilometer of the road will have been cut down by the end of 2002 . Once that happens, both small- and large-scale logging operations will move deeper into the forest, via an ever-spreading network of small logging roads throughout the zone.
Even in places far from the new highway, where forests remain standing, the influx of hunters and fishermen can seriously compromise the integrity of biological communities. Commercial hunting of deer, paca, and tapir appears to be on the rise. Even rather small-scale hunting-whether for food (peccaries, large monkeys, tapirs, curassows and other large birds, deer), protection of livestock (jaguars and pumas, birds of prey), or for sale (jaguar pelts, parrot feathers) can cause serious imbalances in the area's animal populations, leading to long-term disruptions of the regional ecosystem. For example, removing most of the large, fruit-eating birds and monkeys from otherwise intact forest could eventually lead to a serious collapse in regional tree diversity. The resulting breakdown in the forest's seed-dispersal mechanism makes it much harder for seeds and seedlings to escape herbivores and diseases (Janzen-Connell effects) concentrated around their parents (Janzen 1970, Connell 1971, Terborgh et al. in press).

Indigenous communities are just as capable of overhunting as more recent colonists, and this is a major threat in other Amazonian forests (Peres and Zimmerman 2001). A well-documented example from eastern Ecuador is Mena et al.'s (1997) description of the unsustainably high woolly monkey harvests in forests around Huaorani communities. Likewise, a decline in piping guan populations around the Cofán community of Zábalo recently led hunters there to implement a strict program of seasons and limits ( $R$. Borman, pers. obs.). Given the small population density in the Cofán community of Bermejo and the small footprint of the community of Sinangoe, overhunting by indigenous inhabitants does not appear to be a severe threat at this time, but it may become one as the communities continue to grow and change.

In Bermejo, the long-term conservation outlook depends greatly on the development plans of the oil company that operates the oilfields just a few kilometers southeast of the Alto Bermejo community. Tecpecuador, a subsidiary of the Argentinian company Tecpetrol, produces 7,700 barrels of petroleum a day 
in the Bermejo field and holds a concession (permission to explore and develop petroleum resources) that extends throughout the lower Bermejo River valley, as far as the Cofán community of Chandia $\mathrm{Na}$ 'e. A largescale expansion of oil operations in the future would bring with it many of the same problems associated with the new Interoceanic Highway, in addition to the potential for oil spills and chemical leaks like those that have poisoned huge areas of ancestral Cofán forests around Lago Agrio and Cuyabeno over the last 40 years. Since the completion of the new Interoceanic Highway, colonization and forest clearing have intensified along the roads in the Bermejo oilfield. Large stretches of forest were cleared in the six months leading up to our inventory (February-August 2001); stacks of recently cut timber dot the roadside. It is not clear at this point whether oil company operations will expand in the region, what form that expansion might take, or which areas would be most affected, but this is clearly an important threat to monitor.

In the Sinangoe region, the greatest threat is an intensification of existing pressures along the eastern border of the Cayambe-Coca Ecological Reserve. Unauthorized hunting and fishing expeditions into the reserve by colonists are common at present, though they are probably still too small and infrequent to pose much danger to the animal communities there. One exception is the occasional use of dynamite and poison to harvest fish in the Ccuccono and Cofanes Rivers, which can be devastating even on a small scale. These incursions threaten to become much more severe in the near future, especially as game becomes scarce along the new highway. If, as we recommend below, a new protected area is established in the highlands north of the Bermejo River valley, similar incursions will be a major threat there: much of the newly claimed land along the highway is only a short hike from the proposed western border.

Small-scale mining is another occasional activity in the Cayambe-Coca reserve, mostly along the rocky sandbars of the Cofanes River. During our inventory we met one colonist family traversing the
Shishicho ridge on a week-long mining trip. The activity is probably too scattered and infrequent at present to pose a real threat, but a large strike could set off a flurry of activity, or even attract the interest of commercial mining companies, with very dangerous consequences for the forests in and around CayambeCoca. Commercial mining companies have shown intermittent interest in the mineral resources of both the Bermejo and Sinangoe regions for several years, especially when the market value of precious metals is high (R. Borman, pers. obs.).

Augmenting these hazards to the region's forests is the civil war across the border in Colombia, with great potential for disrupting long-term plans in Ecuadorian frontier communities. Satellite images of the border area make heartbreakingly clear how grim the conflict has been for Colombia's biological communities (Figure 2). Approximately $80 \%$ of the lowland forests north of the border have vanished under a sea of coca plantations, many of these now defoliated by the Plan Colombia initiative. If history had placed the Colombian border some $25 \mathrm{~km}$ south of its present position, much of the forest we describe in this report would have been totally destroyed by now. 


\section{CONSERVATION TARGETS}

The following species and communities are of primary focus for conservation within the Cofán foothills region because of their : 1 ) global or regional rarity, 2) influence on community dynamics, and/or $3)$ importance in ecosystem processes, like watershed protection.

\begin{tabular}{|c|c|}
\hline Organism Group & Conservation Targets \\
\hline \multirow[t]{6}{*}{ Biological communities } & $\begin{array}{l}\text { Low-stature ridgeline forests and unique plant communities growing on exposed } \\
\text { acidic rock }\end{array}$ \\
\hline & $\begin{array}{l}\text { Upper hill forests and montane forests, with high concentrations of restricted- } \\
\text { range species }\end{array}$ \\
\hline & Streams and rivulets (important habitats for fishes, amphibians, and reptiles) \\
\hline & $\begin{array}{l}\text { Diverse lowland tree communities with populations of Cedrelinga (tornillo), } \\
\text { Cedrela (cedro), and other valuable and overharvested timber species }\end{array}$ \\
\hline & Isolated paramo in the Cordillera Murallas, west of Bermejo (Figure 2) \\
\hline & $\begin{array}{l}\text { Functional, representative samples of all habitat types; stretches of contiguous } \\
\text { forest types spanning the entire elevational gradient }\end{array}$ \\
\hline
\end{tabular}

Plants
Cedrela odorata and C. fissilis (cedro, Meliaceae)
Dacryodes olivifera (copal, Burseraceae)
Billia rosea (Hippocastanaceae)
Endemic taxa (plant species unique to Ecuador or with restricted geographic
ranges), especially in the families Orchidaceae, Bromeliaceae,
Gesneriaceae, and Araceae

Reptiles and amphibians

Enyalioides cofanorum and other lowland species formerly shared with Santa Cecilia but now extinct there

Centrolenidae (glass frogs) and Colostethus (poison-arrow frogs) species potentially experiencing population declines

Herpetological communities at higher elevations

$\begin{array}{ll}\text { Birds } & \text { Bird communities of upper hill forests } \\ & \text { Endemic and elevation-restricted birds } \\ & \text { Large gamebirds (e.g., Crax, Aburria) } \\ & \text { Large parrots, especially Ara militaris }\end{array}$

Mammals

Primates (particularly Lagothrix lagothricha and Ateles belzebuth)

Seed dispersers and seed predators

Atelocynus microtis (short-eared dog; rare)

Other CITES I and CITES II species:

Lontra longicaudis (neotropical otter), Panthera onca (jaguar),

Priodontes maximus (giant armadillo), Speothos venaticus (bush dog),

Tapirus terrestris (tapir), Tayassu pecari (white-lipped peccary),

Tremarctos ornatus (spectacled bear) 
Even the short time we spent in the field was sufficient to demonstrate that the forests around Bermejo and Sinangoe have outstanding biological value and merit long-term protection. Beyond protecting important conservation targets (see above), the Serranías Cofán offer the rare opportunity to conserve intact biological communities along a 2,000 - m elevational gradient.

A strong new reserve here would also protect unique Colombiancentered biota - not found anywhere else in Ecuador - that have been obliterated by deforestation and coca fields to the north of the international border. Following, we highlight some of the long-term benefits that conservation of this region will bring to Ecuador and the world.

1) A globally important new conservation area in Ecuador, linking protected montane forests from Colombia to central Peru. The wet slopes of the eastern Andes - stretching from Venezuela to Bolivia - pack unique species and assemblages of plants and animals along their entire length. Many Andean species are limited to one segment of the cordillera: if that block or elevational band is eliminated, so are the biological communities that exist nowhere else. Conservation of the Serranías Cofán will add a vital link to the chain of protected areas connecting these distinct communities along the Andes.

\section{2) Effective protection of a newly vulnerable sector of the Cayambe-Coca} Ecological Reserve, one of the largest conservation areas in Ecuador. The ecological reserve, already facing an array of challenges, is confronting intense new pressure along the recently completed Interoceanic Highway (Figure 2A). Strong interest from the resident Cofán community to participate in conservation and patrolling activities - and the possibility of the reserve's expansion to the north and west (Anexo 2 in Figure 2; Appendix 6)-would effectively safeguard one of Ecuador's primary conservation areas. 
3) Protection of the major watersheds in the Sucumbios region. Sucumbios already is experiencing greater floods because of deforestation along river margins. Preservation of the headwaters will prevent huge fluctuations along with their devastating consequences to the province.

4) Preservation of important reservoirs of wet forest habitat. As global warming accelerates in the next century, the Amazon Basin will become increasingly drier. Areas close to the base of the Andes, especially those near the equator where seasonal changes are least severe, will be increasingly important reservoirs of moist habitat. These areas will become safe havens for populations of species that may otherwise vanish during extreme droughts.

5) A model of successful, science-based conservation stewardship of ancestral lands by an indigenous community. A Cofán-operated conservation center will provide resident-based protection to this highly vulnerable region and will form a nucleus for long-term management rooted in rigorous science and cultural tradition. 


\section{RECOMMENDATIONS}

The conservation future we envision for the region-one in which small Cofán communities at once protect and benefit from the wilderness surrounding them-is not dramatically different from the current state of the landscape. Achieving this vision will require action, however, because of imminent and longterm threats. Here we outline some preliminary recommendations for (1) protection and management to confront immediate dangers, (2) conservation planning for the medium term and future, and (3) information to sharpen conservation goals and strategies. To be successful, these actions will require coordinated financial planning and sustained funding.

\section{Protection and} management: Bermejo
1) Designate formal, legal conservation status for the forests in the headwaters of the Bermejo, Chandia Na'e, and San Miguel Rivers, and throughout the Sur Pax ridge complex. Rapid protection is crucial; otherwise, the active colonization front along the new Interoceanic Highway will overtake these intact forests. We recommend the immediate modification of the borders of the Cayambe-Coca Ecological Reserve to include much of the Bermejo area as a new annex, administered jointly with the Cofán (Anexo 1 in Figure 2). The proposed annex, measuring ca. 50,000 ha, will protect forests from the Colombian border in the north to the Bermejo River valley in the south, and from the Chingual River watershed in the west to the Amazonian lowlands in the east. Once the annex is in place, we recommend reclassifying the existing Bosque Protector Bermejo south of the Bermejo River (now degraded by colonization and petroleum operations) as a buffer zone.

2) Negotiate a written, legally binding agreement (convenio legal) between the Cofán Federation (FEINCE) and the Ecuadorian Ministry of the Environment to ensure the long-term conservation of biological communities in the area. The Ministry would promote conservation interest in the reserve at national and international levels, and would provide legal and institutional support for preventing misuse within its borders or large-scale incursions of settlers or commercial interests. For their part, the Cofán Federation and local Cofán communities would commit to a science-based management plan ensuring that $85-90 \%$ of the new reserve is maintained in perpetuity as conservation land, combining wildlands with ecologically compatible human use around existing settlements. The cooperative relationship between the Cofan community of Zábalo and the Cuyabeno Wildlife Reserve could be a model for similar management of the Bermejo area. 


\section{RECOMMENDATIONS}

3) Establish a biological corridor between the new Bermejo annex and the Cayambe-Coca Ecological Reserve. Because the land separating the two is itself wilderness of high biological value (especially the isolated paramo of the Cordillera Murallas, a logical solution would be to extend current reserve boundaries northward, to include the natural areas surrounding the towns of La Sofía and La Bonita (Anexo 2 in Figure 2). To be successful, this modification must have the support of local communities and regional authorities. We recommend that conservation planning in the region build on the excellent work of the La Bonita-Sucumbíos Foundation. This local nongovernmental group, based in La Bonita, has carried out biological inventories, drawn up a detailed map of the area, and begun conservation planning with local communities throughout the zone (Appendix 6). It would be an appropriate coordinator of conservation efforts in this region.

4) Protect the forests of La Ranchería, across the Colombian border from the proposed annex and contiguous to it. Other than La Corota (an 8-ha reserve $80 \mathrm{~km}$ from the international border), this 25,000-ha tract of forest managed by the Cofán is the only protected area in this region of Colombia. As soon as politically feasible, we recommend that the Colombian Ministry of the Environment and the Cofán of Colombia take conservation action for the longterm preservation of La Rancheria's forests. A long-term goal could be the declaration of the joint Bermejo and La Ranchería reserves as a multinational park, managed by Ecuador, Colombia, and the Cofán.

5) Map, mark, and publicize the boundaries of the new Bermejo reserve. Especially important will be well-marked borders (/inderos) and signs posted at access trails along the western border of the new reserve, closest to settlements along the Interoceanic Highway. The signs will be a clear reminder of the area's conservation status and of the regulations to be observed within its boundaries.

6) Establish a high-profile conservation presence in the areas most vulnerable to incursions, particularly along the western border of the proposed reserve. A small team of Cofán park guards should patrol the border and nearby trails from a well-placed Cofán guard station. We envision an arrangement similar to those in the Cofán communities of Zábalo (with the Cuyabeno Wildlife Reserve) and Sinangoe (with the Cayambe-Coca Ecological Reserve). To be effective protectors of biodiversity, these guards must have authority to enforce regulations. 


\section{RECOMMENDATIONS}

7) Develop conservation programs with the Cofán communities of Alto Bermejo, Chandia Na'e, and Tayuso Canqque, based on biological values, regional threats, and local needs. To be successful, these programs must balance new responsibilities (e.g., patrolling the new reserve, enforcing limits and seasons for hunting large game) with environmentally sensitive economic alternatives to meet the communities' needs. Outreach activities, led by the local Cofán communities, should engage neighboring colonists in conservation work along protected area borders.

8) Manage harvests of gamebird, large-mammal, and large-fish populations around Cofán communities inside the proposed protected area. Until a more detailed system of seasons, limits, and zoning can be developed, our recommendation is to keep fishing and hunting pressures at current levels (i.e., for subsistence by local residents only).

Protection and management: Sinangoe
1) Establish an agreement between the Ecuadorian Ministry of the Environment and the Cofán Federation that outlines a clear conservation strategy for the traditional Cofán territories within the Cayambe-Coca Ecological Reserve (Figure 2). This should expand on the existing agreement between the Cofán community of Sinangoe and the Ministry of the Environment and respond to the intensifying threats to the region, using the convenio between the Cofán community of Zábalo and the Ministry of the Environment as a model. One key feature of the relationship should be regular meetings to review current conservation threats and opportunities, and to coordinate action.

2) Establish a long-term, high-profile conservation presence along the northern and eastern borders of the ecological reserve. Regular, frequent patrols by Cofán park guards should concentrate on areas where hunting or colonization pressure is most severe. These patrols will require some infrastructure, in the form of three or four additional guard stations in strategic locations between the Aguarico and Due Rivers, and a trail system linking them.

3) Post signs at access trails along the eastern border of the Cayambe-Coca Reserve. These markers should be clear reminders of the area's conservation status and of the regulations to be observed within its boundaries.

4) Remove the cable car that allows easy access across the Aguarico River from Puerto Libre to the undisturbed forests of Cayambe-Coca. Its removal will immediately diminish incursions by unauthorized hunters and fishers. 
RECOMMENDATIONS

5) Prevent construction of roads or logging infrastructure within the ecological reserve. Monitoring similar activity on the western and southern edges of the new Interoceanic Highway (see Monitoring, below) will complement this goal.

Information management: Bermejo and Sinangoe

1) Initiate and maintain a map-referenced database of the region's physical, biological, and political features. This geographical information system (GIS) should incorporate basic geographic and political features, as well as information derived from monitoring programs. By renewing and analyzing layers of information in this database, reserve managers will be able to develop and revise management strategies, identify and update threats to the reserve, and better understand its communities, both human and nonhuman.

2) Establish a network for data sharing among stakeholders.

Further inventory: Bermejo and Sinangoe
1) Carry out an inventory of physical features not included in the rapid biological inventory. Among the needs identified during our field work are:

a. A survey of water and soil quality in watersheds at risk from petroleum, mining, or logging activities. Prominent among these are the lower Bermejo River valley and the Cofanes River and its tributaries. This inventory will provide the baseline data against which to measure effects of increased road-building or large-scale extractive activities in the region.

b. An inventory of the area's surface geology. This information, to be incorporated into the regional GIS, is vital for identifying unique or vulnerable plant and animal communities and for protecting the area against mining incursions. 


\section{RECOMMENDATIONS}

2) Fill the most prominent gaps in the geographic and taxonomic coverage of inventories to date:

a. Inventories of ecosystems that remain poorly explored, especially at higher elevations. In the Bermejo region these areas include the high ridges and valleys between the Pax and Sur Pax mountains (Figure $3 A$ ); the isolated valley that forms the headwaters of the Chandia Na'e River; and the ridgeline of the exposed escarpments on the northern banks of the Bermejo River. In Sinangoe, the areas of immediate interest are the high ridges in the western section of the Ccuccono River drainage (especially the 2,686-m high point of that ridge and a peak taller than $3,100 \mathrm{~m}$ on a different ridge system to the south); and the peaks to the west of the Shishicho ridge, especially a mountain indicated on the IGM topographic map as the Cerro de Cal (Limestone Mountain). These sites are described in more detail in the Overview of Inventory Sites section of the Technical Report, below.

b. An expanded program of botanical exploration and collection, focusing on times, places, and taxa not covered well to date. Needs include botanical collections throughout the year (especially in January and February), at higher elevations, and of small, herbaceous, epiphytic plants.

c. Inventories of the Bermejo herpetofauna, at both high and low elevations. Complete surveys of the frog taxa possibly undergoing population declines (Centrolenidae and Colostethus) are also of highest priority (see below).

d. A short, focused expedition to Cerro Sur Pax to assess reports of a new primate species. Reports of other unusual mammal species in the Bermejo region should also be investigated.

Research:

Bermejo and Sinangoe
1) Determine the effects of large-scale threats on forest dynamics and inhabitants. Colonization and illegal incursions, road building, and wholesale deforestation are among the most obvious threats at this scale. Information from frequent patrols by Cofán park guards would contribute strongly to this research. Analysis in the regional GIS would identify problem areas and emerging threats.

2) Assess the region's carrying capacity for fishing and hunting. Peccaries, tapirs, monkeys, and cracids are the game animals that appear to be under greatest pressure. 


\section{RECOMMENDATIONS}

3) Investigate the causes of apparent population declines and fluctuations among the region's amphibians. Of special concern are glass frogs (Centrolenidae) and poison-arrow frogs in the genus Colostethus (Dendrobatidae). This long-term research may require studies of biogeography, habitat preferences, and reproductive schedules.

4) Promote the use of existing field stations as sites for long-term studies in conservation biology. Unlike many other biodiversity-rich, remote sites in the Andean foothills, these forests are accessible and have a resident community ready and willing to participate in gathering information. We particularly recommend exploration of :

a. The composition, structure, and function of communities (plants, birds, and amphibians) on multiple ridge systems, along the whole elevational gradient. These studies would provide information on the distribution, population sizes, and conservation status of rare or geographically restricted species.

b. The interaction between plant species and their seed dispersers. Research in other parts of the tropics has revealed that alterations in the community of animal seed dispersers can degrade otherwise intact plant communities, and details of this relationship are critically important for effective management and conservation of inhabited forests.

Monitoring:

Bermejo and Sinangoe
1) Measure the effectiveness of conservation strategies in reaching goals. Variables to be measured might include the effect of boundary marking and patrols on incursions and resource misuse, the outcome of conservation education and outreach programs in local communities, and the popularity, percent implementation, and effectiveness of hunting and fishing regulations, among many others. Participation of community residents in planning and implementing these monitoring projects will be crucial to success.

2) Monitor amphibian populations through regular censuses. Special attention should be given to taxa for which declines have been observed in nearby areas, e.g., glass frogs (Centrolenidae) and poison-arrow frogs in the genus Colostethus (Dendrobatidae), and to species around streams and waterfalls. 


\section{Technical Report}

\section{OVERVIEW OF INVENTORY SITES}

The 2001 biological inventory team based its exploration of the Bermejo and Sinangoe regions out of six main campsites. Two of these were wooden houses built over the last year by the local Cofán communities and intended as permanent bases for scientific researchers and park guards; the other four were temporary forest camps. In this section we summarize the salient features of each of these sites and the trails we explored in their vicinity. We also include a brief description of the areas visited in a preliminary plant-collecting trip in July 2000.

Many of the trails, campsites, ridges, and streams described here were unnamed at the time of our visit, and have been newly christened to make future exploration of the area easier. Spelling of traditional Cofán names may differ in some cases from that on maps of the area. Additional information about visiting or carrying out research at the Bermejo or Sinangoe field stations is available from the Cofán Survival Fund (www.cofan.org).

\section{BERMEJO}

\section{Bermejo field station}

$\left(00^{\circ} 14^{\prime} 44.7^{\prime \prime} \mathrm{N}, 77^{\circ} 23^{\prime} 04.9^{\prime \prime} \mathrm{W}, \mathrm{ca} .450 \mathrm{~m}\right)$

This house in the Cofán community of Alto Bermejo was the starting point and base camp for our exploration of the Bermejo River valley. We reached it via a four-hour hike from the nearest road, a trailhead at Pozo Dos (Wellsite Two) in the Bermejo oilfield. The trail in makes a long, gradual descent some $200 \mathrm{~m}$ into the valley, passing through mostly mature lowland forest and traversing two major ridges and creeks.

The Alto Bermejo community consists of half a dozen scattered houses and crop clearings on a low terrace on the southern banks of the Bermejo River. On satellite images it is visible as a tiny speck in a sea of forest (Figure 2). The station house stands in a small clearing surrounded by primary and secondary forest and neighboring crop gardens. The forest around the community is crisscrossed by dozens of trails, three of which we explored: 
Pozo Seco trail - This trail leads away from the river, climbing up the southern side of the valley towards an abandoned wellsite, Pozo Seco (Dry Well). The first kilometer of the trail passes through a dense population of the understory palm Chelyocarpus ulei; in the higher portions huge old Cedrelinga and Parkia trees are common. The trail traverses tall, upper and lower hill forests, crossing deep ravines before climbing a long, steep ridge to ca. 1,100 $\mathrm{m}$ and then descending again to the dry well, at ca. $600 \mathrm{~m}$. The strenuous climb is amply rewarded with gorgeous vistas from several outlooks.

Escarpment trail - Beginning on the northern side of the Bermejo River, this trail leads up a long, steep, forested slope, before following the edge of the tall, red clay escarpments that are such a striking feature of the northern banks of the Bermejo. Most of the forest along the trail is structurally and floristically similar to that in the vicinity of the station, though this trail also passes through large areas of successional forest growing on old landslides.

River trails - We explored a number of semipermanent trails that lead along the Bermejo River. The river itself was low enough and its banks were broad enough that it was possible to hike up and down its bed, lined by overhanging Inga ruiziana (Mimosaceae) trees. Other trails ran along the edge of the woods, across the steep slopes and occasional strips of floodplain forest that border the river. Most of these trails appear to be very old, and have been used by Cofán for generations. Populations of most game animals were present but wary in the forest close to the community. Only the woolly monkey and some cracids seem to have been hunted out of the immediate area.

\section{Bermejo Vista camp}

$\left(00^{\circ} 18^{\prime} 13.8^{\prime \prime} \mathrm{N}, 7^{\circ} 24^{\prime} 32.0^{\prime \prime W}\right.$, ca. $\left.1,200 \mathrm{~m}\right)$

This was our mid-elevation base in Bermejo, reached by a five-hour climb from the community below. The trail up from the Bermejo field station, on the floor of the valley, follows a tributary of the Bermejo (the Sisipa) for the first hour, then ascends steeply to the meseta that forms the top of the escarpments on the northern banks of the Bermejo River. The vegetation on top of this meseta is very similar to the lowland forest around the station, with only a scattering of montane tree species. It is only after the long traverse of the meseta, interrupted by occasional ravines, that the trail climbs up to a wet shelf where montane tree species are more frequent.

We made camp on this wet shelf, where a hectare-sized clearing $800 \mathrm{~m}$ above the floor of the valley gives a commanding view of the surrounding landscape. To the east the Amazonian lowlands stretch to the horizon; to the south one looks across the valley to the Bermejo oilfields on the opposite ridge and the volcanoes Reventador and Sumaco on the horizon; and to the north one looks up at a near-vertical southern flank of the Sur Pax mountain complex, marked by the long waterfalls of the descending Ttonoe River. From this perspective the forests of the region appear essentially undisturbed in every direction. The only obvious signs of human presence are the nighttime flickering of the Bermejo oilfield gas flares, a bright beacon at the Colombian border, and the lights of the small Amazonian cities on the horizon.

Chandia Na'e trail - This trail leads east from the camp clearing, sloping down to meet the Chandia Na'e River. The one- to two-hour hike to the river descends ca. 200-300 $\mathrm{m}$ in elevation along a narrow forested ridge dotted to either side with successional forest on recent landslides. The trail emerges at the junction of the Chandia Na'e with the smaller Ttonoe River. The narrow Chandia Na'e tumbles down a steep gradient of huge white quartzite boulders, giving it an appearance that is strikingly different from most of the other streams we saw in the Bermejo area. Note that this river is marked on maps of the area as the Zarayacu or Sarayacu; because that rather recent Quichua name is barely familiar to the inhabitants of the area, in this report we use the traditional Cofán name.

Chingual trail - To the west of the Vista camp, a trail descends steeply westwards, crossing the upper reaches of the Bermejo River and leading to the colonist farms along the Chingual River. We did not 
explore this trail, but it will be a key route for park guards to patrol when a reserve is established in this area. Under good conditions, the walk to the road takes roughly eight hours.

\section{Bermejo Bear Ridge camp}

$\left(00^{\circ} 19^{\prime} 17.7^{\prime \prime} \mathrm{N}, 77^{\circ} 25^{\prime} 10.0^{\prime \prime} \mathrm{W}, \mathrm{ca} .1,920 \mathrm{~m}\right)$

This was the highest campsite of the expedition, accessed by a steep climb up from the Vista camp and a hike along an ascending ridge through very wet, low, and tangled forest. Camp was established on a thin ridge an hour's walk below Sur Pax. The low forest around camp appears to grow on a tangle of mosscovered roots, with no rocks or mineral soil visible on the surface and a near-permanent drip from the constant cloud and fog cover (Figure 3C). Another feature of the area is a persistent cool breeze cutting across the ridge, periodically switching from easterly to westerly. A small lookout at the camp clearing looks steeply down on the Shishicho ridge and the Sinangoe field station to the south (see description below) and on the Chingual River and the new Interoceanic Highway to the west.

\section{Bear Ridge trail - The main trail from this} campsite continued north along an ascending ridge, passing through the same very wet and tangled forest type that surrounds the campsite. As elevation increases the forest becomes lower in stature, with the vegetation around the summit reaching only 10-20 $\mathrm{m}$ above the trail. After an hour's climb the trail reaches a 2,275-m summit just southeast of Cerro Sur Pax proper (summit coordinates: $00^{\circ} 19^{\prime} 54.5^{\prime \prime} \mathrm{N}$, $\left.77^{\circ} 25^{\prime} 25.4^{\prime} \mathrm{W}\right)$. An impassable ravine prohibited us from reaching Sur Pax itself from this direction, though it was clearly visible and would have been a mere half-hour's walk away if a trail had existed. A large, eastward-looking clearing at the 2,275-m summit allowed a clear view of the high, horseshoeshaped ridgeline surrounding the upper reaches of the Chandia Na'e River. The highest points of that ridge appeared to support a forest type that we saw nowhere else-stunted, shrubby vegetation much lower than that on Sur Pax. There is no doubt that extending the trail northwards (or cutting a new one up from the Chingual River) to reach more of the high-elevation ridges north of Sur Pax will allow biologists access to entire biological communities that we missed on this survey (Figure $3 \mathrm{~A}$ ).

Ttonoe trail - This trail was our attempt to reach an intriguing feature on topographic maps of the Sur Pax area-a broad-bottomed valley ca. $3 \mathrm{~km}$ to the east of the peak. The valley is especially interesting because it is very deep (more than a vertical kilometer below the summit of Sur Pax); it is effectively cut off from similar-elevation forest by steep slopes on all four sides; and it has a curiously broad, flat floodplain that is very unlike the $\mathrm{V}$-shaped ravines that characterize most valleys in the area. The access trail, which stopped short of this valley, cuts steeply downhill to the east of the main trail between the camp and Sur Pax. It eventually crosses the boulders of the rushing Ttonoe River, which forms the waterfalls visible from the Vista camp (see above) and ends after traversing one more ridge. The forest along the Ttonoe, in contrast to that of the ridge, is characterized by tall old trees growing on relatively gentle slopes. It was here that one member of the team saw a spectacled bear.

\section{SINANGOE}

\section{Sinangoe field station}

$\left(00^{\circ} 10^{\prime} 49.4{ }^{\prime \prime} \mathrm{N}, 77^{\circ} 29^{\prime} 50.0^{\prime} \mathrm{W}\right.$, ca. $\left.600 \mathrm{~m}\right)$

In July 2000 the Sinangoe community constructed a small house near the junction of the Sieguyo and Aguarico Rivers, directly across the Aguarico River from the town of Puerto Libre (Figures 2, 6C). The station's proximity to Puerto Libre and the new Interoceanic Highway-just a two-minute canoe trip across the Aguarico-made it an ideal base camp for our inventories in the Sinangoe region. The station is close to the start of the two major trails in the area, one accessing the Ccuccono River system to the west and the other leading north, up and over the Shishicho ridge complex and thence to the Cofanes River (see descriptions of these areas below). Because of its 
strategic location on the border of the Cayambe-Coca Ecological Reserve (the Aguarico forms the park border in this area), park guards operating out of the field station can play a major role in preventing the rapid colonization along the new highway from spilling over into the reserve.

Station loop trail - The forest in the vicinity of the Sinangoe station is compositionally similar to the lower hill forest of the Bermejo River valley, though drier and with a much stronger secondary element. Significant areas here are dominated by mature old trees in the pioneer family Cecropiaceae. Unlike in Bermejo, where most of the successional forest is clearly related to old landslide patches, the abundance of pioneer species around Sinangoe is something of a mystery. A small fraction of the succession is taking place on abandoned clearings and homesites (the station clearing itself was once a rice field), and some other patches may correspond to much older settlements. The rest appears to be the consequence of a large natural disturbance, perhaps a large-scale windstorm or flooding episode in the last 100 years.

Botanical trails - During the 2000 and 2001 trips, Robin Foster, Roberto Aguinda, and José Omenda identified more than 300 plant species along trails close to the Sinangoe field station. These plants have been marked with laminated labels that give both the scientific and Cofán names, so that visiting botanists can learn Cofán plant names, Cofán botanists can learn scientific (Linnaean) names, and other visiting researchers can teach themselves how to identify some of the more common plant species in the area (Figure 6D).

Candoe trail - This trail leads west-southwest from the Sinangoe station, crossing the Fetsavoe River before ascending a broad, gently sloping ridge to about $1,000 \mathrm{~m}$. It then circles around the headwaters of the Fetsavoe, narrowing to a knife-edge ridge that separates the Fetsavoe from the Candoe. Recent landslides tangled with young regrowth alternate with old Dacryodes forests. We were especially interested in visiting this area because Cofán hunting is permitted here under the Sinangoe management plan. We found little difference in occurrence of wildlife or in the wariness of individual animals encountered, indicating low usage of the region. This trail eventually connects with one linking the station to Ccuccono (see below), above the headwaters of the Candoe.

\section{Ccuccono Beach and Ridge camps}

$\left(00^{\circ} 07^{\prime} 48.5^{\prime \prime} \mathrm{N}, 77^{\circ} 33^{\prime} 19.9^{\prime \prime} \mathrm{W}\right.$, ca. $940 \mathrm{~m}$, and $00^{\circ} 08^{\prime} 09.0^{\prime \prime} \mathrm{N}, 77^{\circ} 32^{\prime} 48.1$ ” W, ca. $980 \mathrm{~m}$ )

To reach the Ccuccono River drainage, we hiked five hours west from the Sinangoe field station, along a gradually ascending ridge that peaks at ca. $1,100 \mathrm{~m}$ and then drops rapidly down into the watershed. The trail passes through old successional forest for the first several kilometers, before the high canopy of old pioneer trees in the family Cecropiaceae eventually gives way to a much more mature forest. We also noted an apparent moisture gradient along this ridgeline, with the drier, epiphyte-poor lower forest near the station giving way to a much wetter, epiphyteladen, higher forest dominated by huge old hardwoods closer to the Ccuccono.

Once at the Ccuccono watershed, the bird and herpetofauna team established a base in the Dacryodes forest on a low ridge just above the Ccangopacho Stream (Figure 3D), a tributary of the Smaller Ccuccono River. The plant and mammal group followed the Ccangopacho down to its junction with the Smaller Ccuccono and camped on the open beaches of the river itself.

Very little of the present-day landscape in the Ccuccono drainage can be understood without reference to a massive earthquake that struck the area in March 1987, triggering simultaneous landslides across several thousand square kilometers of forest. As the temporary dams formed by these landslides were breached, a series of towering flash floods-high enough to wash out the Lumbaqui bridge more than $15 \mathrm{~km}$ downstream-scoured the valley clean of vegetation at least $20 \mathrm{~m}$ above the current river level, leaving mature forest only on the high ridges along the river. Indeed, present-day satellite images of the area 
show as much as half of some areas of the watershed in the same stage of regeneration (Figure 2). Given the unstable geology of the region, the frequency of earthquakes, and the proximity of active volcanoes, we expect that catastrophes of this kind are a relatively frequent feature of the Ccuccono landscape, at least on ecological and geological time scales.

The river in the vicinity of our beach camp still showed clear evidence of the 1987 damage. Cofán team members who had camped at the same site before the earthquake were surprised to find the rather narrow, pretty river they remembered now open to the sky at least $50 \mathrm{~m}$ across, littered with boulder fields, sandbars, and weedy islands to either side of the modest (ca. $5 \mathrm{~m}$ wide) current. Even along the smaller tributaries of the Smaller Ccuccono, like the Ccangopacho Stream, large stretches of riverbank that would traditionally be covered with tall gallery forest were still buried under a tangled mess of vines and weedy low trees. This was especially noticeable in the inside bends of the rivers, where flashflood scouring would have been most destructive.

Apart from the station-to-Ccuccono trail, we investigated a variety of small tributaries and ridge systems around our two campsites, and describe the most interesting of these below:

\section{Ccopaye Fensi (Oilbird) Stream trail -}

This is a minor tributary that empties into the Smaller Ccuccono just opposite our beach campsite, from which it extends back ca. $200 \mathrm{~m}$ through flat, mostly successional forest to a waterfall. One of the most interesting features of this small stream is a small overhanging cliff on which three or four birdsmost likely cocks-of-the-rock but possibly oil birdshave nested at eye-level.

Ccuccono Ridge trail - This trail, beginning just upstream from and on the opposite bank of our beach campsite, ascends the ridge dividing the two major branches of the Ccuccono River. Unlike most of the ridges in the vicinity of our camps, which barely exceed $1,500 \mathrm{~m}$, this one climbs to $1,800 \mathrm{~m}$ within a few kilometers. We were able to explore this trail only partially, following tapir and bear tracks up to 1,500 $\mathrm{m}$, but it continues westwards to an unnamed and isolated peak of nearly $2,700 \mathrm{~m}, 12 \mathrm{~km}$ to the west of our beach campsite. This totally unexplored ridgelinealmost as high as the city of Quito-is likely to contain a large number of endemic plant species and should be a high priority for future expeditions to the region.

\section{Shishicho camp}

$\left(00^{\circ} 12^{\prime} 01.3^{\prime \prime} \mathrm{N}, 7^{\circ} 31^{\prime} 54.3\right.$ 'W, ca. $\left.1,020 \mathrm{~m}\right)$

This camp is a two-hour hike uphill from the Sinangoe field station, climbing about $400 \mathrm{~m}$ to the base of the steep, eastern face of Cerro Shishicho. Forest in the vicinity of camp and around the trail from the station is typical mature hill forest, dominated by common lowland tree species (particularly Myristicaceae) and interspersed with small patches of bamboo or successional forest. A few temporary trails lead downhill in different directions from the campsite, through forest very similar to that on the main trail. Just above camp is a several-hectare patch of secondary forest from an old landslide.

Shishicho ridgeline trail - From camp the trail continues directly up the near-vertical slope of Shishicho, gaining almost $400 \mathrm{~m}$ in elevation before reaching a crest just below the main peak. This section of the trail is often rocky underfoot, with patches of loose shale and outcrops of the same material dotting the route. The redeeming feature of this difficult climb is the profusion of spectacular lookouts along the way, which give a panoramic view of the Aguarico River valley (Figure 2B).

Once the peak of Shishicho is reached, the trail levels off and begins to follow the main ridgeline, which curves towards the north as it continues to gain gradually in elevation. Vegetation here is a mixture of surprisingly tall old trees in the lower sections of the ridge and shorter, more heavily epiphyte-laden trees on the higher sections, and some successional forest in areas of past disturbance. An hour's climb from the first crest, one reaches the highest point of the ridge at $1,570 \mathrm{~m}$. As in the Sur Pax summit forest, the trees at this summit are relatively short (to $10 \mathrm{~m}$ tall) and the 
ground disappears under a tangle of moss-covered tree roots. The tree flora here loses most of the lowland elements that are frequent on the lower parts of the ridge and takes on a more obviously montane character, with genera like Viburnum, Brunellia, Tibouchina, and Clusia dominating, and carpets of Sphagnum and other mosses underfoot. The summit forest also appears to be in a rather early successional stage, though it is not clear whether this is chiefly due to wind and storm damage, lightning strikes, or the Cofán habit of felling a few trees in high points for lookouts.

The trail forks at this summit. Both branches continue down to the Cofanes River; one follows the main ridgeline to the north and the other follows a different ridge to the northwest. As is the case on most of the Shishicho ridgeline, the northern trail passes through a rather dry forest, exposed to desiccating winds sweeping up the Aguarico Valley. The northwest trail, which is apparently lower and so sheltered from the winds, makes its way through a tangle of much denser and wetter vegetation.

\section{INTEROCEANIC HIGHWAY}

(between Lumbaqui and La Bonita, ca. 500-1,000 m)

In July 2000, Robin Foster, Roberto Aguinda, Margaret Metz, Terra Theim, and several members of the Sinangoe community made a preliminary floristic survey of plant communities along the new highway that bisects the formerly continuous forest of Bermejo and Sinangoe (Figure 2A). Because at the time of our visit the highway was still under construction and large-scale colonization of the land along its margin had not yet taken place, the trip gave us rare easy access to intact, botanically unexplored forest. Now that the highway has opened, colonization in the adjacent forest is advancing rapidly. By the time this report is published, most of the forest we explored in 2000 probably will have vanished.

\section{GEOLOGY, PHYSIOGRAPHY, AND CLIMATE}

Authors: Nigel Pitman and Robin Foster

\section{BASIC GEOLOGY AND PHYSIOGRAPHY}

The landscape around Bermejo and Sinangoe is a jumble of different rock types and geological formations, and for good reason. For the last ten million years, throughout the Andean mountain-building, huge slabs of rock of different ages and materials have been snapped in two and wrenched upwards here, buckled and folded around each other, and then subjected to extreme weathering. Much of the uplifted rock is of Cretaceous age (65-146 million years old), but older Jurassic and even Pre-Cambrian formations also dot the landscape (Baldock 1982, Nieto 1991). To complicate the picture further, these different rock groups include individual strata that vary from shales to conglomerates to limestones to sandstones. Each of these are different in the effect they have on the soils derived from them, leaving one to guess at the edaphic characters of any particular site.

At a larger scale, the geological setting is more similar to the non-volcanic southern Ecuadorian provinces of Morona-Santiago, Zamora-Chinchipe, and Loja than to adjacent areas in central Ecuador. The reason is that the Serranías Cofán lie just to the north of the zone of young, active volcanoes from Sangay to Reventador. Though their southern portion is affected by Reventador's activity (see below), the northern portion may be more closely affiliated with the non-volcanic eastern cordillera of Colombia, and the non-volcanic provinces in southern Ecuador.

Topography in the area is just as varied as geology, and is generally determined by the tilt and composition of the uplifted formations. In the lowlands, most geological blocks have been uplifted without much tilting, resulting in the flat-topped terraces just north of the Bermejo and Aguarico Rivers. Closer to the main body of the Andes, where the geological history is much more complex, steeply tilted and twisted formations, weathered for millions of 
years, have given rise to the sheer-walled cliffs and gorges around Cerro Sur Pax and the Cofanes River.

\section{CATASTROPHIC DISTURBANCE}

Just as important as a picture of the region's surface geology is the recognition that all of it is subject to change at any moment. Immense natural disasters have reworked the landscape around Bermejo and Sinangoe with unsettling frequency, stripping away successive layers of surface material during earthquakes, volcanic eruptions, floods, and landslides. Because the area is already a jumble of different rock strata, the consequence of this constant building up and tearing down of the landscape is that the particular rock group and soil chemistry under a given patch of forest may change greatly in only a few decades or centuries, as different layers of rock are exposed.

Just $10 \mathrm{~km}$ south of the southernmost site we visited (Ccuccono) sits one of the most active volcanoes in the eastern Andes: the 3,562-m Reventador. This stratovolcano has erupted at least 24 times since 1541, littering the landscape around it with tons of ash and lava, periodically building itself up and then exploding. During the 20th century, the volcano erupted continuously from 1900 to 1906 , then again in 1912, 1926, $1929,1936,1944,1955,1958,1960,1972,1973-$ 1974, and 1976. The implication of all this activity, which dates back at least to the Pliocene, is that the southern portion of the Cofán foothills have been blanketed with ashfalls and peppered with pyroclastic bombs from Reventador on a regular basis for at least the last 2 million years (Nieto 1991).

The area is also intersected by a spiderweb of fault lines, along which the landscape shifts occasionally, and with great violence, as part of the ongoing Andean orogeny. On the night of March 5, 1987, back-to-back earthquakes measuring 6.1 and 6.9 on the Richter scale struck the foothills region. The quakes, which were preceded by heavy rains, caused an estimated 100 million cubic meters of soil to peel away from the steep slopes in avalanches of mud and forest, leaving thousands of square kilometers stripped to the bedrock.
Aerial photos taken after the disaster indicate that an area of at least $2,500 \mathrm{~km}^{2}$ lost $75-100 \%$ of its forests to landslides. An area at least three times larger lost $25-75 \%$ of its forest cover (Nieto et al. 1991).

These massive landslides temporarily dammed a large number of rivers in the area; a few kilometers downriver from the epicenter, the bed of the Coca River dried up entirely for several hours following the quakes (Nieto et al. 1991). The breaching of these dams triggered towering flood surges that scoured clean (or buried under debris) the floodplain forests along most rivers in the area, including those throughout the portion of the Ccuccono River basin we visited. Indeed, the epicenters of these quakes have been traced to directly beneath the Ccuccono watershed, and almost exactly below the campsites we used during the rapid biological inventory (Espinosa et al. 1991).

Even when the landscape is not being torn apart at the seams by catastrophic physical processes, a large proportion of it is quietly collapsing in a less dramatic fashion. The Bermejo Valley basin is encircled by a ring of eroding cliffs that slip into the river with such frequency that the water of the Bermejo has a permanently reddish color. Satellite images of the area are dotted with the scars of landslips large and small, recent and old (Figure 2). These slides are so frequent at the very base of the Andes that they form a nearly continuous line tracing the first line of foothills. Not coincidentally, it is at these elevations (roughly 1,000 $\mathrm{m})$ that the precipitation is heaviest in this part of the Andes (OAS 1987).

Large-scale flooding events are also frequent phenomena in the Serranías, and probably have been so ever since the Andes began to rise some 10 million years ago. The community of Alto Bermejo was destroyed by a flood within the last decade. Stories of other catastrophic floods are a mainstay of Cofán legends. Quaternary pollen gathered a few kilometers to the east have led paleoecologists to suggest that a massive, prolonged flooding episode reworked the eastern Ecuadorian landscape as recently as 800-1,300 
years ago (Colinvaux et al. 1988). Huge quartzite boulders like those currently lining the banks of the Aguarico River also dot the terraces nearby, providing a reminder of past washouts.

\section{CLIMATE AND PHENOLOGY}

Climate in the Cofán foothills is unrelentingly wet, because the prevailing winds on the equator-blowing from east to west-collect evaporation over the Amazonian lowlands and drop it as rain when they hit the Andes. Annual rainfall at the three closest weather stations (Reventador, El Chaco, and Santa Cecilia) ranges from $2.5 \mathrm{~m}$ to more than $6 \mathrm{~m}$, and the heavy epiphyte load and moss density at Bermejo and Sinangoe suggest that the sites we visited fall at the high end of this range (OAS 1987). Even in this relatively small area, however, the amount of precipitation that a given site receives may vary dramatically across the landscape. Intermediate elevations receive more rain than higher or lower ones (with the peak at 1,000 m; OAS 1987), and sites at the same elevation but in different drainages may receive dramatically different amounts of moisture, because the complicated topography generates a complex pattern of rain shadows.

Rain here falls year-round, punctuated by weak dry seasons of short duration. The driest time seems to be January-February, which corresponds to the Northern Hemisphere dry season (not unexpected given the latitude here just north of the equator; OAS 1987). Short, unpredictable dry periods can occur at any time of year, but with a greater probability in August, which corresponds to the Southern Hemisphere dry season. These droughts are probably most severely felt on ridges that are low enough to fall below the cloudline but exposed enough to be swept by desiccating winds. At elevations over $950 \mathrm{~m}$, where the vegetation is frequently enveloped in clouds, condensation probably adds significantly to the total amount of precipitation landing on the ground.

Temperature in the Serranías varies linearly with elevation, due to adiabatic cooling. In the lower hill forest, temperatures average around $25^{\circ} \mathrm{C}$ year- round; at $1,000 \mathrm{~m}$, the average drops to $\mathrm{ca} .20^{\circ} \mathrm{C}$; and at $2,000 \mathrm{~m}$, to ca. $15^{\circ} \mathrm{C}$ (OAS 1987 ).

In spite of the general lack of seasonality and minimal change in daylength throughout the year, many plant species seem to be roughly synchronized in their reproductive and leaf-flushing behavior. This synchrony is probably triggered for most species by the usual, but not reliable, short dry period in January and February. For some it may be the sudden drop in temperature accompanying a specific rainstorm, or a few days of drought stress coming at any time of year. An example is one species of Faramea (Rubiaceae), a shrub in which all the individuals came into flower and finished during one week of our trip. Another is the common tree Dacryodes olivifera (Burseraceae), in which all the adult trees seemed to be flushing new leaves during our stay.

\section{A somewhat smaller set of species had} flowering, fruiting, or leaf-flushing individuals mixed in the same population, or even on the same individual tree. These asynchronous species may either be responding to repeated signals throughout the year, or merely responding to internal signals of the nutrient status of the tree or branch. An example is the common tree Billia rosea (Hippocastanaceae), which we found sometimes with flowers, sometimes with ripe fruit (Figure 4D), and sometimes with neither but flushing new leaves. The wild cherry at upper elevations, Prunus berthae (Rosaceae), was unusual in that all the individuals observed on the slopes above Bermejo were in fruiting condition, whereas on the high ridges of Sinangoe they were all in flower. The most likely explanation for this is some local climatic event that affected one side of the Aguarico and Chingual Valleys but not the other. 


\section{FLORA AND VEGETATION}

Participants/Authors: Robin Foster, Nigel Pitman, and Roberto Aguinda

Conservation targets: Upper and lower hill forests; montane forests; stunted ridgeline and summit forests; plant communities on acidic outcrops; lowland forests with commonly overexploited trees

\section{METHODS}

This was a short, fast-moving survey of a large region, with the goal of sketching a quick portrait of the area's vegetation. During our three weeks in the field we were constantly on the move, hiking from one site to another in an attempt to cover as much terrain and visit as many habitats as possible. We used a variety of formal and informal sampling techniques, and drew whenever possible from the lifelong experience of the Cofán naturalists who inhabit the area.

The groundwork for our exploration of the Bermejo and Sinangoe area was laid by the excellent earlier work of Carlos Cerón and colleagues (1994) from Ecuador's Universidad Central. Some of the observations here also draw on previous visits of RF, RA, M. Metz, T. Theim, and G. Baker to Sinangoe and the new Interoceanic Highway in June 1999 and July 2000. No quantitative sampling was carried out during those visits, but several hundred plants were collected or photographed.

Throughout the 2001 inventory we continued to collect and photograph as many unrecognized species as possible, and kept a running list of species identified in the field but not collected. The database now includes more than 1,000 herbarium specimens representing at least 800 species, and 1,400 photographs of at least 700 species. The preliminary list, given in Appendix 1, incorporates and updates the inventory of Cerón et al. (1994) in the vicinity of the Sinangoe community. This obviously is not a complete catalog of the flora, just as our ecological work is an initial overview to stimulate additional research in the area's plant communities.
We also gathered quantitative data along transects in several of the major habitat types, sampling 969 trees and shrubs in total. Transects were established as opportunity permitted (i.e., adequate time without rain), with priority given to canopy trees and the shrub layer. Sampling followed the rationale of Foster et al. (unpublished manuscript) for variable transects laid out along existing trails. We sampled canopy trees in single, continuous transects of 100 individuals, or fewer if time ran out. Tree transects were $20 \mathrm{~m}$ wide $(10 \mathrm{~m}$ on either side of the observer) and included all trees with a trunk diameter measuring greater than $30 \mathrm{~cm}$ at breast height (DBH; ca. $1.3 \mathrm{~m}$ from the ground). Species identifications, often to temporary "morphospecies," were made using binocular observations of the canopy, fallen leaves, and cuts in the bark. Trees with insufficient visible leaf material were ignored. The shrub layer was sampled separately, in "interrupted" transects incorporating 100 to 200 free-standing stems measuring $1-10 \mathrm{~cm} \mathrm{dbh}$. These transects were $1 \mathrm{~m}$ wide on one side of the trail, with subsamples of 20 individuals each separated by 100-m intervals. Vouchers were collected for most fertile morphospecies and for the most abundant morphospecies. We collected and made observations on plants in all habitats, but concentrated our quantitative sampling in upper hill forest, with additional transects in mountain ridge forest and lower hill forest. We did not establish transects in the mountain summit or slope vegetation, or in the riverine plant communities.

These data were supplemented with qualitative observations on vegetation dynamics, habitat composition, and other aspects of plant ecology. In addition, because one of us (RA) speaks the Cofán language, we were able to record the indigenous names and uses of several plants by interviewing Cofán elders in the communities of Alto Bermejo and Sinangoe.

Collections were preserved in alcohol in the field and subsequently dried in Quito. Fertile specimens were deposited at the National Herbarium of Ecuador (QCNE), with additional duplicates sent when available to the Field Museum (F), to family specialists, and to the Catholic University of Ecuador (QCA). 


\section{FLORISTIC RICHNESS, COMPOSITION, AND DOMINANCE}

Our preliminary vascular plant list (see Appendix 1) lists 1,596 species. Based on field observations to date and on our experience in better-known areas of the Neotropics, we estimate a total vascular flora of 2,000 to 3,000 species for the Bermejo and Sinangoe area. This is obviously a broad approximation, and the true number will depend on how one draws the boundaries of the area (i.e., how much of adjacent lowland and Andean forests is included). As in other Andean forests, a good estimate of the area's floristic diversity will depend on a good estimate of its orchid diversity; that family typically accounts for a major part of the flora in forests this wet.

Both the regional- and local-scale diversity in the Cofán foothills seem typical of eastern Andean forests-extremely high, especially in the families Orchidaceae, Melastomataceae, Rubiaceae, Piperaceae, and Bromeliaceae. The diversity at intermediate spatial scales (i.e., one to several hundred square kilometers) may be lower than in other parts of the Ecuadorean Andean slopes, which have more geological or microclimatic extremes.

The obvious exception in the Serranías Cofán is the astonishing concentration of species in the coffee family, Rubiaceae. We encountered at least 39 genera and over 129 species in the family in a relatively short time of observation and collection. This family has the largest number of species of woody plants in the Neotropical lowlands and is usually abundant in the understory of Neotropical forests. In our experience, however, no other area of Ecuador, South America, or the world has as great a concentration of Rubiaceae as found in the area we visited during this inventory.

The Pacific slopes of Ecuador and Colombia have long been recognized by botanists as a center of diversity for the families Gesneriaceae, Araceae, and Ericaceae. For the Gesneriaceae (41 species encountered) and Anthurium (the largest genus of Araceae; 38 species encountered), the species richness around Bermejo and Sinangoe probably rivals that of a similar-sized area on the Pacific slope, and is certainly higher than in any other forests we have studied at the eastern base of the Andes. For the Ericaceace and the rest of the Araceae, on the other hand, the area does not seem especially diverse. The presence of at least a dozen treefern species (mostly Cyathea) in the area seems high to us by comparison with any area south of the Marañón River, but may be shared with the Cordillera del Cóndor and north into the Putumayo drainage.

\section{FOREST TYPES AND VEGETATION}

The diversity of habitats and plant communities in the Bermejo-Sinangoe region is typical for the base of the Andes. While the region is a jumble of different geological formations, it does not have as many extremes in underlying rock chemistry as some areas, such as the Cordillera del Cóndor (Schulenberg and Awbrey 1997). In that sense it is not as rich in habitats, and there are also no extreme differences in moisture availability at any given elevation. But there is a magnificent, undisturbed transition up the southern slopes of the Cerro Sur Pax complex, from lowland forest habitats up to cloud forests, including all the smaller-scale habitats of ridges, slopes, ravines, and landslides. Such intact elevational transects are becoming increasingly rare on the slopes of the Andes, and this one provides an outstanding outdoor laboratory to study the changes in plant populations and communities along an altitudinal gradient.

Here we use the general term "hill forest" for most of the forest in the Serranías Cofán, distinguishing for the purposes of this report three broad habitat types: lower hill forest, upper hill forest, and forest on mountain ridges and summits. Within each of these we have identified a few obvious smaller-scale habitats such as stream margins, successional forest on landslides, and vegetation on acidic outcrops. All such classifications are subjective, especially in areas like this, where species distributions are very patchy and most vegetation change is gradual. Our major categories reflect altitudinal differences in species presence, species relative abundance, and structure of the vegetation. 
LOWER Hill Forest (400-950 m)

This forest type covers much of the Bermejo River valley, and the low ridges and uplifted, sloping terraces between the Ccuccono River and the Sinangoe community. Our best opportunities to study lower hill forests were in the vicinity of the Bermejo and Sinangoe field stations, and on the walks to and from the Bermejo Vista camp and the Shishicho camp. The forest at these elevations is a somewhat less diverse extension of the Amazonian lowland forest just a few kilometers to the east. Like the plant communities around Yasuní National Park and the Cuyabeno Wildlife Refuge, this is tall, closed-canopy forest, where the local diversity of trees is among the highest on Earth and most species are rare. Species composition in these forests can vary dramatically from one small area to another in a way that remains poorly understood by ecologists, while at the same time a small group of species occurs fairly consistently, albeit at low densities, across the landscape.

As in the lowland forests farther to the east, the most common canopy tree across the lower hill forest is the ubiquitous palm Iriartea deltoidea (Figure 3E). Palms in general are frequent on the landscape, sharing dominance with the families Myristicaceae, Fabaceae s.l., Meliaceae, Euphorbiaceae, Melastomataceae, Rubiaceae, Vochysiaceae, and Moraceae. In a transect of 100 canopy trees on the moderately steep ridges south of Bermejo, at 500-600 m, the most common species were Minquartia guianensis (Olacaceae) and Vochysia braceliniae (Vochysiaceae), though neither of them made up more than $10 \%$ of the trees. One consequence of this lack of canopy dominants-so characteristic of Ecuador's Amazonian forests-is that these are extremely diverse tree communities. Of the 100 canopy trees sampled in our transect, we recorded 59 different species. Cerón et al. (1994) report similarly high diversity for trees and shrubs in four plots established in low hill forest around Sinangoe.

The high density of very tall trees (40-45 m) was another conspicuous feature of the lower hill forest on the ridge we sampled. Prominent among these were several giant legumes, including Cedrelinga cateniformis, several species in the genus Parkia, and what is possibly the world's largest Melastomataceae: a 50-m tall Tessmannianthus heterostemon with a stem diameter of $1 \mathrm{~m}$. We were surprised to encounter a "cannonball tree," Couroupita guianensis (Lecythidaceae), on the ridge, since it is usually encountered on floodplains. Other conspicuous trees of the low hill forest canopy are the various Sterculia (Sterculiaceae) species with their large roundish leaves, and in the case of $S$. apeibophylla, large, round fruit littering the forest floor beneath them. Both Otoba parvifolia and O. glycycarpa (Myristicaceae) are common in the canopy, along with several species of Virola. The lower hill forests on the small ridges around Sinangoe appear to have similar canopy composition (Cerón et al. 1994).

At somewhat higher elevations in the lower hill forest, on top of the flat terrace north of Bermejo at $800-900 \mathrm{~m}$, the forest appeared considerably wetter. The canopy here was 30-35 $\mathrm{m}$ tall and with few largediameter trees, but diversity was just as impressive, with 41 species recorded in a transect of 70 canopy trees. Again, the legumes and the Myristicaceae were the dominant families of canopy trees. The most abundant smaller species was Matisia bracteolosa s.l. (Bombacaceae), which accounted for $13 \%$ of the trees. The subcanopy tree Tovomita weddelliana (Clusiaceae)-perhaps the most common small tree in the region, and abundant across a broad altitudinal zone-was conspicuously more abundant in the understory here than in other areas of lower hill forest. The shrub layer (plants up to $5 \mathrm{~m}$ tall) was dense with Rubiaceae and Melastomataceae, along with a relatively high abundance of treeferns-all of these characteristic as well at higher elevations in the Serranías. Terrestrial ferns, especially species of Danaea, probably account for half the herbaceous ground cover here (Figure 4C), while dense stands of the aroid Dieffenbachia harlingii were almost invariably present in wetter depressions. The long-leaved Marantaceae, Ctenanthe ericae, is the dominant herb species, covering most of the slopes in 
the lower hill forest of Sinangoe, up to about $900 \mathrm{~m}$. Ctenanthe is completely missing, however, from the Bermejo area.

An understory fan-palm, Chelyocarpus ulei, is the most abundant and conspicuous small tree over several square kilometers in the vicinity of the Alto Bermejo community, but was not seen anywhere else in the region. It appears abruptly on the trail from Pozo Dos to Bermejo, becoming almost immediately common a few small streams west of the Rayo River, on the south side of the Bermejo River. The population extends upslope to the south for about a kilometer on the trail to Pozo Seco, but does not appear to cross to the north side of the Bermejo River-somewhat strangely, for a species with a small, bird-dispersed fruit. We have observed a similar large patch of C. ulei in the lowland forests of Yasuní National Park, similarly unrelated to any obvious edaphic or topographic features. The population we encountered in Bermejo is the northernmost known in South America.

While these lower hill forests do share most elements with Amazonian forests to the east, we were surprised to note some conspicuous absences. Several species that are common in the lowlands were not registered here at all, including Spondias mombin and Astronium graveolens (Anacardiaceae); Astrocaryum chambira and Geonoma deversa (Arecaceae); Hevea guianensis, Omphalea diandra, and Pausandra trianae (Euphorbiaceae); Casearia aculeata and C. sylvestris (Flacourtiaceae); and Swartzia arborescens (Fabaceae), Ficus paraensis (Moraceae), Palicourea guianensis (Rubiaceae), and Rinorea lindeniana (Violaceae). Ant-gardens, the ant nests with characteristic plant species cultivated and protected by the ants, are noticeably rare here and consist of little more than the bromeliad Aechmea longifolia and the herb Codonanthe (Gesneriaceae), rather than the more diverse assortment of species found farther from the Andes.

Other taxa, though present, are noticeably scarcer here, including Attalea and Bactris (Arecaceae); Brownea and Hymenaea (Caesalpiniaceae); Brosimum and Naucleopsis (Moraceae); Hamelia patens and
Geophila (Rubiaceae); and Anaxagorea (Annonaceae), Cordia nodosa (Boraginaceae), Hirtella (Chrysobalanaceae), Heliconia velutina (Heliconiaceae), Gustavia (Lecythidaceae), Mouriri (Melastomataceae), Zygia (Mimosaceae), Ouratea (Ochnaceae), Chrysophyllum (Sapotaceae), and Petrea (Verbenaceae). Presumably all these taxa prefer somewhat drier soils than are found in this area.

\section{River and Stream Margins}

Floodplain forest is very rare in the Cofán foothills. In some cases this is because the valleys are too young and steep to have developed any alluvial plains, with slopes right down to the rocky river beds (as along the Bermejo and Sieguyo Rivers). In other cases-particularly in the flatter Ccuccono Valley-it is because huge areas of floodplain forest have been destroyed by a major recent washout (flash flooding associated with major landslides; see Overview of Inventory Sites).

The vegetation associated with rivers and streams, while showing some variation with respect to the size and substrate of the watercourse, was fairly regular in composition throughout the region, even though individual streams were almost always distinguished by a few locally abundant species not common elsewhere. Along all the rivers, large and small, is Blakea repens (Melastomataceae), which occurs as either a hemi-epiphyte on the lower trunk of a riverbank tree, spreading into the sun out over the river, or growing on rocks or fallen trunks. This same species grows frequently in the forest away from the river as a hemi-epiphyte, but it is only along tree-lined rivers that it is conspicuous as a dominant. Other characteristic riverbank species are Trophis caucana (Moraceae), Myriocarpa stipitata (Urticaceae), Baubinia tarapotensis (Caesalpiniaceae), and Calliandra trinervia (Mimosaceae).

The larger rivers and occasionally the smaller ones have developed some areas of meander, with relatively stable sand or gravel beaches. The most common tree on older parts of these areas is Inga 
ruiziana (Mimosaceae), a characteristic floodplain species of the upper Amazon. On the stable gravel banks grow dense stands of a probably undescribed cane species in the genus Gynerium (Poaceae). This species is similar to, but clearly distinct from, the robust and cosmopolitan caña brava, Gynerium sagittatum; we observed the two taxa growing together without any evidence of intermediate forms. While the smaller cane is so far considered by grass taxonomists as nothing more than a form of G. sagittatum, the taxon clearly deserves recognition as a distinct species.

Other beach strand species, less predictable in their occurrence, include Brugmansia candida and Solanum spp. (both Solanaceae), Cleome sp. (Capparidaceae), Tovaria pendula (Tovariaceae), Tessaria integrifolia and Mikania micrantha (both Asteraceae), Commelina erecta (Commelinaceae), and even an occasional Bocconia integrifolia (Papaveraceae). On one tributary stream of the Ccuccono, the abundance of Canna jaegeri (Cannaceae)-a species widely cultivated by the Cofán and other Amazonian communities for its seeds, which are used as the principal small bead in their necklaces-suggests former human occupation in the area.

On the rocks lining most of these rivers grow a set of shrublets and perennial herbs that can survive frequent flooding. The most cosmopolitan of these is a pale, medium-sized Cuphea (Lythraceae), found along all rivers and streams with enough sunlight exposure. Other common members of this rock community include a smaller species of Cuphea, two species of Justicia (Acanthaceae), Liabum amplexicaule (Asteraceae), Thelypteris angustifolia (Pteridophyta), and, on the sides of large stable rocks, the elegant lady-slipper orchid Phragmipedium pearcei. Another important herbaceous community grows on the branches of riverside trees, and many of these also seem to be characteristic of stream habitats. These especially include ferns, but also orchids, Peperomia (Piperaceae), and bromeliads.

Most other plant species along the riverbanks are species characteristic of disturbance regeneration, typically found growing in disturbed patches on the slopes of the hill forest following landslides or major windthrow. It is only along the rivers and streams that their "patch" is a long linear one. These include two species of Sanchezia (Acanthaceae); Acalypha sp., Croton lechleri, and Mabea sp. (Euphorbiaceae); Guettarda crispiflora and Isertia laevis (Rubiaceae); and Saurauia cf. berthae (Actinidiaceae), Eirmocephala megaphylla (Asteraceae), Ochroma pyramidale (Bombacaceae), Senna ruiziana (Caesalpiniaceae), Podandrogyne brachycarpa (Capparidaceae), Cecropia putumayonis (Cecropiaceae), Banara guianensis (Flacourtiaceae), Piper umbellatum (Piperaceae), Triplaris americana (Polygonaceae), and Trema micrantha (Ulmaceae). Missing or rare on these riverbanks are the tree Zygia longifolia (Mimosaceae) and the shrubs Calliandra angustifolia (Mimosaceae) and Adenaria floribunda (Lythraceae), so characteristic of riparian vegetation along other small rivers of the upper Amazon. It may be that the clay banks and rocky borders of these rivers are too unstable to support them, but it then is difficult to explain how they are stable enough to support Inga ruiziana.

Smaller but permanent streams, partly shaded and rocky, often had a distinctive set of species associated with them. These usually included the herb Dicranopygium (Cyclanthaceae), various species of Pilea (Urticaceae), and the shrubs Urera baccifera (Urticaceae) and Hoffmannia (Rubiaceae). On some of the small tributaries of the Bermejo, we found a couple of unusual species strictly associated with the stream banks: Calathea gandersii (Marantaceae), which until recently was known only from the type collection near Tena, and an apparently new variety of one of the Neotropics' best-known and most widespread herbaceous species, Cyclanthus bipartitus (Cyclanthaceae; see below in species notes).

\section{UpPer Hill Forest (950-i,500 m)}

We were able to sample this altitudinal range more thoroughly than any other, as we set three of our 
campsites between 950 and 1,200 m. The physical characteristics of forests at this elevation are not greatly different from those of the lower hill forest. The trees are on average not quite as large in height or girth, and the trunks have greater densities of epiphytes, though the bark is still mostly exposed.

Although there is still considerable overlap in species composition with lower elevations, it is in this range that one begins to see abrupt limits to species distributions, apparently associated with elevation. Many plant species seem to appear only above ca. 950 $\mathrm{m}$, while other species suddenly drop out at this elevation. A bright-red-flowered Aphelandra (Acanthaceae), for example, appeared at roughly this elevation at all three sites, while the common herb Ctenanthe ericae (Marantaceae) disappeared from the two Sinangoe sites (the species was absent in the Bermejo area). We did not notice any turnover of this kind at lower elevations, but it would require thorough investigation to establish that fact. There is also turnover in the flora within this band of upper hill forest, e.g., species that grow only above $1,300 \mathrm{~m}$ or species that grow no higher than $1,200 \mathrm{~m}$, but the landscape variation in climate and geology makes it unlikely that these limits would remain constant across the region.

As expected, in our samples of canopy trees in the upper hill forest we found somewhat lower species diversity and more dominance by a few species than in the lower hill forest. We also noted considerable variation in the dominant trees from one site to another. On the steep ridge below the Bermejo Vista camp, a transect of 100 canopy trees contained 47 species (compared to 59 for the comparable lowland transect; see above). Nearly a third of the trees belonged to only two species: Billia rosea (Hippocastanaceae; $18 \%$ of the sample) and Otoba glycycarpa (Myristicaceae; $12 \%)$. On the sloping ridge below Shishicho camp, our 100 -tree transect contained 50 species. Minquartia guianensis (Olacaceae) accounted for $12 \%$ of the trees, while three species of Myristicaceae (Compsoneura ulei, Otoba glycycarpa, and Virola sp.) made up $20 \%$
(7\%, $7 \%$, and $6 \%$, respectively). And on the sloping ridge above Ccuccono Ridge camp, an 80-tree transect contained 37 species. Here the dominants were Dacryodes olivifera (Burseraceae; 26\% of the total), Billia rosea (9\%), and two euphorbs (Conceveiba sp. and Hyeronima macrocarpa; $8 \%$ and $6 \%$, respectively). Other tree species that are conspicuously abundant at these elevations, though not in the transects, are the large emergent Ficus coenulescens (Moraceae), and the subcanopy Grias neuberthii (Lecythidaceae) and Wettinia anomala (Arecaceae).

The dominance of individual species is very patchy, and this patchiness is apparent from the smallest to the largest spatial scales. On one long stretch of the Ccuccono trail ridge, for instance, nearly half of the shrub layer stems appear to be Psychotria deflexa (Rubiaceae), while on two other stretches of the same ridge the dominants are an Alibertia sp. (Rubiaceae) and a Miconia sp. (Melastomataceae), respectively. At a larger scale, the most common understory species in our Shishicho camp transect, the palm Hyospathe elegans, is missing or rare only a couple of kilometers away, on the ridge from the Sinangoe station leading down to Ccuccono. But this species is common again on the Bermejo Vista camp ridge many kilometers away. Some of this variation in dominant species reflects small-scale heterogeneity or dispersal limitation within a site, while some variation represents large-scale environmental differences across the landscape. For example, although Dacryodes olivifera and Compsoneura ulei were absent from our Bermejo Vista camp transect, they were both fairly abundant just above camp, from 1,200 to $1,300 \mathrm{~m}$. By contrast, there is no question that Dacryodes was exceptionally abundant throughout the Ccuccono area, since large patches of its newly flushed, orangish leaves were visible on all the surrounding ridges.

Our only transect sample of the shrub layer in upper hill forest was from the Shishicho camp, from 950 to $1,000 \mathrm{~m}$. The 200 stems sampled contained 90 species, with the most common taxa the small palm Hyospathe elegans (11\% of the stems) and the shrub 
Psychotria bertieroides (Rubiaceae; 7\%). At the family level, Rubiaceae (18 species) and Melastomataceae (14 species) were dominant. These two families account for more than a third of the species in this transect, which supports our casual observations that they dominate the shrub layer of the hill forests throughout this region. In addition to the many Psychotria, the common Rubiaceae include various species of Faramea, Coussarea, Rudgea, and a widespread small tree of Chomelia. The common Melastomataceae include many Miconia, as well as various species of Ossaea and Clidemia.

\section{Acid ridges in upper hill forest - All the} narrow ridgetops in the Sinangoe area above $1,350 \mathrm{~m}$, including the Shishicho ridgeline, seem to be characterized by a stunted vegetation and a flora indicating highly acid soils. Where exposed by landslide, the parent material here is a very hard rock, probably quartzite. The areas we visited had characteristically short forest (ca. 10-15 m tall) and trees with small crowns, a solid mat of roots covering the soil, frequent clumps or carpets of Sphagnum and other mosses on the ground, but little moss cover or other epiphytes on the tree trunks. Except for its stature, this vegetation is very different from that on the higher-elevation mountain summits of the Cerro Sur Pax complex (described below).

This distinctive vegetation grows very narrowly along the spines of the ridges in this "roller coaster" terrain. This is probably because both the acidic soils and the dry conditions caused by the exposure to wind are confined to a very narrow ribbon of forest running along the highest points of the ridges. On the major saddles between the ridgetops and on the slopes flanking them, the soil is once again a dark clay, the trunk-epiphyte load and moss cover is almost as dense as on any of the wetter ridges, and the vegetation is much more like that of typical upper hill forest, with species such as Tovomita weddelliana again prominent in the understory. In traversing the ridgeline, one passes in and out of the acid ridge vegetation.
One of the most distinctive components of this vegetation, in addition to Sphagnum, is Trichomanes cristatum, an erect, terrestrial filmy-fern with orangish hairs. Other conspicuous and characteristic taxa are Graffenrieda and Tibouchina (Melastomataceae), Guzmania squarrosa and Racinaea undulifolia (Bromeliaceae), and Sphaeradenia (Cyclanthaceae). Also apparent here are taxa characteristic of the higher mountains but known to reach lower elevations on acid soils. These include genera such as Brunellia (Brunelliaceae), Symbolanthus (Gentianaceae), Weinmannia (Cunoniaceae), Prunus (Rosaceae), Centronia (Melastomataceae), and Myrsine (Myrsinaceae). Also common here are Miconia (Melastomataceae), Cybianthus (Myrsinaceae), Palicourea (but not Psychotria; Rubiaceae), Vochysia (Vochysiaceae), Ericaceae, Myrtaceae, Sapotaceae, and Chrysobalanaceae. Legumes are uncommon, except for one distinctive Inga that we could not identify with the recent field guide for Ecuadorian Ingas (Pennington and Revelo 1997). The most common palm on the Shishicho ridgeline was a small Geonoma that we encountered in Bermejo only above $1,700 \mathrm{~m}$, on the mountain ridge south of Cerro Sur Pax.

In a transect of the shrub layer on the acid ridges, a small-leaved Myrsine (Myrsinaceae) accounted for $11 \%$ of the individuals, a Miconia (Melatomataceae) $9 \%$, and the Geonoma sp. (Aracaeae) $8 \%$. Out of 120 stems there were 49 species. In a mixed-habitat transect of canopy trees that included some of the acidridge as well as the adjacent clay-soil slopes and saddles, a Pouteria (Sapotaceae) made up $14 \%$ of the individuals, Macrolobium sp. nov. (Caesalpiniaceae) 10\%, Vochysia sp. (Vochysiaceae) 8\%, a Licania (Chrysobalanaceae) 6\%, another Pouteria 5\%, and a new Conceveiba (Euphorbiaceae) for Ecuador $5 \%$. Out of 99 trees there were 39 species. The same Macrolobium was also abundant in patches in the typical upper hill forest at $1,300 \mathrm{~m}$ on the southern slopes of the Cerro Sur Pax complex. The Vochysia, although similar in appearance to $V$. braceliniae of the lowlands, is probably a distinct species. 
In the Bermejo area, there seems to be very little exposure of acidic rock, except perhaps on the highest summits. At lower elevations, quartzite is mostly evident as sheer cliffs. Only on the edges or faces of such cliffs did we find characteristic acidophilic species. The lip of the escarpments directly north of the Bermejo River was the only site where we encountered the tree Humiriastrum diguense (Humiriaceae), a taxon characteristic of acid soils, and an unidentified purpleflowered Gentianaceae. On the edge of a higher cliff at ca. 1,700 m on the Sur Pax complex, we encountered several individuals of Purdiaea mutans (Cyrillaceae), a species known from the acid-rock mountains in the southern provinces of Zamora-Chinchipe and MoronaSantiago, but never collected north of there in Ecuador.

\section{Mountain Ridges and Summits}

$(1,500-2,300 \mathrm{~m})$

Mountain ridges - The major break in floristic composition with elevation occurs at approximately $1,500 \mathrm{~m}$. At this height the flora shifts from one of mainly lowland genera to mainly montane genera. On our route up the southern slopes of Cerro Sur Pax, the transition happened to coincide with the presence of a steep cliff at $1,500 \mathrm{~m}$. The abrupt change in flora there may have been due, in part, to a change in the rock and soil chemistry above and below the cliff, but it is more likely the result of an elevational transition in cloud and moisture conditions. The 1,500-m mark appears to be the lower limit of the cloudline here-the elevation where the clouds hit these mountains with greatest frequency, especially in the dry season.

Above $1,500 \mathrm{~m}$ the canopy is mostly $20-30 \mathrm{~m}$ tall and the leaves noticeably thicker than at lower elevations. Tree trunks here are dense with filmy-ferns and other vascular epiphytes, as well as a relatively thin and patchy layer of different mosses. Also characteristic is a high frequency of large hemi-epiphytes such as Clusia (Clusiaceae), Schefflera (Araliaceae), and Blakea or Topobea (Melastomataceae) growing from the crotches of trees; many large trees with prop-roots and a high frequency of resprouted stems; a high density of succulent shrubs such as Gesneriaceae and terrestrial bromeliads (mainly Guzmania and Pitcaimia); relatively more stumps serving as "nurse logs" (platforms for the germination and establishment of tree seedlings) than in the lower elevation forests; and more organic material and moss (rarely Sphagnum) on the ground.

There are many fewer species of trees on the mountain ridges than in the hill forest, but the flora here is by no means impoverished. In our canopy-tree transect on the ridge ascending Cerro Sur Pax from the south (at 1,900-2,100 m), the 100 trees we sampled represented 24 species. Billia rosea (Hippocastanaceae) made up $17 \%$ of the trees, Calatola sp. $15 \%$ (Icacinaceae; identification in doubt but Calatola fruits found under one of the trees), a freestanding species of Clusia (Clusiaceae) $10 \%$, Tovomita weddelliana (Clusiaceae) 9\%, Myrsine sp. (Myrsinaceae) 8\%, Weinmannia cf. pinnata (Cunoniaceae) $7 \%$, and Clethra revoluta (Clethraceae) $5 \%$. The transect included mostly montane genera, such as Podocarpus (Podocarpaceae), Ilex (Aquifoliaceae), Prunus (Rosaceae), and Cinchona (Rubiaceae). Other, smaller, mostly montane genera in the sample included Meriania (Melastomataceae), Hedyosmum (Chloranthaceae), Ruagea (Meliaceae), and Monnina (Polygalaceae). The aroid Stenospermation, generally a trunk epiphyte at lower elevations, appeared here as a shrubby terrestrial plant.

Except for Disterigma and Sphaerospermum, Ericaceae are not particularly abundant on these high mountain ridges, especially in comparison with the acid ridges we visited in Sinangoe. Rubiaceae are frequently encountered here as trees rather than shrubs, though the most common species is a small-leaved, orangeflowered Palicourea. Also common are an Eschweilera (Lecythidaceae) treelet with recurved leaves, three species of Guatteria (Annonaceae), and several short treeferns and Geonoma palms. Bromeliads are also more conspicuous here as understory epiphytes, in addition to the usual high diversity of Araceae and 
Pteridophytes. One Burmeistera (Campanulaceae) is an exceptionally common climber on tree trunks. The only bamboo we encountered at these elevations was an infrequent, skinny, clambering Chusquea (Poaceae), and the only legume a large tree, Abarema killipii.

Along much of the Andean slopes, like in the Salado River drainage to the south of the Sinangoe area, the palm Dictyocaryum lamarckianum replaces Iriartea above $1,500 \mathrm{~m}$, but not here. While Iriartea drops out at these elevations, only a few juvenile Dictyocaryum were seen in the understory, and a couple of emergent individuals were spotted on the ridges to the north and east of Sur Pax. It may be that Dictyocaryum is more adapted to the acid soils that are scattered and rare in the Bermejo area. Probably this species will show up in abundance in the higher southern part of the Sinangoe area, not far from the Salado River drainage. Two tall understory palms of Wettinia, a genus also related to Iriartea, are similarly abundant in the Cofán foothills. Wettinia maynensis is common in the lower hill forest, and Wettinia anomala is common in the upper hill forest and extends into the mountain ridge forest. The transition between the two species is not well-marked, but may occur at roughly $1,000 \mathrm{~m}$.

The most frequent colonists of landslides and treefall gaps at these elevations are a lobed-leaved species of Croton (Euphorbiaceae), similar in habit to Croton lechleri but replacing it at these elevations, an orange-leaved Vismia (Clusiaceae), and various Miconia (Melastomataceae) species. Rarely there are patches of a large white-leaved species of Cecropia (Cecropiaceae), the kind easily spotted from above on a clear day, but these are not as conspicuous an element here as on the western slopes of the Andes at this latitude.

Mountain summits - The southern peak of Cerro Sur Pax (2,275 m), the highest point we reached in this survey, has a much lower and more open canopy than the ridges below it. Most of the species here also grow along the lower mountain ridgecrests, but the stature of the canopy trees is reduced to $10-20 \mathrm{~m}$, the bark of trees more covered in moss and other trunk epiphytes, species associated with disturbance more frequent, and canopy epiphytes more visible and accessible.

The explanation for the low stature and apparently active disturbance regime seems revealed in the clusters of dead snags scattered over the summit. These are symptoms of frequent lightning strikes that usually hit the tallest trees, especially those with monopodial (Christmas tree-like) growth, but also kill many of the adjacent smaller stems when the lightning heats their sap to the boiling point. The cool temperatures and near-permanent cloud cover may also reduce growth rates of the trees. Both factors probably also explain the great accumulation of dead trunks, branches, moss, and other organic material on the surface, which makes walking precarious here.

The northern peak of Sur Pax, which is only slightly higher $(2,341 \mathrm{~m})$ than the southern peak we visited, appears to have very similar vegetation. But along the ridge to the east of Sur Pax, on a series of high summits forming the northern wall of the Chandia Na'e River headwaters, the plant community is somewhat different. These summits, which we were unable to visit, mostly have much shorter, shrubby vegetation. They are also flanked by steep, recent landslides, which have exposed large areas of flat rock close to the summit. This is a sharp contrast to the open and tangled forest on the slopes of Sur Pax, which, though subject to landslides, show very little exposed rock. It is not clear whether there is a different type of rock underlying these shrubby summits, whether the rock strata there are tilted at such a steep angle that forest never develops, or whether there is simply a greater frequency of lightning on the northern headwall of the valley. The presence there (seen through binoculars) of a few isolated emergent individuals of the palm Dictyocaryum lamarckianum (see previous section) suggests that the stunted vegetation on these eastern ridges may be largely the result of a distinct soil chemistry related to a different underlying rock. 


\section{Natural Disturbance on Slopes and Ridges}

Satellite images show as much as a quarter of the Cofán foothills covered by early successional forest growing on recent landslides. Some of these are tiny patches of less than a hectare; others cover square kilometers. One horseshoe-shaped landslide west of Sinangoe is as large as the entire Shishicho ridge system (Figure 2). The pattern of disturbance on ridges throughout area, whether large-scale or small, is basically the same. As streams erode and undermine the slopes, landslides or lateral slumps wipe out whole sections of vegetation, leaving large expanses of mineral soil exposed to sunlight. These open areas are eventually filled with a succession of pioneer species. On the upper slopes of the landslides, where rock is exposed or the soil is very shallow and unstable, the process is slow. Small herbs, vines, and shrubs may persist for a long time, but trees colonize very slowly. Toward the bottom of the landslide, where deep piles of mixed debris are deposited, the regrowth is rapid, with giant herbs and fast-growing trees shooting up to form a closed-canopy forest. The large bamboo, Guadua angustifolia, is frequently found in dense patches associated with old disturbance, but it is not a consistent member of the regeneration community.

In contrast to the ridges, some of the gradual slopes have a very different disturbance regime. These are subject to continuous lateral sliding of the soil and underlying soft rock. The consequence is that large areas of these unstable sloping terraces (sometimes several square kilometers of forest) are in a state of constant disturbance as the soil buckles and slides downhill. Much of the vegetation survives this slippage-a bit downhill from where it was and often with considerable root damage, and now interspersed with a mosaic of breaks in the soil and canopy, where pioneer species can colonize among the mature-forest species. Lianas and vines also benefit from these slips, by virtue of a highly flexible system for establishing new rooting points (as well as taking advantage of the old ones), quickly expanding into the breaks and up and over damaged trees. Thus a large portion of these unstable slips are covered with a disorganized tangle of plants that is very difficult to penetrate. The local Cofán residents in both areas describe these slopes as having always been in this condition of flux, not the result of an earthquake.

\section{NEW SPECIES AND OTHER SIGNIFICANT RECORDS}

Although most of the plants we collected during the inventory have not yet been identified, many collections have already been confirmed as new species. Of the 23 species of Psychotria (Rubiaceae) we collected in the Sinangoe region in our preliminary trip in 2000 , four $(17 \%)$ have been confirmed as new to science (C. Taylor, pers. comm.). At least two terrestrial bromeliads-one collected on the southern slopes of Sur Pax (Figure 4B) and the other collected on the Shishicho ridgeline-are undescribed (J. M. Manzanares, pers. comm.). One of the few Myrtaceae we collected in reproductive condition is currently being described as a new species of Calyptranthes (M. L. Kawasaki, pers. comm.; see Figure 4A and a more complete description of the plant below). One species of Calathea (Marantaceae) has been confirmed as new, and two others are probably new as well $(\mathrm{H}$. Kennedy, pers. comm.; Figure 4E).

Several other taxa we suspect to be new await confirmation. The most common Inga on the acid ridges at Shishicho is different from any of those described and illustrated in a recent monograph of Inga in Ecuador (Pennington and Revelo 1997). Other taxa that appear to be new species include an Heisteria (Olacaceae) with strikingly tiny leaves, a Gynerium (Poaceae), and a Cyclanthus (Cyclanthaceae).

Many species on our list are not present in the new Catalogue of the Vascular Plants of Ecuador (Jørgensen and León-Yánez 1999), and at least one, a yellow-flowered shrub in Basistemon (Scrophulariaceae), represents a new genus for Ecuador. In some cases, these species may already have been collected in Ecuador but the specimens were either not fertile or not seen by a specialist working on the catalogue. But 
for other species these are clearly the first specimens known from the country. An example is Conceveiba sp. (Euphorbiaceae), one of the most common trees in both the upper hill forest and mountain ridge forest, but quite distinct from the two species of Conceveiba listed for Ecuador. Other species represent significant range extensions. For example, Cassia grandis (Caesalpiniaceae), although known from the Pacific coast of Ecuador, had never before been found in the Ecuadorian Amazon.

We estimate that at least $75 \%$ of the species we collected on Sur Pax and Shishicho have never been reported from the province of Sucumbios. This is because the mountainous, western part of Sucumbíos has had very few visits from botanists. A recent map of plant collection localities in Ecuador shows a gaping hole around the Bermejo area (Jørgensen and LeónYánez 1999).

\section{PLANTS IMPORTANT TO WILDLIFE}

Virtually all the dominant trees in the BermejoSinangoe area have animal-dispersed fruit, as do most of the other canopy species. Many of these, such as the dominants Billia and Dacryodes and the subcanopy Grias, produce big nuts, which are a rich resource for many terrestrial mammals such as deer and peccaries but are probably dispersed only by rodents such as agoutis, pacas, and squirrels. Other dominant trees such as Minquartia, Tapirira, Otoba, Virola, Pouteria, the many Inga and Lauraceae, and the scattered giant Ficus, have fruit that attract large birds, monkeys, and terrestrial mammals. Observations of tapir activity in the Ccuccono Valley suggest that the soft sweet fruit of the common successional melastome tree, Bellucia pentamera, is a favored food ( $\mathrm{R}$. Borman, pers. comm.). In the understory, the preponderance of bird-dispersed shrubs and treelets in the Rubiaceae, Melastomataceae, Myrtaceae, and other families is partly responsible for the region's rich avifauna.

The mamnal team's observations on the mountain ridges of the Cerro Sur Pax complex indicate that spectacled bears there eat the tender leaf bases of dense stands of terrestrial bromeliads (Guzmania and Pitcairnia) and the "hearts" of small Geonoma palms. Whether these are really preferred foods, or just abundant edible resources where mountain bamboo species are in short supply, is not clear. It is interesting that of the two bromeliads most eaten, one is an undescribed species and the other may be new to Ecuador.

\section{PLANTS COMMONLY USED BY THE LOCAL COFÁN COMMUNITIES}

(Roberto Aguinda and Robin Foster)

As with most native communities somewhat isolated from western culture, there is considerable knowledge and use of the native plants in the daily lives of the region's Cofán residents. Especially in the community of Alto Bermejo, which has very limited contact with the outside, botanical knowledge appears to exceed that found among elders of the other Cofán communities. Even species of small, inconspicuous plants that go largely ignored or forgotten in the forests around other Cofán villages are readily distinguished from each other in Bermejo and have names in current use.

An ongoing project among the Cofán is to catalog the names and uses of these plants before more information is lost, and to link Cofán taxonomy to specimen collections and Linnaean names. This effort builds on the already published work of Cerón and colleagues (1994) for the area around the Sinangoe community; Cerón $(1986,1988,1995)$, for the area around the Cofán community of Doreno; and a database of collections and images of plants (Aguinda and Foster, unpublished) for the area around the Cofán community of Zábalo. The following is a brief summary of the plants that the Cofán foothill communities use most frequently, according to interviews and observations.

For house construction, the underlying posts are usually made of the very durable seña'mba quinicco (Minquartia guianensis, Olacaceae), the floors from split trunks of the common palm bom'bo 
(Iriartea deltoidea, Arecaceae), and the cross beams of strong but flexible small trees, often in the Annonaceae, especially tsao quini'cco (Cremastosperma gracilipes).

In Bermejo, with its dense stands of the small fan-palm tananácco (Chelyocarpus ulei), this is the preferred roofing material with a very long life-span. In other areas, uttuvo (Carludovica palmata, Cyclanthaceae), found along the lowland streams, is the next best material for roofs. These plants are not readily available to the downriver Cofán, who usually use Geonoma and Attalea palms (or metal) for roofing.

The larger canoes are usually made from cuticho (Cedrelinga cateniformis, Mimosaceae; chuncho in Ecuadorian Spanish). When older canoes are no longer serviceable, they are recycled into seats and benches and become the principal source of furniture. The large stems of the riverside grass upe caufa (Gynerium sagittatum, Poaceae) are used as canoeing poles, or palancas. Harpoons for fishing are usually made from split trunks of $c$ cu'ye (Wettinia palms) or on the spur of the moment from the small, perhaps undescribed species of Gynerium common along riverbanks (see the section on river and stream margins above). Rope comes primarily from hanging roots of a large Philodendron (Araceae), rather than Heteropsis, which is commonly used elsewhere, and strapping is largely from the bark of Sterculia (Sterculiaceae) trees. Leaves of nijon'cho (Oenocarpus batana) are one source of the elegant backpacks woven together quickly for carrying heavy loads; aerial roots also are used (Figure 6A-B).

Although clothing is now all imported, decorative collars of seeds are made from the flexible leaf rachises of the small spiny Aiphanes palms. The tuinfa palm (Astrocaryum chambira) used for fiber in the Cofán communities downriver is missing here. For perfume and deodorant, the fragrant patisa'cco (Ammandra dasyneura, Arecaceae) and Hedyosmum (Chloranthaceae) from the mountain ridges are used. The resinous gums from Burseraceae trees (mostly the genera Protium, Dacryodes, and Trattinnickia) are used commonly for starting camp fires and as candles.
As in most of Amazonia, the thorny prop-roots of the palm Socratea exorrhiza are used for grating plantains or sweet potatoes (Ipomoea, Convolvulaceae). Cecropia (Cecropiaceae) leaves are used in the fermentation process to produce the important chicha drinks derived from mashed plantains (principally) and yuca. Wild edible fruits are varied, but commonly used ones include all the grapelike wild bocha tsa'ja (Pourouma spp., Cecropiaceae), fiño (Inga spp., Mimosaceae), ttetteccu'cho (Grias neuberthii, Lecythidaceae), tssinimbo suvu (Brosimum spp., Moraceae), Ammandra dasyneura (Arecaceae), and Oenocarpus bataua (Arecaceae), from which a sweet drink is made.

The important drug plants include the famous stimulant yaje (Banisteriopsis caapi, Malpighiaceae), and the more locally known yoco (Paullinia yoco, Sapindaceae). Conguju (Senna ruiziana, Caesalpiniaceae) is commonly used for headache; avune'cho (Begonia rossmanniae, Begoniaceae) to reduce swelling, redness, and pain; shendu (Tournefortia, Boraginaceae) for pain and infections; Croton lechleri (Euphorbiaceae) for wound healing; and both Triolena pileoides (Melastomataceae) and ya'picho (Antrophium cajenense, Pteridophyta) for throat infections. The shamans of course have many other plants in their repertoire.

\section{ADDITIONAL SPECIES NOTES}

- Miconia calvescens (Melastomataceae), with its large, roundish leaves, usually red below when newly emerged, was occasional on stream margins and other disturbed sites, mostly at middle elevations above 800 $\mathrm{m}$. What makes this species important is that it has somehow arrived on Hawaii, Samoa, and many other islands of the Pacific Ocean, and has become one of the principal invasive pests in that region, pushing out the native flora. In this region of Ecuador, it seems to suffer frequent damage from insect herbivores eating holes in the leaves, something not seen on the Pacific islands. The key to controlling this species elsewhere might be found among its natural pests in Ecuador.

- Piper (Piperaceae) is a large genus of shrubs characterized by long skinny spikes of tiny flowers and 
fruits, known to be dispersed mostly by bats (mainly the genus Carollia). The bats remove the entire ripe spike while in flight and consume it later while perched. At higher elevations we encountered in the understory a high frequency of several species of Piper with very short inflorescences, as well as Piper piluliferum, a species with an orbicular inflorescence. Although at least one such species occurred in the lowlands, and a few of the long-spiked species occur on the mountain ridges, the abundance of such Piper species in the mountains suggests that there is a different spectrum of seed-dispersers (or pollinators) available.

- In the Bermejo area we collected a small variety of Cyclanthus bipartitus (Cyclanthaceae), associated with the banks of several of the small shaded streams but also on the north bank of the Bermejo River. In the view of the senior author, this variety will likely be shown to be a new, cryptic species distinct from the usual Cyclanthus, which is now considered a monotypic genus. The new "variety" is found in dense stands along the watercourses, either on rocks or solid banks, and is smaller $(<1 \mathrm{~m})$, narrower, darker, shinier, and with a smaller inflorescence than the common variety. Although difficult to distinguish from the juveniles of the typical variety, it is not found along many of the streams, even when the typical, much larger variety is present.

- The understory palm Hyospathe elegans frequently forms dense patches in the upper hill forest from 950 to $1,300 \mathrm{~m}$, although it is only scattered in the lower hill forest. Although H. elegans is considered to be a highly variable species, the purpleflowered variety with consistently narrow leaflets and more persistent spathe, encountered only in the mountain ridge forest, appears to be sufficiently distinct to merit recognition as a separate species.

- Low shrubs of certain melastomes, such as Clidemia heterophylla and Tococa guianensis, are often found in dense patches associated with abandoned nests of Atta (leaf-cutter) ant colonies. In creating their underground colonies, the Atta place subsoil from their excavations onto the surface, creating a nearly water-impermeable roof over the nest. Once the colonies are abandoned, few plants seem to be able to colonize these areas, but there is little competition for those that can. The ant-associations of these two species, with large formicaria (myrmecodomatia) at the base of their leaf blades, may also play a part in allowing the plants to establish while the Atta colony is still active.

- Another ant-plant, the small tree Duroia hirsuta (Rubiaceae), has other species associated with the clearings created by the ants around its stems. Two of the most frequent associates are the low shrublet Psychotria polyphlebia (Rubiaceae), and the shrub Ossaea boliviensis (Melastomataceae). The latter is also occasionally found on the abandoned Atta nests, although not harboring ants itself.

\section{INFERRED HISTORY OF HUMAN USE}

\section{Alto Bermejo}

The Bermejo community shows the usual patchwork of currently cultivated plots and regenerating old ones. Human impact beyond this is barely noticeable. Even a short distance away on the trails, valuable timber species such as Cedrelinga cateniformis (Mimosaceae) are abundant. Palms and other species important for house construction are harvested nearby, but on a small scale.

Given the tiny footprint of the Bermejo community, it is not surprising that as we walked the several kilometers of trail to ascend from 450 to $2,300 \mathrm{~m}$ we passed little sign of human impact. The exceptions are a few small campsites, near streams or on promontories such as our Vista camp, and a small clearing at 1,600-1,700 $\mathrm{m}$ on the southern slopes of Sur Pax, made ten years ago in an attempt to cultivate potatoes. This clearing has now regenerated into a 10-m tall forest dominated by Croton and Vismia. It is also interesting to note that peach palm (Bactris gasipaes) is frequent along the riverside trails near the 
community. The local residents also describe finding caimito (Pouteria, Sapotaceae), achiote (Bixa orellana, Bixaceae), tobacco, and other frequently cultivated plants growing wild in these sites. All indications point towards a long-term human presence in the area, perhaps with a much higher population density than at present.

\section{Sinangoe}

The Sinangoe field station above the Sieguyo River, our base of operations for this region, is built on a small flat terrace that was cleared for rice cultivation roughly 30 years ago. Other nearby areas to the east appear to have been cleared around the same time. Prior to being cut again for the present station in 2000, the regrowth on this terrace consisted mainly of medium-sized Jacaranda copaia (Bignoniaceae) and Cecropia sciadophylla (Cecropiaceae) trees. Closer to the confluence of the Sieguyo and Aguarico Rivers, there are many small abandoned clearings from colonization attempts during the last decade. All of the failed colonization lends additional support to the impression that the area is poorly suited to agriculture (OAS 1987).

Just north of the Sinangoe field station, the trail to Shishicho passes a large stump of what appears to be a cedro (Cedrela fissilis, Meliaceae), cut into boards with a chainsaw. It seems likely that most of the mature cedro this close to Puerto Libre has already been cut. However, even far from human settlements cedro are only encountered sporadically, leading us to conclude that it has probably never been an important timber resource for the area. It is apparently more common in the vicinity of La Sofía (L. Narvaez, pers. comm.). This trail to Shishicho partly follows an old path, so well-used in the past that it is now marked in places by deep erosion gullies. Scattered on the trail to the Ccuccono River are a few small campsites, but human use seems minimal. Any human impacts in the bottom of the Ccuccono Valley would have been obliterated in the massive washouts following the earthquake of 1987.

\section{ENDEMIC PLANTS}

Participants/Authors: Nigel Pitman, Robin Foster, and Roberto Aguinda

Conservation targets: restricted-range species, especially pleurothallid orchids, terrestrial bromeliads, aroids, and other herbaceous wildflowers

\section{INTRODUCTION}

The foothills of tropical mountain ranges around the world are celebrated for their extravagant levels of plant endemism, meaning that forests there contain large numbers of plant species not known to occur anywhere else (Gentry 1992). In the Cofán foothills, lying at the crossroads of two of the world's most diverse bioregions and bisected by the equatorial line, the expectation is of enormous numbers of endemic plants.

That expectation is borne out in nearby plant communities just a few kilometers to the south. Nearly $20 \%$ of the 4,011 plant species currently considered endemic to Ecuador have been collected in the thin strip of Andean forest stretching from the town of Tena in the south to the Colombian border in the north-an area constituting just $3-4 \%$ of the country's territory (Valencia et al. 2000). On a smaller scale, the narrow triangle of forest between the Sumaco and Reventador volcanoes and the Cordillera de los Guacamayos is swarming with endemics. More than 100 plant species endemic to Ecuador have been collected so far in the Cayambe-Coca Ecological Reserve, and more than 90 have been collected in the Sumaco-Napo-Galeras National Park; these numbers will double, at least, as the area is explored further.

The list of endemics for these protected areas is dominated by small, herbaceous plants, especially epiphytes in the families Orchidaceae, Gesneriaceae, Araceae, and Bromeliaceae. At least 21 orchid species and eight species of bromeliads endemic to Ecuador have been registered in Sumaco-Napo-Galeras, and inventories of other areas of the Ecuadorian Andes suggest that dozens more are waiting to be discovered there. The new reserve we propose for the Bermejo region would protect a large number of these species. 
That is critically important, because plants with restricted ranges face an elevated risk of extinction. In the recently published Red Book of the Endemic Plants of Ecuador, Valencia et al. (2000) outline the precarious conservation status of the country's endemic flora. Fully $36 \%$ of all Ecuadorian endemics are known from a single population, $75 \%$ have never been registered within a protected area, and $83 \%$ qualify as threatened with extinction under World Conservation Union (IUCN) guidelines.

Here we present some initial observations on plant endemism in the Cofán foothills. It is still too early to draw precise conclusions about endemism in this poorly explored region, and we have tried to avoid the trap of thinking that all the strikingly unfamiliar plants we observed in the field were endemic species. Instead, our aim is to open the discussion with some preliminary observations from the field and the herbarium, and to suggest some avenues for further study. Considering the profusion of endemic taxa in adjacent areas of the eastern Andes, our caution will probably prove unwarranted. A large proportion of the plants we registered are most certainly unique to the area.

\section{REGIONAL-SCALE ENDEMISM}

The preliminary list of plants assembled for the Bermejo and Sinangoe region (see Appendix 1 and the preceding chapter) contains at least 15 species currently believed to be endemic to Ecuador. Since most of the plants on our checklist for the region have not yet been identified to species (and since widespread species are often identified first), we predict that the actual number of endemics is at least ten times higher. Ironically, the discovery of these species in the Cofán foothills almost guarantees that most of them will eventually lose their endemic status, because our collection sites are just a few kilometers from the Colombian border. As plant-collecting programs continue in the eastern Andes of Colombia (especially along the Pasto-to-Mocoa road), a large number of species currently considered endemic to Ecuador, and many of those present in our area, will probably be crossed off the list.

The evidence suggests, however, that many of those will prove endemic to a small stretch of the eastern Andean slopes (i.e., a few degrees of latitude). Botanists working along the length of the Andes have documented thousands of plant species that appear to be restricted to very narrow sections of the cordillera (e.g., Henshold 1999, Valencia et al. 2000), and it is unlikely that all of these are artifacts of a scanty collection record.

Prominent among the confirmed Ecuadorian endemics in the Cofán foothills list-and in the list of endemics expected to occur there-are epiphytic orchids and bromeliads. The two undescribed species of bromeliads we collected around Cerro Sur Pax and the Shishicho ridgeline probably have narrowly restricted ranges as well (J. M. Manzanares, pers. comm.). By contrast, we found an oddly meager diversity and abundance of micro-orchids in the tribe Pleurothallinae, and especially in the genus Lepanthes, which contains hundreds of species endemic to the Ecuadorian Andes. In the Pastaza River valley alone, L. Jost has recently documented 90 co-occuring species of Lepanthes; 25-30 of these can occur together on a single mountain covering the same elevational range as Cerro Sur Pax (L. Jost, pers. comm.). But the only site where we found species of Lepanthes during the survey was on the upper-most slopes of Sur Pax, between 1,900 and 2,275 m. Even there, methodical searches of the understory and canopy during our three days of collecting only turned up seven or eight individual plants, of mostly the same species. We may have spent too little time or covered too little ground in the higherelevation forests that these taxa prefer. Or we may simply have overlooked dozens of these notoriously inconspicuous plants (Endara and Jost 2000).

\section{SMALL-SCALE ENDEMISM}

Botanists working on the opposite side of the Ecuadorian Andes have suggested that levels of "micro-endemism" among plants in the western 
foothills may be astronomically high. The idea is that a large number of the species endemic to forests of western Ecuador might, in addition, be restricted to a single ridge, valley, or mountaintop. In Gentry's (1986) famous description of the Centinela ridge, just south of Santo Domingo, he hypothesized that several dozen plant species might not occur anywhere else in the world but that small hill $\left(5-10 \mathrm{~km}^{2}\right)$ at the base of the Andes. Although Gentry's report has proven somewhat premature-most of the putative Centinela endemics have now been collected elsewhere in coastal Ecuador, and only five species are still known only from that mountain (Valencia et al. 2000)-the idea of this single, rather unremarkable ridge harboring five unique plant species is itself astonishing (Dodson and Gentry 1991). If confirmed, the Centinela hypothesis would imply the existence of hundreds of micro-endemics in the Cofán foothills.

The most intriguing example of this sort of endemism that we encountered in the rapid inventory was an undescribed shrub in the genus Calyptranthes (Myrtaceae, the guava family; Figure 4A). This shrub was well known to the Cofán members of the team as ishoaquinico, a plant Cofán communities used, until very recently, in coming-of-age ceremonies for young men. The species was abundant along trails in the vicinity of the Sinangoe station and present on the lower portion of the trail up to the Shishicho campsite, but we did not encounter it anywhere else in the region. Indeed, the Cofán apparently used to make long expeditions to this area of Sinangoe to collect the plant, because they had never found it anywhere else. The species is currently being described as Calyptranthes ishoaquinico sp. nov. by M. L. Kawasaki, a specialist in the taxonomy of Myrtaceae.

We also collected a pair of very similar Calathea species that may illustrate this pattern. One of them, a striking herb with purple flowers and pink bracts (Figure 4E), was a common sight along the trail leading from the Bermejo Vista camp up the southern slopes of Cerro Sur Pax. At the same elevation on the Shishicho ridge, $10 \mathrm{~km}$ to the south, we encountered a superficially similar plant that, on closer inspection, proved distinct in several respects. Whether these taxa are still in the process of speciation or simply replacing each other in alternate drainages remains to be determined. In the meantime, it is interesting to note that the closest taxon to these in the Flora of Ecuador is a species that was first collected on the Centinela ridge by Al Gentry (Kennedy et al. 1988).

\section{OTHER ENDEMICS OF INTEREST}

- Passiflora popenovii (Passifloraceae), a vine endemic to Ecuador but apparently extinct in the wild (Jorgensen 2000), is cultivated along the new road from La Bonita to Puerto Libre (P. Fuentes and X. Aguirre, pers. comm.). The La Bonita-Sucumbíos Foundation in the town of La Bonita is now developing a program to prepare preserves from the fruits.

- The bromeliad Werauhia haltonii was known from just one other population in the Cordillera de los Guacamayos (more than $100 \mathrm{~km}$ to the south) before we found it growing on the 2,275-m summit just south of Cerro Sur Pax.

\section{THREATS AND RECOMMENDATIONS}

These patterns of endemism are important for conservationists because species with small geographic ranges will be the first to go extinct as habitat loss and climate change intensifies. In the case of microendemics, even moderate forest clearing on isolated mountaintops and ridgelines, where endemics may persist in tiny remnant populations, can potentially result in global extinctions (Dodson and Gentry 1991). On the larger scale, restricted-range species are protected by fewer parks and reserves than more common species. Plant species endemic to the San Miguel or Bermejo watersheds-like, apparently, the new species of Guzmania we discovered on Cerro Sur Pax-are not currently protected by any Ecuadorian or Colombian park there, and do not fall within the present borders of the Cayambe-Coca Ecological Reserve. 
Measuring the precise number of species endemic to this area-and to any particular section of the Andean range-is still beyond the reach of scientists. Considering how critical the project is for the effective conservation of the Andean flora, we are astonished that it has attracted so little research attention to date. Within the Cofán foothills, the first step would be to sample systematically ridgetops throughout the region, focusing on taxa with a propensity for endemism (i.e., orchids, bromeliads, Gesneriaceae, etc.). Carefully designed and carried out, such an effort would produce invaluable data for conservationists and biologists alike.

\section{AMPHIBIANS AND REPTILES}

Participants/Authors: Lily 0 . Rodriguez (field) and Felipe Campos (museum)

Conservation targets: species with restricted ranges; species of higher elevations (Hyla phyllognatha, Liophis epinephelus, Neusticurus cochranae, Chironius monticola); taxa with declining populations, e.g., glass frogs (Centrolenidae) and poison-arrow frogs in the genus Colostethus (Dendrobatidae); Enyalioides cofanorum and other lowland species now extinct at Santa Cecilia (Figure 5A).

\section{METHODS}

This report combines L. Rodríguez's fieldwork around Sinangoe during the inventory with longer-term observations of the region's herpetological communities by F. Campos (who was not able to join us in the field). Supplemental observations were made by other members of the rapid inventory team, in the form of photographs taken at Bermejo. Fieldwork was restricted to the lower and upper hill forests around Sinangoe, at elevations between 800 and $1,450 \mathrm{~m}$.

During my (LR) 11 days in the field, I spent 78 hours actively searching for amphibians and reptiles, mostly around the Ccuccono Ridge camp and the Shishicho camp. Sampling consisted of visual and auditory observations during walks on existing trails, both during the day and at night. I focused my searches on the taxa that are less common and widespread and that best characterize the type and condition of different habitats (e.g., Anurans, particulary Eleutherodactylus and Dendrobatidae). I also paid special attention to the stream habitats preferred by many species. I recorded some songs in the field, to compare later with published records. I collected ten species that I could not identify in the field (one specimen apiece) and deposited all specimens in the collections of the zoological museum of the Pontificia Universidad Católica del Ecuador (QCAZ). Two species on the list correspond to photographs taken by other team members in the Bermejo region.

Little prior fieldwork has been done in this mountainous region of Sucumbios. The study conducted by Altamirano and Quiguango (1997) in Sinangoe focused on reptiles and amphibians between 565 and 670 m elevation. Not surprisingly, the species registered in their 34-day inventory (using transects and plots) were all lowland taxa shared with earlier lists from Santa Cecilia, with the exception of Eleutherodactylus cf. incomptus. Campos et al. (2001) inventoried herpetological communities around $\mathrm{La}$ Bonita (between 1,700 and 2,000 m) and Rosa Florida $(1,400 \mathrm{~m})$, and their results are summarized in Appendix 6 of this report.

\section{RESULTS OF THE HERPETOLOGICAL SURVEY}

We observed 85 amphibians and reptiles (excluding tadpoles) during the rapid biological inventory, corresponding to 31 different species. The list includes six species of snake, six lizards, 17 frogs and toads, a salamander, and a caecilian (Appendix 2). Among the most notable records are a new lizard species in the genus Dactyloa (Figure 5E), and the first Ecuadorian record for the lizard Cercosaura ocellata. We expect that a more complete survey, especially at higher elevations, would reveal several additional undescribed species and extend the altitudinal ranges of many known species.

The Cofán foothills lie just $20 \mathrm{~km}$ to the west of Santa Cecilia, whose forests held the world record 
for amphibian diversity until they were destroyed in the 1980s (Duellman 1988; see also Figure 7). The implication is that the lowest elevations of our study site-particularly the floor of the Bermejo River valley, at ca. $450 \mathrm{~m}$-also harbor very diverse communities, including most of the species that were extirpated over the last two decades at Santa Cecilia; see Figure 5A.

Species richness drops significantly as elevation increases, though our data are not sufficient to give a clear picture of how the diversity of this region compares with similar-sized areas elsewhere in the Andes. Between 900 to $1,200 \mathrm{~m}$ in the Andes, one typically expects to find 30 or fewer amphibian species (Duellman 1988; species records for Cordillera del Cóndor and Cordillera del Cutucú in Ecuador, and the foothills of Manu in Peru). In just 11 days in the field, I recorded half this number, probably indicating that species richness in the region is high. By contrast, endemism is low. Most of the species in this region are shared with foothill forests in neighboring Colombia or with lowland forests in western Amazonia (Lynch et al. 1997).

Not surprisingly, the herpetological community in the Cofán foothills is a complex overlap of Amazonian- and Andean-centered fauna. Most of the species we observed in the field have altitudinal ranges rising from the base of the Andes to approximately 2,000 m elevation, and many are mostly known from the adjacent Amazonian lowlands. For example, the black-banded robber frog, Eleutherodactylus nigrovittatus, and at least seven other amphibian species on our list have been collected in Santa Cecilia (Duellman 1978), Yasuní National Park (Ron 2000), and lowland forests farther to the east (Lynch et al. 1997). (As usual in these forests, the small, hard-to-identify frogs in the genus Eleutherodactylus made up a disproportionate number of the species I registered in the field. We list nine in the checklist, though at least four others were seen and not identified.)

Other taxa are more characteristic of montane forest. Among the amphibians, for example, the montane species Hyla phyllognatha (Figure 5C) ranges widely in the Andes from Colombia to Bolivia, always between 600 and $1,700 \mathrm{~m}$. (It is worth noting, however, that the different populations of $H$. phyllognatha might eventually prove to be distinct species; the songs we heard in this survey were different from the typical songs of this species in southeastern Peru [pers. obs.] and from the Ecuador recordings published in Duellman 1972.) It would appear that the herpetological communities in the Andean foothills near the equator have somewhat broader elevational ranges (though similar diversity) compared to foothill communities at higher latitudes, like those in Peru's Manu National Park. This will require more detailed studies to confirm. On the other hand, none of the species in our list that I consider to be taxa of montane forests (Hyla phyllognatha, Liophis epinephelus, Neusticurus cochranae, Chironius monticola) were reported by Altamirano and Quiguango (1997) at their lower-elevation study site around Sinangoe.

While much of the herpetofauna we registered in the Serranías Cofán is shared with lowland sites like Santa Cecilia, most species possess particular adaptations for the steep foothills landscape, where swampy areas are rare and most water is in the form of rushing streams. Thus Eleutherodactylus juveniles hatch directly from eggs, while $H$. phyllognatha and Cochranella midas reproduce in rushing streams.

Reptiles are rarely informative in rapid biological surveys because their population densities are so low as to make observations sporadic. I was surprised, then, to find considerable reptile populations during the survey, registering six snake species without any special effort. One of these was a bushmaster (Lachesis muta) coiled next to one of our tents at the Shishicho campsite (Figure 5B). At least two other snakes-Liophis epinephelus in Shishicho, and Chironius cf. monticola in Ccuccono-appear to be restricted to higher-elevation forest. We also identified six different species of lizards. Neusticurus cochranaea lizard known only from the eastern slopes of the Ecuadorian Andes, where it can reach 1,300 mappears to be common in the region. We found it in 
both the Cuccono and Shishicho camps, close to streams, at ca. 1,000 m. Of all Neusticurus, this species seems to be the least aquatic (Uzzell 1966).

While the density of amphibians fell within a typical range for forests of this kind, the animals did not appear to be in a particularly active season. The large number of juvenile animals we saw and the scarcity of singing males suggest that our survey may have coincided with the end of the mating season. While Crump (1974) and Duellman (1978) pinpoint the beginning of the mating season at Santa Cecilia $(350 \mathrm{~m})$ in August and September, it may be that the reproductive schedule and activity of the species shared with that site is different here due to the higher altitude. This sort of altitudinal variation in the mating schedule of a single species has been documented for amphibians and for forest birds in southeastern Peru.

Notable for their absence in the survey were species in the genera Colostethus (Dendrobatidae), Bufo and Rhamphophryne (Bufonidae), and Hemiphractus (Hylidae), as well as glass frogs (Centrolenidae), all of which are normally present in forests at this altitude. These absences may be related to the alarming declines observed elsewhere in the Cayambe-Coca Ecological Reserve (see below and Appendix 6). Yet the presence of Hyla phyllognatha, Cochranella midas, and other species in the streams around our campsites suggests that these absences were not related to environmental quality. More intensive surveys may eventually register the missing species, at low population densities. It is also possible that microhylid frogs like Syncope antenori are present in the moss-covered Shishicho ridge, or in the common epiphytic bromeliads in the Ccuccono watershed. Similarly, we found perfectly good habitat for Colostethus cf. marchesianus in the forest below our Shishicho campsite and in the vicinity of our Ccuccono Ridge camp, but not the frog itself. I heard (but was not able to record) songs that may have been this species; the species may simply have escaped detection.

Even after such a short time in the field (four days at each site), simple abundance patterns and differences between sites are fairly clear.

Eleutherodactylus nigrovittatus was the most common amphibian species in Shishicho, while Bolitoglossa peruviana dominated in Ccuccono and Epipedobates femoralis in Sinangoe. Of the three, E. nigrovittatus appears to have the broadest local distribution, as it was recorded at all three sites. The dominant species in an earlier survey at Sinangoe (Eleutherodactylus lanthanites; Altamirano and Quiguango 1997) was only moderately abundant in our survey, and the most common amphibian at Santa Cecilia (Eleutherodactylus variabilis; Duellman 1978) was not even recorded. This sort of temporal and spatial variability points to habitat differences among sites, but the details are not at all understood.

\section{THREATS AND RECOMMENDATIONS}

Some alarming but poorly understood declines have been observed among amphibian populations in this part of Ecuador, particularly at higher elevations in the Cayambe-Coca Ecological Reserve (see also Appendix 6). Most notably, several species in the families Centrolenidae (glass frogs) and Dendrobatidae (poisonarrow frogs; especially the genus Colostethus) that were previously common at elevations between 1,000 and 2,000 $\mathrm{m}$ have shown dramatic fluctuations in the past 10-15 years. Most of the species in these groups were once frequently encountered along streams and waterfalls but have now largely vanished, with the sole (and puzzling) exception of Colostethus bocagei.

Uncovering the factors responsible for these population declines (or fluctuations) is an immediate priority for conservation in the area. If, as has happened in amphibian communities worldwide, these declines eventually spread to other taxa in the region, effective conservation action will require baseline information on (1) the distribution and abundance of individual species at different elevations and in different habitats throughout the Bermejo and Cayambe-Coca forests, and (2) the seasonality of reproduction of individual species. Neither set of information currently exists. 
BIRDS

Participant/Author: Thomas S. Schulenberg

Conservation targets: Bird communities of hill forests; rangeand elevation-restricted birds; large gamebirds; Ara militaris.

\section{METHODS}

The principal ornithologist on the rapid biological inventory team (July-August 2001) was Thomas S. Schulenberg. Supplemental observations were made by other members of the survey team, but primarily by Debra K. Moskovits and Randy Borman. In addition, our records from Bermejo are supplemented by the list of species recorded there by Douglas F. Stotz, Moskovits, and Jennifer M. Shopland during a short visit from 7 to 9 November 1998.

The basic protocol for the rapid surveys involved walking trails through the forest to locate and identify birds. I attempted to be in the field from first light (or very shortly thereafter), although early morning rains sometimes resulted in a later start. Usually I would remain in the field until late afternoon or dusk. I made an effort to survey all habitats in the area, but focused most of my efforts on closed-canopy forest. I carried a portable cassette tape recorder and directional microphone to make sound recordings of bird species. These sound recordings will be deposited at the Macaulay Library of Natural Sounds in the Laboratory of Ornithology at Cornell University. I did not conduct transects or point counts, but tallied the number of individuals observed for each bird species daily, to aid in the assessment of relative abundances.

\section{RESULTS OF THE BIRD SURVEYS}

The team recorded a total of 350 species during the three weeks in the field in the Serranías Cofán, and an additional 49 species were recorded in the Bermejo area by Stotz and others in November 1998. The avifauna documented by us to date totals 399 species (see Appendix 3).
Very little prior field work had been done in this region of Sucumbíos. The Academy of Natural Sciences of Philadelphia (ANSP) conducted a short ornithological survey from 11 to 17 March 1993 at $850-1,000 \mathrm{~m}$ in the Bermejo oil fields, at a site about 12-13 km south-southeast of the Cofán community of Alto Bermejo (M. Robbins, pers. comm.; the field team was Mark B. Robbins, Francisco Sornoza M., and Marco Jacome). Separately, Mena (1997) reported on the birds observed at the Cofán community of Sinangoe, and at two sites about $8 \mathrm{~km}$ to the southwest of Sinangoe. His list includes around 70 species not recorded by our rapid inventories. On the basis of the species listed by Mena (discounting the few apparent misidentifications, e.g., Heliodoxa jacula, a species of the western cordillera) as well as on a more general consideration of Ecuadorian bird distribution (Ridgely and Greenfield 2001), I estimate that the total number of bird species found in the Serranías Cofán may exceed 700 species. This would represent an essentially "complete" avifauna for the elevational range found in this area.

Of the 399 bird species recorded during the rapid biological inventory and Stotz's earlier visit, fully $85 \%$ (339 species) were observed in the Bermejo region. In contrast, our totals for Shishicho (135 species; 34\% of the total) and Ccuccono/Sinangoe (209 species; 52\% of the total) are notably lower. There are several reasons for these disparities. The list for Bermejo reflects in part the more intensive coverage that this site received (all or part of 13 days during the rapid biological survey, plus three days by Stotz, as compared to all or part of five days for Shishicho and all or part of ten days for Ccuccono and Sinangoe). Bermejo also has been visited during different seasons (July and August during the rapid biological inventory, and November by Stotz), so the list for that region reflects seasonal variations in the bird community that are not documented at the two other sites. Finally, the Bermejo valley encompasses the greatest range of elevations of any of the study sites (440-2,250 m), and for that reason alone would be expected to have the greatest 
bird species diversity. Indeed, we no doubt would have recorded many more species around Bermejo were it not for the periods of rain on 3-4 August.

In the Serranías Cofán, the avifauna of the Amazonian lowlands overlaps with, and at higher elevations is replaced by, an Andean avifauna. In the forests from $400 \mathrm{~m}$ up to about 900 or $1,000 \mathrm{~m}$ (referred to throughout this report as lower hill forest), the avifauna is primarily lowland in composition, with only a few Andean species present where the hills first emerge from the Amazonian floodplain at about 400 $\mathrm{m}$. At higher elevations, typically above $1,000-1,100$ $\mathrm{m}$, virtually all of the Amazonian species have dropped out, and the bird community is primarily Andean in character (upper hill forest). This bird community, in turn, is replaced at higher elevations by a different suite of Andean bird species, representative of what might be called mountain forest or cloud forest. Elements of this cloud forest community occur on the higher peaks that we visited in the Serranías Cofán, including several species with very limited distribution within Ecuador, or with globally small, threatened populations. I review the bird communities of these forest types in the following sections.

\section{Birds of the Lower Hill forest \\ (400 TO 900- I, 000 m)}

The extensive lower hill forests in the Serranías Cofán are where the greatest species richness is expected, because of that forest type's similarity to the adjacent, and extremely diverse, lowlands. Endemism, on the other hand, is low here, with most of the species widely distributed. Although my best opportunities to study this avifauna were cut short by rain (especially at Bermejo), we did record some species of interest.

One interesting discovery was Hemitriccus zosterops (White-eyed Tody-Tyrant), an Amazonian species that was of regular occurrence in lower hill forest throughout the Serranías Cofán. This species previously was known in Ecuador only from areas south of the Napo River (Ridgely and Greenfield 2001), although
Mena (1997) also recorded H. zosterops at all of his study sites near Sinangoe, and there are a few records for $H$. zosterops in adjacent Amazonian Colombia (Hilty and Brown 1986). Our records both extend the distribution of the species in Ecuador and help to "fill in" what had been an anomalous hole in its distribution.

Relatively few truly Andean bird species are found in the lower hill forests of the Serranías Cofán, but among these are several of particular interest. Chlorothraupis carmioli (Carmiol's Tanager) is known in Ecuador primarily from Sucumbíos. The narrow distribution of this species in Ecuador is something of a surprise, as farther south (in southern Peru and Bolivia) C. carmioli is very widespread and common in lower hill forest. In contrast, Snowornis subalaris (Gray-tailed Piha), a bird of the hill forests that is known from rather few localities within its geographic distribution, occurred all the way down to around 450 $\mathrm{m}$ near Bermejo, perhaps the lowest elevation at which this species has been found.

It was in the lower hill forest, at the Sinangoe field station, that I had very good looks at a rare and poorly known swift, Cypseloides lemosi (White-chested Swift). I suspected the presence of this species over the Bermejo station as well, but was never able to confirm it there. Until recently, Cypseloides lemosi was only recorded from southwestern Colombia, but in recent years there have been records from several sites in eastern Ecuador and at one site in Peru (Schulenberg et al. 1997). This bird does not use the lower hill forest itself, but it presumably roosts, and perhaps even breeds, in the cliffs and waterfalls at higher elevations of the Serranías. Other, even lesser-known swifts, such as C. cryptus (White-chinned Swift) and C. cherriei (Spot-fronted Swift), also may occur in the Serranías Cofán. Due to the great similarities among all Cypseloides, and especially between C. cryptus and C. cherriei, their presence in the region would be very difficult to confirm. Attention should be paid, however, to the possible presence of these species near waterfalls and other likely nesting sites. 
We recorded Crax salvini (Salvin's Curassow) at the uppermost elevations in the lower hill forest $(900$ to 1,000 or $1,100 \mathrm{~m}$ ) at all three of our study sites. This large gamebird is primarily a lowland species, and is known only from parts of the northwestern Amazon basin, from southern Colombia across eastern Ecuador and south into northwestern Peru. The Crax is heavily hunted, and already has been exterminated from many areas within its range (especially in Ecuador). Although it was encouraging to find this species still widely distributed within the Serranías Cofan, the fact that the curassow seemed to be much more common in, or even restricted to, the uppermost elevations of lower hill forest within the region may be a telling indication of the hunting pressure it faces, even in an area with a relatively low human population.

We had no records during our brief inventory of Heliodoxa gularis (Pink-throated Brilliant), a hummingbird that is regarded as globally nearthreatened (BirdLife International 2000) or threatened (vulnerable; Ridgely and Greenfield 2001). This rare species was found, however, at the ANSP study site southeast of Bermejo, and also along the Due River (Ridgely and Greenfield 2001). The ANSP survey also recorded another near-threatened species, Pipreola chlorolepidota (Fiery-throated Fruiteater). Both of these species surely occur at or close to our study sites.

Although not recorded during our 2001 survey, Falco deiroleucus (Orange-breasted Falcon) was observed by Stotz during his earlier visit to Bermejo. This falcon is a widespread species that is nonetheless scarce throughout its range. Other interesting species recorded by Stotz include Tinamus tao (Gray Tinamou) and Touit purpurata (Sapphire-rumped Parrotlet), two species with wide geographic distributions that are known in Ecuador from only a few records each (Ridgely and Greenfield 2001).

\section{Birds of the Upper Hill Forest \\ ( I,OOO-I,IOO TO I, $500 \mathrm{~m}$ )}

The upper hill forest, a narrow and fragile ribbon of habitat running the length of the Andes, has one of the most poorly studied avifaunas in South America. Although some elements of this region's bird communities are widely distributed, it also is characterized by a large number of bird species that occupy very restricted geographic or elevational ranges. Historically, the bird communities of the upper hill forest in Ecuador were best known from the Sumaco region, perhaps because this area was visited repeatedly, over many years, by collectors, ornithologists, and birdwatchers. Some of the rarer bird species of that region have since been discovered at additional localities in eastern Ecuador, but even these still are known, in most cases, from only a very few locations each. The avifauna of the upper hill forest in Sucumbíos province in particular seems to have been almost unknown prior to our visit.

Even during the short period of our rapid biological inventory, and though we visited only a few sites, we encountered some of the least-known and most geographically restricted bird species of the upper hill forest. The most important of these may be Myiopagis olallai (Foothill Elaenia), a species that was discovered only very recently (Coopmans and Krabbe 2000). This small flycatcher previously was known from only three localities: Sumaco and the valley of the Bombuscaro River in eastern Ecuador, and from a site in south-central Peru. We expected that this poorly known bird would be discovered eventually at additional localities; our record from the Serranías Cofán, however, is also a significant range extension.

Another major discovery was the first record for Ecuador of Tinamus osgoodi (Black Tinamou). This rare bird previously was known from only two small regions, in the head of the Magdalena valley in southern Colombia and in the Andes east of Cusco in southern Peru. It may be more widespread in Ecuador, however: birds believed to be this species have been seen as far south as Coca Falls (R. Borman, pers. comm.). Tinamus osgoodi is regarded as globally threatened (vulnerable; BirdLife International 2000).

Other highlights among the species of the upper hill forest include Hylophilus semibrunneus 
(Rufous-naped Greenlet), which prior to our inventory was known in Ecuador only from Sumaco and the adjacent Archidona road; Hemitriccus rufigularis (Buff-throated Tody-Tyrant), previously registered at only three sites within Ecuador (and not known from Colombia); and Phlogophilus hemileucurus (Ecuadorian Piedtail), a small hummingbird known previously in Ecuador from only five sites (and elsewhere from only a single site in Colombia, and two sites in northern Peru).

Two important aspects of the bird community of upper hill forests in the Serranías Cofán are that many of these species-even those that are considered among the rarest and most locally distributed-were found (1) at all of our study sites and (2) on a regular basis. For example, Campylopterus villaviscensio (Napo Sabrewing), Phylloscartes gualaquizae (Ecuadorian Tyrannulet), and Snowornis subalaris all seemed much more common in the Serranías Cofán than at any other site where I have encountered them. The high relative abundance of these species is particularly important because two of them (Campylopterus villaviscensio and Phylloscartes gualaquizae) are, like the Phlogophilus hummingbird, entirely restricted to a small area of the Andes between Colombia or eastern Ecuador to the north, and northernmost Peru to the south, and these species typically occupy only a narrow elevational band within this region.

Also present in the Serranías Cofán is a population of Ara militaris (Military Macaw). Although this species has a wide distribution, it is decreasing in abundance throughout its range, its populations are increasingly fragmented, and the species is regarded as globally threatened (vulnerable; BirdLife International 2000). Within Ecuador, A. militaris previously was known from only six sites (none of them in the province of Sucumbíos). Since we encountered the species at all of our study sites (although always in small numbers), the Serranías Cofán may be an important refuge in Ecuador for this spectacular parrot.

We recorded Aburria aburri (Wattled Guan) at several of our sites. Aburria has a relatively large geographic distribution, but populations are declining and the species is considered to be globally nearthreatened (BirdLife International 2000). We did not encounter Chamaepetes goudotii (Sickle-winged Guan) during our short visit, although it is reported to be present in the area (R. Borman, pers. comm.). Chamaepetes remains relatively common in Ecuador, but Aburria is generally uncommon in this part of its range and may be vulnerable to hunting pressure.

We have a little data on the presence in the Serranías Cofán of nearctic migrants (bird species that breed in the Northern Hemisphere and spend the northern winter in tropical latitudes), thanks to Stotz's visit to Bermejo in November 1998. During the three days that he was present in the region, Stotz recorded eight species of nearctic migrants, which is about half the number of migrant passerine species that would be expected to occur in forested habitats of the Serranía.

Dendroica cerulea (Cerulean Warbler) was not recorded by Stotz, but the ANSP survey team found it southeast of Bermejo in March (M. Robbins, pers. comm.). Populations of D. cerulea are experiencing sharp declines in their North American breeding grounds, and this is a species of conservation concern (Robbins et al. 1992).

\section{Birds of the Mountain Forests}

( I,500 TO 2,300 m)

Given the relatively small area of mountain forest habitat at the crest of the ridges of Cerro Sur Pax, it was something of a surprise to encounter as many montane bird species there as we did. Among the numerous birds characteristic of higher elevations but present on Sur Pax were several species with extremely limited distributions within Ecuador. Perhaps the most significant of these is Grallaria alleni (Moustached Antpitta). This species currently is considered to be globally threatened (endangered; BirdLife International 2000). Until recently it was known only from two specimens from Colombia, but now has been found at additional sites in Ecuador (Krabbe and Coopmans 
2000). Though G. alleni remains a poorly known bird recorded at only a few places within a limited geographic area, a ranking of "endangered" may overstate the level of threat. Also of interest were Eriocnemis alinae (Emerald-bellied Puffleg), a small hummingbird previously known from only three other sites in Ecuador, and Campylorhamphus pucherani (Greater Scythebill), a scarce species that previously had been recorded at only six sites in Ecuador.

Other clearly montane species observed on Cerro Sur Pax include Adelomyia melanogenys (Speckled Hummingbird), Coeligena torquata (Collared Inca), Haplophaedia aureliae (Greenish Puffleg), Aglaiocercus kingi (Long-tailed Sylph), Trogon personatus (Masked Trogon), Andigena nigrirostris (Black-billed MountainToucan), Dendrocincla tyrannina (Tyrannine Woodcreeper), Xiphorhynchus triangularis (Olive-backed Woodcreeper), Pseudocolaptes boissonneautii (Streaked Tuftedcheek), Thamnophilus unicolor (Uniform Antshrike), Scytalopus spillmanni (Spillmann's Tapaculo), Mecocerculus minor (Sulphur-bellied Tyrannulet), Leptopogon rufipectus (Rufous-breasted Flycatcher), Pseudotriccus ruficeps (Rufous-headed Pygmy-Tyrant), Hemitriccus granadensis (Black-throated Tody-Tyrant), Myiophobus pulcher (Handsome Flycatcher), Ochthoeca diadema (Yellow-bellied Chat-Tyrant), Pipreola riefferii (Green-and-black Fruiteater), Snowornis cryptolophus (Olivaceous Piha), Cinnycerthia olivascens (Sharpe's Wren), Cyphorhinus thoracicus (Chestnut-breasted Wren), Basilenterus luteoviridis (Citrine Warbler), Chlorornis riefferii (Grass-green Tanager), and Chlorospingus ophthalmicus (Common Bush-Tanager).

We also were surprised to find evidence of species turnover at the higher elevations, with some congeneric replacements occurring even between the Bear Ridge camp and the ridgeline just below the crest of Cerro Sur Pax. Coeligena coeligena (Bronzy Inca), for example, reached the elevation of our ridgeline camp at $1,900 \mathrm{~m}$, but was replaced just above, at $2,100 \mathrm{~m}$, by Coeligena torquata.

\section{BERMEjo}

We surveyed three sites in the Bermejo area, between 24 July and 5 August 2001. Our base was the Bermejo field station $(440 \mathrm{~m})$, where I spent the nights of 24 July and 2-4 August. I made casual observations along the trail to Pozo Dos as I entered (24 July) and left ( 5 August) the Bermejo area, both on days with remarkably clear weather. In addition, I spent parts of 3-4 August investigating the trail to Pozo Seco, but frequent rains both days hampered field work. The nights of 25-26 July and 30 July-1 August I spent at the Bermejo Vista camp $(1,200 \mathrm{~m})$. At this site I surveyed the lower part of the trail from the Vista camp towards the Bear Ridge camp, back down the main trail towards Bermejo (to about $850 \mathrm{~m}$ ), and down the trail to the Chandia Na'e River, to about $900 \mathrm{~m}$. We spent only three nights (27-29 July) at the Bear Ridge (Sur Pax) camp at 1,900 m. From here, I surveyed the trail from the camp up to the summit at $2,275 \mathrm{~m}$, and, on one occasion, back down the trail towards the Vista camp, to about $1,700 \mathrm{~m}$.

The Bermejo station was notable for the presence, at such a low elevation, of Snowornis subalaris, a species of the hill forest that is known from only a small number of sites within its geographic range. I also was impressed at Bermejo by the relatively high abundance of Frederickena unduligera (Undulated Antshrike), an Amazonian species with a wide distribution, but which usually is very scarce.

The area around the Vista camp was where I had my first indications that the Serranías Cofán contained a significant number of hill forest bird species that are elevationally or geographically restricted. Among these were a few species that, during our survey, were noted only at Bermejo, such as Myiopagis olallai and Ampelioides tschudii (Scaled Fruiteater). Most of the species found at Bermejo, however, later were noted at our other sites as well, such as Campylopterus villaviscensio, Heliodoxa schriebersii (Black-throated Brilliant), Phylloscartes gualaquizae, Hemitriccus rufigularis, and Snowornis subalaris. Another such species, Phlogophilus hemileucurus, not observed by us 
in the Bermejo region, was found by Stotz at about $900 \mathrm{~m}$ on a ridge between Pozo Seco and the community of Bermejo.

Army ants were active around Bermejo to the surprisingly high elevation of $1,400 \mathrm{~m}$, and we observed a large number of obligate and regular ant-following birds, generally considered to be lowland species, as high as $1,200 \mathrm{~m}$ : Neomorphus geoffroyi (Rufousvented Ground-Cuckoo), Myrmeciza fortis (Sooty Antbird), Pithys albifrons (White-plumed Antbird), and Gymnopithys leucaspis (Bicolored Antbird). Also notable at this site was a family group (two adults and two juveniles) of Aramides calopterus (Rufous-winged Wood-Rail), a widespread but scarce species that has been reported only a few times in Ecuador.

Our brief visit to the crest of Sur Pax was our only investigation of the higher areas of the Serranias Cofán (those above ca. 1,500 m). The ridges that we surveyed in the Serranias Cofán only barely reach the elevation at which the avifauna of the upper hill forest typically is replaced, in part, by a montane bird community. Often in such situations most or all of the expected higher-elevation bird species are lacking (presumably because the area of suitable habitat on top of the ridge is too small), and the bird species of lower elevations may extend their distributions up to higher altitudes than would be the case on higher ridges. In the Serranías Cofán, however, we found a significant degree of turnover in the bird community at the crests of the highest ridges.

In view of the tiny extent of these mountain forests on the ridges that we surveyed, I was somewhat surprised to find some species with extremely limited distributions within Ecuador. The most significant were the rare Grallaria alleni, the near-threatened Campyloramphus pucherani, and the scarce and local Eriocnemis alinae.

\section{SHISHICHO}

I was present at the Shishicho camp $(1,000 \mathrm{~m})$ during the nights of 6-9 August. Casual observations were made along the trail between the Sinangoe field station and Shishicho during the ascent (6 August) and descent (10 August). From Shishicho, I primarily explored the higher elevations along the ridge farther out the trail (7, 9 August), to about $1,500 \mathrm{~m}$. The day of 8 August, however, I spent at elevations of 900-1,000 m along the trail between Shishicho and the Sinangoe station.

The most important discovery at Shishicho was of the poorly known tinamou Tinamus osgoodi, previously known only from two isolated populations, one in southern Colombia and one in southern Peru. A single bird was seen well at $1,400 \mathrm{~m}$ on 7 August, and I heard a tinamou song that I assume to belong to this species at rare intervals at comparable elevations both on 7 and 9 August.

Among other species noted only at Shishicho were the scarce hummingbird Colibri delphinae (Brown Violetear), feeding on a blue-flowered Palicourea tree; Pipreola frontalis (Scarlet-breasted Fruiteater), a cotinga that has not been recorded in Colombia (previously known north only to the Sumaco region); and Piranga flava (Hepatic Tanager), a species that is widespread in the Andes but not known from the eastern Andes of Colombia (the few prior records for eastern Ecuador all are from the south, in the provinces of Morona-Santiago and Zamora-Chinchipe). Also interesting was an unidentified Knipolegus flycatcher seen once at $1,450 \mathrm{~m}$; this individual differed from the expected species, $K$. poecilurus (Rufous-tailed Tyrant), by having a brown (not reddish) iris and appearing medium brown (not pale gray or grayish brown) above, with the upper tail coverts more rufescent than the back, buffy wing bars, and blurry streaking on buffy brown underparts.

\section{Ccuccono and Sinangoe}

I spent the nights of 11-14 August at Ccuccono, on a ridge above the river, at $1,000 \mathrm{~m}$. The days of 12 and 14 August I worked northeast along the trail from the Ccuccono camp back towards the Sinangoe station, down to elevations of about $900 \mathrm{~m}$. On 14 August I 
descended from the camp to the Ccuccono River, and worked areas along the Ccangopacho and Ccopaye Fensi streams as well. I stayed at the Sinangoe station the nights of 5, 10, and 15-16 August. During most of these visits, we were en route to another site such as Shishicho or Ccuccono, and I made only casual observations around the station. Much of 16 August, however, I spent investigating trails near the station, primarily the lower part of the trail towards Ccuccono, and also from the station down the Sieguyo River towards the Aguarico River.

Ccuccono was the only site where I saw

Phlogophilus hemileucurus during the rapid inventory. It was registered in the Bermejo area, however, by both Stotz and the ANSP team, and seems to be widespread in the region. This small hummingbird can be locally common, as it was at Ccuccono, but it has a limited geographic distribution encompassing a few localities from extreme southern Colombia south to extreme northern Peru. Another noteworthy observation at Ccuccono was an army ant swarm noted at $1,000 \mathrm{~m}$. This was not attended by obligate ant-following antbirds, but on two successive days I observed a Neomorphus geoffryoi at this swarm.

Several large, empty, cup-shaped nests were noted on the face of a small cliff near a stream feeding into the Ccuccono River. Piles of palm seeds and germinating palm seedlings were present beneath these nests, at the base of the cliff. The initial identification of these as Oilbird (Steatornis caripensis) nests led the team to name the adjacent stream Ccopaye Fensi ("Oilbird Creek" in Cofán), but the substantial size of the nest cups suggests that they may have been nests of another species (Rupicola peruviana, Andean Cockof-the-Rock) instead.

\section{CONSERVATION IMPORTANCE}

Even our brief survey of the Serranías Cofán was sufficient to establish the presence of a rich hill forest bird community, especially in the upper hill forest. Two features of this bird community make it of special importance for conservation: the presence of a significant number of species that are endemic to a small geographic area of the Andes, or which have been recorded at only a few locations; and the fact that most of these species were encountered at most or all of our study sites, indicating that the Serranías are an important center of population for these species. Among these are birds that are considered to be globally threatened, such as Tinamus osgoodi, Touit stictoptera (Spot-winged Parrotlet, considered vulnerable; BirdLife International 2000), and Grallaria alleni (but see my note on this last species above), as well as several species that are regarded as nearthreatened, such as Aburria aburri, Campylopterus villaviscensio, Phlogophilus hemileucurus, Campylorhamphus pucherani, and Hemitriccus rufigularis. Indeed, the number of threatened and nearthreatened bird species recorded from even this brief survey of the Serranías Cofán are sufficient to make this region one of the most important sites for bird conservation in eastern Ecuador (Wege and Long 1995).

Other species of special conservation interest include birds known from relatively few sites or with constricted distributions, such as Myiopagis olallai, Phylloscartes gualaquizae, and Hemitriccus rufigularis. More intensive surveys almost surely would discover the presence of additional range-restricted species within the Serranías.

\section{THREATS AND RECOMMENDATIONS}

The Serranías Cofán are an important refuge for populations of large, vulnerable birds, like the parrot Ara militaris and the large cracids Crax salvini and Aburria aburri. Ara militaris is considered globally threatened (BirdLife International 2000). Both Crax salvini and Aburria aburri are declining in Ecuador, and Aburria is considered to be globally near-threatened. These cracids are threatened not only by habitat loss (deforestation), but also by hunting, as they commonly are shot for food. It is not known what level of hunting pressure these gamebirds can sustain, but hunting within the Serranías will need to be strictly regulated to maintain stable populations for the long term. 
The Cofán community at Zábalo has implemented a community-based regulation of hunting loads and initiated a program of wildlife censusing ( $R$. Borman, pers. comm.) that is a good model for Cofán residents in this area.

Most, if not all, of the region's bird species that are of conservation importance are restricted to relatively undisturbed habitats. Consequently, this avifauna is at risk from the colonization currently taking place along the Interoceanic Highway from Tulcán to Lago Agrio (Figure 2A). Species that are hunted for food (such as the guans and curassows) will be particularly vulnerable to the growing human presence, and even to relatively transient impacts (e.g., miners who enter the region only for short periods).

Additional surveys of the avifauna of the Serranías Cofán undoubtedly will increase the total number of species known from the region. Particular species that would be expected to occur in these foothills, and that should be targets of future investigations, include two threatened species that are regarded as vulnerable (BirdLife International 2000), Galbula pastazae (Coppery-chested Jacamar) and Dysithamnus occidentalis (Bicolored Antvireo), as well as several nearthreatened bird species: Heliodoxa gularis, Xenerpestes singularis (Equatorial Graytail), Pipreola chlorolepidota, and Chloropipo flavicapilla (Yellow-headed Manakin).

\section{LARGE MAMMALS}

Participant/Author: Randall Borman A.

Conservation targets: Mammals classified as CITES I (threatened with extinction) and CITES II (potentially threatened if no action is taken), including Alouatta seniculus, Aotus vociferans, Ateles belzebuth, Callicebus moloch cupreus, Callicebus torquatus, Cebuella pygmaea, Cebus albifrons, Cebus apella, Herpailurus yaguarondi, Lagothrix lagothricha humboldtii, Leopardus pardalis, Leopardus wiedii, Lontra longicaudis, Myrmecophaga tridactyla, Panthera onca, Pithecia monachus, Priodontes maximus, Puma concolor, Saimiri sciureus, Sanguinus nigricollis, Speothos venaticus, Tapirus terrestris, Tayassu pecari, Tayassu tajacu, and Tremarctos ornatus; also, rare mammals (Atelocynus microtis), and seed dispersers and seed predators. Names generally follow Emmons and Feer (1997).

\section{METHODS}

The large-mammal fauna of the Serranías Cofán was a blank spot on the map for biologists at the time of this inventory, though it has been well-known for centuries to the Cofán hunters and naturalists inhabiting the area. Because I grew up within the Cofán culture, speak the language, and have hunted and fished with Cofán for most of my life, it was easy to draw up a checklist of expected species. The challenge during the inventory was to confirm the presence of the species already known to the Cofán inhabitants, and to estimate their local abundances, over the course of our 24 days in the field.

We first compiled a list of 46 expected mammal species, spanning six orders and 14 families, based on the taxonomic literature, personal experience, and interviews with Cofán who live in the Bermejo and Sinangoe areas. We excluded bats, marsupials, and most small rodents from the list, because inventorying these groups effectively in such a quick survey is next to impossible. Instead, we concentrated on species that are either important to the Cofán inhabitants as game animals or provide a good indication of the ecological health of the region.

In the field, I tried to cover as much ground and as many habitats as possible in each area we visited, often following unmarked paths or animal trails away from the main trails. I remained alert for visual sightings, but also recorded identifiable tracks, scat, smells, and feeding sites. I also kept a record of all mammals sighted by others during the rapid inventory-both by the members of the scientific team and by the more than 30 Cofán who assisted us in the field. From these data, supplemented by conversations with local Cofán and by my own prior experience in the area, I derived estimates of population size for each species.

\section{RESULTS OF THE MAMMAL SURVEY}

Of the 46 species of large mammals expected to occur in the area, 42 were confirmed and 32 directly detected 
during the inventory (see Appendix 4 for the species list and abundance estimates). The tally includes 12 species of primates, nine of which were detected in our 24 days in the field. We also found dozens of records of tapirs and peccaries throughout the area, indicating a rich and largely intact mammal community, despite the small-scale hunting by the local residents. Another ten species are confirmed by local Cofán inhabitants, leaving four species unverified (Mazama rufina, Nasuella olivacea, Tapirus pinchaque, and Aotus lemurinus). These are all montane species that are similar to lowland species and could easily be confused by local residents.

Several of the mammal species confirmed for the Serranías Cofán are extremely rare or considered globally threatened by the World Conservation Union (IUCN). Eight species are listed in CITES Appendix I, 17 in Appendix II, and six in Appendix III. The recently published Libro Rojo de Mamiferos de Ecuador (Tirira 2001) lists six of our 42 confirmed species as threatened, with one of these classified as endangered (Priodontes maximus) and five as vulnerable. Two of the four unconfirmed species are listed in CITES Appendices I or II; the first of these qualifies as endangered (Tapirus pinchaque), while the second is considered vulnerable (Aotus lemurinus). Several additional species we recorded, like the short-eared dog, Atelocynus microtis, are so rare that their conservation status is entirely unknown but potentially critical.

During the field work we were unable to validate reports from local Cofán hunters of a miniature woolly monkey said to inhabit the higher elevation forests of Bermejo. The animal has reportedly been spotted several times and hunted twice by Cofán, who insist that it is different not only in size but in habits, sounds, and color patterns from the more common Lagothrix lagothricha. Note that the Cofán hunters I accompanied on an earlier trip to Cerro Sur Pax had never before seen the brown capuchin monkey, Cebus apella, that we collected there, and it may be that the Bermejo region's unusually dark and thickly haired individuals of that species are the basis for the stories of the small woolly. On the other hand, when confronted with the unfamiliar C. apella specimen, the Cofán hunters immediately stated that it was not the small woolly they had collected. There remains some possibility that a new species or subspecies of Lagothrix inhabits these forests, and resolving the issue is a high priority for mammal studies in the area.

We were likewise unable to verify reports of several other unusual mammals in the region. Bermejo hunters, for example, claim to have seen a smallish blonde bear in the high-elevation forests we investigated around Cerro Sur Pax. In previous visits to Bermejo, I have observed two different opossums-one a captive juvenile and the other a wild adult-that I have been unable to identify. One of the most common squirrels in Bermejo and Sinangoe, a large gray animal with a white underside, appears to be an undescribed species. For the time being, all of these apparent novelties await confirmation.

The large-mammal communities of Bermejo and Sinangoe are very similar in composition, but animal densities appear to be substantially higher in Sinangoe. I suspect that these differences are driven by higher productivity in the Sinangoe forests. An alternative hypothesis, given that Cofán communities hunt for food in both forests, is that the Bermejo community is harvesting animals more intensively than the Sinangoe community. This hypothesis can probably be rejected, however. Sinangoe's Cofán population is ten times larger than Bermejo's, and the Sinangoe forest is also occasionally hunted by outsiders, suggesting that animals are being harvested much more intensively there than in Bermejo. It is true that hunters in Bermejo range more widely and hunt more aggressively than those in Sinangoe, but I suspect that this is a consequence of low animal densities, not their cause. The real cause of the discrepancy probably lies in richer soils leading to higher fruit production, coupled with a better distribution of habitat types in the Sinangoe region. 


\section{BERMEJO}

My initial assessment of Bermejo's large-mammal community divides the region into three important subregions, distinguished by differences in elevation and productivity: (1) rather unproductive lowlands; (2) more productive mid-elevation forest; and (3) steep slopes and ridges of the higher-elevation forest.

Much of the lower-elevation forest in the Bermejo River valley - at elevations of 400-1,000 mgrows on hills of soft red silt that are very unstable and constantly eroding. Sizeable landslides seem to occur with every rain, giving the Bermejo River its distinctive reddish color, and the waterlogged, nutrient-poor soils are probably as unproductive for wild fruit crops as they are for agriculture. As a result, natural forests in this subregion are dotted with patches of successional forest choked with vines and brush. Deer, armadillos, and the larger forest rodents thrive in this landscape, but collared peccaries (Tayassu tajacu), which usually adapt well to secondary forests and easily resist hunting pressure, were surprisingly scarce.

Collared peccaries were far more common in the more mature forests of the second sub-region, from $1,000 \mathrm{~m}$ up to $1,200 \mathrm{~m}$. This sub-region is characterized by dark organic soils that seem to provide far larger fruit crops than the reddish, unstable soils around Bermejo. Landslides are still common here, but the relative areas of mature forests, old successional forest, and recent successional scrub are more evenly distributed, providing mammals with several large habitats. Collared peccaries, tapirs (Tapirus terrestris), woolly monkeys (Lagothrix lagothricha), howler monkeys (Alouatta seniculus), and other smaller mammals were all abundant in this rich region. Spectacled bears (Tremarctos ornatus) were also present, though not as frequent as at higher elevations. We had multiple records of white-fronted capuchins (Cebus albifrons) and squirrel monkeys (Saimiri sciureus) here, but neither seemed to climb above $1,200 \mathrm{~m}$. Cat signs likewise cease here. The lowland deer (Mazama americana and M. gouazoubira) are common throughout this region.
The third sub-region corresponds to the relatively steep slopes and ridges of the Cerro Sur Pax mountain complex, above 1,200 m. Quartzite boulders and deep organic mud are the surface characteristics, with tall forests growing increasingly moss- and epiphyte-laden as one climbs. Woolly monkeys, howler monkeys, deer, and tapir all range along the lower slopes, but drop out at higher elevations, starting with deer and tapir (1,200 m), followed by howler monkeys $(1,350 \mathrm{~m})$ and woolly monkeys $(1,500 \mathrm{~m})$. The brown capuchin (Cebus apella) and the white-bellied spider monkey (Ateles belzebuth) appear near the crest, at 1,600 $\mathrm{m}$ and upwards. At some point on these slopes we began to register an unidentified species of coati with light red fur and an unringed tail (perhaps not Nasuella olivacea), apparently native to the higherelevation forests. Spectacled bears are common throughout this region, and we frequently encountered heavily traveled trails and large feeding areas. Small deer prints at the 1,800-m mark are probably indications of the little red brocket, Mazama rufina.

The stunted, moss-laden forests that grow along the ridges between 1,600 and 2,200 $\mathrm{m}$ are often so narrow as to give the impression that they are not an important habitat for mammals. However, both bears and brown capuchin monkeys occur there, probably attracted to the bromeliads that grow abundantly along the ridges. The unidentified coati also uses this habitat. This was also the area where we had our most frequent sightings of the unidentified large grey squirrel. Notable for its absence was Tapirus pinchaque, which is common above $2,000 \mathrm{~m}$ elsewhere in the eastern Andes. It should be present in the higherelevation areas north of Cerro Sur Pax.

\section{SINANGOE}

The Sinangoe landscape appears far simpler than Bermejo in its geology and habitat heterogeneity, in part because it lacks the poor red soils that dominate much of the lower-elevation forest in Bermejo. Distribution of important habitats for mammals is 
much more even, and species distributions less patchy. For instance, the two major sub-regions in the Sinangoe area-the huge, mostly flat alluvial plain between the Ccuccono and Aguarico Rivers, and the more mountainous and rugged landscape to the north and west-show few differences in mammal composition, apart from some predictable turnover related to elevation.

One of the few differences we noted between the mammals of the two sub-regions was the surprising absence of most large primate species from the alluvial plain. We sampled this region on three different occasions, and discussed its fauna at length with the Sinangoe community. Remarkably, and in spite of a great deal of available habitat, the only common large primate here is the howler monkey. Interviews with older Cofán inhabitants confirmed that while spider monkeys have occasionally been seen in the region, woolly monkeys have never been sighted. This is puzzling, especially given that hunting pressures have been quite low for at least a century and that we spotted several groups of woolly monkeys in the adjacent Cerro Shishicho. It may be that one of the catastrophic geological events that seem to be a common occurrence in the Ccuccono River drainage (e.g., earthquakes, floods, volcanic eruptions) eliminated woolly monkey populations in the recent past, and that subsequent recolonization is occurring at a slow pace.

\section{SPECIES NOTES:}

\section{Cebus apella (Brown Capuchin Monkey)}

We encountered this species only once during the inventory, at 2,100 $\mathrm{m}$ on the southern slopes of Cerro Sur Pax. I have seen it on at least three separate occasions in the same area, between 1,800 and 2,000 $\mathrm{m}$, over the last two years. The abundance of partially eaten fruits and sucked bromeliad leaves bearing tooth marks that correspond to C. apella dentition suggest that the species is common at these elevations-up to $600 \mathrm{~m}$ higher than the upper elevational limit of 1,500 m suggested by Emmons and Feer (1997).
I believe that the two specimens I hunted here in 1999 constitute the only confirmed records of C. apella north of the Pastaza River watershed in Ecuador. My own decades of field experience in Ecuadorian Amazonia and numerous conversations with Cofán, Secoya, Siona, Quichua, and Huaorani hunters have failed to turn up any indications of the species' presence in the Napo and Aguarico watersheds. Reports of C. apella from Cuyabeno and Yasuni have generally been made by scientists unfamiliar with C. apella populations in other regions, and in most cases I believe they can be attributed to confusion with the large, dark, and thickly haired C. albifrons males. Adding to the confusion is the fact that indigenous hunters in lowland Amazonia often have a distinct name for these males.

\section{Ateles belzebuth (White-bellied Spider Monkey)}

This species does not appear to be common in the Bermejo region. Cofán hunters reported only one encounter, nearly a decade old, near Cerro Sur Pax. We located only one group in Bermejo, of more than ten individuals, also near Sur Pax. The monkeys were very tame and curious, coming over to investigate the noise of our trail construction. Two days later, we encountered a single individual much lower, at 1,600 $\mathrm{m}$. The low density of spider monkeys in the areaand their apparent restriction to high-elevation forests, along with C. apella-may be a result of low food availability. Human hunting does not seem to be responsible for these patterns, as only one individual spider monkey is known to have been killed in the area over the last generation.

In sharp contrast to the situation in Bermejo, A. belzebuth was common in the Sinangoe region. Once again, it seems to be confined to fairly high altitudes, overlapping only narrowly with Lagothrix lagothricha (see below). Groups were detected on five separate occasions on Cerro Shishicho, always above $1,300 \mathrm{~m}$. The monkeys there were tame and curious, in spite of the fact that the Shishicho trail has been used heavily by colonists and indigenous people for at least 
the past century. This is partly because Shishicho is now off-limits to Cofán hunters (see below).

\section{Lagothrix lagothricha humboldtii (Woolly Monkey)}

Although no woolly monkeys were sighted by the team during our Bermejo inventory, the Bermejo residents encountered at least four groups in hunting trips during the same time. All four encounters were in the relatively productive area on the meseta below the Bermejo Vista camp, between 600 and $900 \mathrm{~m}$. Cofán familiar with woolly monkeys in eastern Ecuador were surprised by the robustness of the individuals at Bermejo.

In the Sinangoe region, the distribution of L. lagothricha shows several interesting patterns. Farther downstream, the Aguarico River forms the border between the subspecies humboldtii (to the north) and papaegi (to the south). In the headwaters of the Aguarico, this border follows the Due River, a major and wide-channeled tributary of the Aguarico. It appears humboldtii was able to cross the upper Aguarico tributaries (the Chingual and Cofanes) but not the Due. Just as interesting is the patchy distribution of woolly monkeys between the Due and the Aguarico (see discussion in Sinangoe section above).

The fact that healthy populations of Ateles and Lagothrix seem to occur around Cerro Shishicho, a region designated off limits to hunting by the Sinangoe community, suggests that these populations will be viable and stable for the long term if colonist incursions can be minimized. They can then serve as "seed" populations to recolonize adjacent areas.

\section{Tremarctos ornatus (Spectacled Bear)}

On the basis of indirect evidence, spectacled bears are common in both the Bermejo and Sinangoe regions; one member of the 2001 inventory team sighted one briefly near Cerro Sur Pax. Bear trails, torn-apart bromeliads and palms, and other signs are obvious and ubiquitous at higher elevations throughout the region, and in Bermejo I registered signs for spectacled bear as low as $450 \mathrm{~m}$.

\section{Atelocynus microtis (Short-eared Dog)}

This animal, perhaps the most elusive and least-studied carnivore in the Amazon basin, was sighted in Bermejo by D. Moskovits. At 4:30 PM on a rainy afternoon, she observed a solitary dog trotting towards her along a heavily used trail in mature forest near the Bermejo Vista camp, just above 1,200 m elevation. Apparently oblivious to her presence, the animal passed within ca. $30 \mathrm{~cm}$ of her before disappearing into the undergrowth. This is the highest elevation at which Atelocynus has ever been recorded (Leite and Williams in press).

\section{THREATS AND PRELIMINARY RECOMMENDATIONS}

Developing appropriate management plans for these forests will require studies on current hunting practices and their effects. The Sinangoe community has already implemented some simple rules for hunters, mostly by establishing some areas that are off-limits and others that are fair game. Our observations of dense animal communities at both Shishicho (off-limits) and the Candue (fair game) suggest that management in those areas is on the right track, at least for the time being. In Bermejo, on the other hand, no attempts have been made to manage game populations, and the apparent abundance of monkeys there is a simple consequence of the small population of hunters. Establishing simple hunting rules for Cofán hunters in Bermejo, and reinforcing the rules in Sinangoe, should be one of the highest priorities for the conservation and management of the area's wildlife. Initially, a system of zoning will probably give the best results, with further management tools being developed in tune with the community's ethic and needs. Engaging local Cofán residents in wildlife censusing programs will provide important data on population dynamics and hunting levels, and these will help construct a sensible management plan. 
Apéndices/Appendices 


\section{PLANTASI PLANTS}

\begin{tabular}{|c|c|c|c|c|}
\hline Familia /Family & Género/Genus & Especie/Species & $\begin{array}{l}\text { Forma } \\
\text { de Vida/ } \\
\text { Habit }\end{array}$ & Fuente/Source \\
\hline \multicolumn{5}{|c|}{$\begin{array}{l}\text { SPERMATOPSIDA } \\
\text { (Plantas con Semillas/Seed Plants) }\end{array}$} \\
\hline Acanthaceae & Aphelandra & aurantiaca & $\mathrm{H} / \mathrm{S}$ & $\mathrm{CC} / \mathrm{RF}$ \\
\hline Acanthaceae & Aphelandra & (1 sp.) & $\mathrm{S}$ & RA1041/RF \\
\hline Acanthaceae & Fittonia & albivenis & $\mathrm{H}$ & $\mathrm{RF}$ \\
\hline Acanthaceae & Justicia & (6 spp.) & $\mathrm{H}$ & RA/RF \\
\hline Acanthaceae & Pseuderanthemum & ctenospermum & $\mathrm{H} / \mathrm{S}$ & RA690/CC/RF \\
\hline Acanthaceae & Ruellia & chartacea & $\mathrm{H} / \mathrm{S}$ & RA973/CC/RF \\
\hline Acanthaceae & Ruellia & (1 sp.) & $\mathrm{H} / \mathrm{S}$ & $\mathrm{CC}$ \\
\hline Acanthaceae & Sanchezia & (3 spp.) & $\mathrm{S}$ & $\mathrm{RA} / \mathrm{RF}$ \\
\hline Acanthaceae & (3 spp.) & - & $\mathrm{H} / \mathrm{S}$ & RA \\
\hline Actinidiaceae & Saurauia & herthae cf. & $\mathrm{S} / \mathrm{T}$ & RA/RF \\
\hline Alstroemeriaceae & Bomarea & pardina & $\mathrm{H} N$ & $\mathrm{RF}$ \\
\hline Alstroemeriaceae & Bomarea & (2 spp.) & $\mathrm{HN}$ & RA/RF \\
\hline Amaranthaceae & Cyathula & achyranthoides & $\mathrm{H}$ & RF \\
\hline Amaryllidaceae & Crinum & erubescens & $\mathrm{H}$ & RA965 \\
\hline Amaryllidaceae & Eucharis & (1 sp.) & $\mathrm{H}$ & RA711/RF \\
\hline Anacardiaceae & Tapirira & guianensis & $\mathrm{T}$ & $\mathrm{CC} / \mathrm{RF}$ \\
\hline Annonaceae & Annona & (2 spp.) & $\mathrm{S} / \mathrm{T}$ & RA/RF \\
\hline Annonaceae & Cremastosperma & gracilipes & $\mathrm{S} / \mathrm{T}$ & $\mathrm{CC}$ \\
\hline Annonaceae & Duguetia & spixiana & $\mathrm{T}$ & $\mathrm{CC} / \mathrm{RF}$ \\
\hline Annonaceae & Guatteria & brevicuspis & $\mathrm{T}$ & $\mathrm{CC}$ \\
\hline Annonaceae & Guatteria & decurrens & $\mathrm{T}$ & $\mathrm{CC}$ \\
\hline Annonaceae & Guatteria & multivenia & $\mathrm{T}$ & $\mathrm{CC}$ \\
\hline Annonaceae & Guatteria & recurvisepala & $\mathrm{T}$ & $\mathrm{CC}$ \\
\hline Annonaceae & Guatteria & (6 spp.) & $\mathrm{T}$ & RA/RF \\
\hline Annonaceae & Oxandra & acuminata & $\mathrm{T}$ & $\mathrm{CC}$ \\
\hline Annonaceae & Porcelia & mediocris & $\mathrm{T}$ & RF \\
\hline Annonaceae & Rollinia & pittieri & $\mathrm{T}$ & $\mathrm{CC} / \mathrm{RF}$ \\
\hline Annonaceae & Rollinia & (1 sp.) & $\mathrm{S} / \mathrm{T}$ & RA1044 \\
\hline Annonaceae & Unonopsis & (2 spp.) & $\mathrm{T}$ & RA \\
\hline Annonaceae & Xylopia & sericea & $\mathrm{T}$ & $\mathrm{CC}$ \\
\hline Annonaceae & (2 spp.) & - & $T$ & RA \\
\hline Apiaceae & Eryngium & foetidum & $\mathrm{H}$ & $\mathrm{CC}$ \\
\hline Apiaceae & Hydrocotyle & (2 spp.) & $\mathrm{H}$ & RF \\
\hline Apocynaceae & (1 sp.) & - & V & RA925 \\
\hline Apocynaceae & Allamanda & cathartica & $\mathrm{V}$ & $\mathrm{CC}$ \\
\hline Apocynaceae & Aspidosperma & (3 spp.) & $\mathrm{T}$ & RF \\
\hline Apocynaceae & Himatanthus & bracteatus & $\mathrm{T}$ & $\mathrm{CC}$ \\
\hline Apocynaceae & Himatanthus & sucuuba & $\mathrm{T}$ & RF \\
\hline Apocynaceae & Lacmellea & lactescens & $\mathrm{T}$ & $\mathrm{CC} / \mathrm{RF}$ \\
\hline Apocynaceae & Lacmellea & (1 sp.) & $\mathrm{T}$ & RF \\
\hline Apocynaceae & Tabernaemontana & heterophylla & $\mathrm{S} / \mathrm{T}$ & RA/RF \\
\hline Apocynaceae & Tabernaemontana & sananho & $\mathrm{S} / \mathrm{T}$ & RA859/RF \\
\hline Aquifoliaceae & Ilex & (1 sp.) & $\mathrm{T}$ & RA/RF \\
\hline Araceae & Alocasia & macrorrhizos & $\mathrm{H}$ & $\mathrm{CC}$ \\
\hline
\end{tabular}

Species of vascular plants recorded for the Serranias Cofán, Sucumbios province, northeastern Ecuador, in a rapid biological inventory from 24 July to 16 August 2001. The list also includes collections made by R. Foster, R. Aguinda, T. Theim, M. Metz, and G. Baker during earlier visits to Sinangoe in June 1999 and the Interoceanic Highway in July 2000, and species registered by Cerón et al. (1994) in the vicinity of Sinangoe. Compiled by R. Foster. Rapid biological inventory botany team members:

R. Foster, R. Aguinda, and N. Pitman. Updated information will be posted at www.fieldmuseum.org/rbi.

Forma de Vida/Habit:

$\mathrm{E}=$ Epifita/Epiphyte

$H=$ Hierba terrestre/

Terrestrial herb

$\mathrm{P}=$ Parásito/Parasite

$\mathrm{S}=$ Arbusto/Shrub

$T=$ Árbol/Tree

$V=$ Trepadora/Climber

Fuente/Source

$\mathrm{CC}=$ Registrado por Cerón et al. (1994)/Listed by Cerón et al. (1994)

$\mathrm{RA}=$ Colecciones de Roberto Aguinda; los números corresponden a los especímenes depositados en el Herbario Nacional del Ecuador/Roberto Aguinda collections; numbers refer to voucher specimens deposited in The National Herbarium of Ecuador (QCNE)

$\mathrm{RF}=$ Fotos o observaciones de campo de Robin Foster/ Robin Foster photographs or field notes 
Especies de plantas vasculares registradas para las Serranias Cofán, Provincia de Sucumbios, Ecuador, durante un inventario biológico rápido La lista también incluye colecciones anteriores realizadas por $R$. Foster, durante una visita a Sinangoe en junio del 1999 y otra a la Via Interoceánica en julio del 2000, y especies registradas por Cerón et al. (1994) en los alrededores de Sinangoe. Compilación por R. Foster. Miembros del equipo del inventario N. Pitman. La información presentada aqui se irá actualizando y estará disponible en la página Web en wrww.fieldmuseum.org/rbi. del 24 de julio al 16 de agosto 2001. R. Aguinda, T. Theim, M. Metz y G. Baker botánico rápido: R. Foster, R. Aguinda y

\section{PLANTASI PLANTS}

\begin{tabular}{|c|c|c|c|c|}
\hline Familia/Family & Género/Genus & Especie/Species & $\begin{array}{l}\text { Forma } \\
\text { de Vida/ } \\
\text { Habit }\end{array}$ & Fuente/Source \\
\hline Araceae & Anthurium & apaporanum & $\mathrm{V} / \mathrm{E}$ & RA1359/CC/RF \\
\hline Araceae & Anthurium & aristatum & $\mathrm{V} / \mathrm{E}$ & RA/RF \\
\hline Araceae & Anthurium & brachypodum & V/E & RA1081,1099/RF \\
\hline Araceae & Anthurium & draconopterum & V/E & $\mathrm{CC}$ \\
\hline Araceae & Anthurium & eminens & V/E & $\mathrm{RA} / \mathrm{CC} / \mathrm{RF}$ \\
\hline Araceae & Anthurium & formosum & V/E & RA997 \\
\hline Araceae & Anthurium & gracile & V/E & RA1362 \\
\hline Araceae & Anthurium & harlingianum & $\mathrm{V} / \mathrm{E}$ & $\mathrm{CC} / \mathrm{RF}$ \\
\hline Araceae & Anthurium & microspadix & V/E & RA1404 \\
\hline Araceae & Anthurium & mindense & $\mathrm{V} / \mathrm{E}$ & RA1168 \\
\hline Araceae & Anthurium & palaciosanum & $\mathrm{H}$ & RA1095/RF \\
\hline Araceae & Anthurium & rugulosum cf. & V/E & RA1490/RF \\
\hline Araceae & Anthurium & triphyllum & V/E & RA1101 \\
\hline Araceae & Anthurium & truncicola & V/E & RA1192/RF \\
\hline Araceae & Anthurium & variegatum & $\mathrm{H}$ & RA1 126,1182/RF \\
\hline Araceae & Anthurium & versicolor & $\mathrm{V} / \mathrm{E}$ & RA1213 \\
\hline Araceae & Anthurium & (22 spp.) & $\mathrm{V} / \mathrm{E}$ & $\mathrm{RA}$ \\
\hline Araceae & Caladium & bicolor & $\mathrm{H}$ & $\mathrm{CC} / \mathrm{RF}$ \\
\hline Araceae & Chlorospatha & atropurpurea & $\mathrm{H}$ & $\mathrm{CC}$ \\
\hline Araceae & Colocasia & esculenta & $\mathrm{H}$ & $\mathrm{CC}$ \\
\hline Araceae & Dieffenbachia & daguensis & $\mathrm{H}$ & $\mathrm{CC}$ \\
\hline Araceae & Dieffenbachia & harlingii & $\mathrm{H}$ & $\mathrm{RF}$ \\
\hline Araceae & Dieffenbachia & (1 sp.) & $\mathrm{H}$ & RA1191 \\
\hline Araceae & Dracontium & spruceanum & $\mathrm{H}$ & $\mathrm{RA} / \mathrm{CC} / \mathrm{RF}$ \\
\hline Araceae & Monstera & lechleriana & V/E & $\mathrm{CC}$ \\
\hline Araceae & Monstera & obliqua & V/E & $\mathrm{RF}$ \\
\hline Araceae & Monstera & (1 sp.) & V/E & RA \\
\hline Araceae & Philodendron & ernestii & $E$ & $\mathrm{CC} / \mathrm{RF}$ \\
\hline Araceae & Philodendron & heleniae & $\mathrm{E}$ & $\mathrm{CC}$ \\
\hline Araceae & Philodendron & heterophyllum & $E$ & $\mathrm{RF}$ \\
\hline Araceae & Philodendron & megalophyllum & $\mathrm{E}$ & $\mathrm{CC}$ \\
\hline Araceae & Philodendron & (4 spp.) & $E$ & $\mathrm{RF}$ \\
\hline Araceae & Rhodospatha & (1 sp.) & $\mathrm{H}$ & $\mathrm{RF}$ \\
\hline Araceae & Spathiphyllum & cannifolium & $\mathrm{H}$ & $\mathrm{CC}$ \\
\hline Araceae & Stenospermation & (3 spp.) & $\mathrm{V} / \mathrm{E}$ & $\mathrm{RF}$ \\
\hline Araceae & Urospatha & sagittifolia & $\mathrm{H}$ & $\mathrm{CC}$ \\
\hline Araceae & Xanthosoma & viviparum & $\mathrm{H}$ & RF \\
\hline Araceae & Xanthosoma & (1 sp.) & $\mathrm{H}$ & RA1151/RF \\
\hline Araliaceae & Dendropanax & arboreus & $\mathrm{S} / \mathrm{T}$ & $\mathrm{CC} / \mathrm{RF}$ \\
\hline Araliaceae & Dendropanax & quercetorum & $S / T$ & RA782/CC/RF \\
\hline Araliaceae & Dendropanax & (1 sp.) & $\mathrm{T}$ & $\mathrm{RF}$ \\
\hline Araliaceae & Oreopanax & (2 spp.) & $\mathrm{T}$ & RA/RF \\
\hline Araliaceae & Schefflera & diplodactyla & $\mathrm{T}$ & RA $1154 / C C$ \\
\hline Araliaceae & Schefflera & morototoni & $\mathrm{T}$ & $\mathrm{CC} / \mathrm{RF}$ \\
\hline Araliaceae & Schefflera & (7 spp.) & $E / T$ & RAVRF \\
\hline Arecaceae & Aiphanes & ulei & $S / T$ & RA1178/RF \\
\hline
\end{tabular}


PLANTASI PLANTS

\begin{tabular}{|c|c|c|c|c|}
\hline Familia /Family & Género/Genus & Especie/Species & $\begin{array}{l}\text { Forma } \\
\text { de Vida/ } \\
\text { Habit }\end{array}$ & Fuente/Source \\
\hline Arecaceae & Ammandra & dasyneura & $\mathrm{S} / \mathrm{T}$ & $\mathrm{CC} / \mathrm{RF}$ \\
\hline Arecaceae & Astrocaryum & urostachys & $\mathrm{T}$ & $\mathrm{CC} / \mathrm{RF}$ \\
\hline Arecaceae & Bactris & gasipaes & $T$ & $\mathrm{CC} / \mathrm{RF}$ \\
\hline Arecaceae & Bactris & simplicifrons & $\mathrm{S}$ & RF \\
\hline Arecaceae & Bactris & (1 sp.) & $\mathrm{S}$ & $\mathrm{RF}$ \\
\hline Arecaceae & Chamaedorea & pauciflora & $\mathrm{S}$ & $\mathrm{RF}$ \\
\hline Arecaceae & Chamaedorea & pinnatifrons & $\mathrm{S} / \mathrm{T}$ & RA701/RF \\
\hline Arecaceae & Chelyocarpus & ulei & $\mathrm{S} / \mathrm{T}$ & RF \\
\hline Arecaceae & Desmoncus & giganteus & V & RF \\
\hline Arecaceae & Desmoncus & mitis & V & $\mathrm{RF}$ \\
\hline Arecaceae & Desmoncus & polyacanthos & V & $\mathrm{RF}$ \\
\hline Arecaceae & Dictyocaryum & lamarckianum & $\mathrm{T}$ & $\mathrm{RF}$ \\
\hline Arecaceae & Euterpe & precatoria & $\mathrm{T}$ & $\mathrm{RF}$ \\
\hline Arecaceae & Geonoma & arundinacea & $\mathrm{S}$ & $\mathrm{CC}$ \\
\hline Arecaceae & Geonoma & brongniartii & $\mathrm{S}$ & $\mathrm{CC}$ \\
\hline Arecaceae & Geonoma & interrupta & $\mathrm{S}$ & $\mathrm{CC}$ \\
\hline Arecaceae & Geonoma & macrostachys & $\mathrm{S}$ & $\mathrm{RF}$ \\
\hline Arecaceae & Geonoma & stricta & $S$ & $\mathrm{RF}$ \\
\hline Arecaceae & Geonoma & triglochin & $\mathrm{S}$ & $\mathrm{RF}$ \\
\hline Arecaceae & Geonoma & undata & $\mathrm{S}$ & $\mathrm{RF}$ \\
\hline Arecaceae & Geonoma & (4 spp.) & $S$ & RA/RF \\
\hline Arecaceae & Hyospathe & elegans & $\mathrm{S}$ & $\mathrm{RF}$ \\
\hline Arecaceae & Hyospathe & (1 sp.) & $\mathrm{S}$ & RA1238/RF \\
\hline Arecaceae & Iriartea & deltoidea & $\mathrm{T}$ & $\mathrm{RF}$ \\
\hline Arecaceae & Mauritia & flexuosa & $\mathrm{T}$ & $\mathrm{CC}$ \\
\hline Arecaceae & Mauritiella & armata & $\mathrm{T}$ & $\mathrm{CC}$ \\
\hline Arecaceae & Oenocarpus & bataua & $\mathrm{T}$ & $\mathrm{RF}$ \\
\hline Arecaceae & Oenocarpus & mapora & $\mathrm{T}$ & $\mathrm{RF}$ \\
\hline Arecaceae & Phytelephas & tenuicaulis & $\mathrm{T}$ & $\mathrm{RF}$ \\
\hline Arecaceae & Prestoea & schultzeana & $\mathrm{S} / \mathrm{T}$ & $\mathrm{RA} 1259 / \mathrm{CC} / \mathrm{RF}$ \\
\hline Arecaceae & Socratea & exorrhiza & $\mathrm{T}$ & $\mathrm{RF}$ \\
\hline Arecaceae & Wettinia & anomala & $\mathrm{T}$ & $\mathrm{RF}$ \\
\hline Arecaceae & Wettinia & maynensis & $\mathrm{T}$ & $\mathrm{RF}$ \\
\hline Asclepiadaceae & Matelea & rivularis & $\mathrm{S}$ & $\mathrm{CC}$ \\
\hline Asteliaceae & Cordyline & terminalis & $\mathrm{S}$ & $\mathrm{CC}$ \\
\hline Asteraceae & Adenostemma & fosbergii & $\mathrm{H}$ & $\mathrm{CC}$ \\
\hline Asteraceae & Clibadium & surinamense & $\mathrm{S}$ & $\mathrm{CC}$ \\
\hline Asteraceae & Eirmocephala & megaphylla & $\mathrm{S}$ & RF \\
\hline Asteraceae & Erato & polymnioides & $\mathrm{H} / \mathrm{S}$ & $\mathrm{RA} / \mathrm{CC} / \mathrm{RF}$ \\
\hline Asteraceae & Liabum & acuminatum & $\mathrm{H} / \mathrm{S}$ & $\mathrm{CC}$ \\
\hline Asteraceae & Liabum & amplexicaule & $\mathrm{H}$ & $\mathrm{RF}$ \\
\hline Asteraceae & Mikania & micrantha & V & $\mathrm{RF}$ \\
\hline Asteraceae & Mikania & (3 spp.) & V & $\mathrm{RF}$ \\
\hline Asteraceae & Tessaria & integrifolia & $\mathrm{S} / \mathrm{T}$ & $\mathrm{RF}$ \\
\hline Asteraceae & Vernonanthura & patens & $\mathrm{S} / \mathrm{T}$ & $\mathrm{CC} / \mathrm{RF}$ \\
\hline Asteraceae & (5 spp.) & - & $\mathrm{S} / \mathrm{N}$ & RA \\
\hline
\end{tabular}

Species of vascular plants recorded for the Serranias Cofán, Sucumbios province, northeastern Ecuador, in a rapid biological inventory from 24 July to 16 August 2001. The list also includes collections made by R. Foster, R. Aguinda, T. Theim, M. Metz, and G. Baker during earlier visits to Sinangoe in June 1999 and the Interoceanic Highway in July 2000, and species registered by Cerón et al. (1994) in the vicinity of Sinangoe. Compiled by R. Foster. Rapid biological inventory botany team members: R. Foster, R. Aguinda, and N. Pitman. Updated information will be posted at www.fieldmuseum.org/rbi.

Forma de Vida/Habit :

$\mathrm{E}=$ Epífita/Epiphyte

$\mathrm{H}=$ Hierba terrestre/

Terrestrial herb

$\mathrm{P}$ = Parásito/Parasite

$\mathrm{S}=$ Arbusto/Shrub

$\mathrm{T}=$ Árbol/Tree

$V=$ Trepadora/Climber

\section{Fuente/Source}

$\mathrm{CC}=$ Registrado por Cerón et al. (1994)/Listed by Cerón et al. (1994)

$\mathrm{RA}=$ Colecciones de Roberto Aguinda; los números corresponden a los especímenes depositados en el Herbario Nacional del Ecuador/Roberto Aguinda collections; numbers refer to voucher specimens deposited in The National Herbarium of Ecuador (QCNE)

$\mathrm{RF}=$ Fotos 0 observaciones de campo de Robin Foster/ Robin Foster photographs or field notes 
Especies de plantas vasculares registradas para las Serranias Cofán, Provincia de Sucumbios, Ecuador, durante un inventario biológico rápido del 24 de julio al 16 de agosto 2001. La lista también incluye colecciones anteriores realizadas por R. Foster, R. Aguinda, T. Theim, M. Metz y G. Baker durante una visita a Sinangoe en junio del 1999 y otra a la Via Interoceánica en julio del 2000, y especies registradas por Cerón et al. (1994) en los alrededores de Miembros del equipo del inventario botánico rápido: $R$. Foster, $R$. Aguinda $y$ N. Pitman. La información presentada aqui se irá actualizando y estará disponible en la página Web en www.fieldmuseum.orglrbi. Sinangoe. Compilación por R. Foster.

PLANTASIPLANTS

\begin{tabular}{|c|c|c|c|c|}
\hline Familia/Family & Género/Genus & Especie/Species & $\begin{array}{l}\text { Forma } \\
\text { de Vida/ } \\
\text { Habit }\end{array}$ & Fuente/Source \\
\hline Balanophoraceae & Ombrophytum & (1 sp.) & $\mathrm{H} / \mathrm{P}$ & $\mathrm{RF}$ \\
\hline Begoniaceae & Begonia & glabra & V & RA1697/RF \\
\hline Begoniaceae & Begonia & parviflora & $\mathrm{S}$ & $\mathrm{RF}$ \\
\hline Begoniaceae & Begonia & rossmanniae & V/E & $\mathrm{RA} / \mathrm{CC} / \mathrm{RF}$ \\
\hline Begoniaceae & Begonia & semiovata & $\mathrm{H}$ & $\mathrm{CC}$ \\
\hline Begoniaceae & Begonia & (6 spp.) & $\mathrm{H}$ & RA/RF \\
\hline Bignoniaceae & Amphilophium & paniculatum & $\mathrm{V}$ & $\mathrm{CC}$ \\
\hline Bignoniaceae & Arrabidaea & affinis & V & $\mathrm{CC}$ \\
\hline Bignoniaceae & Arrabidaea & candicans & $\mathrm{V}$ & $\mathrm{CC}$ \\
\hline Bignoniaceae & Arrabidaea & verrucosa & V & $\mathrm{RF}$ \\
\hline Bignoniaceae & Callichlamys & latifolia & V & $\mathrm{CC}$ \\
\hline Bignoniaceae & Jacaranda & copaia & $\mathrm{T}$ & $\mathrm{CC}$ \\
\hline Bignoniaceae & Jacaranda & glabra & $\mathrm{S} / \mathrm{T}$ & $\mathrm{CC}$ \\
\hline Bignoniaceae & Lundia & puberula & $\mathrm{V}$ & $\mathrm{CC}$ \\
\hline Bignoniaceae & Mansoa & standleyi & V & $\mathrm{CC}$ \\
\hline Bignoniaceae & Mansoa & verrucifera & $\mathrm{V}$ & $\mathrm{RF}$ \\
\hline Bignoniaceae & Mussatia & hyacinthina & V & $\mathrm{RF}$ \\
\hline Bignoniaceae & Spathicalyx & xanthophylla & V & $\mathrm{RF}$ \\
\hline Bignoniaceae & Stizophyllum & riparium & V & $\mathrm{RF}$ \\
\hline Bignoniaceae & Tynanthus & polyanthus & $\mathrm{V}$ & $\mathrm{RF}$ \\
\hline Bixaceae & Bixa & orellana & $\mathrm{S} / \mathrm{T}$ & $\mathrm{CC}$ \\
\hline Bombacaceae & Matisia & bolivarii s.l. & $\mathrm{T}$ & RA1611/RF \\
\hline Bombacaceae & Matisia & bracteolosa & $\mathrm{T}$ & RA/RF \\
\hline Bombacaceae & Matisia & obliquifolia & $\mathrm{T}$ & $\mathrm{CC} / \mathrm{RF}$ \\
\hline Bombacaceae & Matisia & stenopetala & $\mathrm{T}$ & $\mathrm{RF}$ \\
\hline Bombacaceae & Ochroma & pyramidale & $\mathrm{T}$ & $\mathrm{CC} / \mathrm{RF}$ \\
\hline Bombacaceae & Pachira & aquatica & $\mathrm{T}$ & $\mathrm{CC}$ \\
\hline Bombacaceae & Patinoa & paraensis & $\mathrm{T}$ & $\mathrm{RF}$ \\
\hline Bombacaceae & Phragmotheca & (1 sp.) & $\mathrm{T}$ & $\mathrm{RF}$ \\
\hline Bombacaceae & Spirotheca & rimbachii & $\mathrm{T}$ & RA1297,1711/RF \\
\hline Boraginaceae & Cordia & alliodora & $\mathrm{T}$ & $\mathrm{RF}$ \\
\hline Boraginaceae & Cordia & bifurcata & $\mathrm{S} / \mathrm{V}$ & $\mathrm{RF}$ \\
\hline Boraginaceae & Cordia & hebeclada & $\mathrm{T}$ & $\mathrm{CC}$ \\
\hline Boraginaceae & Cordia & nodosa & $\mathrm{S} / \mathrm{T}$ & $\mathrm{CC} / \mathrm{RF}$ \\
\hline Boraginaceae & Cordia & spinescens & $\mathrm{S} N$ & $\mathrm{CC}$ \\
\hline Boraginaceae & Cordia & ucayaliensis & $\mathrm{T}$ & $\mathrm{CC}$ \\
\hline Boraginaceae & Cordia & (2 spp.) & $\mathrm{T}$ & RA/RF \\
\hline Boraginaceae & Tournefortia & (1 sp.) & $\mathrm{H} / \mathrm{S}$ & RA/RF \\
\hline Bromeliaceae & Aechmea & hoppii & $E$ & $\mathrm{RF}$ \\
\hline Bromeliaceae & Aechmea & nidularioides & $E$ & $\mathrm{RA} / \mathrm{RF}$ \\
\hline Bromeliaceae & Aechmea & roeseliae & $E$ & RA1179/RF \\
\hline Bromeliaceae & Aechmea & tessmannii & $E$ & $\mathrm{RA}$ \\
\hline Bromeliaceae & Aechmea & (2 spp.) & $E$ & RA/RF \\
\hline Bromeliaceae & Ananas & comosus & $\mathrm{H}$ & $\mathrm{CC}$ \\
\hline Bromeliaceae & Catopsis & sessiliflora & $E$ & RA1618 \\
\hline Bromeliaceae & Guzmania & acuminata & $E$ & RA1347/CC/RF \\
\hline
\end{tabular}




\section{PIANTAS I IANTS}

\begin{tabular}{|c|c|c|c|c|}
\hline Familia/Family & Género/Genus & Especie/Species & $\begin{array}{l}\text { Forma } \\
\text { de Vida/ } \\
\text { Habit }\end{array}$ & Fuente/Source \\
\hline Bromeliaceae & Guzmania & bipartita & $E$ & RA/RF \\
\hline Bromeliaceae & Guzmania & hollinensis & $\mathrm{H}$ & RA1586/CC/RF \\
\hline Bromeliaceae & Guzmania & pearcei & $\mathrm{H}$ & RA1417/RF \\
\hline Bromeliaceae & Guzmania & retusa & $E$ & RA1202/RF \\
\hline Bromeliaceae & Guzmania & $\begin{array}{l}\text { sp. nov. fide J. M. } \\
\text { Manzanares }\end{array}$ & $H$ & RA1413/RF \\
\hline Bromeliaceae & Guzmania & squarrosa & $E$ & RA1229/RF \\
\hline Bromeliaceae & Guzmania & (1 sp.) & $E$ & RA/RF \\
\hline Bromeliaceae & Pepinia & (1 sp.) & $\mathrm{H}$ & RA1394/RF \\
\hline Bromeliaceae & Pitcairnia & arcuata & $\mathrm{H}$ & RA1509/CC/RF \\
\hline Bromeliaceae & Pitcairnia & cosangaensis & $\mathrm{H}$ & RA1216/RF \\
\hline Bromeliaceae & Pitcairnia & $\begin{array}{l}\text { sp. nov. fide J. M. } \\
\text { Manzanares }\end{array}$ & $\mathrm{H}$ & RA1682/RF \\
\hline Bromeliaceae & Pitcairnia & (1 sp.) & $\mathrm{H}$ & RA/RF \\
\hline Bromeliaceae & Racinaea & parviflora & $E$ & RA1641/RF \\
\hline Bromeliaceae & Racinaea & schumanniana & $E$ & RA1517 \\
\hline Bromeliaceae & Racinaea & spiculosa & $E$ & RA1102/RF \\
\hline Bromeliaceae & Racinaea & undulifolia & $E$ & $\mathrm{RF}$ \\
\hline Bromeliaceae & Ronnbergia & deleonii & $E$ & RA1573 \\
\hline Bromeliaceae & Streptocalyx & (1 sp.) & $E$ & $\mathrm{RF}$ \\
\hline Bromeliaceae & Tillandsia & confinis & $E$ & RA1521,1710/RF \\
\hline Bromeliaceae & Tillandsia & (2 spp.) & $E$ & RA/RF \\
\hline Bromeliaceae & Vriesea & rubrobracteata & $\mathrm{E}$ & RA1574 \\
\hline Bromeliaceae & Werauhia & haltonii & $E$ & RA1481 \\
\hline Brunelliaceae & Brunellia & stenoptera & $\mathrm{T}$ & RA1649/RF \\
\hline Burmanniaceae & Gymnosiphon & (1 sp.) & $\mathrm{H}$ & RA1372/RF \\
\hline Burmanniaceae & (1 sp.) & - & $\mathrm{H}$ & RA1310/RF \\
\hline Burseraceae & Crepidospermum & rhoifolium cf. & $\mathrm{T}$ & $\mathrm{RF}$ \\
\hline Burseraceae & Dacryodes & olivifera & $\mathrm{T}$ & $\mathrm{RF}$ \\
\hline Burseraceae & Dacryodes & peruviana & $\mathrm{T}$ & $\mathrm{CC}$ \\
\hline Burseraceae & Protium & amazonicum & $\mathrm{T}$ & $\mathrm{CC} / \mathrm{RF}$ \\
\hline Burseraceae & Protium & aracouchini & $\mathrm{T}$ & $\mathrm{RF}$ \\
\hline Burseraceae & Protium & nodulosum & $\mathrm{T}$ & $\mathrm{RF}$ \\
\hline Burseraceae & Protium & sagotianum & $\mathrm{T}$ & $\mathrm{RF}$ \\
\hline Burseraceae & Protium & subserratum & $\mathrm{T}$ & $\mathrm{RF}$ \\
\hline Burseraceae & Protium & (3 spp.) & $\mathrm{T}$ & $\mathrm{RF}$ \\
\hline Burseraceae & Tetragastris & panamensis & $\mathrm{T}$ & $\mathrm{RF}$ \\
\hline Burseraceae & Trattinnickia & (1 sp.) & $\mathrm{T}$ & $\mathrm{R}$ \\
\hline Cactaceae & Disocactus & amazonicus & $E$ & $\mathrm{RF}$ \\
\hline Caesalpiniaceae & Bauhinia & guianensis & V & $\mathrm{RF}$ \\
\hline Caesalpiniaceae & Bauhinia & tarapotensis & $\mathrm{T}$ & $\mathrm{CC} / \mathrm{RF}$ \\
\hline Caesalpiniaceae & Brownea & grandiceps & $\mathrm{T}$ & $\mathrm{CC}$ \\
\hline Caesalpiniaceae & Cassia & grandis & $\mathrm{T}$ & $\mathrm{RF}$ \\
\hline Caesalpiniaceae & Macrolobium & sp. nov. & $T$ & RA1065,1292/RF \\
\hline Caesalpiniaceae & Schizolobium & parahyba & $\mathrm{T}$ & $\mathrm{RF}$ \\
\hline Caesalpiniaceae & Senna & bacillaris & $\mathrm{T}$ & $\mathrm{CC}$ \\
\hline
\end{tabular}

Species of vascular plants recorded for the Serranias Cofán, Sucumbios province, northeastern Ecuador, in a rapid biological inventory from 24 July to 16 August 2001. The list also includes collections made by R. Foster, R. Aguinda, T. Theim, M. Metz, and G. Baker during earlier visits to Sinangoe in June 1999 and the Interoceanic Highway in July 2000, and species registered by Cerón et al. (1994) in the vicinity of Sinangoe. Compiled by R. Foster, Rapid biological inventory botany team members: R. Foster, R. Aguinda, and N. Pitman. Updated information will be posted at www.fieldmuseum.org/rbi.

Forma de Vida/Habit:

$E$ = Epifita/Epiphyte

$\mathrm{H}=$ Hierba terrestre/

Terrestrial herb

$\mathrm{P}=$ Parásito/Parasite

$\mathrm{S}=$ Arbusto/Shrub

$\mathrm{T}=$ Árbol/Tree

$V=$ Trepadora $/$ Climber

Fuente/Source

$\mathrm{CC}=$ Registrado por Cerón et al. (1994)/Listed by Cerón et al. (1994)

$\mathrm{RA}=$ Colecciones de Roberto Aguinda; los números corresponden a los especímenes depositados en el Herbario Nacional del Ecuador/Roberto Aguinda collections; numbers refer to voucher specimens deposited in The National Herbarium of Ecuador (QCNE)

RF $=$ Fotos o observaciones de campo de Robin Foster/ Robin Foster photographs or field notes 
Especies de plantas vasculares registradas para las Serranias Cofán, Provincia de Sucumbios, Ecuador, durante un inventario biológico rápido del 24 de julio al 16 de agosto 2001. La lista también incluye colecciones anteriores realizadas por $R$. Foster, R. Aguinda, T. Theim, M. Metz y G. Baker durante una visita a Sinangoe en junio del 1999 y otra a la Via Interoceánica en julio del 2000, y especies registradas por Cerón et al. (1994) en los alrededores de Sinangoe. Compilación por R. Foster. Miembros del equipo del inventario botánico rápido: $R$. Foster, R. Aguinda y N. Pitman. La información presentada aqui se irá actualizando y estará disponible en la página Web en uww.fieldmuseum.org/rbi.

\section{BLANTASI PLANTS}

\begin{tabular}{|c|c|c|c|c|}
\hline Familia/Family & Género/Genus & Especie/Species & $\begin{array}{l}\text { Forma } \\
\text { de Vida/ } \\
\text { Habit }\end{array}$ & Fuente/Source \\
\hline Caesalpiniaceae & Senna & macrophylla & $\mathrm{T}$ & $\mathrm{CC}$ \\
\hline Caesalpiniaceae & Senna & multijuga & $\mathrm{T}$ & $\mathrm{RF}$ \\
\hline Caesalpiniaceae & Senna & ruiziana & $\mathrm{T}$ & RA1679/RF \\
\hline Caesalpiniaceae & Tachigali & (1 sp.) & $\mathrm{T}$ & RA1040/RF \\
\hline Campanulaceae & Burmeistera & glabrata & V/E & $\mathrm{CC}$ \\
\hline Campanulaceae & Burmeistera & pallida & $\mathrm{V} / \mathrm{E}$ & RA1566/RF \\
\hline Campanulaceae & Burmeistera & (1 sp.) & V/E & RA1244/RF \\
\hline Campanulaceae & Centropogon & cornutus & $\mathrm{H}$ & $\mathrm{RF}$ \\
\hline Campanulaceae & Centropogon & curvatus & $\mathrm{H}$ & RA1123/RF \\
\hline Campanulaceae & Centropogon & granulosus & $\mathrm{H} N$ & $\mathrm{RF}$ \\
\hline Campanulaceae & Centropogon & loretensis & $\mathrm{H}$ & $\mathrm{CC}$ \\
\hline Campanulaceae & Centropogon & solanifolius & $\mathrm{H}$ & RA1556/RF \\
\hline Campanulaceae & Centropogon & (5 spp.) & $\mathrm{H}$ & RA \\
\hline Campanulaceae & Siphocampy/us & scandens & $\mathrm{V}$ & RA1479/RF \\
\hline Cannaceae & Canna & indica & $\mathrm{H}$ & $\mathrm{CC}$ \\
\hline Cannaceae & Canna & jaegeriana & $\mathrm{H}$ & $\mathrm{CC} / \mathrm{RF}$ \\
\hline Capparidaceae & Capparis & detonsa & $\mathrm{T}$ & $\begin{array}{l}\text { RA803,1613, } \\
\text { 1617/RF }\end{array}$ \\
\hline Capparidaceae & Cleome & (1 sp.) & $\mathrm{H}$ & $\mathrm{RF}$ \\
\hline Capparidaceae & Podandrogyne & brachycarpa & $\mathrm{H} / \mathrm{S}$ & RA1590/RF \\
\hline Capparidaceae & Podandrogyne & glabra & $\mathrm{H} / \mathrm{S}$ & RA1602/RF \\
\hline Capparidaceae & Podandrogyne & (1 sp.) & $\mathrm{H} / \mathrm{S}$ & RA888/RF \\
\hline Caprifoliaceae & Viburnum & hallii & $\mathrm{S} / \mathrm{T}$ & RA1671/RF \\
\hline Caricaceae & Carica & microcarpa & $\mathrm{S}$ & $\mathrm{RA} 1150 / \mathrm{CC} / \mathrm{RF}$ \\
\hline Caricaceae & Carica & рарауа & $\mathrm{T}$ & $\mathrm{CC}$ \\
\hline Caricaceae & Jacaratia & digitata & $\mathrm{T}$ & $\mathrm{CC}$ \\
\hline Caryocaraceae & Caryocar & glabrum & $\mathrm{T}$ & $\mathrm{RF}$ \\
\hline Cecropiaceae & Cecropia & engleriana & $\mathrm{T}$ & $\mathrm{CC}$ \\
\hline Cecropiaceae & Cecropia & ficifolia & $\mathrm{T}$ & $\mathrm{CC} / \mathrm{RF}$ \\
\hline Cecropiaceae & Cecropia & herthae & $\mathrm{T}$ & $\mathrm{RF}$ \\
\hline Cecropiaceae & Cecropia & putumayonis & $\mathrm{T}$ & $\mathrm{CC} / \mathrm{RF}$ \\
\hline Cecropiaceae & Cecropia & sciadophylla & $\mathrm{T}$ & RA940/RF \\
\hline Cecropiaceae & Cecropia & (3 spp.) & $\mathrm{T}$ & RF \\
\hline Cecropiaceae & Coussapoa & crassivenosa & $\mathrm{E} / \mathrm{T}$ & $\mathrm{CC}$ \\
\hline Cecropiaceae & Coussapoa & ovalifolia & $\mathrm{E} / \mathrm{T}$ & $\mathrm{RF}$ \\
\hline Cecropiaceae & Coussapoa & (2 spp.) & $\mathrm{T}$ & $\mathrm{RF}$ \\
\hline Cecropiaceae & Pourouma & bicolor & $\mathrm{T}$ & $\mathrm{CC} / \mathrm{RF}$ \\
\hline Cecropiaceae & Pourouma & cecropiifolia & $\mathrm{T}$ & $\mathrm{CC} / \mathrm{RF}$ \\
\hline Cecropiaceae & Pourouma & cucura & $\mathrm{T}$ & $\mathrm{CC}$ \\
\hline Cecropiaceae & Pourouma & minor & $\mathrm{T}$ & $\mathrm{CC} / \mathrm{RF}$ \\
\hline Cecropiaceae & Pourouma & napoensis & $\mathrm{T}$ & $\mathrm{CC}$ \\
\hline Cecropiaceae & Pourouma & tomentosa & $\mathrm{T}$ & $\mathrm{CC}$ \\
\hline Cecropiaceae & Pourouma & (2 spp.) & $\mathrm{T}$ & $\mathrm{RF}$ \\
\hline Celastraceae & Maytenus & (2 spp.) & $\mathrm{T}$ & RA/RF \\
\hline Celastraceae & Zinowiewia & australis & $\mathrm{T}$ & $\mathrm{CC}$ \\
\hline Chloranthaceae & Hedyosmum & racemosum & $\mathrm{S} / \mathrm{T}$ & RA1652/RF \\
\hline
\end{tabular}




\section{PLANTASI PLANTS}

\begin{tabular}{|c|c|c|c|c|}
\hline Familia/Family & Género/Genus & Especie/Species & $\begin{array}{l}\text { Forma } \\
\text { de Vida/ } \\
\text { Habit }\end{array}$ & Fuente/Source \\
\hline Chrysobalanaceae & Hirtella & (1 sp.) & $\mathrm{T}$ & $\mathrm{RF}$ \\
\hline Chrysobalanaceae & Licania & (5 spp.) & $\mathrm{T}$ & RA/RF \\
\hline Chrysobalanaceae & Parinari & (1 sp.) & $\mathrm{T}$ & $\mathrm{RF}$ \\
\hline Clethraceae & Clethra & revoluta & $\mathrm{T}$ & RA1489/RF \\
\hline Clusiaceae & Calophyllum & brasiliense & $\mathrm{T}$ & $\mathrm{CC} / \mathrm{RF}$ \\
\hline Clusiaceae & Chrysochlamys & bracteolata & $\mathrm{T}$ & $\mathrm{CC}$ \\
\hline Clusiaceae & Chrysochlamys & (7 spp.) & $\mathrm{S} / \mathrm{T}$ & RA/RF \\
\hline Clusiaceae & Clusia & hamelliana & $\mathrm{V} / \mathrm{E}$ & $\mathrm{RF}$ \\
\hline Clusiaceae & Clusia & lineata & $\mathrm{T}$ & $\mathrm{CC}$ \\
\hline Clusiaceae & Clusia & octandra & $E / T$ & $\mathrm{CC}$ \\
\hline Clusiaceae & Clusia & pallida & $E / T$ & $\mathrm{CC}$ \\
\hline Clusiaceae & Clusia & (6 spp.) & $\mathrm{E} / \mathrm{T}$ & RA/RF \\
\hline Clusiaceae & Garcinia & macrophylla & $\mathrm{T}$ & $\mathrm{RF}$ \\
\hline Clusiaceae & Garcinia & madruno & $\mathrm{T}$ & $\mathrm{CC} / \mathrm{RF}$ \\
\hline Clusiacea & Marila & laxiflora & $\mathrm{T}$ & $\mathrm{RF}$ \\
\hline Clusiaceae & Marila & tomentosa & $\mathrm{T}$ & $\mathrm{CC}$ \\
\hline Clusiaceae & Symphonia & globulifera & $\mathrm{T}$ & $\mathrm{CC} / \mathrm{RF}$ \\
\hline Clusiaceae & Tovomita & weddelliana & $\mathrm{T}$ & RA1337/CC/RF \\
\hline Clusiaceae & Tovomita & (3 spp.) & $\mathrm{S} / \mathrm{T}$ & RA/RF \\
\hline Clusiaceae & Vismia & baccifera & $\mathrm{T}$ & $\mathrm{CC}$ \\
\hline Clusiaceae & Vismia & sprucei & $\mathrm{T}$ & RA1370/RF \\
\hline Clusiaceae & Vismia & (2 spp.) & $\mathrm{T}$ & RA/RF \\
\hline Combretaceae & Buchenavia & parvifolia & $\mathrm{T}$ & $\mathrm{RF}$ \\
\hline Combretaceae & Buchenavia & (1 sp.) & $\mathrm{T}$ & $\mathrm{RF}$ \\
\hline Combretaceae & Terminalia & amazonia & $\mathrm{T}$ & $\mathrm{CC} / \mathrm{RF}$ \\
\hline Combretaceae & Terminalia & oblonga & $\mathrm{T}$ & $\mathrm{RF}$ \\
\hline Commelinaceae & Commelina & erecta & $\mathrm{H}$ & $\mathrm{RF}$ \\
\hline Commelinaceae & Dichorisandra & hexandra & V & $\mathrm{RF}$ \\
\hline Commelinaceae & Dichorisandra & ulei & $\mathrm{H}$ & $\mathrm{RF}$ \\
\hline Commelinaceae & Dichorisandra & (1 sp.) & $\mathrm{H}$ & RA1198 \\
\hline Commelinaceae & Floscopa & (2 spp.) & $\mathrm{H}$ & RF \\
\hline Commelinaceae & Geogenanthus & ciliatus & $\mathrm{H}$ & RA1348/CC/RF \\
\hline Commelinaceae & Tradescantia & zanonia & $\mathrm{H}$ & $\mathrm{RF}$ \\
\hline Convolvulaceae & Dicranostyles & (1 sp.) & V & $\mathrm{RF}$ \\
\hline Convolvulaceae & Ipomoea & (3 spp.) & V & $\mathrm{CC}$ \\
\hline Convolvulaceae & Maripa & nicaraguensis & V & RA1016/RF \\
\hline Costaceae & Costus & scaber & $\mathrm{H}$ & $\mathrm{RF}$ \\
\hline Costaceae & Costus & (3 spp.) & $\mathrm{H}$ & $\mathrm{RF}$ \\
\hline Cucurbitaceae & Calycophysum & pedunculatum & V & RA1570/RF \\
\hline Cucurbitaceae & Cayaponia & granatensis & V & $\mathrm{CC}$ \\
\hline Cucurbitaceae & Cayaponia & ophthalmica & V & $\mathrm{CC}$ \\
\hline Cucurbitaceae & Gurania & eriantha & V & $\mathrm{RA} 1021 / \mathrm{CC} / \mathrm{RF}$ \\
\hline Cucurbitaceae & Gurania & guentheri & V & RA1156/RF \\
\hline Cucurbitaceae & Gurania & latiloba & V & $\mathrm{CC} / \mathrm{RF}$ \\
\hline Cucurbitaceae & Gurania & (1 sp.) & V & RA/RF \\
\hline Cunoniaceae & Weinmannia & pinnata cf. & $\mathrm{T}$ & RA1708 \\
\hline
\end{tabular}

Forma de Vida/Habit:

$E$ = Epífita/Epiphyte

$\mathrm{H}=$ Hierba terrestre/

Terrestrial herb

$\mathrm{P}=$ Parásito $/$ Parasite

$\mathrm{S}=$ Arbusto/Shrub

$\mathrm{T}=$ Árbol/Tree

$\mathrm{V}=$ Trepadora/Climber

Fuente/Source

CC = Registrado por Cerón et al. (1994)/Listed by Cerón et al. (1994)

$\mathrm{RA}=$ Colecciones de Roberto Aguinda; los números corresponden a los especímenes depositados en el Herbario Nacional del Ecuador/Roberto Aguinda collections; numbers refer to voucher specimens deposited in The National Herbarium of Ecuador (QCNE)

$\mathrm{RF}=$ Fotos o observaciones de campo de Robin Foster/ Robin Foster photographs or field notes 
Especies de plantas vasculares registradas para las Serranias Cofán, Provincia de Sucumbios, Ecuador, durante un inventario biológico rápido del 24 de julio al 16 de agosto 2001. La lista también incluye colecciones anteriores realizadas por $R$. Foster, R. Aguinda, T. Theim, M. Metz y G. Baker durante una visita a Sinangoe en junio del 1999 y otra a la Via Interoceánica en julio del 2000, y especies registradas por Cerón et al. (1994) en los alrededores de Sinangoe. Compilación por R. Foster. Miembros del equipo del inventario botánico rápido: $R$. Foster, $R$. Aguinda y N. Pitman. La información presentada aquí se irá actualizando y estará disponible en la página Web en www.fieldmuseum.org/rbi.

\section{PLANTASIPLANTS}

\begin{tabular}{|c|c|c|c|c|}
\hline Familia/Family & Género/Genus & Especie/Species & $\begin{array}{l}\text { Forma } \\
\text { de Vida/ } \\
\text { Habit } \\
\end{array}$ & Fuente/Source \\
\hline Cunoniaceae & Weinmannia & sorbifolia cf. & $\mathrm{T}$ & $\mathrm{RF}$ \\
\hline Cyclanthaceae & Asplundia & (3 spp.) & $E$ & $\mathrm{RF}$ \\
\hline Cyclanthaceae & Carludovica & palmata & $\mathrm{H}$ & $\mathrm{CC} / \mathrm{RF}$ \\
\hline Cyclanthaceae & Cyclanthus & bipartitus & $\mathrm{H}$ & $\mathrm{CC} / \mathrm{RF}$ \\
\hline Cyclanthaceae & Cyclanthus & (1 sp.) & $\mathrm{H}$ & RA/RF \\
\hline Cyclanthaceae & Dicranopygium & yacu-sisa & $\mathrm{H}$ & $\mathrm{CC}$ \\
\hline Cyclanthaceae & Dicranopygium & (1 sp.) & $\mathrm{H}$ & $\mathrm{RF}$ \\
\hline Cyclanthaceae & Evodianthus & funifer & V/E & $\mathrm{RF}$ \\
\hline Cyclanthaceae & Sphaeradenia & (2 spp.) & $H / S$ & $\mathrm{RA} / \mathrm{RF}$ \\
\hline Cyclanthaceae & Thoracocarpus & bissectus & V/E & RA1 $125 / C C / R F$ \\
\hline Cyperaceae & Cyperus & (1 sp.) & $\mathrm{H}$ & RA \\
\hline Cyperaceae & Kyllinga & (1 sp.) & $\mathrm{H}$ & $\mathrm{RF}$ \\
\hline Cyperaceae & Scleria & secans & V & $\mathrm{RF}$ \\
\hline Cyrillaceae & Purdiaea & nutans & $\mathrm{S} / \mathrm{T}$ & $\mathrm{RF}$ \\
\hline Dichapetalaceae & Dichapetalum & odoratum & $\mathrm{v}$ & RA1320 \\
\hline Dichapetalaceae & Dichapetalum & spruceanum cf. & $\mathrm{v}$ & $\mathrm{RF}$ \\
\hline Dichapetalaceae & Tapura & peruviana & $\mathrm{T}$ & $\mathrm{RF}$ \\
\hline Dilleniaceae & Doliocarpus & $(1 \mathrm{sp})$. & V & $\mathrm{RF}$ \\
\hline Dioscoreaceae & Dioscorea & (2 spp.) & V & RA/RF \\
\hline Elaeocarpaceae & Sloanea & grandiflora & $\mathrm{T}$ & $\mathrm{CC} / \mathrm{RF}$ \\
\hline Elaeocarpaceae & Sloanea & guianensis & $\mathrm{T}$ & $\mathrm{CC} / \mathrm{RF}$ \\
\hline Ericaceae & Cavendishia & tarapotana & $E / S$ & $\mathrm{CC}$ \\
\hline Ericaceae & Cavendishia & $(1 \mathrm{sp})$. & $\mathrm{V} / \mathrm{E}$ & RA1662 \\
\hline Ericaceae & Disterigma & $(1 \mathrm{sp})$. & $S / E$ & $\mathrm{RF}$ \\
\hline Ericaceae & Psammisia & $(1 \mathrm{sp})$. & $\mathrm{V} / \mathrm{E}$ & RA1540 \\
\hline Ericaceae & Satyria & panurensis & $E / S$ & RA946/CC/RF \\
\hline Ericaceae & Sphaerospermum & (4 spp.) & V/E & $\mathrm{RA}$ \\
\hline Ericaceae & (11 spp.) & - & $\mathrm{V} / \mathrm{E}$ & RA/RF \\
\hline Erythroxylaceae & Erythroxylum & citrifolium & $\mathrm{T}$ & RA1612/RF \\
\hline Erythroxylaceae & Erythroxylum & gracilipes cf. & $\mathrm{S} / \mathrm{T}$ & RA1155/RF \\
\hline Erythroxylaceae & Erythroxylum & macrophyllum & $\mathrm{S} / \mathrm{T}$ & $\mathrm{CC}$ \\
\hline Erythroxylaceae & Erythroxylum & $(1 \mathrm{sp})$. & $\mathrm{S} / \mathrm{T}$ & $\mathrm{RF}$ \\
\hline Euphorbiaceae & Acalypha & cuneata & $\mathrm{S} / \mathrm{T}$ & $\mathrm{CC}$ \\
\hline Euphorbiacea & Acalypha & diversifolia & $\mathrm{S}$ & $\mathrm{RF}$ \\
\hline Euphorbiaceae & Acalypha & salicifolia & $\mathrm{S}$ & RA1307 \\
\hline Euphorbiaceae & Acalypha & (2 spp.) & $S / T$ & $\mathrm{RF}$ \\
\hline Euphorbiaceae & Alchornea & glandulosa & $T$ & $\mathrm{RA} 1232 / \mathrm{CC} / \mathrm{RF}$ \\
\hline Euphorbiaceae & Alchornea & triplinervia & $\mathrm{T}$ & $\mathrm{CC} / \mathrm{RF}$ \\
\hline Euphorbiaceae & Alchornea & (1 sp.) & $\mathrm{T}$ & $\mathrm{RF}$ \\
\hline Euphorbiaceae & Alchorneopsis & floribunda & $T$ & $\mathrm{CC}$ \\
\hline Euphorbiaceae & Aparisthmium & cordatum & $\mathrm{S} / \mathrm{T}$ & $\mathrm{RF}$ \\
\hline Euphorbiaceae & Caryodendron & orinocense & $T$ & $\mathrm{CC} / \mathrm{RF}$ \\
\hline Euphorbiaceae & Conceveiba & (1 sp.) & $\mathrm{T}$ & RA/RF \\
\hline Euphorbiaceae & Croton & lechleri & $T$ & $\mathrm{RF}$ \\
\hline Euphorbiaceae & Croton & sampatik & $T$ & $\mathrm{CC}$ \\
\hline Euphorbiaceae & Croton & tessmannii & $\mathrm{T}$ & $\mathrm{CC}$ \\
\hline
\end{tabular}




\section{PLANTASIRLANTS}

\begin{tabular}{|c|c|c|c|c|}
\hline Familia/Family & Género/Genus & Especie/Species & $\begin{array}{l}\text { Forma } \\
\text { de Vida/ } \\
\text { Habit }\end{array}$ & Fuente/Source \\
\hline Euphorbiaceae & Croton & (3 spp.) & $\mathrm{T}$ & $\mathrm{RF}$ \\
\hline Euphorbiaceae & Drypetes & amazonica & $\mathrm{S} / \mathrm{T}$ & $\mathrm{CC}$ \\
\hline Euphorbiaceae & Hyeronima & alchorneoides & $\mathrm{T}$ & $\mathrm{CC} / \mathrm{RF}$ \\
\hline Euphorbiaceae & Hyeronima & duquei & $\mathrm{T}$ & RA1190 \\
\hline Euphorbiaceae & Hyeronima & macrocarpa & $\mathrm{S} / \mathrm{T}$ & RA1610/RF \\
\hline Euphorbiaceae & Hyeronima & oblonga & $\mathrm{T}$ & RA1511/CC/RF \\
\hline Euphorbiaceae & Mabea & piriri & $\mathrm{T}$ & $\mathrm{CC}$ \\
\hline Euphorbiaceae & Mabea & speciosa & $\mathrm{T}$ & $\mathrm{CC}$ \\
\hline Euphorbiaceae & Mabea & (1 sp.) & $\mathrm{T}$ & RA99/RF \\
\hline Euphorbiaceae & Manihot & brachyloba & $\mathrm{S} / \mathrm{T}$ & RA1628/RF \\
\hline Euphorbiaceae & Manihot & esculenta & $\mathrm{S}$ & $\mathrm{CC}$ \\
\hline Euphorbiaceae & Margaritaria & nobilis & $\mathrm{T}$ & $\mathrm{CC}$ \\
\hline Euphorbiaceae & Pera & (1 sp.) & $\mathrm{T}$ & RF \\
\hline Euphorbiaceae & Phyllanthus & anisolobus & $\mathrm{S} / \mathrm{T}$ & $\mathrm{CC}$ \\
\hline Euphorbiaceae & Phyllanthus & attenuatus & $\mathrm{S} / \mathrm{T}$ & RA1580 \\
\hline Euphorbiaceae & Sapium & glandulosum & $\mathrm{T}$ & $\mathrm{CC}$ \\
\hline Euphorbiaceae & Sapium & marmieri & $\mathrm{T}$ & $\mathrm{CC} / \mathrm{RF}$ \\
\hline Euphorbiaceae & Sapium & peruvianum & $\mathrm{T}$ & $\mathrm{CC}$ \\
\hline Euphorbiaceae & Sapium & (1 sp.) & $\mathrm{T}$ & $\mathrm{RF}$ \\
\hline Euphorbiaceae & Tetrorchidium & macrophyllum & $\mathrm{S} / \mathrm{T}$ & $\mathrm{CC} / \mathrm{RF}$ \\
\hline Fabaceae & Andira & inermis & $\mathrm{T}$ & $\mathrm{RF}$ \\
\hline Fabaceae & Andira & macrothyrsa & $\mathrm{T}$ & $\mathrm{CC}$ \\
\hline Fabaceae & Arachis & hypogea & $\mathrm{H}$ & $\mathrm{CC}$ \\
\hline Fabaceae & Clitoria & arborea & $\mathrm{T}$ & $\mathrm{CC}$ \\
\hline Fabaceae & Crotalaria & nitens & $\mathrm{H} / \mathrm{S}$ & RF \\
\hline Fabaceae & Desmodium & purpusii & V & RA1265/RF \\
\hline Fabaceae & Desmodium & (1 sp.) & $\mathrm{H}$ & RF \\
\hline Fabaceae & Diplotropis & purpurea & $T$ & $\mathrm{RF}$ \\
\hline Fabaceae & Dussia & tessmannii & $\mathrm{T}$ & $\mathrm{CC} / \mathrm{RF}$ \\
\hline Fabaceae & Erythrina & amazonica & $\mathrm{T}$ & $\mathrm{RF}$ \\
\hline Fabaceae & Erythrina & poeppigiana & $\mathrm{T}$ & $\mathrm{CC} / \mathrm{RF}$ \\
\hline Fabaceae & Erythrina & ulei & $\mathrm{T}$ & RF \\
\hline Fabaceae & Gliricidia & sepium & $\mathrm{T}$ & $\mathrm{CC} / \mathrm{RF}$ \\
\hline Fabaceae & Hymenolobium & heterocarpum & $\mathrm{T}$ & $\mathrm{CC}$ \\
\hline Fabaceae & Lecointea & peruviana & $\mathrm{T}$ & $\mathrm{CC}$ \\
\hline Fabaceae & Lonchocarpus & nicou & $\mathrm{TN}$ & $\mathrm{CC}$ \\
\hline Fabaceae & Machaerium & cuspidatum & V & $\mathrm{CC} / \mathrm{RF}$ \\
\hline Fabaceae & Machaerium & floribundum & V & RA1328/CC/RF \\
\hline Fabaceae & Mucuna & elliptica cf. & V & RA979,1569/RF \\
\hline Fabaceae & Pachyrhizus & tuberosus & V & $\mathrm{CC}$ \\
\hline Fabaceae & Platymiscium & stipulare & $\mathrm{T}$ & RF \\
\hline Fabaceae & Pterocarpus & rohrii & $\mathrm{T}$ & $\mathrm{CC}$ \\
\hline Fabaceae & Pterocarpus & (1 sp.) & $\mathrm{T}$ & $\mathrm{RF}$ \\
\hline Fabaceae & Tephrosia & sinapou & $\mathrm{S}$ & $\mathrm{CC}$ \\
\hline Fabaceae & (7 spp.) & - & $\mathrm{T}$ & RF \\
\hline Flacourtiaceae & Banara & guianensis & $\mathrm{S} / \mathrm{T}$ & RF \\
\hline
\end{tabular}

Forma de Vida/Habit:

$E=$ Epífita/Epiphyte

$H=$ Hierba terrestre/

Terrestrial herb

$\mathrm{P}=$ Parásito $/$ Parasite

$\mathrm{S}=$ Arbusto/Shrub

$\mathrm{T}=$ Árbol/Tree

$V$ = Trepadora/Climber

Fuente/Source

$\mathrm{CC}=$ Registrado por Cerón et al. (1994)/Listed by Cerón et al. (1994)

$\mathrm{RA}=$ Colecciones de Roberto Aguinda; los números corresponden a los especímenes depositados en el Herbario Nacional del Ecuador/Roberto Aguinda collections; numbers refer to voucher specimens deposited in The National Herbarium of Ecuador (QCNE)

$\mathrm{RF}=$ Fotos o observaciones de campo de Robin Foster/ Robin Foster photographs or field notes 
Especies de plantas vasculares registradas para las Serranias Cofán, Provincia de Sucumbios, Ecuador, durante un inventario biológico rápido del 24 de julio al 16 de agosto 2001. La lista también incluye colecciones anteriores realizadas por $R$. Foster, R. Aguinda, T. Theim, M. Metz y G. Baker durante una visita a Sinangoe en junio del 1999 y otra a la Via Interoceánica en julio del 2000, y especies registradas por Cerón et al. (1994) en los alrededores de Sinangoe. Compilación por R. Foster. Miembros del equipo del inventario botánico rápido: $R$. Foster, R. Aguinda y N. Pitman. La información presentada aqui se irá actualizando y estará disponible en la página Web en www.fieldmuseum.org/rbi.
PLANTASIPLANTS

\begin{tabular}{|c|c|c|c|c|}
\hline Familia/Family & Género/Genus & Especie/Species & $\begin{array}{l}\text { Forma } \\
\text { de Vida/ } \\
\text { Habit }\end{array}$ & Fuente/Source \\
\hline Flacourtiaceae & Carpotroche & longifolia & $\mathrm{s}$ & $\mathrm{RF}$ \\
\hline Flacourtiaceae & Casearia & fasciculata & $\mathrm{S} / \mathrm{T}$ & RA1336/RF \\
\hline Flacourtiaceae & Casearia & mariquitensis & $\mathrm{S} / \mathrm{T}$ & $\mathrm{CC}$ \\
\hline Flacourtiaceae & Casearia & nigricans & $T$ & $\mathrm{CC}$ \\
\hline Flacourtiaceae & Casearia & pitumba & $\mathrm{S} / \mathrm{T}$ & $\mathrm{CC}$ \\
\hline Flacourtiaceae & Casearia & prunifolia cf. & $\mathrm{S} / \mathrm{T}$ & $\mathrm{RA} / \mathrm{CC} / \mathrm{RF}$ \\
\hline Flacourtiaceae & Hasseltia & floribunda & $T$ & $\mathrm{RF}$ \\
\hline Flacourtiaceae & Lunania & parviflora & $\mathrm{S} / \mathrm{T}$ & $\mathrm{RF}$ \\
\hline Flacourtiaceae & Mayna & grandifolia & $\mathrm{S} / \mathrm{T}$ & RA983,989/RF \\
\hline Flacourtiaceae & Mayna & odorata & $\mathrm{S}$ & $\mathrm{CC} / \mathrm{RF}$ \\
\hline Flacourtiaceae & Neosprucea & grandifiora & $\mathrm{S} / \mathrm{T}$ & $\mathrm{RA} 930 / \mathrm{CC} / \mathrm{RF}$ \\
\hline Flacourtiaceae & Neosprucea & sucumbiensis & $\mathrm{S} / \mathrm{T}$ & $\mathrm{CC}$ \\
\hline Flacourtiaceae & Ryania & speciosa & $\mathrm{s} / \mathrm{T}$ & RA1059,1070/RF \\
\hline Flacourtiaceae & Tetrathylacium & macrophyllum & $T$ & $\mathrm{CC} / \mathrm{RF}$ \\
\hline Flacourtiaceae & (2 spp.) & - & $\mathrm{T}$ & $\mathrm{RF}$ \\
\hline Gentianaceae & Irlbachia & alata & $\mathrm{H}$ & $\mathrm{RF}$ \\
\hline Gentianaceae & Irlbachia & (1 sp.) & $\mathrm{H}$ & RA1381/RF \\
\hline Gentianaceae & Macrocarpaea & (2 spp.) & $\mathrm{H} / \mathrm{S}$ & $\mathrm{RA} / \mathrm{RF}$ \\
\hline Gentianaceae & Potalia & resinifera & $\mathrm{S}$ & $\mathrm{RF}$ \\
\hline Gentianaceae & Symbolanthus & calygonus & $\mathrm{s}$ & RA1630/RF \\
\hline Gentianaceae & Voyria & (1 sp.) & $H / P$ & $\mathrm{RF}$ \\
\hline Gesneriaceae & Alloplectus & (1 sp.) & $\mathrm{H} / \mathrm{S}$ & RA1338 \\
\hline Gesneriaceae & Besleria & (3 spp.) & $S$ & RA/RF \\
\hline Gesneriaceae & Besleria & barbata & $s$ & RA/RF \\
\hline Gesneriaceae & Besleria & barclayi cf. & $\mathrm{s}$ & RA/RF \\
\hline Gesneriaceae & Codonanthe & (1 sp.) & $E$ & $\mathrm{RF}$ \\
\hline Gesneriaceae & Codonanthopsis & dissimulata & $E$ & $\mathrm{CC}$ \\
\hline Gesneriaceae & Columnea & angustata & $E$ & $\mathrm{RF}$ \\
\hline Gesneriaceae & Columnea & ericae & $E$ & $\mathrm{RF}$ \\
\hline Gesneriaceae & Columnea & guttata cf. & $\mathrm{E}$ & $\mathrm{RF}$ \\
\hline Gesneriaceae & Columnea & inaequilatera & $E$ & $\mathrm{RF}$ \\
\hline Gesneriaceae & Columnea & picta & $E$ & $\mathrm{RF}$ \\
\hline Gesneriaceae & Columnea & tenensis & $E$ & RA1064/RF \\
\hline Gesneriaceae & Columnea & villosissima & $E$ & $\mathrm{RF}$ \\
\hline Gesneriaceae & Corytoplectus & cutucuensis cf. & $\mathrm{H}$ & $\mathrm{RF}$ \\
\hline Gesneriaceae & Drymonia & affinis & V/E & $\mathrm{RF}$ \\
\hline Gesneriaceae & Drymonia & coccinea & $\mathrm{V} / \mathrm{E}$ & $\mathrm{RF}$ \\
\hline Gesneriaceae & Drymonia & coriacea & $E$ & $\mathrm{CC}$ \\
\hline Gesneriaceae & Drymonia & crenatiloba & $\mathrm{H}$ & $\mathrm{RF}$ \\
\hline Gesneriaceae & Drymonia & hoppii & $\mathrm{V} / \mathrm{E}$ & RA/RF \\
\hline Gesneriaceae & Drymonia & macrophylla & $\mathrm{HN}$ & $\mathrm{RF}$ \\
\hline Gesneriaceae & Drymonia & pendula & V/E & $\mathrm{CC}$ \\
\hline Gesneriaceae & Drymonia & serrulata & $\mathrm{V} / \mathrm{E}$ & $\mathrm{RF}$ \\
\hline Gesneriaceae & Drymonia & urceolata & $\mathrm{H}$ & $\mathrm{CC} / \mathrm{RF}$ \\
\hline Gesneriaceae & Drymonia & warszewicziana & V/E & RA1343/RF \\
\hline Gesneriaceae & Drymonia & (3 spp.) & $\mathrm{H}$ & RA/RF \\
\hline
\end{tabular}


PIANTASIPIANTS

\begin{tabular}{|c|c|c|c|c|}
\hline Familia/Family & Género/Genus & Especie/Species & $\begin{array}{l}\text { Forma } \\
\text { de Vida/ } \\
\text { Habit }\end{array}$ & Fuente/Source \\
\hline Gesneriaceae & Monopyle & macrocarpa & $\mathrm{H}$ & $\mathrm{RF}$ \\
\hline Gesneriaceae & Monopyle & (1 sp.) & $\mathrm{H}$ & RF \\
\hline Gesneriaceae & Paradrymonia & decurrens cf. & $E$ & RF \\
\hline Gesneriaceae & Paradrymonia & longifolia & V/E & $\mathrm{CC}$ \\
\hline Gesneriaceae & Pearcea & abunda & $\mathrm{H}$ & $\mathrm{CC} / \mathrm{RF}$ \\
\hline Gesneriaceae & Pearcea & hispidissima & $\mathrm{H}$ & RA1599/RF \\
\hline Gesneriaceae & Pearcea & sprucei & $\mathrm{H}$ & $\mathrm{CC} / \mathrm{RF}$ \\
\hline Gesneriaceae & Reldia & multiflora & $\mathrm{H}$ & RF \\
\hline Gesneriaceae & (4 spp.) & - & $\mathrm{H}$ & RA/RF \\
\hline Gnetaceae & Gnetum & nodiflorum & $\mathrm{V}$ & RA980/RF \\
\hline Haemodoracaeae & Xiphidium & caeruleum & $\mathrm{H}$ & RA715/RF \\
\hline Heliconiaceae & Heliconia & aemygdiana & $\mathrm{H}$ & RA1011/CC/RF \\
\hline Heliconiaceae & Heliconia & hirsuta & $\mathrm{H}$ & RA1317/RF \\
\hline Heliconiaceae & Heliconia & pastazae & $\mathrm{H}$ & RA1408/RF \\
\hline Heliconiaceae & Heliconia & schumanniana & $\mathrm{H}$ & RF \\
\hline Heliconiaceae & Heliconia & spathocircinata & $\mathrm{H}$ & RF \\
\hline Heliconiaceae & Heliconia & stricta & $\mathrm{H}$ & $\mathrm{RF}$ \\
\hline Heliconiaceae & Heliconia & vellerigera & $\mathrm{H}$ & $\mathrm{RF}$ \\
\hline Heliconiaceae & Heliconia & velutina & $\mathrm{H}$ & RF \\
\hline Heliconiaceae & Heliconia & (1 sp.) & $\mathrm{H}$ & RA1010/RF \\
\hline Hippocastanaceae & Billia & rosea & $\mathrm{T}$ & $\begin{array}{l}\text { RA1068,1420/ } \\
\text { CC/RF }\end{array}$ \\
\hline Hippocrateaceae & Salacia & (1 sp.) & V & RF \\
\hline Hippocrateaceae & Tontelea & attenuata & V & $\mathrm{CC}$ \\
\hline Hippocrateaceae & (1 sp.) & - & V & RA1277 \\
\hline Humiriaceae & Humiriastrum & diguense & $T$ & RA1371/RF \\
\hline Icacinaceae & Calatola & costaricensis & $\mathrm{T}$ & $\mathrm{CC} / \mathrm{RF}$ \\
\hline Icacinaceae & Citronella & incarum & $\mathrm{S} / \mathrm{T}$ & $\mathrm{CC} / \mathrm{RF}$ \\
\hline Icacinaceae & Discophora & guianensis & $\mathrm{T}$ & RA1634/RF \\
\hline Icacinaceae & Metteniusa & tessmanniana cf. & $\mathrm{T}$ & RA994/RF \\
\hline Lacistemataceae & Lacistema & nena & $\mathrm{S} / \mathrm{T}$ & $\mathrm{CC}$ \\
\hline Lacistemataceae & Lozania & klugii & $\mathrm{T}$ & RA/CC \\
\hline Lamiaceae & Scutellaria & coccinea & $\mathrm{H} / \mathrm{S}$ & RA953,1363/RF \\
\hline Lauraceae & Aniba & guianensis & $\mathrm{T}$ & $\mathrm{CC}$ \\
\hline Lauraceae & Aniba & hostmanniana & $\mathrm{T}$ & $\mathrm{CC}$ \\
\hline Lauraceae & Aniba & riparia & $\mathrm{T}$ & $\mathrm{CC}$ \\
\hline Lauraceae & Aniba & (1 sp.) & $\mathrm{T}$ & RF \\
\hline Lauraceae & Beilschmiedia & sulcata & $\mathrm{T}$ & $\mathrm{CC}$ \\
\hline Lauraceae & Endlicheria & bracteata & $\mathrm{T}$ & $\mathrm{CC}$ \\
\hline Lauraceae & Endlicheria & dysodantha & $\mathrm{T}$ & $\mathrm{CC}$ \\
\hline Lauraceae & Endlicheria & pyriformis & $\mathrm{S} / \mathrm{T}$ & $\mathrm{CC}$ \\
\hline Lauraceae & Endlicheria & sericea & $\mathrm{S} / \mathrm{T}$ & $\mathrm{CC}$ \\
\hline Lauraceae & Licaria & cannella & $\mathrm{T}$ & $\mathrm{CC}$ \\
\hline Lauraceae & Nectandra & crassiloba & $\mathrm{T}$ & $\mathrm{CC}$ \\
\hline Lauraceae & Nectandra & reticulata & $\mathrm{T}$ & $\mathrm{CC} / \mathrm{RF}$ \\
\hline Lauraceae & Nectandra & (3 spp.) & $\mathrm{T}$ & RA/RF \\
\hline
\end{tabular}

Species of vascular plants recorded for the Serranias Cofán, Sucumbios province, northeastern Ecuador, in a rapid biological inventory from 24 July to 16 August 2001. The list also includes collections made by R. Foster, R. Aguinda, T. Theim, M. Metz, and G. Baker during earlier visits to Sinangoe in June 1999 and the Interoceanic Highway in July 2000, and species registered by Cerón et al. (1994) in the vicinity of Sinangoe. Compiled by R. Foster. Rapid biological inventory botany team members: R. Foster, R. Aguinda, and N. Pitman. Updated information will be posted at www.fieldmuseum.org/rbi.

Forma de Vida/Habit:

$E$ = Epifita/Epiphyte

$\mathrm{H}=$ Hierba terrestre/

Terrestrial herb

$\mathrm{P}$ = Parásito/Parasite

$\mathrm{S}=$ Arbusto/Shrub

$\mathrm{T}=$ Árbol/Tree

$V=$ Trepadora/Climber

\section{Fuente/Source}

$\mathrm{CC}=$ Registrado por Cerón et al. (1994)/Listed by Cerón et al. (1994)

$\mathrm{RA}=$ Colecciones de Roberto Aguinda; los números corresponden a los especímenes depositados en el Herbario Nacional del Ecuador/Roberto Aguinda collections; numbers refer to voucher specimens deposited in The National Herbarium of Ecuador (QCNE)

$\mathrm{RF}=$ Fotos o observaciones de campo de Robin Foster/ Robin Foster photographs or field notes 
Especies de plantas vasculares registradas para las Serranias Cofán, Provincia de Sucumbios, Ecuador, durante un inventario biológico rápido del 24 de julio al 16 de agosto 2001. La lista también incluye colecciones anteriores realizadas por $R$. Foster, R. Aguinda, T. Theim, M. Metz y G. Baker durante una visita a Sinangoe en junio del 1999 y otra a la Via Interoceánica en julio del 2000, y especies registradas por Cerón et al. (1994) en los alrededores de Sinangoe. Compilación por R. Foster. Miembros del equipo del inventario botánico rápido: $R$. Foster, R. Aguinda y N. Pitman. La información presentada aquí se irá actualizando y estará disponible en la página Web en www.fieldmuseum.org/rbi.

PLANTASIPLANTS

\begin{tabular}{|c|c|c|c|c|}
\hline Familia/Family & Género/Genus & Especie/Species & $\begin{array}{l}\text { Forma } \\
\text { de Vida/ } \\
\text { Habit }\end{array}$ & Fuente/Source \\
\hline Lauraceae & Ocotea & aciphyl/a & $\mathrm{T}$ & $\mathrm{CC}$ \\
\hline Lauraceae & Ocotea & bofo & $T$ & $\mathrm{CC}$ \\
\hline Lauraceae & Ocotea & cernua & $\mathrm{T}$ & $\mathrm{CC}$ \\
\hline Lauraceae & Ocotea & floccifera & $\mathrm{T}$ & $\mathrm{CC}$ \\
\hline Lauraceae & Ocotea & floribunda & $\mathrm{T}$ & $\mathrm{CC}$ \\
\hline Lauraceae & Ocotea & javitensis & $\mathrm{T}$ & $\mathrm{CC} / \mathrm{RF}$ \\
\hline Lauraceae & Ocotea & (2 spp.) & $\mathrm{T}$ & RA/RF \\
\hline Lauraceae & Persea & americana & $\mathrm{T}$ & $\mathrm{CC}$ \\
\hline Lauraceae & Persea & (2 spp.) & $\mathrm{T}$ & RA/RF \\
\hline Lauraceae & Pleurothyrium & trianae & $T$ & $\mathrm{CC}$ \\
\hline Lauraceae & Rhodostemonodaphne & grandis & $\mathrm{T}$ & $\mathrm{CC}$ \\
\hline Lauraceae & (18 spp.) & - & $\mathrm{T}$ & RA/RF \\
\hline Lecythidaceae & Couratari & guianensis & $T$ & RF \\
\hline Lecythidaceae & Couroupita & guianensis & $\mathrm{T}$ & RF \\
\hline Lecythidaceae & Eschweilera & andina & $\mathrm{T}$ & $\mathrm{RF}$ \\
\hline Lecythidaceae & Eschweilera & rimbachii & $T$ & $\mathrm{CC}$ \\
\hline Lecythidaceae & Eschweilera & (4 spp.) & $\mathrm{T}$ & RA/RF \\
\hline Lecythidaceae & Grias & neuberthii & $\mathrm{T}$ & $\mathrm{CC} / \mathrm{RF}$ \\
\hline Lecythidaceae & Gustavia & macarenensis & $\mathrm{T}$ & $\mathrm{CC}$ \\
\hline Lentibulariaceae & Utricularia & asplundii & $H / E$ & $\begin{array}{l}\text { RA914,1322, } \\
1365 / \text { RF }\end{array}$ \\
\hline Lentibulariaceae & Utricularia & jamesoniana cf. & $\mathrm{H} / \mathrm{E}$ & RA1651 \\
\hline Lentibulariaceae & Utricularia & unifolia & $\mathrm{H} / \mathrm{E}$ & RA1482/RF \\
\hline Loganiaceae & Strychnos & peckii & V & $\mathrm{CC}$ \\
\hline Loganiaceae & Strychnos & (2 spp.) & V & RA/RF \\
\hline Loranthaceae & Oryctanthus & alveolatus & $S / P$ & $\mathrm{CC}$ \\
\hline Loranthaceae & (8 spp.) & - & - & RA \\
\hline Lythraceae & Cuphea & sucumbiensis & $\mathrm{H} / \mathrm{S}$ & $\mathrm{CC}$ \\
\hline Lythraceae & Cuphea & (2 spp.) & $\mathrm{H} / \mathrm{S}$ & RA/RF \\
\hline Malpighiaceae & Banisteriopsis & caapi & $\mathrm{V}$ & $\mathrm{CC}$ \\
\hline Malpighiaceae & Banisteriopsis & pubipetala & $\mathrm{S} / \mathrm{V}$ & $\mathrm{CC}$ \\
\hline Malpighiaceae & Bunchosia & argentea & $\mathrm{S} / \mathrm{T}$ & RA1346/CC \\
\hline Malpighiaceae & Byrsonima & (1 sp.) & $\mathrm{T}$ & $\mathrm{RF}$ \\
\hline Malpighiaceae & Diplopterys & cabrerana & V & $\mathrm{CC}$ \\
\hline Malpighiaceae & Hiraea & (1 sp.) & V & RF \\
\hline Malpighiaceae & Stigmaphyllon & (1 sp.) & $\mathrm{V}$ & RF \\
\hline Malpighiaceae & Tetrapterys & (1 sp.) & $\mathrm{V}$ & RA1579 \\
\hline Malpighiaceae & (1 sp.) & - & V & RA1189 \\
\hline Malvaceae & Malvaviscus & (1 sp.) & $\mathrm{S} / \mathrm{N}$ & $\mathrm{RF}$ \\
\hline Malvaceae & Pavonia & (1 sp.) & $\mathrm{H}$ & RA891/RF \\
\hline Malvaceae & Sida & (2 spp.) & $\mathrm{H} / \mathrm{S}$ & RF \\
\hline Marantaceae & Calathea & altissima & $\mathrm{H}$ & RF \\
\hline Marantaceae & Calathea & bantae & $\mathrm{H}$ & RA1078/RF \\
\hline Marantaceae & Calathea & crotalifera & $\mathrm{H}$ & $\mathrm{CC}$ \\
\hline Marantaceae & Calathea & ecuadoriana & $\mathrm{H}$ & RF \\
\hline Marantaceae & Calathea & fucata & $\mathrm{H}$ & $\mathrm{CC} / \mathrm{RF}$ \\
\hline
\end{tabular}


PIANTASIPLANTS

\begin{tabular}{|c|c|c|c|c|}
\hline Familia/Family & Género/Genus & Especie/Species & $\begin{array}{l}\text { Forma } \\
\text { de Vida/ } \\
\text { Habit }\end{array}$ & Fuente/Source \\
\hline Marantaceae & Calathea & gandersii & $\mathrm{H}$ & RF \\
\hline Marantaceae & Calathea & lutea & $\mathrm{H}$ & RF \\
\hline Marantaceae & Calathea & micans & $\mathrm{H}$ & RA1276/RF \\
\hline Marantaceae & Calathea & poeppigiana & $\mathrm{H}$ & RF \\
\hline Marantaceae & Calathea & standleyi & $\mathrm{H}$ & RA1290/CC/RF \\
\hline Marantaceae & Calathea & variegata & $\mathrm{H}$ & RF \\
\hline Marantaceae & Calathea & (8 spp.) & $\mathrm{H}$ & RA/RF \\
\hline Marantaceae & Ctenanthe & ericae & $\mathrm{H}$ & RF \\
\hline Marantaceae & Ischnosiphon & cerotus & $\mathrm{H}$ & $\mathrm{CC}$ \\
\hline Marantaceae & Ischnosiphon & puberulus & $\mathrm{H} / \mathrm{N}$ & $\mathrm{CC}$ \\
\hline Marantaceae & Ischnosiphon & (2 spp.) & $\mathrm{H} N$ & RF \\
\hline Marantaceae & Stromanthe & stromanthoides & $\mathrm{H}$ & RA1142/CC/RF \\
\hline Marcgraviaceae & Marcgravia & (3 spp.) & V & $\mathrm{RA} / \mathrm{RF}$ \\
\hline Marcgraviaceae & Souroubea & (1 sp.) & $\mathrm{S} N \mathrm{~N}$ & RF \\
\hline Melastomataceae & Aciotis & (1 sp.) & $\mathrm{H}$ & RF \\
\hline Melastomataceae & Adelobotrys & (1 sp.) & V & RA1255/RF \\
\hline Melastomataceae & Bellucia & pentamera & $T$ & RA165/RF \\
\hline Melastomataceae & Blakea & bracteata & V/E & RA1601/RF \\
\hline Melastomataceae & Blakea & repens & $\mathrm{E} / \mathrm{S} / \mathrm{T}$ & $\mathrm{RA} / \mathrm{CC} / \mathrm{RF}$ \\
\hline Melastomataceae & Blakea & sawadae & $\mathrm{S} / \mathrm{T}$ & $\mathrm{CC}$ \\
\hline Melastomataceae & Blakea & (3 spp.) & $E / S$ & RA \\
\hline Melastomataceae & Centronia & (1 sp.) & $T$ & RA1631 \\
\hline Melastomataceae & Clidemia & allardii & $\mathrm{S}$ & $\mathrm{CC} / \mathrm{RF}$ \\
\hline Melastomataceae & Clidemia & dimorphica & $\mathrm{S}$ & $\mathrm{RF}$ \\
\hline Melastomataceae & Clidemia & epiphytica & V & $\mathrm{RF}$ \\
\hline Melastomataceae & Clidemia & heterophylla & $\mathrm{S}$ & RF \\
\hline Melastomataceae & Clidemia & septuplinervia & $\mathrm{S}$ & RF \\
\hline Melastomataceae & Clidemia & (10 spp.) & $\mathrm{S}$ & $\mathrm{RF}$ \\
\hline Melastomataceae & Conostegia & (1 sp.) & $\mathrm{S} / \mathrm{T}$ & RA1272 \\
\hline Melastomataceae & Graffenrieda & intermedia & $\mathrm{S} / \mathrm{T}$ & $\mathrm{CC}$ \\
\hline Melastomataceae & Graffenrieda & (2 spp.) & $\mathrm{T}$ & RA/RF \\
\hline Melastomataceae & Henriettella & (2 spp.) & $\mathrm{S} / \mathrm{T}$ & $\mathrm{RA} / \mathrm{RF}$ \\
\hline Melastomataceae & Leandra & (2 spp.) & $\mathrm{H} / \mathrm{S}$ & $\mathrm{RA} / \mathrm{RF}$ \\
\hline Melastomataceae & Maieta & guianensis & $\mathrm{S}$ & $\mathrm{RF}$ \\
\hline Melastomataceae & Meriania & denticulata & $\mathrm{S} / \mathrm{T}$ & RA1527/RF \\
\hline Melastomataceae & Meriania & rigida cf. & $\mathrm{S} / \mathrm{T}$ & RA1483/RF \\
\hline Melastomataceae & Miconia & abbreviata & $\mathrm{S}$ & $\mathrm{CC}$ \\
\hline Melastomataceae & Miconia & bubalina & $\mathrm{S}$ & RF \\
\hline Melastomataceae & Miconia & calvescens & $\mathrm{T}$ & RF \\
\hline Melastomataceae & Miconia & elata & $\mathrm{T}$ & $\mathrm{CC} / \mathrm{RF}$ \\
\hline Melastomataceae & Miconia & grandifolia & $\mathrm{S} / \mathrm{T}$ & $\mathrm{RF}$ \\
\hline Melastomataceae & Miconia & lamprophylla & $\mathrm{S} / \mathrm{T}$ & RF \\
\hline Melastomataceae & Miconia & longifolia & $\mathrm{S} / \mathrm{T}$ & $\mathrm{RF}$ \\
\hline Melastomataceae & Miconia & nervosa & $S$ & RF \\
\hline Melastomataceae & Miconia & paleacea & $S$ & RF \\
\hline Melastomataceae & Miconia & pilgeriana & $\mathrm{S} / \mathrm{T}$ & $\mathrm{CC}$ \\
\hline
\end{tabular}

Species of vascular plants recorded for the Serranias Cofán, Sucumbios province, northeastern Ecuador, in a rapid biological inventory from 24 July to 16 August 2001. The list also includes collections made by R. Foster, R. Aguinda, T. Theim, M. Metz, and G. Baker during earlier visits to Sinangoe in June 1999 and the Interoceanic Highway in July 2000, and species registered by Cerón et al. (1994) in the vicinity of Sinangoe. Compiled by R. Foster. Rapid biological inventory botany team members: R. Foster, R. Aguinda, and N. Pitman. Updated information will be posted at www.fieldmuseum.org/rbi.

Forma de Vida/Habit :

$E$ = Epifita/Epiphyte

$\mathrm{H}=$ Hierba terrestre/

Terrestrial herb

$\mathrm{P}$ = Parásito/Parasite

$\mathrm{S}=$ Arbusto/Shrub

$\mathrm{T}=$ Árbol/Tree

$V$ = Trepadora/Climber

\section{Fuente/Source}

$\mathrm{CC}=$ Registrado por Cerón et al. (1994)/Listed by Cerón et al. (1994)

$\mathrm{RA}=$ Colecciones de Roberto Aguinda; los números corresponden a los especímenes depositados en el Herbario Nacional del Ecuador/Roberto Aguinda collections; numbers refer to voucher specimens deposited in The National Herbarium of Ecuador (QCNE)

$\mathrm{RF}=$ Fotos 0 observaciones de campo de Robin Foster/ Robin Foster photographs or field notes 
Especies de plantas vasculares registradas para las Serranías Cofán, Provincia de Sucumbios, Ecuador, durante un inventario biológico rápido del 24 de julio al 16 de agosto 2001. La lista también incluye colecciones anteriores realizadas por $R$. Foster, R. Aguinda, T. Theim, M. Metz y G. Baker durante una visita a Sinangoe en junio del 1999 y otra a la Via Interoceánica en julio del 2000, y especies registradas por Cerón et al. (1994) en los alrededores de Sinangoe. Compilación por R. Foster. Miembros del equipo del inventario botánico rápido: R. Foster, R. Aguinda y N. Pitman. La información presentada aquí se irá actualizando y estará disponible en la página Web en www.fieldmuseum.org/rbi.
PLANTASI PLANTS

\begin{tabular}{|c|c|c|c|c|}
\hline Familia/Family & Género/Genus & Especie/Species & $\begin{array}{l}\text { Forma } \\
\text { de Vida/ } \\
\text { Habit }\end{array}$ & Fuente/Source \\
\hline Melastomataceae & Miconia & punctata & $\mathrm{T}$ & $\mathrm{CC}$ \\
\hline Melastomataceae & Miconia & splendens & $\mathrm{S} / \mathrm{T}$ & $\mathrm{CC}$ \\
\hline Melastomataceae & Miconia & tomentosa & $\mathrm{T}$ & $\mathrm{RF}$ \\
\hline Melastomataceae & Miconia & trinervia & $\mathrm{T}$ & $\mathrm{RF}$ \\
\hline Melastomataceae & Miconia & triplinervis & $S$ & $\mathrm{RF}$ \\
\hline Melastomataceae & Miconia & (18 spp.) & $\mathrm{S} / \mathrm{T}$ & RA/RF \\
\hline Melastomataceae & Monolena & primulaeflora & $H / E$ & $\mathrm{CC} / \mathrm{RF}$ \\
\hline Melastomataceae & Ossaea & boliviensis & $\mathrm{S}$ & $\mathrm{RF}$ \\
\hline Melastomataceae & Ossaea & (4 spp.) & $\mathrm{S}$ & RAVRF \\
\hline Melastomataceae & Tessmannianthus & heterostemon & $T$ & RA1015/RF \\
\hline Melastomataceae & Tibouchina & (1 sp.) & $\mathrm{S}$ & RA1669/RF \\
\hline Melastomataceae & Tococa & caquetana & $\mathrm{S}$ & $\mathrm{CC} / \mathrm{RF}$ \\
\hline Melastomataceae & Tococa & guianensis & $\mathrm{S}$ & $\mathrm{RA} 1341 / \mathrm{CC} / \mathrm{RF}$ \\
\hline Melastomataceae & Tococa & parviflora & $\mathrm{S}$ & RA/RF \\
\hline Melastomataceae & Tococa & platyphylla & $\mathrm{S}$ & RA1603/RF \\
\hline Melastomataceae & Tococa & symphyandra & $\mathrm{S}$ & RA1419/RF \\
\hline Melastomataceae & Triolena & obliqua & $\mathrm{S}$ & $\mathrm{RA} / \mathrm{CC} / \mathrm{RF}$ \\
\hline Melastomataceae & Triolena & pileoides & $\mathrm{S}$ & RA1583/CC/RF \\
\hline Melastomataceae & Triolena & pluvialis & $\mathrm{S}$ & RA/RF \\
\hline Melastomataceae & (4 spp.) & - & $\mathrm{S} / \mathrm{T}$ & $\mathrm{RA}$ \\
\hline Meliaceae & Cabralea & canjerana & $T$ & $\mathrm{CC} / \mathrm{RF}$ \\
\hline Meliaceae & Cedrela & fissilis & $T$ & $\mathrm{RF}$ \\
\hline Meliaceae & Cedrela & odorata & $T$ & $\mathrm{CC}$ \\
\hline Meliaceae & Guarea & (4 spp.) & $\mathrm{T}$ & RF \\
\hline Meliaceae & Guarea & grandifolia & $T$ & $\mathrm{CC}$ \\
\hline Meliaceae & Guarea & guidonia & $\mathrm{T}$ & $\mathrm{CC} / \mathrm{RF}$ \\
\hline Meliaceae & Guarea & kunthiana & $T$ & RA952/RF \\
\hline Meliaceae & Guarea & macrophylla & $\mathrm{T}$ & $\mathrm{CC}$ \\
\hline Meliaceae & Guarea & pterorhachis & $\mathrm{T}$ & $\mathrm{CC} / \mathrm{RF}$ \\
\hline Meliaceae & Guarea & pubescens & $T$ & $\mathrm{CC}$ \\
\hline Meliaceae & Guarea & silvatica & $\mathrm{T}$ & RA740/CC/RF \\
\hline Meliaceae & Ruagea & (1 sp.) & $T$ & $\mathrm{RF}$ \\
\hline Meliaceae & Trichilia & elsae & $T$ & $\mathrm{RF}$ \\
\hline Meliaceae & Trichilia & pallida & $T$ & RA1557/CC/RF \\
\hline Meliaceae & Trichilia & septentrionalis & $\mathrm{T}$ & $\mathrm{CC} / \mathrm{RF}$ \\
\hline Meliaceae & Trichilia & (4 spp.) & $T$ & RA/RF \\
\hline Mendonciaceae & Mendoncia & pedunculata & V & $\mathrm{CC}$ \\
\hline Mendonciaceae & Mendoncia & (1 sp.) & V & RA1145/RF \\
\hline Menispermaceae & Abuta & grandifolia & $\mathrm{S} / \mathrm{T}$ & $\mathrm{CC} / \mathrm{RF}$ \\
\hline Menispermaceae & Abuta & pahnii & $\mathrm{V}$ & $\mathrm{RF}$ \\
\hline Menispermaceae & Abuta & (1 sp.) & V & $\mathrm{RA}$ \\
\hline Menispermaceae & Anomospermum & (1 sp.) & $\mathrm{V}$ & $\mathrm{RF}$ \\
\hline Menispermaceae & Cissampelos & (1 sp.) & V & RA904 \\
\hline Menispermaceae & Curarea & toxicofera & V & $\mathrm{CC}$ \\
\hline Menispermaceae & Odontocarya & (1 sp.) & V & $\mathrm{RF}$ \\
\hline Mimosaceae & Abarema & jupunba & $\mathrm{T}$ & $\mathrm{CC}$ \\
\hline
\end{tabular}


PLANTASIPLANTS

\begin{tabular}{|c|c|c|c|c|}
\hline Familia/Family & Género/Genus & Especie/Species & $\begin{array}{l}\text { Forma } \\
\text { de Vida/ } \\
\text { Habit }\end{array}$ & Fuente/Source \\
\hline Mimosaceae & Abarema & killipii & $T$ & RA1141 \\
\hline Mimosaceae & Abarema & laeta & $T$ & RA1084,1656/RF \\
\hline Mimosaceae & Acacia & glomerosa & $\mathrm{T}$ & $\mathrm{CC}$ \\
\hline Mimosaceae & Acacia & (1 sp.) & $\mathrm{V}$ & RF \\
\hline Mimosaceae & Albizia & (1 sp.) & $T$ & RF \\
\hline Mimosaceae & Calliandra & angustifolia & $S$ & $\mathrm{CC} / \mathrm{RF}$ \\
\hline Mimosaceae & Calliandra & trinervia & $\mathrm{T}$ & $\mathrm{CC} / \mathrm{RF}$ \\
\hline Mimosaceae & Cedrelinga & cateniformis & $\mathrm{T}$ & RF \\
\hline Mimosaceae & Entada & polystachya & V & RF \\
\hline Mimosaceae & Inga & acreana & $\mathrm{T}$ & $\mathrm{CC}$ \\
\hline Mimosaceae & Inga & capitata & $\mathrm{T}$ & $\mathrm{CC}$ \\
\hline Mimosaceae & lnga & ciliata & $\mathrm{T}$ & $\mathrm{CC} / \mathrm{RF}$ \\
\hline Mimosaceae & lnga & densiflora & $\mathrm{T}$ & $\mathrm{CC}$ \\
\hline Mimosaceae & Inga & edulis & $\mathrm{T}$ & $\mathrm{CC}$ \\
\hline Mimosaceae & lnga & marginata & $\mathrm{T}$ & $\mathrm{CC}$ \\
\hline Mimosaceae & lnga & oerstediana & $\mathrm{T}$ & $\mathrm{CC} / \mathrm{RF}$ \\
\hline Mimosaceae & lnga & punctata & $T$ & $\mathrm{CC} / \mathrm{RF}$ \\
\hline Mimosaceae & Inga & ruiziana & $T$ & $\mathrm{CC} / \mathrm{RF}$ \\
\hline Mimosaceae & Inga & sarayacuensis & $\mathrm{S} / \mathrm{T}$ & RF \\
\hline Mimosaceae & lnga & spectabilis & $\mathrm{T}$ & $\mathrm{CC} / \mathrm{RF}$ \\
\hline Mimosaceae & lnga & stenoptera & $\mathrm{T}$ & RF \\
\hline Mimosaceae & lnga & stipulacea & $\mathrm{T}$ & RA1576/RF \\
\hline Mimosaceae & Inga & thibaudiana & $\mathrm{T}$ & $\mathrm{CC} / \mathrm{RF}$ \\
\hline Mimosaceae & lnga & umbellifera & $\mathrm{T}$ & RA1288/RF \\
\hline Mimosaceae & lnga & vismiifolia & $\mathrm{T}$ & $\mathrm{CC}$ \\
\hline Mimosaceae & lnga & (7 spp.) & $\mathrm{T}$ & $\mathrm{RA} / \mathrm{RF}$ \\
\hline Mimosaceae & Mimosa & myriadenia & $\mathrm{H} N$ & $\mathrm{CC}$ \\
\hline Mimosaceae & Mimosa & polydactyla & $\mathrm{H}$ & $\mathrm{CC}$ \\
\hline Mimosaceae & Parkia & multijuga & $\mathrm{T}$ & RF \\
\hline Mimosaceae & Parkia & velutina & $\mathrm{T}$ & RF \\
\hline Mimosaceae & Parkia & (2 spp.) & $\mathrm{T}$ & RF \\
\hline Mimosaceae & Piptadenia & (1 sp.) & $\mathrm{T}$ & RF \\
\hline Mimosaceae & Stryphnodendron & porcatum & $\mathrm{T}$ & $\mathrm{CC} / \mathrm{RF}$ \\
\hline Mimosaceae & Zygia & longifolia & $\mathrm{T}$ & $\mathrm{CC}$ \\
\hline Mimosaceae & Zygia & (1 sp.) & $\mathrm{S} / \mathrm{T}$ & RA1405/RF \\
\hline Mimosaceae & (3 spp.) & - & $\mathrm{T}$ & RF \\
\hline Monimiaceae & Mollinedia & (4 spp.) & $\mathrm{S} / \mathrm{T}$ & RA/RF \\
\hline Monimiaceae & Siparuna & (6 spp.) & $S$ & RA/RF \\
\hline Moraceae & Artocarpus & altilis & $\mathrm{T}$ & $\mathrm{CC}$ \\
\hline Moraceae & Batocarpus & costaricensis & $\mathrm{T}$ & RF \\
\hline Moraceae & Batocarpus & orinocensis & $\mathrm{T}$ & $\mathrm{CC}$ \\
\hline Moraceae & Brosimum & guianense & $\mathrm{S} / \mathrm{T}$ & RF \\
\hline Moraceae & Brosimum & utile & $\mathrm{T}$ & $\mathrm{CC} / \mathrm{RF}$ \\
\hline Moraceae & Clarisia & biflora & $\mathrm{T}$ & $\mathrm{CC} / \mathrm{RF}$ \\
\hline Moraceae & Clarisia & racemosa & $T$ & $\mathrm{CC} / \mathrm{RF}$ \\
\hline Moraceae & Ficus & caballina & $E / S$ & RF \\
\hline
\end{tabular}

Species of vascular plants recorded for the Serranias Cofan, Sucumbios province, northeastern Ecuador, in a rapid biological inventory from 24 July to 16 August 2001. The list also includes collections made by R. Foster, R. Aguinda, T. Theim, M. Metz, and G. Baker during earlier visits to Sinangoe in June 1999 and the Interoceanic Highway in July 2000 , and species registered by Cerón et al. (1994) in the vicinity of Sinangoe. Compiled by R. Foster. Rapid biological inventory botany team members:

R. Foster, R. Aguinda, and N. Pitman. Updated information will be posted at www.fieldmuseum. org/rbi.

Forma de Vida/Habit:

$\mathrm{E}=$ Epifita/Epiphyte

$\mathrm{H}=$ Hierba terrestre/

Terrestrial herb

$\mathrm{P}=$ Parásito/Parasite

$\mathrm{S}=$ Arbusto $/$ Shrub

$\mathrm{T}=$ Árbol/Tree

$\mathrm{V}=$ Trepadora/Climber

Fuente/Source

$\mathrm{CC}=$ Registrado por Cerón et al. (1994)/Listed by Cerón et al. (1994)

$\mathrm{RA}=$ Colecciones de Roberto Aguinda; los números corresponden a los especímenes depositados en el Herbario Nacional del Ecuador/Roberto Aguinda collections; numbers refer to voucher specimens deposited in The National Herbarium of Ecuador (QCNE)

$\mathrm{RF}=$ Fotos 0 observaciones de campo de Robin Foster/ Robin Foster photographs or field notes 
Especies de plantas vasculares registradas para las Serranias Cofán, Provincia de Sucumbios, Ecuador, durante un inventario biológico rápido del 24 de julio al 16 de agosto 2001. La lista también incluye colecciones anteriores realizadas por $R$. Foster, R. Aguinda, T. Theim, M. Metz y G. Baker durante una visita a Sinangoe en junio del 1999 y otra a la Via Interoceánica en julio del 2000, y especies registradas por Cerón et al. (1994) en los alrededores de Sinangoe. Compilación por R. Foster. Miembros del equipo del inventario botánico rápido: $R$. Foster, R. Aguinda y N. Pitman. La información presentada aqui se irá actualizando y estará disponible en la página Web en urww.fieldmuseum.org/rbi.
PLANTASIPLANTS

\begin{tabular}{|c|c|c|c|c|}
\hline Familia/Family & Género/Genus & Especie/Species & $\begin{array}{l}\text { Forma } \\
\text { de Vida/ } \\
\text { Habit }\end{array}$ & Fuente/Source \\
\hline Moraceae & Ficus & coerulescens & $\mathrm{T}$ & $\mathrm{RF}$ \\
\hline Moraceae & Ficus & gommelleira & $T$ & $C C$ \\
\hline Moraceae & Ficus & guianensis & $T$ & $\mathrm{RF}$ \\
\hline Moraceae & Ficus & maxima & $T$ & $\mathrm{RF}$ \\
\hline Moraceae & Ficus & obtusifolia cf. & $\mathrm{T}$ & $\mathrm{RF}$ \\
\hline Moraceae & Ficus & pertusa & $E / T$ & $\mathrm{RF}$ \\
\hline Moraceae & Ficus & tonduzii & $T$ & $\mathrm{RA} / \mathrm{CC} / \mathrm{RF}$ \\
\hline Moraceae & Ficus & yoponensis & $T$ & $\mathrm{CC}$ \\
\hline Moraceae & Ficus & (8 spp.) & $T$ & RA/RF \\
\hline Moraceae & Helicostylis & tomentosa & $T$ & $\mathrm{CC}$ \\
\hline Moraceae & Helicostylis & tovarensis & $\begin{array}{lll}T \\
\end{array}$ & RA1696 \\
\hline Moraceae & Maquira & calophylla & $T$ & $\mathrm{CC} / \mathrm{RF}$ \\
\hline Moraceae & Perebea & angustifolia & $\mathrm{T}$ & $\mathrm{CC}$ \\
\hline Moraceae & Perebea & guianensis & T & CC/RF \\
\hline Moraceae & Perebea & humilis & $S$ & RA1325/RF \\
\hline Moraceae & Perebea & xanthochyma & $\mathrm{S} / \mathrm{T}$ & $\mathrm{CC} / \mathrm{RF}$ \\
\hline Moraceae & Perebea & $(1 \mathrm{sp})$. & $T$ & RA1071 \\
\hline Moraceae & Poulsenia & armata & $\mathrm{T}$ & $\mathrm{RF}$ \\
\hline Moraceae & Pseudolmedia & laevigata & $\mathrm{T}$ & $\mathrm{RF}$ \\
\hline Moraceae & Pseudolmedia & laevis & $T$ & $\mathrm{RF}$ \\
\hline Moraceae & Pseudolmedia & macrophylla & $T$ & $\mathrm{RF}$ \\
\hline Moraceae & Pseudolmedia & rigida & $T$ & $\mathrm{CC} / \mathrm{RF}$ \\
\hline Moraceae & Sorocea & steinbachii & $\mathrm{S} / \mathrm{T}$ & $\mathrm{CC} / \mathrm{RF}$ \\
\hline Moraceae & Trophis & caucana & $\mathrm{S} / \mathrm{T}$ & $\mathrm{RF}$ \\
\hline Musaceae & Musa & acuminata & $\mathrm{H}$ & $\mathrm{CC}$ \\
\hline Musaceae & Musa & paradisiaca & $\mathrm{H}$ & $\mathrm{CC}$ \\
\hline Myristicaceae & Compsoneura & ulei & $T$ & $\mathrm{RF}$ \\
\hline Myristicaceae & Iryanthera & grandis & $T$ & $\mathrm{CC}$ \\
\hline Myristicaceae & Iryanthera & juruensis & $T$ & $\mathrm{CC}$ \\
\hline Myristicaceae & Iryanthera & macrophylla & $\mathrm{T}$ & $\mathrm{CC}$ \\
\hline Myristicaceae & Otoba & glycycarpa & $T$ & $\mathrm{CC} / \mathrm{RF}$ \\
\hline Myristicaceae & Otoba & parvifolia & $T$ & $\mathrm{CC} / \mathrm{RF}$ \\
\hline Myristicaceae & Virola & calophylla & $T$ & $\mathrm{RF}$ \\
\hline Myristicaceae & Virola & duckei cf. & $\mathrm{T}$ & $\mathrm{CC} / \mathrm{RF}$ \\
\hline Myristicaceae & Virola & elongata & $\mathrm{T}$ & $\mathrm{CC}$ \\
\hline Myristicaceae & Virola & flexuosa & $T$ & $\mathrm{CC} / \mathrm{RF}$ \\
\hline Myristicaceae & Virola & multinervia & $T$ & $\mathrm{CC}$ \\
\hline Myristicaceae & Virola & pavonis & $T$ & $\mathrm{CC}$ \\
\hline Myristicaceae & Virola & peruviana & $T$ & $\mathrm{CC}$ \\
\hline Myristicaceae & Virola & sebifera & $T$ & $\mathrm{RF}$ \\
\hline Myrsinaceae & Cybianthus & peruvianus & $\mathrm{S} / \mathrm{T}$ & $\mathrm{CC}$ \\
\hline Myrsinaceae & Cybianthus & poeppigii & $\mathrm{S} / \mathrm{T}$ & $\mathrm{CC}$ \\
\hline Myrsinaceae & Cybianthus & schlimii & T & $\mathrm{CC}$ \\
\hline Myrsinaceae & Cybianthus & (4 spp.) & $S / T$ & $\mathrm{RF}$ \\
\hline Myrsinaceae & Geissanthus & ecuadorensis & $\mathrm{S} / \mathrm{T}$ & $\mathrm{CC}$ \\
\hline Myrsinaceae & Myrsine & (3 spp.) & $\mathrm{T}$ & $\mathrm{RF}$ \\
\hline
\end{tabular}


PUANTASIPLANTS

\begin{tabular}{|c|c|c|c|c|c|}
\hline Familia/Family & Género/Genus & Especie/Species & $\begin{array}{l}\text { Forma } \\
\text { de Vida/ } \\
\text { Habit }\end{array}$ & Fuente/Source & \multirow{10}{*}{$\begin{array}{l}\text { Species of vascular plants recorded } \\
\text { for the Serranias Cofan, Sucumbios } \\
\text { province, northeastern Ecuador, in a } \\
\text { rapid biological inventory from } \\
24 \text { July to } 16 \text { August } 2001 \text {. The list } \\
\text { also includes collections made by } \\
\text { R. Foster, R. Aguinda, T. Theim, } \\
\text { M. Metz, and G. Baker during earlier } \\
\text { visits to Sinangoe in June } 1999 \text { and the } \\
\text { Interoceanic Highway in July } 2000, \\
\text { and species registered by Cerón et al. } \\
\text { (1994) in the vicinity of Sinangoe. } \\
\text { Compiled by R. Foster. Rapid biological } \\
\text { inventory botany team members: } \\
\text { R. Foster, R. Aguinda, and N. Pitman. } \\
\text { Updated information will be posted at } \\
\text { www.fieldmuseum.orgirbi. }\end{array}$} \\
\hline Myrsinaceae & Stylogyne & bracteolata & $\mathrm{S} / \mathrm{T}$ & $\mathrm{CC}$ & \\
\hline Myrsinaceae & Stylogyne & (1 sp.) & $T$ & RA/RF & \\
\hline Myrsinaceae & (4 spp.) & - & $\mathrm{S} / \mathrm{T}$ & RA & \\
\hline Myrtaceae & Calyptranthes & simulata cf. & $\mathrm{S} / \mathrm{T}$ & RA1512 & \\
\hline Myrtaceae & Calyptranthes & $\begin{array}{l}\text { sp. nov. fide } \\
\text { M. L. Kawasaki }\end{array}$ & $\mathrm{S}$ & RA1345/RF & \\
\hline Myrtaceae & Calyptranthes & speciosa & $\mathrm{S} / \mathrm{T}$ & RA1066,1089 & \\
\hline Myrtaceae & Calyptranthes & (1 sp.) & $\mathrm{S} / \mathrm{T}$ & RA1493 & \\
\hline Myrtaceae & Eugenia & biflora & $\mathrm{S} / \mathrm{T}$ & $\begin{array}{l}\text { RA1373,1466, } \\
1467\end{array}$ & \\
\hline Myrtaceae & Eugenia & florida & $\mathrm{T}$ & $\mathrm{RA} 1331,1468 / \mathrm{CC}$ & \\
\hline Myrtaceae & Eugenia & multirimosa & $\mathrm{S} / \mathrm{T}$ & RA1184 & \\
\hline Myrtaceae & Eugenia & muricata & $\mathrm{S} / \mathrm{T}$ & $\mathrm{CC}$ & \\
\hline Myrtaceae & Eugenia & stipitata & $\mathrm{S} / \mathrm{T}$ & $\mathrm{CC}$ & \\
\hline Myrtaceae & Eugenia & (4 spp.) & $\mathrm{S} / \mathrm{T}$ & $\mathrm{RF}$ & \\
\hline Myrtaceae & Myrcia & (2 spp.) & $\mathrm{S} / \mathrm{T}$ & $\mathrm{RF}$ & \\
\hline Myrtaceae & Myrciaria & floribunda & $\mathrm{S} / \mathrm{T}$ & RA1152 & \\
\hline Myrtaceae & Plinia & (1 sp.) & $\mathrm{S} / \mathrm{T}$ & RA1470 & \\
\hline Myrtaceae & Psidium & guajava & $\mathrm{S} / \mathrm{T}$ & $\mathrm{CC} / \mathrm{RF}$ & \\
\hline Myrtaceae & Siphoneugena & densiflora & $\mathrm{T}$ & RA1171/RF & \\
\hline Myrtaceae & (5 spp.) & - & $\mathrm{S} / \mathrm{T}$ & $\mathrm{RF}$ & \\
\hline Nyctaginaceae & Neea & divaricata & $T$ & $\mathrm{CC}$ & \\
\hline Nyctaginaceae & Neea & parviflora & $\mathrm{S} / \mathrm{T}$ & $\mathrm{CC}$ & Forma de Vida/Habit: \\
\hline Nyctaginaceae & Neea & spruceana & $T$ & $\mathrm{CC}$ & $E=$ Epífita/Epiphyte \\
\hline Nyctaginaceae & Neea & verticillata & $\mathrm{T}$ & $\mathrm{CC}$ & $\begin{array}{r}\mathrm{H}=\text { Hierba terrestre } / \\
\text { Terrestrial herb }\end{array}$ \\
\hline Nyctaginaceae & Neea & (8 spp.) & $\mathrm{s}$ & $\mathrm{RF}$ & $\mathrm{P}=$ Parásito $/$ Parasite \\
\hline Nyctaginaeae & Guapira & (2 spp.) & $T$ & $\mathrm{RF}$ & $S=$ Arbusto $/$ Shrub \\
\hline Ochnaceae & Cespedesia & spathulata & $T$ & RF & $\begin{aligned} \mathrm{T} & =\text { Árbol } / \text { Tree } \\
\mathrm{V} & =\text { Trepadora } / \text { Climber }\end{aligned}$ \\
\hline Ochnaceae & Sauvagesia & erecta & $\mathrm{H}$ & RF & $V=$ Irepadora/climber \\
\hline Olacaceae & Heisteria & acuminata & $\mathrm{S} / \mathrm{T}$ & RA846/CC/RF & \\
\hline Olacaceae & Heisteria & latifolia cf. & $T$ & RA1053/RF & Fuente/Source \\
\hline Olacaceae & Heisteria & (1 sp.) & $\mathrm{S} / \mathrm{T}$ & RA1006/RF & $\begin{aligned} & =1 \text { al. }(1994) / \text { Listed by }\end{aligned}$ \\
\hline Olacaceae & Minquartia & guianensis & $T$ & RA1094/CC/RF & Cerón et al. (1994) \\
\hline Onagraceae & Ludwigia & (2 spp.) & $\mathrm{S}$ & $\mathrm{RF}$ & RA $=$ Colecciones de Roberto \\
\hline Orchidaceae & Dichaea & laxa & $E$ & $\mathrm{CC}$ & $\begin{array}{l}\text { Aguinda; los numeros } \\
\text { corresponden a los }\end{array}$ \\
\hline Orchidaceae & Elleanthus & (3 spp.) & $E$ & RA & especímenes depositados \\
\hline Orchidaceae & Epidendrum & compressum & $E$ & $\mathrm{CC}$ & en el Herbario Nacional \\
\hline Orchidaceae & Epidendrum & coriifolium & $E$ & $\mathrm{RF}$ & $\begin{array}{l}\text { del Ecuador/Roberto } \\
\text { Aguinda collections: }\end{array}$ \\
\hline Orchidaceae & Epidendrum & (5 spp.) & $E$ & RA & numbers refer to voucher \\
\hline Orchidaceae & Erythrodes & (4 spp.) & $\mathrm{H}$ & $\mathrm{RA}$ & specimens deposited in \\
\hline Orchidaceae & Lepanthes & (2 spp.) & $E$ & RF & The National Herbarium \\
\hline Orchidaceae & Maxillaria & (6 spp.) & $E$ & RA & $\mathrm{RF}=$ Fotos o observaciones de \\
\hline Orchidaceae & Oncidium & (1 sp.) & $E$ & RA1484 & campo de Robin Foster/ \\
\hline Orchidaceae & Palmorchis & (1 sp.) & $\mathrm{H}$ & RA1326/RF & Robin Foster photographs \\
\hline Orchidaceae & Phragmipedium & pearcei & $\mathrm{H}$ & RA1560/CC/RF & \\
\hline Orchidaceae & Platystele & (1 sp.) & $E$ & $\mathrm{RF}$ & \\
\hline
\end{tabular}


Especies de plantas vasculares registradas para las Serranias Cofán, Provincia de Sucumbios, Ecuador, durante un inventario biológico rápido del 24 de julio al 16 de agosto 2001. La lista también incluye colecciones anteriores realizadas por $R$. Foster, R. Aguinda, T. Theim, M. Metz y G. Baker durante una visita a Sinangoe en junio del 1999 y otra a la Via Interoceánica en julio del 2000, y especies registradas por Cerón et al. (1994) en los alrededores de Sinangoe. Compilación por R. Foster. Miembros del equipo del inventario botánico rápido: $R$. Foster, $R$. Aguinda y N. Pitman. La información presentada aqui se irá actualizando y estará disponible en la página Web en www.fieldmuseum.org/rbi.

\section{PLANTASIPLANTS}

\begin{tabular}{|c|c|c|c|c|}
\hline Familia/Family & Género/Genus & Especie/Species & $\begin{array}{l}\text { Forma } \\
\text { de Vida/ } \\
\text { Habit }\end{array}$ & Fuente/Source \\
\hline Orchidaceae & Pleurothallis & (6 spp.) & $E$ & $\mathrm{RA}$ \\
\hline Orchidaceae & Psygmorchis & (1 sp.) & $E$ & RF \\
\hline Orchidaceae & Stelis & (5 spp.) & $E$ & RA \\
\hline Orchidaceae & Trigonidium & (1 sp.) & $E$ & RA/RF \\
\hline Orchidaceae & Vanilla & planifolia & $\mathrm{V} / \mathrm{E}$ & $\mathrm{CC}$ \\
\hline Orchidaceae & (10 spp.) & - & $E$ & $\mathrm{RA}$ \\
\hline Oxalidaceae & Biophytum & (1 sp.) & $\mathrm{H}$ & RA788/RF \\
\hline Papaveraceae & Bocconia & integrifolia & $\mathrm{S}$ & $\mathrm{RF}$ \\
\hline Passifloraceae & Dilkea & (1 sp.) & V & $\mathrm{RF}$ \\
\hline Passifloraceae & Passiflora & vitifolia & $\mathrm{V}$ & $\mathrm{CC} / \mathrm{RF}$ \\
\hline Passifloraceae & Passiflora & (2 spp.) & $\mathrm{S} / \mathrm{V}$ & RA/RF \\
\hline Phytolaccaceae & Phytolacca & rivinoides & $\mathrm{H} / \mathrm{S}$ & $\mathrm{CC} / \mathrm{RF}$ \\
\hline Piperaceae & Peperomia & hernandiifolia & $\mathrm{H} / \mathrm{E}$ & $\mathrm{RF}$ \\
\hline Piperaceae & Peperomia & serpens & $\mathrm{H} / \mathrm{E}$ & $\mathrm{RF}$ \\
\hline Piperaceae & Peperomia & (22 spp.) & $\mathrm{E}$ & RA/RF \\
\hline Piperaceae & Piper & aduncum & $\mathrm{s}$ & $\mathrm{CC}$ \\
\hline Piperaceae & Piper & arboreum & $\mathrm{S}$ & $\mathrm{CC}$ \\
\hline Piperaceae & Piper & augustum & $\mathrm{S}$ & RA1624/RF \\
\hline Piperaceae & Piper & crassinervium & $\mathrm{S}$ & $\mathrm{RF}$ \\
\hline Piperaceae & Piper & longifolium & $\mathrm{S}$ & $\mathrm{RF}$ \\
\hline Piperaceae & Piper & maranyonense & $\mathrm{S}$ & $\mathrm{CC}$ \\
\hline Piperaceae & Piper & obliquum & $\mathrm{S} / \mathrm{T}$ & RA1196/CC/RF \\
\hline Piperaceae & Piper & obtusilimbum & $\mathrm{S}$ & $\mathrm{CC}$ \\
\hline Piperaceae & Piper & ottoniifolium & $\mathrm{S} N$ & $\mathrm{CC}$ \\
\hline Piperaceae & Piper & umbellatum & $\mathrm{H} / \mathrm{S}$ & $\mathrm{RF}$ \\
\hline Piperaceae & Piper & (30 spp.) & $\mathrm{H} / \mathrm{S}$ & RA/RF \\
\hline Piperaceae & Sarcorhachis & sydowii & $\mathrm{S} N$ & $\mathrm{CC}$ \\
\hline Poaceae & Axonopus & scoparius & $\mathrm{H}$ & $\mathrm{CC}$ \\
\hline Poaceae & Chusquea & (1 sp.) & $\mathrm{S} N \mathrm{~N}$ & RA1231/RF \\
\hline Poaceae & Coix & lacrymajobi & $\mathrm{H}$ & $\mathrm{CC}$ \\
\hline Poaceae & Cryptochloa & unispiculata & $\mathrm{H}$ & $\mathrm{CC}$ \\
\hline Poaceae & Cymbopogon & citratus & $\mathrm{H}$ & $\mathrm{CC}$ \\
\hline Poaceae & Echinochloa & polystachya & $\mathrm{H}$ & $\mathrm{CC}$ \\
\hline Poaceae & Guadua & angustifolia & $\mathrm{T}$ & $\mathrm{CC} / \mathrm{RF}$ \\
\hline Poaceae & Guadua & weberbaueri & $\mathrm{T}$ & $\mathrm{RF}$ \\
\hline Poaceae & Gynerium & sagittatum & $\mathrm{H} / \mathrm{S}$ & $\mathrm{CC} / \mathrm{RF}$ \\
\hline Poaceae & Gynerium & (1 sp.) & $\mathrm{H}$ & $\mathrm{RF}$ \\
\hline Poaceae & Lasiacis & (1 sp.) & $\mathrm{H} / \mathrm{N}$ & $\mathrm{RF}$ \\
\hline Poaceae & Olyra & latifolia & $\mathrm{H}$ & $\mathrm{CC}$ \\
\hline Poaceae & Olyra & (1 sp.) & $\mathrm{H}$ & $\mathrm{RF}$ \\
\hline Poaceae & Orthoclada & laxa & $\mathrm{H}$ & $\mathrm{RF}$ \\
\hline Poaceae & Pariana & radiciflora & $\mathrm{H}$ & $\mathrm{CC}$ \\
\hline Poaceae & Paspalum & virgatum & $\mathrm{H}$ & $\mathrm{CC}$ \\
\hline Poaceae & Pennisetum & purpureum & $\mathrm{H}$ & $\mathrm{CC}$ \\
\hline Poaceae & Pharus & latifolius & $\mathrm{H}$ & $\mathrm{RF}$ \\
\hline Poaceae & Saccharum & officinarum & $\mathrm{H}$ & $\mathrm{CC}$ \\
\hline
\end{tabular}




\section{PLANTASIPLANTS}

\begin{tabular}{|c|c|c|c|c|}
\hline Familia/Family & Género/Genus & Especie/Species & $\begin{array}{l}\text { Forma } \\
\text { de Vida/ } \\
\text { Habit }\end{array}$ & Fuente/Source \\
\hline Poaceae & Setaria & sphacelata & $\mathrm{H}$ & $\mathrm{CC}$ \\
\hline Poaceae & Sorghum & vulgare & $\mathrm{H}$ & $\mathrm{CC}$ \\
\hline Poaceae & Zea & mays & $\mathrm{H}$ & $\mathrm{CC}$ \\
\hline Poaceae & (1 sp.) & - & $\mathrm{H}$ & RA1360 \\
\hline Podocarpaceae & Podocarpus & oleifolius & $\mathrm{T}$ & $\begin{array}{l}\text { RA1522,1502/ } \\
\text { RF }\end{array}$ \\
\hline Polygalaceae & Monnina & (3 spp.) & $\mathrm{S}$ & RA \\
\hline Polygalaceae & Moutabea & (1 sp.) & $\mathrm{V}$ & $\mathrm{RF}$ \\
\hline Polygalaceae & Securidaca & (1 sp.) & $\mathrm{V}$ & RA1314 \\
\hline Polygonaceae & Coccoloba & densifrons & $\mathrm{T}$ & $\mathrm{CC} / \mathrm{RF}$ \\
\hline Polygonaceae & Coccoloba & fallax & $\mathrm{T}$ & $\mathrm{RF}$ \\
\hline Polygonaceae & Coccoloba & (1 sp.) & $\mathrm{T}$ & RF \\
\hline Polygonaceae & Triplaris & americana & $\mathrm{T}$ & $\mathrm{CC} / \mathrm{RF}$ \\
\hline Pontederiaceae & Pontederia & (1 sp.) & $\mathrm{H}$ & RF \\
\hline Proteaceae & Roupala & montana & $\mathrm{S} / \mathrm{T}$ & $\mathrm{RF}$ \\
\hline Quiinaceae & Quiina & amazonica cf. & $\mathrm{S} / \mathrm{T}$ & RA1003/RF \\
\hline Quiinaceae & Quiina & (1 sp.) & $\mathrm{T}$ & $\mathrm{RF}$ \\
\hline Rhamnaceae & Colubrina & (1 sp.) & $\mathrm{T}$ & RF \\
\hline Rhamnaceae & Gouania & colombiana & V & $\mathrm{CC}$ \\
\hline Rhamnaceae & Gouania & lupuloides & $\mathrm{V}$ & $\mathrm{RF}$ \\
\hline Rhamnaceae & Gouania & (2 spp.) & V & RF \\
\hline Rosaceae & Prunus & herthae & $\mathrm{T}$ & RA1169,1476/RF \\
\hline Rosaceae & Rubus & (1 sp.) & $S$ & RF \\
\hline Rubiaceae & Alibertia & isernii & $\mathrm{T}$ & RA1395 \\
\hline Rubiaceae & Alibertia & (2 spp.) & $\mathrm{S} / \mathrm{T}$ & RA/RF \\
\hline Rubiaceae & Alseis & lugonis & $\mathrm{T}$ & RF \\
\hline Rubiaceae & Amphidasya & colombiana & $\mathrm{H}$ & RF \\
\hline Rubiaceae & Bertiera & guianensis & $\mathrm{S}$ & RF \\
\hline Rubiaceae & Borojoa & claviflora & $\mathrm{T}$ & RF \\
\hline Rubiaceae & Capirona & decorticans & $\mathrm{T}$ & $\mathrm{RF}$ \\
\hline Rubiaceae & Chimarrhis & glabriflora & $\mathrm{T}$ & $\mathrm{CC}$ \\
\hline Rubiaceae & Chomelia & barbellata cf. & $\mathrm{S}$ & RA1545/RF \\
\hline Rubiaceae & Cinchona & officinalis & $\mathrm{S} / \mathrm{T}$ & $\mathrm{CC}$ \\
\hline Rubiaceae & Cinchona & (1 sp.) & $\mathrm{T}$ & RA1110/RF \\
\hline Rubiaceae & Coffea & arabica & $\mathrm{S}$ & $\mathrm{CC}$ \\
\hline Rubiaceae & Condaminea & corymbosa & $\mathrm{T}$ & $\mathrm{RF}$ \\
\hline Rubiaceae & Cosmibuena & (1 sp.) & $\mathrm{E} / \mathrm{S}$ & RF \\
\hline Rubiaceae & Coussarea & klugii & $\mathrm{S}$ & RA1352,1389 \\
\hline Rubiaceae & Coussarea & paniculata cf. & $\mathrm{S}$ & RA1388/RF \\
\hline Rubiaceae & Coussarea & pilosula & $S$ & RA1390/RF \\
\hline Rubiaceae & Coussarea & (4 spp.) & $\mathrm{S} / \mathrm{T}$ & $\mathrm{RA} / \mathrm{RF}$ \\
\hline Rubiaceae & Duroia & hirsuta & $\mathrm{T}$ & $\mathrm{CC} / \mathrm{RF}$ \\
\hline Rubiaceae & Elaeagia & (2 spp.) & $\mathrm{T}$ & $\mathrm{RA} / \mathrm{RF}$ \\
\hline Rubiaceae & Faramea & glandulosa & $\mathrm{S} / \mathrm{T}$ & RA1616/RF \\
\hline Rubiaceae & Faramea & multiflora & $\mathrm{S} / \mathrm{T}$ & RA1392/CC/RF \\
\hline Rubiaceae & Faramea & oblongifolia & $\mathrm{S}$ & RA1406,1453/RF \\
\hline
\end{tabular}

Forma de Vida/Habit:

E = Epifita/Epiphyte

$\mathrm{H}=$ Hierba terrestre/

Terrestrial herb

$\mathrm{P}=$ Parásito/Parasite

$S=$ Arbusto/Shrub

$\mathrm{T}=$ Árbol/Tree

$V=$ Trepadora/Climber

Fuente/Source

$\mathrm{CC}=$ Registrado por Cerón et al. (1994)/Listed by Cerón et al. (1994)

$\mathrm{RA}=$ Colecciones de Roberto Aguinda; los números corresponden a los especímenes depositados en el Herbario Nacional del Ecuador/Roberto Aguinda collections; numbers refer to voucher specimens deposited in The National Herbarium of Ecuador (QCNE)

$\mathrm{RF}=$ Fotos o observaciones de campo de Robin Foster/ Robin Foster photographs or field notes 
Especies de plantas vasculares registradas para las Serranias Cofán, Provincia de Sucumbios, Ecuador, durante un inventario biológico rápido del 24 de julio al 16 de agosto 2001. La lista también incluye colecciones anteriores realizadas por $R$. Foster, R. Aguinda, T. Theim, M. Metz y G. Baker durante una visita a Sinangoe en junio del 1999 y otra a la Via Interoceánica en julio del 2000, y especies registradas por Cerón et al. (1994) en los alrededores de Sinangoe. Compilación por R. Foster. Miembros del equipo del inventario botánico rápido: R. Foster, R. Aguinda y $N$. Pitman. La información presentada aqui se irá actualizando y estará disponible en la página Web en www.fieldmuseum.org/rbi.

\section{PLANTASIPLANTS}

\begin{tabular}{|c|c|c|c|c|}
\hline Familia/Family & Género/Genus & Especie/Species & $\begin{array}{l}\text { Forma } \\
\text { de Vida/ } \\
\text { Habit }\end{array}$ & Fuente/Source \\
\hline Rubiaceae & Faramea & quinqueflora & $\mathrm{S}$ & RA866/CC/RF \\
\hline Rubiaceae & Faramea & sp. nov. fide C. Taylor & $\mathrm{S}$ & RA1332,1423/RF \\
\hline Rubiaceae & Faramea & uncinata & $\mathrm{S}$ & RA1342 \\
\hline Rubiaceae & Faramea & uniflora & $\mathrm{S}$ & RA1691 \\
\hline Rubiaceae & Gonzalagunia & affinis & $\mathrm{S}$ & RF \\
\hline Rubiaceae & Guettarda & crispiflora & $\mathrm{S}$ & RA795/CC/RF \\
\hline Rubiaceae & Hamelia & macrantha & $\mathrm{S}$ & RA/RF \\
\hline Rubiaceae & Hamelia & patens & $\mathrm{S}$ & $\mathrm{RF}$ \\
\hline Rubiaceae & Hoffmannia & (3 spp.) & $\mathrm{S}$ & RA/RF \\
\hline Rubiaceae & Isertia & laevis & $\mathrm{T}$ & $\mathrm{RF}$ \\
\hline Rubiaceae & Ixora & uleicf. & $\mathrm{S}$ & $\begin{array}{l}\text { RA1036,1057, } \\
1185,1609 \\
\end{array}$ \\
\hline Rubiaceae & Joosia & (2 spp.) & $\mathrm{S} / \mathrm{T}$ & RA1181,1514 \\
\hline Rubiaceae & Ladenbergia & macrocarpa & $\mathrm{T}$ & RA1504,1542/RF \\
\hline Rubiaceae & Ladenbergia & oblongifolia & $\mathrm{T}$ & RA1209/RF \\
\hline Rubiaceae & Ladenbergia & (2 spp.) & $\mathrm{T}$ & RA/RF \\
\hline Rubiaceae & Manettia & divaricata cf. & V & RA1340 \\
\hline Rubiaceae & Palicourea & andrei & $\mathrm{S}$ & RA1485,1491/RF \\
\hline Rubiaceae & Palicourea & angustifolia & $\mathrm{S} / \mathrm{T}$ & RA1647/RF \\
\hline Rubiaceae & Palicourea & lasiantha & $\mathrm{S} / \mathrm{T}$ & $\mathrm{RA} 1437 / \mathrm{CC} / \mathrm{RF}$ \\
\hline Rubiaceae & Palicourea & macarthurorum & $\mathrm{S}$ & RA1027,1054 \\
\hline Rubiaceae & Palicourea & nigricans & $\mathrm{S}$ & CC/RF \\
\hline Rubiaceae & Palicourea & sp. nov. fide C. Taylor & $\mathrm{S}$ & RA1220/RF \\
\hline Rubiaceae & Palicourea & subalata & $\mathrm{S}$ & RA1432 \\
\hline Rubiaceae & Palicourea & subspicata & $\mathrm{H} / \mathrm{S}$ & $\mathrm{CC} / \mathrm{RF}$ \\
\hline Rubiaceae & Palicourea & (1 sp.) & $\mathrm{S}$ & RA1600,1713/RF \\
\hline Rubiaceae & Pentagonia & macrophylla & $\mathrm{S} / \mathrm{T}$ & $\mathrm{CC}$ \\
\hline Rubiaceae & Pentagonia & parvifolia & $\mathrm{T}$ & $\mathrm{CC} / \mathrm{RF}$ \\
\hline Rubiaceae & Pentagonia & (1 sp.) & $\mathrm{S}$ & $\mathrm{RF}$ \\
\hline Rubiaceae & Posoqueria & coriacea cf. & $\mathrm{T}$ & RA1615 \\
\hline Rubiaceae & Posoqueria & latifolia & $\mathrm{S} / \mathrm{T}$ & $\mathrm{RF}$ \\
\hline Rubiaceae & Posoqueria & panamensis & $\mathrm{S} / \mathrm{T}$ & $\begin{array}{l}\text { RA1344,1568/ } \\
\text { CC/RF }\end{array}$ \\
\hline Rubiaceae & Psychotria & aequatoriana & $\mathrm{H} / \mathrm{S}$ & RA756/RF \\
\hline Rubiaceae & Psychotria & allenii & $\mathrm{S}$ & RA1144,1438 \\
\hline Rubiaceae & Psychotria & anonothyrsa & $S$ & $\mathrm{RF}$ \\
\hline Rubiaceae & Psychotria & bahiensis & $\mathrm{S}$ & $\mathrm{CC}$ \\
\hline Rubiaceae & Psychotria & bertieroides & $S$ & $\begin{array}{l}\text { RA693,795,851/ } \\
\text { RF }\end{array}$ \\
\hline Rubiaceae & Psychotria & caerulea & $\mathrm{S}$ & RA1118/RF \\
\hline Rubiaceae & Psychotria & capacifolia & $\mathrm{S}$ & RA879 \\
\hline Rubiaceae & Psychotria & cenepensis & $\mathrm{S}$ & RA1284/RF \\
\hline Rubiaceae & Psychotria & cuatrecasii & $\mathrm{S} / \mathrm{T}$ & RA725,921,1354 \\
\hline Rubiaceae & Psychotria & deflexa & $\mathrm{S}$ & RA1079/RF \\
\hline Rubiaceae & Psychotria & epiphytica & $\mathrm{E} / \mathrm{S}$ & $\mathrm{RF}$ \\
\hline Rubiaceae & Psychotria & erecta & $\mathrm{S}$ & RA1253 \\
\hline
\end{tabular}




\section{PLANTASIPLANTS}

\begin{tabular}{|c|c|c|c|c|}
\hline Familia/Family & Género/Genus & Especie/Species & $\begin{array}{l}\text { Forma } \\
\text { de Vida/ } \\
\text { Habit }\end{array}$ & Fuente/Source \\
\hline Rubiaceae & Psychotria & flaviflora & $\mathrm{S}$ & RF \\
\hline Rubiaceae & Psychotria & gracilenta & $\mathrm{S}$ & RA1379 \\
\hline Rubiaceae & Psychotria & herzogii & $\mathrm{S}$ & RA/RF \\
\hline Rubiaceae & Psychotria & iodotricha & $\mathrm{H} / \mathrm{S}$ & RA987 \\
\hline Rubiaceae & Psychotria & klugii & $\mathrm{S}$ & RA1428 \\
\hline Rubiaceae & Psychotria & lateriflora & $\mathrm{H}$ & RA896/RF \\
\hline Rubiaceae & Psychotria & leucantha & $\mathrm{H} / \mathrm{S}$ & $\begin{array}{l}\text { RA818,882,1459/ } \\
\text { RF }\end{array}$ \\
\hline Rubiaceae & Psychotria & longirostris & $\mathrm{S}$ & RF \\
\hline Rubiaceae & Psychotria & macrophylla & $\mathrm{H} / \mathrm{S}$ & RF \\
\hline Rubiaceae & Psychotria & marcgraviella & $\mathrm{S}$ & RA958/RF \\
\hline Rubiaceae & Psychotria & micrantha & $\mathrm{S}$ & RA998/RF \\
\hline Rubiaceae & Psychotria & officinalis & $S$ & $\begin{array}{l}\text { RA1045, } \\
1048,1083 / \text { RF }\end{array}$ \\
\hline Rubiaceae & Psychotria & ostreophora & $\mathrm{S}$ & RA1382 \\
\hline Rubiaceae & Psychotria & pandensis & $\mathrm{S}$ & RA1279/RF \\
\hline Rubiaceae & Psychotria & pilosa & $S$ & RA721/RF \\
\hline Rubiaceae & Psychotria & plagiantha & $\mathrm{H} / \mathrm{S}$ & RA792,1375/RF \\
\hline Rubiaceae & Psychotria & platypoda & $\mathrm{S}$ & RA1383 \\
\hline Rubiaceae & Psychotria & poeppigiana & $S$ & RA723/RF \\
\hline Rubiaceae & Psychotria & polyphlebia & $\mathrm{H}$ & RA785/RF \\
\hline Rubiaceae & Psychotria & $\begin{array}{l}\text { prob. sp. nov. } \\
\text { fide C. Taylor }\end{array}$ & $S$ & RA1418 \\
\hline Rubiaceae & Psychotria & $\begin{array}{l}\text { prob. sp. nov. } \\
\text { fide C. Taylor }\end{array}$ & $S$ & RA1421 \\
\hline Rubiaceae & Psychotria & $\begin{array}{l}\text { prob. sp. nov. } \\
\text { fide C. Taylor }\end{array}$ & $\mathrm{S}$ & RA1424,1655 \\
\hline Rubiaceae & Psychotria & $\begin{array}{l}\text { prob. sp. nov. } \\
\text { fide C. Taylor }\end{array}$ & $\mathrm{S}$ & RA1614 \\
\hline Rubiaceae & Psychotria & $\begin{array}{l}\text { prob. sp. nov. } \\
\text { fide C. Taylor }\end{array}$ & $S$ & RA1532 \\
\hline Rubiaceae & Psychotria & quinquepyrena & $\mathrm{S}$ & RA1113 \\
\hline Rubiaceae & Psychotria & racemosa & $\mathrm{S}$ & RA778/RF \\
\hline Rubiaceae & Psychotria & remota & $S$ & RA772/RF \\
\hline Rubiaceae & Psychotria & rufiramea cf. & $\mathrm{S}$ & RA1487 \\
\hline Rubiaceae & Psychotria & sacciformis & $\mathrm{S}$ & RA1258,1334/RF \\
\hline Rubiaceae & Psychotria & sp. nov. fide C. Taylor & $S$ & RA840/RF \\
\hline Rubiaceae & Psychotria & sp. nov. fide C. Taylor & $S$ & RA775,841 \\
\hline Rubiaceae & Psychotria & sp. nov. fide C. Taylor & $\mathrm{S}$ & RA717 \\
\hline Rubiaceae & Psychotria & stenostachya & $\mathrm{S}$ & $\mathrm{RA} / \mathrm{CC} / \mathrm{RF}$ \\
\hline Rubiaceae & Psychotria & tinctoria & $\mathrm{S} / \mathrm{T}$ & RA911,1422 \\
\hline Rubiaceae & Psychotria & triaxillaris aff. & $S$ & RA824/RF \\
\hline Rubiaceae & Psychotria & villosa & $\mathrm{S}$ & RF \\
\hline Rubiaceae & Psychotria & zevallosii & $\mathrm{S}$ & RA705/RF \\
\hline Rubiaceae & Raritebe & palicoureoides & $\mathrm{T}$ & RA1098,1386/RF \\
\hline Rubiaceae & Rondeletia & (1 sp.) & $\mathrm{S} / \mathrm{T}$ & RA1435 \\
\hline Rubiaceae & Rudgea & cornifolia & $\mathrm{S} / \mathrm{T}$ & RF \\
\hline
\end{tabular}

Forma de Vida/Habit:

$E$ = Epifita/Epiphyte

$\mathrm{H}=$ Hierba terrestre/ Terrestrial herb

$\mathrm{P}=$ Parásito $/$ Parasite

$\mathrm{S}=$ Arbusto/Shrub

$\mathrm{T}=$ Árbol/Tree

$V=$ Trepadora/Climber

Fuente/Source

$\mathrm{CC}=$ Registrado por Cerón et al. (1994)/Listed by Cerón et al. (1994)

$R A=$ Colecciones de Roberto Aguinda; los números corresponden a los especímenes depositados en el Herbario Nacional del Ecuador/Roberto Aguinda collections; numbers refer to voucher specimens deposited in The National Herbarium of Ecuador (QCNE)

$\mathrm{RF}=$ Fotos o observaciones de campo de Robin Foster/ Robin Foster photographs or field notes 
Especies de plantas vasculares registradas para las Serranias Cofán, Provincia de Sucumbios, Ecuador, durante un inventario biológico rápido del 24 de julio al 16 de agosto 2001. La lista también incluye colecciones anteriores realizadas por $R$. Foster, R. Aguinda, T. Theim, M. Metz y G. Baker durante una visita a Sinangoe en junio del 1999 y otra a la Via Interoceánica en julio del 2000, y especies registradas por Cerón et al. (1994) en los alrededores de Sinangoe. Compilación por R. Foster. Miembros del equipo del inventario botánico rápido: $R$. Foster, R. Aguinda y N. Pitman. La información presentada aqui se irá actualizando y estará disponible en la página Web en www.fieldmuseum.org/rbi.

\section{PLANTASIPLANTS}

\begin{tabular}{|c|c|c|c|c|}
\hline Familia/Family & Género/Genus & Especie/Species & $\begin{array}{l}\text { Forma } \\
\text { de Vida/ } \\
\text { Habit }\end{array}$ & Fuente/Source \\
\hline Rubiaceae & Rudgea & sp. nov. fide C. Taylor & $S$ & $\begin{array}{l}\text { RA777,784,1062, } \\
1090,1657 / \text { RF }\end{array}$ \\
\hline Rubiaceae & Rudgea & (3 spp.) & $\mathrm{S} / \mathrm{T}$ & $\mathrm{RA} / \mathrm{RF}$ \\
\hline Rubiaceae & Rustia & rubra & $\mathrm{T}$ & RA1 193,1440 \\
\hline Rubiaceae & Sabicea & villosa & V & RF \\
\hline Rubiaceae & Schradera & (1 sp.) & V & RA1589 \\
\hline Rubiaceae & Sphinctanthus & maculatus & $S$ & $\begin{array}{l}\text { RA681,935,1582/ } \\
\text { RF }\end{array}$ \\
\hline Rubiaceae & Tocoyena & williamsii & $\mathrm{T}$ & RA1549,1587/RF \\
\hline Rubiaceae & Uncaria & guianensis & $\mathrm{S} / \mathrm{N}$ & $\mathrm{RF}$ \\
\hline Rubiaceae & Uncaria & tomentosa & V & $\mathrm{RF}$ \\
\hline Rubiaceae & Warszewiczia & coccinea & $\mathrm{S} / \mathrm{T}$ & $\mathrm{RF}$ \\
\hline Rubiaceae & Warszewiczia & cordata & $\mathrm{T}$ & $\mathrm{RF}$ \\
\hline Rubiaceae & (1 sp.) & - & $\mathrm{T}$ & $\mathrm{RF}$ \\
\hline Rutaceae & Citrus & aurantifolia & $\mathrm{S} / \mathrm{T}$ & $\mathrm{CC}$ \\
\hline Rutaceae & Esenbeckia & amazonica & $T$ & RA1042 \\
\hline Rutaceae & Zanthoxylum & (2 spp.) & $\mathrm{T}$ & RA153/RF \\
\hline Sabiaceae & Meliosma & boliviensis aff. & $\mathrm{T}$ & RA1452/RF \\
\hline Sabiaceae & Meliosma & herbertii & $\mathrm{T}$ & $\mathrm{CC}$ \\
\hline Sabiaceae & Ophiocaryon & (1 sp.) & $\mathrm{T}$ & RA1254/RF \\
\hline Sapindaceae & Allophylus & pilosus & $\mathrm{T}$ & $\mathrm{CC}$ \\
\hline Sapindaceae & Allophy/us & punctatus & $\mathrm{T}$ & $\mathrm{CC}$ \\
\hline Sapindaceae & Allophylus & (1 sp.) & $\mathrm{T}$ & $\mathrm{RF}$ \\
\hline Sapindaceae & Cupania & (1 sp.) & $\mathrm{T}$ & $\mathrm{RF}$ \\
\hline Sapindaceae & Matayba & (1 sp.) & $\mathrm{T}$ & $\mathrm{RF}$ \\
\hline Sapindaceae & Paullinia & bracteosa & V & $\mathrm{RF}$ \\
\hline Sapindaceae & Paullinia & fimbriata & v & $\mathrm{CC}$ \\
\hline Sapindaceae & Paullinia & obovata & V & $\mathrm{CC}$ \\
\hline Sapindaceae & Paullinia & pachycarpa & $\mathrm{V}$ & $\mathrm{RF}$ \\
\hline Sapindaceae & Paullinia & rugosa & V & $\mathrm{RF}$ \\
\hline Sapindaceae & Paullinia & yoco & V & $\mathrm{CC} / \mathrm{RF}$ \\
\hline Sapindaceae & Paullinia & (3 spp.) & V & RA \\
\hline Sapindaceae & Serjania & (1 sp.) & V & $\mathrm{RF}$ \\
\hline Sapotaceae & Micropholis & venulosa & $\mathrm{T}$ & $\mathrm{CC} / \mathrm{RF}$ \\
\hline Sapotaceae & Micropholis & (1 sp.) & $\mathrm{T}$ & $\mathrm{RF}$ \\
\hline Sapotaceae & Pouteria & caimito & $\mathrm{T}$ & $\mathrm{CC}$ \\
\hline Sapotaceae & Pouteria & platyphylla & $\mathrm{T}$ & $\mathrm{CC}$ \\
\hline Sapotaceae & Pouteria & torta & $\mathrm{S} / \mathrm{T}$ & $\mathrm{CC}$ \\
\hline Sapotaceae & Pouteria & (8 spp.) & $\mathrm{T}$ & RA/RF \\
\hline Scrophulariaceae & Basistemon & (1 sp.) & $\mathrm{S}$ & RA1658 \\
\hline Scrophulariaceae & Scoparia & dulcis & $\mathrm{H}$ & $\mathrm{CC} / \mathrm{RF}$ \\
\hline Simaroubaceae & Picramnia & latifolia & $\mathrm{S} / \mathrm{T}$ & $\mathrm{CC} / \mathrm{RF}$ \\
\hline Simaroubaceae & Picramnia & sellowii & $\mathrm{S} / \mathrm{T}$ & $\mathrm{CC}$ \\
\hline Simaroubaceae & Picramnia & (4 spp.) & $S$ & RA/RF \\
\hline Simaroubaceae & Simarouba & amara & $\mathrm{T}$ & $\mathrm{RF}$ \\
\hline Smilacaceae & Smilax & (2 spp.) & V & $\mathrm{RF}$ \\
\hline
\end{tabular}


PLANTASIBLANTS

\begin{tabular}{|c|c|c|c|c|}
\hline Familia /Family & Género/Genus & Especie/Species & $\begin{array}{l}\text { Forma } \\
\text { de Vida/ } \\
\text { Habit }\end{array}$ & Fuente/Source \\
\hline Solanaceae & Brugmansia & $\mathrm{X}$ candida & $\mathrm{S}$ & RF \\
\hline Solanaceae & Brunfelsia & grandifiora & $\mathrm{S}$ & RA1563/CC \\
\hline Solanaceae & Capsicum & annuum & $\mathrm{H} / \mathrm{S}$ & $\mathrm{CC}$ \\
\hline Solanaceae & Cestrum & megalophy/lum & $\mathrm{s}$ & $\mathrm{RF}$ \\
\hline Solanaceae & Cestrum & (4 spp.) & $\mathrm{S} / \mathrm{T}$ & RA \\
\hline Solanaceae & Lycianthes & (2 spp.) & V & RA/RF \\
\hline Solanaceae & Physalis & angulata & $\mathrm{H}$ & $\mathrm{CC}$ \\
\hline Solanaceae & Physalis & pubescens & $\mathrm{H}$ & $\mathrm{CC}$ \\
\hline Solanaceae & Solanum & anisophyllum & $\mathrm{S}$ & $\mathrm{CC}$ \\
\hline Solanaceae & Solanum & barbeyanum & V & $\mathrm{CC}$ \\
\hline Solanaceae & Solanum & circinatum & $\mathrm{S}$ & $\mathrm{CC}$ \\
\hline Solanaceae & Solanum & dimorphandrum & $\mathrm{S}$ & RF \\
\hline Solanaceae & Solanum & endopogon & $\mathrm{S}$ & $\mathrm{CC}$ \\
\hline Solanaceae & Solanum & grandiflorum & $\mathrm{S} / \mathrm{T}$ & $\mathrm{CC}$ \\
\hline Solanaceae & Solanum & lepidotum & $\mathrm{S} / \mathrm{T}$ & $\mathrm{CC}$ \\
\hline Solanaceae & Solanum & mammosum & $\mathrm{H} / \mathrm{S}$ & $\mathrm{CC}$ \\
\hline Solanaceae & Solanum & pedemontanum & $\mathrm{V}$ & RA1029/RF \\
\hline Solanaceae & Solanum & sessiliflorum & $S$ & $\mathrm{CC}$ \\
\hline Solanaceae & Solanum & stramoniifolium & $\mathrm{S}$ & $\mathrm{CC}$ \\
\hline Solanaceae & Solanum & viridipes & V & RF \\
\hline Solanaceae & Solanum & (14 spp.) & $\mathrm{S}$ & RA/RF \\
\hline Solanaceae & Trianaea & speciosa & $\mathrm{S} / \mathrm{N} / \mathrm{E}$ & $\mathrm{CC}$ \\
\hline Solanaceae & Witheringia & solanacea & $\mathrm{H} / \mathrm{S}$ & $\mathrm{CC}$ \\
\hline Staphyleaceae & Huertea & glandulosa & $\mathrm{T}$ & RF \\
\hline Staphyleaceae & Turpinia & occidentalis & $T$ & $\mathrm{RF}$ \\
\hline Sterculiaceae & Ayenia & (1 sp.) & $\mathrm{S} / \mathrm{T}$ & RA/RF \\
\hline Sterculiaceae & Byttneria & asterotricha & $\mathrm{S}$ & RF \\
\hline Sterculiaceae & Guazuma & ulmifolia & $\mathrm{T}$ & RF \\
\hline Sterculiaceae & Herrania & balaensis & $\mathrm{S}$ & $\mathrm{CC}$ \\
\hline Sterculiaceae & Herrania & (2 spp.) & $\mathrm{S}$ & RF \\
\hline Sterculiaceae & Sterculia & apeibophylla & $\mathrm{T}$ & $\mathrm{CC} / \mathrm{RF}$ \\
\hline Sterculiaceae & Sterculia & apetala & $\mathrm{T}$ & RF \\
\hline Sterculiaceae & Sterculia & colombiana & $\mathrm{T}$ & $\mathrm{CC} / \mathrm{RF}$ \\
\hline Sterculiaceae & Sterculia & rugosa cf. & $T$ & $\mathrm{CC} / \mathrm{RF}$ \\
\hline Sterculiaceae & Sterculia & tessmannii & $T$ & $\mathrm{CC} / \mathrm{RF}$ \\
\hline Sterculiaceae & Sterculia & (1 sp.) & $\mathrm{T}$ & RF \\
\hline Sterculiaceae & Theobroma & bicolor & $\mathrm{T}$ & $\mathrm{CC}$ \\
\hline Sterculiaceae & Theobroma & subincanum & $\mathrm{T}$ & $\mathrm{CC} / \mathrm{RF}$ \\
\hline Styracaceae & Styrax & (1 sp.) & $T$ & RA1241 \\
\hline Symplocaceae & Symplocos & (1 sp.) & $\mathrm{T}$ & RA943 \\
\hline Theaceae & Ternstroemia & (1 sp.) & $\mathrm{T}$ & RA1111,1475 \\
\hline Theophrastaceae & Clavija & venosa & $\mathrm{S}$ & RA1559/RF \\
\hline Theophrastaceae & Clavija & weberbaueri & $\mathrm{S} / \mathrm{T}$ & $\mathrm{CC}$ \\
\hline Theophrastaceae & Clavija & (2 spp.) & $\mathrm{S}$ & RF \\
\hline Thymelaeaceae & Daphnopsis & equatorialis & $\mathrm{T}$ & RA1117 \\
\hline Thymelaeaceae & Schoenobiblus & daphnoides & $\mathrm{T}$ & $\mathrm{CC}$ \\
\hline
\end{tabular}

Species of vascular plants recorded for the Serranias Cofán, Sucumbios province, northeastern Ecuador, in a rapid biological inventory from 24 July to 16 August 2001. The list also includes collections made by R. Foster, R. Aguinda, T. Theim, M. Metz, and G. Baker during earlier visits to Sinangoe in June 1999 and the Interoceanic Highway in July 2000, and species registered by Cerón et al. (1994) in the vicinity of Sinangoe. Compiled by R. Foster. Rapid biological inventory botany team members: R. Foster, R. Aguinda, and N. Pitman. Updated information will be posted at www.fieldmuseum.org/rbi.

Forma de Vida/Habit:

$E=$ Epifita/Epiphyte

$H=$ Hierba terrestre/ Terrestrial herb

$\mathrm{P}=$ Parásito/Parasite

$\mathrm{S}=$ Arbusto $/$ Shrub

$\mathrm{T}=$ Árbol/Tree

$V=$ Trepadora/Climber

Fuente/Source

$\mathrm{CC}=$ Registrado por Cerón et al. (1994)/Listed by Cerón et al. (1994)

$\mathrm{RA}=$ Colecciones de Roberto Aguinda; los números corresponden a los especímenes depositados en el Herbario Nacional del Ecuador/Roberto Aguinda collections; numbers refer to voucher specimens deposited in The National Herbarium of Ecuador (QCNE)

$\mathrm{RF}=$ Fotos o observaciones de campo de Robin Foster/ Robin Foster photographs or field notes 
Especies de plantas vasculares registradas para las Serranias Cofán, Provincia de Sucumbios, Ecuador, durante un inventario biológico rápido del 24 de julio al 16 de agosto 2001. La lista también incluye colecciones anteriores realizadas por $R$. Foster, R. Aguinda, T. Theim, M. Metz y G. Baker durante una visita a Sinangoe en junio del 1999 y otra a la Via Interoceánica en julio del 2000, y especies registradas por Cerón et al. (1994) en los alrededores de Sinangoe. Compilación por R. Foster. Miembros del equipo del inventario botánico rápido: R. Foster, R. Aguinda y N. Pitman. La información presentada aquí se irá actualizando y estará disponible en la página Web en www.fieldmuseum.org/rbi.

\section{PLANTASI PLANTS}

\begin{tabular}{|c|c|c|c|c|}
\hline Familia/Family & Género/Genus & Especie/Species & $\begin{array}{l}\text { Forma } \\
\text { de Vida/ } \\
\text { Habit }\end{array}$ & Fuente/Source \\
\hline Tiliaceae & Apeiba & membranacea & $\mathrm{T}$ & $\mathrm{CC} / \mathrm{RF}$ \\
\hline Tiliaceae & Mollia & lepidota & $\mathrm{T}$ & $\mathrm{CC}$ \\
\hline Tiliaceae & Triumfetta & (1 sp.) & $\mathrm{S}$ & RF \\
\hline Tovariaceae & Tovaria & pendula & $\mathrm{H} / \mathrm{S}$ & RF \\
\hline Tropaeolaceae & Tropaeolum & adpressum & V & RA1409/RF \\
\hline Ulmaceae & Ampelocera & edentula & $T$ & RF \\
\hline Ulmaceae & Celtis & iguanaea & $\mathrm{T}$ & RF \\
\hline Ulmaceae & Celtis & schippii & $\mathrm{T}$ & RF \\
\hline Ulmaceae & Trema & micrantha & $\mathrm{T}$ & RF \\
\hline Urticaceae & Boehmeria & (1 sp.) & $\mathrm{S}$ & RF \\
\hline Urticaceae & Myriocarpa & stipitata & $\mathrm{S} / \mathrm{T}$ & $\mathrm{RF}$ \\
\hline Urticaceae & Pilea & fasciata cf. & $\mathrm{H}$ & $\mathrm{RF}$ \\
\hline Urticaceae & Pilea & submissa & $\mathrm{H}$ & $\mathrm{CC}$ \\
\hline Urticaceae & Pilea & (4 spp.) & $\mathrm{H}$ & $\mathrm{RA}$ \\
\hline Urticaceae & Pouzolzia & (1 sp.) & $S$ & RF \\
\hline Urticaceae & Urera & baccifera & $\mathrm{S} / \mathrm{T}$ & RF \\
\hline Urticaceae & Urera & caracasana & $\mathrm{S} / \mathrm{T}$ & RF \\
\hline Urticaceae & Urera & laciniata & $\mathrm{S}$ & $\mathrm{CC}$ \\
\hline Verbenaceae & Aegiphila & cordata & $\mathrm{S}$ & CC/RF \\
\hline Verbenaceae & Aegiphila & integrifolia & $\mathrm{T}$ & $\mathrm{CC}$ \\
\hline Verbenaceae & Aegiphila & (1 sp.) & $\mathrm{T}$ & RA1230/RF \\
\hline Verbenaceae & Citharexylum & poeppigii & $\mathrm{T}$ & $\mathrm{CC} / \mathrm{RF}$ \\
\hline Verbenaceae & Citharexylum & (1 sp.) & $\mathrm{T}$ & $\mathrm{RF}$ \\
\hline Verbenaceae & Vitex & gigantea & $\mathrm{T}$ & $\mathrm{CC}$ \\
\hline Verbenaceae & Vitex & triflora & $\mathrm{S}$ & RF \\
\hline Violaceae & Gloeospermum & equatoriense & $\mathrm{S} / \mathrm{T}$ & $\mathrm{CC}$ \\
\hline Violaceae & Gloeospermum & longifolium & $\mathrm{T}$ & RA1043/RF \\
\hline Violaceae & Leonia & crassa & $T$ & $\mathrm{CC}$ \\
\hline Violaceae & Leonia & glycycarpa & $\mathrm{T}$ & $\mathrm{CC} / \mathrm{RF}$ \\
\hline Violaceae & Rinorea & viridifolia & $\mathrm{S}$ & $\mathrm{CC} / \mathrm{RF}$ \\
\hline Vitaceae & Cissus & verticillata & V & $\mathrm{CC}$ \\
\hline Vochysiaceae & Qualea & paraensis & $\mathrm{T}$ & RF \\
\hline Vochysiaceae & Vochysia & biloba & $\mathrm{T}$ & $\mathrm{CC}$ \\
\hline Vochysiaceae & Vochysia & braceliniae & $\mathrm{T}$ & $\mathrm{CC} / \mathrm{RF}$ \\
\hline Vochysiaceae & Vochysia & grandis & $\mathrm{T}$ & RF \\
\hline Vochysiaceae & Vochysia & (1 sp.) & $T$ & RA1327 \\
\hline Zingiberaceae & Renealmia & alpinia & $\mathrm{H}$ & $\mathrm{CC}$ \\
\hline Zingiberaceae & Renealmia & breviscapa & $\mathrm{H}$ & $\mathrm{CC}$ \\
\hline Zingiberaceae & Renealmia & monosperma & $\mathrm{H}$ & $\mathrm{CC}$ \\
\hline Zingiberaceae & Renealmia & nicolaioides & $\mathrm{H}$ & $\mathrm{CC}$ \\
\hline Zingiberaceae & Renealmia & thyrsoidea & $\mathrm{H}$ & $\mathrm{RF}$ \\
\hline \multicolumn{5}{|c|}{$\begin{array}{l}\text { PTERIDOPHYTA } \\
\text { (HELECHOS/FERNS AND ALLIES) }\end{array}$} \\
\hline Aspleniaceae & Asplenium & rutaceum & $\mathrm{H} / \mathrm{E}$ & RA1055,1692/RF \\
\hline Aspleniaceae & Asplenium & (7 spp.) & $\mathrm{H} / \mathrm{E}$ & RA \\
\hline Blechnaceae & Salpichlaena & volubilis & $\mathrm{H}$ & RF \\
\hline
\end{tabular}




\section{PLANTASI PLANTS}

\begin{tabular}{|c|c|c|c|c|}
\hline Familia/Family & Género/Genus & Especie/Species & $\begin{array}{l}\text { Forma } \\
\text { de Vida/ } \\
\text { Habit }\end{array}$ & Fuente/Source \\
\hline Cyatheaceae & Alsophila & (1 sp.) & $\mathrm{S}$ & $\mathrm{RF}$ \\
\hline Cyatheaceae & Cyathea & bipinnatifida & $\mathrm{S}$ & $\mathrm{CC}$ \\
\hline Cyatheaceae & Cyathea & lasiosora & $\mathrm{S}$ & $\mathrm{RF}$ \\
\hline Cyatheaceae & (12 spp.) & - & $\mathrm{S}$ & $\mathrm{RF}$ \\
\hline Dennstaedtiaceae & Lindsaea & (2 spp.) & $\mathrm{H}$ & RA738,1519 \\
\hline Dennstaedtiaceae & Saccoloma & (1 sp.) & $\mathrm{H}$ & $\mathrm{RF}$ \\
\hline Dryopteridaceae & Bolbitis & oligarchia & $\mathrm{H}$ & $\mathrm{RF}$ \\
\hline Dryopteridaceae & Didymochlaena & truncatula & $\mathrm{H}$ & RA1462/RF \\
\hline Dryopteridaceae & Diplazium & aberrans & $\mathrm{H}$ & $\mathrm{RA} / \mathrm{RF}$ \\
\hline Dryopteridaceae & Diplazium & chimborazense & $\mathrm{H}$ & RA1287/RF \\
\hline Dryopteridaceae & Diplazium & pinnatifidum & $\mathrm{H}$ & $\mathrm{RF}$ \\
\hline Dryopteridaceae & Elaphoglossum & erinaceum & $E$ & RA/RF \\
\hline Dryopteridaceae & Elaphoglossum & raywaense & $E$ & $\mathrm{CC}$ \\
\hline Dryopteridaceae & Elaphoglossum & (7 spp.) & $E$ & RA/RF \\
\hline Dryopteridaceae & Hemidictyum & marginatum & $\mathrm{H}$ & $\mathrm{RF}$ \\
\hline Dryopteridaceae & Lomariopsis & (1 sp.) & $\mathrm{V} / \mathrm{E}$ & RA1548/RF \\
\hline Dryopteridaceae & Oleandra & (1 sp.) & V & $\mathrm{RF}$ \\
\hline Dryopteridaceae & Peltapteris & peltata & $E$ & RA1268/RF \\
\hline Dryopteridaceae & Polybotrya & crassirhizoma & $E$ & $\mathrm{CC}$ \\
\hline Dryopteridaceae & Polybotrya & osmundacea & $E$ & $\mathrm{CC}$ \\
\hline Dryopteridaceae & Polybotrya & (1 sp.) & V/E & RA1203 \\
\hline Dryopteridaceae & Tectaria & incisa & $\mathrm{H}$ & $\mathrm{CC} / \mathrm{RF}$ \\
\hline Dryopteridaceae & Tectaria & (1 sp.) & $\mathrm{H}$ & $\mathrm{RF}$ \\
\hline Equisetaceae & Equisetum & myriochaetum & $\mathrm{H}$ & $\mathrm{CC}$ \\
\hline Gleicheniaceae & Gleichenella & pectinata & $\mathrm{H}$ & RF \\
\hline Gleicheniaceae & Sticherus & (2 spp.) & V & RA/RF \\
\hline Grammitidaceae & (3 spp.) & - & $E$ & RA \\
\hline Hymenophyllaceae & Trichomanes & ankersii & $E$ & RA1002/RF \\
\hline Hymenophyllaceae & Trichomanes & cristatum & $E$ & $\mathrm{RF}$ \\
\hline Hymenophyllaceae & Trichomanes & elegans & $\mathrm{H}$ & RF \\
\hline Hymenophyllaceae & Trichomanes & membranaceum & $\mathrm{H} / \mathrm{E}$ & RA1260/RF \\
\hline Hymenophyllaceae & Trichomanes & (4 spp.) & $\mathrm{H} / \mathrm{E}$ & RA \\
\hline Lophosoriaceae & Lophosoria & quadripinnata & $\mathrm{T}$ & RA/RF \\
\hline Lycopodiaceae & (5 spp.) & - & $E$ & RA \\
\hline Marattiaceae & Danaea & nodosa & $\mathrm{H}$ & RA967 \\
\hline Marattiaceae & Danaea & (3 spp.) & $\mathrm{H}$ & RA \\
\hline Ophioglossaceae & Cheiroglossa & palmata & $\mathrm{H} / \mathrm{E}$ & RA1689/RF \\
\hline Polypodiaceae & Campyloneurum & nitidissimum & $\mathrm{H} / \mathrm{E}$ & RA1677/RF \\
\hline Polypodiaceae & Campyloneurum & (1 sp.) & $\mathrm{E}$ & RA1061 \\
\hline Polypodiaceae & Enterosora & trifurcata & $H / E$ & RA1286/RF \\
\hline Polypodiaceae & Lellingeria & subsessilis & $E$ & RA1464/RF \\
\hline Polypodiaceae & Microgramma & fuscopunctata & $E$ & RF \\
\hline Polypodiaceae & Microgramma & percussa & $\mathrm{H} / \mathrm{E}$ & RA1266/RF \\
\hline Polypodiaceae & Microgramma & (1 sp.) & $E$ & RA757 \\
\hline Polypodiaceae & Polypodium & fraxinifolium & $E$ & RA1247/RF \\
\hline Polypodiaceae & Polypodium & levigatum & $E$ & RA903,1207/RF \\
\hline
\end{tabular}

Species of vascular plants recorded for the Serranias Cofán, Sucumbios province, northeastern Ecuador, in a rapid biological inventory from 24 July to 16 August 2001. The list also includes collections made by R. Foster, R. Aguinda, T. Theim, M. Metz, and G. Baker during earlier visits to Sinangoe in June 1999 and the Interoceanic Highway in July 2000, and species registered by Cerón et al. (1994) in the vicinity of Sinangoe. Compiled by R. Foster. Rapid biological inventory botany team members:

R. Foster, R. Aguinda, and N. Pitman. Updated information will be posted at www.fieldmuseum.org/rbi.

Forma de Vida/Habit:

$\mathrm{E}=$ Epifita/Epiphyte

$\mathrm{H}=$ Hierba terrestre/

Terrestrial herb

$\mathrm{P}=$ Parásito $/$ Parasite

$\mathrm{S}=$ Arbusto/Shrub

$T=$ Árbol/Tree

$V=$ Trepadora/Climber

\section{Fuente/Source}

$\mathrm{CC}=$ Registrado por Cerón et al. (1994)/Listed by Cerón et al. (1994)

$\mathrm{RA}=$ Colecciones de Roberto Aguinda; los números corresponden a los especimenes depositados en el Herbario Nacional del Ecuador/Roberto Aguinda collections; numbers refer to voucher specimens deposited in The National Herbarium of Ecuador (QCNE)

$\mathrm{RF}=$ Fotos o observaciones de campo de Robin Foster/ Robin Foster photographs or field notes 
Especies de plantas vasculares registradas para las Serranias Cofán, Provincia de Sucumbios, Ecuador, durante un inventario biológico rápido del 24 de julio al 16 de agosto 2001. La lista también incluye colecciones anteriores realizadas por $R$. Foster, R. Aguinda, T. Theim, M. Metz y G. Baker durante una visita a Sinangoe en junio del 1999 y otra a la Via Interoceánica en julio del 2000, y especies registradas por Cerón et al. (1994) en los alrededores de Sinangoe. Compilación por R. Foster. Miembros del equipo del inventario botánico rápido: R. Foster, R. Aguinda y N. Pitman. La información presentada aquí se irá actualizando y estará disponible en la página Web en www.fieldmuseum.org/rbi.

\section{PLANTASI PLANTS}

\begin{tabular}{|c|c|c|c|c|}
\hline Familia/Family & Género/Genus & Especie/Species & $\begin{array}{l}\text { Forma } \\
\text { de Vida/ } \\
\text { Habit }\end{array}$ & Fuente/Source \\
\hline Polypodiaceae & Solanopteris & bifrons & $E$ & $\mathrm{CC} / \mathrm{RF}$ \\
\hline Pteridaceae & Adiantum & (1 sp.) & $\mathrm{H}$ & RA1309 \\
\hline Pteridaceae & Eriosorus & (1 sp.) & V & $\mathrm{RF}$ \\
\hline Pteridaceae & Pityrogramma & calomelanos & $\mathrm{H}$ & $\mathrm{RF}$ \\
\hline Pteridaceae & Pityrogramma & trifoliata & $\mathrm{H}$ & $\mathrm{RF}$ \\
\hline Pteridaceae & Pteris & (1 sp.) & $\mathrm{H}$ & RA1457 \\
\hline Schizaeaceae & Lygodium & (1 sp.) & V & RF \\
\hline Selaginellaceae & Selaginella & exaltata & V & CC/RF \\
\hline Selaginellaceae & Selaginella & (4 spp.) & $\mathrm{H}$ & RF \\
\hline Thelypteridaceae & Thelypteris & (1 sp.) & $\mathrm{HN}$ & RA1318/RF \\
\hline Thelypteridaceae & Thelypteris & angustifolia & $\mathrm{H}$ & RF \\
\hline Vittariaceae & Antrophyum & cajenense & $E$ & RA755/CC \\
\hline Vittariaceae & Vittaria & (3 spp.) & $E$ & RA \\
\hline (Pteridophyta) & (5 spp.) & - & $\mathrm{H} / \mathrm{E}$ & RA \\
\hline
\end{tabular}




\section{ANIILOS Y REPTILESIAMPHIBIANS AND REPTILES}

\begin{tabular}{|c|c|c|c|}
\hline Especie/Species & $\begin{array}{l}\text { Sitio registrado/ } \\
\text { Locality }\end{array}$ & $\begin{array}{l}\text { Observado a/ } \\
\text { Observed at }(\mathrm{m})\end{array}$ & $\begin{array}{l}\text { Rango altitudinal publicado/ } \\
\text { Published elevational range }^{* *}(\mathrm{~m})\end{array}$ \\
\hline \multicolumn{4}{|l|}{ AMPHIBIA } \\
\hline \multicolumn{4}{|l|}{ Caecilidae } \\
\hline 01. Caecilia cf. tentaculata* & $\mathrm{B}$ & 1200 & - \\
\hline \multicolumn{4}{|l|}{ Plethodontidae } \\
\hline 02. Bolitoglossa cf. peruviana & C & 1000 & $350-1240^{1}$ \\
\hline \multicolumn{4}{|l|}{ Bufonidae } \\
\hline 03. Bufo typhonius group & SI & 600 & - \\
\hline \multicolumn{4}{|l|}{ Centrolenidae } \\
\hline 04. Cochranella midas & $\mathrm{SH}$ & 1050 & $<400$ \\
\hline \multicolumn{4}{|l|}{ Hylidae } \\
\hline 05. Hyla cf. phyllognatha & C, SH & $900-1100$ & $600-1740$ \\
\hline 06. Hyla boans & SI & 600 & - \\
\hline 07. Osteocephalus cf. fuscifacies & C, SI & $600-1000$ & $<250^{4}$ \\
\hline \multicolumn{4}{|l|}{ Leptodactylidae } \\
\hline 08. Eleutherodactylus croceoinguinus & $\mathrm{C}, \mathrm{SH}$ & 1100 & $340-1140^{2}$ \\
\hline 09. Eleutherodactylus lanthanites & SI & 600 & $<1500 ?^{2}$ \\
\hline 10. Eleutherodactylus martiae & $\mathrm{SH}$ & 1300 & $<1050^{3}$ \\
\hline 11. Eleutherodacty/us nigrovittatus & $\mathrm{C}, \mathrm{SH}, \mathrm{SI}$ & $600-1370$ & $<1935^{2}$ \\
\hline 12. Eleutherodactylus quaquaversus & $\mathrm{C}, \mathrm{SH}$ & $900-1100$ & $340-1740^{2}$ \\
\hline 13. Eleutherodactylus conspicillatus group & $\mathrm{SH}$ & 1050 & - \\
\hline 14. Eleutherodactylus unistrigatus group, sp. 1 & camino a $\mathrm{C}$ & 850 & - \\
\hline 15. Eleutherodacty/us unistrigatus group, sp. 2 & $\mathrm{C}$ & 950 & - \\
\hline 16. Eleutherodacty/us sp. & C & 1000 & - \\
\hline 17. Lithodytes lineatus & SI & 600 & $<800 ?$ \\
\hline \multicolumn{4}{|l|}{ Dendrobatidae } \\
\hline 18. Epipedobates femoralis & SI, camino a C & $<800$ & $?$ \\
\hline 19. Epipedobates hanheli & SI & 600 & $<1500 ?^{1}$ \\
\hline \multicolumn{4}{|l|}{ REPTILIA } \\
\hline \multicolumn{4}{|l|}{ Colubridae } \\
\hline 20. Liophis epinephelus & $\mathrm{SH}$ & 1300 & - \\
\hline 21. Chironius cf. monticola & $\mathrm{C}$ & 1000 & - \\
\hline 22. Clelia clelia & $\mathrm{SH}$ & 1020 & - \\
\hline \multicolumn{4}{|l|}{ Viperidae } \\
\hline 23. Bothrops atrox & $\mathrm{C}$ & 980 & - \\
\hline 24. Lachesis muta & $\mathrm{SH}$ & 1020 & - \\
\hline \multicolumn{4}{|l|}{ Elapidae } \\
\hline 25. Micrurus lemniscatus & $\mathrm{C}$ & 1000 & - \\
\hline \multicolumn{4}{|l|}{ Hoplocercidae } \\
\hline 26. Enyalioides cofanorum & $\mathrm{SH}$ & 1100 & - \\
\hline 27. Enyalioides laticeps & $\mathrm{C}$ & 1000 & - \\
\hline \multicolumn{4}{|l|}{ Gymnophthalmidae } \\
\hline 28. Cercosaura ocellata & $\mathrm{SH}$ & 1200 & - \\
\hline 29. Neusticurus cochranae & $\mathrm{C}$ & $950-1000$ & - \\
\hline 30. Leposoma parietale & $\mathrm{SH}$ & 1200 & $<800 ?$ \\
\hline \multicolumn{4}{|l|}{ Polichcrotidae } \\
\hline 31. Dactyloa sp.* & $\mathrm{B}$ & $1500 ?$ & - \\
\hline
\end{tabular}


APÉNDICE/APPENDIX 2

Anfibios y Reptiles/Amphibians and Reptiles
Especies de anfibios y reptiles registrados en los alrededores de Sinangoe,

Provincia de Sucumbios, Ecuador, del 5 al 16 de agosto, 2001. Miembros del equipo:

L. O. Rodriguez (campo) y F. Campos (museo).
Macrohábitat/

Macrohabitat

Microhábitat

Microhabitat

Abundancia/

Abundance

L

$\mathrm{D} ?$

01.

UHF

F

VH

$\mathrm{N}$

02 .

03.

UHF

$-$

$\mathrm{T}$

$-$

04.

LHF/UHF

05.

UHF

LHF

LHF/UHF

$R$
$R$
A

$\mathrm{H}$

L

$\mathrm{D} ?$

07.

LHF/UHF

08.

LHF

LV

09.

10.

LHF/UHF

LHF/UHF

LHF/UHF

UHF

13.

14.

LHF

UHF

16.

UHF

LHF

LV

LV

LV

T

LV

LV

LV

LV

LV

$\mathrm{T}$

$\begin{array}{ll}18 . & \text { LHF } \\ 19 . & \text { LHF }\end{array}$

$\frac{\mathrm{LHF}}{\mathrm{LHF}}$

$\mathrm{T}$

$\mathrm{T}$

VH

D

D
Hora de actividad/

Time active
Sitio registrado/Locality

$\mathrm{B}=$ Bermejo

C = Ccuccono

$\mathrm{SH}=$ Shishicho

SI = Estación de Sinangoe/ Sinangoe field station

Macrohábitats/Macrohabitats

LHF = Bosque de laderas bajas $/$ Lower hill forest

$\mathrm{UHF}=$ Bosque de laderas altas / Upper hill forest

Microhábitats/Microhabitats

$\mathrm{A}=$ Arbóreo/Arboreal

$\mathrm{F}=$ Fossorial

LV = Vegetación baja/ Low vegetation

$\mathrm{R}=$ Ripario/Riparian

$\mathrm{T}=$ Terrestre/Terrestrial

Abundancia/Abundance

$\mathrm{L} \quad=$ Bajo/Low

$\mathrm{M}=$ Mediano/Medium

$\mathrm{H}=$ Alto/High

$\mathrm{VH}=$ Muy Alto/Very High

$X \quad=$ Presente $/$ Present

Hora de actividad/Time active

$\mathrm{D}=\mathrm{Di} / \mathrm{Lay}$

$N=$ Noche/Night

* Identificado de una foto sacada por el equipo en Bermejo / Identified from a picture taken by the team in Bermejo

* "Según/According to:

${ }^{1}$ Ruiz-Carranza et aJ. 1996

${ }^{2}$ Lynch and Duellman 1980

${ }^{3}$ Flores and McDiarmid 1989

${ }^{4}$ Ron and Pramuk 1999 



\section{ANTIBIOS Y REPTILESIAMPHIBIANS AND REPTILES}

\section{Especie/Species} Sitio registradol
Locality

Observado af Rango altitudinal publicado

AMPHIBIA

Caecilidae 1200

01. Caecilia ch.

\begin{tabular}{l} 
Plethodontidae \\
\hline 02. Bolitoglossa cf. perviana \\
\hline
\end{tabular}

Bufonidae

$350-1240^{1}$

03. Bufo typhonius group

04. Cochranella midas $\quad$ SH 1050

Hylidae

05. Hyla cf. phyllognatha - C, SH -2

06. Hyla boans

Leptodactylidae

08. Eleutherodactylus croceoinguinus $\quad \mathrm{C}, \mathrm{SH}-1100-340-1140^{2}$

09. Eleutherodactylus lanthanites

10. Eleutherodacty/us martiae

11. Eleutherodacty/us nigrovittatus

$\mathrm{SH}-\frac{600}{1300}$

$\mathrm{CH}, \overline{\mathrm{SI}}-\frac{1300}{600-1370}$

C. SH

$600-1370 \quad<1935^{2}$

13. Eleutherodactylus conspicillatus group $\quad \mathrm{SH}$

4. Eleutherodactylus unistrigatus group, $\mathrm{sp} .1$

$900-1100$

1050

C 950

$\begin{array}{lll}17 . \text { Lithodytes lineatus } & \mathrm{C} 1 & 600\end{array}$

Oendrobatidae

SI $600<<$ BOO?

18. Epipedobates femoralis

SI, camino a C

$<800$

600

EPTILIA

Colubridae

20. Liophis epinephelus $\quad$ SH 130

\begin{tabular}{lll} 
20. Liophis epinephelus & SH & 100 \\
21. Chironius cf. monticola & C & 1020 \\
\hline 22. Clelia clelia & SH
\end{tabular}

Viperidae

23. Bothrops atrox

24. Lachesis mut

Elapidae

25. Micrurus lemniscatus $\quad$ C 1000

Hoplocercidae

26. Enyalioides cofanorum $\quad$ SH 1100

27. Enyalioides laticeps

Gymnophthalmidae

28. Cercosaura ocellata

1000

\begin{tabular}{ll}
$\mathrm{SH}$ & 1200 \\
\hline
\end{tabular}

29. Neusticurus cochranae
30. Leposoma parietale
P... SH

Policherotidae

B

$1500 ?$

\begin{tabular}{ll}
\hline 00 & - \\
\hline 00 & - \\
\hline 20 & - \\
\hline 00 & - \\
\hline 00 & - \\
\hline 100 & \\
\hline 000 & - \\
\hline 500 & - \\
\hline 500 & - \\
\hline 5000 & - \\
\hline
\end{tabular}

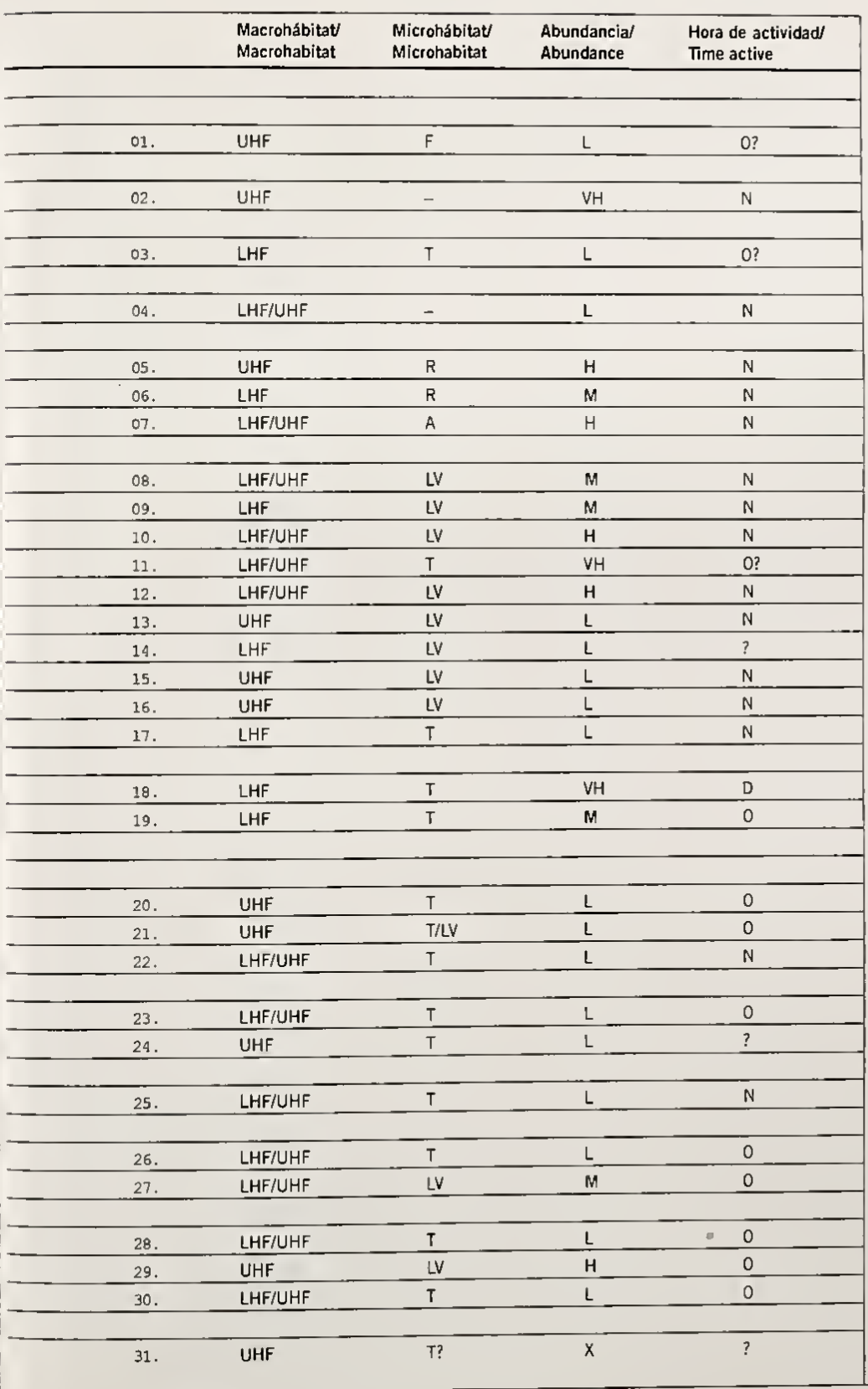

Sitio registrado/Locality

$B \quad=$ Bermejo
$C \quad=$ Ccuccono

$\mathrm{SH}=$ Shishicho
$\mathrm{SI}=$ Estación de Sinangoe/

Sinangoe field station

Macrohábitats/Macrohabitats LHF = Bosque de laderas bajas $!$ $U \mathrm{HF}=$ Bosque de laderas altas/ $=$ Bosque de laders

Microhábitats/Microhabitats

A $=$ Arbóreo/Arboreal

$F=$ Fossorial

LV = Vegetación baja

R $=$ Ripario/Riparian

$T=$ Terrestre/Terrestrial

Abundancia/Abundance

$\begin{aligned} L & =B \text { ajo/Low } \\ M & =\text { Mediano/Me }\end{aligned}$

$\begin{aligned} M & =\text { Altodano/Medium } \\ H & =\text { Alto/High }\end{aligned}$

$\mathrm{H}=$ Alto/High
$\mathrm{VH}=$ Muy Alto/ $/$ ery High
$\mathrm{X}=$ Presente/Present

Hora de actividad/Time active

$\begin{aligned} & =\text { Ola/Oay } \\ \mathrm{N} & =\text { Noche/Night }\end{aligned}$

- Identificado de una foro sacada

por el equipo en Bermejo/

the team in Bermejo

* Según / According to:
I Ruzz-Carranza er al.

'Luz-Carranza er al. 1996

'F Fores and McDiarmid 1989
' Ron and Pramuk 1999 
Birds observed at three sites in the Serranias Cofán, Sucumbios province, Ecuador, 24 July-16 August 2001. Principal ornithologist: Thomas S. Schulenberg, with observations by Debra K. Moskovits, Randy Borman, and others; also included are species observed at Bermejo by Douglas F. Stotz in November 1998 (species

A $\Sigma S I B I R D S$

recorded only during the November visit are indicated with an asterisk).

\begin{tabular}{|c|c|c|c|}
\hline \multirow[b]{2}{*}{ Especie/Species } & \multirow[b]{2}{*}{ Nombre común/Common name } & \multicolumn{2}{|c|}{ Bermejo } \\
\hline & & $\begin{array}{l}\text { Abundancia relativa/ } \\
\text { Relative abundance }\end{array}$ & $\begin{array}{l}\text { Rango altitudinal/ } \\
\text { Elevational range (m) }\end{array}$ \\
\hline \multicolumn{4}{|l|}{ Tinamidae $(6)$} \\
\hline 001. Tinamus major & Great Tinamou/Perdiz Grande & $x$ & - \\
\hline 002. Tinamus guttatus* & White-throated Tinamou/Perdiz de Garganta Blanca & $x$ & - \\
\hline 003. Tinamus osgoodi & Black Tinamou/Perdiz Negra & - & - \\
\hline 004. Tinamus tao* & Gray Tinamou/Perdiz Azulada & $x$ & - \\
\hline 005. Crypturellus cinereus & Cinereous Tinamou/Perdiz Cinérea & $\mathrm{FC}$ & 450 \\
\hline 006. Crypturellus soui & Little Tinamou/Perdiz Chica & - & - \\
\hline 007. tinamou (unidentified species) & tinamou (species)/perdiz (especie) & $x$ & 1900 \\
\hline \multicolumn{4}{|l|}{ Ardeidae (1) } \\
\hline 008. Tigrisoma sp. & tiger-heron (species)/garza-tigre (especie) & - & - \\
\hline \multicolumn{4}{|l|}{ Cathartidae (2) } \\
\hline 009. Cathartes aura* & Turkey Vulture/Gallinazo de Cabeza Roja & $x$ & - \\
\hline $\begin{array}{l}\text { 010. Cathartes melambrotus } \\
\text { Cabeza Amarilla Mayor }\end{array}$ & Greater Yellow-headed Vulture/Gallinazo de & $\mathrm{U}$ & 450 \\
\hline \multicolumn{4}{|l|}{ Accipitridae (12) } \\
\hline 011. Elanoides forficatus & Swallow-tailed Kite/Gavilán Tijereta & $\mathrm{FC}$ & $450-1200$ \\
\hline 012. Harpagus bidentatus & Double-toothed Kite/Gavilán Bidentado & $x$ & $450-850$ \\
\hline 013. Ictinia plumbea & Plumbeous Kite/Gavilán Plomizo & $\mathrm{FC}$ & $450-1200$ \\
\hline 014. Leucopternis albicollis* & White Hawk/Gavilán Blanco & $x$ & 900 \\
\hline 015. Leucopternis melanops & Black-faced Hawk/Gavilán de Cara Negra & $x$ & 1200 \\
\hline 016. Leucopternis princeps & Barred Hawk/Gavilán Príncipe & $x$ & 1900 \\
\hline 017. Buteogallus urubitinga & Great Black Hawk/Gavilán Negro & - & - \\
\hline 018. Harpyhaliaetus solitarius & Solitary Eagle/Aguila Solitaria & $x$ & 1200 \\
\hline 019. Buteo magnirostris & Roadside Hawk/Aguilucho de Caminos & $\mathrm{FC}$ & $450-750$ \\
\hline 020. Spizaetus ornatus & Ornate Hawk-Eagle/Aguila de Penacho & $x$ & 450 \\
\hline 021. Spizaetus tyrannus & Black Hawk-Eagle/Aguila Negra & $x$ & $900+$ \\
\hline 022. Oroaetus isidori & Black-and-chestnut Eagle/Aguila Negra y Castaña & $x$ & 2100 \\
\hline \multicolumn{4}{|l|}{ Falconidae (6) } \\
\hline 023. Ibycter americanus & Red-throated Caracara/Caracara de Vientre Blanco & $\mathrm{FC}$ & $<900$ \\
\hline 024. Daptrius ater & Black Caracara/Caracara Negro & - & - \\
\hline 025. Micrastur gilvicollis & Lined Forest-Falcon/Halcón de Monte Listado & $x$ & 1200 \\
\hline 026. Micrastur mirandollei & $\begin{array}{l}\text { Slaty-backed Forest-Falcon/ } \\
\text { Halcón de Monte de Dorso Gris }\end{array}$ & $x$ & 450 \\
\hline 027. Micrastur ruficollis & Barred Forest-Falcon/Halcón de Monte Rayado & - & - \\
\hline 028. Falco deiroleucus* & Orange-breasted Falcon/Halcón de Pecho Anaranjado & $x$ & 450 \\
\hline \multicolumn{4}{|l|}{ Cracidae (6) } \\
\hline 029. Ortalis guttata & Speckled Chachalaca/Chachalaca Jaspeada & $x$ & 450-ca.1000 \\
\hline
\end{tabular}

Abundancia Relativa/Relative Abundance

$\mathrm{FC}=$ Bastante común (registrada diariamente en su hábitat apropiado)/Fairly common (recorded daily in suitable habitat)

$\mathrm{U}=$ Poco común (presente pero no registrada diariamente en su hábitat apropriado)/Uncommon (present, but not recorded daily, even in suitable habitat)

$\mathrm{R}=$ Raro/Rare

$X=$ Presente pero con datos insuficientes para estimar abundancia/Present, but with insufficient data to assess relative abundance

\section{Rango Altitudinal/Elevational Range}

Los datos presentados aquí sólo indican las elevaciones a las cuales cada especie fue observada durante el inventario rápido y no representan la distribución altitudinal de las especies a través de la región./The elevational ranges presented in this table refer only to the altitudes at which each species was observed during the rapid biological inventory, and are not meant to describe the complete elevational distribution of each species in the region. 
A PENDICE/APPENDIX 3 Aves/Birds
Especies de aves registradas en tres sitios de las Serranías Cofán, Provincia de Sucumbios, Ecuador, del 24 de julio al 16 de agosto 2001. Omitólogo principal: Thomas S. Schulenberg. Observaciones adicionales de Debra K. Moskovits, Randy Borman y otros. También se incluyen especies observadas por Douglas F. Stotz durante una visita a Bermejo en noviembre del 1998. Las especies que solamente fueron observadas en la visita de Stotz están marcadas con un asterisco.

\section{Shishicho}

\begin{tabular}{ll}
\hline Abundancia relativa/ & Rango altitudinal/ \\
Relative abundance & Elevational range $(\mathrm{m})$
\end{tabular}

\section{Ccuccono \& Sinangoe}

\begin{tabular}{ll}
\hline Abundancia relativa/ & Rango altitudinal/ \\
Relative abundance & Elevational range $(\mathrm{m})$
\end{tabular}

Hábitats/ Habitats

\begin{tabular}{|c|c|c|c|c|c|}
\hline 001. & - & - & $\mathrm{FC}$ & 600 & Fhl \\
\hline 002. & - & - & - & - & - \\
\hline 003. & $\mathrm{FC}$ & $1000-1350$ & - & - & Fhi \\
\hline 004. & - & - & - & - & - \\
\hline 005. & - & - & $\mathrm{FC}$ & 600 & $\mathrm{Fh}$ \\
\hline 006. & - & - & $x$ & 1000 & Fht \\
\hline 007. & - & - & - & - & $\mathrm{Fm}$ \\
\hline 008. & - & - & $x$ & 900 & $\mathrm{Rm}$ \\
\hline 009. & - & - & $x$ & 900 & 0 \\
\hline 010. & - & - & - & - & 0 \\
\hline
\end{tabular}

\begin{tabular}{|c|c|c|c|c|c|}
\hline 011. & $\mathrm{R}$ & 1000 & $x$ & 1400 & 0 (Fhl, Fhu) \\
\hline 012. & - & - & - & - & Fhl \\
\hline 013. & - & - & $x$ & 900 & 0 (Fhl, Fhu) \\
\hline 014. & - & - & - & - & - \\
\hline 015. & - & - & - & - & Fhu \\
\hline 016. & - & - & - & - & Fhu \\
\hline 017. & - & - & $x$ & 900 & Frp \\
\hline 018. & - & - & - & - & $\mathrm{O}$ (Fhu) \\
\hline 019. & - & - & - & - & $\mathrm{Fe}$ \\
\hline 020. & - & - & - & - & Fhl \\
\hline 021. & - & - & - & - & Fhu \\
\hline 022. & - & - & - & - & $0(\mathrm{Fm})$ \\
\hline 023. & - & - & $\mathrm{U}$ & 600 & Fhl \\
\hline 024. & - & - & $\mathrm{U}$ & $900-1100$ & Frp \\
\hline 025. & - & - & - & - & Fhu \\
\hline 026. & - & - & - & - & Fhl \\
\hline 027. & $\mathrm{FC}$ & 1000 & $\mathrm{U}$ & 1000 & Fhu \\
\hline 028. & - & - & - & - & Fhl \\
\hline 029. & - & - & - & - & $\mathrm{Fe}$ \\
\hline
\end{tabular}

Hábitats/Habitats

$\mathrm{Fe}=$ Bordes del bosque (incluye vegetación secundaria y regeneración en áreas de derrumbe)/Forest edges (includes early regenerating habitats, such as on landslides)

$\mathrm{Fhl}=$ Bosque de laderas bajas/Lower hill forest

Fhu = Bosque de laderas altas/Upper hill forest

$\mathrm{Fm}=$ Bosque nuboso/Mountain forest or cloud forest

Frp = Bosque ripario/Riparian forest

Fsm = Bosques al márgen de las quebradas $/$ Forest stream margins
Fhl

Fhu, Fm

Fhl

Fhu

$\mathrm{Fm}$

$\mathrm{Rm}$ 

\begin{tabular}{ll}
\hline \multicolumn{3}{c}{ Bermejo } \\
\hline $\begin{array}{l}\text { Abundancia relatival } \\
\text { Relative abundance altitudinall }\end{array}$ \\
\hline
\end{tabular}

Especie/Species

Nombre común/Common name

\section{Tinamidae (6)}

001. Tinamus major

002. Tinamus guttatus"

003. Tnamus osgood

004. Tinamus tao*
005. Crypturellus ciner

006 . Cypturellus soui

Great Tinamou/Perdiz Grande $\begin{array}{lll}\text { Great Tinamou/Perdiz Grande } & x & - \\ \text { White-throated Tinamou/Perdiz de Garganta Blanca } & x & -\end{array}$ Black Tinamou/Perdiz Negra Gray Tinamou/Perdiz Azulada Ardeidae (1)

008 . Tigrisoma

Cathartidae (2)

009. Cathartes aura*

10. Cathartes mehmbrotus

ccipitridae (12)

011. Elanoides forficatus

012. Harpagus bidentatus

013. Ictinia plumbea

014. Leucopternis albicollis*

015. Leucopternis meannops

016. Leucopternis princeps

017. Buteogal/us urubitinga

018. Harpyhaliaetus solitarius

019. Buteo magnirostris

020. Spizaetus ornatus

021. Spizaetus tyrannus

022. Oroaetus

023. Ibycter americanus

024. Daptrius ater

025. Micrastur givicollis

026. Micrastur mirandollei

027. Micrastur nuficollis

028. Falco deiroleucus"

Cracidae (6)

29. Ortalis guttata

tinamou (species)/perdiz (especie)

1900

tiger-heron (species)/garza-tigre (especie)

Turkey Vulture/Gallinazo de Cabeza Roja

Greater Yellow-headed Vulture/Gallinazo de

$\mathrm{x}$

$x$

450

Swallow-tailed Kite/Gavilán Tijereta

Double-toothed Kite/Gavilán Bidentado

Plumbeous Kite/Gavilán Plomizo

White Hawk/Gavilán Blanco

$\begin{array}{rr}F C & 450-1200 \\ x & -900-1200\end{array}$

$\begin{array}{lll} & X & \\ & X & 1200\end{array}$

Bared HawkGavilán Principe

Great Black Hawk/Gavilán Negro

Solitary Eagle/Aguila Solitaria $\quad X \quad 1200$

Roadside Hawk/Aguilucho de Caminos $\quad$ FC $\quad 450-750$

Ornate Hawk-Eagle/Aguila de Penacho $\quad x \quad 450$

Black Hawk-Eagle/Aguila Negra $\quad x \quad x \quad .900+$

Black-and-chestnut Eagle/Aguila Negra y Castaña

$x \quad 2100$

Red-throated Caracara/Caracara de Vientre Blanco __ FC $\quad<900$

Black Caracara/Caracara Negro

Lined Forest-Falcon/Halcón de Monte Listado $\quad$ X 120

Slaty-backed Forest-Falcont

Barred Forest-Falcon/Halcón de Monte Rayado -

Orange-breasted Falcon/Halcón de Pecho Anaranjado $\quad X \quad 450$

Abundancia Relativa/Relative Abundance
$\mathrm{FC}=$ Bastante comun (registrada diariam

$\mathrm{C}=$ Bastante comùn (registrada diariamente en su hábitat

= Poco común (presente pero no registrada diariamente

en su hábitat apropriado)/Uncommon (present, but

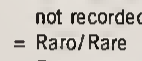

= Presente pero con datos insuficientes para estimar abundancia/Present, but with insufficient data to assess ve abundanc

\section{Rango Altitudinal/Elevational Range}

Los datos presentados aqul sólo indican las elevaciones a rápido y no representan la distribución altitudinal de las especies a través de la región.The elevational ranges presented in this table refer only to the altitudes at whic each species was observed during the rapid biological elevational distribution of each species in the region.

40

$0-1200$

00

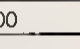

750

450

a

INFORMEIRE PORT NO. 3

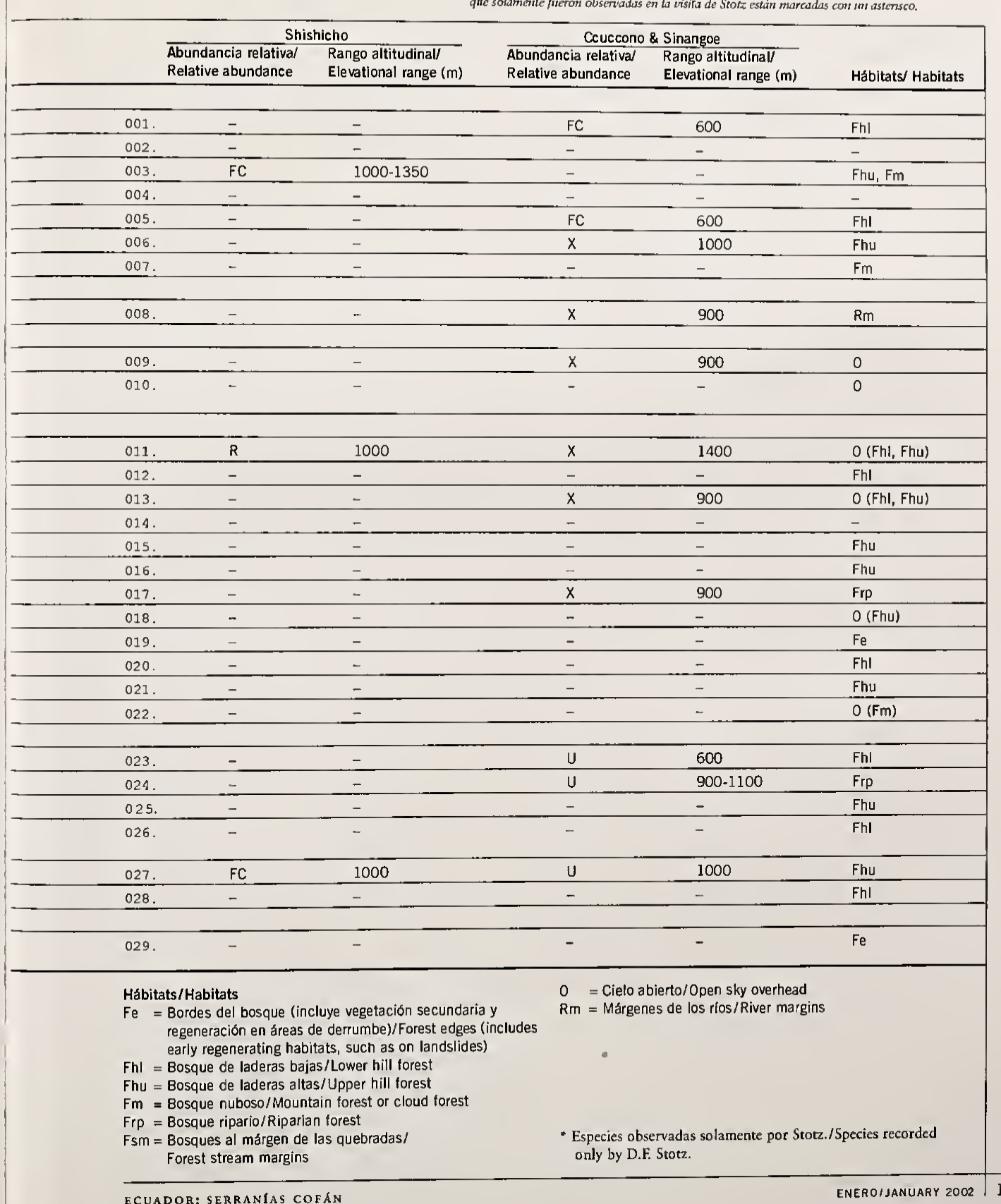

ECUADOR: SERRANIAS COFAN 
Birds observed at three sites in the Serranias Cofán, Sucumbios province, Ecuador, 24 July-16 August 2001. Principal ornithologist: Thomas S. Schulenberg, with observations by Debra K. Moskovits, Randy Borman, and others; also included are species observed at Bermejo by Douglas F. Stotz in November 1998 (species AVESIBIR D recorded only during the November visit are indicated with an asterisk).

\begin{tabular}{|c|c|c|c|}
\hline \multirow[b]{2}{*}{ Especie/Species } & \multirow[b]{2}{*}{ Nombre común/Common name } & \multicolumn{2}{|c|}{ Bermejo } \\
\hline & & $\begin{array}{l}\text { Abundancia relativa/ } \\
\text { Relative abundance }\end{array}$ & $\begin{array}{l}\text { Rango altitudinal/ } \\
\text { Elevational range (m) }\end{array}$ \\
\hline 030. Penelope jacquacu* & Spix's Guan/Pava de Spix & $x$ & 450 \\
\hline 031. Pipile cumanensis & Blue-throated Piping-Guan/Pava de Garganta Azul & - & - \\
\hline 032. Aburria aburri & Wattled Guan/Pava Carunculada & $\mathrm{FC}$ & 1200 \\
\hline 033. Nothocrax urumutum* & Nocturnal Curassow/Paujil Nocturno & $x$ & 450 \\
\hline 034. Crax salvini & Salvin's Curassow/Paujil de Salvin & $\mathrm{U}$ & 900 \\
\hline \multicolumn{4}{|l|}{ Psophiidae (1) } \\
\hline 035. Psophia crepitans & Gray-winged Trumpeter/Trompetero de Ala Gris & $x$ & 900 \\
\hline \multicolumn{4}{|l|}{ Rallidae (4) } \\
\hline 036. Aramides cajanea & $\begin{array}{l}\text { Gray-necked Wood-Rail/ } \\
\text { Rascón de Monte de Cuello Gris }\end{array}$ & $U$ & 450 \\
\hline 037. Aramides calopterus & $\begin{array}{l}\text { Red-winged Wood-Rail/ } \\
\text { Rascón de Monte de Alas Rojas }\end{array}$ & $x$ & 1200 \\
\hline 038. Anurolimnas castaneiceps & Chestnut-headed Crake/Gallineta de Cabeza Castaña & $\mathrm{U}$ & 450 \\
\hline 039. Laterallus melanophaius* & Rufous-sided Crake/Gallineta de Flancos Rufos & $\mathrm{x}$ & - \\
\hline \multicolumn{4}{|l|}{ Eurypygidae (1) } \\
\hline 040. Eurypyga helias & Sunbittern/Tigana & - & - \\
\hline \multicolumn{4}{|l|}{ Scolopacidae (1) } \\
\hline 041. Actitis macularia & Spotted Sandpiper/Playero Coleador & - & - \\
\hline \multicolumn{4}{|l|}{ Columbidae (5) } \\
\hline 042. Columba cayennensis* & Pale-vented Pigeon/Paloma Colorada & $x$ & - \\
\hline 043. Columba plumbea & Plumbeous Pigeon/Paloma Plomiza & $U$ & $900-1200$ \\
\hline 044. Columba subvinacea & Ruddy Pigeon/Paloma Morada & $\mathrm{U}$ & 1900 \\
\hline 045. Leptoptila rufaxilla & Gray-fronted Dove/Paloma de Frente Gris & $x$ & 450 \\
\hline 046. Geotrygon frenata & $\begin{array}{l}\text { White-throated Quail-Dove/Paloma-Perdiz de } \\
\text { Garganta Blanca }\end{array}$ & $\mathrm{x}$ & 1100 \\
\hline \multicolumn{4}{|l|}{ Psittacidae (14) } \\
\hline 047. Ara ararauna* & Blue-and-yellow Macaw/Guacamayo Azul y Amarillo & $x$ & 450 \\
\hline 048. Ara militaris & Military Macaw/Guacamayo Militar & $\mathrm{U}$ & 1200 \\
\hline 049. Aratinga leucophthalmus & White-eyed Parakeet/Cotorra de Ojo Blanco & - & - \\
\hline 050. Pyrrhura melanura & Maroon-tailed Parakeet/Perico de Cola Marrón & $\mathrm{FC}$ & $450-1200$ \\
\hline 051. Forpus sclateri & Dusky-billed Parrotlet/Periquito de Pico Oscuro & - & - \\
\hline 052. Brotogeris cyanoptera & Cobalt-winged Parakeet/Periquito de Ala Cobalto & $\mathrm{U}$ & $450-750$ \\
\hline 053. Touit purpurata* & $\begin{array}{l}\text { Sapphire-rumped Parrotlet/ } \\
\text { Lorito de Rabadilla Púrpura }\end{array}$ & $x$ & 750 \\
\hline 054. Touit stictoptera & Spot-winged Parrotlet/Lorito de Ala Moteada & $\mathrm{U}$ & 1200 \\
\hline 055. Pionites melanocephala & Black-headed Parrot/Lorito de Cabeza Negra & $\mathrm{U}$ & 450 \\
\hline 056. Pionopsitta barrabandi & Orange-cheeked Parrot/Lorito de Mejillas Amarillas & - & - \\
\hline 057. Pionus menstruus & Blue-headed Parrot/Loro de Cabeza Azúl & $\mathrm{U}$ & 450 \\
\hline
\end{tabular}

Abundancia Relativa/Relative Abundance

$\mathrm{FC}=$ Bastante común (registrada diariamente en su hábitat apropiado)/Fairly common (recorded daily in suitable habitat)

$\mathrm{U}=$ Poco común (presente pero no registrada diariamente en su hábitat apropriado)/Uncommon (present, but not recorded daily, even in suitable habitat)

$\mathrm{R}=$ Raro/Rare

$X=$ Presente pero con datos insuficientes para estimar abundancia/Present, but with insufficient data to assess relative abundance

\section{Rango Altitudinal/Elevational Range}

Los datos presentados aquí sólo indican las elevaciones a las cuales cada especie fue observada durante el inventario rápido y no representan la distribución altitudinal de las especies a través de la región./The elevational ranges presented in this table refer only to the altitudes at which each species was observed during the rapid biological inventory, and are not meant to describe the complete elevational distribution of each species in the region. 
APENDICE/APPENDIX 3

Aves/Birds
Especies de aves registradas en tres sitios de las Serranias Cofán, Provincia de Sucumbios, Ecuador, del 24 de julio al 16 de agosto 2001. Onitólogo principal: Thomas S. Schulenberg. Observaciones adicionales de Debra K. Moskovits, Randy Borman y otros. Tanibién se incluyen especies observadas por Douglas F. Stotz durante una visita a Bermejo en noviembre del 1998. Las especies que solamente fueron observadas en la visita de Stotz están marcadas con un asterisco.

\section{Shishicho}

Abundancia relativa/
Relative abundance

Rango altitudinal/

Relative abundance

Elevational range $(\mathrm{m})$

\section{Ccuccono \& Sinangoe}

\begin{tabular}{ll}
\hline Abundancia relativa/ & Rango altitudinal/ \\
Relative abundance & Elevational range $(\mathrm{m})$
\end{tabular}

Hábitats/Habitats

Fhl

Fhu

$<1000$

1000

$-$

$600-1000$

$\begin{array}{lll}- & - & F h \\ X & 900-1000 & F h\end{array}$

Fhu, Fm

Fhl

U $900 \quad$ Fhl

U

900-1100

Fhl, Fhu

035.

U

036.

$-$

$-$

Fhl

037.

$-$

$-$

$-$

Fhu

038.

039.

-

040.

$-$

$-$

X

900

$\mathrm{Rm}$

041.

$-$

$-\quad-\quad x$

X

900

$\mathrm{Rm}$

\begin{tabular}{lll}
042. & - & - \\
043. & - & - \\
044. & - & - \\
045. & - & - \\
\hline 046. & - & -
\end{tabular}

-
-
-
-

\begin{tabular}{l}
- \\
- \\
FC \\
\hline $\mathrm{U}$ \\
$\mathrm{X}$
\end{tabular}

$\begin{array}{ll}- & \text { Fe } \\ - & \text { Fhu } \\ 9000-1100 & \text { Fhu } \\ 900-1000 & \text { Fhu (cerca de/near Fe) } \\ 1100 & \text { Fhu }\end{array}$

047.

048 .

049 .

050 .

051.

052.

053.

$\begin{array}{ll}- & - \\ U & 1000\end{array}$

U

$-$

FC $\quad 900-1000$

U

$\mathrm{U}$

1000

$\mathrm{X}$

FC

$-\quad \mathrm{Fhl}$

X

$-$

600

O (Fhu)

600

$\mathrm{O}$ (Fhl)

$600-1100$

Fhl, Fhu

900

Fhu, Frp

600

Fhl

Fhl

$\begin{array}{lll}054 . & - & \\ 055 . & - & - \\ 056 . & - & - \\ 057 . & - & -\end{array}$

\section{Hábitats/Habitats}

$\mathrm{Fe}=$ Bordes del bosque (incluye vegetación secundaria y regeneración en áreas de derrumbe)/Forest edges (includes early regenerating habitats, such as on landslides)

$\mathrm{Fhl}=$ Bosque de laderas bajas $/$ Lower hill forest

Fhu = Bosque de laderas altas/Upper hill forest

$\mathrm{Fm}=$ Bosque nuboso/Mountain forest or cloud forest

Frp = Bosque ripario/Riparian forest

Fsm = Bosques al márgen de las quebradas / Forest stream margins

\footnotetext{
* Especies observadas solamente por Stotz./Species recorded only by D.F. Stotz.
}

0 = Cielo abierto/Open sky overhead

$\mathrm{Rm}=$ Márgenes de los ríos/River margins

O (Fhu)

$-$

\begin{tabular}{ll}
- & O (Fhu) \\
- & Fhl \\
\hline 600 & Fhl \\
\hline 600 & Fhl
\end{tabular}



Especie/Species Nombre común/Common name

$\begin{array}{ll}\text { Abundancia relativa/ } & \text { Rermejo } \\ \text { Relative abundance } & \text { El }\end{array}$

030. Penelope jacquacu*

031. Pipile cumanen

032. Aburria aburri

Spix's Guan/Pava de Spix

Relative abundance Rango altitudinal/

Wattled Guan/Pava Carunculada $\quad$ FC 1200

034. Cocturnal Curassow/Paujil Nocturno

Salvin's Curassow/Paujil de Salvin $\quad$ U

Psophiidae (1)

035. Psophia crepitan

Gray-winged Trumpeter/Trompetero de Ala Gris

036. Aramides cajanea

037. Aramides calopterus

Gray-necked Wood-Rail/

Rascón de Monte de Cuello Gris

Red-winged Wood-Rail/
Rascón de Monte de Alas Rojas

39. Laterallus me brophaius* Rufous-sided Crake/Gallineta de Flancos Rufos

Eurypygidae (1)

040. Eurypyg.

Scolopacidae (1)

041. Actitis

Columbidae (5)

042 Columba cayennensis"

043. Columba plumbea $\quad$ Plumbeous Pigeon/Paloma Plomiza

044. Columba subvinacea R__Ruddy Pigeon/Patoma Morada

045. Leptoptila rufaxilla Gray-fronted Oove/Paloma de Frente Gris

046. Geotygon frenata

White-throated Quail-Oove/Paloma-Perdiz Garganta Blanca

\section{Psittacidae (14)}

\begin{tabular}{|c|c|c|c|}
\hline 042. Columba cayennensis* & Pale-vented Pigeon/Paloma Colorada & $x$ & \\
\hline 043. Columba plumbea & Plumbeous Pigeon/Paloma Plomiza & $u$ & $900 \cdot 1200$ \\
\hline 044. Columba subvinacea & Ruddy Pigeon/Paloma Morada & $\underline{U}$ & 1900 \\
\hline 045. Leptoptila rufaxilla & Gray-fronted Oove/Paloma de Frente Gris & $x$ & 450 \\
\hline 046. Geotrygon frenata & $\begin{array}{l}\text { White-throated Quail-Oove/Paloma.Perdiz de } \\
\text { Garganta Blanca }\end{array}$ & $\bar{x}$ & 1100 \\
\hline \multicolumn{4}{|l|}{ Psittacidae (14) } \\
\hline 047. Arra ararauna* & Blue-and-yellow Macaw/Guacamayo Azul y Amarillo & $x$ & 450 \\
\hline 048. Ara militaris & Military Macaw/Guacamayo Militar & $u$ & 1200 \\
\hline 049. Aratinga leucophthalmus & White-eyed Parakeet/Cotorra de 0jo Blanco & - & - \\
\hline 050. Pyrrhura melanura & Maroon-tailed Parakeet/Perico de Cola Marrón & $\mathrm{FC}$ & $450 \cdot 1200$ \\
\hline 051. Forpus sclateri & Ousky-billed Parrotlet/Periquito de Pico Oscuro & $=$ & - \\
\hline 052. Brotogeris cyanoptera & Cobalt-winged ParakeetPeriquito de Ala Cobalto & $u$ & $450-750$ \\
\hline 053. Touit purpurata* & $\begin{array}{l}\text { Sapphire-rumped Parrotlet/ } \\
\text { Lorito de Rabadilla Púrpura }\end{array}$ & $x$ & 750 \\
\hline 054. Touit stictoptera & Spot-winged ParrotletLorito de Ala Moteada & $u$ & 1200 \\
\hline 055. Pionites melanocephala & Black-headed Parrot/Lorito de Cabeza Negra & $u$ & 450 \\
\hline 056. Pionopsitta barrabandi & Orange-cheeked ParrotLorito de Mejillas Amarillas & - & - \\
\hline 057. Pionus menstruus & Blue-headed ParrotLoro de Cabeza Azül & $u$ & 450 \\
\hline
\end{tabular}

057. Pions ma barrab Blue-headed ParrotLoro de Cabeza Azül

\section{Abundancia Relativa/Relative Abundance}

Rango Altitudina/Elestonl Rante

$=$ Bastante común (registrada diariamente en su hóbitat

$=$ Poco común (presente pero no registrada diariamente en su hábitat apropriado)/Uncommon (present, but

$\begin{aligned} & \text { not recorded daily, even in surtable habitat) } \\ = & \text { Raro/Rare } \\ = & \text { Presente pero con datos insuficientes para estimar }\end{aligned}$

Los datos presentados aquí sollo indican las elevaciones a to especies a través de la región. The elevational ranges presented in this table refer only to the altitudes at which

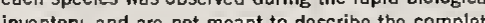
elevational distribution of each species in the region.

\begin{tabular}{|c|c|c|c|c|c|}
\hline & \multicolumn{2}{|c|}{ Shishicho } & \multicolumn{2}{|c|}{ Ccuccono \& Sinangoe } & \multirow[b]{2}{*}{ Hobbitats/Habitats } \\
\hline & $\begin{array}{l}\text { Abundancia relativa/ } \\
\text { Relative abundance }\end{array}$ & $\begin{array}{l}\text { Rango altitudinal/ } \\
\text { Elevational range (m) }\end{array}$ & $\begin{array}{l}\text { Abundancia relativa/ } \\
\text { Relative abundance } \\
\end{array}$ & $\begin{array}{l}\text { Ranno altitudinal/ } \\
\text { Elevational range }(\mathrm{m})\end{array}$ & \\
\hline 030. & - & - & - & - & $\mathrm{Fhl}$ \\
\hline 031. & $x$ & $<1000$ & $x$ & $900-1000$ & Fhu \\
\hline 032. & $x$ & 1000 & - & $=$ & $\mathrm{Fhu}, \mathrm{Fm}$ \\
\hline 033. & - & - & - & - & Fhl \\
\hline 034. & $x$ & 1000 & $u$ & 900 & $\mathrm{Fhl}$ \\
\hline 035. & $u$ & $600-1000$ & $u$ & $900-1100$ & Fhl, Fhu \\
\hline 036. & - & - & - & - & Fhl \\
\hline 037. & - & - & - & - & Fhu \\
\hline 038. & - & - & - & - & $\mathrm{Fe}$ \\
\hline 039. & - & - & - & - & - \\
\hline 040. & - & - & $x$ & 900 & $\mathrm{Rm}$ \\
\hline 041. & - & - & $x$ & 900 & $\mathrm{Rm}$ \\
\hline 042. & - & - & - & - & $\mathrm{Fe}$ \\
\hline 043. & $=$ & - & - & - & Fhu \\
\hline 044. & $=$ & $=$ & $\mathrm{FC}$ & $900-1100$ & Fhu \\
\hline 045. & - & - & $u$ & $900 \cdot 1000$ & Fhu (cerca de/near $\mathrm{Fe}$ ) \\
\hline 046. & - & - & $x$ & 1100 & Fhu \\
\hline 047. & - & - & - & - & FhI \\
\hline 048. & $u$ & 1000 & $u$ & 600 & $O$ (Fhu) \\
\hline 049. & - & $=$ & $u$ & 600 & $O\left(F h_{1}\right)$ \\
\hline 050. & FC & $900-1000$ & $u$ & $600-1100$ & Fhl, Fhu \\
\hline 051. & $x$ & 1000 & $x$ & 900 & Fhu, Frp \\
\hline 052. & - & - & $\mathrm{FC}$ & 600 & $\mathrm{Fhl}$ \\
\hline 053. & - & - & - & - & Fhl \\
\hline 054. & - & - & - & - & $O$ (Fhu) \\
\hline 055. & - & - & - & - & Fhl \\
\hline 056. & - & - & $x$ & 600 & Fhl \\
\hline 057. & - & - & $\mathrm{FC}$ & 600 & Fhl \\
\hline
\end{tabular}

Hábitats/Habitats

= Bordes del bosque (incluye vegetación secundaria y regeneración en áreas de derrumbe)//Forest edges (inc

$\mathrm{Fhl}=$ Bosque de laderas bajas /Lower hill forest

Fhu $=$ Bosque de laderas altas/Upper hill forest

$\mathrm{Fm}=$ Bosque nuboso/Mountain forest or cloud
$\mathrm{Frp}=$ Bosque ripario/Riparian forest

$\mathrm{Fsm}=$ Bosques al márgen de las quebradas/ Forest stream margins

ECUADOR: SERrantas COFAN

\section{$0=$ Cielo abierto/Open sky overhead} abundancia/Present
relative abundance

- Especies observadas solamente por Stotz./Species recorded Especies observadaa
only by D.F. Stotz. 
Birds observed at three sites in the Serranias Cofän, Sucumbios province, Ecuador, 24 July-16 August 2001. Principal ornithologist: Thomas S. Schulenberg, with observations by Debra K. Moskovits, Randy Borman, and others; also included are species observed at Bermejo by Douglas F. Stotz in November 1998 (species AVESIBIRDS recorded only during the November visit are indicated with an asterisk).

\begin{tabular}{|c|c|c|c|}
\hline \multirow[b]{2}{*}{ Especie/Species } & \multirow[b]{2}{*}{ Nombre común/Common name } & \multicolumn{2}{|c|}{ Bermejo } \\
\hline & & $\begin{array}{l}\text { Abundancia relativa/ } \\
\text { Relative abundance }\end{array}$ & $\begin{array}{l}\text { Rango altitudinal/ } \\
\text { Elevational range }(\mathrm{m})\end{array}$ \\
\hline 058. Amazona amazonica* & Orange-winged Parrot/Loro de Ala Naranja & $x$ & 450 \\
\hline 059. Amazona farinosa & Mealy Parrot/Loro Harinoso & $x$ & 450 \\
\hline 060. Amazona mercenaria & Scaly-headed Parrot/Loro Verde & - & - \\
\hline \multicolumn{4}{|l|}{ Cuculidae (3) } \\
\hline 061. Piaya cayana & Squirrel Cuckoo/Cucu Ardilla & FC & $450-1200$ \\
\hline 062. Crotophaga ani & Smooth-billed Ani/Garrapatero de Pico Liso & $\mathrm{FC}$ & 450 \\
\hline 063. Neomorphus geoffroyi & $\begin{array}{l}\text { Rufous-vented Ground-Cuckoo/Cuco- } \\
\text { Terrestre de Vientre Rufo }\end{array}$ & $x$ & 1200 \\
\hline \multicolumn{4}{|l|}{ Strigidae (8) } \\
\hline 064. Otus choliba* & Tropical Screech-Owl/Lechuza Común & $\mathrm{x}$ & 450 \\
\hline 065. Otus guatemalae & Vermiculated Screech-Owl/Lechuza Vermiculada & $\mathrm{U}$ & 1200 \\
\hline 066. Otus watsonii & Tawny-bellied Screech-Owl/Lechuza Orejuda & FC & 450 \\
\hline 067. Lophostrix cristata & Crested Owl/Búho Penachudo & $\mathrm{U}$ & 450 \\
\hline 068. Pulsatrix melanota & Band-bellied Owl/Búho de Vientre Listado & - & - \\
\hline 069. Pulsatrix perspicillata & Spectacled Owl/Búho de Anteojos & $\mathrm{U}$ & 450 \\
\hline 070. Glaucidium brasilianum & Ferruginous Pygmy-Owl/Lechucita Ferruginosa & $\mathrm{FC}$ & 450 \\
\hline 071. Aegolius harrisii & Buff-fronted Owl/Lechuza Acanelada & $\mathrm{U}$ & 1900 \\
\hline \multicolumn{4}{|l|}{ Nyctibiidae (2) } \\
\hline 072. Nyctibius grandis & Great Potoo/Nictibio Grande & - & - \\
\hline 073. Nyctibius griseus & Common Potoo/Nictibio Común & $x$ & 450-ca. 1000 \\
\hline \multicolumn{4}{|l|}{ Apodidae (6) } \\
\hline 074. Streptoprocne zonaris & White-collared SwiftNencejo de Collar Blanco & $\mathrm{FC}$ & 450 \\
\hline 075. Cypseloides lemosi & White-chested Swift/Vencejo Pechiblanco & $?$ & 450 \\
\hline 076. Cypseloides rutilus & Chestnut-collared Swift/Vencejo de Cuello Castaño & U & $450-1200$ \\
\hline 077. Chaetura brachyura & Short-tailed SwiftNencejo de Cola Corta & FC & 450 \\
\hline 078. Chaetura cinereiventris & Gray-rumped SwiftNencejo de Dorso Gris & $\mathrm{U}$ & 450 \\
\hline 079. Tachornis squamata* & Fork-tailed Palm-Swift/Nencejo Tijereta de Palmeras & $x$ & - \\
\hline \multicolumn{4}{|l|}{ Trochilidae (29) } \\
\hline 080. Doryfera ludoviciae & Green-fronted Lancebill/Pico-Lanza de Frente Verde & $\mathrm{U}$ & 1200 \\
\hline 081. Threnetes leucurus & Pale-tailed Barbthroat/Ermitaño de Cola Blanca & - & - \\
\hline 082. Phaethornis bourcieri* & Straight-billed Hermit/Ermitaño de Pico Recto & $x$ & 450 \\
\hline 083. Phaothornis griseogularis & Gray-chinned Hermit/Ermitaño de Barbilla Gris & FC & 1200 \\
\hline 084. Phaethornis guy & Green Hermit/Ermitaño Verde & FC & $900-1200$ \\
\hline 085. Phaethornis longuemareus & Little Hermit/Ermitaño Pequeño & - & - \\
\hline 086. Phaethornis ruber & Reddish Hermit/Ermitaño Rufo & FC & 450 \\
\hline 087. Phaethornis superciliosus & Long-tailed Hermit/Ermitaño de Cola Larga & $x$ & $450-900$ \\
\hline 088. Eutoxeres condamini & Buff-tailed Sicklebill/Pico-de-Hoz de Cola Canela & - & - \\
\hline
\end{tabular}

\section{Abundancia Relativa/Relative Abundance}

$\mathrm{FC}=$ Bastante común (registrada diariamente en su hábitat apropiado)/Fairly common (recorded daily in suitable habitat)

$\mathrm{U}=$ Poco común (presente pero no registrada diariamente en su hábitat apropriado)/Uncommon (present, but not recorded daily, even in suitable habitat)

$\mathrm{R}=$ Raro/Rare

$X=$ Presente pero con datos insuficientes para estimar abundancia/Present, but with insufficient data to assess relative abundance
Rango Altitudinal/Elevational Range

Los datos presentados aquí sólo indican las elevaciones a las cuales cada especie fue observada durante el inventario rápido y no representan la distribución altitudinal de las especies a través de la región./The elevational ranges presented in this table refer only to the altitudes at which each species was observed during the rapid biological inventory, and are not meant to describe the complete elevational distribution of each species in the region. 
APENDICE/APPENDIX 3

Aves/Birds
Especies de aves registradas en tres sitios de las Serranias Cofán, Provincia de Sucumbios, Ecuador, del 24 de julio al 16 de agosto 2001. Omitólogo principal: Thomas S. Schulenberg. Observaciones adicionales de Debra K. Moskovits, Randy Borman y otros. También se incluyen especies observadas por Douglas F. Stotz durante una visita a Bermejo en noviembre del 1998. Las especies que solamente fueron observadas en la visita de Stotz están marcadas con un asterisco.
Shishicho

\begin{tabular}{ll}
\hline Abundancia relativa/ & Rango altitudinal/ \\
Relative abundance & Elevational range $(\mathrm{m})$
\end{tabular}

Ccuccono \& Sinangoe

\begin{tabular}{ll}
\hline Abundancia relativa/ & Rango altitudinal/ \\
Relative abundance & Elevational range $(\mathrm{m})$
\end{tabular}

Hábitats/Habitats

\begin{tabular}{l}
- \\
- \\
$1300-1400$ \\
\hline $900-1350$ \\
- \\
-
\end{tabular}

\begin{tabular}{lll}
- & - & - \\
\hline$U$ & 600 & Fhl \\
\hline$U$ & $900-1100$ & Fhu, Fm \\
\hline FC & & \\
- & $600-1100$ & Fhl, Fhu, Fe \\
$X$ & - & Fe \\
\hline & 1000 & Fhu
\end{tabular}

\begin{tabular}{lll}
- & - & - \\
\hline$U$ & 600 & Fhl \\
\hline$U$ & $900-1100$ & Fhu, Fm \\
\hline FC & & \\
- & $600-1100$ & Fhl, Fhu, Fe \\
$X$ & - & Fe \\
\hline & 1000 & Fhu
\end{tabular}

\begin{tabular}{|c|c|c|c|c|c|}
\hline 064. & - & - & - & - & $\mathrm{Fe}$ \\
\hline 065. & $\mathrm{U}$ & 1000 & $\mathrm{U}$ & $600-1000$ & Fhu, Fhl \\
\hline 066. & - & - & - & - & Fhl \\
\hline 067. & - & - & $\mathrm{U}$ & 600 & Fhl \\
\hline 068. & $\mathrm{U}$ & 1000 & $\mathrm{U}$ & 1000 & Fhu \\
\hline 069. & - & - & - & - & Fhl \\
\hline 070. & - & - & - & - & Fhl \\
\hline 071. & - & - & - & - & $\mathrm{Fm}$ \\
\hline 072. & - & - & $x$ & 600 & Fhl \\
\hline 073. & $x$ & 1000 & $x$ & $<1000$ & Fhl, Fhu \\
\hline 074. & - & - & - & - & 0 \\
\hline 075. & - & - & $\mathrm{U}$ & 600 & 0 \\
\hline 076. & - & - & $\mathrm{U}$ & 600 & 0 \\
\hline 077. & - & - & - & - & 0 \\
\hline 078. & - & - & - & - & 0 \\
\hline 079. & - & - & - & - & 0 \\
\hline 080. & $\mathrm{FC}$ & $1200-1475$ & $\mathrm{U}$ & $900-1100$ & Fhu, Fm \\
\hline 081. & $x$ & $<1000$ & - & - & Fhl \\
\hline 082. & - & - & - & - & Fhl \\
\hline 083. & $\mathrm{FC}$ & $1200-1400$ & U & $1000-1100$ & Fhu, Fm \\
\hline 084. & $\mathrm{U}$ & 1300 & $\mathrm{FC}$ & $900-1100$ & Fhu, Fm \\
\hline 085. & - & - & $x$ & 600 & Fhl \\
\hline 086. & - & - & - & - & Fhl \\
\hline 087. & - & - & - & - & Fhl \\
\hline 088. & $U$ & $<1000$ & $x$ & 1000 & Fhu \\
\hline
\end{tabular}

\section{Hábitats/Habitats}

$\mathrm{Fe}=$ Bordes del bosque (incluye vegetación secundaria y regeneración en áreas de derrumbe)/Forest edges (includes early regenerating habitats, such as on landslides)

$\mathrm{Fhl}=$ Bosque de laderas bajas/Lower hill forest

Fhu = Bosque de laderas altas/Upper hill forest

$\mathrm{Fm}$ = Bosque nuboso/Mountain forest or cloud forest

Frp = Bosque ripario/Riparian forest

$\mathrm{Fsm}=$ Bosques al márgen de las quebradas $/$ Forest stream margins
0 = Cielo abierto/Open sky overhead

$\mathrm{Rm}$ = Márgenes de los ríos/River margins 



\section{Especie/Species} Nombre común/Common name

Abundancia relativa/ Rango altitudinal/

058. Amazona amazonica Relative abundance
Elevational range $(\mathrm{m})$

059. Amazon

060 . Amazona mercenaria

Orange-winged Parrot/Loro de Ala Naranja 450

Mealy ParrotLoro Harinoso Scaly-headed Parrot/Loro Verd

Cuculidae (3)

\begin{tabular}{l} 
061. Piaya cayana \\
\hline 062. Crotophaga an
\end{tabular} 063. Neomorphus geoffroy Squirrel Cuckoo/Cucu Ardilla

$\begin{array}{ll}x & 450 \\ x & 450 \\ - & -\end{array}$

\section{Strigidae (8)}

064. Otus choliba:

065. Otus guatemalae Rufous-vented Ground-Cuckoo/Cuco-

\begin{tabular}{ll}
$F C$ & $450-1200$ \\
$F C$ & 450 \\
\hline
\end{tabular}
Terrestre de Vientre Rufo

067. Lophostrix cristat Tropical Screech-0w1/Lechuza Comủn

067. Lophostrix cristata Vermiculated Screech-OW/Lechuza Vermiculad

068. Pulsatrix melanota Tawny-bellied Screech-Ow/Lechuza Orejuda 1200 070. Glaucidium brasilianum 071. Aegolius harrIsi Crested Owl/Büho Penachudo

$\mathrm{X}$
$\mathrm{y}$
OC $\quad F \quad 450$ Nyctibiidae (2) \begin{tabular}{llll} 
073. Nyctibius griseus & Great Potoo/Nictibio Grande & - & - \\
\hline Common Potoo/Nictibio Comün & $x$ & 450 -ca. 1000
\end{tabular} Apodidae (6)

\begin{tabular}{|c|c|c|c|}
\hline 074. Streptoprocne zonaris & White-collared SwiftVencejo de Collar Blanco & FC & 450 \\
\hline 075. Cypseloides lemosi & White-chested SwiftNencejo Pechiblanco & $?$ & 450 \\
\hline 076. Cypseloides rutlus & Chestnut-collared SwiftNencejo de Cuello Castaño & $u$ & $450-1200$ \\
\hline 077. Chaetura brachyura & Short-tailed SwiftNencejo de Cola Corta & $\mathrm{FC}$ & 450 \\
\hline 078. Chaetura cinereiventris & Gray-rumped SwiftNencejo de Oorso Gris & $u$ & 450 \\
\hline 079. Tachornis squamata* & Fork-tailed Palm-SwiftNencejo Tijereta de Palmeras & $x$ & - \\
\hline \multicolumn{4}{|l|}{ Trochilidae (29) } \\
\hline 080. Donfera fudoviciae & Green-fronted Lancebill/Pico-Lanza de Frente Verde & $u$ & 1200 \\
\hline 081. Threnetes leucurus & Pale-tailed Barbthroat/Ermitaño de Cola Blanca & - & - \\
\hline 082. Phaethornis bourcieri" & Straight-billed HermitErmitaño de Pico Recto & $x$ & 450 \\
\hline 083. Phaothornis griseogularis & Gray-chinned HermitErmitaño de Barbilla Gris & FC & 1200 \\
\hline 084. Phaethornis guy & Green Hermit/Ermitaño Verde & $\mathrm{FC}$ & $900-1200$ \\
\hline 085. Phathornis longuemareus & Little HermitEermitaño Pequeño & - & - \\
\hline 086. Phaethornis ruber & Reddish Hermit/Ermitaño Rufo & $\mathrm{FC}$ & 450 \\
\hline 087. Phaethornis superciliosus & Long-tailed HermitErmitaño de Cola Larga & $x$ & $450-900$ \\
\hline 088. Eutoxeres condamini & Buff-tailed Sicklebill/Pica-de-Hoz de Cola Canela & - & - \\
\hline
\end{tabular}
088. Eutoxeres condamin Buff-tailed Sicklebill/Pica-de-Hoz de Cola Canel

\section{Abundancia Relativa/Relative Abundance}

$\mathrm{C}=$ Bastante común (registrada diariamente en su hábitat $=$ Poco común (presente pero no registrada diariamente en su hábitat apropriado)/Uncommon (present, but not recorded daily, even in sultable habitat)

$\mathrm{R}=$ Raro/Rare
$\mathrm{X}=$ Presente Presente pero con datos insuficientes para estimar relative abundance

\section{Rango Altitudinal/Elevational Range}

las cuales cada especie fue observada durante el inventario rápido y no representan la distribución altitudinal de las especies a través de la región. $/$ he elevational ranges presented in this table reter only to the altitudes at which each species was observed during the rapid biological elevational distribution of each species in the region.

50

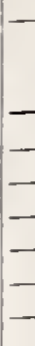

\begin{tabular}{|c|c|c|c|c|}
\hline \multicolumn{2}{|c|}{ Shishicho } & \multicolumn{2}{|c|}{ Ccuccono \& Sinangoe } & \\
\hline $\begin{array}{l}\text { Abundancia relativa/ } \\
\text { Relative abundance }\end{array}$ & $\begin{array}{l}\text { Rango altitudinal/ } \\
\text { Elevational range (m) }\end{array}$ & $\begin{array}{l}\text { Abundancia relatival } \\
\text { Relative abundance }\end{array}$ & $\begin{array}{l}\text { Rango altitudinall } \\
\text { Elevational range }(m)\end{array}$ & Hábitats/Habitats \\
\hline
\end{tabular}

\begin{tabular}{rlllll}
058. & - & - & - & - & - \\
\hline 059. & - & - & $U$ & 600 & Fhl \\
\hline 060. & $U$ & $1300-1400$ & $U$ & $900-1100$ & Fhu, Fm \\
\hline
\end{tabular}

\begin{tabular}{rrrrrr}
\hline 061, & FC & $900-1350$ & FC & $600-1100$ & Fhl, Fhu, Fe \\
\hline 062. & - & - & - & - & Fe
\end{tabular}

\begin{tabular}{|c|c|c|c|c|c|}
\hline 062. & - & - & - & - & $\mathrm{Fe}$ \\
\hline 063. & - & - & $x$ & 1000 & Fhu \\
\hline 064. & - & - & - & - & $\mathrm{Fe}$ \\
\hline 065. & $u$ & 1000 & $u$ & $600-1000$ & Fhu, Fhl \\
\hline 066. & - & - & - & - & $\mathrm{FhI}$ \\
\hline 067. & - & - & U & 600 & $\mathrm{Fhl}$ \\
\hline 068. & u & 1000 & $u$ & 1000 & Fhu \\
\hline 069. & - & $=$ & - & - & Fhl \\
\hline 070. & - & - & - & - & Fhl \\
\hline 071. & - & $=$ & - & - & $\mathrm{Fm}$ \\
\hline 072. & - & - & $x$ & 600 & $\mathrm{Fhl}$ \\
\hline 073. & $x$ & 1000 & $x$ & $<1000$ & Fhl, Fhu \\
\hline 074. & - & - & - & - & 0 \\
\hline 075. & - & - & $U$ & 600 & 0 \\
\hline 076. & - & $=$ & $u$ & 600 & 0 \\
\hline 077. & - & - & - & - & 0 \\
\hline 078. & - & - & - & - & 0 \\
\hline 079. & - & - & - & - & 0 \\
\hline 080. & FC & $1200-1475$ & $u$ & $900-1100$ & $\mathrm{Fhu}, \mathrm{Fm}$ \\
\hline 081. & $x$ & $<1000$ & - & $=$ & $\mathrm{Fhl}$ \\
\hline 082. & - & - & - & - & $\mathrm{Fhl}$ \\
\hline 083. & $F C$ & $1200-1400$ & $u$ & $1000-1100$ & Fhu, Fm \\
\hline 084. & $u$ & 1300 & $\mathrm{FC}$ & $900-1100$ & Fhu, Fm \\
\hline 085. & - & - & $x$ & 600 & FhI \\
\hline 086. & - & $=$ & - & - & $\mathrm{Fhl}$ \\
\hline 087. & - & - & - & - & $\mathrm{Fhl}$ \\
\hline 088. & $u$ & $<1000$ & $x$ & 1000 & Fhu \\
\hline
\end{tabular}

$0=$ Cielo abierto/0pen sky overhead
$\mathrm{Rm}=$ Márgenes de los rios/River margins
Fe $=$ Bordes del bosque (incluye vegetación secundaria y

(egeneración en áreas de derumbe)/Forest edges (inctur

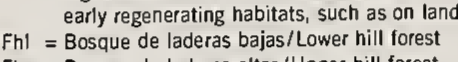

$F$ hu $=$ Bosque de laderas altas $/$ Upper hill forest
$F m=$ Bosque nuboso/Mountain forest or cloud for

$\mathrm{Fm}=$ Bosque nuboso/Mountain forest
$\mathrm{Frp}=$ Bosque ripario/Riparian forest

Frp $=$ Bosque fipario/Riparian forest
$\mathrm{Fsm}=$ Bosques al márgen de las quebradas $/$ Forest stream margins

ECUADOR: SERRANIAS COFAN
- Especies observadas solamente por Stotz./Species recorded only by D.F. Stoz. 
Birds observed at three sites in the Serranias Cofán, Sucumbios province, Ecuador, 24 July-16 August 2001. Principal ornithologist: Thomas S. Schulenberg, with observations by Debra K. Moskovits, Randy Borman, and others; also included are species observed at Bermejo by Douglas F. Stotz in November 1998 (species AVISIBIBDS recorded only during the November visit are indicated with an asterisk).

\begin{tabular}{|c|c|c|c|}
\hline \multirow[b]{2}{*}{ Especie/Species } & \multirow[b]{2}{*}{ Nombre común/Common name } & \multicolumn{2}{|c|}{ Bermejo } \\
\hline & & $\begin{array}{l}\text { Abundancia relativa/ } \\
\text { Relative abundance }\end{array}$ & $\begin{array}{l}\text { Rango altitudinal/ } \\
\text { Elevational range (m) }\end{array}$ \\
\hline 089. Campylopterus largipennis & $\begin{array}{l}\text { Gray-breasted Sabrewing/ } \\
\text { Ala-de-Sable de Pecho Gris }\end{array}$ & $x$ & 450 \\
\hline 090. Campylopterus villaviscensio & Napo Sabrewing/Ala-de-Sable del Napo & $x$ & 1200 \\
\hline 091. Colibri delphinae & Brown Violetear/Oreja-Violeta Marrón & - & - \\
\hline 092. Colibri thalassinus & Green Violetear/Oreja-Violeta Verde & $x$ & 900 \\
\hline 093. Thalurania furcata & Fork-tailed Woodnymph/Ninfa de Cola Horquillada & $\mathrm{FC}$ & $450-900$ \\
\hline 094. Chrysuronia oenone & Golden-tailed Sapphire/Zafiro de Cola Dorada & $\mathrm{FC}$ & 1200 \\
\hline 095. Adelomyia melanogenys & Speckled Hummingbird/Colibri Moteado & $\mathrm{FC}$ & $1900-2250$ \\
\hline 096. Urosticte ruficrissa & Rufous-vented Whitetip/Colibri de Caudales Rufas & - & - \\
\hline 097. Phlogophilus hemileucurus & Ecuadorian Piedtail/Cola-pintado Ecuatoriano & $\mathrm{x}$ & 900 \\
\hline 098. Heliodoxa aurescens & Gould's Jewelfront/Brillante de Cuello Castaño & $\mathrm{x}$ & 1200 \\
\hline 099. Heliodoxa schreibersii & Black-throated Brilliant/Brillante de Garganta Negra & $\mathrm{FC}$ & $900-1200$ \\
\hline 100. Urochroa bougueri & White-tailed Hillstar/Picaflor-Andino de Cola Blanca & - & - \\
\hline 101. Coeligena coeligena & Bronzy Inca/Inca Bronceado & $\mathrm{FC}$ & $1600-1900$ \\
\hline 102. Coeligena torquata & Collared Inca/Inca de Collar & $\mathrm{U}$ & 2100 \\
\hline 103. Eriocnemis alinae & $\begin{array}{l}\text { Emerald-bellied Puffleg/Calzadito } \\
\text { de Vientre Esmeralda }\end{array}$ & $\mathrm{FC}$ & $1850-2250$ \\
\hline 104. Haplophaedia aureliae & Greenish Puffleg/Calzadito Verdoso & $\mathrm{U}$ & 1850 \\
\hline 105. Ocreatus underwoodii & Booted Rackettail/Colibrí Cola de Hoja & $x$ & 1600 \\
\hline 106. Aglaiocercus kingi & Long-tailed Slyph/Sílfo de Cola Larga & $\mathrm{FC}$ & $1850-1900$ \\
\hline 107. Schistes geoffroyi & Wedge-billed Hummingbird/Colibrí Pico de Cuña & - & - \\
\hline 108. Heliothryx aurita & Black-eared Fairy/Colibrí-Hada de Oreja Negra & - & - \\
\hline \multicolumn{4}{|l|}{ Trogonidae (4) } \\
\hline 109. Trogon collaris & Collared Trogon/Trogón Acollarado & $\mathrm{FC}$ & $450-1200$ \\
\hline 110. Trogon melanurus & Black-tailed Trogon/Trogón de Cola Negra & $\mathrm{x}$ & 450 \\
\hline 111. Trogon personatus & Masked Trogon/Trogón Enmascarado & $\mathrm{U}$ & $2000-2100$ \\
\hline 112. Trogon viridis & White-tailed Trogon/Trogón de Cola Blanca & $\mathrm{U}$ & 450 \\
\hline \multicolumn{4}{|l|}{ Alcedinidae (1) } \\
\hline 113. Chloroceryle americana & Green Kingfisher/Martín Pescador Verde & - & - \\
\hline \multicolumn{4}{|l|}{ Momotidae (1) } \\
\hline 114. Baryphthengus martii* & Rufous Motmot/Momoto Rufo & $x$ & 650 \\
\hline \multicolumn{4}{|l|}{ Galbulidae (1) } \\
\hline 115. Jacamerops aurea & Great Jacamar/Jacamar Grande & $\mathrm{U}$ & $450-900$ \\
\hline \multicolumn{4}{|l|}{ Bucconidae (4) } \\
\hline 116. Notharchus macrorhynchos & White-necked Puffbird/Chacurú de Cuello Blanco & $\mathrm{U}$ & 450 \\
\hline 117. Nystalus striolatus & Striolated Puffbird/Buco Estriolado & $\mathrm{U}$ & 1200 \\
\hline 118. Monasa morphoeus & White-fronted Nunbird/Monja de Frente Blanca & $\mathrm{U}$ & 900 \\
\hline
\end{tabular}


APÉNDICE/APPENDIX 3

Aves/Birds
Especies de aves registradas en tres sitios de las Serranias Cofán, Provincia de Sucumbios, Ecuador, del 24 de julio al 16 de agosto 2001. Omitólogo principal: Thomas S. Schulenberg. Observaciones adicionales de Debra K. Moskovits, Randy Borman y otros. También se incluyen especies observadas por Douglas F. Stotz durante una visita a Bermejo en noviembre del 1998. Las especies que solamente fueron observadas en la visita de Stotz están marcadas con un asterisco.
Shishicho

\begin{tabular}{ll}
\hline Abundancia relativa/ & Rango altitudinal/ \\
Relative abundance & Elevational range (m)
\end{tabular}

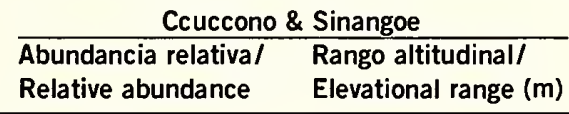

Hábitats/Habitats

$\mathrm{Fe}$

$\begin{array}{lll}\text { FC } & 900-1100 & \mathrm{Fh} \\ - & - & \mathrm{Fe} \\ - & - & \mathrm{Fe} \\ \mathrm{U} & 600-900 & \mathrm{Fh} \\ \mathrm{U} & 1000 & \mathrm{Fe} \\ - & - & \mathrm{Fm}\end{array}$

$-$

FC

$-$

$-\quad \mathrm{Fm}$

1000-1100 Fhu

$-\quad$ Fhu

$\begin{array}{llll}099 . & \text { FC } & 900 & \text { FC } \\ 100 . & - & - & X\end{array}$

101.

102 .

103.

$-$

$\begin{array}{llll}104 . & - & - & - \\ 105 & - & - & - \\ 106 . & - & - & -\end{array}$

$107 . \quad X \quad 1400$

108.

$\mathrm{x}$

1100

$\mathrm{FC}$

900-1000 Fhu

$900 \quad$ Fhu (Fsm)

- $\quad$ Fhu, Fm

- $\quad \mathrm{Fm}$

$\mathrm{Fm}$

$\begin{array}{lll}- & - & \mathrm{Fm} \\ - & - & \mathrm{Fhu} \\ - & - & \mathrm{Fm} \\ - & - & \mathrm{Fm} \\ \text { FC } & 900 & \mathrm{Fe}\end{array}$

\begin{tabular}{lll}
109. & FC & $900-1400$ \\
110. & - & - \\
111. & $\mathrm{X}$ & 1450 \\
112. & $\mathrm{U}$ & 900 \\
\hline
\end{tabular}

\begin{tabular}{lll} 
FC & $600-1100$ & Fhl, Fhu \\
$X$ & 600 & Fhl \\
- & - & Fm \\
\hline U & 600 & Fhl, Fhu
\end{tabular}

113.

$$
-
$$

$-$

$\mathrm{X}$

900

Fsm

114

$-$

$-$

- $\quad$ FhI

$\begin{array}{lll}- & & \mathrm{Fhl}\end{array}$

115.

$-$

$-$

U

$\begin{array}{ll}600 & \text { Fhl } \\ - & \text { Fhu } \\ - & \text { Fhu }\end{array}$

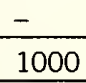

0 = Cielo abierto/Open sky overhead

$\mathrm{Rm}$ = Márgenes de los ríos/River margins
Hábitats/Habitats

$\mathrm{Fe}=$ Bordes del bosque (incluye vegetación secundaria y regeneración en áreas de derrumbe)/Forest edges (includes early regenerating habitats, such as on landslides)

$\mathrm{Fhl}=$ Bosque de laderas bajas/Lower hill forest

Fhu $=$ Bosque de laderas altas/Upper hill forest

$\mathrm{Fm}=$ Bosque nuboso/Mountain forest or cloud forest

Frp = Bosque ripario/Riparian forest

Fsm $=$ Bosques al márgen de las quebradas $/$ Forest stream margins
* Especies observadas solamente por Stotz./Species recorded only by D.F. Stotz. 

Especie/Species Nombre común/Common name Bermejo

089. Campylopterus largipennis Gray-breasted Sabrewing/

$\frac{\text { Bermejo }}{\text { Abundancia relativa/ Rango altitudinal/ }}$

Napo Sabrewing/Ala-de-Sable del Napo

091. Colibri delphinae Brown Violetear/Oreja-Violeta Marrón

091. Collori delphinae

093. Thalurania furcata Green Violetear/Oreja-Violeta Verde

094. Chrysuronia oenone Fork-tailed Woodnymph/Ninfa de Cola Horquillada

Golden-tailed Sapphire/Zatiro de Cola Dora
Speckled Hummingbird/Colibri Moteado

096. Urosticte ruficrissa

Relative abundance Elevational range $(\mathrm{m})$

097. Phlogophilus hemileucurus Rus

099. Heliodoxa schreibersi

100. Urochroa bougueri

101. Coeligena coeligena

102. Coeligena torquata

Black-throated BrilliantBrillante de Garganta Negra

White-tailed Hillstar/Picaflor-An

Bronzy Inca/nca Bronceado

450

103. Eriocnemis alinae

Collared Inca/Inca de Colla

Emerald-bellied Puffleg/Calzadito

104. Haplophaedia aureliae Greenish Puffleg/Calzadito Verdoso

105. Ocreatus underwoodii

Booted Rackettail/Colibrl Cola de Hoia

Long-tailed Slyph/Sillo de Cola Larga

Wedge-billed Hummingbird/Colibri Pico de Cuña Black-eared FairylColibrl-Hada de Oreja Negra

107. Schistes geoffro

108. Heliothryx aurita

Trogonidae (4)

109. Trogon collaris

110. Trogon melanurus

Collared Trogon/Trogón Acollarad

Black-tailed Trogon/rogón de Cola Neg

Masked Trogon/Trogón Enmascarado

White-tailed Trogon/Trogón de Cola Blanca

\begin{tabular}{ll}
$x$ & 450 \\
$\times$ & 1200 \\
\hline
\end{tabular}

200

\begin{tabular}{ll}
\hline$X$ & 900 \\
\hline$F C$ & $450-900$ \\
\hline$F C$ & 1200 \\
\hline
\end{tabular}

FC 1200

$\begin{array}{ll}- & - \\ x & -900 \\ x & -1200\end{array}$

\begin{tabular}{ll}
$X$ & 900 \\
$X$ & 1200 \\
$F C$ & $900-1200$ \\
\hline
\end{tabular}

200

FC $1600-1900$

$\mathrm{U}-2100$

FC 1850.2250

111. Trogon persona

Alcedinidae (1)

113. Chloroceryle americana Green Kingfisher/Martin Pescador Verde

Momotidae (1)

Rufous Motmot/Momoto Rufo

$\frac{-1}{x}$

$\times \quad 650$

Galbulidae (1)

115. Jacamerops aurea Great JacamarlJacamar Grande

U $\quad 450-900$

116. Notharchus macrorhynchos White-necked Puffibird/Chacurú de Cuello Blanco

117. Nystalus striolatus

Striolated Puffibird/Buco Estriolado

White-fronted Nunbird/Monja de Frente Blanca

\begin{tabular}{ll}
$U$ & 450 \\
\hline & 1200
\end{tabular}

450

118. Monasa morphoeus

Rango Altitudinal/Elevational Range

Abundancia Relativa/Relative Abundance

Los datos presentados aqul sólo indican las elevaciones a

- Bastante común (registrada diariamente en su habitat

apropiado)/Fairly common (recorded daily in suitable habital
$=$ Poco común (presente pero no registrada diariamente en su hábitat apropriado)/Uncommon (present, but not recorded daily, even in suttable habitat)

$R=$ Raro $/$ Rare
$X=$ Presente

= Presente pero con datos insuficientes para estimar bundancia/Present, but with insufficient data to assess relative abundance

列

rápido y no representan la distribución altitudinal de las

presented in this table refer only to the altitudes at which

each species was observed during the rapid biological

inventory, and are not meant to describe the complete
elevational distribution of each species in the region.

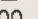

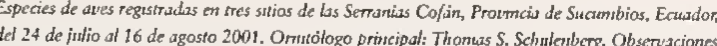

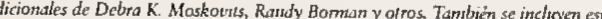

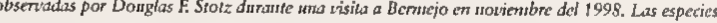

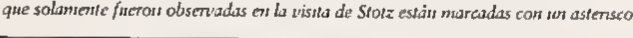

\begin{tabular}{|c|c|c|c|c|c|}
\hline & \multicolumn{2}{|c|}{ Shishicho } & \multicolumn{2}{|c|}{ Ccuccono \& Sinangoe } & \multirow[b]{2}{*}{ Hábitats/Habitats } \\
\hline & $\begin{array}{l}\text { Abundancia relativa/ } \\
\text { Relative abundance }\end{array}$ & $\begin{array}{l}\text { Rango altitudinal' } \\
\text { Elevational range (m) }\end{array}$ & $\begin{array}{l}\text { Abundancia relativa/ } \\
\text { Relative abundance } \\
\end{array}$ & $\begin{array}{l}\text { Ranno altitudinal/ } \\
\text { Elevational range }(\mathrm{m})\end{array}$ & \\
\hline 089. & - & - & - & - & $\mathrm{Fe}$ \\
\hline 090 , & $\mathrm{u}$ & $950-1100$ & FC & $900-1100$ & Fhu \\
\hline 091. & $\mathrm{FC}$ & 1100 & - & - & $\mathrm{Fe}$ \\
\hline 092. & $\mathrm{FC}$ & 1100 & - & - & $\mathrm{Fe}$ \\
\hline 093. & - & - & $u$ & 600.900 & $\mathrm{Fhl}$ \\
\hline 094. & $\mathrm{FC}$ & 1100 & u & 1000 & $\mathrm{Fe}$ \\
\hline 095. & - & $=$ & - & - & $\mathrm{Fm}$ \\
\hline 096. & FC & $1200-1450$ & - & - & $\mathrm{Fm}$ \\
\hline 097. & - & - & FC & $1000-1100$ & Fhu \\
\hline 098. & - & - & - & - & Fhu \\
\hline 099. & $\mathrm{FC}$ & 900 & FC & $900-1000$ & Fhu \\
\hline 100. & - & - & $x$ & 900 & Fhu $(\mathrm{Fsm})$ \\
\hline 101. & - & - & - & - & Fhu, Fm \\
\hline 102. & - & - & - & - & $\mathrm{Fm}$ \\
\hline 103. & - & - & - & - & $\mathrm{Fm}$ \\
\hline 104. & - & $=$ & - & - & $\mathrm{Fm}$ \\
\hline 105. & - & - & $=$ & - & Fhu \\
\hline 106. & $=$ & - & - & - & $\mathrm{Fm}$ \\
\hline 107. & $x$ & 1400 & - & - & $\mathrm{Fm}$ \\
\hline 108. & $x$ & 1100 & $\mathrm{FC}$ & 900 & $\mathrm{Fe}$ \\
\hline 109. & $\mathrm{FC}$ & $900-1400$ & $F C$ & $600-1100$ & Fhl, Fhu \\
\hline 110. & - & - & $x$ & 600 & Fhl \\
\hline 111. & $x$ & 1450 & - & - & $\mathrm{Fm}$ \\
\hline 112. & u & 900 & $u$ & 600 & Fhl, Fhu \\
\hline 113. & - & - & $x$ & 900 & Fsm \\
\hline 114. & - & - & - & - & Fhl \\
\hline 115. & - & $=$ & - & - & $\mathrm{Fhl}$ \\
\hline 116. & - & - & $u$ & 600 & $\mathrm{Fhl}$ \\
\hline 117. & $u$ & 1000 & - & - & Fhu \\
\hline 118. & - & - & - & - & Fhu \\
\hline
\end{tabular}

Habitats/Habitats

= Bordes del bosque (incluye vegetación secundaria y

0 Cielo abiertol open sky overhead

regeneración en áreas de derrumbe)/Forest edges (inc

$F \mathrm{Fl}=$ Bosque de laderas bajas $/$ Lower hill forest

Fhu $=$ Bosque de laderas altas/ Upper hill for est

$\mathrm{Fm}=$ Bosque nuboso/Mountain fore
$\mathrm{Frp}=$ Bosque ripario/ Riparian forest

Fsm $=$ Bosques al márgen de las quebradas Forest stream margins

- Especies observadas solamente por Stozz./Species recorded

ECUADOR: SERRANIAS COFAN 
Birds observed at three sites in the Serranias Cofán, Sucumbios province, Ecuador, 24 July-16 August 2001. Principal ornithologist: Thomas S. Schulenberg, with observations by Debra K. Moskovits, Randy Borman, and others; also included are species observed at Bermejo by Douglas F. Stotz in November 1998 (species AVESIBIRDS recorded only during the November visit are indicated with an asterisk).

\begin{tabular}{|c|c|c|c|}
\hline \multirow[b]{2}{*}{ Especie/Species } & \multirow[b]{2}{*}{ Nombre común/Common name } & \multicolumn{2}{|c|}{ Bermejo } \\
\hline & & $\begin{array}{l}\text { Abundancia relativa/ } \\
\text { Relative abundance }\end{array}$ & $\begin{array}{l}\text { Rango altitudinal/ } \\
\text { Elevational range }(\mathrm{m})\end{array}$ \\
\hline 119. Chelidoptera tenebrosa* & Swallow-winged Puffbird/Chacurú Golondrina & $x$ & - \\
\hline \multicolumn{4}{|l|}{ Ramphastidae (10) } \\
\hline 120. Capito aurovirens* & Scarlet-crowned Barbet/Barbudo de Corona Escarlata & $x$ & 450 \\
\hline 121. Capito auratus & Gilded Barbet/Bardudo Brilloso & $\mathrm{FC}$ & $450-1200$ \\
\hline 122. Eubucco bourcieri & Red-headed Barbet/Bardudo de Cabeza Roja & $\mathrm{FC}$ & $950-1200$ \\
\hline 123. Eubucco richardsoni & $\begin{array}{l}\text { Lemon-throated Barbet/ } \\
\text { Bardudo de Garganta Amarilla }\end{array}$ & $x$ & $450-700$ \\
\hline 124. Pteroglossus pluricinctus & Many-banded Aracari/Arasari Multi bandeado & $\mathrm{FC}$ & $450-1200$ \\
\hline 125. Selenidera reinwardtii & Golden-collared Toucanet/Tucancito de Collar Dorado & $\mathrm{U}$ & 450 \\
\hline 126. Andigena nigrirostris & $\begin{array}{l}\text { Black-billed Mountain-Toucan/ } \\
\text { Tucan-Andino de Pico Negro }\end{array}$ & $U$ & $1900-2100$ \\
\hline 127. Ramphastos ambiguus & Black-mandibled Toucan/Tucán de Pico Negro & $\mathrm{U}$ & 1200 \\
\hline 128. Ramphastos tucanus & White-throated Toucan/Tucán de Garganta Blanca & FC & $450-900$ \\
\hline 129. Ramphastos vitellinus & Channel-billed Toucan/Tucán de Pico Acanelado & - & - \\
\hline \multicolumn{4}{|l|}{ Picidae (13) } \\
\hline 130. Melanerpes cruentatus & $\begin{array}{l}\text { Yellow-tufted Woodpecker/ } \\
\text { Carpintero de Penacho Amarillo }\end{array}$ & FC & 450 \\
\hline 131. Veniliornis affinis & Red-stained Woodpecker/Carpintero Teñido de Rojo & $x$ & 450 \\
\hline 132. Veniliornis dignus & $\begin{array}{l}\text { Yellow-vented Woodpecker/ } \\
\text { Carpintero de Vientre Amarillo }\end{array}$ & $x$ & 2000 \\
\hline 133. Veniliornis fumigatus & Smoky-brown Woodpecker/Carpintero Pardo & - & - \\
\hline 134. Piculus flavigula* & $\begin{array}{l}\text { Yellow-throated Woodpecker/ } \\
\text { Carpintero de Garganta Amarilla }\end{array}$ & $\mathrm{x}$ & 450 \\
\hline 135. Piculus leucolaemus & $\begin{array}{l}\text { White-throated Woodpecker/ } \\
\text { Carpintero de Garganta Blanca }\end{array}$ & $\mathrm{FC}$ & 1200 \\
\hline 136. Piculus rubiginosus & Golden-olive Woodpecker/Carpintero Oliva y Dorado & $\mathrm{U}$ & 1200 \\
\hline 137. Colaptes punctigula & $\begin{array}{l}\text { Spot-breasted Woodpecker/ } \\
\text { Carpintero de Pecho Punteado }\end{array}$ & $x$ & $450-600$ \\
\hline 138. Celeus flavus & Cream-colored Woodpecker/Carpintero Crema & $\mathrm{FC}$ & 450 \\
\hline 139. Dryocopus lineatus & Lineated Woodpecker/Carpintero Crema & $\mathrm{U}$ & $450-600$ \\
\hline 140. Campephilus haematogaster & $\begin{array}{l}\text { Crimson-bellied Woodpecker/ } \\
\text { Carpintero de Vientre Rojo }\end{array}$ & FC & 1200 \\
\hline 141. Campephilus melanoleucos & $\begin{array}{l}\text { Crimson-crested Woodpecker/ } \\
\text { Carpintero de Cresta Roja }\end{array}$ & FC & $450-850$ \\
\hline 142. Campephilus rubricollis & Red-necked Woodpecker/Carpintero de Cuello Rojo & $\mathrm{U}$ & $<900$ \\
\hline \multicolumn{4}{|l|}{ Dendrocolaptidae (11) } \\
\hline 143. Dendrocincla fuliginosa & Plain-brown Woodcreeper/Trepador Marrón & $\mathrm{U}$ & $450-1200$ \\
\hline 144. Dendrocincla merula* & $\begin{array}{l}\text { White-chinned Woodcreeper/ } \\
\text { Trepador de Barbilla Blanca }\end{array}$ & $x$ & $450-600$ \\
\hline
\end{tabular}

\section{Abundancia Relativa/Relative Abundance}

$\mathrm{FC}=$ Bastante común (registrada diariamente en su hábitat apropiado)/Fairly common (recorded daily in suitable habitat)

$\mathrm{U}=$ Poco común (presente pero no registrada diariamente en su hábitat apropriado)/Uncommon (present, but not recorded daily, even in suitable habitat)

$\mathrm{R}=$ Raro/Rare

$X=$ Presente pero con datos insuficientes para estimar abundancia/Present, but with insufficient data to assess relative abundance

\section{Rango Altitudinal/Elevational Range}

Los datos presentados aquí sólo indican las elevaciones a las cuales cada especie fue observada durante el inventario rápido y no representan la distribución altitudinal de las especies a través de la región./The elevational ranges presented in this table refer only to the altitudes at which each species was observed during the rapid biological inventory, and are not meant to describe the complete elevational distribution of each species in the region. 
APENDICE/APPENDIX 3

Aves/Birds
Especies de aves registradas en tres sitios de las Serranias Cofán, Provincia de Sucumbios, Ecuador, del 24 de julio al 16 de agosto 2001. Ornitólogo principal: Thomas S. Schulenberg. Observaciones adicionales de Debra K. Moskovits, Randy Borman y otros. También se incluyen especies observadas por Douglas F. Stotz durante una visita a Bermejo en noviembre del 1998. Las especies que solamente fueron observadas en la visita de Stotz están marcadas con un asterisco.

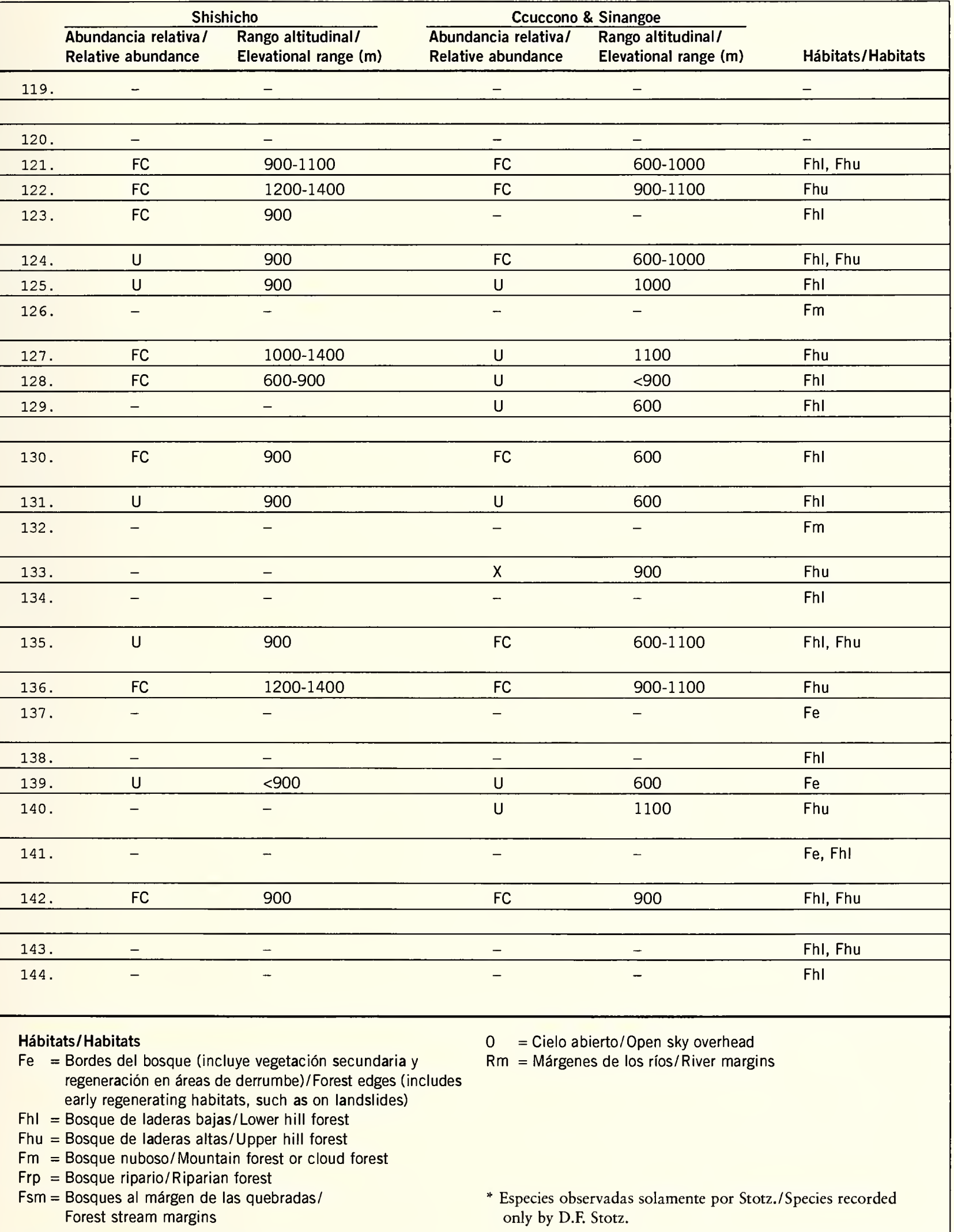





\section{Bermejo}

Especie/Species Nombre común/Common nam

Abundancia relativa/ Rango altitudinal/ 119. Chelidoptera tenebrosa* Swallow-winged Puffbird/Chacuru Golondrina $x$

Ramphastidae (10)

120. Capito aurovirens"

121. Capin

122. Eubucco bourcie

123. Eubucco richardsoni

Scarlet-crowned Barbet/Barbudo de Corona Escarlata Gilded Barbet/Bardudo Brilloso

124. Pteroglossus pluricinctus

125. Selenidera reinwardt

126. Andigena nigrirostris

127. Ramphastos ambiguus

128. Ramphastos tucanus

129. Ramphastos vitellinus

Red-headed Barbet/Bardudo de Cabeza Roja

Many-banded Aracari/Arasari Multi bandeado $\quad$ FC $\quad 450-1200$

Golden-collared ToucanetTucancito de Collar Dorado Black-billed Mountain-Toucan/ \begin{tabular}{lll} 
White-throated Toucann/Tucán de Garganta Blanca & FC & 1200 \\
\hline
\end{tabular}

icidae (13)

130. Melanerpes cruentatus Channel-billed Toucan/Tucán de Pico Acanelado

131. Veniliornis affinis

Yellow. tuted Woodpeckert

o de Penacho Amarillo

2. Veniliornis dignus

Red-stained Woodpecker/Carpintero Teñido de Rojo Yellow-vented Woodpecker/

450

$450-1200$

$450-1200$

$900-2100$

$450-900$

133. Veniliornis fumigatus

134. Piculus flavigula"

Smoky. brown Woodpecker/Carpintero Pardo

Yellow-throated Woodpeckert

Yellow-throated Woodpeckerl
Carpintero de Garganta Amarill

White-throated Woodpeckerl

Crointero de Garganta Blanca

135. Piculus leucolaemus

Golden-olive Woodpecker/Carp

36. Piculus rubiginasus pot-breasted Woodpecker/

138. Celeus flavus

Cream-colored Woodpecker/Carpintero Crema $\quad$ FC 450

39. Dryocopus lineatus

ineated Woodpecker/Carpintero Crema $\quad U$ U $450-600$

140. Campephilus haematogaster Crimson-bellied Woodpeckerl

Carpintero de Vientre Rojo

141. Campephilus melanoleucos Crimson-crested Woodpecker/

142. Campephilus rubricollis

Red u

endrocolaptidae (11) $\begin{array}{llll}\text { 143. Dendrocincla fultginosa } & \text { Plain-brown Woodcreeper/Trepador Marrón } & U & 450-1200 \\ \text { 144. Dendrocincla merula* } & \begin{array}{l}\text { White-chinned Woodcreeper/ } \\ \text { Trepador de Barbilla Blanca }\end{array} & x & 450-600\end{array}$ Trepador de Barbilla Blance

\section{Abundancia Relativa/Relative Abundance}

$\mathrm{C}$ = $=$ Bastante comin (registrada diariamente en su habitat

apropiado)/Fairly common (recorded daily in suitable habitat) en su hábitat apropriado)/Uncommon (present, but not recorded daily, even in sultable habitat)

$R=$ Raro/Rare
$x$

$=$ Presente pero con datos insuficientes para estimar abundancia/Present, but with insufficient data to assess relative abundance

\section{Rango Altitudinal/Elevational Range}

Los datos presentados aqul sólo indican las elevaciones a

las cuales cada especie fue observada durante el inventario

especies a través de la región. The elevational ranges

presented in this table refer only to the altitudes at which

ach species was observed during the rapid biological

inventory, and are not meant to describe the complete
elevational distribution of each species in the region.

\begin{tabular}{|c|c|c|c|c|c|}
\hline & \multicolumn{2}{|c|}{ Snishicho } & \multicolumn{2}{|c|}{ Ccuccono \& Sinangoe } & \multirow[b]{2}{*}{ Hábitats/Habitats } \\
\hline & $\begin{array}{l}\text { Abundancia relativa/ } \\
\text { Relative abundance } \\
\end{array}$ & $\begin{array}{l}\text { Rango altitudinal/ } \\
\text { Elevational range (m) }\end{array}$ & $\begin{array}{l}\text { Abundancia relativa/ } \\
\text { Relative abundance } \\
\end{array}$ & $\begin{array}{l}\text { Rango altitudinal/ } \\
\text { Elevational range }(\mathrm{m})\end{array}$ & \\
\hline 119. & - & $=$ & 二 & - & - \\
\hline 120. & - & - & - & - & - \\
\hline 121. & $\mathrm{FC}$ & $900-1100$ & FC & $600-1000$ & Fhl, Fhu \\
\hline 122. & FC & $1200-1400$ & $\mathrm{FC}$ & $900-1100$ & Fhu \\
\hline 123. & $\mathrm{FC}$ & 900 & - & - & Fil \\
\hline 124. & $\mathrm{u}$ & 900 & FC & $600-1000$ & Fhl, Fhu \\
\hline 125. & $u$ & 900 & $u$ & 1000 & Fil \\
\hline 126. & - & - & - & - & $\mathrm{Fm}$ \\
\hline 127. & FC & $1000-1400$ & $u$ & 1100 & Fhu \\
\hline 128. & FC & $600-900$ & $u$ & $<900$ & Fhl \\
\hline 129. & - & - & $u$ & 600 & $\mathrm{Fhl}$ \\
\hline 130. & FC & 900 & FC & 600 & $\mathrm{Fhl}$ \\
\hline 131. & $\mathrm{u}$ & 900 & $u$ & 600 & Fhl \\
\hline 132. & - & - & - & - & $\mathrm{Fm}$ \\
\hline 133. & - & - & $x$ & 900 & Fhu \\
\hline 134. & - & - & - & - & $\mathrm{Fhl}$ \\
\hline 135. & $u$ & 900 & FC & $600 \cdot 1100$ & Fhl, Fhu \\
\hline 136. & $\mathrm{FC}$ & $1200-1400$ & $F C$ & $900-1100$ & Fhu \\
\hline 137. & - & - & - & - & $\mathrm{Fe}$ \\
\hline 138. & - & - & - & - & Fhl \\
\hline 139. & $u$ & $<900$ & $u$ & 600 & $\mathrm{Fe}$ \\
\hline 140. & - & - & u & 1100 & Fhu \\
\hline 141. & - & - & - & - & $\mathrm{Fe}, \mathrm{Fhl}$ \\
\hline 142. & FC & 900 & $F C$ & 900 & Fhl, Fhu \\
\hline
\end{tabular}

144 $\mathrm{Fhl}$

\section{Hábitats/Habitats}

Bordes del bosque (incluye vegetación secundaria y egeneración en áreas de derrumbe)/Forest edges (inture

$\mathrm{hl}=$ Bosque de laderas bajas/Lower hill forest

$F$ Fu $=$ Bosque de laderas altas/Upper hill forest

$\mathrm{Fm}=$ Bosque nuboso/Mountain forest or cloud fores

$\mathrm{Frp}=$ Bosque ripario/Ripartian lorest

$\begin{aligned} & =\text { Bosques al márgen de } \\ & \text { Forest stream margins }\end{aligned}$

ECUADOR: SERRANIAS COFÁN
$0=$ Cielo abierto/Open sky overhead
$\mathrm{Rm}=$ Márgenes de los flos/River margins

Especies observadas solamente por Stoz./Species recorded nly by D.F. Stotz. 
Birds observed at three sites in the Serranias Cofán, Sucumbios province, Ecuador, 24 July-16 August 2001. Principal ornithologist: Thomas S. Schulenberg, with observations by Debra K. Moskovits, Randy Borman, and others; also included are species observed at Bermejo by Douglas F. Stotz in November 1998 (species AVESTIRDS recorded only during the November visit are indicated with an asterisk).

\begin{tabular}{|c|c|c|c|}
\hline \multirow[b]{2}{*}{ Especie/Species } & \multirow[b]{2}{*}{ Nombre común/Common name } & \multicolumn{2}{|c|}{ Bermejo } \\
\hline & & $\begin{array}{l}\text { Abundancia relativa/ } \\
\text { Relative abundance }\end{array}$ & $\begin{array}{l}\text { Rango altitudinal/ } \\
\text { Elevational range }(\mathrm{m})\end{array}$ \\
\hline 145. Dendrocincla tyrannina & Tyrannine Woodcreeper/Trepador Tiranino & $\mathrm{U}$ & 2000 \\
\hline 146. Glyphorynchus spirurus & Wedge-billed Woodcreeper/Trepador Pico de Cufia & FC & $450+$ \\
\hline 147. Dendrexetastes rufigula & $\begin{array}{l}\text { Cinnamon-throated Woodcreeper/ } \\
\text { Trepador de Garganta Canela }\end{array}$ & $x$ & - \\
\hline 148. Xiphocolaptes promeropirhynchus & sStrong-billed Woodcreeper/Trepador de Pico Fuerte & $\mathrm{U}$ & 450 \\
\hline 149. Dendrocolaptes certhia & Barred Woodcreeper/Trepador Barreteado & - & - \\
\hline 150. Xiphorhynchus guttatus & $\begin{array}{l}\text { Buff-throated Woodcreeper/ } \\
\text { Trepador de Garganta Anteada }\end{array}$ & FC & $450-700$ \\
\hline 151. Xiphorhynchus ocellatus & Ocellated Woodcreeper/Trepador Ocelado & $\mathrm{FC}$ & 1200 \\
\hline 152. Xiphorhynchus triangularis & Olive-backed Woodcreeper/Trepador de Dorso Oliva & FC & $1900-2200$ \\
\hline 153. Campylorhamphus pucherani & Greater Scythebill/Pico-Guadaña Grande & $\mathrm{x}$ & 2100 \\
\hline \multicolumn{4}{|l|}{ Furnariidae (18) } \\
\hline 154. Synallaxis moesta & Dusky Spinetail/Cola-Espina Oscura & $\mathrm{FC}$ & $750-1200$ \\
\hline 155. Cranioleuca curtata & Ash-browed Spinetail/Cola-Espina de Ceja Ceniza & $\mathrm{U}$ & 1200 \\
\hline 156. Premnoplex brunnescens & Spotted Barbtail/Cola-Púa Moteada & $\mathrm{FC}$ & $1600-1900$ \\
\hline 157. Pseudocolaptes boissonneautii & Streaked Tuftedcheek/Barba-blanca Rayado & $\mathrm{FC}$ & 2000 \\
\hline 158. Hyloctistes subulatus & Striped Woodhaunter/Rondador-Bosque Listado & - & - \\
\hline 159. Ancistrops strigilatus & $\begin{array}{l}\text { Chestnut-winged Hookbill/ } \\
\text { Pico-gancho de Ala Castaña }\end{array}$ & $x$ & 450 \\
\hline 160. Syndactyla subalaris & Lineated Foliage-gleaner/Limpia-follaje Lineado & - & - \\
\hline 161. Anabacerthia striaticollis & Montane Foliage-gleaner/Limpia-follaje Montano & $\mathrm{U}$ & 1200 \\
\hline 162. Philydor erythropterus* & $\begin{array}{l}\text { Chestnut-winged Foliage-gleaner/ } \\
\text { Limpia-follaje de Ala Castaña }\end{array}$ & $x$ & 450 \\
\hline 163. Philydor pyrrhodes & $\begin{array}{l}\text { Cinnamon-rumped Foliage-gleaner/ } \\
\text { Limpia-follaje de Rabadilla Canela }\end{array}$ & $\mathrm{U}$ & 450 \\
\hline 164. Philydor enythrocerus/ruficaudatus & s foliage-gleaner (species)/limpia-follaje (especie) & U & 900 \\
\hline 165. Automolus ochrolaemus & $\begin{array}{l}\text { Buff-throated Foliage-gleaner/ } \\
\text { Hoja-Rasquero de Garganta Anteada }\end{array}$ & FC & $450-1000$ \\
\hline 166. Automolus rubiginosus & Ruddy Foliage-gleaner/Hoja-Rasquero Rojizo & U & 1200 \\
\hline 167. Thripadectes melanorhynchus & Black-billed Treehunter/Trepa-palo de Pico Negro & - & - \\
\hline 168. Xenops minutus & Plain Xenops/Pico-Lezna Simple & $\mathrm{U}$ & 975 \\
\hline 169. Xenops rutilans & Streaked Xenops/Pico-Lezna Rayado & - & - \\
\hline 170. Sclerurus caudacutus & Black-tailed Leaftosser/Tira-hoja de Cola Negra & $x$ & - \\
\hline 171. Lochmias nematura & Sharp-tailed Streamcreeper/Riachuelero & - & - \\
\hline \multicolumn{4}{|l|}{ Thamnophilidae (33) } \\
\hline 172. Cymbilaimus lineatus & Fasciated Antshrike/Batará Lineado & $\mathrm{FC}$ & $450-1200$ \\
\hline 173. Frederickena unduligera & Undulated Antshrike/Batará Ondulado & $\mathrm{FC}$ & $450-1100$ \\
\hline 174. Taraba major* & Great Antshrike/Batará Grande & $x$ & - \\
\hline
\end{tabular}

\section{Abundancia Relativa/Relative Abundance}

$\mathrm{FC}=$ Bastante común (registrada diariamente en su hábitat apropiado)/Fairly common (recorded daily in suitable habitat)

$\mathrm{U}=$ Poco común (presente pero no registrada diariamente en su hábitat apropriado)/Uncommon (present, but not recorded daily, even in suitable habitat)

$\mathrm{R}=$ Raro/Rare

$X=$ Presente pero con datos insuficientes para estimar abundancia/Present, but with insufficient data to assess relative abundance
Rango Altitudinal/Elevational Range

Los datos presentados aquí sólo indican las elevaciones a las cuales cada especie fue observada durante el inventario rápido y no representan la distribución altitudinal de las especies a través de la región./The elevational ranges presented in this table refer only to the altitudes at which each species was observed during the rapid biological inventory, and are not meant to describe the complete elevational distribution of each species in the region. 
APÉNDICE/APPENDIX 3

Aves/Birds
Especies de aves registradas en tres sitios de las Serranias Cofán, Provincia de Sucumbios, Ecuador, del 24 de julio al 16 de agosto 2001. Ornitólogo principal: Thomas S. Schulenberg. Observaciones adicionales de Debra K. Moskovits, Randy Borman y otros. También se incluyen especies observadas por Douglas F. Stotz durante una visita a Bermejo en noviembre del 1998. Las especies que solamente fueron observadas en la visita de Stotz están marcadas con un asterisco.
Shishicho

\begin{tabular}{ll}
\hline Abundancia relativa/ & Rango altitudinal/ \\
Relative abundance & Elevational range (m)
\end{tabular}

\section{Ccuccono \& Sinangoe}

\begin{tabular}{ll}
\hline Abundancia relativa/ & Rango altitudinal/ \\
Relative abundance & Elevational range $(\mathrm{m})$
\end{tabular}

\section{Hábitats/Habitats}

$\mathrm{Fm}$

Fhl, Fhu

Fhl

FC $600-9006$

\begin{tabular}{lll}
\hline$U$ & $600-1000$ & $F h$ \\
$U$ & 600 & $F h$ \\
$U$ & 600 & $F h$
\end{tabular}

Fhl

Fhl
$900-1000$

$-$

150 .

- n - - n

151. FC

$900-1000$

FC

\begin{tabular}{ll}
$600-1100$ & Fhl, Fhu \\
- & $\mathrm{Fm}$ \\
\hline- & $\mathrm{Fm}$
\end{tabular}

153.

$-$

154.
155.
156.
157.
158.
159.

FC

U 1400

U 1400

1100

-
FC
FC
-

\begin{tabular}{ll}
- & - \\
\hline & 900
\end{tabular}

FC

U

900-1100

$\mathrm{Fe}$

\begin{tabular}{lll}
160. & FC & 1400 \\
\hline 161. & FC & $1200-1400$ \\
162. & - & -
\end{tabular}

$-$

$600-1100$

$-$

Fhu

Fhu, Fsm

$\mathrm{Fm}$

Fhl, Fhu

Fhl

163.

$-$

- $\quad$ Fhu

- Fhu

- $\quad \mathrm{Fhl}$

$\begin{array}{rrrrrr}164 . & \mathrm{U} & 900 & \text { FL } & 900-1100 & \text { Fhu }\end{array}$

\begin{tabular}{|c|c|c|c|c|c|}
\hline 165. & FC & $900-1000$ & FC & $600+$ & Fhl \\
\hline 166. & U & 1000 & U & 1100 & Fhu \\
\hline 167. & - & - & $\mathrm{U}$ & 1100 & Fhu \\
\hline 168. & - & - & - & - & Fhu \\
\hline 169. & - & - & FC & $1000-1100$ & Fhu \\
\hline 170. & - & - & $\mathrm{U}$ & 600 & Fhl \\
\hline 171. & - & - & $x$ & 900 & Fsm \\
\hline
\end{tabular}

$\begin{array}{lll}172 . & - & - \\ 173 . & - & - \\ 174 . & - & -\end{array}$

$\mathrm{FC}$

$600-1100$

Fhl, Fhu

$600-900$

Fhl

$0=$ Cielo abierto/Open sky overhead

$\mathrm{Rm}=$ Márgenes de los ríos/River margins

$\mathrm{Fe}=$ Bordes del bosque (incluye vegetación secundaria $\mathrm{y}$ regeneración en áreas de derrumbe)/Forest edges (includes

early regenerating habitats, such as on landslides)

$\mathrm{Fhl}=$ Bosque de laderas bajas/Lower hill forest

Fhu $=$ Bosque de laderas altas/Upper hill forest

$\mathrm{Fm}=$ Bosque nuboso/Mountain forest or cloud forest

$\operatorname{Frp}=$ Bosque ripario/Riparian forest

Fsm = Bosques al márgen de las quebradas $/$ Forest stream margins

\footnotetext{
* Especies observadas solamente por Stotz./Species recorded only by D.F. Stotz.
} 

Especie/Species \begin{tabular}{ll}
\multicolumn{2}{c}{ Bermejo } \\
\begin{tabular}{ll}
\hline Abundancia relativa/ & Rango altitudinall \\
Relative abundance & Elevational range $(\mathrm{m})$
\end{tabular}
\end{tabular} Nombre común/Comman name

145. Dendrocincla tyrannina

146. Glyphoynchus spirurus

Tyrannine Woodcreeper/Trepador Tiranino 2000

47. Dendrexetastes rufigula

Wede-billed Wodcrepertepa

148. Xiphocolaptes promeropinynchus Strong-billed Woodcreeper Trepador de pico Fuere

149. Dendrocolaptes certhia

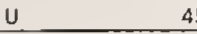

151. Xiphorhynchus ocellatus

Barred Woodcreeper/Trepador Barreteado

Buff-throated Woodcreeper/

Ocellated Woodcreeper/Trepador Ocelado

\begin{tabular}{ll}
$U$ & 2000 \\
\hline $\mathrm{FC}$ & $450+$ \\
\hline
\end{tabular}

52. xiphom nchus triangularis

Olive-backed Woodcreeper/Trepador de Oorso Oliv

153. Campylorhamphus pucherani Greater Scythebill/Pico-Guadaña Grande

\section{Furnariidae (18)}

\begin{tabular}{|c|c|c|c|}
\hline 154. Synallaxis moesta & Ousky Spinetail/Cola-Espina Oscura & FC & $750-1200$ \\
\hline 155. Cranioleuca curtata & Ash-browed Spinetail/Cola-Espina de Ceja Ceniza & $\mathrm{u}$ & 1200 \\
\hline 156. Premnoplex brunnescens & Spotted Barbtail/Cola-Pủa Moteada & $\mathrm{FC}$ & $1600-1900$ \\
\hline 157. Pseudocolaptes boissonneautii & Streaked Tuftedcheek/Barba-blanca Rayado & $\mathrm{FC}$ & 2000 \\
\hline 158. Hyloctistes subulatus & Striped Woodhaunter/Rondador-Bosque Listado & - & - \\
\hline 159. Ancistrops strigilatus & $\begin{array}{l}\text { Chestnut-winged Hookbill/ } \\
\text { Pico-gancho de Ala Castaña }\end{array}$ & $\mathrm{x}$ & 450 \\
\hline 160. Syndactyla subalaris & Lineated Foliage-gleaner/Limpia-follaje Lineado & - & - \\
\hline 161. Anabacerthia striaticollis & Montane Foliage-gleaner/Limpia-follaje Montano & $\mathrm{U}$ & 1200 \\
\hline 162. Philydor enthropterus* & $\begin{array}{l}\text { Chestnut-winged Foliage-gleaner/ } \\
\text { Limpia-follaje de Ala Castaña }\end{array}$ & $\mathrm{x}$ & 450 \\
\hline 163. Philydor pyrrhodes & $\begin{array}{l}\text { Cinnamon-rumped Foliage-gleaner/ } \\
\text { Limpia-follaje de Rabadilla Canela }\end{array}$ & $\mathrm{u}$ & 450 \\
\hline \multicolumn{2}{|c|}{ 164. Philydor erythrocerus/nficaudatus foliage-gleaner (species)/limpia-follaje (especie) } & $\mathrm{u}$ & 900 \\
\hline 165. Automolus ochrolaemus & $\begin{array}{l}\text { Buff-throated Foliage. gleaner/ } \\
\text { Hoja-Rasquero de Garganta Anteada }\end{array}$ & FC & $450-1000$ \\
\hline 166. Automolus rubiginosus & Ruddy Foliage-gleaner/Hoja-Rasquero Rojizo & $\mathrm{u}$ & 1200 \\
\hline 167. Thripadectes melanorhynchus & Black-billed Treehunter/Trepa-palo de Pico Negro & - & - \\
\hline 168. Xenops minutus & Plain Xenops/Pico-Lezna Simple & $u$ & 975 \\
\hline 169. Xenops rutilans & Streaked Xenops/Pico-Lezna Rayado & - & - \\
\hline 270. Sclerurus caudacutus & Black-tailed Leaftosser/Tira-hoja de Cola Negra & $x$ & - \\
\hline 171. Lochmias nematura & Sharp-tailed Streamcreeper/Riachuelero & $=$ & - \\
\hline \multicolumn{4}{|l|}{ Thamnophilidae (33) } \\
\hline 172. Cymbilaimus lineatus & Fasciated Antshrike/Batará Lineado & $\mathrm{FC}$ & $450-1200$ \\
\hline 173. Frederickena unduligera & Undulated Antshrike/Batará Ondulado & $\mathrm{FC}$ & $450-1100$ \\
\hline 174. Taraba major* & Great Antshrike/Batará Grande & $x$ & - \\
\hline
\end{tabular}

\section{Abundancia Relativa/Relative Abundance}

450

$450-700$

\begin{tabular}{ll} 
FC & $450-700$ \\
FC & 1200 \\
\hline
\end{tabular}

$\begin{array}{ll}\mathrm{FC} & 1200 \\ \mathrm{FC} & 1900-2200 \\ \mathrm{X} & 2100\end{array}$

$C=$ Bastante común (registrada diariamente en su hábitat apropiado)/Fairly common (recorded daily in suitable habita = Poco comin (presente pero no registrada diariament
en su habbitat apropriado)/ Uncommon (present, but
not recorded daily, even in suitable habitat) $=$ Raro/Rare

Rango Altitudinal/Elevational Range

Los datos presentados aqui soblo indican las elevaciones a las cuales cada especie fue observada durante el inventario rápido y no representan la distribución altitudinal de las especies a través de la región. . The elevational ranges each species was observed during the rapid biological

$x=$ Presente pero con datos insuficientes para estimar inventory, and are not meant to describe the complete abundancia/Present, but with insufficient data to assess elevational distribution of each species in the region.

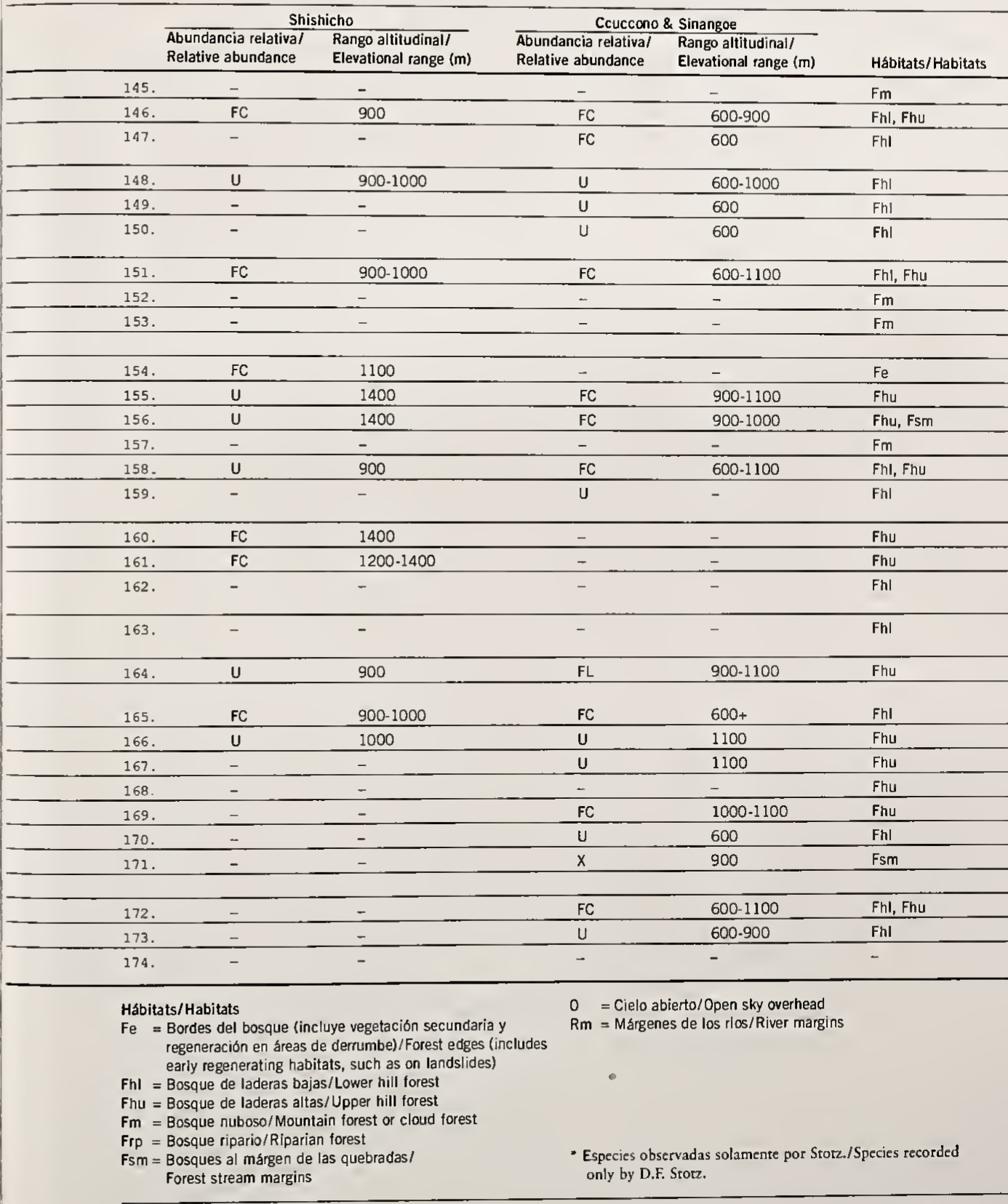

CUADOR: SERTANIAS COFAN 
Birds observed at three sites in the Serranias Cofán, Sucumbios province, Ecuador, 24 July-16 August 2001. Principal ornithologist: Thomas S. Schulenberg, with observations by Debra K. Moskovits, Randy Borman, and others; also included are species observed at Bermejo by Douglas F. Stotz in November 1998 (species AVES/ I I D S recorded only during the November visit are indicated with an asterisk).

\begin{tabular}{|c|c|c|c|}
\hline \multirow[b]{2}{*}{ Especie/Species } & \multirow[b]{2}{*}{ Nombre común/Common name } & \multicolumn{2}{|c|}{ Bermejo } \\
\hline & & $\begin{array}{l}\text { Abundancia relativa/ } \\
\text { Relative abundance }\end{array}$ & $\begin{array}{l}\text { Rango altitudinal/ } \\
\text { Elevational range (m) }\end{array}$ \\
\hline 175. Thamnophilus palliatus & Lined Antshrike/Batará Listado & $\mathrm{U}$ & 1200 \\
\hline 176. Thamnophilus unicolor & Uniform Antshrike/Batará Unicolor & $\mathrm{FC}$ & 1900 \\
\hline 177. Thamnophilus schistaceus & Plain-winged Antshrike/Batará de Ala Llana & $\mathrm{FC}$ & $450-1000$ \\
\hline 178. Thamnistes anabatinus & Russet Antshrike/Batará Bermejo & $\mathrm{FC}$ & 1200 \\
\hline 179. Dysithamnus leucostictus & White-streaked Antvireo/Batará Rayado de Blanco & $U$ & 1100 \\
\hline 180. Dysithamnus mentalis & Plain Antvireo/Batarito de Cabeza Gris & $\mathrm{FC}$ & $900-1200$ \\
\hline 181. Thamnomanes ardesiacus & Dusky-throated Antshrike/Batará de Garganta Oscura & $\mathrm{FC}$ & 450 \\
\hline 182. Myrmotherula axillaris & $\begin{array}{l}\text { White-flanked Antwren/ } \\
\text { Hormiguerito de Flancos Blancos }\end{array}$ & FC & $450-1000$ \\
\hline 183. Myrmotherula behni & Plain-winged Antwren/Hormiguerito de Ala Llana & $U$ & $1100-1200$ \\
\hline 184. Myrmotherula erythrura* & Rufous-tailed Antwren/Hormiguerito de Cola Rufa & $\mathrm{x}$ & 450 \\
\hline 185. Myrmotherula menetriesii ${ }^{\star}$ & Gray Antwren/Hormiguerito Gris & $\mathrm{x}$ & 450 \\
\hline 186. Myrmotherula obscura & Short-billed Antwren/Hormiguerito de Pico Corto & $\mathrm{FC}$ & 450 \\
\hline 187. Myrmotherula ornata & Ornate Antwren/Hormiguerito Bajo Andino & - & - \\
\hline 188. Myrmotherula spodionota & Foothill Antwren/Hormiguerito Bajo Andino & $\mathrm{FC}$ & $1000-1200$ \\
\hline 189. Herpsilochmus axillaris & $\begin{array}{l}\text { Yellow-breasted Antwren/ } \\
\text { Hormiguerito Pecho Amarillo }\end{array}$ & $U$ & 1200 \\
\hline 190. Herpsilochmus rufimarginatus & Rufous-winged Antwren/Hormiguerito de Ala Rufa & $\mathrm{FC}$ & $900-1200$ \\
\hline 191. Terenura callinota & $\begin{array}{l}\text { Rufous-rumped Antwren/ } \\
\text { Hormiguerito de Rabadilla Rufa }\end{array}$ & - & - \\
\hline 192. Cercomacra cinerascens & Gray Antbird/Hormiguero Gris & $\mathrm{FC}$ & $450-1200$ \\
\hline 193. Cercomacra serva & Black Antbird/Hormiguero Negro & $\mathrm{FC}$ & $450-1200$ \\
\hline 194. Pyriglena leuconota & $\begin{array}{l}\text { White-backed Fire-eye/ } \\
\text { Ojo-de-Fuego de Dorso Blanco }\end{array}$ & FC & 1200 \\
\hline 195. Myrmoborus myotherinus & Black-faced Antbird/Hormiguero de Cara Negra & $U$ & $450-900$ \\
\hline 196. Hypocnemis cantator & Warbling Antbird/Hormiguero Gorjeador & $\mathrm{U}$ & 450 \\
\hline 197. Percnostola leucostigma & Spot-winged Antbird/Hormiguero de Ala Moteada & $\mathrm{FC}$ & $450-900$ \\
\hline 198. Myrmeciza fortis & Sooty Antbird/Hormiguero Tiznado & $\mathrm{U}$ & 1200 \\
\hline 199. Myrmeciza melanoceps & $\begin{array}{l}\text { White-shouldered Antbird/ } \\
\text { Hormiguero de Hombros Blancos }\end{array}$ & - & - \\
\hline 200. Pithys albifrons & $\begin{array}{l}\text { White-plumed Antbird/ } \\
\text { Hormiguero de Plumón Blanco }\end{array}$ & $U$ & 1200 \\
\hline 201. Gymnopithys leucaspis & Bicolored Antbird/Hormiguero Bicolor & $\mathrm{U}$ & 1200 \\
\hline 202. Rhegmatorhina melanosticta & Hairy-crested Antbird/Hormiguero de Cresta Canosa & $x$ & 900 \\
\hline 203. Hylophylax naevia & Spot-backed Antbird/Hormiguero de Dorso Moteado & $\mathrm{FC}$ & $900-1200$ \\
\hline 204. Hylophylax poecilinota & $\begin{array}{l}\text { Scale-backed Antbird/ } \\
\text { Hormiguero de Dorso Escamado }\end{array}$ & $\mathrm{FC}$ & $450-900$ \\
\hline
\end{tabular}

Abundancia Relativa/Relative Abundance

$\mathrm{FC}=$ Bastante común (registrada diariamente en su hábitat apropiado)/Fairly common (recorded daily in suitable habitat)

$\mathrm{U}=$ Poco común (presente pero no registrada diariamente en su hábitat apropriado)/Uncommon (present, but not recorded daily, even in suitable habitat)

$\mathrm{R}=$ Raro/Rare

$X=$ Presente pero con datos insuficientes para estimar abundancia/Present, but with insufficient data to assess relative abundance
Rango Altitudinal/Elevational Range

Los datos presentados aquí sólo indican las elevaciones a las cuales cada especie fue observada durante el inventario rápido y no representan la distribución altitudinal de las especies a través de la región./The elevational ranges presented in this table refer only to the altitudes at which each species was observed during the rapid biological inventory, and are not meant to describe the complete elevational distribution of each species in the region. 
APÉNDICE/APPENDIX 3

Aves/Birds
Especies de aves registradas en tres sitios de las Serranias Cofán, Provincia de Sucumbios, Ecuador, del 24 de julio al 16 de agosto 2001. Omitólogo principal: Thomas S. Schulenberg. Observaciones adicionales de Debra K. Moskovits, Randy Borman y otros. También se incluyen especies observadas por Douglas F. Stotz durante una visita a Bermejo en noviembre del 1998. Las especies que solamente fueron observadas en la visita de Stotz están mareadas con un asterisco.

\begin{tabular}{|c|c|c|c|c|c|}
\hline & \multicolumn{2}{|c|}{ Shishicho } & \multicolumn{2}{|c|}{ Ccuccono \& Sinangoe } & \multirow[b]{2}{*}{ Hábitats/Habitat } \\
\hline & $\begin{array}{l}\text { Abundancia relativa/ } \\
\text { Relative abundance }\end{array}$ & $\begin{array}{l}\text { Rango altitudinal/ } \\
\text { Elevational range }(\mathrm{m})\end{array}$ & $\begin{array}{l}\text { Abundancia relativa/ } \\
\text { Relative abundance }\end{array}$ & $\begin{array}{l}\text { Rango altitudinal/ } \\
\text { Elevational range }(\mathrm{m})\end{array}$ & \\
\hline 175. & FC & 1100 & FC & $900-1000$ & $\mathrm{Fe}$ \\
\hline 176. & FC & 1400 & - & - & Fhu \\
\hline 177. & FC & $900-1000$ & FC & $600-1100$ & Fhl, Fhu \\
\hline 178. & FC & 900 & $\mathrm{U}$ & 900 & Fhu \\
\hline 179. & $u$ & 1400 & - & - & Fhu \\
\hline 180. & FC & $900-1400$ & FC & $900-1100$ & Fhu \\
\hline 181. & - & - & FC & 600 & $\mathrm{Fhl}$ \\
\hline 182. & - & - & FC & 600 & $\mathrm{Fhl}$ \\
\hline 183. & - & - & $\mathrm{U}$ & 1100 & Fhu \\
\hline 184. & - & - & - & - & $\mathrm{Fhl}$ \\
\hline 185. & - & - & - & - & Fhl \\
\hline 186. & FC & 700 & FC & 600 & Fhl \\
\hline 187. & - & - & FC & $600-900$ & $\mathrm{Fhl}$ \\
\hline 188. & FC & 900 & FC & $900-1100$ & Fhu \\
\hline 189. & - & - & - & - & Fhu \\
\hline 190. & FC & $900-1400$ & FC & $900-1100$ & Fhl, Fhu \\
\hline 191. & - & - & $u$ & 1100 & Fhu \\
\hline 192. & $\mathrm{FC}$ & $900-1000$ & FC & $600-1100$ & Fhl, Fhu \\
\hline 193. & FC & 1100 & FC & $900-1000$ & $\mathrm{Fe}, \mathrm{Fsm}$ \\
\hline 194. & FC & $1200-1400$ & U & 900 & Fhu \\
\hline 195. & - & - & - & - & $\mathrm{Fhl}$ \\
\hline 196. & - & - & - & - & $\mathrm{Fhl}$ \\
\hline 197. & - & - & $x$ & 900 & Fhl, Fsm \\
\hline 198. & - & - & $x$ & 900 & Fhu \\
\hline 199. & - & - & $x$ & 600 & Fsm \\
\hline 200. & - & - & U & 900 & Fhl, Fhu \\
\hline 201. & - & - & - & - & Fhu \\
\hline 202. & - & 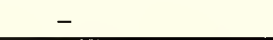 & - & - & ? \\
\hline 203. & FC & 900 & FC & $900-1100$ & Fhu \\
\hline 204 & $x$ & 850 & FC & $900-1100$ & Fhl, Fhu \\
\hline
\end{tabular}

\section{Hábitats/Habitats}

$\mathrm{Fe}=$ Bordes del bosque (incluye vegetación secundaria y regeneración en áreas de derrumbe)/Forest edges (includes early regenerating habitats, such as on landslides)

Fhl = Bosque de laderas bajas/Lower hill forest

Fhu $=$ Bosque de laderas altas/Upper hill forest

$\mathrm{Fm}=$ Bosque nuboso/Mountain forest or cloud forest

Frp = Bosque ripario/Riparian forest

Fsm = Bosques al márgen de las quebradas $/$ Forest stream margins
0 = Cielo abierto/Open sky overhead

$\mathrm{Rm}=$ Márgenes de los ríos/River margins

* Especies observadas solamente por Stotz./Species recorded only by D.F. Stotz. 

175. Thamnophilus palliatus Relative abundance Elevationat range ( $\mathrm{m}$ )

Lined Antshrike/Batará Listado

U 1200

176. Thamnophilus unicolor Uniform Antshrike/Bataráanicolor $\quad$ FC 1900

177. Thamnophtlus schistaceus Plain-winged Antshrike/Batará de Ala Llana

F $\quad 450 \cdot 1000$

178. Thamnistes anabatinus

Russet Antshrike/Batará Bermejo

FC $\quad 1200$

180. Dysithamnus mentalis

White-streaked Antvireo/Batará Rayado de Blanco

$-\frac{1100}{900-1200}$

The Ousky-throated Antshrike/Batará de Garganta Oscura _ _ FC _ _ _ 450

181. Mamnomanes ardesiacus Whotherula axillaris White-flanked Antwren

FC $450-1000$

Hormian 1100.1200

183. Myrmotherula behni

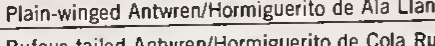

184. Myrmotherula erythrura* Rufous-tailed Antwren//Mormiguerito

186. Short-billed Antwren/Hormiguerito de Pico Corto

186. Mor morula obscu

Ornate Antwren/Hormiguerito Bajo Andino

Foothill Antwren/Hormiguerito Bajo Andino

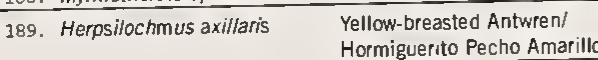

450

$x-\frac{450}{450}$

$\mathrm{X}-\frac{450}{450}$

FC $-\frac{1000-1200}{1200}$

190. Herpsilochmus rufimarginatus

\section{Tufous.rumped Antwren}

Rutous-rumped Antwren/
Hormiguerito de Rabadilla Rufa

192. Cercomacra cinerascens Gray Antbird/Hormiguero Gris

193. Cercomacra serva

Black Antbird/Hormiguero Negro

White-backed Fire-eye/
Ojo-de-Fuego de Dorso Blanco

195. Myrmoborus myotherinus

196. Hypocnemis cantator

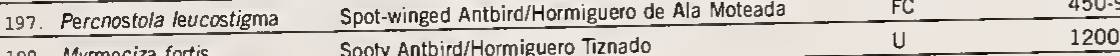

Black-taced Antbird/Hormiguero de Cara Negra

$\mathrm{FC}-900-1200$

Warbling Antbird/Hormiguero Gorjea

\begin{tabular}{l}
$\mathrm{FC}-450-1200$ \\
\hline $\mathrm{FC}$
\end{tabular}

199. Myrmeciza melanoceps White-shouldered Antbird/

200. Pithys albifrons - Hormiguero de Hombros Blances

Hormiguero de Plumón Blanco

201. Gymnooithys leucaspis Bicolored Antbird/Hormiguero Bicolor

201. Gymnopithys leucaspis Rhegmatorhina me/anosticta Hairy-crested Antbird/Hormiguero de Cresta Canosa

203. Hylophylax naevi

Scale-backed Antbird/ Hormiguero de Oorso Escamado

1200

1200

$\begin{array}{ll}U & 1200 \\ X & 900 \\ F C & 900-1200 \\ F C & 450-900\end{array}$

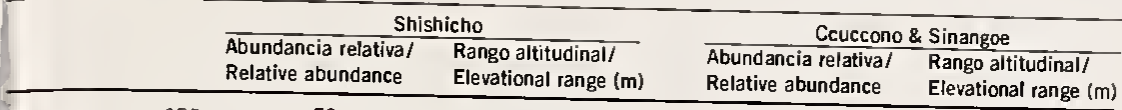

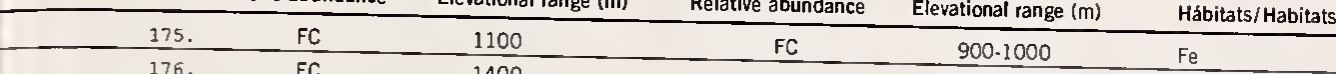

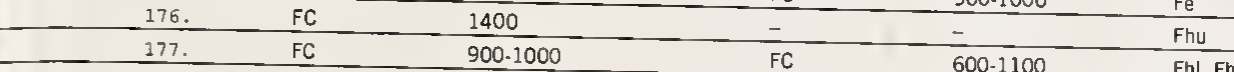

\begin{tabular}{lllll} 
178. & FC & 900 & $-600-1100$ & Fhl, Fhu \\
\hline 179 & $U$ & $U$ & 900 & Fhu
\end{tabular}

180. $-\mathrm{FC}-900-1400-\mathrm{FC}-900-1100-$ Fhu

\begin{tabular}{rlllll}
180. & $\mathrm{FC}$ & $900-1400$ & $\mathrm{FC}$ & $900-1100$ & Fhu \\
\hline 181. & - & - & $\mathrm{FC}$ & 600 & $\mathrm{Fhl}$ \\
\hline 182. & - & - & $\mathrm{FC}$ & 600 & $\mathrm{Fhl}$ \\
\hline
\end{tabular}

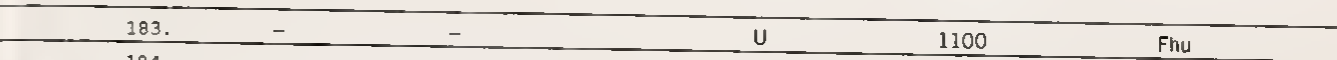

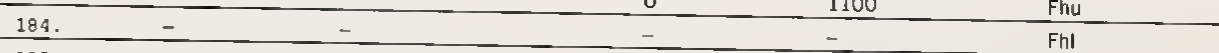

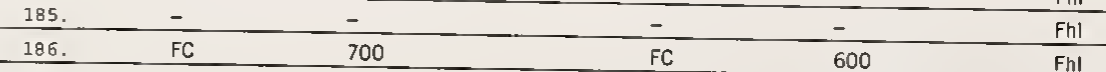

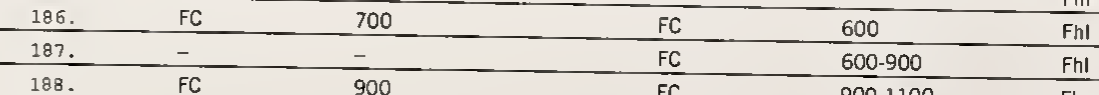

\begin{tabular}{|c|c|c|c|c|c|}
\hline & & & $\mathrm{FC}$ & $600-900$ & Fhl \\
\hline 188 & $\mathrm{FC}$ & 900 & $F C$ & $900-110$ & \\
\hline
\end{tabular}

\begin{tabular}{|c|c|c|c|c|c|}
\hline 190. & FC & $900 \cdot 1400$ & $\mathrm{FC}$ & $900-1100$ & Fhl, Fhu \\
\hline 191. & 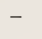 & - & u & 1100 & Fhu \\
\hline 192. & $\mathrm{FC}$ & $900-1000$ & $F C$ & $600-1100$ & Fhl, Fhu \\
\hline 193. & $\mathrm{FC}$ & 1100 & $\mathrm{FC}$ & $900-1000$ & $\mathrm{Fe}, \mathrm{Fsm}$ \\
\hline 194. & $\mathrm{FC}$ & $1200-1400$ & u & 900 & Fhu \\
\hline 195. & - & - & - & - & Fhl \\
\hline 196. & $=$ & - & - & - & Fhl \\
\hline 197. & $=$ & - & $x$ & 900 & $\mathrm{Fhl}, \mathrm{Fsm}$ \\
\hline 198. & - & - & $x$ & 900 & Fhu \\
\hline 199. & - & - & $x$ & 600 & Fsm \\
\hline 200. & - & - & u & 900 & Fhl, Fhu \\
\hline
\end{tabular}

\begin{tabular}{|llllll|}
\hline 201. & - & - & - & - & Fhu \\
\hline 202. & - & - & - & - & $?$ \\
\hline 203. & FC & 900 & FC & $900 \cdot 1100$ & Fhu \\
\hline 204. & $X$ & B50 & FC & $900 \cdot 1100$ & Fhl, Fhu \\
\hline
\end{tabular}

\section{Abundancia Relativa/Refative Abundance}

$C=$ Bastante común (registrada dlariamente en su hábitat

apropiado)/Fainy conmon (recorded darly in suitable hab

= Poco común (presente pero no registrada diariamente

not recorded daily, even in suitable habitat)

$R=$ Raro $/$ Rare

$x=$ Presente pero con datos insuficientes para estimar Presente pero con datos insuficientes para estimar
abundancia/Present, but with insufficient data to asses
relative abundance

Rango Altitudinal/Elevational Range

indican las elevaciones a

repido y representan la distribución altitudinal de las

especies a través de la región./The elevational ranges

presented in this table refer only to the altitudes at whic

each species was observed during the rapid biological

inventry, and are nation
Hábitats/Habitats

$=$ Bordes del bosque (incluye vegetación secundaria y

regeneración en áreas de derrumbe)/Forest edges (incl
early regenerating habitats, such as on landslides)

$\mathrm{Fhl}=$ Bosque de laderas bajas $/$ Lower hill forest

$\mathrm{Fhu}=$ Bosque de laderas altas/Upper hill forest
$\mathrm{Fm}=$ Bosque nuboso/Mountain forest or cloud fores

$\mathrm{Fm}=$ Bosque nuboso/Mountain forest
$\mathrm{Frp}=$ Bosque ripario/Riparian forest

Fsm = Bosques al márgen de las quebradas Forest stream margins

CUADOR: SERRANIAS COFÁN
$0=$ Cielo abierto/Open sky overhead

$\mathrm{Rm}=$ Márgenes de los rlos/River margins Especies observadas solamente por Stozz./Species recorded
only by D.F. Stozz. 
Birds observed at three sites in the Serranias Cofän, Sucumbios province, Ecuador, 24 July-16 August 2001. Principal ornithologist: Thomas S. Schulenberg, with observations by Debra K. Moskovits, Randy Borman, and others; also included are species observed at Bermejo by Douglas F. Stotz in November 1998 (species AVESIRIRDS recorded only during the November visit are indicated with an asterisk).

\begin{tabular}{|c|c|c|c|}
\hline \multirow[b]{2}{*}{ Especie/Species } & \multirow[b]{2}{*}{ Nombre común/Common name } & \multicolumn{2}{|c|}{ Bermejo } \\
\hline & & $\begin{array}{l}\text { Abundancia relativa/ } \\
\text { Relative abundance }\end{array}$ & $\begin{array}{l}\text { Rango altitudinal/ } \\
\text { Elevational range }(\mathrm{m})\end{array}$ \\
\hline \multicolumn{4}{|l|}{ Formicariidae (9) } \\
\hline 205. Formicarius analis & $\begin{array}{l}\text { Black-faced Antthrush/ } \\
\text { Gallito-Hormiguero de Cara Negra }\end{array}$ & FC & $450+$ \\
\hline 206. Formicarius colma* & $\begin{array}{l}\text { Rufous-capped Antthrush/ } \\
\text { Gallito-Hormiguero de Gorra Rufa }\end{array}$ & $x$ & $450-750$ \\
\hline 207. Chamaeza campanisona & Short-tailed Antthrush/Rasconzuelo de Cola Corta & FC & $900-1200$ \\
\hline 208. Grallaria alleni & Moustached Antpitta/Tororoi Bigotudo & $x$ & 2000 \\
\hline 209. Grallaria guatimalensis & Scaled Antpitta/Tororoi Escamado & - & - \\
\hline 210. Grallaria haplonota & Plain-backed Antpitta/Tororoi de Dorso Llano & $\mathrm{FC}$ & 1200 \\
\hline 211. Grallaria ruficapilla & $\begin{array}{l}\text { Chestnut-crowned Antpitta/ } \\
\text { Tororoi de Corona Castaña }\end{array}$ & $\mathrm{U}$ & $1900-2100$ \\
\hline 212. Hylopezus fulviventris & White-lored Antpitta/Tororoi de Lorum Blanco & - & - \\
\hline 213. Myrmothera campanisona & Thrush-like Antpitta/Tororoi Campanero & $\mathrm{FC}$ & $450+$ \\
\hline \multicolumn{4}{|l|}{ Conopophagidae (1) } \\
\hline 214. Conopophaga castaneiceps & $\begin{array}{l}\text { Chestnut-crowned Gnateater/ } \\
\text { Jejenero de Corona Castaña }\end{array}$ & FC & $900-1200$ \\
\hline \multicolumn{4}{|l|}{ Rhinocryptidae (4) } \\
\hline 215. Liosceles thoracicus & Rusty-belted Tapaculo/Tapaculo de Faja Rojiza & $\mathrm{FC}$ & $450+$ \\
\hline 216. Scytalopus atratus & White-crowned Tapaculo/Tapaculo de Frente Blanca & - & - \\
\hline 217. Scytalopus micropterus & Long-tailed Tapaculo/Tapaculo de Cola Larga & $\mathrm{FC}$ & $1500-2000$ \\
\hline 218. Scytalopus spillmanni & Spillmann's Tapaculo/Tapaculo de Spillmann & $\mathrm{FC}$ & $1900-2200$ \\
\hline \multicolumn{4}{|l|}{ Tyrannidae (64) } \\
\hline 219. Phyllomyias zeledoni & $\begin{array}{l}\text { White-fronted Tyrannulet/ } \\
\text { Moscareta de Frente Blanca }\end{array}$ & $?$ & - \\
\hline 220. Zimmerius chrysops & Golden-faced Tyrannulet/Moscareta de Cara Dorada & $\mathrm{FC}$ & $900-2100$ \\
\hline 221. Zimmerius gracilipes* & Slender-footed Tyrannulet/Moscareta de Patas Finas & $x$ & 450 \\
\hline 222. Ornithion inerme & White-lored Tyrannulet/Moscareta de Lorum Blanco & $\mathrm{U}$ & 450 \\
\hline 223. Tyrannulus elatus & $\begin{array}{l}\text { Yellow-crowned Tyrannulet/ } \\
\text { Moscareta de Corona Amarilla }\end{array}$ & $U$ & 450 \\
\hline 224. Myiopagis caniceps* & Gray Elaenia/Elainia Gris & $\mathrm{x}$ & 450 \\
\hline 225. Myiopagis gaimardii* & Forest Elaenia/Elainia de Selva & $x$ & 450 \\
\hline 226. Myiopagis olallai & Foothill Elaenia/Elainia Bajo Andino & $\mathrm{U}$ & 1200 \\
\hline 227. Mecocerculus minor & $\begin{array}{l}\text { Sulphur-bellied Tyrannulet/ } \\
\text { Tiranillo de Vientre Azufrado }\end{array}$ & $\mathrm{FC}$ & 2000 \\
\hline 228. Mionectes oleagineus & $\begin{array}{l}\text { Ochre-bellied Flycatcher/ } \\
\text { Mosquerito de Vientre Ocráceo }\end{array}$ & $U$ & 450 \\
\hline 229. Mionectes olivaceus & Olive-striped Flycatcher/Mosquerito Rayado de Oliva & $\mathrm{FC}$ & $450-1200$ \\
\hline 230. Leptopogon rufipectus & Rufous-breasted Flycatcher/Mosquerito de Pecho Ruf & ufo & 2000 \\
\hline
\end{tabular}

Abundancia Relativa/Relative Abundance

$\mathrm{FC}=$ Bastante común (registrada diariamente en su hábitat apropiado)/Fairly common (recorded daily in suitable habitat)

$U=$ Poco común (presente pero no registrada diariamente en su hábitat apropriado)/Uncommon (present, but not recorded daily, even in suitable habitat)

$\mathrm{R}=$ Raro/Rare

$X=$ Presente pero con datos insuficientes para estimar abundancia/Present, but with insufficient data to assess relative abundance

\section{Rango Altitudinal/Elevational Range}

Los datos presentados aquí sólo indican las elevaciones a las cuales cada especie fue observada durante el inventario rápido y no representan la distribución altitudinal de las especies a través de la región./The elevational ranges presented in this table refer only to the altitudes at which each species was observed during the rapid biological inventory, and are not meant to describe the complete elevational distribution of each species in the region. 
APENDICE/APPENDIX 3

Aves/Birds
Especies de aves registradas en tres sitios de las Serranias Cofán, Provincia de Sucumbios, Ecuador, del 24 de julio al 16 de agosto 2001. Ornitólogo principal: Thomas S. Schulenberg. Observaciones adicionales de Debra K. Moskovits, Randy Borman y otros. También se incluyen especies observadas por Douglas F. Stotz durante una visita a Bermejo en noviembre del 1998. Las especies que solamente fueron observadas en la visita de Stotz están marcadas con un asterisco.

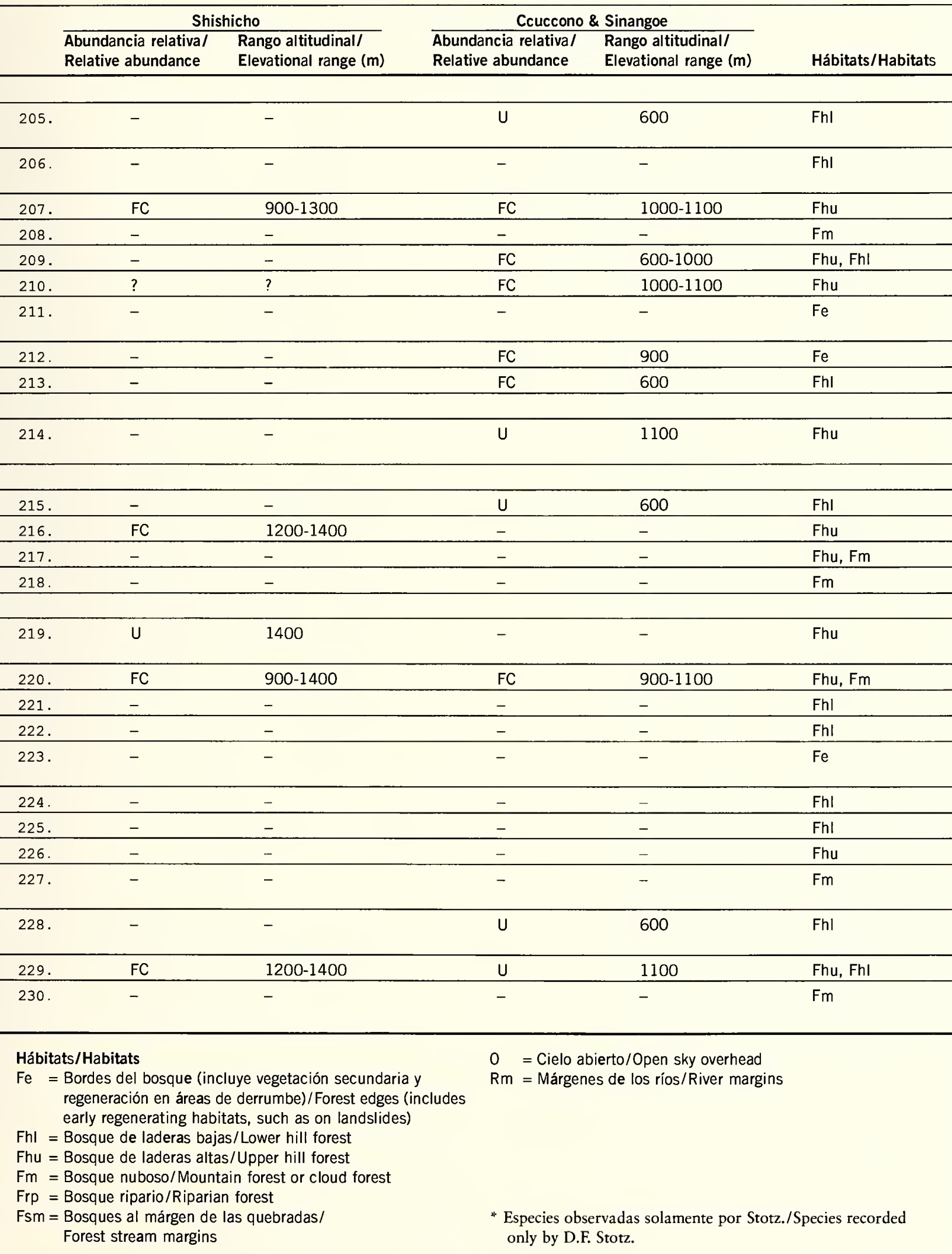



$\frac{\text { Bermejo }}{\text { Abundancia relativa/ Rango altitudinal/ }}$

\section{Formicariidae (9)} Nombre común/Common nam

$\begin{array}{lll} & \text { Rango altitudinal/ } \\ \text { Rejative abundance } & \text { Elevational range }(m)\end{array}$

\begin{tabular}{|c|c|c|c|c|}
\hline 205. & Formicarius analis & $\begin{array}{l}\text { Black-faced Antthrushl } \\
\text { Gallito-Hormiguero de Cara Negra }\end{array}$ & $\mathrm{FC}$ & $450+$ \\
\hline & Formicarius colma* & $\begin{array}{l}\text { Rufous-capped Antthrush/ } \\
\text { Gallito-Hormiguero de Gorra Rufa }\end{array}$ & $\mathrm{x}$ & $450-750$ \\
\hline 207. & Chamzeza campanisona & Short-tailed Antthrush/Rasconzuelo de Cola Corta & FC & $900-1200$ \\
\hline 208. & Grallaria alleni & Moustached Antpitta/Tororoi Bigotudo & $x$ & 2000 \\
\hline 209. & Grallaria guatmatensis & Scaled AntpittarTororoi Escamado & $=$ & - \\
\hline 210. & Grallaria haplonota & Plain-backed Antpitta/Tororoi de Dorso Llano & $\mathrm{FC}$ & 1200 \\
\hline 211. & Grallaria ruficapilla & $\begin{array}{l}\text { Chestnut-crowned Antpitta/ } \\
\text { Tororoi de Corona Castaña }\end{array}$ & $u$ & $1900-2100$ \\
\hline 212. & Hylopezus fulviventris & White-lored Antpitta/Tororoi de Lorum Blanco & - & - \\
\hline 213. & Mymothera campanisona. & Thrush-like Antpitta/Tororoi Campanero & $\mathrm{FC}$ & $450+$ \\
\hline \multicolumn{5}{|c|}{ Conopophagidae (1) } \\
\hline 214. & Conopophaga castaneiceps & $\begin{array}{l}\text { Chestnut-crowned Gnateater/ } \\
\text { Jejenero de Corona Castaña }\end{array}$ & $\mathrm{FC}$ & $900-1200$ \\
\hline \multicolumn{5}{|c|}{ Rhinocryptidae (4) } \\
\hline 215. & Liosceles thoracicus & Rusty-belted Tapaculo/Tapaculo de Faja Rojiza & $\mathrm{FC}$ & $450+$ \\
\hline 216. & Scytalopus atratus & White-crowned Tapaculo/Tapaculo de Frente Blanca & $=$ & - \\
\hline 217. & Scytalopus micropterus & Long-tailed Tapaculo/Tapaculo de Cola Larga & FC & $1500-2000$ \\
\hline 218.. & Scytalopus spilmanni & Spillmann's Tapaculo/Tapaculo de Spillmann & $\mathrm{FC}$ & $1900-2200$ \\
\hline \multicolumn{5}{|c|}{ Tyrannidae (64) } \\
\hline 219. & Phyllomyias zeledoni & $\begin{array}{l}\text { White-fronted Tyrannulet/ } \\
\text { Moscareta de Frente Blanca }\end{array}$ & $?$ & - \\
\hline 220. & Zimmerius chrysops & Golden-faced Tyrannulet/Moscareta de Cara Oorada & FC & $900-2100$ \\
\hline 221. 2 & Zimmerius gracilipes" & Slender-footed Tyrannulet/Moscareta de Patas Finas & $\mathrm{x}$ & 450 \\
\hline 222. & Urnithion ineme & White-lored TyrannuletMoscareta de Lorum Blanco & $u$ & 450 \\
\hline 223. & Tyrannulus elatus & $\begin{array}{l}\text { Yellow-crowned Tyrannulet/ } \\
\text { Moscareta de Corona Amarilla }\end{array}$ & $u$ & 450 \\
\hline 224. 1 & Myiopagis caniceps ${ }^{*}$ & Gray Elaenia/Elainia Gris & $\mathrm{x}$ & 450 \\
\hline 225.1 & Myiopagis gamardii* & Forest Elaenia/Elainia de Selva & $\mathrm{x}$ & 450 \\
\hline 226. 1 & Myiopagis olallai & Foothill Elaenia/Elainia Bajo Andino & u & 1200 \\
\hline 227. & Mecocerculus minor & $\begin{array}{l}\text { Sulphur-bellied Tyrannulet/ } \\
\text { Tiranillo de Vientre Azufrado }\end{array}$ & $\mathrm{FC}$ & 2000 \\
\hline 228.1 & Mionectes oleagineus & $\begin{array}{l}\text { Ochre-bellied Flycatcherl } \\
\text { Mosquerito de Vientre Ocráceo }\end{array}$ & $u$ & 450 \\
\hline 229. & Mionectes olivaceus & Olive-striped Flycatcher/Mosquerito Rayado de Oliva & $\mathrm{FC}$ & $450-1200$ \\
\hline 230. & Leptopogon rufipectus & Rufous-breasted Flycatcher/Mosquerito de Pecho R & u & 2000 \\
\hline
\end{tabular}

\section{Abundancia Relativa/Relative Abundance}

Rufous-breasted Flycatcher/Mosquerito de Pecho Rufo U 2000

$\mathrm{C}=$ Bastante común (registrada diariamente en su hábita

apropiado)/Fairly common (recorded daily in suitable habit
$=$ Poco comün (Presente pero no registrada diariamente en su hábitat apropriado)/Uncommon (present, but not recorded daily, even in sultable habitat

$R=$ Rarol Rare

Presente pero con datos insuficientes para estimar abundancia/Present, but with insufficient data to assess

Rango Altitudinal/Elevational Range

Los datos presentados aquí sólo indican las elevaciones a los cuales cada especie fue observada durante el invent especies a través de la región. The elevational ranges presented in this table refer only to the altitudes at which each species was observed during the rapid biological elevational distribution of each species in the region.

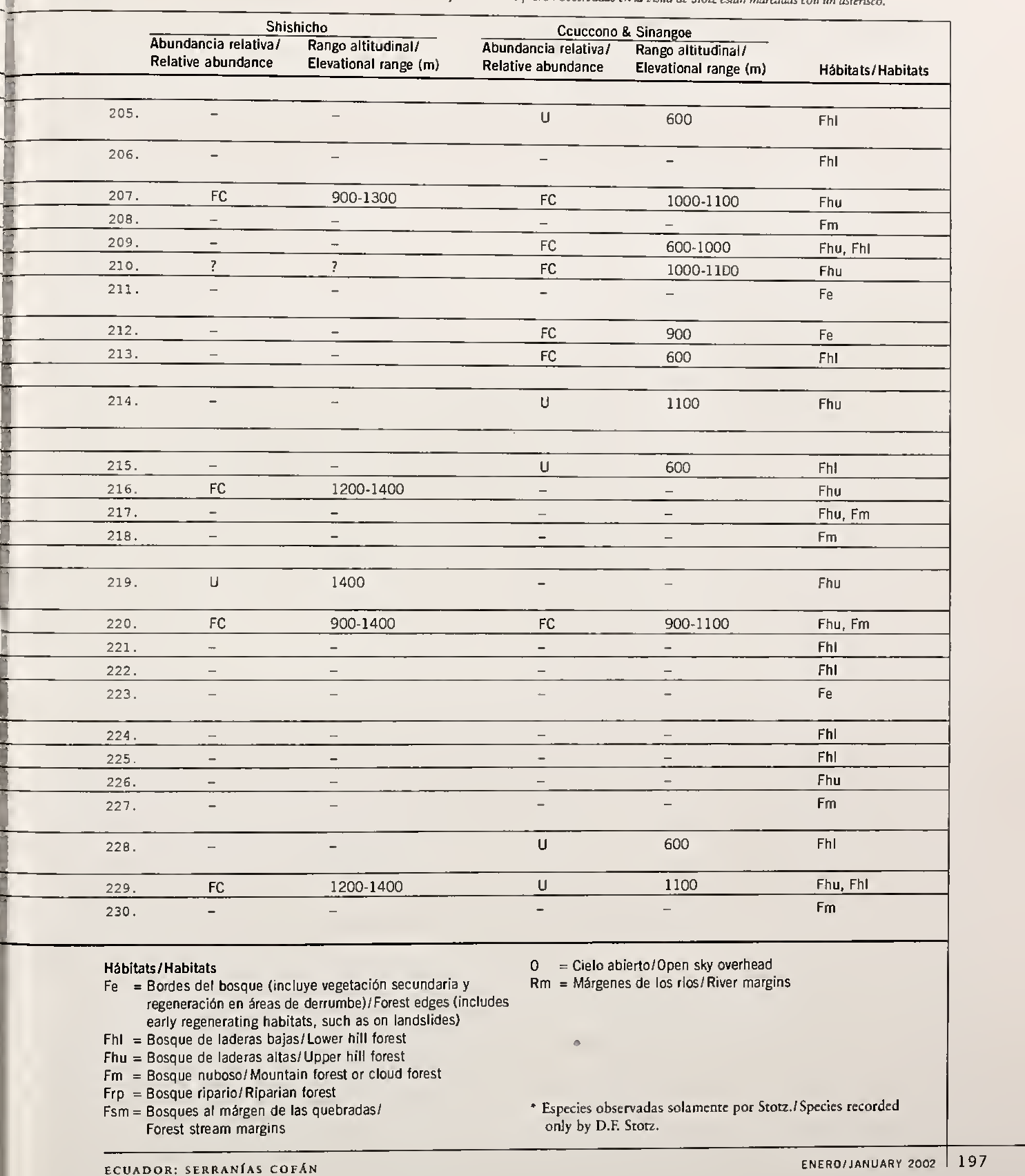


Birds observed at three sites in the Serranias Cofán, Sucumbios province, Ecuador, 24 July-16 August 2001. Principal ornithologist: Thomas S. Schulenberg, with observations by Debra K. Moskovits, Randy Borman, and others; also included are species observed at Bermejo by Douglas F. Stotz in November 1998 (species AVESI BIR DS recorded only during the November visit are indicated with an asterisk).

\begin{tabular}{|c|c|c|c|}
\hline \multirow[b]{2}{*}{ Especie/Species } & \multirow[b]{2}{*}{ Nombre común/Common name } & \multicolumn{2}{|c|}{ Bermejo } \\
\hline & & $\begin{array}{l}\text { ncia relativa/ } \\
\text { abundance }\end{array}$ & $\begin{array}{l}\text { Rango altitudinal/ } \\
\text { Elevational range }(\mathrm{m})\end{array}$ \\
\hline 231. Leptopogon superciliaris & $\begin{array}{l}\text { Slaty-capped Flycatcher/ } \\
\text { Mosquerito de Gorro Pizarroso }\end{array}$ & FC & $975-1200$ \\
\hline 232. Phylloscartes gualaquizae & Ecuadorian Tyrannulet/Moscareta Ecuatoriana & $\mathrm{FC}$ & $1000-1200$ \\
\hline 233. Phylloscartes orbitalis & $\begin{array}{l}\text { Spectacled Bristle-Tyrant/ } \\
\text { Moscareta-Cerdosa de Anteojos }\end{array}$ & - & - \\
\hline 234. Pseudotriccus ruficeps & $\begin{array}{l}\text { Rufous-headed Pygmy-Tyrant/ } \\
\text { Tirano-Pigmeo de Cabeza Rufa }\end{array}$ & FC & $2000-2100$ \\
\hline 235. Lophotriccus pileatus & $\begin{array}{l}\text { Scale-crested Pygmy-Tyrant/ } \\
\text { Tirano-Pigmeo de Cresta Escamada }\end{array}$ & FC & $850-1200$ \\
\hline 236. Hemitriccus granadensis & $\begin{array}{l}\text { Black-throated Tody-Tyrant/ } \\
\text { Tirano-Todi de Garganta Negra }\end{array}$ & $\mathrm{U}$ & $2000-2100$ \\
\hline 237. Hemitriccus rufigularis & $\begin{array}{l}\text { Buff-throated Tody-Tyrant/ } \\
\text { Tirano-Todi de Garganta Anteada }\end{array}$ & FC & 1200 \\
\hline 238. Hemitriccus zosterops & White-eyed Tody-Tyrant/Tirano-Todi de Ojos Blancos & FC & 450 \\
\hline 239. Poecilotriccus calopterus & $\begin{array}{l}\text { Golden-winged Tody-Flycatcher/ } \\
\text { Espatulilla de Ala Dorada }\end{array}$ & - & - \\
\hline 240. Todirostrum cinereum & Common Tody-Flycatcher/Espatulilla Común & - & - \\
\hline 241. Ramphotrigon ruficauda* & Rufous-tailed Flatbill/Pico-Plano de Cola Rufa & $x$ & 450 \\
\hline 242. Rhynchocyclus fulvipectus & Fulvous-breasted Flatbill/Pico-Plano de Pecho Fulvo & $\mathrm{U}$ & 1900 \\
\hline 243. Rhynchocyclus olivaceus & Olivaceous Flatbill/Pico-Plano Oliváceo & $\mathrm{U}$ & $450-800$ \\
\hline 244. Tolmomyias assimilis & $\begin{array}{l}\text { Yellow-margined Flycatcher/ } \\
\text { Pico-Ancho de Ala Amarilla }\end{array}$ & $\mathrm{U}$ & 450 \\
\hline 245. Tolmomyias poliocephalus & Gray-crowned Flycatcher/Pico-Ancho de Corona Gris & FC & 450 \\
\hline 246. Tolmomyias viridiceps & Olive-faced Flycatcher/Pico-Ancho Cabecioliváceo & $\mathrm{U}$ & 450 \\
\hline 247. Platyrinchus mystaceus & White-throated Spadebill/Pico-Chato de Garganta Blanca & $\mathrm{U}$ & 1200 \\
\hline 248. Myiotriccus ornatus & Ornate Flycatcher/Mosquerito Adornado & $\mathrm{FC}$ & $450-1250$ \\
\hline 249. Myiophobus cryptoxanthus & Olive-chested Flycatcher/Mosquerito de Pecho Olivo & $\mathrm{FC}$ & 1200 \\
\hline 250. Myiophobus pulcher & Handsome Flycatcher/Mosquerito Hermoso & $\mathrm{U}$ & 2000 \\
\hline 251. Pyrrhomyias cinnamomea & Cinnamon Flycatcher/Mosquerito Canela & $\mathrm{FC}$ & $2000-2200$ \\
\hline 252. Contopus cooperi* & Olive-sided Flycatcher/Pibí Boreal & $x$ & $750-900$ \\
\hline 253. Contopus sordidulus* & Western Wood-Pewee/Pibí Occidental & $\mathrm{x}$ & 900 \\
\hline 254. Contopus virens* & Eastern Wood-Pewee/Pibi Oriental & $x$ & $450-900$ \\
\hline 255. Lathrotriccus euleri & Euler's Flycatcher/Mosquerito de Euler & - & - \\
\hline 256. Sayornis nigricans & Black Phoebe/Mosquero de Agua & - & - \\
\hline 257. Ochthoeca diadema & Yellow-bellied Chat-Tyrant/Pitajo de Vientre Amarillo & $\mathrm{U}$ & 2100 \\
\hline 258. Knipolegus sp. & tyrant (species)/viudita (especie) & - & - \\
\hline 259. Colonia colonus & Long-tailed Tyrant/Atrapamosca de Cola Larga & FC & $750-1200$ \\
\hline 260. Hirundinea ferruginea & Cliff Flycatcher/Tirano de Riscos & $x$ & 750 \\
\hline 261. Attila spadiceus & Bright-rumped Attila/Atila Polimorfo & $x$ & $>450$ \\
\hline
\end{tabular}

Abundancia Relativa/Relative Abundance

$\mathrm{FC}=$ Bastante común (registrada diariamente en su hábitat apropiado)/Fairly common (recorded daily in suitable habitat)

$U=$ Poco común (presente pero no registrada diariamente en su hábitat apropriado)/Uncommon (present, but not recorded daily, even in suitable habitat)

$\mathrm{R}=$ Raro/Rare

$X=$ Presente pero con datos insuficientes para estimar abundancia/Present, but with insufficient data to assess relative abundance

\section{Rango Altitudinal/Elevational Range}

Los datos presentados aquí sólo indican las elevaciones a las cuales cada especie fue observada durante el inventario rápido y no representan la distribución altitudinal de las especies a través de la región./The elevational ranges presented in this table refer only to the altitudes at which each species was observed during the rapid biological inventory, and are not meant to describe the complete elevational distribution of each species in the region. 
APÉNDICE/APPENDIX 3

Aves/Birds
Especies de aves registradas en tres sitios de las Serranias Cofán, Provincia de Sucumbios, Ecuador, del 24 de julio al 16 de agosto 2001. Omitólogo principal: Thomas S. Schulenberg. Observaciones adicionales de Debra K. Moskovits, Randy Borman y otros. También se incluyen especies observadas por Douglas F. Stotz durante una visita a Bermejo en noviembre del 1998. Las especies que solamente fueron observadas en la visita de Stotz están marcadas con un asterisco.

\begin{tabular}{|c|c|c|c|}
\hline & \multicolumn{2}{|c|}{ Shishicho } & \multirow{2}{*}{$\begin{array}{l}\text { Abundanc } \\
\text { Relative a }\end{array}$} \\
\hline & $\begin{array}{l}\text { Abundancia relativa/ } \\
\text { Relative abundance }\end{array}$ & $\begin{array}{l}\text { Rango altitudinal/ } \\
\text { Elevational range }(\mathrm{m})\end{array}$ & \\
\hline 231. & FC & $900-1400$ & \\
\hline 232. & U & $900-1300$ & \\
\hline 233. & - & - & \\
\hline 234. & - & - & \\
\hline 235. & - & - & \\
\hline 236. & - & - & \\
\hline 237. & $\mathrm{FC}$ & $900-1400$ & \\
\hline 238. & $?$ & $?$ & \\
\hline 239. & - & - & \\
\hline 240 . & $x$ & 1100 & \\
\hline 241. & - & - & \\
\hline 242 . & - & - & \\
\hline 243. & - & - & \\
\hline 244. & - & - & \\
\hline 245. & - & - & \\
\hline 246. & - & - & \\
\hline 247. & - & - & \\
\hline 248. & $\mathrm{FC}$ & $1200-1400$ & \\
\hline 249. & - & - & \\
\hline 250. & - & - & \\
\hline 251. & - & - & \\
\hline 252. & - & - & \\
\hline 253. & - & - & \\
\hline 254. & - & - & \\
\hline 255. & U & 1000 & \\
\hline 256. & - & - & \\
\hline 257. & - & - & \\
\hline 258. & U & 1400 & \\
\hline 259. & $\mathrm{FC}$ & 1100 & \\
\hline 260. & - & - & \\
\hline 261. & - & - & \\
\hline
\end{tabular}

\section{Ccuccono \& Sinangoe}

Abundancia relativa/ Rango altitudinal/

FC 900-1100 Fhu

FC $\quad 1000-1100 \quad$ Fhu

$\begin{array}{lll}- & - & \mathrm{Fm}\end{array}$

$\begin{array}{lll}\text { U } & 900-1000 & \text { Fhu }\end{array}$

$\begin{array}{lll}- & \mathrm{Fm}\end{array}$

FC $1000-1100 \quad$ Fhu

$\begin{array}{lll}\text { FC } & 600-1000 & \text { Fhl, Fhu } \\ X & 900 & \text { Fe }\end{array}$

$\begin{array}{lll}X & 900 & \mathrm{Fe}\end{array}$

$-\quad-\quad F h l$

$-\quad-\quad$ Fhu

$U \quad 600 \quad$ Fhl

FC $600 \quad$ Fhl

\begin{tabular}{lll|}
\hline$U$ & 600 & $\mathrm{Fhl}$ \\
-- & - & $\mathrm{Fe}$ \\
- & - & $\mathrm{Fhu}$ \\
$\mathrm{FC}$ & $900-1100$ & $\mathrm{Fhu}$ \\
$\mathrm{FC}$ & 900 & $\mathrm{Fe}$ \\
\hline- & - & $\mathrm{Fm}$ \\
\hline- & - & $\mathrm{Fm}$ \\
- & - & $\mathrm{Fhl}$ \\
- & - & $\mathrm{Fhl}$ \\
- & - & $\mathrm{Fhl}$ \\
\hline- & - & $\mathrm{Fhu}$ \\
$U$ & 600 & $\mathrm{Rm}$ \\
\hline- & - & $\mathrm{Fm}$ \\
\hline- & - & $\mathrm{Fm}$ \\
- & - & $\mathrm{Fe}$ \\
- & - & $\mathrm{Fe}$ \\
\hline $\mathrm{FC}$ & $900-1000$ & $\mathrm{Fhl}$ \\
\hline
\end{tabular}

Hábitats/Habitats

$\mathrm{Fe}=$ Bordes del bosque (incluye vegetación secundaria y

0 = Cielo abierto/Open sky overhead

$\mathrm{Rm}=$ Márgenes de los ríos/River margins

regeneración en áreas de derrumbe)/Forest edges (includes

early regenerating habitats, such as on landslides)

Fhl = Bosque de laderas bajas/Lower hill forest

Fhu $=$ Bosque de laderas altas/Upper hill forest

$\mathrm{Fm}=$ Bosque nuboso/Mountain forest or cloud forest

Frp = Bosque ripario/Riparian forest

Fsm = Bosques al márgen de las quebradas $/$

Forest stream margins
* Especies observadas solamente por Stotz./Species recorded only by D.F. Stotz. 



\section{Especie/Species}

231. Leptopogon superciliaris

232. Phylloscartes gualaquiza

233. Phylloscartes orbitals

234. Pseudotriccus ruficeps

235. Lophotriccus pileatus

36. Hemitriccus granadensis

37. Hemitriccus rufigularis

238. Hemitriccus zosterops

39. Poecilotriccus calopterus

240. Todirostrum cinereum

241. Ramphotrigon ruficauda*

242. Rhynchocyclus fulvipectus

243. Rhynchocyclus olivace Tolmomyias assimilis

245. Tolmomyias poliocephalus 246. To/momyias viridiceps

247. Platyrinchus mystaceus

248. Myiotriccus ornatus

249. Myiophobus cryptoxanthes

250. Myiophobus pulcher

Nombre común/Common name

Slaty-capped Flycatcher/
Mosquerito de Gorro Pizarroso

Bermejo

$\begin{array}{ll}\begin{array}{l}\text { Abundancia relativa/ } \\ \text { Relative abundance }\end{array} & \begin{array}{l}\text { Rango altitudinal/ } \\ \text { Elevational range }(m)\end{array}\end{array}$

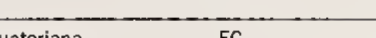

Spectacled Bristle-Tyrant/

Moscareta-Cerdosa de Anteojos

Rufous-headed Pygmy-Tyrant/

Scale. rested Pygmy-Tyrant

Scale-crested Pygmy-Tyrant/
Tirano-Pigmeo de Cresta Escamad

Black-throated Tody-Tyrant

Tirano-Todi de Garganta Negra

Buff-throated Tody-Tyrant/

Burfano-Todi de Garganta Anteada

$1000-1200$

White-eyed Tody-Tyrant/Tirano-To Golden-winged Tody-Flycatc
Espatulilla de Ala Oorada

Common Tody-Flycatcher/Espatulilla Común

Rufous-tailed Flatbillipico-Plano de Cola Rufa $\quad x \quad 450$

Fulvous-breasted Flatbill//Pico-Plano de Pecho Fulvo

Olvaceous Flatbill/Pico-Plano Oliváceo

Yellow-margined Flycatcher!
Pico-Ancho de Ala Amarilla

Gray-crowned FlycatcherlPico-Ancho de Corona Gris $\quad$ FC $\quad 450$

Olive-faced Flycatcher/Pico-Ancho Cabecioliváceo $\quad U \quad 450$

White-throated Spadebill/Pico-Chato de Garganta Blanca $U$ U 1200

Ornate Flycatcher/Mosquerito Adornado $\quad$ FC $450-1250$

Olive-chested Flycatcher/Mosquerito de Pecho Olivo _... FC $\quad \ldots . .1200$

$\begin{array}{llll}\text { Handsome Flycatcher/Mosquerito Hermoso } & \text { U } & 2000 \\ \text { Cinnamon Flycatcher/Mosquerito Canela } & . . . . & \text { FC } & \ldots . .2000-2200\end{array}$

\begin{tabular}{|ll|}
\hline 251. Pyrrhomyias cinnamomea & Cinnamon Flycatcher/Mosquerito Can \\
\hline 252. Contopus cooperit & Olive-sided Flycatcher/Pibl Boreal \\
\hline
\end{tabular}

253. Contopus sordidulus" Western Wood-Pewee/Pibl Occidental

Eastern Wood-Pewee/Pibl Oriental

Euler's Flycatcher/Mosquerito de Euler

Black Phoebe/Mosquero de Agua

255. Lathrotriccus euleri

256. Sayornis nigricans

257. Ochthoeca diaden Yellow-bellied Chat-TyrantPitajo de

Tyrant (species)/viudita (especie)

260. Hirundinea ferruginea Cliff Flycatcher/Trano de Riscos 261. Attila spadiceus Cliff Flycatcher/Tirano de Riscos

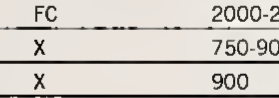

$x+\frac{900}{4}+\ldots 00$

\section{Abundancia Relativa/Relative Abundance}

$C=$ Bastante comủn (registrada diariamente en su hábitat

$=$ apropiado)/Fairly common (recorded daily in suitable habitat)

en su hábitat apropriado)/Uncommon (present, but

not recorded daily, even in suitable habitat)

$=$ Raro/Rare

Presente pero con datos insuficientes para estimar relative abundance las cuales cada especie fue observada durante el inventario rápido y no representan la distribución altitudinal de las especies a través de la región./The elevational ranges presented in this table refer only to the altitudes at which

each species was observed during the rapid biological

inventory, and are not meant to describe the complete
elevational distribution of each species in the region.

INFORME/REPORT NO
APÉNDTCE/APPENDIX 3
Aves/Birds

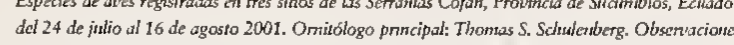
adicionales de Debra K. Maskoyilis, Randy Boman y otros. Tambuén se inclingen especies

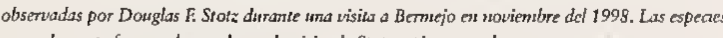

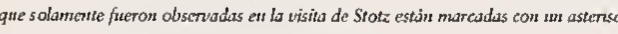

\begin{tabular}{|c|c|c|c|c|c|}
\hline & \multicolumn{2}{|c|}{ Shishicho } & \multicolumn{2}{|c|}{ Ccuccono \& Sinangoe } & \multirow[b]{2}{*}{ Hábitats/Habitats } \\
\hline & $\begin{array}{l}\text { Ábundancia relativa/ } \\
\text { Relative abundance }\end{array}$ & $\begin{array}{l}\text { Rango altitudinal/ } \\
\text { Elevational range (m) }\end{array}$ & $\begin{array}{l}\text { Abundancia relativa/ } \\
\text { Relative abundance }\end{array}$ & $\begin{array}{l}\text { Rango altitudinal/ } \\
\text { Elevational range (m) }\end{array}$ & \\
\hline 231. & $\mathrm{FC}$ & $900-1400$ & $\mathrm{FC}$ & $900-1100$ & Fhu \\
\hline 232. & $\mathrm{u}$ & $900-1300$ & $\mathrm{FC}$ & $1000-1100$ & Fhu \\
\hline 233. & - & - & $u$ & $1000-1100$ & Fhu \\
\hline 234. & - & - & - & - & $\mathrm{Fm}$ \\
\hline 235. & - & - & u & 900-1000 & Fhu \\
\hline 236. & - & - & - & - & $\mathrm{Fm}$ \\
\hline 237. & $\mathrm{FC}$ & $900-1400$ & $\mathrm{FC}$ & $1000-1100$ & Fhu \\
\hline 238. & $?$ & $?$ & $\mathrm{FC}$ & $600-1000$ & Fhl, Fhu \\
\hline 239. & - & - & $x$ & 900 & $\mathrm{Fe}$ \\
\hline 240. & $x$ & 1100 & $x$ & 900 & $\mathrm{Fe}$ \\
\hline 241. & - & - & - & - & Fhl \\
\hline 242. & - & - & - & - & Fhu \\
\hline 243. & - & - & U & 600 & $\mathrm{Fhl}$ \\
\hline 244. & - & - & $\mathrm{FC}$ & 600 & Fhl \\
\hline 245. & $=$ & - & $u$ & 600 & Fhl \\
\hline 246. & $=$ & - & - & - & $\mathrm{Fe}$ \\
\hline 247. & $=$ & - & $=$ & $=$ & Fhu \\
\hline 248. & $\mathrm{FC}$ & $1200-1400$ & $\mathrm{FC}$ & $900-1100$ & Fhu \\
\hline 249. & - & - & $\mathrm{FC}$ & 900 & $\mathrm{Fe}$ \\
\hline 250. & - & $=$ & $=$ & - & $\mathrm{Fm}$ \\
\hline 251. & - & - & - & - & $\mathrm{Fm}$ \\
\hline 252. & $=$ & - & - & $=$ & Fhl \\
\hline 253. & $=$ & $=$ & - & - & Fhl \\
\hline 254. & $=$ & $=$ & $=$ & - & Fhl \\
\hline 255. & $u$ & 1000 & $=$ & - & Fhu \\
\hline 258. & $\bar{U}$ & 1400 & - & - & $\mathrm{Fm}$ \\
\hline 259. & $\mathrm{FC}$ & 1100 & - & $=$ & $\mathrm{Fe}$ \\
\hline 260. & - & $=$ & - & - & $\mathrm{Fe}$ \\
\hline & & - & $\mathrm{FC}$ & $900-1000$ & Fhl \\
\hline
\end{tabular}

Hábitats/Habitats

$=$ Bordes del bosque (incluye vegetación secundaria $y$

$0=$ Cielo abierto/Open sky overhead
$\mathrm{Rm} \approx$ Márgenes de los rlos/River margins

regeneración en áreas de derrumbe)/Forest edges (includes

$\mathrm{FhI}=$ Bosque de laderas bajas/Lower hill forest

Fhu $=$ Bosque de laderas altas $/$ Upper hill forest

$\mathrm{Fm}=$ Bosque nuboso/Mountain forest or cloud fore

$\mathrm{Frp}=$ Bosque ripario/Riparian forest

Fsm = Bosques al márgen de las quebradas $/$

Forest stream margins

ECUADOR: SERRANIAS COFAN
Especies observadas
only by D.F. Stotz. 
Birds observed at three sites in the Serranias Cofán, Sucumbios province, Ecuador, 24 July-16 August 2001. Principal ornithologist: Thomas S. Schulenberg, with observations by Debra K. Moskovits, Randy Borman, and others; also included are species observed at Bermejo by Douglas F. Stotz in November 1998 (species

AVESIBIR DS

recorded only during the November visit are indicated with an asterisk).

\begin{tabular}{|c|c|c|c|}
\hline \multirow[b]{2}{*}{ Especie/Species } & \multirow[b]{2}{*}{ Nombre común/Common name } & \multicolumn{2}{|c|}{ Bermejo } \\
\hline & & $\begin{array}{l}\text { Abundancia relatival } \\
\text { Relative abundance }\end{array}$ & $\begin{array}{l}\text { Rango altitudinal/ } \\
\text { Elevational range }(\mathrm{m})\end{array}$ \\
\hline 262. Rhytipterna simplex & Grayish Mourner/Plañidero Grisáceo & FC & $450-1100$ \\
\hline 263. Sirystes sibilator ${ }^{*}$ & Sirystes/Siristes & $x$ & 450 \\
\hline 264. Myiarchus cephalotes & Pale-edged Flycatcher/Copetón de Corona Tiznada & $\mathrm{U}$ & 2000 \\
\hline 265. Myiarchus ferox & Short-crested Flycatcher/Copetón de Cresta Corta & $\mathrm{U}$ & 450 \\
\hline 266. Myiarchus tuberculifer & Dusky-capped Flycatcher/Copetón de Cresta Oscura & $\mathrm{FC}$ & $450-1200$ \\
\hline 267. Pitangus sulphuratus & Great Kiskadee/Bienteveo Grande & $\mathrm{U}$ & 450 \\
\hline 268. Megarynchus pitangua & Boat-billed Flycatcher/Mosquero Picudo & $\mathrm{FC}$ & 450 \\
\hline 269. Myiozetetes granadensis & Gray-capped Flycatcher/Mosquero de Gorra Gris & $U$ & 450 \\
\hline 270. Myiozetetes luteiventris & $\begin{array}{l}\text { Dusky-chested Flycatcher/ } \\
\text { Mosquero de Pecho Oscuro }\end{array}$ & U & 450 \\
\hline 271. Myiozetetes similis & Social Flycatcherr/Mosquero Social & $\mathrm{U}$ & 450 \\
\hline 272. Conopias cinchoneti & Lemon-browed Flycatcher/Mosquero de Ceja Limón & $\mathrm{U}$ & 1200 \\
\hline 273. Tyrannus melancholicus & Tropical Kingbird/Tirano Tropica & $\mathrm{U}$ & 450 \\
\hline 274. Pachyramphus albogriseus & Black-and-white Becard/Cabezón Blanco y Negro & $\mathrm{U}$ & 1200 \\
\hline 275. Pachyramphus castaneus & $\begin{array}{l}\text { Chestnut-crowned Becard/ } \\
\text { Cabezón de Corona Castaña }\end{array}$ & $u$ & 450 \\
\hline 276. Pachyramphus marginatus & Black-capped Becard/Cabezón de Gorro Negro & $x$ & 450 \\
\hline 277. Pachyramphus minor & Pink-throated Becard/Cabezón de Garganta Rosada & FC & 450 \\
\hline 278. Pachyramphus polychopterus & White-winged Becard/Cabezón de Ala Blanca & FC & 450 \\
\hline 279. Pachyramphus xanthogenys & $\begin{array}{l}\text { Yellow-cheeked Becard/ } \\
\text { Cabezón de Cachetes Amarillos }\end{array}$ & - & - \\
\hline 280. Tityra cayana* & Black-tailed Tityra/Titira de Cola Negra & $x$ & 450 \\
\hline 281. Tityra inquisitor & Black-crowned Tityra/Titira de Corona Negra & $\mathrm{U}$ & 450 \\
\hline 282. Tityra semifasciata & Masked Tityra/Titira Enmascarada & $\mathrm{U}$ & 1200 \\
\hline \multicolumn{4}{|l|}{ Cotingidae (11) } \\
\hline 283. Pipreola frontalis & $\begin{array}{l}\text { Scarlet-breasted Fruiteater/ } \\
\text { Frutero de Pecho Escarlata }\end{array}$ & - & - \\
\hline 284. Pipreola riefferii & Green-and-black Fruiteater/Frutero Verde y Negro & FC & $2000-2200$ \\
\hline 285. Ampelioides tschudii & Scaled Fruiteater/Frutero Escamado & $\mathrm{u}$ & 1050 \\
\hline 286. Snowornis cryptolophus & Olivaceous Piha/Piha Olivácea & $u$ & 2000 \\
\hline 287. Snowornis subalaris & Gray-tailed Piha/Piha de Cola Gris & FC & $450-1200$ \\
\hline 288. Lipaugus vociferans & Screaming Piha/Piha Gritona & - & - \\
\hline 289. Cotinga cayana & Spangled Cotinga/Cotinga Lentejuelada & U & 450 \\
\hline 290. Cotinga maynana & Plum-throated Cotinga/Cotinga de Garganta Morada & $u$ & 450 \\
\hline 291. Querula purpurata & $\begin{array}{l}\text { Purple-throated Fruitcrow/ } \\
\text { Cuervo-Frutero de Garganta Púrpura }\end{array}$ & $\mathrm{FC}$ & $450-800$ \\
\hline 292. Cephalopterus ornatus & $\begin{array}{l}\text { Amazonian Umbrellabird/ } \\
\text { Pájaro-Paraguas Amazónico }\end{array}$ & $U$ & 900 \\
\hline
\end{tabular}

Abundancia Relativa/Relative Abundance

$\mathrm{FC}=$ Bastante común (registrada diariamente en su hábitat apropiado)/Fairly common (recorded daily in suitable habitat)

$U=$ Poco común (presente pero no registrada diariamente en su hábitat apropriado)/Uncommon (present, but not recorded daily, even in suitable habitat)

$\mathrm{R}=$ Raro/Rare

$X=$ Presente pero con datos insuficientes para estimar abundancia/Present, but with insufficient data to assess relative abundance

\section{Rango Altitudinal/Elevational Range}

Los datos presentados aquí sólo indican las elevaciones a las cuales cada especie fue observada durante el inventario rápido y no representan la distribución altitudinal de las especies a través de la región./The elevational ranges presented in this table refer only to the altitudes at which each species was observed during the rapid biological inventory, and are not meant to describe the complete elevational distribution of each species in the region. 
APÉNDICE/APPENDIX 3

Aves/Birds
Especies de aves registradas en tres sitios de las Serranías Cofán, Provincia de Sucumbios, Ecuador, del 24 de julio al 16 de agosto 2001. Ornitólogo principal: Thomas S. Schulenberg. Observaciones adicionales de Debra K. Moskovits, Randy Borman y otros. También se incluyen especies observadas por Douglas F. Stotz durante una visita a Bermejo en novientbre del 1998. Las especies que solamente fueron observadas en la visita de Stotz están marcadas con un asterisco.

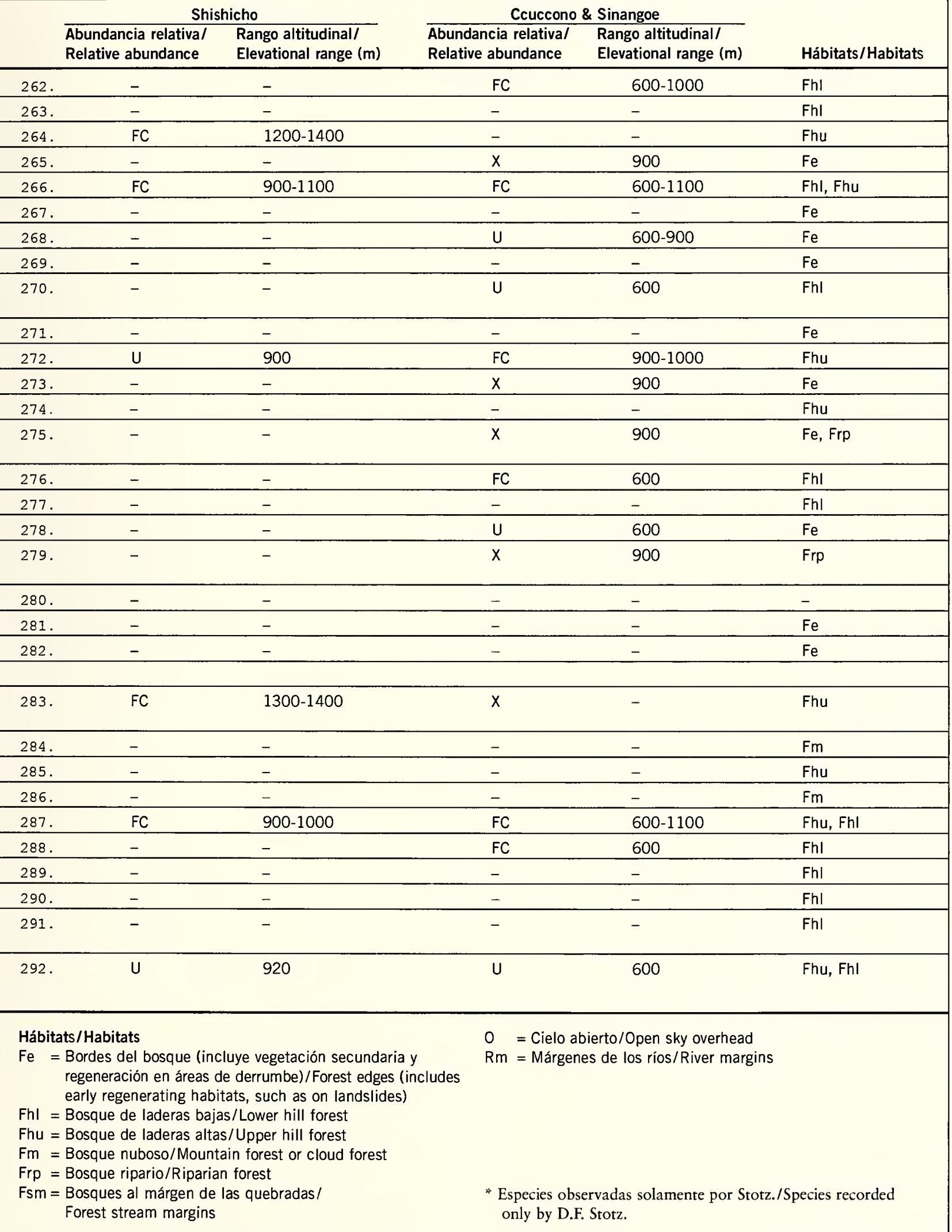



Especie/Species Nombre común/Common name

Bermejo

262. Rhytipterna simplex

263. Sinstes sibilator ${ }^{*}$

264. Mylarchus cephaloter

266. Myiarchus tuberculifer

267. Pitangus sulphuratus

268. Megarynchus pitangua

270. Myiozetetes /uteiventris

271. Myiozetetes similis

272. Conopias cinchoneti

273. Tyrannus melancholicus

274. Pachyramphus albogriseus

275. Pachyramohus castaneurs

276. Pachyramohus marginatus

277. Pachyramphus mino

Pink-throated Becard/Cabezón de Garganta Rosa

279. Pachyramphus xanthogenys Yellow-cheeked Becard/

\begin{tabular}{llll} 
280. Tityra cayana $*^{*}$ & Black-tailed TityräTitira de Cola Negra & $X$ & 450 \\
\hline 281. Tityra inquisitor & Black-crowned Tityra/Titira de Corona Negra & $U$ & 450 \\
\hline
\end{tabular}

282. Tityra semifasciata $\quad$ Masked TityraTitira Enmascarada $\quad$ U

Cotingidae (11)

283. Pipreola frontalis Scarlet-breasted Fruiteaterl

284. Pioreola riefferii Green-and-black Fruiteater/Frutero Verde y Neg10 FC FC 2000-2200

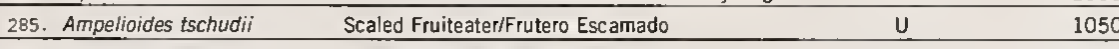

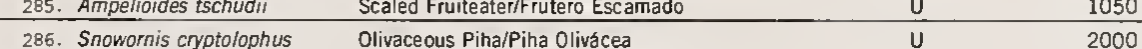

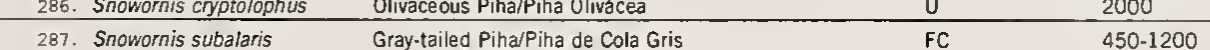

288. Lipaugus vociferans Screaming Piha/Piha Gritona

289. Cotinga cayana

Screaming Piha/Piha Gritona

290. Cotinga maynana

Plum-throated Cotinga/Cotinga de Garganta Morada Purple-throated Fruitcrow/

292. Cephalopterus ornatus Cuervo-Frutero de Garganta Pürpura

$\begin{array}{ll}\text { 292. Cephalopterus ornatus } & \text { Amazonian Umbrellabird/ } \\ \text { Pajaro-Paraguas Amazónico }\end{array}$

$\begin{array}{ll}U & 450 \\ \mathrm{FC} & 450\end{array}$

450

$450-800$

Abundancia Relativa/Relative Abundance

$=$ Bastante común (registtada diariamente en su hábitat

apropiado)/Fairly common (1ecorded daily in suitable habita

Poco comun (presente pelo no registrada diariamente

not recorded daily, even in suitable habitat)

$R=$ Raro/Rare

Presente pero con datos insuficientes para estimar abundancia/Present, but with insufficient data to asses

Rango Altitudinal/Elevational Rang

Los datos presentados aqul sólo indican las elevaciones a las cuales cada especie fue observada durante el inventario rapido y no representan la distribución altitudinal de las presented in this table refec only to the altitudes at which each species was observed during the rapid biological inventory, and are not meant to describe the complete elevational distribution of each species in the region.
Especies observada
only by D.F. Stoz.

0 = Cielo abierto/Open sky overhead

regeneración en áreas de derrumbe)/Forest edges (includ

early regenerating habitats, such as on landslides)

$\mathrm{Fhl}=$ Bosque de laderas bajas/Lower hill forest

$\mathrm{Fm}=$ Bosque nuboso/Mountain forest or cloud forest

Frp $=$ Bosque ripario/Riparian forest

$\mathrm{Fm}=$ Bosques al márgen de las quebradas

Forest stream margins

ECUMDOR: SERRANTAS COFAN

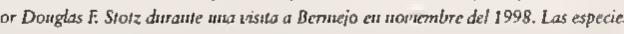

a

$600-1000$

Hábitats/Habitats

Fhl

Fhl $\mathrm{Fhu}$

(1)

(-

$600 \quad \mathrm{Fhl}$

his

Fhu

Fh Fil -

$\mathrm{Fe}$

$\mathrm{Fm}$

$\mathrm{Fhl}$

Fhu, Fhl 
Birds observed at three sites in the Serranias Cofán, Sucumbios province, Ecuador, 24 July-16 August 2001. Principal ornithologist: Thomas S. Schulenberg, with observations by Debra K. Moskovits, Randy Borman, and others; also included are species observed at Bermejo by Douglas F. Stotz in November 1998 (species

\section{AVESIRIRDS}

recorded only during the November visit are indicated with an asterisk).

\begin{tabular}{|c|c|c|c|}
\hline \multirow[b]{2}{*}{ Especie/Species } & \multirow[b]{2}{*}{ Nombre común/Common name } & \multicolumn{2}{|c|}{ Bermejo } \\
\hline & & $\begin{array}{l}\text { Abundancia relativa/ } \\
\text { Relative abundance }\end{array}$ & $\begin{array}{l}\text { Rango altitudinal/ } \\
\text { Elevational range }(\mathrm{m})\end{array}$ \\
\hline 293. Rupicola peruviana & $\begin{array}{l}\text { Andean Cock-of-the-Rock/ } \\
\text { Gallito-de-las-Rocas Andino }\end{array}$ & FC & 975 \\
\hline \multicolumn{4}{|l|}{ Pipridae (9) } \\
\hline 294. Chloropipo holochroa & Green Manakin/Saltarín Verde & - & - \\
\hline 295. Tyranneutes stolzmanni & Dwarf Tyrant-Manakin/Tirano-Piprido Enano & FC & 450 \\
\hline 296. Chiroxiphia pareola* & Blue-backed Manakin/Saltarín de Dorso Azul & $x$ & 450 \\
\hline 297. Pipra erythrocephala & Golden-headed Manakin/Saltarín de Cabeza Dorada & $\mathrm{x}$ & 450 \\
\hline 298. Dixiphia pipra & White-crowned Manakin/Saltarín de Corona Blanca & $\mathrm{FC}$ & 1200 \\
\hline 299. Lepidothrix coronata & Blue-crowned Manakin/Saltarín de Corona Azul & FC & $450-975$ \\
\hline 300. Lepidothrix isidorei & Blue-rumped Manakin/Saltarín de Rabadilla Azul & $\mathrm{FC}$ & 1200 \\
\hline 301. Schiffornis turdinus & Thrush-like Manakin/Schiffornis Pardo & $\mathrm{FC}$ & $900-1200$ \\
\hline 302. Piprites chloris & Wing-barred Manakin/Piprites de Ala Bandeada & $\mathrm{FC}$ & $450-975$ \\
\hline \multicolumn{4}{|l|}{ Vireonidae (7) } \\
\hline 303. Vireolanius leucotis & $\begin{array}{l}\text { Slaty-capped Shrike-Vireol } \\
\text { Vireón de Gorro Apizarrado }\end{array}$ & FC & $450-1200$ \\
\hline 304. Vireo leucophrys & Brown-capped Vireo/Vireo de Gorro Marrón & - & - \\
\hline 305. Vireo olivaceus* & Red-eyed Vireo/Vireo de Ojo Rojo & $x$ & 450 \\
\hline 306. Hylophilus hypoxanthus & Dusky-capped Greenlet/Verdillo de Gorro Oscuro & $\mathrm{FC}$ & $450-975$ \\
\hline 307. Hylophilus ochraceiceps & Tawny-crowned GreenletNerdillo de Corona Leonada & $U$ & 450 \\
\hline 308. Hylophilus olivaceus & Olivaceous Greenlet/Verdillo Oliváceo & - & - \\
\hline 309. Hylophilus semibrunneus & Rufous-naped Greenlet/Verdillo de Nuca Rufa & $\mathrm{FC}$ & 1200 \\
\hline \multicolumn{4}{|l|}{ Corvidae (1) } \\
\hline 310. Cyanocorax violaceus & Violaceous Jay/Urraca Violácea & $\mathrm{FC}$ & $450-900$ \\
\hline \multicolumn{4}{|l|}{ Hirundinidae (5) } \\
\hline 311. Tachycineta albiventer* & White-winged Swallow/Golondrina de Ala Blanca & $x$ & 450 \\
\hline 312. Progne chalybea* & Gray-breasted Martin/Martín de Pecho Gris & $x$ & - \\
\hline 313. Notiochelidon cyanoleuca & Blue-and-white Swallow/Golondrina Azul y Blanca & $x$ & - \\
\hline 314. Neochelidon tibialis & $\begin{array}{l}\text { White-thighed Swallow/ } \\
\text { Golondrina de Muslos Blancos }\end{array}$ & $x$ & 450 \\
\hline 315. Stelgidopteryx ruficollis & $\begin{array}{l}\text { Southern Rough-winged Swallow/ } \\
\text { Golondrina Ala-Rasposa Sureña }\end{array}$ & $\mathrm{FC}$ & 450 \\
\hline \multicolumn{4}{|l|}{ Troglodytidae (9) } \\
\hline 316. Campylorhynchus turdinus & Thrush-like Wren/Cucarachero Zorzal & $\mathrm{FC}$ & $450-750$ \\
\hline 317. Cinnycerthia olivascens & Sharpe's Wren/Cucarachero de Sharpe & $\mathrm{FC}$ & $2000-2200$ \\
\hline 318. Thryothorus coraya & Coraya Wren/Cucarachero Coraya & $\mathrm{FC}$ & $450-1200$ \\
\hline 319. Troglodytes aedon & House Wren/Cucarachero Común & $\mathrm{FC}$ & 450 \\
\hline 320. Henicorhina leucophrys & $\begin{array}{l}\text { Gray-breasted Wood-Wren/ } \\
\text { Cucarachero-Montés de Pecho Gris }\end{array}$ & $\mathrm{FC}$ & $1800-2200$ \\
\hline
\end{tabular}

Abundancia Relativa/Relative Abundance

$\mathrm{FC}=$ Bastante común (registrada diariamente en su hábitat apropiado)/Fairly common (recorded daily in suitable habitat)

$U=$ Poco común (presente pero no registrada diariamente en su hábitat apropriado)/Uncommon (present, but not recorded daily, even in suitable habitat)

$\mathrm{R}=$ Raro/Rare

$X=$ Presente pero con datos insuficientes para estimar abundancia/Present, but with insufficient data to assess relative abundance

\section{Rango Altitudinal/Elevational Range}

Los datos presentados aquí sólo indican las elevaciones a las cuales cada especie fue observada durante el inventario rápido y no representan la distribución altitudinal de las especies a través de la región./The elevational ranges presented in this table refer only to the altitudes at which each species was observed during the rapid biological inventory, and are not meant to describe the complete elevational distribution of each species in the region. 
APÉNDICE/APPENDIX 3 Aves/Birds
Especies de aves registradas en tres sitios de las Serranias Cofán, Provincia de Sucumbios, Ecuador, del 24 de julio al 16 de agosto 2001. Omitólogo principal: Thomas S. Schulenberg. Observaciones adicionales de Debra K. Moskovits, Randy Borman y otros. También se incluyen especies observadas por Douglas F. Stotz durante una visita a Bermejo en noviembre del 1998. Las especies que solamente fueron observadas en la visita de Stotz están marcadas con un asterisco.

\section{Shishicho}

Abundancia relativa/ Rango altitudinal/

293.

Relative abundance

Elevational range $(\mathrm{m})$

900

\section{Ccuccono \& Sinangoe}

\begin{tabular}{ll}
\hline Abundancia relativa/ & Rango altitudinal/ \\
Relative abundance & Elevational range $(\mathrm{m})$
\end{tabular}

$600-1100$

Hábitats/Habitats

FC
Fhu, Fhl

$\begin{array}{lll}294 . & U & \\ 295 . & - & - \\ 296 . & - & - \\ 297 . & - & -\end{array}$

$\begin{array}{llll}298 . & \text { FC } & 900-1400 & \text { U } \\ 299 & \text { U } & 900 & \text { FC }\end{array}$

\begin{tabular}{|c|c|c|}
\hline 299. & U & 900 \\
\hline & $\mathrm{U}$ & 900 \\
\hline
\end{tabular}

$301 . \quad F C$

302 .

$\mathrm{U}$

$850-900$

900

FC

$\begin{array}{ll}1000-1100 & \text { Fhu } \\ 600 & \text { Fhl } \\ - & ?\end{array}$

FC $600+\quad$ Fhl

U $900 \quad$ Fhu

FC 600-900 Fhl

$\mathrm{U} \quad 1000 \quad$ Fhu

FC $\quad 1000-1100 \quad$ Fhu

FC 900-1100 Fhl

$\begin{array}{llllll}\text { 303. FC } & 1200-1400 & \text { FC } & 600-1100 & \text { Fhl, Fhu }\end{array}$

\begin{tabular}{|c|c|c|c|c|}
\hline 304. & FC & $1200-1400$ & - & - \\
\hline 305. & - & - & - & - \\
\hline 306. & $\mathrm{FC}$ & $900-1000$ & $\mathrm{FC}$ & $600+$ \\
\hline 307. & - & - & $\mathrm{U}$ & 600 \\
\hline 308. & $\mathrm{U}$ & 1100 & $\mathrm{FC}$ & 1000 \\
\hline 309. & FC & $1200-1400$ & FC & $1000-1100$ \\
\hline
\end{tabular}

310

$-$

$-\quad F C$

$600-1000$

Fhl

311.

312.

313.

$-$

314 .

- -

315.

U

$-$

1100

$\frac{-}{-}$

\begin{tabular}{ll}
- & - \\
- & - \\
- & 0 \\
\hline 900 & Fhl
\end{tabular}

FC

$900-1000$

$O(F h l, F e)$

$\begin{array}{lllllll}316 . & - & - & \text { FC } & 600-900 & \text { Fe } \\ 317 . & - & - & - & - & \mathrm{Fm} \\ 318 . & \text { FC } & 1100 & - & \text { FC } & 900-1000 & \mathrm{Fe} \\ 319 . & - & - & - & - & \mathrm{Fe} \\ 320 . & - & & - & - & \mathrm{Fm}\end{array}$

\section{Hábitats/Habitats}

$\mathrm{Fe}=$ Bordes del bosque (incluye vegetación secundaria y regeneración en áreas de derrumbe)/Forest edges (includes early regenerating habitats, such as on landslides)

Fhl = Bosque de laderas bajas/Lower hill forest

$\mathrm{Fhu}=$ Bosque de laderas altas/Upper hill forest

$\mathrm{Fm}=$ Bosque nuboso/Mountain forest or cloud forest

Frp = Bosque ripario/Riparian forest

Fsm = Bosques al márgen de las quebradas $/$ Forest stream margins
0 = Cielo abierto/Open sky overhead

$\mathrm{Rm}=$ Márgenes de los ríos/River margins 

Birds observed at three sites in the Serranias Cofán, Sucumbios province, Ecuador, 24 July-16 August 2001. Principal ornithologist: Thomas S. Schulenberg, with observations by Debra K. Moskovits, Randy Borman, and others; also included are species observed at Bermejo by Douglas F. Stotz in November 1998 (species AVESIRIRDS recorded only during the November visit are indicated with an asterisk).

\begin{tabular}{|c|c|c|c|}
\hline \multirow[b]{2}{*}{ Especie/Species } & \multirow[b]{2}{*}{ Nombre común/Common name } & \multicolumn{2}{|c|}{ Bermejo } \\
\hline & & $\begin{array}{l}\text { Abundancia relatival } \\
\text { Relative abundance }\end{array}$ & $\begin{array}{l}\text { Rango altitudinal/ } \\
\text { Elevational range }(\mathrm{m})\end{array}$ \\
\hline 321. Henicorhina leucosticta & $\begin{array}{l}\text { White-breasted Wood-Wren/ } \\
\text { Cucarachero-Montés de Pecho Blanco }\end{array}$ & FC & $450-1200$ \\
\hline 322. Microcerculus marginatus & $\begin{array}{l}\text { Southern Nightingale Wren/ } \\
\text { Cucarachero-Ruiseñor Sureño }\end{array}$ & $\mathrm{FC}$ & $450-1200$ \\
\hline 323. Cyphorhinus arada & Musician Wren/Cucarachero Musical & $\mathrm{U}$ & $450-1000$ \\
\hline 324. Cyphorhinus thoracicus & $\begin{array}{l}\text { Chestnut-breasted Wren/ } \\
\text { Cucarachero de Pecho Castaño }\end{array}$ & $\mathrm{U}$ & 2000 \\
\hline \multicolumn{4}{|l|}{ Polioptilidae (1) } \\
\hline 325. Microbates cinereiventris & Tawny-faced Gnatwren/Soterillo de Cara Leonada & - & - \\
\hline \multicolumn{4}{|l|}{ Turdidae (6) } \\
\hline 326. Myadestes ralloides & Andean Solitaire/Solitario Andino & - & - \\
\hline 327. Catharus dryas & Spotted Nightingale-Thrush/Zorzal Moteado & $\mathrm{FC}$ & 1200 \\
\hline 328. Catharus ustulatus* & Swainson's Thrush/Zorzal de Swainson & $x$ & $450-750$ \\
\hline 329. Turdus albicollis & White-necked Thrush/Mirlo de Cuello Blanco & $x$ & - \\
\hline 330. Turdus fulviventris & Chestnut-bellied Thrush/Mirlo de Vientre Castaño & $\mathrm{FC}$ & $1900-2200$ \\
\hline 331. Turdus lawrencii* & Lawrence's Thrush/Mirlo de Lawrence & $x$ & $450+$ \\
\hline \multicolumn{4}{|l|}{ Parulidae (8) } \\
\hline 332. Parula pitiayumi & Tropical Parula/Parula Tropical & $\mathrm{FC}$ & $975-1200$ \\
\hline 333. Dendroica striata* & Blackpoll Warbler/Reinita Estriada & $x$ & 750 \\
\hline 334. Seiurus noveboracensis* & Northern Waterthrush/Reinita Acuática Norteña & $x$ & 750 \\
\hline 335. Myioborus miniatus & $\begin{array}{l}\text { Slate-throated Redstart/ } \\
\text { Candelita de Garganta Plomiza }\end{array}$ & $\mathrm{FC}$ & $1200-2100$ \\
\hline 336. Basileuterus fulvicauda & Buff-rumped Warbler/Reinita de Rabadilla Anteada & $\mathrm{FC}$ & 450 \\
\hline 337. Basileuterus luteoviridis & Citrine Warbler/Reinita Citrina & $U$ & 2100 \\
\hline 338. Basileuterus tristriatus & Three-striped Warbler/Reinita de Cabeza Listada & $\mathrm{U}$ & 1900 \\
\hline 339. Coereba flaveola & Bananaquit/Reinita Mielera & $\mathrm{FC}$ & 1200 \\
\hline \multicolumn{4}{|l|}{ Thraupidae (49) } \\
\hline 340. Cissopis leveriana & Magpie Tanager/Tangara Urraca & $\mathrm{FC}$ & $450-1200$ \\
\hline 341. Chlorornis riefferii & Grass-green Tanager/Tangara Verde Esmeralda & U & 2100 \\
\hline 342. Chlorospingus flavigularis & $\begin{array}{l}\text { Yellow-throated Bush-Tanager/ } \\
\text { Tangara de Monte de Garganta Amarilla }\end{array}$ & $\mathrm{FC}$ & $900-1200$ \\
\hline 343. Chlorospingus ophthalmicus & Common Bush-Tanager/Tangara de Monte Común & $\mathrm{FC}$ & $1900-2100$ \\
\hline 344. Hemithraupis flavicollis & Yellow-backed Tanager/Tangara de Dorso Amarillo & $\mathrm{U}$ & $450-1000$ \\
\hline 345. Chlorothraupis carmioli & Carmiol's Tanager/Frutero Aceitunado & $\mathrm{U}$ & 450 \\
\hline 346. Lanio fulvus & Fulvous Shrike-Tanager/Tangara Fulva & $\mathrm{FC}$ & $450-975$ \\
\hline 347. Creurgops verticalis & Rufous-crested Tanager/Tangara de Cresta Rufa & $\mathrm{U}$ & 2100 \\
\hline 348. Tachyphonus cristatus & Flame-crested Tanager/Tangara de Cresta Rojiza & U & $450-975$ \\
\hline 349. Tachyphonus Iuctuosus & White-shouldered Tanager/Tangara de Hombros Blancos & - & - \\
\hline
\end{tabular}

\section{Abundancia Relativa/Relative Abundance}

$\mathrm{FC}=$ Bastante común (registrada diariamente en su hábitat apropiado)/Fairly common (recorded daily in suitable habitat)

$\mathrm{U}=$ Poco común (presente pero no registrada diariamente en su hábitat apropriado)/Uncommon (present, but not recorded daily, even in suitable habitat)

$R=$ Raro/Rare

$X=$ Presente pero con datos insuficientes para estimar abundancia/Present, but with insufficient data to assess relative abundance

\section{Rango Altitudinal/Elevational Range}

Los datos presentados aquí sólo indican las elevaciones a las cuales cada especie fue observada durante el inventario rápido y no representan la distribución altitudinal de las especies a través de la región./The elevational ranges presented in this table refer only to the altitudes at which each species was observed during the rapid biological inventory, and are not meant to describe the complete elevational distribution of each species in the region. 
A PÉNDICE/APPENDIX 3

Aves/Birds
Especies de aves registradas en tres sitios de las Serranias Cofán, Provincia de Sucumbios, Ecuador, del 24 de julio al 16 de agosto 2001. Ornitólogo principal: Thomas S. Schulenberg. Observaciones adicionales de Debra K. Moskovits, Randy Borman y otros. También se incluyen especies observadas por Douglas F. Stotz durante una visita a Bermejo en noviembre del 1998. Las especies que solamente fueron observadas en la visita de Stotz están marcadas con un asterisco.

\section{Shishicho \\ Abundancia relativa/ \\ Rango altitudinal/ \\ Relative abundance \\ Elevational range (m)}

\begin{tabular}{ccl}
\multicolumn{2}{c}{ Ccuccono \& Sinangoe } & \\
$\begin{array}{c}\text { Abundancia relativa/ } \\
\text { Relative abundance }\end{array}$ & $\begin{array}{l}\text { Rango altitudinal/ } \\
\text { Elevational range (m) }\end{array}$ & Hábitats/Habitats \\
\hline FC & $600-1100$ & Fhl, Fhu \\
\hline FC & $600-1100$ & Fhl, Fhu \\
\hline FC & $600-1000$ & Fhl \\
\hline- & - & Fm
\end{tabular}

$900-1000$

$900-1000$
Ccuccono \& Sinangoe

$\begin{array}{lllllll}\text { 321. } & \text { FC } & 900-1000 & \text { FC } & 600-1100 & \text { Fhl, Fhu } \\ 322 . & \text { FC } & 900-1000 & \text { FC } & 600-1100 & \text { Fhl, Fhu } \\ 323 . & - & - & \text { FC } & 600-1000 & \text { Fhl } \\ 324 . & - & - & - & - & \text { Fm }\end{array}$

325

\begin{tabular}{ll}
326. & $\mathrm{U}$ \\
327. & FC \\
328. & - \\
329. & - \\
330. & - \\
331. & - \\
\hline
\end{tabular}

$\begin{array}{lll}332 . & \text { FC } & 1 \\ 333 . & - & - \\ 334 . & - & - \\ 335 . & \text { FC } & 120\end{array}$

\begin{tabular}{lll}
\hline 336. & - & - \\
\hline 337. & - & - \\
\hline 338. & $\mathrm{U}$ & 1400 \\
\hline 339. & FC & 1100 \\
\hline & & 1100 \\
\hline 340. & FC & - \\
\hline 341. & - & $900-1400$ \\
\hline 342. & FC & - \\
\hline 343. & - & - \\
\hline 344. & - & - \\
\hline 345. & - & $900-1000$ \\
\hline 346. & FC & - \\
\hline 347. & - & - \\
\hline 348. & - & - \\
\hline 349. & - & \\
\hline
\end{tabular}

\section{Hábitats/Habitats}

$\mathrm{Fe}=$ Bordes del bosque (incluye vegetación secundaria y regeneración en áreas de derrumbe)/Forest edges (includes early regenerating habitats, such as on landslides)

$\mathrm{Fhl}=$ Bosque de laderas bajas/Lower hill forest

$\mathrm{Fhu}=$ Bosque de laderas altas/Upper hill forest

$\mathrm{Fm}=$ Bosque nuboso/Mountain forest or cloud forest

Frp = Bosque ripario/Riparian forest

Fsm = Bosques al márgen de las quebradas $/$ Forest stream margins
U $600 \quad$ Fhl

$\begin{array}{lll}- & - & \text { Fm } \\ \text { FC } & 900-1100 & \text { Fhu } \\ - & - & \text { Fhl } \\ \text { FC } & 600-1100 & \text { Fhl } \\ - & - & \text { Fhu } \\ - & - & \text { Fhl }\end{array}$

\begin{tabular}{lll} 
FC & $900-1100$ & Fhu \\
- & - & Fhl \\
- & - & Fhl \\
\hline FC & $900-1100$ & Fhu, Fm
\end{tabular}

\begin{tabular}{lll} 
FC & 900 & Fsm \\
- & - & Fm \\
- & - & Fhu \\
FC & $900-1100$ & Fe \\
\hline & & \\
FC & $900-1000$ & Fe \\
- & - & Fm \\
FC & $900-1100$ & Fhu
\end{tabular}

$\begin{array}{lll}- & - & \text { Fm } \\ \text { FC } & 1000-1100 & \text { Fhl } \\ \text { FC } & 600-1000 & \text { Fhl } \\ \text { FC } & 600-1100 & \text { Fhl } \\ - & - & \text { Fm } \\ - & - & \text { Fhl } \\ \text { X } & 900 & \text { Frp }\end{array}$

$0=$ Cielo abierto/Open sky overhead

$\mathrm{Rm}=$ Márgenes de los ríos/River margins

* Especies observadas solamente por Stotz./Species recorded only by D.F. Stotz. 



\section{AVES/BIBDS}

Especie/Species

321. Henicorhina leucosticta

322. Microcerculus marginatus

323. Cyphorhinus arada

39. Cyphortinus thoracicus

Nombre común/Common name

White-breasted Wood-Wren/

Cucarachero-Montés de Pecho Blanco

Bermejo

Southern Nightinge de Pecho

-Ruiseñor Sureño

Musician Wren/Cucarachero Musical

Cucarachero de Pecho Castaño

Polioptilidae (1)

Abundancia relativa/ Rango altitudinal/

vational range $(\mathrm{m})$

Turdidae (6)

32.6. Myadestes ralloides

327. Catharus dryas

328. Catharus ustulatus

329. Turdus albicollis

330. Turdus fulviventris

331. Turdus lawrenciit

Parulidae (B)

332. Parula pitiayumi

334. Seiurus noveboracensis"

335. Myioborus miniatus

336. Basileuterus fulvicauda

337. Basileuterus luteoviridis

38. Basileuterus tristriatus

339. Coereba flaveola

Thraupidae (49)

340. Cissopis leverian

341. Chlorornis riefferii

342. Chlorospingus flavigularis

3. Chlorospingus ophthalmicus

45. Chlorothraupis carmio

346. Lanio fulvus

347. Creurgops verticalis

438. Tachyphonus cristatus

349. Tachyphonus luctuosus

Tawny-faced Gnatwren/Soterillo de Cara Leonada

Andean Solitaire/Solitario Andino Spotted Nightingale-Thrush/Zorzal Motead Swainson's Thrush Zorzal de Swainson

White-necked Thrush/Mirlo de Cuello Blanco

Chestnut-bellied Thrush/Mirlo de Viente Castaño

abundance

450-1200 Lawrence's Thrush/Mitlo de Lawrence

450-1200

$450-1000$

Tropical Parula/Parula Tropical

Blackpoll Warbler/Reinita Estriada

Northern Waterthrush/Reinita Acuática Norteña

Slate-throated Redstart/

Buff-rumped Warbler/Reinita de Rabadilla Anteada

Citrine Warbler/Reinita Citrina

Three-striped Warbler/Reinita de Cabeza Listada

BananaquitReinita Mielera

(3)

Magpie Tanager Tangara Urace

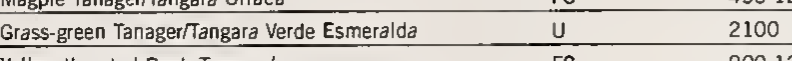

Vellow-hroated Bush-Tanager/

conmen

Yellow-backed Tanager/Tangara de Oorso Amarillo

Carmiol's Tanager//Frutero Aceitunado

Rufous-crested Tanaget/Tangara de Cresta Rufa

Flame-crested Tanager/Tangara de Cresta Rojiza

White-shouldered Tanager/Tangara de Hombros Blancos

\begin{tabular}{ll}
\hline $\mathrm{FC}$ & 1200 \\
\hline $\mathrm{X}$ & $450-750$ \\
\hline $\mathrm{X}$ & - \\
$\mathrm{FC}$ & $1900-2200$ \\
\hline $\mathrm{X}$ & $450+$ \\
\hline $\mathrm{FC}$ & $975-1200$ \\
$\mathrm{X}$ & 750 \\
$\mathrm{X}$ & 750 \\
\hline $\mathrm{FC}$ & $1200-2100$ \\
\hline $\mathrm{FC}$ & 450 \\
\hline $\mathrm{U}$ & 2100 \\
\hline$U$ & 1900 \\
\hline$F C$ & 1200 \\
\hline
\end{tabular}

APENDICE / APPENDIX 3

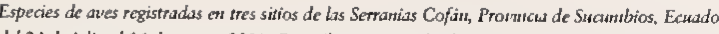
del 24 de istio al 16 de agosto 2001. Onutólogo prineppal: Thomus S. Schulenberg. Observacione dicionales de Debra K. Moskouits, Randy Borman y orros. Tanbien se inchryen especies

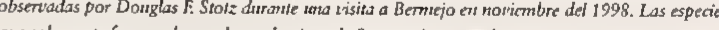

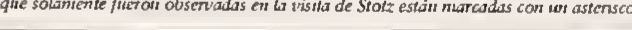

\begin{tabular}{|c|c|c|c|c|c|}
\hline & \multicolumn{2}{|c|}{ Shishicho } & \multicolumn{2}{|c|}{ Ccuccono \& Sinangoe } & \multirow[b]{2}{*}{ Hábitats/Habitats } \\
\hline & $\begin{array}{l}\text { Abundancia relativa/ } \\
\text { Relative abundance }\end{array}$ & $\begin{array}{l}\text { Rango altitudinal/ } \\
\text { Elevational range }(\mathrm{m})\end{array}$ & $\begin{array}{l}\text { Abundancia relativa/ } \\
\text { Relative abundance }\end{array}$ & $\begin{array}{l}\text { Rango altitudinal/ } \\
\text { Elevational range (m) }\end{array}$ & \\
\hline 321. & FC & $900-1000$ & FC & $600-1100$ & Fhl, Fhu \\
\hline 322. & FC & $900-1000$ & $\mathrm{FC}$ & $600-1100$ & Fhl, Fhu \\
\hline 323. & - & $=$ & $\mathrm{FC}$ & $600-1000$ & Fhl \\
\hline 324. & - & - & - & - & $\mathrm{Fm}$ \\
\hline 325. & - & - & $u$ & 600 & Fhl \\
\hline 326. & $u$ & 1400 & $=$ & - & $\mathrm{Fm}$ \\
\hline 327. & $\mathrm{FC}$ & $1200-1400$ & $\mathrm{FC}$ & $900-1100$ & Fhu \\
\hline 328. & - & - & - & - & Fhl \\
\hline 329. & - & - & $\mathrm{FC}$ & $600-1100$ & Fhl \\
\hline 330. & - & - & - & - & Fhu \\
\hline 331. & - & - & - & - & Fhl \\
\hline 332. & $\mathrm{FC}$ & $1200-1400$ & $\mathrm{FC}$ & $900-1100$ & Fhu \\
\hline 333. & - & - & - & - & $\mathrm{Fhl}$ \\
\hline 334. & - & $=$ & - & - & Fhl \\
\hline 335. & $\mathrm{FC}$ & $1200-1400$ & $\mathrm{FC}$ & $900-1100$ & Fhu, Fm \\
\hline 336. & - & - & $\mathrm{FC}$ & 900 & Fsm \\
\hline 337. & - & - & - & - & $\mathrm{Fm}$ \\
\hline 338. & $u$ & 1400 & - & - & Fhu \\
\hline 339. & $\mathrm{FC}$ & 1100 & $\mathrm{FC}$ & $900-1100$ & $\mathrm{Fe}$ \\
\hline 340. & $\mathrm{FC}$ & 1100 & FC & $900-1000$ & $\mathrm{Fe}$ \\
\hline 341. & - & - & - & - & $\mathrm{Fm}$ \\
\hline 342. & $\mathrm{FC}$ & $900-1400$ & $\mathrm{FC}$ & $900-1100$ & Fhu \\
\hline 343. & - & - & - & - & $\mathrm{Fm}$ \\
\hline 344. & - & - & $\mathrm{FC}$ & $1000-1100$ & $\mathrm{Fhl}$ \\
\hline 345. & - & - & $\mathrm{FC}$ & $600-1000$ & $\mathrm{Fhl}$ \\
\hline 346. & $\mathrm{FC}$ & $900-1000$ & $\mathrm{FC}$ & $600-1100$ & Fhl \\
\hline 347. & - & - & - & - & $\mathrm{Fm}$ \\
\hline 348. & - & - & - & - & $\mathrm{Fhl}$ \\
\hline 349. & - & - & $x$ & 900 & Ftp \\
\hline
\end{tabular}

Hábitats/Habitats

$0=$ Cielo abierto/Open sky overhead

bbundancia Relativa/Relative Abundance Poco comun (presente pero no registrada diabr en su hábitat apropriado)/Uncommon (present, but $=$ Raro/Rare

$R=$ Raro/Rare
$X=$ Presente peroco

Presente pero con datos insuficientes para estimar abundancia/Presen,
relative abundance
Rango Altitudinal/Elevational Range
Los datos presentados aquí solo indican las elevaciones a
las cuales cada especie fue obsenvada durante el inventario rápido y no representan la distribución altitudinal de las especies a través de la región./The elevational ranges presented in this table refer only to the altudes at which each species was observed ding the rapid biological

$1900-2100$ $450-1000$

$450-975$

100

inventory, and are not meant to describe the complete
elevational distribution of each species in the region.
Especies observadas
only by D.F. Stozz.

regeneración en áreas de derumbe)/Forest edges (includes

early regenerating habitats, such as on landslides)

$\mathrm{Fhu}=$ Bosque de laderas altas/Loper hill forest

$\mathrm{Fm}=$ Bosque nuboso/Mountain forest or cloud forest Forest stream margins

ECUADOR: SERRANAAS COFAN
$\mathrm{Fsm}=$ Bosques al márgen de las quebradas 
Birds observed at three sites in the Serranias Cofán, Sucumbios province, Ecuador, 24 July-16 August 2001. Principal ornithologist: Thomas S. Schulenberg, with observations by Debra K. Moskovits, Randy Borman, and others; also included are species observed at Bermejo by Douglas F. Stotz in November 1998 (species

A V ESIBIRDS recorded only during the November visit are indicated with an asterisk).

\begin{tabular}{|c|c|c|c|}
\hline \multirow[b]{2}{*}{ Especie/Species } & \multirow[b]{2}{*}{ Nombre común/Common name } & \multicolumn{2}{|c|}{ Bermejo } \\
\hline & & $\begin{array}{l}\text { Abundancia relativa/ } \\
\text { Relative abundance }\end{array}$ & $\begin{array}{l}\text { Rango altitudinal/ } \\
\text { Elevational range }(\mathrm{m})\end{array}$ \\
\hline 350. Tachyphonus surinamus & Fulvous-crested Tanager/Tangara de Cresta Fulva & $\mathrm{FC}$ & 450 \\
\hline 351. Habia rubica* & $\begin{array}{l}\text { Red-crowned Ant-Tanager/ } \\
\text { Tangara-Hormiguera de Corona Roja }\end{array}$ & $x$ & 450 \\
\hline 352. Piranga flava & Hepatic Tanager/Piranga Bermeja & - & - \\
\hline 353. Ramphocelus carbo & Silver-beaked Tanager/Tangara de Pico Plateado & $x$ & - \\
\hline 354. Ramphocelus nigrogularis & Masked Crimson Tanager/Tangara Enmascarada & U & 450 \\
\hline 355. Thraupis episcopus & Blue-gray Tanager/Azulejo Azul y Gris & $\mathrm{FC}$ & $450+$ \\
\hline 356. Thraupis palmarum & Palm Tanager/Azulejo de Palmera & $\mathrm{U}$ & $450+$ \\
\hline 357. Anisognathus somptuosus & $\begin{array}{l}\text { Blue-winged Mountain-Tanager/ } \\
\text { Tangara-de-Montaña de Ala Azul }\end{array}$ & $\mathrm{FC}$ & $1900-2200$ \\
\hline 358. Iridisornis analis & $\begin{array}{l}\text { Yellow-throated Tanager/ } \\
\text { Tangara de Garganta Amarilla }\end{array}$ & - & - \\
\hline 359. Euphonia chrysopasta* & Golden-bellied Euphonia/Eufonia de Vientre Dorado & $x$ & 450 \\
\hline 360. Euphonia laniirostris & Thick-billed Euphonia/Eufonia de Pico Grueso & $\mathrm{U}$ & 450 \\
\hline 361. Euphonia mesochrysa & Bronze-green Euphonia/Eufonia Bronce y Verde & $\mathrm{U}$ & 1200 \\
\hline 362. Euphonia minuta* & $\begin{array}{l}\text { White-vented Euphonia/ } \\
\text { Eufonia de Subcaudales Blancos }\end{array}$ & $\mathrm{x}$ & 450 \\
\hline 363. Euphonia rufiventris ${ }^{\star}$ & Rufous-bellied Euphonia/Eufonia de Vientre Rufo & $x$ & 450 \\
\hline 364. Euphonia xanthogaster & Orange-bellied Euphonia/Eufonia de Vientre Naranja & FC & $450-2100$ \\
\hline 365. Chlorophonia cyanea & Blue-naped Chlorophonia/Clorofonia de Nuca Azul & - & - \\
\hline 366. Chlorochrysa calliparaea & Orange-eared Tanager/Tangara de Oreja Naranja & $\mathrm{FC}$ & $1200-1900$ \\
\hline 367. Tangara arthus & Golden Tanager/Tangara Dorada & $\mathrm{FC}$ & 1200 \\
\hline 368. Tangara callophrys* & Opal-crowned Tanager/Tangara de Corona Opalina & $\mathrm{x}$ & 450 \\
\hline 369. Tangara chilensis & Paradise Tanager/Tangara del Paraíso & $\mathrm{FC}$ & $450-1200$ \\
\hline 370. Tangara chrysotis & Golden-eared Tanager/Tangara de Oreja Dorada & $\mathrm{U}$ & 1200 \\
\hline 371. Tangara cyanicollis & Blue-necked Tanager/Tangara de Cuello Azul & $\mathrm{FC}$ & $900-1200$ \\
\hline 372. Tangara cyanotis & Blue-browed Tanager/Tangara de Ceja Azul & $\mathrm{U}$ & 1200 \\
\hline 373. Tangara gyrola & Bay-headed Tanager/Tangara de Cabeza Baya & $\mathrm{FC}$ & $450-1200$ \\
\hline 374. Tangara mexicana & Turquoise Tanager/Tangara Turquesa & $\mathrm{x}$ & $>450$ \\
\hline 375. Tangara nigrocincta & Masked Tanager/Tangara Enmascarada & $\mathrm{U}$ & 450 \\
\hline 376. Tangara nigroviridis & $\begin{array}{l}\text { Beryl-spangled Tanager/ } \\
\text { Tangara con Lentejuelas de Berilo }\end{array}$ & $U$ & 2100 \\
\hline 377. Tangara parzudakii & Flame-faced Tanager/Tangara Cara de Fuego & $\mathrm{FC}$ & $1900-2200$ \\
\hline 378. Tangara pulcherrima & $\begin{array}{l}\text { Golden-collared Honeycreeper/ } \\
\text { Mielero de Cuello Dorado }\end{array}$ & $\mathrm{U}$ & 1200 \\
\hline 379. Tangara punctata & Spotted Tanager/Tangara Moteada & $\mathrm{FC}$ & $975-1200$ \\
\hline 380. Tangara schrankii & Green-and-gold Tanager/Tangara Verde y Dorada & $\mathrm{FC}$ & 450 \\
\hline 381. Tangara xanthocephala & Saffron-crowned Tanager/Tangara de Corona Azafrán & $\mathrm{FC}$ & $2000-2200$ \\
\hline
\end{tabular}

Abundancia/Relative Abundance

$\mathrm{FC}=$ Bastante común (registrada diariamente en su hábitat apropriado)/Fairly common (recorded daily in suitable habitat)

$\mathrm{U}=$ Poco común (presente pero no registrada diariamente en su hábitat apropriado)/Uncommon (present, but not recorded daily, even in suitable habitat)

$X=$ Presente pero con datos insuficientes para estimar abundancia/Present, but with insufficient data to assess relative abundance
Rango Altitudinal/Elevational Range

Los datos presentados aquí sólo indican las elevaciones a las cuales cada especie fue observada durante el inventario rápido y no representan la distribución altitudinal de las especies a través de la región./The elevational ranges presented in this table refer only to the altitudes at which each species was observed during the rapid biological inventory, and are not meant to describe the complete elevational distribution of each species in the region. 
APÉNDICE/APPENDIX 3

Aves/Birds
Especies de aves registradas en tres sitios de las Serranias Cofán, Provincia de Sucumbios, Ecuador del 24 de julio al 16 de agosto 2001. Omitólogo principal: Thonzas S. Schulenberg. Observaciones adicionales de Debra K. Moskovits, Randy Borman y otros. Tantbién se incluyen especies observadas por Douglas F. Stotz durante una visita a Bermejo en noviembre del 1998. Las especies que solamente fueron observadas en la visita de Stotz están marcadas con un asterisco.

\begin{tabular}{|c|c|c|c|c|c|}
\hline & \multicolumn{2}{|c|}{ Shishicho } & \multicolumn{2}{|c|}{ Ccuccono \& Sinangoe } & \multirow[b]{2}{*}{ Hábitats/Habitats } \\
\hline & $\begin{array}{l}\text { Abundancia relativa/ } \\
\text { Relative abundance }\end{array}$ & $\begin{array}{l}\text { Rango altitudinal/ } \\
\text { Elevational range }(m)\end{array}$ & $\begin{array}{l}\text { Abundancia relativa/ } \\
\text { Relative abundance }\end{array}$ & $\begin{array}{l}\text { Rango altitudinal/ } \\
\text { Elevational range }(\mathrm{m})\end{array}$ & \\
\hline 350. & - & - & - & - & Fhl \\
\hline 351. & - & - & - & - & Fhl \\
\hline 352. & $\mathrm{U}$ & 1100 & - & - & Fhu \\
\hline 353. & - & - & $x$ & 900 & $\mathrm{Fe}$ \\
\hline 354. & - & - & - & - & $\mathrm{Fe}$ \\
\hline 355. & - & - & - & - & $\mathrm{Fe}$ \\
\hline 356. & $\mathrm{U}$ & 1100 & - & - & $\mathrm{Fe}$ \\
\hline 357. & - & - & - & - & $\mathrm{Fm}$ \\
\hline 358. & $\mathrm{U}$ & 1450 & - & - & $\mathrm{Fm}$ \\
\hline 359. & - & - & - & - & $\mathrm{Fhl}$ \\
\hline 360. & - & - & - & - & Fhl \\
\hline 361. & $\mathrm{U}$ & $1200-1400$ & - & - & Fhu, Fm \\
\hline 362. & - & - & - & - & Fhl \\
\hline 363. & - & - & - & - & $\mathrm{Fhl}$ \\
\hline 364. & $\mathrm{FC}$ & $900-1400$ & $\mathrm{FC}$ & $600-1100$ & $\mathrm{Fhl}, \mathrm{Fhu}, \mathrm{Fm}$ \\
\hline 365. & $\mathrm{U}$ & $900-1000$ & $\mathrm{U}$ & 900 & Fhu \\
\hline 366. & $\mathrm{U}$ & 1000 & FC & $1000-1100$ & Fhu \\
\hline 367. & FC & $1200-1400$ & FC & $900-1100$ & Fhu \\
\hline 368. & - & - & - & - & $\mathrm{Fhl}$ \\
\hline 369. & FC & $900-1000$ & $\mathrm{FC}$ & $600+$ & Fhl, Fhu \\
\hline 370. & $\mathrm{U}$ & 900 & $\mathrm{U}$ & $900-1100$ & Fhu \\
\hline 371. & $U$ & 1100 & $\mathrm{FC}$ & $900-1100$ & Fhu \\
\hline 372. & $\mathrm{U}$ & $1200-1400$ & - & - & Fhu \\
\hline 373. & $\mathrm{FC}$ & $1100-1400$ & $\mathrm{FC}$ & $900-1100$ & Fhu, Fhl \\
\hline 374. & - & - & $U$ & 600 & Fhl \\
\hline 375. & - & - & $\mathrm{U}$ & 600 & $\mathrm{Fhl}$ \\
\hline 376. & - & - & - & - & $\mathrm{Fm}$ \\
\hline 377. & - & - & - & - & $\mathrm{Fm}$ \\
\hline 378. & - & - & - & - & Fhu \\
\hline 379. & $\mathrm{FC}$ & $1100-1400$ & $\mathrm{FC}$ & $900-1100$ & Fhu \\
\hline 380. & FC & $900-1000$ & $\mathrm{FC}$ & $600-900$ & $\mathrm{Fhl}$ \\
\hline 381. & - & - & - & - & Fhu \\
\hline
\end{tabular}

\section{Hábitats/Habitats}

$\mathrm{Fe}=$ Bordes del bosque (incluye vegetación secundaria y regeneración en áreas de derrumbe)/Forest edges (includes

early regenerating habitats, such as on landslides)

$\mathrm{Fhl}=$ Bosque de laderas bajas/Lower hill forest

Fhu $=$ Bosque de laderas altas $/$ Upper hill forest

$\mathrm{Fm}=$ Bosque nuboso/Mountain forest or cloud forest

Frp = Bosque ripario/Riparian forest

Fsm = Bosques al márgen de las quebradas /

Forest stream margins
0 = Cielo abierto/Open sky overhead

$\mathrm{Rm}=$ Márgenes de los ríos/River margins 

Especie/Species

Nombre común/Common name

$\frac{\text { Bermejo }}{\text { Abundancia relativa/ Rango altitudinal/ }}$ Relative abundance Elevational range $(\mathrm{m})$

\begin{tabular}{|c|c|c|c|c|}
\hline 350. & Tachyphonus surinamus & Fulvous-crested Tanager/Tangara de Cresta Fulva & $\mathrm{FC}$ & 450 \\
\hline 351. & Habia rubica* & $\begin{array}{l}\text { Red-crowned Ant-Tanager/ } \\
\text { Tangara-Hormiguera de Corona Roja }\end{array}$ & $x$ & 450 \\
\hline 352. & Piranga flava & Hepatic Tanager/Piranga Bermeja & - & $=$ \\
\hline 353. & Ramphocelus carbo & Silver-beaked Tanager/Tangara de Pico Plateado & $x$ & - \\
\hline 354. & Ramphoce/us nigrogulans & Masked Crimson Tanager/Tangara Enmascarada & $u$ & 450 \\
\hline 355. & Thraupis episcopus & Blue-gray Tanager/Azulejo Azul y Gris & $\mathrm{FC}$ & $450+$ \\
\hline 356. & Thraupis palmarum & Palm Tanager/Azulejo de Palmera & $u$ & $450+$ \\
\hline 357. & Anisognathus somptuosus & $\begin{array}{l}\text { Blue-winged Mountain-Tanager/ } \\
\text { Tangara-de-Montaña de Ala Azul }\end{array}$ & $\mathrm{FC}$ & $1900-2200$ \\
\hline 358. & Irridsornis analis & $\begin{array}{l}\text { Yellow-throated Tanager/ } \\
\text { Tangara de Garganta Amarilla }\end{array}$ & - & - \\
\hline 359. & Euphonia chrysopasta" & Golden-bellied Euphonia/Eufonia de Vientre Oorado & $x$ & 450 \\
\hline 360. & Euphonia fanirrostris & Thick-billed Euphonia/Eufonia de Pico Grueso & $u$ & 450 \\
\hline 361. & Euphonia mesochrysa & Bronze-green Euphonia/Eufonia Bronce y Verde & $u$ & 1200 \\
\hline 362. & Euphonia minuta* & $\begin{array}{l}\text { White-vented Euphonial } \\
\text { Eufonia de Subcaudales Blancos }\end{array}$ & $\mathrm{x}$ & 450 \\
\hline 363. & Euphonia rufiventris* & Rufous-bellied Euphonia/Eufonia de Vientre Rufo & $x$ & 450 \\
\hline 364. & Euphonia xanthogaster & Orangebellied Euphonia/Eufonia de Vientre Naranja & $\mathrm{FC}$ & $450-2100$ \\
\hline 365. & Chtorophonia cyanea & Blue-naped Chlorophonia/Clorofonia de Nuca Azul & - & - \\
\hline 366. & Chlorochrysa calliparaea & Orange-eared Tanager/Tangara de Oreja Naranja & $\mathrm{FC}$ & $1200-1900$ \\
\hline 367. & Tangara arthus & Golden Tanager/Tangara Dorada & $\mathrm{FC}$ & 1200 \\
\hline 368. & Tangara cal/ophrys" & Opal-crowned Tanager/Tangara de Corona Opalina & $x$ & 450 \\
\hline 369. & Tangara chilensis & Paradise Tanager/Tangara del Paraiso & $\mathrm{FC}$ & $450-1200$ \\
\hline 370. & Tangara chrysotis & Golden-eared Tanager/Tangara de Oreja Oorada & $u$ & 1200 \\
\hline 371. & Tangara cyanico/lis & Blue-necked Tanager/Tangara de Cuello Azul & $\mathrm{FC}$ & $900-1200$ \\
\hline 372. & Tangara cyanotis & Blue-browed Tanager/Tangara de Ceja Azul & $u$ & 1200 \\
\hline 373. & Tangara gyrola & Bay-headed Tanager/Tangara de Cabeza Baya & $\mathrm{FC}$ & $450-1200$ \\
\hline 374. & Tangara mexicana & Turquoise Tanager/Tangara Turquesa & $x$ & $>450$ \\
\hline 375. & Tangara nigrocincta & Masked Tanager/Tangara Enmascarada & $u$ & 450 \\
\hline 376. & Tangara nigroviridis & $\begin{array}{l}\text { Beryl-spangled Tanager/ } \\
\text { Tangara con Lentejuelas de Berilo }\end{array}$ & $u$ & 2100 \\
\hline 377. & Tangara parzudakii & Flame-faced Tanager/Tangara Cara de Fuego & $\mathrm{FC}$ & $1900-2200$ \\
\hline 378. & Tangara pulcherrima & $\begin{array}{l}\text { Golden-collared Honeycreepert } \\
\text { Mielero de Cuello Dorado }\end{array}$ & $u$ & 1200 \\
\hline 379. & Tangara punctata & Spotted Tanager/Tangara Moteada & $\mathrm{FC}$ & $975-1200$ \\
\hline 380. & Tangara schrankii & Green-and-gold Tanager/Tangara Verde y Oorada & $\mathrm{FC}$ & 450 \\
\hline 381. & Tangara xanthocepha/a & Saffiron-crowned Tanager/Tangara de Corona Azafrán & $\mathrm{FC}$ & $2000-2200$ \\
\hline
\end{tabular}

381. Tangara xanthocepha.

\section{Abundancia/Relative Abundance}

ariamente en su hábitat habitat)

$=$ Poco común (presente pero no registrada diariamente en su hábitat apropriado)/Uncommon (present, bu

$x=$ Presente pero con datos insufficientes para estima abundancia/Present, but with insufficient data to assess relative abundance
Rango Altitudinal/Elevational Range

Los datos presentados aqul sollo indican las elevaciones a es cada especie fue observada durante el inventario especies a traves de la región. The elevational ranges presented in this table refer only to the altitudes at which each species was observed during the rapid biological elevational distribution of each species in the region.

\begin{tabular}{|c|c|c|c|c|c|}
\hline & \multicolumn{2}{|c|}{ Shishicho } & \multicolumn{2}{|c|}{ Ccuccono \& Sinangoe } & \multirow[b]{2}{*}{ Hábitats/Habitats } \\
\hline & $\begin{array}{l}\text { Abundancia relativa/ } \\
\text { Relative abundance }\end{array}$ & $\begin{array}{l}\text { Rango altitudinal/ } \\
\text { Elevational range }(\mathrm{m})\end{array}$ & $\begin{array}{l}\text { Abundancia relativa/ } \\
\text { Relative abundance }\end{array}$ & $\begin{array}{l}\text { Rango altitudinal/ } \\
\text { Elevational range (m) }\end{array}$ & \\
\hline 350. & - & - & - & - & $\mathrm{Fhl}$ \\
\hline 351. & - & - & - & - & Fhl \\
\hline 352. & $u$ & 1100 & - & - & Finu \\
\hline 353. & $=$ & - & $x$ & 900 & $\mathrm{Fe}$ \\
\hline 354. & - & $=$ & - & - & $\mathrm{Fe}$ \\
\hline 355. & - & - & - & - & $\mathrm{Fe}$ \\
\hline 356. & $u$ & 1100 & - & - & $\mathrm{Fe}$ \\
\hline 357. & - & - & - & - & $\mathrm{Fm}$ \\
\hline 358. & U & 1450 & - & - & $\mathrm{Fm}$ \\
\hline 359. & - & - & - & - & $\mathrm{Fhl}$ \\
\hline 360. & $=$ & - & - & - & $\mathrm{Fhl}$ \\
\hline 361. & $u$ & $1200-1400$ & - & - & $\mathrm{Fhu}, \mathrm{Fm}$ \\
\hline 362. & - & - & - & - & $\mathrm{Fhl}$ \\
\hline 363. & - & - & - & - & Fhl \\
\hline 364. & FC & $900-1400$ & $\mathrm{FC}$ & $600-1100$ & Fhl, Fhu, Fm \\
\hline 365. & $u$ & $900-1000$ & $u$ & 900 & Fhu \\
\hline 366. & $u$ & 1000 & $\mathrm{FC}$ & $1000-1100$ & Fhu \\
\hline 367. & $\mathrm{FC}$ & $1200-1400$ & $\mathrm{FC}$ & $900-1100$ & Fhu \\
\hline 368. & - & - & $=$ & - & $\mathrm{Fhl}$ \\
\hline 369. & $\mathrm{FC}$ & $900-1000$ & FC & $600+$ & Fhl, Fhu \\
\hline 370. & $u$ & 900 & $u$ & $900-1100$ & Fhu \\
\hline 371. & $u$ & 1100 & $\mathrm{FC}$ & $900-1100$ & Fhu \\
\hline 372. & U. & $1200-1400$ & - & - & Fhu \\
\hline 373. & $\mathrm{FC}$ & $1100-1400$ & $\mathrm{FC}$ & $900-1100$ & Fhu, Fhl \\
\hline 374. & - & - & $u$ & 600 & Fhl \\
\hline 375. & - & $=$ & u & 600 & FhI \\
\hline 376. & - & - & - & - & $\mathrm{Fm}$ \\
\hline 377. & - & - & $=$ & $=$ & $\mathrm{Fm}$ \\
\hline 378. & - & - & - & - & Fhu \\
\hline 379. & $\mathrm{FC}$ & $1100-1400$ & $\mathrm{FC}$ & $900-1100$ & Fhu \\
\hline 380. & $\mathrm{FC}$ & $900-1000$ & $\mathrm{FC}$ & $600-900$ & $\mathrm{Fhl}$ \\
\hline 381 & - & & - & - & Fhu \\
\hline
\end{tabular}

Hábitats/Habitats

= Bordes del bosque (incluye vegetación secundaria y regeneración en áreas de derrumbe)/Forest edges (includes

arly regenerating habitats, such as on landslides'

$\mathrm{Fhl}=$ Bosque de laderas bajas/Lower hill forest

Fhu $=$ Bosque de laderas altas/Upper hill forest

$\mathrm{Fm}_{\mathrm{rp}}=$ = Bosque ripario/Riparian forest

$\mathrm{Fsm}=$ Bosques al márgen de las quebradas / Forest stream margins

ECUADOR: SERRANIAS COFAN
$0=$ Cielo abierto/Open sky overhead
$\mathrm{Rm}=$ Márgenes de los rlos/River margins

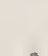

- Especies observadas solamente por Stoz./Species recorde only by D.F. Stoz. 
Birds observed at three sites in the Serranias Cofán, Sucumbios province, Ecuador, 24 July-16 August 2001. Principal ornithologist: Thomas S. Schulenberg, with observations by Debra K. Moskovits, Randy Borman, and others; also included are species observed at Bermejo by Douglas F. Stotz in November 1998 (species

A V ESIBIR D recorded only during the November visit are indicated with an asterisk).

\begin{tabular}{|c|c|c|c|}
\hline \multirow[b]{2}{*}{ Especie/Species } & \multirow[b]{2}{*}{ Nombre común/Common name } & \multicolumn{2}{|c|}{ Bermejo } \\
\hline & & $\begin{array}{l}\text { Abundancia relativa/ } \\
\text { Relative abundance }\end{array}$ & $\begin{array}{l}\text { Rango altitudinal/ } \\
\text { Elevational range }(\mathrm{m})\end{array}$ \\
\hline 382. Tangara xanthogastra & Yellow-bellied Tanager/Tangara de Vientre Amarillo & - & - \\
\hline 383. Dacnis cayana & Blue Dacnis/Dacnis Azul & FC & $450-1200$ \\
\hline 384. Dacnis flaviventer & Yellow-bellied Dacnis/Dacnis de Vientre Amarillo & - & - \\
\hline 385. Dacnis lineata & Black-faced Dacnis/Dacnis de Cara Negra & FC & $450-1200$ \\
\hline 386. Chlorophanes spiza & Green Honeycreeper/Mielero Verde & $\mathrm{U}$ & $450-1200$ \\
\hline 387. Cyanerpes caeruleus & Purple Honeycreeper/Mielero Púrpura & $\mathrm{U}$ & 450 \\
\hline 388. Diglossa glauca & $\begin{array}{l}\text { Deep-blue Flower-piercer/ } \\
\text { Pincha-Flor de Azul Intenso }\end{array}$ & FC & $2000-2200$ \\
\hline \multicolumn{4}{|l|}{ Emberizidae (6) } \\
\hline 389. Ammodramus aurifrons & Yellow-browed Sparrow/Gorrión de Ceja Amarilla & $\mathrm{FC}$ & 450 \\
\hline 390. Volatinia jacarina* & Blue-black Grassquit/Semillerito Negro Azulado & $x$ & - \\
\hline 391. Sporophila castaneiventris* & $\begin{array}{l}\text { Chestnut-bellied Seedeater/ } \\
\text { Espiguero de Vientre Castaño }\end{array}$ & $x$ & - \\
\hline 392. Oryzoborus angolensis & Lesser Seed-Finch/Semillero Menor & FC & 450 \\
\hline 393. Arremon aurantiirostris & Orange-billed Sparrow/Gorrión de Pico Naranja & $\mathrm{U}$ & $450-1200$ \\
\hline 394. Buarremon brunneinucha & $\begin{array}{l}\text { Chestnut-capped Brush-Finch/ } \\
\text { Matorralero de Gorro Castaño }\end{array}$ & FC & $1900-2000$ \\
\hline \multicolumn{4}{|l|}{ Cardinalidae (2) } \\
\hline 395. Pitylus grossus & Slate-colored Grosbeak/Picogrueso de Pico Rojo & $\mathrm{U}$ & 1200 \\
\hline 396. Saltator maximus & $\begin{array}{l}\text { Buff-throated Saltator/ } \\
\text { Saltador de Garganta Anteada }\end{array}$ & $\mathrm{U}$ & $450-1100$ \\
\hline \multicolumn{4}{|l|}{ Icteridae (4) } \\
\hline 397. Icterus chrysocephalus & Moriche Oriole/Bolsero Moriche & $\mathrm{U}$ & 450 \\
\hline 398. Psarocolius angustifrons & $\begin{array}{l}\text { Russet-backed Oropendola/ } \\
\text { Oropéndola de Dorso Bermejo }\end{array}$ & FC & $450-1200$ \\
\hline 399. Psarocolius decumanus & Crested Oropendola/Oropéndola Crestada & $\mathrm{U}$ & 450 \\
\hline 400. Cacicus cela & $\begin{array}{l}\text { Yellow-rumped Cacique/ } \\
\text { Cacique de Rabadilla Amarilla }\end{array}$ & $\mathrm{U}$ & 450 \\
\hline
\end{tabular}

Abundancia Relativa/Relative Abundance

$\mathrm{FC}=$ Bastante común (registrada diariamente en su hábitat apropiado)/Fairly common (recorded daily in suitable habitat)

$\mathrm{U}=$ Poco común (presente pero no registrada diariamente en su hábitat apropriado)/Uncommon (present, but not recorded daily, even in suitable habitat)

$\mathrm{R}=$ Raro/Rare

$X=$ Presente pero con datos insuficientes para estimar abundancia/Present, but with insufficient data to assess relative abundance
Rango Altitudinal/Elevational Range

Los datos presentados aquí sólo indican las elevaciones a las cuales cada especie fue observada durante el inventario rápido y no representan la distribución altitudinal de las especies a través de la región./The elevational ranges presented in this table refer only to the altitudes at which each species was observed during the rapid biological inventory, and are not meant to describe the complete elevational distribution of each species in the region. 
APÉNDICE/APPENDIX 3

Aves/Birds
Especies de aves registradas en tres sitios de las Serranias Cofán, Provincia de Sucumbios, Ecuador, del 24 de julio al 16 de agosto 2001. Omitólogo principal: Thomas S. Schulenberg. Observaciones adicionales de Debra K. Moskovits, Randy Borman y otros. También se incluyen especies observadas por Douglas F. Stotz durante una visita a Bermejo en noviembre del 1998. Las especies que solamente fueron observadas en la visita de Stotz están marcadas con un asterisco.

\begin{tabular}{|c|c|c|c|c|c|}
\hline & \multicolumn{2}{|c|}{ Shishicho } & \multicolumn{2}{|c|}{ Ccuccono \& Sinangoe } & \multirow[b]{2}{*}{ Hábitats/Habitats } \\
\hline & $\begin{array}{l}\text { Abundancia relativa/ } \\
\text { Relative abundance }\end{array}$ & $\begin{array}{l}\text { Rango altitudinal/ } \\
\text { Elevational range (m) }\end{array}$ & $\begin{array}{l}\text { Abundancia relativa/ } \\
\text { Relative abundance }\end{array}$ & $\begin{array}{l}\text { Rango altitudinal/ } \\
\text { Elevational range (m) }\end{array}$ & \\
\hline 382. & $\mathrm{U}$ & 1000 & U & 600 & Fhl \\
\hline 383. & - & - & - & - & Fhl, Fhu \\
\hline 384. & $\mathrm{U}$ & 650 & - & - & Fhl \\
\hline 385. & - & - & FC & $600-1100$ & Fhl, Fhu \\
\hline 386. & - & - & $U$ & 600 & Fhl, Fhu \\
\hline 387. & - & - & $U$ & 600 & Fhl \\
\hline 388 . & $\mathrm{FC}$ & $1200-1400$ & - & - & Fhu, Fm \\
\hline 389. & - & - & $x$ & 900 & $\mathrm{Fe}$ \\
\hline 390. & - & - & - & - & - \\
\hline 391. & - & - & - & - & - \\
\hline 392. & - & - & - & - & $\mathrm{Fe}$ \\
\hline 393. & - & - & U & 1100 & Fhl, Fhu \\
\hline 394. & - & - & - & - & $\mathrm{Fm}$ \\
\hline 395. & U & 900 & $\mathrm{FC}$ & $600-1100$ & Fhl, Fhu \\
\hline 396. & - & - & $\mathrm{FC}$ & $600-1100$ & Fhl, Fhu \\
\hline 397. & - & - & $U$ & 600 & $\mathrm{Fhl}$ \\
\hline 398. & $\mathrm{FC}$ & $900-1200$ & $\mathrm{FC}$ & $600-1100$ & Fhl, Fhu \\
\hline 399. & - & - & FC & 600 & $\mathrm{Fhl}$ \\
\hline 400 & - & - & U & 600 & Fhl \\
\hline
\end{tabular}

\section{Hábitats/Habitats}

$\mathrm{Fe}=$ Bordes del bosque (incluye vegetación secundaria y regeneración en áreas de derrumbe)/Forest edges (includes early regenerating habitats, such as on landslides)

Fhl = Bosque de laderas bajas/Lower hill forest

Fhu = Bosque de laderas altas/Upper hill forest

$\mathrm{Fm}=$ Bosque nuboso/Mountain forest or cloud forest

Frp = Bosque ripario/Riparian forest

$\mathrm{Fsm}=$ Bosques al márgen de las quebradas $/$ Forest stream margins
0 = Cielo abierto/Open sky overhead

$\mathrm{Rm}=$ Márgenes de los ríos/River margins 

Bermejo

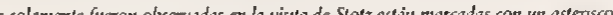

Abundancia relativa/ Rango altitudinal/

Especie/Species

382. Tangara xanthogastra Nombre comün/Common name

Relative abundance Elevational range $(\mathrm{m})$

383. Dacnis cayana

384. Dacnis flaviventer

Yellow-bellied Tanager/Tangara de Vientre Amarillo

385. Dacnis lineata Blue Oacnis/Dacnis Azul

$\begin{array}{ll}- & - \\ \text { FC } & 450-1200\end{array}$
396. Chlorophanes spiza
387. Cyanerpes caeruleus Yellow-bellied Oacnis/Oacnis de Vientre Amarillo 388. Diglossa glauca

\section{Emberizidae (6)}

Green Honeycreeper/Mielero Verde

389. Ammodramus aurifrons
390. Volatinia jacarina*

作

Pincha-Flor de Azul Intenso

450-1200

G

FC $\quad 450-1200$

Yellow-browed Sparrow/Gorrión de Ceja Amarilla

FC

\begin{tabular}{l}
$450-1200$ \\
\hline $5000-2200$
\end{tabular}

\section{Sporophila castaneiventris \\ 1. 392. Dryzoborus angolensis}

450

393. Arremon aurantirrostris

Chestnut-bellied Seedeater/

Lesser Seed Finch/semillero Menor

394. Buarremon brunneinucha

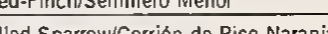

Chestnut-capped Brush-Finch/

\begin{tabular}{|c|}
\hline Cardinalidae (2) \\
\hline 395. Pitylus grossus \\
\hline
\end{tabular}

396. Saltator maximus

Slate-colored Grosbeak/Picogrueso de Pico Rojo

Saltador de Garganta Anteada

Icteridae (4)

397. Icterus chrysocephalus

Moriche Oriole/Bolsero Moriche

Russet-backed Oropendola/
Oropendola de Oorso Bermejo

U $\quad 450$

199. Psarocolius decumanus

Crested Oropendola/Oropéndola Crestad

400. Cacicus cela Yellow-rumped Cacique/
Cacique de Rabadilla Amaril

\begin{tabular}{ll}
$F C$ & 450 \\
\hline$X$ & - \\
\hline$X$ & - \\
\hline$F C$ & 450 \\
\hline$U$ & $450 \cdot 1200$ \\
$F C$ & $1900-2000$
\end{tabular}

1200

$450-1100$

450

450

\begin{tabular}{|lllc}
\hline 400. Cacicus cela & $\begin{array}{l}\text { Yellow-rumped Caciquel } \\
\text { Cacique de Rabadilla Amarilla }\end{array}$ & U & 450 \\
\hline
\end{tabular}

Abundancia Relativa/Relative Abundance
$\mathrm{FC}=$ Bastante comùn (registrada diariam

trada diariamente en su hábitat apropiado)/Fairly common (recorded daily in suitable habita Poco comun (presente pero no registrada diariamente not recorded daily, even in sultable habitat)

$\mathrm{R}=$ Raro/ Rare
$\mathrm{X}=$ Presente

abundancia con datos insuficientes para estimar relative abundance
Rango Altitudinal/Elevational Range

Los datos presentados aqul sólo indican las elevaciones a.

las cuales cada especie fue observada durante el inventario

rápido y no representan la distribución altitudinal de las

especies a traves de la región. The elevational ranges

presented in this table refer only to the altitudes at which

each species was observed during the rapid biological
inventory, and are not meant to describe the complete

elevational distribution of each species in the region.

\begin{tabular}{|c|c|c|c|c|c|}
\hline & \multicolumn{2}{|c|}{ Shishicho } & \multicolumn{2}{|c|}{ Ccuccono \& Sinangoe } & \multirow[b]{2}{*}{ Hábitats/Habitats } \\
\hline & $\begin{array}{l}\text { Abundancia relativa/ } \\
\text { Relative abundance }\end{array}$ & $\begin{array}{l}\text { Rango altitudinal/ } \\
\text { Elevational range (m) }\end{array}$ & $\begin{array}{l}\text { Abundancia relatival } \\
\text { Relative abundance }\end{array}$ & $\begin{array}{l}\text { Rango altitudinal/ } \\
\text { Elevational range (m) }\end{array}$ & \\
\hline 382. & $u$ & 1000 & $u$ & 600 & $\mathrm{Fhl}$ \\
\hline 383. & - & - & - & - & Fhl, Fhu \\
\hline 384. & $\bar{u}$ & 650 & - & - & $\mathrm{Fhl}$ \\
\hline 385. & - & - & FC & $600-1100$ & Fhl, Fhu \\
\hline 386. & - & - & $\mathrm{U}$ & 600 & Fhl, Fhu \\
\hline 387. & $=$ & - & $\mathrm{U}$ & 600 & $\mathrm{Fhl}$ \\
\hline 388. & $\mathrm{FC}$ & $1200-1400$ & - & - & Fhu, Fm \\
\hline 389. & - & - & $x$ & 900 & $\mathrm{Fe}$ \\
\hline 390. & $=$ & - & - & - & - \\
\hline 391. & - & - & - & - & - \\
\hline 392. & - & $=$ & - & $=$ & $\mathrm{Fe}$ \\
\hline 393. & - & - & $U$ & 1100 & Fhl, Fhu \\
\hline 394. & - & - & - & - & $\mathrm{Fm}$ \\
\hline 395. & $u$ & 900 & $\overline{F C}$ & $600-1100$ & Fhl, Fhu \\
\hline 396. & - & - & $F C$ & $600-1100$ & Fhl, Fhu \\
\hline 397. & - & - & $u$ & 600 & $\mathrm{Fhl}$ \\
\hline 398. & $F C$ & $900-1200$ & $\mathrm{FC}$ & $600-1100$ & Fhl, Fhu \\
\hline 399. & - & - & FC & 600 & $\mathrm{Fhl}$ \\
\hline 400. & - & - & $u$ & 600 & Fhl \\
\hline
\end{tabular}

Hábitats/Habitats

Bordes del bosque (incluye vegetación secundaria y

regeneración en áreas de derrumbe)/Forest edges

$\mathrm{Fhl}=$ Bosque de laderas bajas/Lower hill forest

Fhu $=$ Bosque de laderas altas/Upper hill forest
$\mathrm{Fm}=$ Bosque nuboso/Mountain forest or cloud fores

Frp $=$ Bosque ripario/Riparian forest

$\mathrm{Fsm}=$ Bosques al márgen de las quebradas $l$ Forest stream margins

ECUADOR: SERRANIAS COFAN
Especies observadas solamente por Stoz./Species recorded

$0=$ Cielo abierto/Open sky overhead

Rm $=$ Mangenes delos nly by D.F. Storz.

ENERO/ IANUARY 2002 200 


\section{MAMIFEROS GRANDESILARGE MAMMALS}

\begin{tabular}{|c|c|c|c|c|}
\hline \multirow[b]{2}{*}{ Especie/Species } & \multirow[b]{2}{*}{$\begin{array}{l}\text { Nombre Cofán/ } \\
\text { Cofán name }\end{array}$} & \multirow[b]{2}{*}{$\begin{array}{l}\text { Nombre en español/ } \\
\text { Spanish name }\end{array}$} & \multicolumn{2}{|c|}{ Bermejo } \\
\hline & & & $\begin{array}{l}\text { No. de registros/ } \\
\text { No. of records** }\end{array}$ & $\begin{array}{l}\text { Abundancia estimada/ } \\
\text { Estimated abundance }\end{array}$ \\
\hline \multicolumn{5}{|l|}{ ARTIODACTYLA } \\
\hline \multicolumn{5}{|l|}{ Cervidae } \\
\hline 01. Mazama americana & shan'cco & venado rojo & $>10$ & $\mathrm{C}_{+}$ \\
\hline 02. Mazama gouazoubira & ciafaje shan'cco & venado gris & 0 & $x$ \\
\hline 03. Mazama rufina & ccottacco'su shan'cco & venado de montaña & $4 ?$ & $\mathrm{X}$ ? \\
\hline \multicolumn{5}{|l|}{ Tayassuidae } \\
\hline 04. Tayassu pecari & munda & puerco juangana & 1 & $\mathrm{U}$ \\
\hline 05. Tayassu tajacu & saquira & sahíno & $>10$ & $\mathrm{C}$ \\
\hline \multicolumn{5}{|l|}{ CARNIVORA } \\
\hline \multicolumn{5}{|l|}{ Canidae } \\
\hline 06. Atelocynus microtis & tsampi'su ain & perro de orejas cortas & 1 & $x$ \\
\hline 07. Speothos venaticus* & chipiri tsampi'su ain & perro de monte & 0 & $\mathrm{R}$ \\
\hline \multicolumn{5}{|l|}{ Felidae } \\
\hline 08. Herpailurus yaguarondi* & quiya ttesi & yaguarundi & $?$ & $x$ \\
\hline 09. Leopardus pardalis & ampashanccu chimindi & tigrillo grande & $1(4 ?)$ & $\mathrm{C}$ \\
\hline 10. Leopardus wiedii* & totopa chimindi & tigrillo de cola larga & $?$ & $x$ \\
\hline 11. Panthera onca & zen'zia ttesi & tigre & 2 & $\mathrm{U}$ \\
\hline 12. Puma concolor ${ }^{\star}$ & cuvo ttesi & león & 0 & U \\
\hline \multicolumn{5}{|l|}{ Mustelidae } \\
\hline 13. Eira barbara & pando & cabeza de mata & $>10$ & $\mathrm{C}$ \\
\hline 14. Lontra longicaudis & choni & nutria & 4 & $\mathrm{U}$ \\
\hline \multicolumn{5}{|l|}{ Procyonidae } \\
\hline 15. Bassaricyon gabbii* & chipiri consinsi & olingo & $?$ & $x$ \\
\hline 16. Nasua nasua & coshombi & tejón, coatí & 8 & $\mathrm{C}$ \\
\hline 17. Nasuella olivacea* & coshombi & - & $?$ & $X ?$ \\
\hline 18. Potos flavus & consinsi & martica & 1 & C \\
\hline \multicolumn{5}{|l|}{ Ursidae } \\
\hline 19. Tremarctos ornatus & ocomari & oso de anteojos & $>10$ & $\mathrm{C}+$ \\
\hline \multicolumn{5}{|l|}{ PERISSODACTYLA } \\
\hline \multicolumn{5}{|l|}{ Tapiridae } \\
\hline 20. Tapirus pinchaque* & ccottaccosu ccovi & tapir de montaña & 0 & $?$ \\
\hline 21. Tapirus terrestris & ccovi & tapir, danta & $>10$ & $\mathrm{C}$ \\
\hline \multicolumn{5}{|l|}{ PRIMATES } \\
\hline \multicolumn{5}{|l|}{ Callitrichidae } \\
\hline 22. Cebuella pygmaea* & tinfacho chi'me & chambira chichico & 0 & $?$ \\
\hline 23. Saguinus nigricollis & chi'me & chichico & 4 & C \\
\hline \multicolumn{5}{|l|}{ Cebidae } \\
\hline 24. Alouatta seniculus & a'cho & mono aullador & $>10$ & $\mathrm{C}$ \\
\hline 25. Aotus lemurinus & macoro & mono de noche & $?$ & $x$ \\
\hline 26. Aotus vociferans & macoro & mono de noche & $?$ & $X ?$ \\
\hline 27. Ateles belzebuth & duye & mono araña & 2 & $\mathrm{R}$ \\
\hline 28. Callicebus moloch cupreus* & cu'a tso'ga & mono tití & 0 & $\mathrm{R}$ \\
\hline 29. Callicebus torquatus* & si'an tso'ga & cotoncillo & 0 & $\mathrm{R}$ \\
\hline 30. Cebus albifrons & ongu & capuchín, machin & 4 & $\mathrm{C}$ \\
\hline 31. Cebus apella & ccottacco'su ongu & capuchín & 1 & $\mathrm{U}$ \\
\hline
\end{tabular}


APÉNDICE/APPENDIX 4

Mamíferos Grandes/Large Mammals
Lista de especies de mamiferos grandes registrados por el equipo del inventario rápido o reportado por los habitantes locales en los alrededores de Bermejo y Sinangoe, Provincia de Sucumbios, en el nororiente del Ecuador, del 24 julio al 16 agosto del 2001.

\section{Sinangoe}

No. de registros/ No. of records**

Abundancia estimada/ Estimated abundance CITES UICN/IUCN

\begin{tabular}{llllll}
01. & $>10$ & $\mathrm{C}$ & $\mathrm{III}$ & $\mathrm{DD}$ \\
\hline 02. & 1 & $\mathrm{X}$ & - & $\mathrm{DD}$ \\
\hline 03. & 0 & - & - & $\mathrm{NT}$ \\
\hline & & & & \\
\hline 04. & 0 & $\mathrm{U}$ & $\mathrm{II}$ & - \\
\hline 05. & $>10$ & $\mathrm{C}$ & $\mathrm{II}$ & - \\
\hline
\end{tabular}

\begin{tabular}{lllll}
06. & 0 & $\mathrm{X}$ & - & $\mathrm{DD}$ \\
07. & 0 & $\mathrm{R}$ & $\mathrm{I}$ & $\mathrm{VU}$ \\
\hline
\end{tabular}

\begin{tabular}{|lllll|}
\hline 08. & $?$ & $\mathrm{X}$ & $\mathrm{I}$ & - \\
\hline 09. & $6 ?$ & $\mathrm{C}$ & $\mathrm{I}$ & - \\
\hline 10. & $?$ & $\mathrm{X}$ & $\mathrm{I}$ & - \\
\hline 11. & 4 & $\mathrm{C}$ & $\mathrm{I}$ & NT \\
\hline 12. & 0 & $\mathrm{U}$ & $\mathrm{II}$ & - \\
\hline
\end{tabular}

$\begin{array}{lllll}13 . & >10 & \mathrm{C} & \text { III } & - \\ 14 . & 3 & \mathrm{U} & \mathrm{I} & \mathrm{DD}\end{array}$

\begin{tabular}{llllll}
15. & $?$ & $\mathrm{X}$ & $\mathrm{III}$ & - \\
\hline 16. & $>10$ & $\mathrm{C}$ & $\mathrm{III}$ & - \\
17. & $?$ & $\mathrm{X} ?$ & - & $\mathrm{DD}$ \\
18. & 2 & $\mathrm{C}$ & $\mathrm{III}$ & - \\
\hline & & & & \\
19. & $>10$ & $\mathrm{C}$ & $\mathrm{I}$ & $\mathrm{VU}$ \\
\hline
\end{tabular}

\begin{tabular}{lllll|}
20. & $1 ?$ & $X ?$ & I & EN \\
\hline 21. & $>10$ & $\mathrm{C}+$ & II & NT \\
\hline
\end{tabular}

\begin{tabular}{lllll}
22. & 0 & $U$ & $\|$ & - \\
23. & 2 & $C$ & $\| 1$ & - \\
\hline
\end{tabular}

\begin{tabular}{|lllll|}
\hline 24. & $>10$ & $\mathrm{C}$ & $\mathrm{II}$ & - \\
\hline 25. & 1 & $\mathrm{X}$ & - & - \\
\hline 26. & $?$ & $\mathrm{X} ?$ & $\mathrm{II}$ & $\mathrm{VU}$ \\
\hline 27. & 7 & $\mathrm{C}$ & $\mathrm{II}$ & $\mathrm{VU}$ \\
\hline 28. & 0 & $\mathrm{R}$ & $\mathrm{II}$ & - \\
\hline 29. & 0 & $\mathrm{R}$ & $\mathrm{II}$ & - \\
\hline 30. & $>10$ & $\mathrm{C}$ & $\mathrm{II}$ & $\mathrm{DD}$ \\
\hline 31. & 0 & - & 11 & - \\
\hline
\end{tabular}

\section{Apéndice CITES/CITES Appendix \\ = En vía de extinción/ \\ Threatened with extinction \\ II = Vulnerables o potencialmente amenazadas/ Vulnerable or potentially threatened}

Categoría UICN/IUCN Category

$\mathrm{EN}=\mathrm{En}$ peligro/Endangered

$\mathrm{VU}=$ Vulnerable/Vulnerable

$\mathrm{DD}=$ Datos Insuficientes/Data Deficient

\section{Abundancia/Abundance:}

$\mathrm{C}+=$ Muy común/Very common

$\mathrm{C}=$ Común/Common

$\mathrm{U}=$ Poco frecuente/Uncommon

$\mathrm{R}=$ Raro/Rare

$X=$ Especie presente/Species present

* Especies que no fueron registradas por el equipo de investigación pero que sí son conocidas por los habitantes de la zona./ Species not encountered by the rapid biological inventory team but reported by local residents.

* Los registros incluyen cualquier evidencia física de la presencia de la especie, p.e., huellas, excremento, contacto visual./Records include all physical evidence of the species' presence, e.g., tracks, scat, markings, and sightings.
NT = Casi Amenazada/Near Threatened 



\section{MAMITEROS GRANDESILAREE MAMMALS}

\begin{tabular}{|c|c|c|c|c|}
\hline \multirow[b]{2}{*}{ Especie/Species } & \multirow[b]{2}{*}{$\begin{array}{l}\text { Nombre Cotán/ } \\
\text { Cofán name }\end{array}$} & \multirow[b]{2}{*}{$\begin{array}{l}\text { Nombre en español/ } \\
\text { Spanish name }\end{array}$} & \multicolumn{2}{|c|}{ Bermejo } \\
\hline & & & $\begin{array}{l}\text { No, de registros } / \\
\text { No. of records } * \star\end{array}$ & $\begin{array}{l}\text { Abundancia estimada/ } \\
\text { Estimated abundance }\end{array}$ \\
\hline \multicolumn{5}{|l|}{ ARTIODACTYLA } \\
\hline \multicolumn{5}{|l|}{ Cervidae } \\
\hline 01. Mazama americana & shan'cco & venado rojo & $>10$ & $C_{+}$ \\
\hline 02. Mazama gouazoubira & ciafaje shan'cco & venado gris & 0 & $x$ \\
\hline 03. Mazama rufina & ccottacco'su shan'cco & venado de montaña & $4 ?$ & $\mathrm{x} ?$ \\
\hline \multicolumn{5}{|l|}{ Tayassuidae } \\
\hline 04. Tayassu pecari & munda & puerco juangana & 1 & $u$ \\
\hline 05. Tayassu tajacu & saquira & sahlno & $>10$ & c \\
\hline \multicolumn{5}{|l|}{ CARNIVORA } \\
\hline Canidae & & & & \\
\hline
\end{tabular}

\begin{tabular}{lllll} 
06. Atelocynus microtis & tsampi'su ain & perro de orejas cortas & 1 & $X$ \\
07. Speothos venaticus & chipiri tsampi'su ain & perro de monte & 0 & $\mathrm{R}$ \\
\hline
\end{tabular}

Felidae

08. Herpailurus yaguarondi* quiya ttesi 1 yaguarundi $\quad$ ?

09. Leopardus pardalis ampashanceu chimindi tigrillo grande

topa chimind

tigrillo de cola larga

$x$

11. Panthera onca zen'zia ttesi tige

12. Puma concolorz cuvo ttesi león

Mustelidae

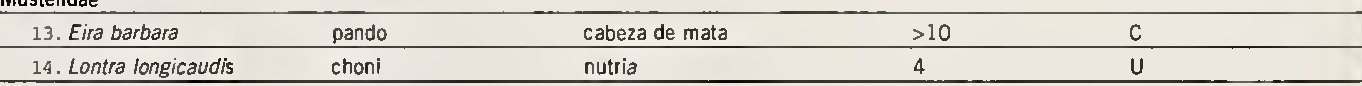

Procyonidae

15. Bassaricyon gabbii* chipiri consinsi ol

16. Nasua nasua coshombi

17. Nesuella olivace

18. Potos flavus $\frac{\text { coshom }}{\text { consins }}$

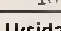

Utsidae Tremarctos ornatus ocomari

oso de anteojos

coats

$\frac{x}{c}$

PERISSODACTYLA

Tapiridae

\begin{tabular}{lllll}
\hline 20. Tapirus pinchaque & ccottaccosu ccovi & tapir de montaña & 0 & $?$ \\
\hline 21. Tapirus terrestris & ccovi & tapir, danta & $>10$ & $\mathrm{C}$ \\
\hline
\end{tabular}

PRIMATES

Callitrichidae

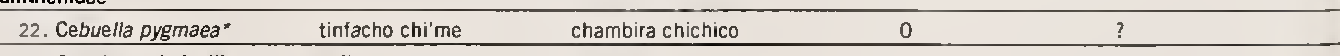

23. Saguinus nigricolli:

24. Alouattla seniculus _.... a'cho

25. Aotus lemurinus _. macoro

mono aullador

28. Callicebus moloch cupreus* cu'a tso'ga chambirat

\begin{tabular}{ll}
0 & $?$ \\
\hline 4 & $\mathrm{C}$ \\
\hline$>10$ & $\mathrm{C}$ \\
$? ?$ & $\mathrm{X}$ \\
\hline$?$ & $\mathrm{X} ?$ \\
\hline 2 & $\mathrm{R}$ \\
0 & $\mathrm{R}$ \\
\hline 0 & $\mathrm{R}$ \\
\hline 4 & $\mathrm{C}$ \\
\hline 1 & $\mathrm{U}$ \\
\hline
\end{tabular}

INFORMEIREPORT NO. 3
26. Aotus vociferans

si'an tso'ga

30. Cebus albifrons

ccottacco'su ongu

mono de noche

mono arah̆a

mono titl

capuchln, machin

210 RAPID BIOLOOICAL INVENTORIES

capuchin,

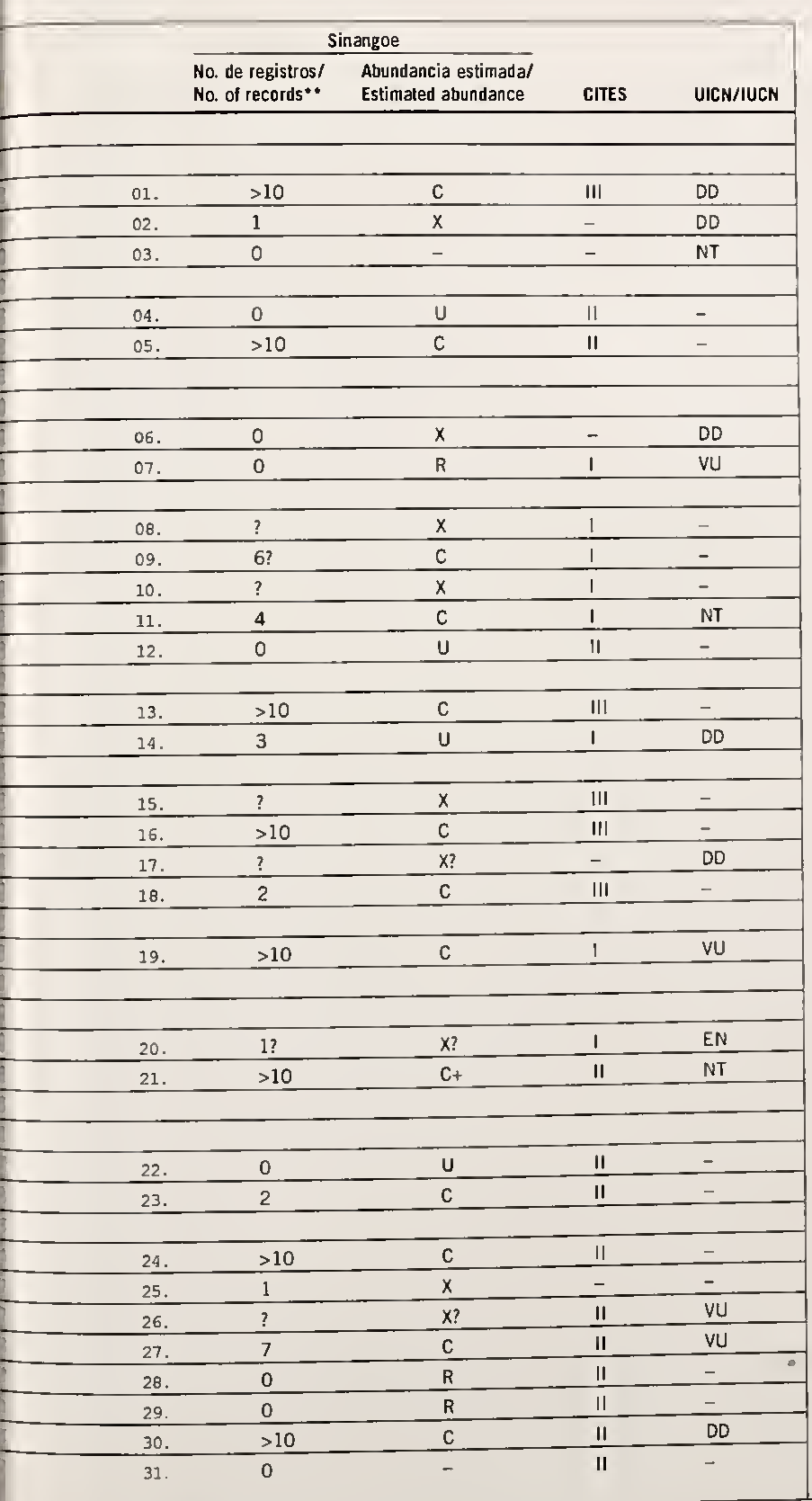

Apéndice CITES/CITES Appendix

$=$ En vfa de extinción/

$=$ Vulnerables 0 potencialmente amenazadas

Vulnerable or potentially threatened

i: = Reguladas/Regulated

Categoría UICN/IUCN Category

$E N=$ En peligro $/$ Endangered
$V U=$ Vulnerable/Vulnerable

$N T=$ Casi Amenazada/Near Threatened
$D D=$ Datos Insuficientes $/$ Data Deficient

Abundancia/Abundance:

$\mathrm{C}_{+}=$Muy cormin/Very common

$U=$ Poco frecuente/Uncommon

$R=$ Raro/Rare
$X=$ Especie presente/Species present

- Especies que no fueron registradas por el
equipo de investigación pero que si son

conocidas por los habitantes de la zona.l

Species not encountered by the rapid biologica
inventory team but repored by local residents.

- Los regissros incluyen cualquier evidencia física

excremento, contacto visual. /Records include

excremento, condente of the species' presence,
all physical veden
c. p., tracks, scat, markings, and sightings.

ECUADOB: SERTANIAS COFÁ 


\section{MAMIFEROS GRANDESILARGE MAMMALS}

\begin{tabular}{|c|c|c|c|c|}
\hline \multirow[b]{2}{*}{ Especie/Species } & \multirow[b]{2}{*}{$\begin{array}{l}\text { Nombre Cotán/ } \\
\text { Cofán name }\end{array}$} & \multirow[b]{2}{*}{$\begin{array}{l}\text { Nombre en español/ } \\
\text { Spanish name }\end{array}$} & \multicolumn{2}{|c|}{ Bermejo } \\
\hline & & & $\begin{array}{l}\text { No. de registros/ } \\
\text { No. of records }{ }^{* *}\end{array}$ & $\begin{array}{l}\text { Abundancia estimada/ } \\
\text { Estimated abundance }\end{array}$ \\
\hline \multicolumn{5}{|l|}{ Cebidae (cont.) } \\
\hline $\begin{array}{l}\text { 32. Lagothrix lagothricha } \\
\text { humboldtii }\end{array}$ & totosi con'si & chorongo, mono lanudo & 4 & C \\
\hline 33. Pithecia monachus* & paravacco & saki & 0 & $x$ \\
\hline 34. Saimiri sciureus & fatsi & barizo & 3 & C \\
\hline \multicolumn{5}{|l|}{ RODENTIA } \\
\hline \multicolumn{5}{|l|}{ Agoutidae } \\
\hline 35. Agouti paca & chanange & guanta & $>10$ & C \\
\hline \multicolumn{5}{|l|}{ Dasyproctidae } \\
\hline 36. Dasyproctus fuliginosa & quiya & guatusa, aguti & $>10$ & $\mathrm{C}_{+}$ \\
\hline \multicolumn{5}{|l|}{ Sciuridae } \\
\hline 37. Sciurius aestuans & chipiri tutuye & ardilla & - & - \\
\hline 38. Sciurius sp. nov.? & ccottacco'su tutuye & ardilla & - & - \\
\hline 39. Sciurius sp. & tutuye & ardilla & - & - \\
\hline 40. Microsciurius sp. & tiriri & ardilla & - & - \\
\hline \multicolumn{5}{|l|}{ XENARTHA (EDENTATA) } \\
\hline \multicolumn{5}{|l|}{ Bradypodidae } \\
\hline 41. Bradypus variegatus* & san'di & perezoso de tres dedos & 0 & $x$ \\
\hline \multicolumn{5}{|l|}{ Dasypodidae } \\
\hline 42. Dasypus novemcinctus & $\mathrm{iji}$ & armadillo común & $>10$ & C \\
\hline 43. Priodontes maximus & cantimba & armadillo gigante & $>10$ & C \\
\hline \multicolumn{5}{|l|}{ Megalonychidae } \\
\hline 44. Choloepus didactylus* & san'di & perezoso de dos dedos & 0 & $x$ \\
\hline \multicolumn{5}{|l|}{ Myrmecophagidae } \\
\hline 45. Myrmecophaga tridactyla & betta & oso hormiguero & 3 & $\mathrm{U}$ \\
\hline 46. Tamandua tetradactyla & itsu & tamanduá & 1 & C \\
\hline
\end{tabular}


APÉNDICE/APPENDIX 4

Mamíferos Grandes/Large Mammals
Lista de especies de mamíferos grandes registrados por el equipo del inventario rápido o reportado por los habitantes locales en los alrededores de Bermejo y Sinangoe, Provincia de Sucumbios, en el nororiente del Ecuador, del 24 julio al 16 agosto del 2001.

\section{Sinangoe}

No. de registros/ No. of records**
Abundancia estimada/ Estimated abundance
CITES

UICN/IUCN

$\begin{array}{lllll}32 . & 5 & \mathrm{C} & \text { II } & \text { VU }\end{array}$

\begin{abstract}
33.
\end{abstract}
0

34.

0

$-$

II

II

35. $>10$ C III

$C_{+}$

36. $>10$

37.

38.

39.

40.

$\frac{-}{-}$

$\frac{-}{-}$

- - -

- -

- -

41. 0 $\mathrm{X}$ $-$

42. $>10$

43.

4

44. 0 $\mathrm{X}$ c EN

45. 46. 1

0

4

U

$-$

I

$-$

DD

II

$-$

VU

\section{Apéndice CITES/CITES Appendix}

I = En vía de extinción /

Threatened with extinction

II = Vulnerables o potencialmente amenazadas/

Vulnerable or potentially threatened

III = Reguladas $/$ Regulated

\section{Categoría UICN/IUCN Category}

$E N=$ En peligro/Endangered

$\mathrm{VU}=$ Vulnerable/Vulnerable

NT = Casi Amenazada/Near Threatened

$D D=$ Datos Insuficientes $/$ Data Deficient

Abundancia/Abundance:

$\mathrm{C}+=$ Muy común/Very common

$\mathrm{C}=$ Común/Common

$U=$ Poco frecuente/Uncommon

$\mathrm{R}=$ Raro/Rare

$X=$ Especie presente/Species present

* Especies que no fueron registradas por e] equipo de investigación pero que sí son conocidas por los habitantes de la zona./ Species not encountered by the rapid biological inventory team but reported by local residents.

* Los registros incluyen cualquier evidencia física de la presencia de la especie, p.e., huellas, excremento, contacto visual./Records include all physical evidence of the species' presence, e.g., tracks, scat, markings, and sightings. 



\section{MAMITEROS GRANDESILARGE MAMMALS}

\begin{tabular}{|lllll|}
\hline Especie/Species & $\begin{array}{l}\text { Nombre Colán/ } \\
\text { Colán name }\end{array}$ & $\begin{array}{l}\text { Nombre en español/ } \\
\text { Spanish name }\end{array}$ & $\begin{array}{l}\text { No. de registros/ } \\
\text { No. of records"* }\end{array}$ & $\begin{array}{l}\text { Abundancia estimada/ } \\
\text { Estimated abundance }\end{array}$ \\
\hline Cebidae (cont.) & & & & \\
\hline $\begin{array}{c}\text { 32. Lagothrix lagothricha } \\
\text { humboldtii }\end{array}$ & totosi con'si & chorongo, mono lanudo & 4 & $\mathrm{C}$ \\
\hline 33. Pithecia monachus" & paravacco & saki & 0 & $\mathrm{X}$ \\
\hline 34. Saimiri sciureus & latsi & barizo & 3 & $\mathrm{C}$ \\
\hline ROOENTIA & & & & \\
\hline
\end{tabular}

Agoutidae

\begin{tabular}{|c|c|c|c|c|}
\hline 35. Agouti paca & chanange & guanta & $>10$ & c \\
\hline \multicolumn{5}{|l|}{ Dasyproctidae } \\
\hline 36. Dasyproctus fuliginosa & quiya & guatusa, aguti & $>10$ & $\mathrm{C}_{+}$ \\
\hline \multicolumn{5}{|l|}{ Sciuridae } \\
\hline 37. Sciurius aes tuans & chipiri tutuye & ardilla & - & - \\
\hline 38. Sciurius sp. nov.? & ccottacco'su tutuye & ardilla & - & - \\
\hline 39. Sciurus sp. & tuluye & ardilla & - & - \\
\hline 40. Microsciurius $\mathrm{sp}$. & tiriri & ardilla & - & - \\
\hline \multicolumn{5}{|l|}{ XENARTHA (EDENTATA) } \\
\hline \multicolumn{5}{|l|}{ Bradypodidae } \\
\hline 41. Bradypus variegatus* & $\operatorname{san}^{\prime} d i$ & perezoso de tres dedos & 0 & $x$ \\
\hline \multicolumn{5}{|l|}{ Dasypodidae } \\
\hline 42. Dasypus novemcinctus & iii & armadillo común & $>10$ & c \\
\hline 43. Priodontes maximus & cantimba & armadillo gigante & $>10$ & c \\
\hline \multicolumn{5}{|l|}{ Megalonychidae } \\
\hline 44. Choloepus didactylus * & san'di & perezoso de dos dedos & 0 & $x$ \\
\hline \multicolumn{5}{|l|}{ Myrmecophagidae } \\
\hline 45. Myrmecophaga tridactyla & betta & oso hormiguero & 3 & $u$ \\
\hline ta & 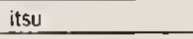 & tamanduá & 1 & c \\
\hline
\end{tabular}

46. Tamandua tetradactyla itsu tamanduá

\begin{tabular}{|c|c|c|c|c|}
\hline & \multicolumn{2}{|c|}{ Sinangoe } & \multirow[b]{2}{*}{ CITES } & \multirow[b]{2}{*}{ UICN/IUCN } \\
\hline & $\begin{array}{l}\text { No. de registros! } \\
\text { No. ol records"* }\end{array}$ & $\begin{array}{l}\text { Abundancia estimada/ } \\
\text { Estimated abundance }\end{array}$ & & \\
\hline 32. & 5 & c & II & vu \\
\hline 33. & 0 & - & II & $D D$ \\
\hline 34. & 0 & $x$ & II & - \\
\hline 35. & $>10$ & c & III & - \\
\hline 36. & $>10$ & $c_{+}$ & - & - \\
\hline 37. & - & - & - & - \\
\hline 38. & - & - & - & - \\
\hline 39. & - & - & - & - \\
\hline 40. & - & - & - & - \\
\hline 41. & 0 & $x$ & - & - \\
\hline 42. & $>10$ & c & - & - \\
\hline 43. & 4 & $U$ & 1 & EN \\
\hline 44. & 0 & $x$ & - & $D D$ \\
\hline 45. & 1 & $u$ & II & vu \\
\hline 46. & 0 & $x$ & - & - \\
\hline
\end{tabular}
= En via de extinción/ II = Vulnerables o potencialmente amenazadas/ Vulnerable or potentially threatened III = Reguladas/Regulated

Categoria UICN/IUCN Category $N=$ En peligro/Endangered $\mathrm{DD}=$ Datos Insuficientes/Data Deficient

Abundancia/Abundance:

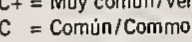
$=$ Poco frecuente/Uncommo

$\mathrm{R}=$ Raro/Rare
$X=$ Especie presente/Species presen

- Especies que no fueron registradas por el equipo de investigación pero que si son
conocidas por los habitantes de la zona Species not encountered by the rapid biologict inventory team but reported by local residents. * Los registros incluyen cualquier evidencia físic de la presencia de la especie, p.e., huellas, excremento, contacto visual./Records include 


\section{INICIATIVAS COFÁN DE CONSERVACIÓN}

A primera vista, parece haber poco que diferencie al pueblo Cofán del nororiente ecuatoriano de cualquier otro grupo indígena de las selvas sudamericanas. Al igual que tantos pueblos autóctonos de la Amazonía, los Cofán cosechan una gran variedad de plantas medicinales silvestres, utilizan la liana Banisteriopsis caapi (Malpighiaceae) para rituales sagrados, cazan animales con dardos envenenados con curare, y se relacionan con envidiable familiaridad con las plantas y animales de los bosques más diversos del mundo.

Pero los Cofán sobresalen desde un punto de vista de conservación. En parte porque una vasta zona de su territorio ancestral en el Oriente ecuatoriano ha sido destruido o contaminado en las últimas décadas, los Cofán han demostrado un compromiso extraordinariamente serio en proteger lo que queda de los bosques que habitan. Esta dedicación es muy aparente en su disposición de combinar sus conocimientos tradicionales sobre el bosque con la conservación basada en la ciencia, en la ejecución de proyectos que apoyan tanto la preservación de la vida silvestre como la calidad de vida de los Cofán. En este apéndice describimos brevemente algunas de esas iniciativas. Información adicional sobre los proyectos de conservación Cofán existe en la página Web de la Fundación para la Sobrevivencia del Pueblo Cofán (Centro Cofán Zábalo), www.cofan.org.

Las alianzas entre los grupos indígenas y conservacionistas se están volviendo cada vez más comunes, y muchos artículos recientes han explorado el desafío de hacer funcionar estas asociaciones a pesar de las profundas diferencias culturales (ver Peres \& Zimmerman 2001 para una revisión objetiva). Notamos pocas actividades no sostenibles en las aldeas Cofán que visitamos durante el inventario rápido, como por ejemplo el exceso de cacería de crácidos (aves grandes como el pauji1) y monos chorongo en las inmediaciones de la comunidad de Alto Bermejo. Estas actividades podrían empeorar, al intensificarse las presiones externas (ver la sección sobre Amenazas y Recomendaciones, bajo Panorama General). Pero también encontramos-y las imágenes de satélite lo demuestran muy claramente-grandes áreas silvestres intactas alrededor de estas antiguas aldeas, en un área que ha sido habitada por los Cofán durante siglos.

Un vistazo a la Figura 7 hace muy claras las implicaciones para la conservación. Al comparar las imágenes satelitales de esa figura, se aprecia la destrucción a gran escala de los bosques alrededor de la ciudad de Lago Agrio, Ecuador, entre los años 1986 y 1996. Sin embargo, vale notar el gran parche de bosque, a $10 \mathrm{~km}$ al sureste de esa ciudad, que ha permanecido relativamente intacto. Este parche es aun más conspicuo en las imágenes de satélite tomadas en el 2001, donde sobresale como una isla de bosque en un mar de pastizales. Esa isla es la comunidad Cofán de Doreno.
Creemos que los Cofán son socios invaluables en la conservación; su historia reciente está llena de estrategias creativas para resolver problemas de conservación. Por ejemplo:

a) La comunidad Cofán de Zábalo, establecida en el 1984, es uno de los pocos ejemplos que hemos encontrado de una comunidad indígena que trabaja conscientemente en torno a una ética de conservación basada en la ciencia. A partir de su esfuerzo y posterior éxito en obtener la tenencia legal de estas tierras ancestrales, la comunidad ha establecido una serie de reglas estrictas para minimizar el impacto de uso en el sector de la Reserva de Producción Faunística Cuyabeno. La comunidad no sólo ha limitado la agricultura y caza en ciertas áreas, sino que ha regulado la cacería a través de un sistema de vedas, temporadas y multas para cazadores que infringen las reglas. $\mathrm{Ha}$ iniciado también un programa de censo de la vida silvestre para asegurar que estos esfuerzos realmente estén protegiendo a las comunidades de animales. La comunidad revisa periódicamente las reglas, conjuntamente con los datos del programa de monitoreo, y las modifican como sea necesario.

b) Zábalo ha negociado también un acuerdo con el Ministerio del Ambiente del Ecuador para custodiar las secciones de su territorio que se superponen con la Reserva de Producción Faunística Cuyabeno. La comunidad Cofán de Sinangoe ha llegado a un acuerdo similar con el Ministerio para custodiar y manejar sus tierras, que quedan dentro de la Reserva Ecológica Cayambe-Coca. Durante nuestro inventario biológico rápido en la zona de Sinangoe, usamos la nueva estación de campo que la comunidad de Sinangoe construyó hace poco para científicos y para los guardabosques Cofán, como base de su patrullaje de los linderos nororientales de la reserva.

c) En el 1991, Zábalo emprendió un gran esfuerzo para revertir la drástica disminución de las poblaciones de dos especies de tortuga de río (Podocnemis expansa y P. unifilis)-alimento de los Cofán-a lo largo del río Aguarico. Estos descensos eran parte de una crisis mayor en la Amazonía, donde las tortugas son cazadas por su carne y sus huevos son recolectados como alimento (Ojasti 1996). Ambas especies constan actualmente en el Apéndice II de CITES; $P$. expansa es considerada en peligro, mientras que $P$. unifilis es considerada vulnerable por la Unión Mundial por la Conservación (UICN). A más de imponer una veda completa sobre la caza de tortugas adultas y sobre la recolección de huevos, los Cofán comenzaron a patrullar las playas para proteger a los nidos de (1) humanos u otros depredadores, y (2) inundaciones naturales. Cuando los nidos están en peligro de ser inundados, los Cofán los llevan a sitios más seguros (con un nivel de éxito sumamente alto). Las crías son tomadas al emerger del nido y mantenidas en piscinas durante un año, hasta que alcanzan un tamaño lo suficientemente grande como para escapar gran parte de la depredación al ser 
soltadas nuevamente al río. Hasta la fecha, la comunidad ha liberado 23.000 tortuguitas, y las poblaciones de tortuga de río del Aguarico están aumentando progresivamente. Este proyecto ha generado también una serie de datos valiosos sobre la conducta de apareamiento y anidamiento y sobre las dinámicas poblacionales de estas especies amenazadas.

d) La comunidad de Zábalo ha sido también pionera en la piscicultura de peces nativos. La crianza de tilapia, un pez de agua dulce importado de África, está ganando terreno en el Oriente ecuatoriano, donde algunos individuos que han escapado representan ya una seria amenaza para las poblaciones de peces nativos (R. Barriga, com. pers.) El proyecto de Zábalo ha demostrado que la piscicultura con especies nativas del río Aguarico es una alternativa práctica y económicamente viable a la crianza de tilapia. La comunidad está buscando financiamiento para ampliar el proyecto y poder exportar sus técnicas a otras comunidades del Oriente ecuatoriano.

e) Uno de los capítulos más dramáticos en la defensa de los bosques por parte de los Cofán cerca de Zábalo ocurrió en el 1993, cuando una compañía petrolera inició la perforación de pozos exploratorios ilegales dentro de la Reserva de Producción Faunística Cuyabeno. Luego de agotar todas las vías oficiales para detener la perforación, guerreros Cofán detuvieron a los trabajadores, cerrando el campamento y escoltándolos pacíficamente fuera del área. Nunca se reanudó el trabajo en los pozos.

f) La Fundación para la Sobrevivencia del Pueblo Cofán lanzó el proyecto EcoCanoa en el 1998 para construir y comercializar canoas de fibra de vidrio en el Oriente ecuatoriano. Las canoas de EcoCanoa son más livianas, más rápidas y más fuertes que las canoas tradicionales utilizadas en la región y duran dos o tres veces más. Aun más importante, las canoas de fibra de vidrio no exigen la tala de árboles enormes, en contraste con las canoas tradicionales, aliviándose así la presión sobre los amenazados bosques del Oriente. Este proyecto tiene por intención generar trabajo y fuentes de ingreso para los Cofán a largo plazo, compatibles con el medio ambiente.

g) En el 1978, los Cofán iniciaron el primer programa de ecoturismo manejado por indígenas en el Ecuador. Miles de visitantes extranjeros y ecuatorianos han visitado desde entonces los bosques Cofán y el programa ha sido elogiado por la Unión Mundial por la Conservación, y Cultural Survival (Sobrevivencia Cultural), como un ejemplo práctico de turismo compatible con el medio ambiente y la cultura. Hasta este año, cuando la escalada inestabilidad al otro lado de la frontera con Colombia interrumpió las operaciones, el ecoturismo empleaba a gran parte de la comunidad de Zábalo.

h) Los Cofán reconocen el valor de la investigación científica externa y tienen una larga historia de alentar a los biólogos para que trabajen en sus bosques. Carlos Cerón y sus colegas, por ejemplo, han publicado ampliamente sobre la flora y etnobotánica de los bosques Cofán, en colaboración con naturalistas Cofán. Este proyecto se reinició en 1999-2000 mediante una colaboración entre el botánico Cofán Roberto Aguinda y el Field Museum. Durante ese período, Aguinda permaneció un mes recolectando plantas en el campo con Robin Foster, y dos meses en Chicago en el Museo, completando una guía visual de las plantas de Zábalo y Sinangoe. Más recientemente, las comunidades de Alto Bermejo y Sinangoe, en colaboración con la Fundación para la Sobrevivencia del Pueblo Cofán y con fondos del MacArthur Foundation, han construido estaciones de campo adecuadas para alojar a investigadores visitantes. Hay más información sobre la realización de investigaciones en los bosques Cofán en la página Web de la Fundación para la Sobrevivencia del Pueblo Cofán (Centro Cofán de Zábalo), en www.cofan.org.

i) Reconociendo que gran parte de las políticas de conservación y levantamiento de fondos se realiza en inglés, los Cofán han realizado un esfuerzo especial por asegurar que los jóvenes Cofán hablen ese idioma, además del Cofán y español. Cuatro jóvenes Cofán hablan ahora de forma fluida el inglés y otros 20 más están estudiando el idioma en colegios en Quito.

j) Por estas y otras actividades de conservación, los Cofán han sido honrados con varios premios durante los últimos años, incluyendo el Premio Amigos de la ONU, por su 50 Aniversario (Categoría Piscicultura y Forestación), en el 1997, y el Premio de Conservación Parker/Gentry, en el 1998.

Appendix 5

\section{COFÁN CONSERVATION INITIATIVES}

At first glance, little seems to distinguish the Cofán people of northeastern Ecuador from other indigenous groups in South American forests. Like so many native Amazonian peoples, the Cofán harvest a wide array of wild-growing medicinal plants, use the vine Banisteriopsis caapi (Malpighiaceae) in sacred rituals, hunt animals with curare-tipped darts, and live in enviable familiarity with the plants and animals of the world's richest forests.

But the Cofán stand out from a conservationist's point of view. Partly because much of their ancestral territory in eastern Ecuador has been destroyed or polluted by outsiders within recent memory, the Cofán have shown an extraordinarily serious commitment to protecting the remaining forests they 
inhabit. This dedication is most apparent in their eagerness to combine their traditional knowledge of the forest with sciencebased conservation, in the service of projects that support wilderness preservation and the Cofán quality of life simultaneously. In this appendix we list and briefly describe some of those initiatives. Additional information about Cofán conservation projects is available on the website of the Cofán Survival Fund, www.cofan.org.

Alliances between indigenous groups and conservationists are increasingly common, and many recent articles have explored the challenge of making these partnerships work in spite of deep cultural differences (see Peres \& Zimmerman 2001 for an even-handed review). We did note some unsustainable activities around the Cofán villages we visited during the rapid inventory, e.g., apparent overhunting of cracids and woolly monkeys in the immediate vicinity of Alto Bermejo, and these may get worse as outside pressures intensify (see the Threats and Recommendations sections of the Overview). But we also found-and satellite pictures show very clearly-large, intact wilderness areas around these old villages, in an area that has been inhabited by the Cofán for centuries.

The implications for conservation are obvious from a glance at Figure 7. The paired satellite images document the wholesale destruction of forests around the Amazonian city of Lago Agrio, Ecuador, between the years 1986 and 1996. Notice, however, the large patch of forest just $10 \mathrm{~km}$ to the southeast of the city that survived relatively unscathed. The patch is even more conspicuous in satellite images taken in 2001, standing out like an island of forest in a sea of pastures. That island is the Cofán community of Doreno.

We believe the Cofán are invaluable conservation partners because their recent history is full of creative strategies to solve conservation problems. For example:

a) The Cofán community of Zábalo, established in 1984, is one of the few examples we have encountered of an indigenous community consciously designed around a science-based conservation ethic. Since fighting for and winning legal ownership of these ancestral lands, the community has drawn up a strict set of rules to minimize impact of use on the surrounding Cuyabeno Wildlife Reserve. Not only has the community limited agriculture and hunting to certain areas, and regulated hunting through a system of limits, seasons, and fines for hunters who break the rules. It has also initiated a wildlife censusing program to ensure that these efforts are in fact protecting animal communities. The rules are periodically reviewed by the community in the light of data from the monitoring program, and modified as needed.

b) Zábalo has also negotiated an agreement with the

Ecuadorian Ministry of the Environment to patrol the sections of thcir territory that ovcrlap with the Cuyabcno Wildlife Reserve.
The Cofán community of Sinangoe has reached a similar agreement with the Ministry to patrol and manage their lands, which are inside the Cayambe-Coca Ecological Reserve. During our rapid biological inventory in the Sinangoe area, we stayed at the new field station the Sinangoe community recently constructed for Cofán park guards to base their patrols of the reserve's northeastern border.

c) In 1991, Zábalo launched a major effort to reverse the sharp decline in populations of two river turtle species (Podocnemis expansa and $P$. unifilis)-favored food items among the Cofánalong the Aguarico River. These local declines are part of a larger crisis across Amazonia, wherever the turtles are hunted for meat and their eggs harvested for food (Ojasti 1996). Both species are currently listed in CITES Appendix II; P. expansa is endangered, while $P$. unifilis is considered vulnerable by the World Conservation Union (IUCN). Besides imposing complete prohibition on the hunting of adult turtles and on the collection of eggs, the Cofán began to patrol the beaches to protect the nests from (1) human or other predators and (2) natural flooding. When nests are in danger of being flooded, the Cofán transfer them (with extremely high success rates) to safer sites. Hatchlings are then collected as they emerge from the nest and kept in pools for one year, until they are large enough to withstand most predation when released back to the wild. To date the community has released into the wild 23,000 individual turtles, and river turtle populations in the Aguarico are growing steadily. The project has also generated a valuable dataset on the mating and nesting behavior and population dynamics of these threatened species.

d) The Zábalo community has also pioneered farming of native fish species. Farming of tilapia, a fresh-water fish imported from Africa, is gaining ground in eastern Ecuador, where escaped individuals already pose a serious threat to native fish populations (R. Barriga, pers. comm.). The Zábalo project has demonstrated that aquaculture with fish species native to the Aguarico River is a practical and economically viable alternative to tilapia farming. The community is currently seeking financing to expand the project, and to export the techniques to other communities in eastern Ecuador.

e) One of the most dramatic chapters in the Cofán's defense of the forests near Zábalo occurred in 1993, when an oil company began drilling illegal exploratory wells inside the Cuyabeno Wildlife Reserve. After exhausting official avenues to stop the drilling, Cofán warriors arrested the workers, shut down their camp, and escorted them peacefully out of the area. Work at the wells was never resumed.

f) The Cofán Survival Fund launched the EcoCanoa project in 1998 to build and sell fiberglass canoes in eastern Ecuador. 
EcoCanoa canoes are lighter, faster, and stronger than the wooden dugouts traditionally used in the region, and they last two or three times as long. More importantly, the fiberglass canoes do not require felling massive old trees, which relieves pressure on the Oriente's beleaguered forests. The project, directed by the Cofán Survival Fund, is intended to provide a long-term, environmentally friendly source of income for the Cofán.

g) In 1978, the Cofán initiated the first indigenous-managed ecotourism program in Ecuador. Thousands of foreign and Ecuadorian visitors have since toured Cofán forests, and the program has been lauded by the World Conservation Union and Cultural Survival as a practical example of environmentally and culturally friendly tourism. Until this year, when heightened instability across the border in Colombia disrupted operations, ecotourism employed much of the community of Zábalo.

h) The Cofán recognize the value of scientific research by outsiders, and have a long history of encouraging biologists to work in their forests. Carlos Cerón and colleagues, for instance, have published extensively on the floristics and ethnobotany of Cofán forests in collaboration with Cofán naturalists. That project was reinitiated in 1999-2000, in a collaboration between Roberto
Aguinda and The Field Museum, during which Aguinda spent a month collecting plants in the field with Robin Foster and two months in Chicago at the Museum, completing a visual guide to the plants of Zábalo and Sinangoe. Most recently, the communities of Alto Bermejo and Sinangoe, in collaboration with the Cofán Survival Fund, have constructed field stations for visiting researchers. Additional information on carrying out research in Cofán forests is available at the website of the Cofán Survival Fund, www.cofan.org.

i) Recognizing that much of conservation politics and fundraising are carried out in English, the Cofán have made a special effort to ensure that young Cofán speak that language in addition to Cofán and Spanish. Four young Cofán are now perfectly fluent in English, and 20 more are studying English at schools in Quito.

j) For these and other conservation activities, the Cofán have been recognized with several awards in recent years, including the Friends of the UN 50th Anniversary Award (Fisheries and Forestry Category) in 1997, and the Parker/Gentry Award for Conservation in 1998. 


\section{Opportunidades para la conservación alrededor de La Bonita: Resultados de un estudio del corredor biológico al norte de la Reserva Ecológica Cayambe- Coca, provincia de Sucumbios, Ecuador}

\section{INTRODUCCION}

Recomendamos el establecimiento de un corredor biológico importante entre el nuevo anexo de Bermejo propuesto en este informe y la Reserva Ecológica Cayambe-Coca, mediante una ampliación hacia el norte de los linderos actuales de la reserva (ver página 34 y Figura 2). Este corredor, que incluye el aislado páramo de la cordillera Murallas, protegería una gran extensión de área silvestre que se encuentra actualmente dentro del área de amortiguamiento al norte de la reserva, extendiéndose desde el río Cofanes en el sur hasta la cordillera del Mirador y la población de La Bonita en el norte (Figura 2), incluyendo la población de La Sofía. No visitamos esta zona durante el inventario biológico rápido, pero otro equipo de biólogos realizó hace poco un estudio en el lugar (Fuentes y Aguirre 2001). Aquí resumimos sus hallazgos, que representan

un recurso esencial para la modificación de los linderos actuales de la Reserva Ecológica, y los comparamos brevemente con nuestros resultados en la zona de Bermejo y Sinangoe.

El estudio de Patricio Fuentes y Ximena Aguirre fue realizado entre septiembre del 1997 y mayo del 2000, en asociación con la Universidad Central del Ecuador, The Nature Conservancy, y la Fundación La Bonita-Sucumbíos. Felipe Campos, Jorge Izquierdo y Patricio Fuentes realizaron un estudio complementario de la herpetofauna de la región en mayo del 2000 y mayo del 2001. Los resultados del estudio principal fueron presentados por Fuentes y Aguirre (2001), en su tesis doctoral para la Universidad Central del Ecuador; el informe herpetológico preliminar por Campos et al. (2001) se incluye en la tesis en forma de apéndice. $\mathrm{El}$ proyecto contó con el apoyo de The Nature Conservancy, el Centro de Datos para la Conservación (CDC-Ecuador), la Fundación Antisana, el Herbario Nacional del Ecuador, el Missouri Botanical Garden, EcoCiencia, la Facultad de Biología de la Universidad Central del Ecuador, la municipalidad de Sucumbíos y el Ministerio del Ambiente del Ecuador.

El equipo de la Universidad Central se enfocó en describir la flora, la herpetofauna y las condiciones socioeconómicas, con la meta de identificar los problemas y las oportunidades ambientales y bosquejar una visión de conservación pragmática para la zona. Llevaron a cabo estudios de campo en cinco sitios ubicados a diferentes elevaciones desde los $800 \mathrm{~m}$ (La Barquilla) hasta los $4.000 \mathrm{~m}$ (cordillera del Mirador), principalmente a lo largo de la nueva Vía Interoceánica. Los autores combinaron estos nuevos datos de campo con información de estudios anteriores y colecciones de museo del área en un sistema de información geográfica (SIG) que almacena, exhibe y analiza información sobre el paisaje físico, la biota, el aprovechamiento y tenencia de la tierra y las amenazas en la región. Éste es un modelo práctico y efectivo del SIG que recomendamos se establezca para la zona de Bermejo y Sinangoe (ver página 111).

\section{VISIÓN GENERAL DE LOS RESULTADOS}

\section{PLANTAS}

El equipo botánico utilizó una variedad de métodos para describir la vegetación de la zona. Comenzando con el mapa base de Sierra (1999) de la vegetación ecuatoriana, añadieron un análisis de las fotos aéreas, observaciones de campo, un inventario completo de las colecciones botánicas en la zona, sus propias colecciones botánicas generales y cuatro estudios cuantitativos de 0.1-ha de la vegetación. Sus resultados fueron mayormente paralelos a nuestros propios hallazgos en la región de Bermejo y Sinangoe: una flora rica, intacta, esencialmente no explorada, con un gran número de especies de plantas no descritas y un grado alto de endemismo.

Fuentes y Aguirre (2001) calculan en base a las fotografías aéreas que más del $85 \%$ de la región está cubierta de vegetación natural. Ya que su estudio abarcó un rango mucho más amplio de elevaciones $(800-4.000 \mathrm{~m})$ que nuestro inventario rápido en Bermejo y Sinangoe (400-2.300 m), documentaron una diversidad más amplia de tipos de vegetación. Estos varían entre los mismos bosques de laderas altas y bajas que nosotros visitamos, hasta bosque nuboso y páramo. El suyo fue el primer inventario biológico sostenido de la zona, registrando por lo menos 427 especies, 233 géneros y 98 familias de plantas vasculares.

Al igual que en el caso de Bermejo y Sinangoe, muchas de estas especies parecen ser endémicas o restringidas en su rango geográfico. De las especies que han podido ser identificadas hasta la fecha, 25 son endémicas del Ecuador, incluyendo por lo menos cinco especies de orquídeas. Entre sus colecciones endémicas más importantes están Podandrogyne brevipedunculata (Capparidaceae), clasificada como en peligro por Cornejo y Espinoza (2000), Passiflora popenovii (Passifloraceae)-probablemente extinta en su hábitat natural pero todavía cultivada en esta región por sus frutos (Jørgensen 2000) - y cinco especies más clasificadas como vulnerables. Varias de las especies de plantas recolectadas durante el estudio han sido confirmadas también como especies nuevas para la ciencia; de hecho, cuatro de las especies no descritas de Rubiaceae que nosotros también reportamos de la región de Bermejo y Sinangoe fueron descubiertas primero por Ximena Aguirre al norte de Cayambe-Coca.

Los bosques de elevaciones bajas estudiados por el equipo de la Universidad Central parecen ser muy similar en su composición y diversidad a los que estudiamos en Bermejo y 
Sinangoe. Muchos de los árboles registrados como dominantes en sus transectos son también dominantes en los nuestros, incluyendo Iriartea deltoidea (Arecaceae), Billia rosea (Hippocastanaceae) y Dacryodes olivifera (Burseraceae). No encontramos apenas unas pocas especies de dosel que ellos registraron como comunes, por ejemplo, Rauvolfia sanctorum (Apocynaceae). En el sotobosque, ellos reportan un predomino de arbustos y arbolitos en las familias Melastomataceae y Rubiaceae, y una comunidad herbácea con un componente rico de la familia Gesneriaceae, ambos reflejando nuestros propios hallazgos (ver páginas 47-59). La implicación es que una extensión de los linderos de la reserva hacia el norte y entrando a esta zona protegería muchos de los mismos objetos de conservación que identificamos en Bermejo y Sinangoe.

\section{ANFIBIOS Y REPTILES}

El inventario herpetológico de Campos et al. (2001, manuscrito inédito) se centró en los bosques alrededor de La Bonita (entre los 1.700 y $2.000 \mathrm{~m}$ ) y Rosa Florida $(1.400 \mathrm{~m})$. En transectos y colecciones generales realizadas en mayo del 2000 y mayo del 2001, el equipo documentó 65 especies de anfibios y reptiles; se espera encontrar unas 42 especies adicionales en la zona, en base a un análisis de los patrones de distribución y las colecciones de museo (Campos et al. 2001, manuscrito inédito). La lista del estudio incluye 28 ranas, 21 culebras, 13 lagartijas, dos ranas y un cecílido. Muchas de las especies en la lista fueron también registradas por Lily Rodríguez y Felipe Campos durante nuestro inventario rápido de la zona de Sinangoe, aunque hubo algunas especies de elevaciones altas que no registramos, como la culebra colúbrida Atractus occipitoalbus.

El informe de La Bonita y Rosa Florida registra la peculiar ausencia de muchas especies que típicamente se reproducen en corrientes rápidas, particularmente ranas de cristal de la familia Centrolenidae y ranas veneno flecho del género Colostethus. Campos et al. (2001, manuscrito inédito) afirman que ninguna de las siete especies de ranas de cristal o de las tres especies de Colostethus esperadas para la región fueron vistas o escuchadas durante los estudios en mayo del 2000 , y muy pocas fueron encontradas en mayo del 2001. Especulan que hasta cinco anfibios esperados para la región podrian estar ya extintos, por razones desconocidas: Atelopus ignescens, A. pachydermus, Coslosthetus jacobuspetersi, C. kingsburyi y Myniobates abditus.

Hay un alto endemismo en la fauna anfibia de la región, pero baja en la fauna de los reptiles. Los autores encontraron que el $27 \%$ de las especies que registraron son endémicas del Ecuador y el $42 \%$ tienen rangos geográficos restringidos al norte de Ecuador y sur de Colombia. En contraste, la mayoría de las especies de reptiles registradas en el área tienen una amplia distribución geográfica. Especies endémicas del Ecuador notorias incluyen a las lagartijas Dactyloa fitchi y Phenacosaurus vanzolinus, a mbas endémicas del Ecuador.
El equipo encontró $P$. vanzolinus-especie rara en desaparición en otras localidades-de forma común en La Bonita, especialmente en el camino a La Fama.

\section{CONDICIONES SOCIOECONÓMICAS}

El equipo de la Universidad Central también entrevistó a los moradores y autoridades sobre las condiciones socioeconómicas de la región. Describen una reducida comunidad de agricultores y ganaderos a pequeña escala, concentrados alrededor de unos pueblos pequeños. En el 1993, la población regional humana (2.441) era apenas un poco mayor que la población regional de ganado (2.000), resultando en una densidad de población humana de aproximadamente una persona y media por kilómetro cuadrado. La población ha crecido rápidamente desde entonces, en parte como respuesta a las nuevas tierras disponibles a lo largo de la Vía Interoceánica y en parte por el aumento de la migración colombiana debido al Plan Colombia.

Los datos muestran también un cuadro oscuro de una región donde por lo general no existen servicios básicos. El acceso a la educación, atención de salud, agua limpia, electricidad y servicios telefónicos es uniformemente bajo, mientras que la falta de políticas adecuadas y protección militar significa que las condiciones de vida son precarias cerca de la frontera colombiana y la guerra civil de ese país. La mayoría de los moradores de la región viven de una agricultura y ganadería lechera de subsistencia. Los principales cultivos en las elevaciones más altas son maíz y papa; a elevaciones bajas son remplazados con fréjol, yuca, plátano y otros cultivos típicos de los trópicos. Fuentes y Aguirre (2001) calculan la cantidad de bosque convertida hasta la fecha para estas actividades en aproximadamente el $15 \%$ del paisaje, pero en rápido crecimiento debido al mayor acceso que proporciona la nueva carretera.

Una contribución muy importante del inventario socioeconómico es un registro de todos los proyectos de desarrollo pasados y actuales en la región, con un perfil de los grupos gubernamentales y no gubernamentales activos en la zona y una lista de los impactos ambientales actuales más importantes. Los autores presentan también un catálogo de tenencia y uso de la tierra. Esta pacienciosa recolección de detalles sobre las condiciones políticas locales sentará las bases para una ampliación exitosa de los linderos de la Reserva Cayambe-Coca.

\section{RECOMENDACIONES}

Sobre la base de los datos biológicos y socioeconómicos recolectados en el campo, los autores recomiendan que la mayor parte de la zona sea asignada como área protegida. Notan que para tener éxito, esto exigirá una cuidadosa coordinación con los moradores 
locales y un manejo y zonificación adecuados. Sustentándose en su base de datos geográficos de la vegetación, tenencia y aprovechamiento de la tierra, sugieren que el $77 \%$ de la zona de amortiguamiento sea asignada como área protegida para preservar una variedad de comunidades naturales intactas y añadir efectividad de la Reserva Ecológica Cayambe-Coca hacia el sur.

El $23 \%$ restante del territorio de la región, principalmente en las inmediaciones de La Sofía y La Bonita y a lo largo de la Vía Interoceánica, recomiendan como zona de amortiguamiento para la nueva (o ampliada) área de protección. Aproximadamente la mitad de esta zona de amortiguamiento corresponde a extensiones ya despejadas para campos y pastizales, mientras que la otra mitad cubre áreas a lo largo de la carretera en proceso de ser colonizadas o que posiblemente serán colonizadas en el futuro cercano. En estas áreas, los moradores tendrían libertad para continuar con una agricultura y ganadería a pequeña escala, aunque con asistencia adicional para mejorar la calidad de vida y la sostenibilidad y compatibilidad ambiental.

Fuentes y Aguirre (2001) consideran una variedad de alternativas para el área protegida propuesta, y concluyen con la recomendación de establecer un Bosque Protector. Su opción se enmarca en consideraciones prácticas y políticas. Los autores reconocen que una ampliación hacia el norte de la Reserva Ecológica Cayambe-Coca le otorgaría una protección legal más firme para las comunidades naturales de la región, pero les preocupa que no sería bien recibido por los moradores locales y presionaría aun más a la sobrecargada administración de la reserva. Creemos que estas importantes preocupaciones pueden ser superadas. La primera preocupación apunta a la importante advertencia de que cualquier ampliación no debe sorprender a los moradores locales, sino ser parte de un proceso de colaboración e integración que respete su larga ocupación del área. La segunda preocupación se relaciona con la primera, en que el grado de carga de la nueva área sobre la administración de la reserva ecológica dependerá del grado en el que los mismos moradores asuman o apoyen el manejo de la nueva área protegida. Fuentes y Aguirre (2001) proponen que gran parte del área sea manejada por la municipalidad de La Bonita, y estamos de acuerdo en que este tipo de control local-_equilibrado con eficientes convenios con el Ministerio del Ambiente-serán necesarios para el éxito de conservación del área a largo plazo.
Appendix 6

\section{Conservation Opoortunities in Adjacent Areas \\ (La Bonita): Additional notes on the proposed \\ biological corridor north of the Cayambe-Coca \\ Ecological Reserve, Sucumbíos province, Ecuador.}

\section{INTRODUCTION}

We recommend the establishment of an important biological corridor between the new Bermejo annex proposed in this report and the existing Cayambe-Coca Ecological Reserve, via a northwards extension of the reserve's limits (see page 109). The corridor would protect a diverse stretch of wilderness, including the isolated paramo of the Cordillera Murallas. Currently in the buffer area to the north of the reserve, this area extends from the Río Cofanes in the south to the Cordillera del Mirador and the town of La Bonita in the north (see Figure 2, Anexo 2), including the town of La Sofía. Although we did not visit this area during the rapid biological inventory, another team of biologists recently carried out a rapid ecological survey there (Fuentes and Aguirre 2001). Here we summarize their findings-an essential resource in the modification of the current boundaries of the Ecological Reserve-and briefly compare them with our own findings in the Bermego and Sinangoe region.

The survey was carried out between September 1998 and May 2000 by Patricio Fuentes and Ximena Aguirre, in association with the Universidad Central del Ecuador, The Nature Conservancy, and the Fundación La Bonita-Sucumbíos. Felipe Campos, Jorge Izquierdo, and Patricio Fuentes undertook a supplementary survey of the region's herpetofauna in May 2000 and May 2001. Results of the primary survey are presented in Fuentes and Aguirre (2001), a doctoral thesis for the Universidad Central del Ecuador; a preliminary herpetological report by Campos et al. (2001) appears in the thesis as an appendix. The project was supported by The Nature Conservancy, the Centro de Datos para la Conservación (CDC-Ecuador), the Fundación Antisana, the National Herbarium of Ecuador, the Missouri Botanical Garden, EcoCiencia, the Escuela de Biología de la Universidad Central del Ecuador, the municipality of Sucumbíos, and the Ecuadorean Ministry of the Environment.

The Universidad Central team focused on describing the region's flora, herpetofauna, and socioeconomic conditions, with the goal of identifying environmental problems and opportunities and sketching a pragmatic, conservation-based vision for the area. They carried out field surveys at five sites ranging in elevation from $800 \mathrm{~m}$ (La Barquilla) to $4,000 \mathrm{~m}$ (Cordillera del Mirador), mostly along the new Interoceanic Highway. The 
authors combined these new field data with older information and museum collections from the area into a geographical information system (GIS) that stores, displays, and analyzes information on the region's physical landscape, biota, land use, and threats. This is a practical, effective model of the GIS that we recommend establishing for the larger region, including the Bermejo annex (see page 111).

\section{OVERVIEW OF RESULTS}

\section{PLANTS}

The botanical team used a battery of methods to describe the area's vegetation. Starting from Sierra's (1999) base map of Ecuadorian vegetation, they added analyses of aerial photos, ground-truthing explorations, a full inventory of historical botanical collections in the area, general botanical collections of their own, and four 0.1ha quantitative vegetation surveys. What they found parallels our own findings in the Bermejo and Sinangoe region: a rich, intact, essentially unexplored flora with a large number of undescribed plant species and a high degree of endemism.

Fuentes and Aguirre (2001) estimate from aerial photographs that more than $85 \%$ of the region is covered by natural vegetation. Because their survey encompassed a much broader range of elevations ( $800-4,000 \mathrm{~m}$ ) than our rapid inventory in Bermejo and Sinangoe (400-2,300 m), they document a much broader diversity of forest types. These range from the same kind of lower and upper hill forest we visited up to high-elevation cloud forests and paramos above treeline. Theirs was the first sustained botanical inventory of the area, recording at least 427 species, 233 genera, and 98 families.

As was the case in Bermejo and Sinangoe, many of these species appear to be endemic or range-restricted. Twenty-five of the species they have identified to date, including five orchid species, are endemic to Ecuador. Among their most important endemic collections are Podandrogyne brevipedunculata (Capparidaceae), classified as Endangered by Cornejo and Espinoza (2000), Passiflora popenovii (Passifloraceae), probably extinct in the wild but still cultivated in this region for its fruits (Jørgensen 2000), and five other species classified as Vulnerable. Several of the plant species collected in the survey have also been confirmed as new species; in fact, four of the undescribed Rubiaceae species we report from the Bermejo and Sinangoe region were discovered first by Ximena Aguirre north of the Cayambe-Coca.

The lower-elevation forests sampled by the Universidad Central team appear very similar in composition and diversity to the ones sampled by us in Bermejo and Sinangoe. Many of the trees recorded as dominant in their transects were also dominant in ours, including Iriartea deltoidea (Arecaceae), Billia rosea (Hippocastanaceae), and Dacryodes olivifera (Burseraceae). Only a few of the canopy species they registered as common were not found by us, e.g., Rauvolfia sanctorum (Apocynaceae). In the understory, they report a predominance of shrubs and treelets in the Melastomataceae and Rubiaceae, and an herbaceous layer rich in Gesneriaceae, both reminiscent of our findings (see pages 122-131). The implication is that an extension of the reserve's boundaries northwards into this area would protect many of the botanical conservation targets we identified in Bermejo and Sinangoe.

\section{AMPHIBIANS AND REPTILES}

The herpetological inventory of Campos et al. (2001, unpublished manuscript) focused on forests around La Bonita (between 1,700 and $2,000 \mathrm{~m}$ ) and Rosa Florida $(1,400 \mathrm{~m})$. In transects and general collections carried out in May 2000 and May 2001, the team documented 65 species of amphibians and reptiles; at least 42 other species are known or believed to occur in the area, on the basis of an analysis of distribution patterns and museum collections (Campos et al. 2001, unpublished manuscript). The inventory checklist includes 28 frogs, 21 snakes, 13 lizards, two toads, and a caecilian. Many of the species on the list were also recorded by Lily Rodríguez and Felipe Campos during our rapid inventory of the Sinangoe area, though there are also several higher-elevation taxa we did not record, such as the colubrid snake Atractus occipitoalbus.

The report from La Bonita and Rosa Florida notes the peculiar absence of many taxa that typically breed in fast-moving streams, particularly glass frogs in the family Centrolenidae and poison arrow frogs in the genus Colostethus. Campos et al. (2001, unpublished manuscript) report that none of the seven species of glass frogs or the three species of Colostethus expected to occur in the region were seen or heard during the May 2000 surveys, and very few were seen in May 2001. They speculate that as many as five amphibians expected to occur in the region may now be extinct, for unknown reasons: Atelopus ignescens, A. pachydermus, Colostethus jacobuspetersi, C. kingsburyi, and Myniobates abditus.

Endemism is high in the region's amphibian fauna, but low for reptiles. The authors found $27 \%$ of the amphibian species they registered to be endemic to Ecuador, and $42 \%$ of them to have geographic ranges restricted to northern Ecuador and southern Colombia. By contrast, most reptile species recorded in the area are widely distributed elsewhere. Notable endemics include the lizards Dactyloa fitchi and Phenacosaurus vanzolinus, both endemic to Ecuador. The team found $P$. vanzolinus, which is vanishingly rare in other localities, to be common around La Bonita, especially on the road to La Fama.

\section{SOCIOECONOMIC CONDITIONS}

The Universidad Central team also interviewed residents and elected officials about socioeconomic conditions in the region. They document a sparse community of small-scale farmers and 
ranchers, concentrated around a few small towns. In 1993, the regional population of people $(2,441)$ was only slightly higher than the regional population of cattle $(2,000)$, resulting in a human population density of roughly one and a half people per square kilometer. Population has risen rapidly since then, partly in response to the newly available land along the Interoceanic Highway and partly in the form of increased Colombian immigration due to Plan Colombia.

The data also draw a dark picture of a region where basic amenities are often unavailable. Access to education, health care, clean water, electricity, and telephone service is uniformly poor, while the lack of adequate police and military protection means that living conditions close to the Colombian border and the nearby civil war are precarious. The majority of the residents in the region live by subsistence agriculture and dairy farming. Major crops in the highcr clevations are corn and potatoes; at lower elevations these are replaced by beans, manioc, bananas, and other crops typical of the warm tropics. Fuentes and Aguirre (2001) estimate the amount of forest converted to date to these activities at roughly $15 \%$ of the landscape but increasing rapidly due to the increased access of the new highway.

An important contribution of the socioeconomic report is an inventory of all past and current development projects in the region, a profile of active governmental and non-governmental groups, and a list of environmental impacts in the region. The authors also present a catalog of land tenure and use that shows what sort of colonization is taking place, and which land is claimed by whom. It is this kind of patient accumulation of detail on local political conditions that will lay the groundwork for a successful extension of the Cayambe-Coca's boundaries.

\section{RECOMMENDATIONS}

On the basis of the biological and socioeconomic data gathered in the field, the authors recommend that the majority of the area be afforded protected area status. They stress that doing so successfully will require careful coordination with local inhabitants and sensible management and zonification. Working from their geographical database of vegetation, land tenure, and land use, they suggest that $77 \%$ of the buffer zone be set aside as a protected area to preserve a diversity of intact natural communities and add to the effectiveness of the Cayambe-Coca Ecological Reserve to the south.

The remaining $23 \%$ of the region's territory, mostly in the vicinity of La Sofía and La Bonita and along the Interoceanic Highway, would be a buffer zone for the new (or newly extended) protected area. Roughly half of this buffer zone corresponds to areas already cleared for fields and pastures, while the other half covers areas along the highway that are in the process of being colonized or are very likely to be colonized in the near future. In these areas residents would be free to continue small-scale agriculture and ranching, though with some additional assistance to improve quality of life and environmental sustainability.

Fuentes and Aguirre (2001) weigh a variety of alternatives for the proposed protected area and conclude by recommending the establishment of a "Bosque Protector." Their choice is framed by practical and political concerns. The authors admit that a northwards extension of the Cayambe-Coca Ecological Reserve would provide stronger legal protection to the region's natural communities, but worry that it would be unpopular among the local residents and would further tax the reserve's already overworked administration. We believe that these important concerns can be overcome. The first concern points to the important caveat that any extension should not come as a surprise to local inhabitants, but as part of a collaborative process that respects their long-term occupation of the area. The second is related to the first, in that the degree to which the new area will burden the administration of the ecological reserve depends on the degree to which local residents themselves can assume or assist management of the new protected area. Fuentes and Aguirre (2001) propose that a large part of the area be managed by the municipality of La Bonita. We strongly agree that this sort of local control-balanced by effective agreements with the Ministry of the Environment-will be necessary for long-term conservation success in the area. 
Altamirano, M. A., and M. A. Quiguango. 1997. Diversidad y abundancia relativa de la herpetofauna en Sinangue, Reserva Ecológica Cayambe-Coca,Sucumbíos, Ecuador. Pages 3-27 in P. Mena, A. Soldi, R. Alarcón, C. Chiriboga, and L. Suárez (eds.), Estudios biológicos para la conservación. Quito: Ecociencia.

Baldock, J. 1982. National geological map of the Republic of Ecuador. Scale 1:1,000,000. Quito: Dirección General de Geología y Minas.

BirdLife International. 2000. Threatened birds of the world. Barcelona and Cambridge, UK: Lynx Edicions and BirdLife International.

Campos, F., J. Izquierdo, and P. Fuentes. 2001. Estudio de la herpetofauna en el área La Bonita-Rosa Florida, Provincia de Sucumbíos, Ecuador. Published as an appendix to F. P. Fuentes P. and L. X. Aguirre U. (authors), Estudio de alternativas de manejo para los bosques montanos del área de influencia norte de la Reserva Ecológica Cayambe-Coca (RECAY). Quito: Doctoral thesis, Universidad Central del Ecuador.

Campos, F., M. Yánez-Muñoz, J. Izquierdo, and P. Fuentes. Unpublished manuscript. Herpetofauna de los bosques montanos del área de influencia norte de la Reserva Ecológica Cayambe-Coca (RECAY), sectores: La Bonita, Rosa Florida, La Sofía, La Barquilla, Sucumbíos, Ecuador.

Cerón, C. E. 1986. Los Cofanes de Dureno. Revista Geográfica 24: 7-16.

Cerón, C. E. 1988. Etnobotánica de los Cofanes de Dureno, provincia de Sucumbíos. Quito: Doctoral thesis, Universidad Central del Ecuador.

Cerón, C. E. 1995. Etnobiología de los Cofanes de Dureno. Quito: Abya-Yala.

Cerón, C. E., C. G. Montalvo, J. Umenda, and E. Chica Umenda. 1994. Etnobotánica y notas sobre la diversidad vegetal en la comunidad Cofán de Sinangüé, Sucumbíos, Ecuador. Quito: EcoCiencia.

Colinvaux, P. A., M. Frost, I. Frost, K-B. Liu, and M. SteinitzKannan. 1988. Three pollen diagrams of forest disturbance in the western Amazon Basin, Ecuador. Review of Palaeobotany and Palynology 55(1-3): 73-82.

Connell, J. H. 1971. On the role of natural enemies in preventing competitive exclusion in some marine animals and in rain forest trees. Pages 298-312 in P. J. den Boer and G. R. Gradwell (eds.), Dynamics of numbers in populations. Wageningen, The Netherlands: Centre for Agricultural Publication and Documentation.
Coopmans, P., and N. Krabbe. 2000. A new species of flycatcher (Tyrannidae: Myiopagis) from eastern Ecuador and eastern Peru. Wilson Bulletin 112: 305-312.

Cornejo, X., and C. Espinosa. 2000. Capparaceae. Page 165 in R. Valencia, N. Pitman, S. León-Yánez, and P. M. Jørgensen (eds.), Libro rojo de las plantas endémicas del Ecuador 2000. Quito: Pontificia Universidad Católica del Ecuador.

Crump, M. 1974. Reproductive strategies in a tropical anuran community. Miscellaneous Publications of the Museum of Natural History of the University of Kansas 61: 1-68.

Dodson, C. H., and A.H. Gentry. 1991. Biological extinction in western Ecuador. Annals of the Missouri Botanical Garden 78: 273-295.

Duellman, W. E. 1972. A review of the Neotropical frogs of the Hyla bogotensis group. Occasional Papers of the Museum of Natural History of the University of Kansas: 11: 1-31.

Duellman, W. E. 1978. The biology of an equatorial herpetofauna in Amazonian Ecuador. Miscellaneous Publications of the Museum of Natural History of the University of Kansas 65: 1-352.

Duellman, W. E. 1988. Patterns of species diversity in anuran amphibians in the American tropics. Annals of the Missouri Botanical Garden 75: 79-104.

Emmons, L. H., and F. Feer. 1997. Neotropical rainforest mammals: A field guide, second edition. Chicago: University of Chicago Press.

Endara, L., and L. Jost. 2000. Orchidaceae. Pages 257-258 in R. Valencia, N. Pitman, S. León-Yánez, and P. M. Jørgensen (eds.), Libro rojo de las plantas endémicas del Ecuador 2000. Quito: Pontificia Universidad Católica del Ecuador.

Espinosa, A. F., M. L. Hall, and H. Yepes. 1991. Tectonics and seismicity. Pages 29-41 in R. M. Chung (ed.), The March 5, 1987, Ecuador earthquakes: Mass wasting and sociocconomic effects. Natural Disaster Studies, Volume 5. Washington, D.C.: National Academy Press.

Fuentes P., F. P., and L. X. Aguirre U. 2001. Estudio de alternativas de manejo para los bosques montanos del área de influencia norte de la Reserva Ecológica Cayambe-Coca (RECAY). Quito: Doctoral thesis, Universidad Central del Ecuador. 
Gentry, A. H. 1986. Endemism in tropical vs. temperate plant communities. Pages 153-181 in M. E. Soulé (ed.), Conservation biology: The science of scarcity and diversity. Sunderland, Massachusetts: Sinauer Associates.

Gentry, A. H. 1992. Tropical forest biodiversity distribution patterns and their conservational significance. Oikos 63(1): 19-28.

Henshold, N. 1999. Las Angiospermas endémicas del Dpto. de Cajamarca, Perú. Arnaldoa 6(2): 141-184.

Hilty, S. L., and W. L. Brown. 1986. A guide to the birds of Colombia. Princeton: Princeton University Press.

Janzen, D. H. 1970. Herbivores and the number of tree species in tropical forests. The American Naturalist 104: 501-528.

Jørgensen, P. M., and S. León-Yánez. 1999. Catalogue of the vascular plants of Ecuador. St. Louis: Missouri Botanical Garden Press.

Jorgensen, P. M. 2000. Passifloraceae. Pages 373-376 in R. Valencia, N. Pitman, S. León-Yánez, and P. M. Jørgensen (eds.), Libro rojo de las plantas endémicas del Ecuador 2000. Quito: Pontificia Universidad Católica del Ecuador.

Kennedy, H., L. Andersson, and M. Hagberg. 1988. 224. Marantaceae. Pages 11-188 in G. Harling and L. Andersson (eds.), Flora of Ecuador 32. Gotenborg, Stockholm, and Quito: University of Gotenborg, Riksmuseum, and Pontificia Universidad Católica del Ecuador.

Krabbe, N., and P. Coopmans. 2000. Rediscovery of Grallaria alleni (Formicariidae) with notes on its range, song and identification. Ibis 142: 183-187.

Leite, M. R. P., and R. S. R. Williams. in press. The short-eared dog (Atelocynus microtis). Chapter in C. Sillero, D. MacDonald, and J. Ginsberg (eds.), Canids: Species status and conservation action plan, second edition. To be published by the IUCN/SSC Canids Specialist Group.

Lynch, J. D., P. M. Ruiz-Carranza, and M. C. Ardila-Robayo. 1997. Biogeographic patterns of Colombian frogs and toads. Revista de la Academia Colombiana de Ciencias Exactas, Físicas y Naturales 21(80): 237-248.

Mena V., P. 1997. Diversidad y abundancia relativa de las aves en Sinangüe, Reserva Ecológica Cayambe-Coca, Sucumbíos, Ecuador. Pages 29-56 in P. A. Mena, A. Soldi, R. Alarcón, C. Chiriboga, and L. Suárez (eds.), Estudios biológicos para la conservación: Diversidad, ecología y etnobiología. Quito: EcoCiencia.
Mena V., P., J. Regalado, and R. Cueva. 1997. Ofertas de animales en el bosque y cacería en la comunidad huaorani de Quehueire'ono, zona de amortiguamiento del Parque Nacional Yasuní, Napo, Ecuador. Pages 395-426 in P. A. Mena, A. Soldi, R. Alarcón, C. Chiriboga, and L. Suárez (eds.), Estudios biológicos para la conservación: Diversidad, ecología y etnobiología. Quito: EcoCiencia.

National Research Council. 1989. Lost crops of the Incas: Littleknown plants of the Andes with promise for worldwide cultivation. Washington, D. C.: National Academy Press.

Nieto, A. S. 1991. General geology of northeastern Ecuador. Pages 23-28 in R. M. Chung (ed.), The March 5,1987, Ecuador earthquakes: Mass wasting and socioeconomic effects. Natural Disaster Studies, Volume 5. Washington, D.C.: National Academy Press.

Nieto, A. S., R. L. Schuster, and G. Plaza-Nieto. 1991. Mass wasting and flooding. Pages 51-82 in R. M. Chung (ed.), The March 5, 1987, Ecuador earthquakes: Mass wasting and socioeconomic effects. Natural Disaster Studies, Volume 5. Washington, D. C.: National Academy Press.

Ojasti, J. 1993. Utilización de la fauna silvestre en América Latina: situación y perspectivas para un manejo sostenible. Guía FAO Conservación 25, Organización de las Naciones Unidas para la Agricultura y la Alimentación, Roma.

Organization of American States. 1987. Plan de ordenamiento y manejo de las cuencas de los Ríos San Miguel y Putumayo. A report of the Comisión Mixta de Cooperación Amazónica-Ecuatoriana-Colombiana. Washington, D. C.

Pennington, T. D., and N. Revelo. 1997. El género Inga en el Ecuador. Kew, U. K.: Royal Botanic Gardens.

Peres, C. A., and B. Zimmerman. 2001. Perils in parks or parks in peril? Reconciling conservation in Amazonian reserves with and without use. Conservation Biology 15(3): 793-797.

Ridgely, R. S., and P. J. Greenfield. 2001. The birds of Ecuador: Status, distribution, and taxonomy. Ithaca: Cornell University Press.

Robbins, C. S., J. W. Fitzpatrick, and P. B. Hamel. 1992. A warbler in trouble: Dendroica cerulea. Pages 549-562 in J. M. Hagan III and D. W. Johnston (eds.), Ecology and conservation of neotropical migrant landbirds. Washington, D. C.: Smithsonian Institution Press.

Ron, S. R. 2000. Annotated checklist of the amphibians of Yasuní, Ecuador: An online reference. Version 1.0. Pontificia Universidad Católica del Ecuador website, www.puce.edu.ec/Zoologia/yasuni/anfyas.htm. 
Schulenberg, T., and K. Awbrey (eds.). 1997. The Cordillera del Cóndor region of Ecuador and Peru: A biological assessment. RAP Working Papers 7. Washington, D. C.:

Conservation International.

Schulenberg, T., T. A. Parker, and W. Wust. 1997. Birds of the Cordillera del Cóndor. Pages 63-71 in T. S. Schulenberg and K. Awbrey (eds.), The Cordillera del Cóndor region of Ecuador and Peru: A biological assessment. RAP Working Papers 7. Washington, D. C.: Conservation International.

Sierra, R. (ed.). 1999. Propuesta preliminar de un sistema de clasificación de vegetación para el Ecuador continental. Quito: INEFAN/GEF-BIRF and Ecociencia.

Sierra, R. 2000. Dynamics and patterns of deforestation in the western Amazon: The Napo deforestation front, 19861996. Applied Geography 20: 1-16.

Terborgh, J., N. Pitman, M. Silman, H. Schichter, and P. Núñez V. in press. Maintenance of tree diversity in tropical forests. Pages 1-17 in D. Levey (ed.). Seed dispersal and frugivory: Ecology, evolution and conservation. Oxon, UK: CABI Publishing.

Tirira, D. 2001. Libro rojo de los mamíferos del Ecuador. Quito: Simboie.

Uzzell, T. M. 1966. Teiid lizards of the genus Neusticurus (Reptilia: Sauria). Bulletin of the American Museum of Natural History 132 (5): 277-328.

Valencia, R., N. Pitman, S. León-Yánez, and P. M. Jørgensen (eds.). 2000. Libro rojo de las plantas endémicas del Ecuador 2000. Quito: Pontificia Universidad Católica del Ecuador.

Wege, D. C., and A. J. Long. 1995. Key areas for threatened birds in the neotropics. BirdLife Conservation Series Number 5 . Cambridge, UK: BirdLife International. 
Alverson, W. S., D. K. Moskovits, and J. M. Shopland (eds.). 2000. Bolivia: Pando, Río Tahuamanu. Rapid Biological Inventories Report 1. Chicago, IL: The Field Museum.

Alverson, W. S., L. O. Rodríguez, and D. K. Moskovits (eds.). 2001. Perú: Biabo Cordillera Azul. Rapid Biological Inventories Report 2. Chicago, IL: The Field Museum. 

in threatened regions of high biological diversity and uniqueness. The scientific teams focus primarily on groups of organtisms that indicate habitat type and condition and that can be surveyed quickly and accurately.

These inventories do not attempt to produce an exhaustive list of organisms. Rather, the rapid surveys use a time-effective, integrated approach (1) to identify the important biological communities in the site or region of interest and (2) to determine whether these communitfes are of outstanding quality and significance in a regional or global context.

In-country scientists are central to the field team. The experience of local experts is especially critical for understanding areas with little or no history of scientific exploration. After the inventory, protection of these natural communities and further research rely on initiatives from local scientists and conservationists.

Once a rapid biological inventory has been completed (typically within a month), the team relays the survey information to local and international decision makers who can set priorities and guide conservation action in the host country. 


\section{Instituciones Participantes/Participating Institutions}

The Field Museum

Fundación para la Sobrevivencia del Pueblo Cofán/

Cofán Survival Fund

Federación Indígena de la Nacionalidad Cofán del Ecuador (FEINCE)

\section{Financiado por/Partial funding by}

The John D. and Catherine T. MacArthur Foundation

The Field Museum Environmental \& Conservation Programs

1400 South Lake Shore Drive, Chicago, Illinois 60605-2496 USA

T 312.665.7430 ₹ 312.665.7433 www.fieldmuseun.org/rbi 

GRÍrrrr

. 7 BOOK BNDERY, INC \begin{tabular}{lll}
0 & 2 \\
\hline$*$ & 0
\end{tabular} SINCE 1854

6B80 GISHOLT DRIVE
MADISON, WISCONSIN 53713
PHONE (GO8) 221-4443 


\section{Instituciones Participantes/Participating Institutions}

The Field Museum

Fundación para la Solrevivencia del Pueblo Cofán/

Cofán Survival Fund

Federación Indigena de la Nacionalichad Cofán del Ecuador (FEINCE)

\section{Financiado por/Partial funding by}

The John D. and Catherine T. MacArthur Foundation

The Field Museum Environmental \& Conservation Programs

1400 South Lake Shore Drive, Chicago, Illinois 60605-2496 USA

T 312.665.7430 F 312.665 .7433 unu.ficldmusenm.org/rbi 